Universidad Politécnica de Madrid

Escuela Técnica Superior de Arquitectura de Madrid (ETSAM)

\title{
APLICACIONES DE LAS PROPIEDADES AUXÉTICAS EN LA ARQUITECTURA
}

Tesis Doctoral

Mạ Dolores Álvarez Elipe

Arquitecto. 

DOCTORADO EN CONSTRUCCIÓN Y TECNOLOGÍA ARQUITECTÓNICAS

Escuela Técnica Superior de Arquitectura de Madrid (ETSAM)

\section{APLICACIONES DE LAS PROPIEDADES AUXÉTICAS EN LA ARQUITECTURA}

Autor: Ma Dolores Álvarez Elipe

Arquitecto.

Director: Jesús Anaya Díaz

Doctor Arquitecto. 

Tribunal nombrado por el Sr. Rector Magfco. de la Universidad Politécnica de Madrid, el día...... de. .de $20 \ldots$.

Presidente:

Vocal:

Vocal:

Vocal:

Secretario:

Suplente:

Suplente:

Realiza do el acto de defensa y lectura de la Tesis el día de de $20 \ldots$ en la E.T.S.I. / Facultad

Calificación

EL PRESIDENTE LOS VOCALES 

No se puede alcanzar ninguna meta sin esfuerzo, ni empezarla sin ilusión. Pero lo más importante no es cómo empieza ni cómo acaba, sino como se ha hecho el camino, por ello quisiera manifestar mi más cálido agradecimiento a las siguientes personas:

A mi madre, porque sin esas charlas después de comer todo sería menos llevadero, y a mi padre, por la ayuda con ciertas tareas que me han liberado de algún estrés.

A mi hermano, porque sin él nunca hubiera podido tener la idea que me ha llevado a desarrollar esta tesis.

A mi tutor Jesús Anaya Díaz, porque ha tenido fe en mis posibilidades desde el inicio y una gran confianza en que sería capaz de alcanzar resultados en algo tan singular.

A Hugo, Humberto y $M^{a}$ Fernanda, por la ayuda con el cálculo estructural en mi estancia en Aveiro (Portugal), y su premura posterior en lo que he ido necesitando en la distancia.

A Juan Rey, Lina Puertas y Fernando Castañón, por sus ayudas puntuales para desarrollar el cálculo de las estructuras autoestabilizadas con tendones planteadas.

A los miembros del Tribunal, que desinteresadamente dedican su tiempo a esta investigación y que la enriquecen con su experiencia y excelencia.

A mis compañeros y a mis alumnos del CEPA Paulo Freire, porque me han facilitado las cosas y me han dado mucha vida durante el último año de tensiones y encierro.

A las personas que, especialmente en la última etapa, han dedicado su tiempo a ayudarme de una u otra manera: Antonio, Cristina Arias, Federico, Laura, Cristina Gonzalo, Carlos...

Y como no mencionar a mi enorme afición por el baile y a la gente con la que la comparto, porque con su enfoque deportivo y social libera todo el estrés acumulado para poder volver a acometer el trabajo con una sonrisa.

A todos vosotros, muchas gracias. 


\section{ÍNDICE}

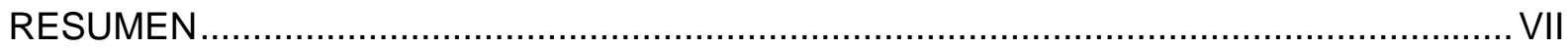

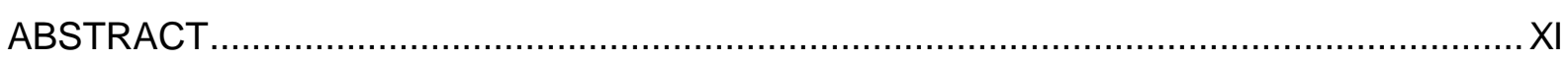

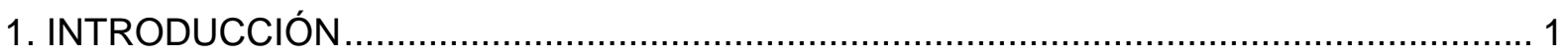

1.1. ¿Qué es un material auxético? .................................................................... 1

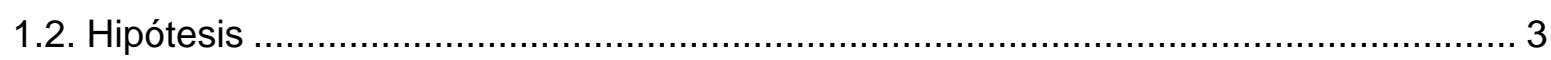

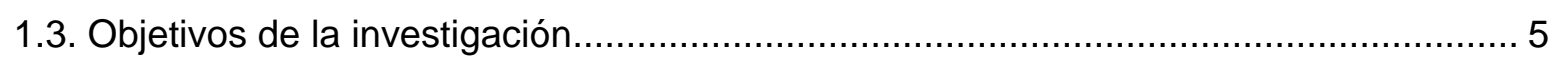

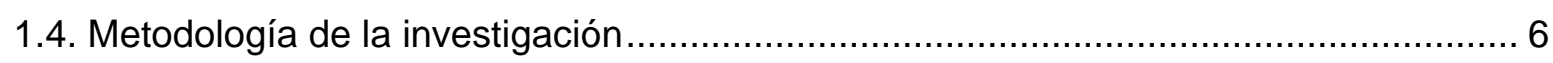

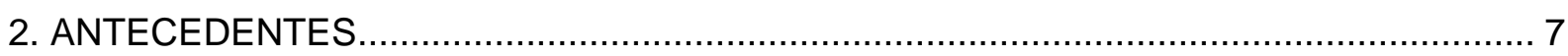

2.1. Antecedentes relacionados con materiales auxéticos ...................................... 7

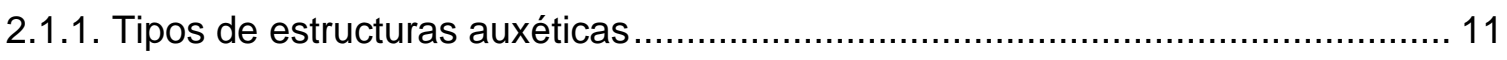

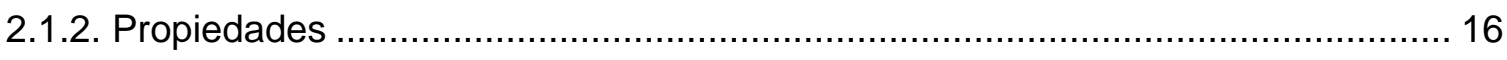

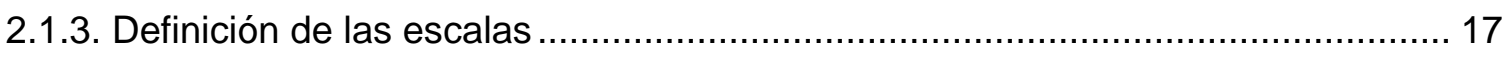

2.2. Antecedentes relacionados con arquitectura .................................................. 18

2.2.1. Formas libres y su simbiosis con la naturaleza ................................................ 19

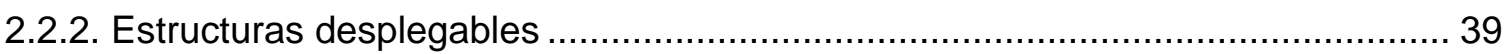

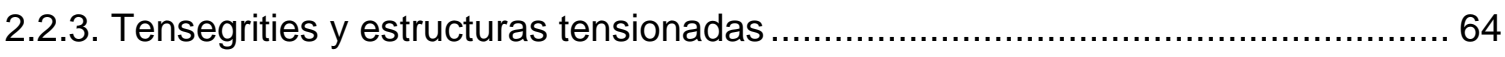

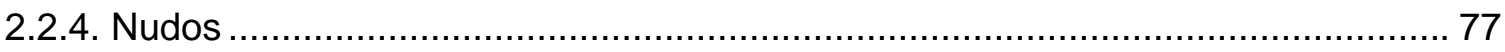

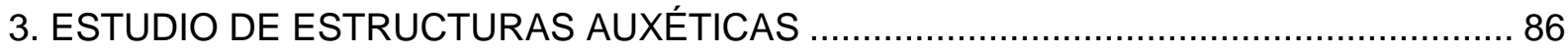

3.1. Estudio geométrico de estructuras auxéticas. Patrones auxéticos desarrollados y su

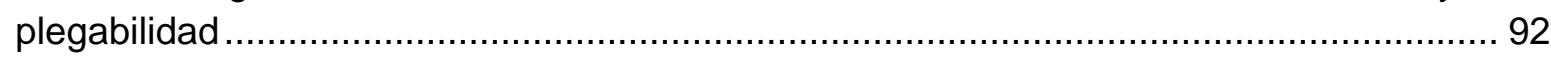

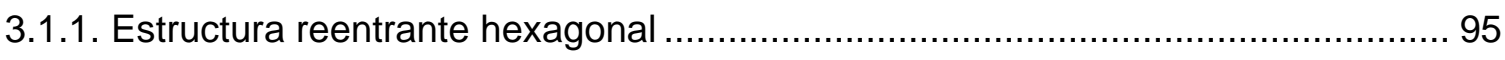

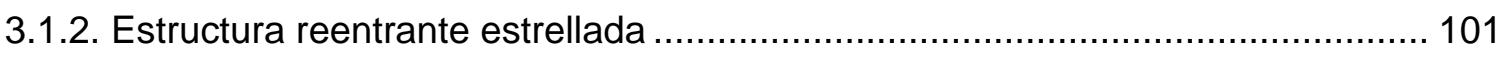

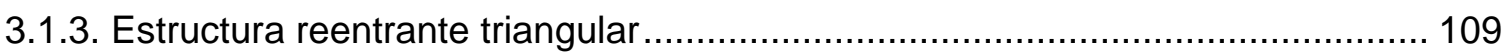

3.1.4. Estructura reentrante cuadrangular ............................................................. 116

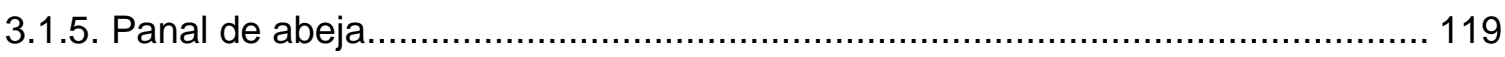

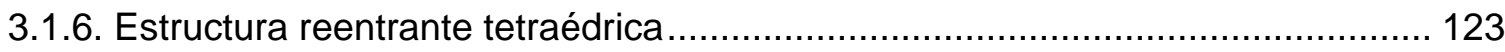

3.1.7. Estructura reentrante hexatruss (idealized)............................................. 127

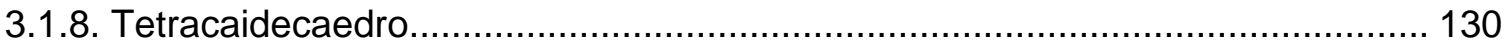

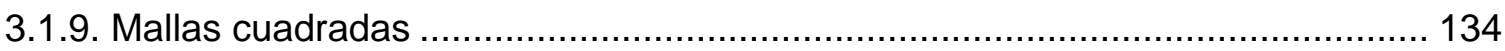

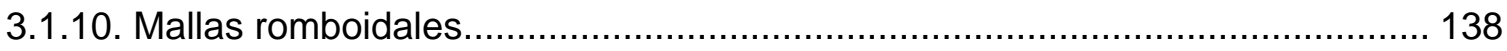

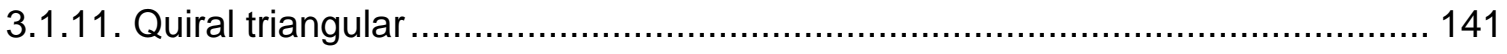

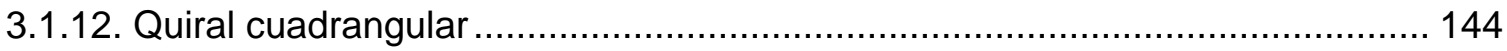




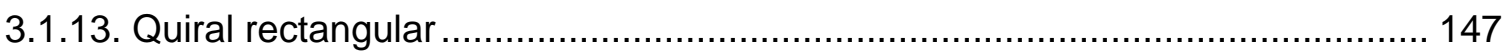

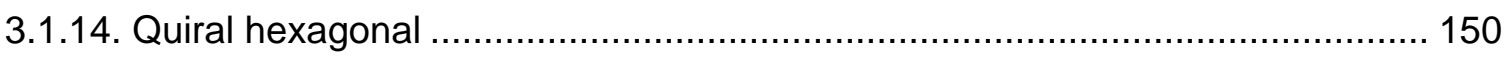

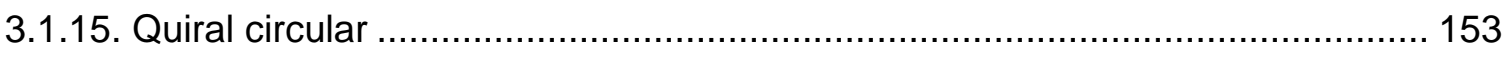

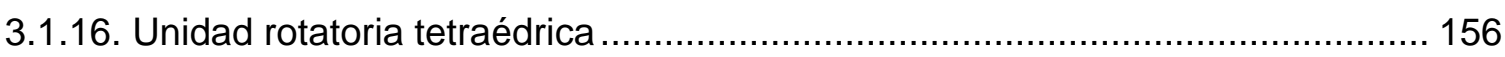

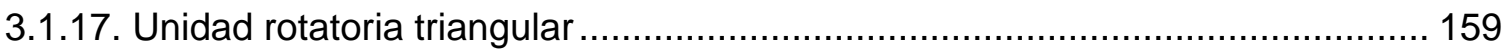

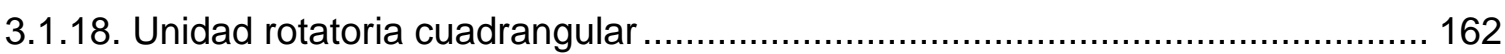

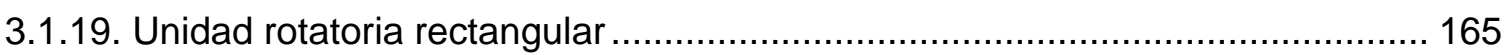

3.1.20. Unidad rotatoria de rectángulos diferentes................................................... 168

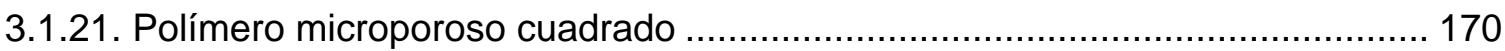

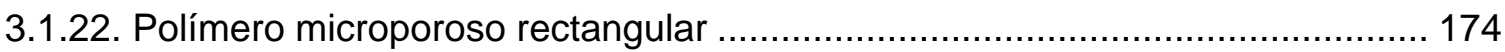

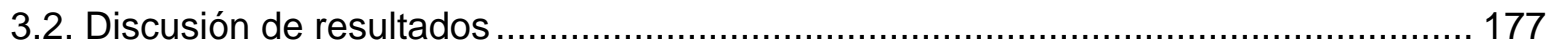

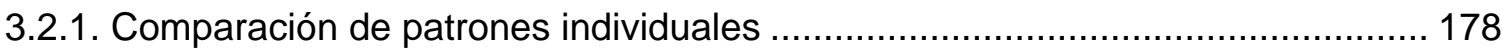

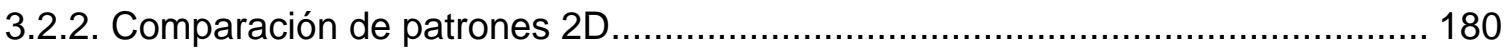

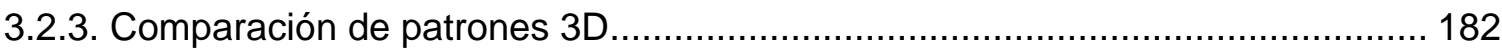

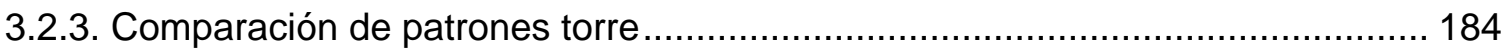

3.3. Cálculo estructural de estructuras auxéticas: estructura reentrante hexagonal......186

3.3.1. Justificación de las hipótesis de cálculo escogidas........................................ 187

3.3.2. Estructura individual reentrante hexagonal de acero con nudos rígidos ............ 189

3.3.2.1. Cálculo para diversas aperturas sin carga y con carga ............................. 189

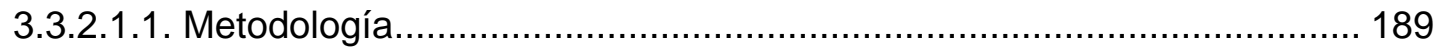

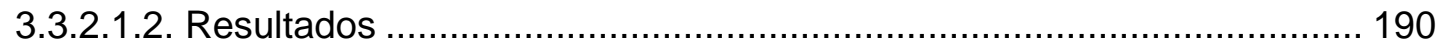

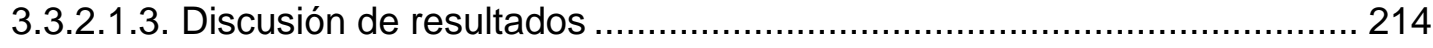

3.3.2.2. Cálculo para apertura de $63^{\circ}$ y aumento de carga progresiva................... 215

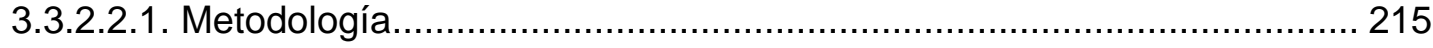

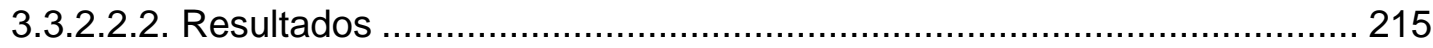

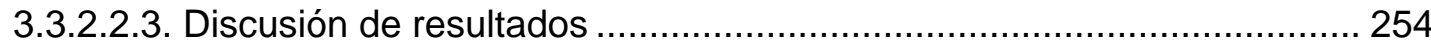

3.3.2.3. Cálculo para apertura de $90^{\circ}$ (tradicional) y aumento de carga progresiva. 255

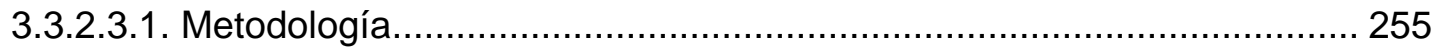

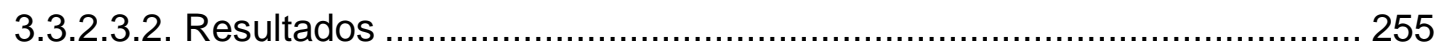

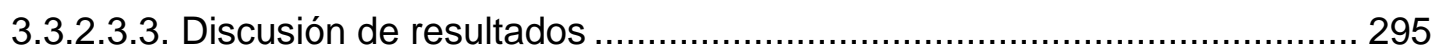

3.3.2.4. Estructura auxética con nudos articulados y tendón interno: cálculo manual. 296

(Tensioned auxetic structures with articulated knots: manual calculus) .................. 296

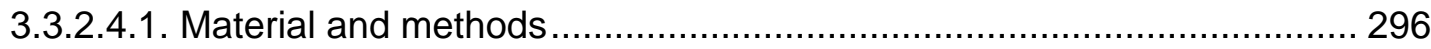




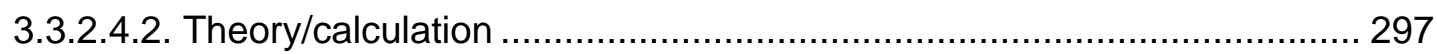

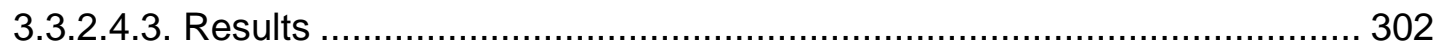

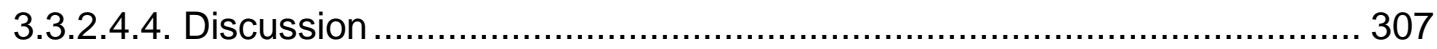

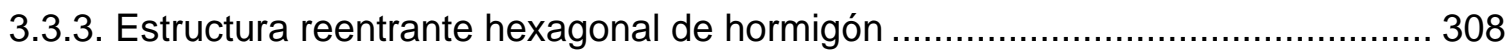

3.3.3.1. Estructura individual reentrante hexagonal de hormigón: estudio comparativo 308

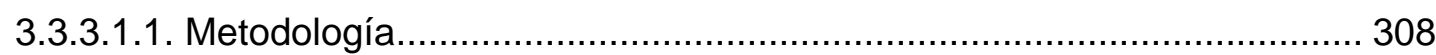

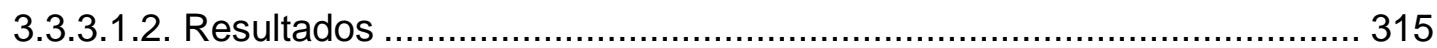

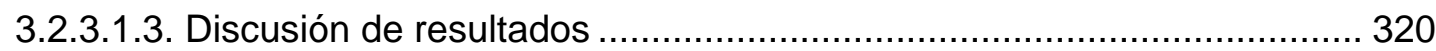

3.3.3.2. Estructura auxética individual reentrante hexatruss de hormigón ................ 320

(Re-entrant individual hexatruss concrete structure) ............................................ 320

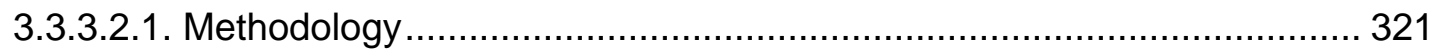

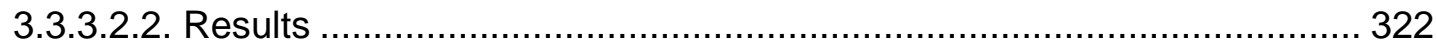

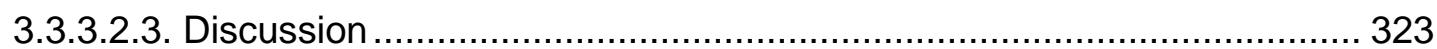

3.3.3.3. Estructura auxética conjunto reentrante hexatruss de hormigón.................. 324

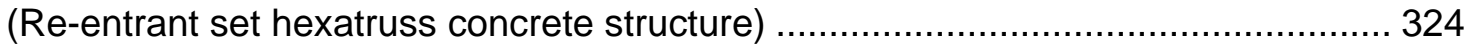

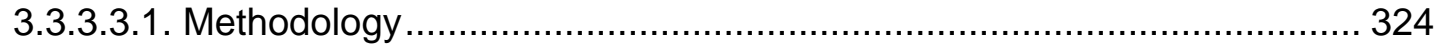

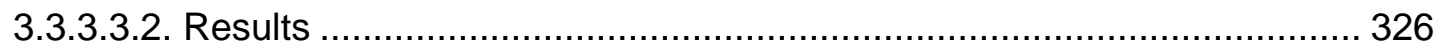

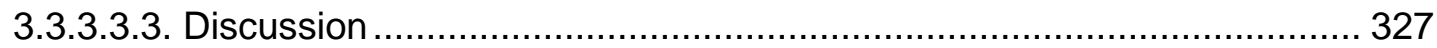

3.4. Desarrollo constructivo de estructuras auxéticas................................................. 329

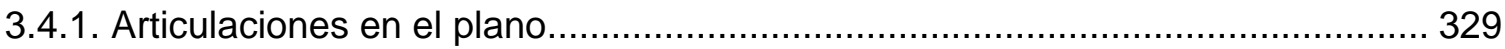

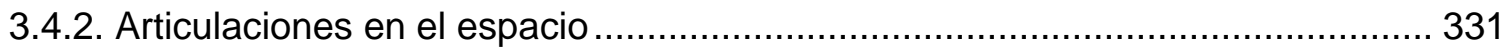

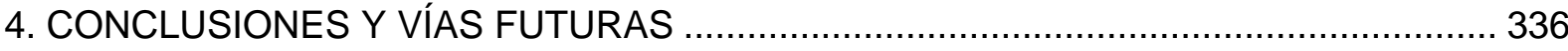

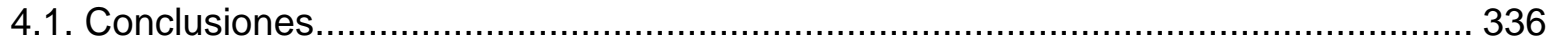

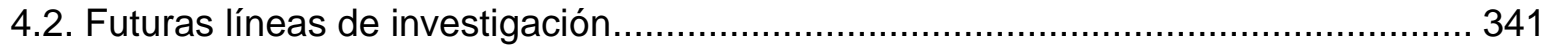

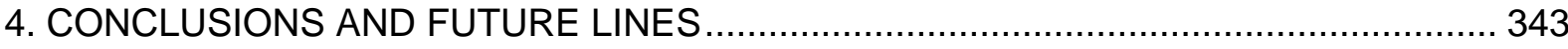

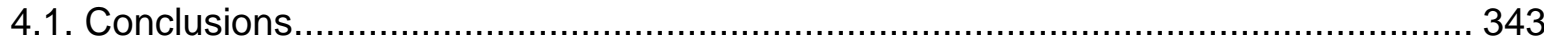

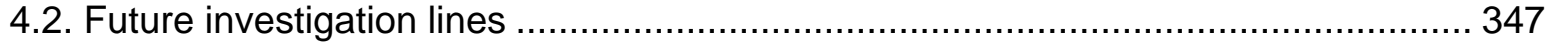

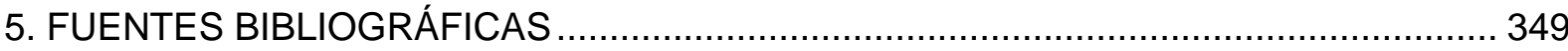

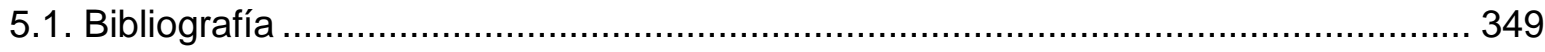

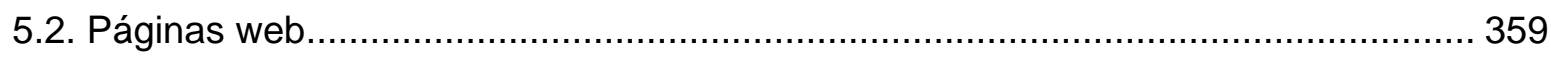

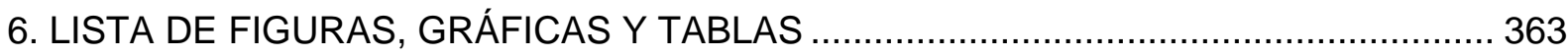

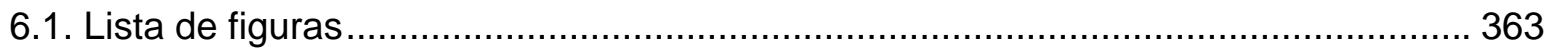


ÍNDICE

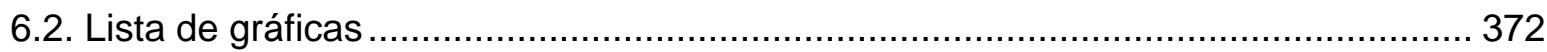

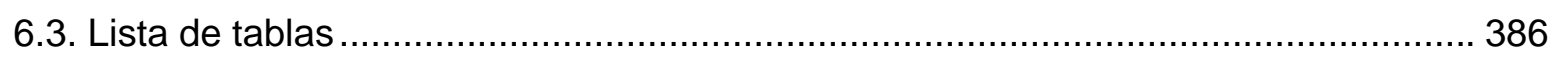

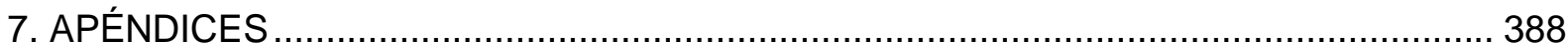

Apéndice 1. Tablas de comportamiento geométrico de estructuras auxéticas................ 388

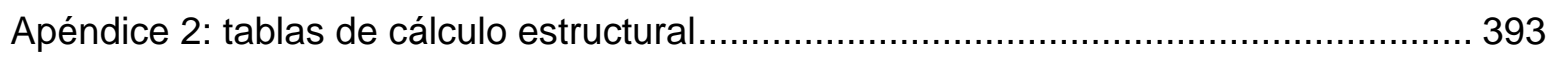

2.1. Estructura individual reentrante hexagonal de acero con nudos rígidos............... 393

2.2. Estructura individual reentrante hexagonal de acero con nudos rígidos con apertura

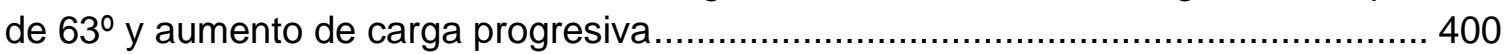

2.3. Estructura individual reentrante hexagonal de acero con nudos rígidos con apertura de $90^{\circ}$ (tradicional) y aumento de carga progresiva ..................................................... 407 


\section{RESUMEN}

Los materiales auxéticos son un tipo especial de materiales que tienen un coeficiente de Poisson negativo: ellos engordan cuando son estirados y adelgazan cuando son comprimidos. El comportamiento auxético es una propiedad independiente de la escala, la cual puede ser lograda a diferentes niveles estructurales, desde el nivel molecular al macroscópico. La estructura interna del material (geometría) juega un papel importante en la obtención del efecto auxético. Debido al coeficiente de Poisson negativo, los materiales auxéticos demuestran una serie de características particulares cuando se comparan con materiales convencionales. En los últimos años, gran variedad de materiales auxéticos han sido diseñados y fabricados para diversas aplicaciones, pero no en arquitectura ni al nivel escalar que esta necesita.

Un gran número de referencias sobre las geometrías auxéticas y sus aplicaciones han sido encontradas durante el trabajo de investigación. Estas referencias se han agrupado por su generación geométrica en siete grupos (Yanping Liu \& Hong Hu, 2010): estructuras reentrantes, quirales, unidades rotatorias, capas angulares laminadas, moléculas duras, polímeros microporosos y polímeros líquidos cristalinos. Estos materiales tienen interesante propiedades de cortante, comportamientos de indentación, tenacidad a la fractura, curvatura sinclástica, absorción de energía y permeabilidad variable.

Además, se han presentado arquitecturas basadas en principios de la naturaleza en los últimos años. Parece que las geometrías de la naturaleza están presentes en algunas arquitecturas, lo que recuerda algunas de las citas de las primeras páginas. Robert Le Ricolais, Darcy Thomson, Ray Kurzweil, Yushang Zhang y otros, Neri Oxman, Kahn, Matsys... son sólo algunos de estos casos. Tomemos, por ejemplo, los estudios desarrollados por este último: utilizó los fundamentos estructurales de las geometrías de la naturaleza para lograr una mejora en sus diseños. Invocó el funcionalismo biológico para apoyar el concepto de que el peso ligero es una medida real de la eficacia estructural.

Algunos arquitectos predijeron una nueva arquitectura con nuevas cualidades: revolucionaria, elástica, ligera, expansible, activa, móvil y dinámica. Es una arquitectura desplegable o transformable. Así, identificaron las características más importantes de las estructuras desplegables y transformables. Un paso importante se logró al encontrar varios ejemplos de prototipos y arquitecturas desplegables y transformables que se aplicaron a la arquitectura y la ingeniería. Algunos autores en este campo son Fuller, Piñero, Moore, 
Zeigler y algunos otros que recientemente han estado interesados en este tipo de estructuras.

Pero la arquitectura desplegable o transformable tiene que ser estabilizada. Se ha estudiado un importante desarrollo en tensegrities en relación con la arquitectura desplegable y transformable. Las propuestas podrían servir como una ilustración de la viabilidad de la tensegridad como una estructura ligera para cubrir grandes luces, puentear distancias más cortas o apoyar infraestructuras ligeras. Por supuesto, una investigación estructural mucho más detallada sería necesaria, pero al menos la idea presupuesta de la tensegridad como un sistema inaplicable ha sido refutada.

Todas estas estructuras necesitan un desarrollo constructivo. Las articulaciones son lo más importante para resolver el mecanismo empleado. Los nudos de las estructuras han sido objeto de patentes desde 1950. Se ha establecido una clasificación para entender su funcionamiento, en la que se han estudiado los nudos articulados y los nudos corredizos. Estos casos son para estructuras desplegables o transformables.

Después comienza el trabajo de analizar geométricamente todas y cada una de las 22 estructuras auxéticas que se han diseñado teniendo en cuenta los patrones auxéticos estudiados previamente. Cuatro tipologías de sistemas auxéticos han sido desarrolladas atendiendo a su formación, que incluyen el patrón individual, estructuras 2D, estructuras 3D y estructuras tipo torre.

Para todas las estructuras desarrolladas se ha analizado la relación entre la cantidad de material usado y la superficie o volumen conseguido, según estemos analizando estructuras en 2 o 3 dimensiones. Para ello se ha contabilizado la longitud total de barras usadas en la construcción de cada estructura, como analogía a la cantidad de material, ya que para conocer esas cantidades de dicho material en unidades de masa tendríamos que definir secciones concretas de barras y materiales concretos. En este estudio se ha buscado un comportamiento general, por lo que la longitud identifica perfectamente esos elementos lineales usados. La relación entre el área $(A)$ o el volumen $(V)$ con la longitud $(L)$ ha dado una relación $(K)$ entre dichas unidades, ayudándonos a comprender los valores de crecimiento de estas estructuras tan particulares. El área de cada figura corresponde al cuadrado, circunferencia o polígono (según corresponda) donde se inscribe la figura; y el volumen corresponde al cubo o cilindro que contiene la estructura. De la división y la resta de $K_{\text {máx }}$ y $K_{\text {mín }}$ se obtienen unos factores de crecimiento FC (:) y FC (-) de cada estructura. 
Después del estudio desarrollado, para las estructuras estudiadas se ha hecho una nueva clasificación en función de sus articulaciones. De este modo tendríamos:

1. Articulaciones en un solo plano de varias barras.

2. Articulaciones en el espacio, con confluencia de tres o más barras.

3. Articulaciones en un solo plano uniendo el vértice de un polígono con el final de una barra.

4. Articulaciones en el espacio uniendo el vértice de un polígono con el final de una barra.

5. Articulaciones en un solo plano uniendo vértices de polígonos.

6. Articulaciones en el espacio uniendo vértices de polígonos.

Además, se ha desarrollado un estudio estructural en el que se concluye que esta estructura trabaja correctamente para las tensiones y las cargas propuestas. Dentro de este estudio estructural se presentan varios casos de estudio en inglés (secciones 3.3.2.4. Estructura auxética con nudos articulados y tendón interno: cálculo manual, 3.3.3.2. Estructura auxética individual reentrante hexatruss de hormigón y 3.3.3.3. Estructura auxética conjunto reentrante hexatruss de hormigón), que junto con las conclusiones y el resumen también en inglés, avalan la tesis como internacional.

La deformación es considerada como una característica útil e importante de estas estructuras auxéticas, que las diferencia del modo de trabajar de las estructuras tradicionales. Las deformaciones que se generan en estructuras auxéticas son mayores que en estructuras tradicionales, pero los valores aptos de esfuerzos constructivos están en el mismo orden para ambos tipos de estructuras. Por tanto, es una nueva posibilidad para explorar dentro del campo de la arquitectura.

Ya que estamos hablando de arquitecturas dinámicas con capacidad de transformación, se pretende ampliar la configuración homotética de una estructura mediante la apertura de los nudos, por lo que es muy importante el diseño de la geometría de dichos nudos, ya que aunque la geometría de las fuerzas en la articulación sea igual a cero y esté controlada, no ocurre lo mismo con la deformación, y las excentricidades en el nudo colapsarían la estructura. De este modo, lo último que se ha hecho para finalizar el trabajo, ha sido definir con claridad la geometría de la estructura, para después poder buscar una solución de deformación angular, para conseguir transformaciones geométricas que sean estables al final, y donde la propia forma establezca el equilibrio. 
Como finalidad se persigue un cambio en el concepto estructural, debido a una mejor tracción (la sección aumenta), y unas nuevas propiedades en la compresión (mayor resistencia y cambios para las estructuras secundarias). Por tanto, las relaciones de equilibrio son diferentes a las habituales. Obtenemos un desarrollo específico en función del crecimiento de la forma, ya que son estructuras desplegables con una dimensión de orden: el límite puede ser desde una línea hasta una estructura 2D o desde un punto hasta una estructura 3D. Esto implica una relación de transparencia en función del crecimiento de la estructura, ya que es una forma variable. Además, debido a su plegabilidad podemos conseguir estructuras "prefabricadas", que gracias a su buen transporte nos permitirán alcanzar estructuras mayores. Incluso podemos tener memoria de forma.

Palabras clave: Auxético, coeficiente de Poisson negativo, escala, geometría, estructura, equilibrio, crecimiento, forma, transparencia, nudo. 


\section{ABSTRACT}

Auxetic materials are a special type of materials that have a negative Poisson's ratio: they get fat when they are stretched and they get slim when they are compressed. Auxetic behavior is a scale-independent property: this auxetic behavior can be achieved at different structural levels, from molecular to macroscopic level. The internal structure of the material (geometry) is very important to obtain the auxetic effect. The negative Poisson's ratio is the reason why auxetic materials show some particular features when they are compared to conventional materials. In recent years, a variety of auxetic materials have been designed and manufactured for various applications, but not in architecture, nor to the scale they needs.

A large number of references about auxetic geometries and their applications have been come across the research work. These references have been grouped by their geometric generation in seven groups (Yanping Liu \& Hong Hu, 2010): re-entrant structures, chiral structures, rotating unit structures, angle-ply laminates, hard molecules, microporous polymer structures and liquid crystalline polymers. The properties of these materials are shear properties, indentation behaviors, fracture toughness, synclastic curvature, energy absorption and variable permeability.

Moreover, natural principles in the last years of Architecture have been presented. It seems like the nature geometries are present in some architectures, which recalls some of the quotations of the first pages. Robert Le Ricolais, Darcy Thomson, Ray Kurzweil, Yushang Zhang and others, Neri Oxman, Kahn, Matsys... are only some of these cases. Take, for instance, the studies developed by the latter: he used the structural fundaments of nature geometries to achieve an improvement in his designs. He invoked biological functionalism to support the concept that lightweight is a real measure of structural effectiveness.

Some architects predicted a new architecture with new qualities: revolutionary, elastic, light, expandable, active, mobile and dynamic. It is deployable or transformable architecture. Thus, they identified the most important features of deployable and transformable structures. An important step was reached by finding several examples of deployable and transformable prototypes and architectures that were applied to Architecture and Engineering. Some authors in this field are Fuller, Piñero, Moore, Zeigler and some other that recently have been interested in this type of structures. 
But deployable or transformable architecture have to be stabilized. An important develop in tensegrities was studied in relation with deployable and transformable architecture. The proposals could serve as an illustration to the feasibility of tensegrity as a lightweight structure to cover large spans, bridge shorter distances or support light infrastructures. Of course, a much more detailed structural investigation would be necessary, but at least the presupposed idea of tensegrity as an inapplicable system has been disproved.

All of these structures need a construction development. The articulations are the most important thing in order to resolve the employed mechanism. The structures knots have been object of patent since 1950. A classification has been established to understand their working, in which articulated knots and sliding knots have been studied. These cases are for deployable or transformable structures.

Then it begins the work of analyzing geometrically each and every one of the 22 auxetic structures that have been designed taking into account the previously studied auxetic patterns. Four typologies of auxetic systems have been developed attending to their formation that can be included in unity pattern, 2D structures, 3D structures and tower structures.

For all developed structures we have analyzed the relationship between the amount of used material and the surface and the volume obtained, in 2 and 3 dimensions structures. To do this, we have counted the total length of bars used in the construction of each structure, as an analogy to the amount of material, since to know those quantities of said material in mass units we would have to define concrete sections of bars and concrete materials. In this study a general behavior has been sought, so the length perfectly identifies those linear elements used. The relationship between area $(A)$ or volume $(V)$ with length $(L)$ has given a relation $(K)$ between these units, helping us to understand the growth values of these very particular structures. The area of each figure corresponds to the square, circumference or polygon (where applicable) where the figure is inscribed; And the volume corresponds to the cube or cylinder containing the structure. From the division and the subtraction of Kmmax and Kmín, FC (:) and FC (-) growth factors of each structure are obtained.

After the developed study, other classification has been developed depending on their joints: joints in only one plane of some bars, joints in some planes with confluence of three or more bars, hinged joints in only one plane that match a polygon corner with the final of a bar, hinged joints in the space that match a polygon corner with the final of a bar, hinged joints in 
only one plane that match polygon corners, and hinged joints in the space that match polygon corners.

A structural study is developed, in which is concluded that this structure work correctly to the tensions and loads proposed. In this structural study, several cases of study are presented in English (sections 3.3.2.4. Tensioned auxetic structures with articulated knots: manual calculus, 3.3.3.2. Re-entrant individual hexatruss concrete structure and 3.3.3.3. Re-entrant set hexatruss concrete structure) that together with the conclusions and the abstract in English too, endorse the thesis as international.

The deformity is considered as a useful and important characteristic of auxetic structures with differences with the behavior in the modes of traditional and auxetic construction of buildings. The deformations that are developed in auxetic structures are greater than in traditional structures, but the apt values of efforts for their construction are in the same order in both types of structures. So, it is a new possibility to explorer in the discipline of architecture.

Since we are talking about dynamic architectures with processing capacity, is to extend the configuration homothetic structure by opening the knots, so it is very important to design the geometry of these knots, as although the geometry of the forces in the joint is equal to zero and is controlled, so with no deformation, and the eccentricities at node collapse the structure. Thus, the first thing to do is clearly define the geometry of the structure to later seek an angular solution of angular deformation to achieve geometric transformations that are stable at the end, and where the form itself set the balance.

Purpose of pursuing a structural change in the structural concept, due to better traction (section increases), and new compression properties (strength and changes to the secondary structures). Therefore, the equilibrium relationships are different from the usual. We obtain a specific development based on growth form, as they are deployable structures with a dimension of order: the limit can be from a line to a $2 \mathrm{D}$ structure or from a point to a 3D structure. This implies a relationship of transparency depending on the growth of the structure, since it is a variable shape. In addition, because of its pliability can get "manufactured" structures; thanks to its good transport we can reach larger structures. We can even have shape memory.

Keywords: Auxetic, negative Poisson's ratio, scale, geometry, structure, balance, growth, shape, transparency, knot. 
Aplicaciones de las propiedades auxéticas en la arquitectura

ABSTRACT 


\section{INTRODUCCIÓN}

\section{1. ¿Qué es un material auxético?}

Cuando cualquiera de nosotros aplasta una pelota de gomaespuma, un trozo de corcho o un juguete de plástico esperamos que, debido a la fuerza que estamos ejerciendo, dicho objeto se haga más ancho en las direcciones transversales a las de aplicación de la fuerza. Esto sucede debido a que es este comportamiento el que se encuentra de forma más normal en el conjunto de la naturaleza. Instintivamente esperamos que si estiramos una cuerda o una goma, su sección disminuya, al igual que si caemos sobre una colchoneta esperamos que se deforme hacia los lados debido a nuestro peso. Pues bien, este comportamiento se produce porque una de las propiedades de estas sustancias, el coeficiente de Poisson ${ }^{1}$, es positivo.

De manera contraria, nadie espera que al aplastar la ya mencionada pelota de gomaespuma con el pie ésta disminuya de tamaño por los lados. Este comportamiento es, no solo factible, sino real, es decir, estos materiales presentan coeficiente de Poisson negativo. Comúnmente se conoce a estos materiales como materiales auxéticos (aunque más tarde también han recibido el nombre de metamateriales), y se caracterizan por engordar cuando son estirados y adelgazar cuando son comprimidos: el comportamiento auxético se produce gracias a las geometrías internas que estos materiales presentan (y que serán presentadas más adelante).

La palabra misma está lejos de ser nueva ${ }^{2}$. Se ha utilizado desde la época medieval como un término retórico en el que el lenguaje repetitivo se utiliza para amplificar o ampliar una declaración. En fisiología vegetal, las sustancias auxéticas tienden a aumentar el crecimiento celular sin división celular. El término relacionado auxina se refiere a una sustancia que hace esto, también llamada una hormona vegetal. Toda esta terminología

${ }^{1}$ El coeficiente de Poisson (Ortiz, 1998), denotado mediante la letra griega $v$, es una constante elástica que proporciona una medida del estrechamiento de sección de un prisma de material elástico lineal e isótropo cuando se estira longitudinalmente y se adelgaza en las direcciones perpendiculares a la de estiramiento. El nombre de dicho coeficiente se le dio en honor al físico francés Simeon Poisson.

2 World Wide Words, diccionario online sobre la evolución de las palabras del habla inglesa nativa (http://www.worldwidewords.org/turnsofphrase/tp-aux1.htm) 
auxética deriva de la palabra griega $\alpha \dot{U} \xi \eta \tau \iota \kappa o ́ s$ (auxetikos) que significa "aquello que tiende a aumentar" y tiene su raíz en la palabra $\alpha$ ủ $\xi \eta \sigma \iota \varsigma, 0$ auxesis, que significa "aumento" (sustantivo). Esta terminología fue acuñada para polímeros que cumplen estas características por Evans (1991), profesor de la Universidad de Exeter.
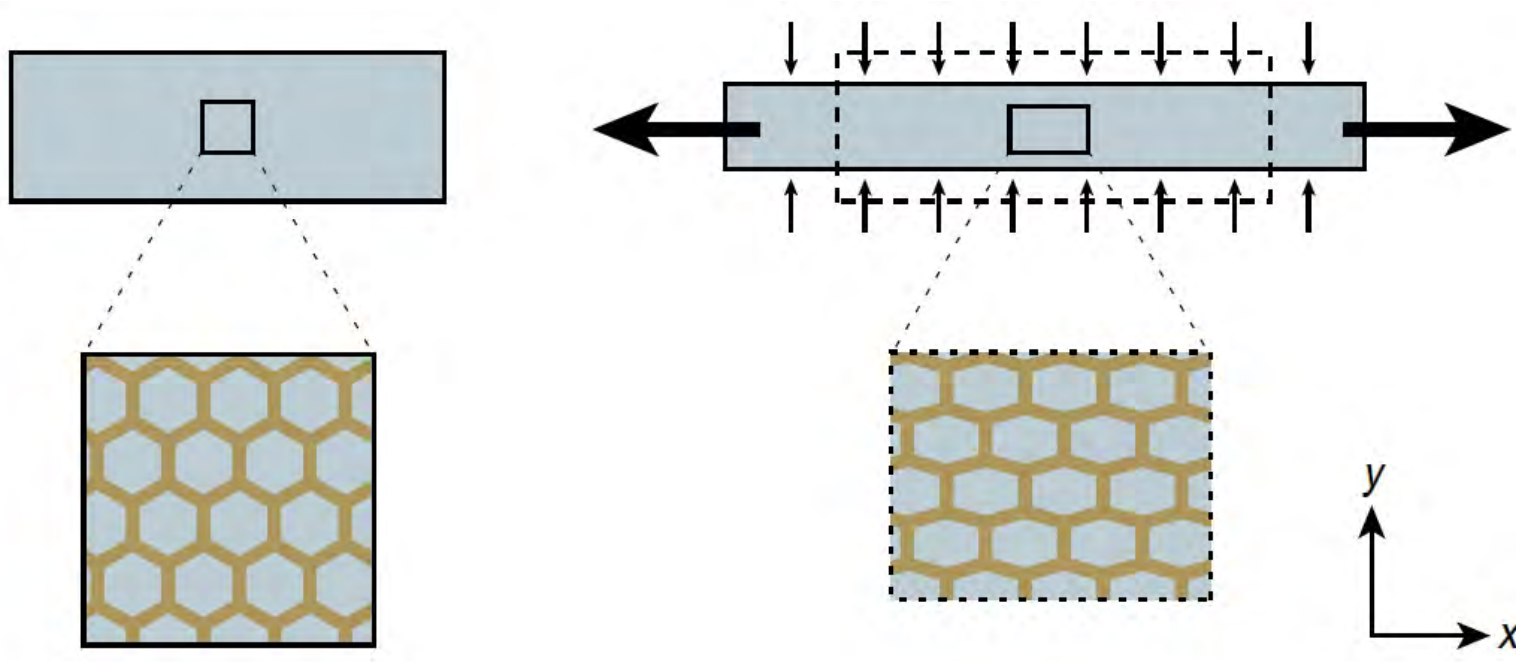

Figura 1 Material no auxético: Cuando el material es estirado las celdas que lo componen se alargan en la dirección $x$ pero se comprimen en la dirección y.
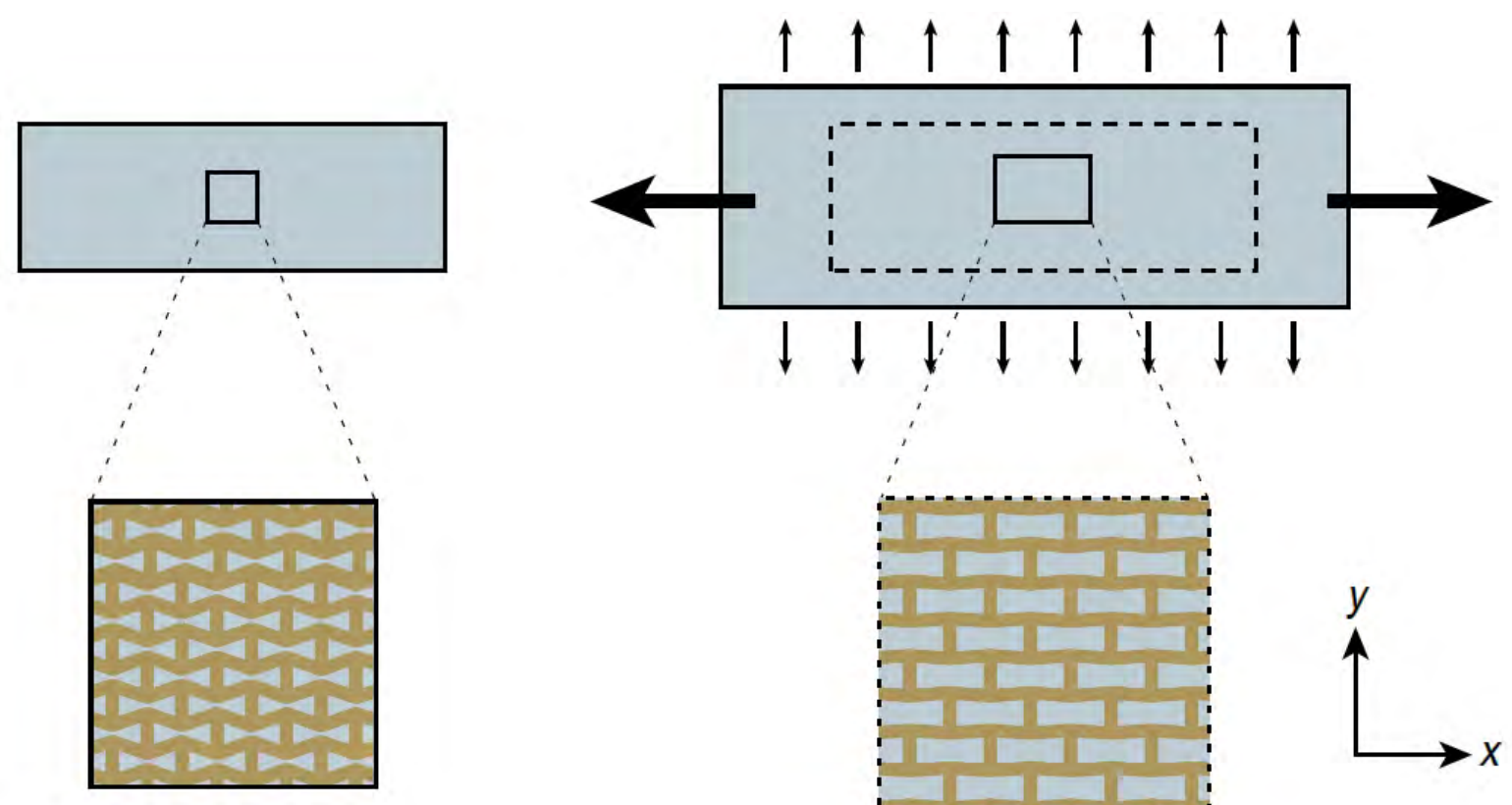

Figura 2 Material auxético: Cuando el material es estirado las celdas que lo componen se alargan tanto en la dirección x como en la dirección y. 
En el caso de los materiales convencionales, si disponemos de unos ejes cartesianos ${ }^{3}$, cuando dicho material es estirado las celdas que lo componen se alargan en la dirección $\mathrm{x}$ pero se comprimen en la dirección y (figura 1); mientras que en el caso de un material auxético, cuando el material es estirado las celdas que lo componen se alargan tanto en la dirección x como en la dirección y (figura 2).

\subsection{Hipótesis}

Los invariantes de la geometría en la naturaleza permiten un comportamiento equivalente estructural, desarrollando espacios a distinta escala. Los polímeros auxéticos transforman su geometría desde una línea a una superficie, y desde una superficie a un volumen o entramado espacial. El trabajo de investigación se fundamentará en establecer aquellas aplicaciones auxéticas y sus soluciones geométricas que permitan construir nuevos espacios de arquitectura.

Se considera que si un material puede cambiar sus propiedades de una manera tan sorprendente por el hecho de tener unas geometrías internas diferentes a las habituales, en arquitectura podrá ocurrir lo mismo, por tanto, se van a estudiar dichas geometrías para aplicarles un cambio de escala y poderlas incorporar al campo de la arquitectura: no es raro encontrar ciertos desarrollos científicos basados en la naturaleza (lo cual corrobora que esta hipótesis es viable), y esto es porque la forma biológica puede reflejar los principios físicos y matemáticos. Sin embargo, dada cierta escala espacial, no se puede tener una forma arbitraria, ya que hay restricciones que imponen las leyes físicas.

Por ejemplo, es factible imaginar una hormiga del tamaño de un elefante, sin embargo las restricciones antes mencionadas impiden su existencia real, ya que simplemente se colapsaría bajo su propio peso. Por lo tanto, la interacción de la geometría y la física restringen la variedad de formas de los organismos: este es uno de los principales principios con los que se va a trabajar, se trata de encontrar un algoritmo matemático que controle

\footnotetext{
${ }^{3}$ Unos ejes cartesianos son un par de rectas reales perpendiculares que nos permiten identificar los distintos puntos del plano. Los distintos ejes tienen nombres propios: el eje horizontal es el eje de abscisas $(x)$ y el eje vertical es el eje de ordenadas (y).
} 
unas geometrías que ya están controladas a escala nanotécnica para poder hacer factible su paso a la gran escala, es decir, se buscan aquellas invariantes geométricas cuyo comportamiento estructural se mantiene uniforme reproduciéndose con el cambio escalar, de tal forma que geometría, estructura y forma van a coincidir.

A la gran diversidad de tamaños posibles se añade la multiplicidad de morfologías, que nos da un amplio abanico de opciones con las que trabajar y aplicar a la arquitectura, lo que generará arquitecturas dinámicas con forma variable y con multitud de nuevas posibilidades. La formación de las estructuras ordenadas con las que se trabajará es resultado de procesos colectivos de repetición de una unidad. En estos sistemas, se hallan involucradas escalas que van de la dimensión de una sola unidad a la que caracteriza a todo el conglomerado; en estos casos el comportamiento individual nada indica -o indica muy poco- de lo que sucede con la colectividad. Estas estructuras ordenadas, de manera genérica, reciben el nombre de patrones.

De este modo, se trata de estudiar el comportamiento que tendrían varios de estos patrones cuando les aumentemos la escala para que entren a formar parte de la arquitectura. Estudiar este comportamiento tan peculiar en una escala tan grande como la de la arquitectura, supone una revolución en el mundo de la construcción, porque cambia de manera rotunda el concepto estructural y su comportamiento (se producen formas muy nuevas que además mejoran con la carga), lo que nos abre nuevas vías de investigación, experimentación e innovación, con las que se pueden resolver problemas latentes en la actualidad.

En el trabajo se siguen reglas matemáticas y geométricas sencillas, en las que los problemas de forma son en primera instancia, problemas matemáticos y geométricos, y los problemas de crecimiento son, esencialmente, problemas físicos, ya que la materia obedece leyes físicas. Por ende, la emergencia de estructuras ordenadas es consecuencia de procesos fisicoquímicos, y de ser así, dado que algunas de las leyes que rigen a éstos se expresan en términos matemáticos, entonces, en última instancia, las matemáticas se hallan en la base de los mecanismos subyacentes que están detrás de la emergencia de las estructuras.

Por lo tanto, se desarrollarán unos modelos matématicos y geométricos que nos permitan conocer cómo funcionan las estructuras auxéticas en la escala de la arquitectura, verificando modelos de nudos rígidos en los que las barras sufren esfuerzos, así como modelos desplegables en los que la estructura adquiere su comportamiento auxético por medio del 
giro de unas barras que se unen en sus extremos a unas articulaciones que permiten su movimiento. Para este último caso, además, habrá que considerar el sistema de estabilización requerido para que estos mecanismos actúen como estructura en un determinado punto de apertura.

Así, podremos conocer los puntos débiles, virtudes, defectos y comportamiento real de las geometrías y estructuras auxéticas a una gran escala, para poder hacer incapié en los factores que caracterizan dicha escala (como podría ser, por ejemplo, el diseño de las uniones, que ya no van a ser algo continuo, y hay que diseñar cómo tendrían que ser esos nudos para que tuvieran un comportamiento correcto y no colapsase la estructura), para desarrollar, a partir de ahí, unas aplicaciones constructivas reales.

\subsection{Objetivos de la investigación}

El principal objetivo de esta investigación después de estudiar los materiales auxéticos será establecer las propiedades geométricas y estructurales que se generan al cambiarles la escala para llevarlos a la arquitectura. En concreto, los objetivos de la investigación son los siguientes:

- Conocer el comportamiento de los materiales auxéticos gracias a sus geometrías para poder aplicarlos a la arquitectura.

- Conocer arquitecturas con desarrollos geométricos y estructurales novedosos que nos sirvan de antecedentes.

- Realizar desarrollos geométricos a partir de las geometrías conocidas y combinarlos entre sí para generar estructuras de arquitectura.

- Dibujar en programas de dibujo asistido por ordenador estas geometrías transformables para entender su comportamiento geométrico.

- Testear estos desarrollos geométricos en programas de cálculo de elementos finitos para conocer su comportamiento estructural en la macroescala.

- Desarrollar el diseño constructivo para que estos desarrollos geométricos sean posibles, pudiendo generar sus consiguientes patentes.

Con todo esto, se comprobará la innovación respecto a otras estructuras existentes, y se propondrán todo tipo de espacios y estructuras arquitectónicas transformables o no, con la 
principal finalidad de identificar las características y las propiedades de estructuras de construcción definidas mediante las propiedades de un material auxético (relación masavolumen, giros en nudos, esfuerzos estructurales...). Geometría, estructura y forma van a coincidir.

\subsection{Metodología de la investigación}

Se propone una metodología que combina tres tipos de estudio:

- Estudio de otras disciplinas distintas a la arquitectura para aplicarlas en este campo: el estudio de las geometrías internas de los polímeros auxéticos y el consiguiente cambio de escala para aplicar estas propiedades a la arquitectura abre nuevas vías de exploración en el campo estructural de esta disciplina.

- Estudio de arquitecturas experimentales que siguen caminos novedosos a partir de estructuras encontradas en la naturaleza o con propiedades y geometrías diferentes a las habituales: este estudio es necesario, pues para toda investigación es necesario un estudio documental que sitúe dónde estamos y a partir de dónde y cómo podemos innovar.

- Realización y estudio de desarrollos geométricos, estructurales y constructivos, aplicables a la arquitectura: una vez conocido aquello en lo que se apoya nuestra investigación (materiales auxéticos y arquitecturas estructuralmente experimentales) el siguiente paso es desarrollar el propio campo de estudio e innovación a partir de lo aprendido.

Con el fin de cumplir con los objetivos previstos, se van a seguir varias líneas de acción, una después de otra:

1. Estudio geométrico de polímeros auxéticos y de arquitecturas desarrolladas a partir de estudios geométricos novedosos.

2. Desarrollo de modelos geométricos a partir de las geometrías que se consideren más adecuadas para la escala de la arquitectura, como rascacielos, estructuras desplegables, etc.

3. Desarrollo de modelos estructurales a partir de las geometrías que se consideren más adecuadas para estructuras de arquitectura, para testearlos mediante programas de cálculo estructural

4. Búsqueda de soluciones constructivas para las estructuras planteadas, con su correspondiente desarrollo de patentes. 


\section{ANTECEDENTES}

\subsection{Antecedentes relacionados con materiales auxéticos}

Como antecedentes se pueden nombrar todos aquellos estudios realizados por autores, tales como Master-Evans, Grima y otros, sobre la geometría, las propiedades y las aplicaciones de los materiales auxéticos a partir de la década de los setenta. Estos antecedentes son tanto teóricos como experimentales.

El primer ejemplo publicado de un material auxético sintético fue en la revista Science, titulado "Estructuras de espuma con una relación de Poisson negativa", por Lakes (1987), de la Universidad de Lowa (aunque, como se ha especificado en la introducción, el uso de la palabra auxético para referirse a esta propiedad probablemente comenzó en 1991). Se produjeron espumas con relaciones de Poisson negativas a partir de espumas de polímero de células abiertas de baja densidad convencionales haciendo que los nervios de cada célula se proyectaran permanentemente hacia adentro, dando como resultado una estructura reentrante (figura 3).
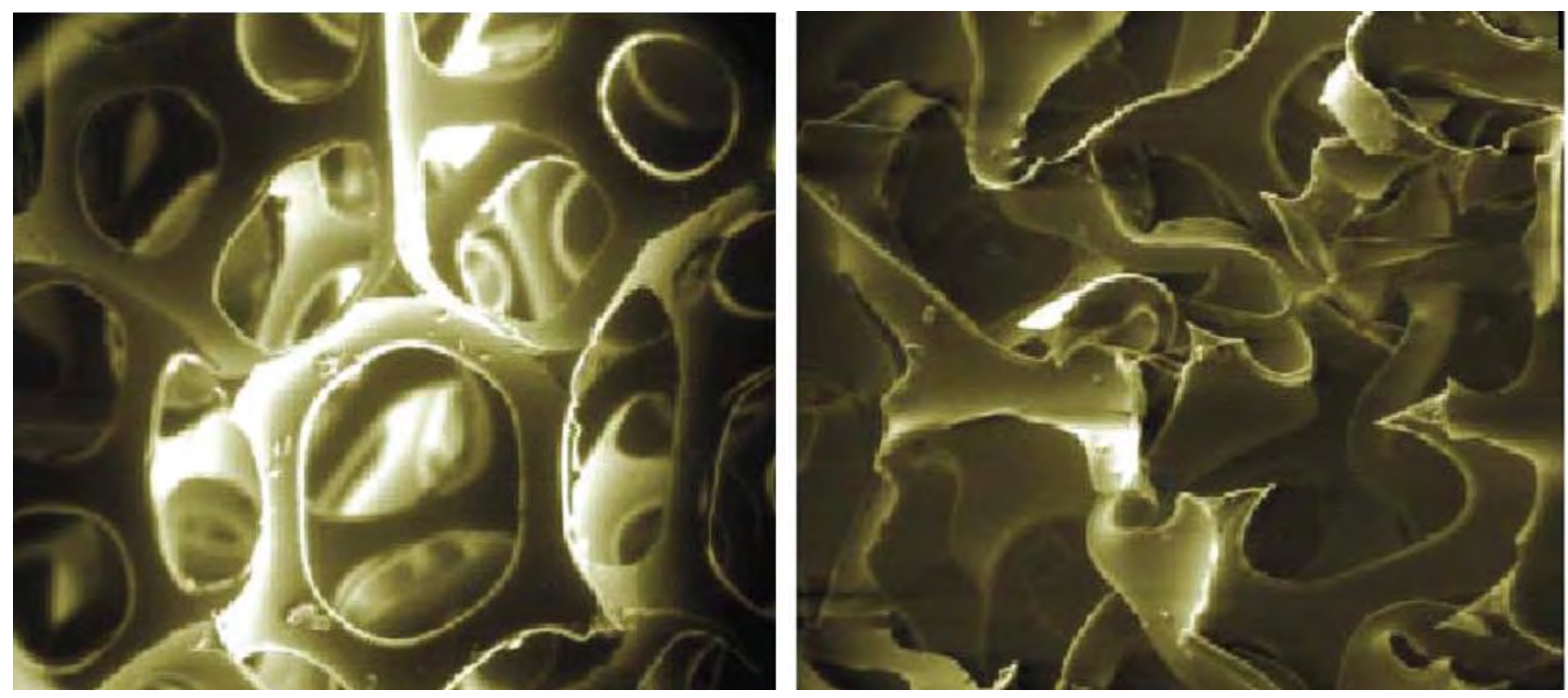

Figura 3. Polímero convencional (izquierda) y polímero auxético (derecha)

El origen físico de la relación de Poisson negativa se puede apreciar en vista de la célula unitaria idealizada (figura 4), desarrollada por Lakes (1987). La tensión aplicada a los enlaces verticales hará que la célula se despliegue y se expanda lateralmente. 


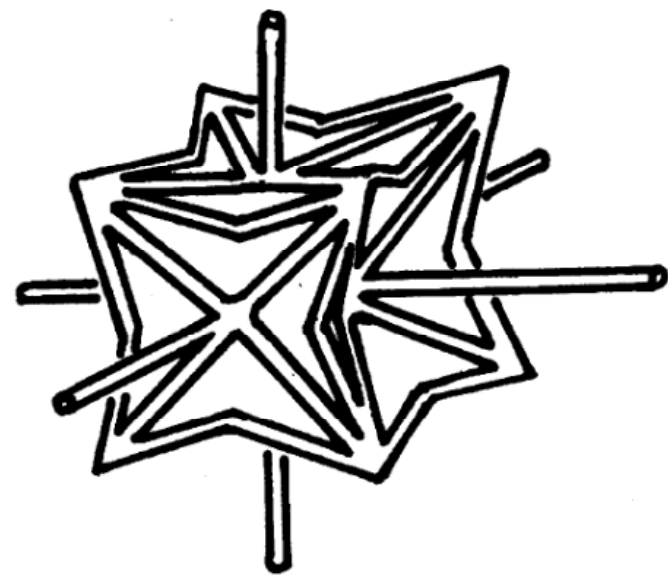

Figura 4. Célula unitaria reentrante idealizada producida por colapso simétrico de un poliedro de 24 caras con simetría cúbica, Lakes (1987)

Evans (1991) llama a los materiales con una relación negativa de Poisson materiales auxéticos, explicando que tienen la fascinante propiedad de engordar cuando se estiran. En su artículo "Auxetic polymers: a new range of materials" describe algunas de las consecuencias de este fenómeno y algunas de las vías para fabricar polímeros con esta propiedad, además de revisar las posibles aplicaciones de estos materiales.

Lakes $^{4}$ lleva a cabo un profundo estudio en 1993 acerca de los materiales auxéticos. Establece el coeficiente de Poisson negativo de poliuretano (PU) con las estructuras reentrantes, lleva a cabo una revisión de todos los materiales auxéticos descubiertos hasta el momento y profundiza en sus métodos de fabricación e implicaciones de tan inusuales propiedades físicas.

Unos años más tarde, Prall et al. (1997) y Gaoyuan et al. (1998) realizan una investigación teórica y experimental acerca de las estructuras quirales de nido de abeja de dos dimensiones y los materiales con coeficientes de Poisson negativo y constatan su alta rigidez de corte, una propiedad útil para muchos tipos de materiales estructurales y funcionales.

Se propone un nuevo modelo para explicar las espumas fabricadas con anterioridad con un coeficiente de Poisson negativo. En el 2000 Smith describe la deformación dependiente del

\footnotetext{
${ }^{4}$ La investigación de Lakes sobre las propiedades auxéticas llega hasta nuestros días, pudiéndose consultar todas sus publicaciones en la web de la Universidad de Wisconsin: http://silver.neep.wisc.edu/ lakes/Poisson.html
} 
comportamiento en función del coeficiente de Poisson de los materiales de nido de abeja y espuma. Alderson et al. (2001), por su parte, estudia el funcionamiento como filtro de los materiales auxéticos desde la macro-escala a la escala nanométrica.

La existencia de la propiedad en los sólidos cristalinos de la clase de simetría monoclínica, en contra del comportamiento tradicional de los cuerpos, que produce que un material se contraiga cuando lateralmente es comprimido y se expanda cuando es estirado, se presenta por primera vez por Rovati (2004).

Los materiales con coeficiente de Poisson negativo se modelizan usando en gran medida mallas regulares 2D. Gaspar et al. (2005) y Guo et al. (2006), con estas herramientas, presentan nuevos resultados para coeficientes de Poisson extremos y cristales elásticos relacionados respectivamente.

La investigación realizada por Brothers et al. (2008) establece las propiedades mecánicas de compresión uniforme y densidad graduada en espumas Al-6061. En su trabajo se observa que la espuma uniforme muestra características de comportamiento de compresión de espumas metálicas convencionales (uniformes) con una tensión casi constante en los planos, las espumas de densidad graduadas, a su vez, exhiben un esfuerzo en los planos suavemente ascendente.

Strek et al. (2008) estudia el comportamiento mecánico de una placa elástica densa, hecha de un material isotrópico mientras que y Gatt et al. (2009) un año más tarde presenta un compuesto estratificado con capas alternas de materiales con coeficiente de Poisson negativo y positivo. Kocer et al. (2009) investiga el comportamiento de las tiras de biomaterial cuando se somete a cambios en la presión hidrostática externa mientras que la problemática de una placa de múltiples capas es analizada por Bhullar et al. (2009) ese mismo año.

SK Bhullar, JL y A. Wegner Mioduchowski (2010) estudian el comportamiento auxético de una placa de capas sometida a una repentina presión normal uniforme, el estrés térmico y la variación de la temperatura de los materiales auxeticos y no auxeticos, y estudian su comparación.

Zheng Dong-Ma, Ann Arbor, MI (EE.UU.) patentan "Estructuras tridimensionales auxeticas y aplicaciones de las mismas" (2011). 
Dirremberger et al. (2013) estudian las propiedades elásticas efectivas de las microestructuras auxéticas, centrando su atención en la anisotropía y las aplicaciones estructurales, considerando en su trabajo tres microestructuras auxéticas periódicas basadas en geometrías 2D, aplicándoles tensión que compensan por su alto módulo de cizalladura.

Recientemente, Jiang, J.-W. et al. (2016) han unido dos campos anteriormente independientes (los materiales auxéticos y los nanomateriales), que han comenzado a intersecarse de formas nuevas e interesantes debido al reciente descubrimiento de la auxeticidad en nanomateriales como el grafeno, nanoplacas metálicas, fósforo negro y otros.

En cualquier caso, las aplicaciones que han surgido hasta nuestros días, incluyen sectores como:

- $\quad$ Textil: Fibras auxéticas, hilos, telas.

- Industrial: Fibras de refuerzo, filtros de aire, juntas, cuerdas, filtros, cierres, remaches, sellados, cojines de asientos, amortiguadores, aislantes, materiales de paquetería, radomos.

- Aeroespacial: Elementos curvados de los aviones, perfiles de ataque de misiles, paneles de los aviones.

Protección: Cascos, chalecos antibalas, espinilleras, rodilleras, guantes, prendas de protección, parachoques.

Biomedicina: Vendajes, hilo dental, válvulas sanguíneas artificiales, piel artificial, suturas quirúrgicas, tendones, medicamentos de liberación sostenida.

- Sensores y actuadores: Hidrófonos, dispositivos piezoeléctricos, sensores miniaturizados.

Pero nunca se han aplicado estos materiales ni este comportamiento auxético a la arquitectura.

En el presente artículo los materiales y estructuras auxéticas se estudian desde el nivel molecular al macroscópico, para formar parte de la arquitectura. 


\subsubsection{Tipos de estructuras auxéticas}

En las últimas décadas, desde el trabajo de Lakes en 1987, se han estudiado numerosas estructuras auxéticas, tanto bidimensionales como tridimensionales, las cuales según Yanping Liu \& Hong Hu (2010) se han clasificado de forma genérica en:

- $\quad$ Estructuras reentrantes. Las primeras estructuras de este tipo fueron sugeridas por Gibson y otros en 1982. Se trata de formas hexagonales donde dos de los vértices se han introducido hacia el interior de la forma de la celdilla genérica (figura 5).

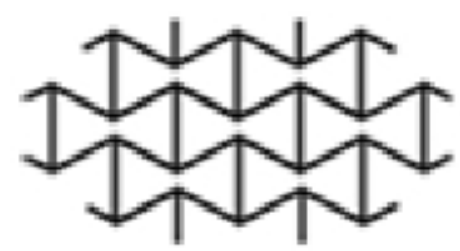

(a)

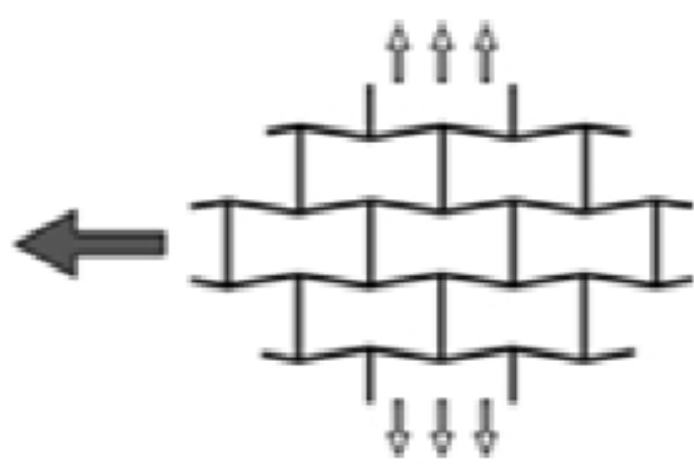

(b)

Figura 5 Estructuras reentrantes hexagonales (a) deformada (b) sin deformar

Este tipo de estructuras se deforman principalmente debido a la flexión de los lados interiores del polígono hexagonal, lo cual es el causante del comportamiento auxético. De las dimensiones de la geometría, así como de los ángulos y la rigidez del material dependerán que se alcance en mayor o menor grado el comportamiento auxético.

Si bien la geometría clásica de las estructuras reentrantes es la mostrada en la figura anterior, existen otros tipos de estructuras de este tipo (figura 6), con forma de estrella, panal de abeja, ligamentos sinusoidales o con forma de esvástica. En este último caso el comportamiento auxético se produce debido a la rotación y extensión de cada lado de la celdilla unidad. 


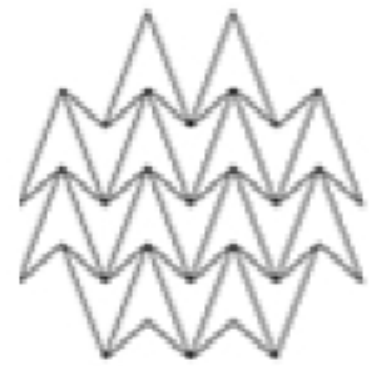

(a)

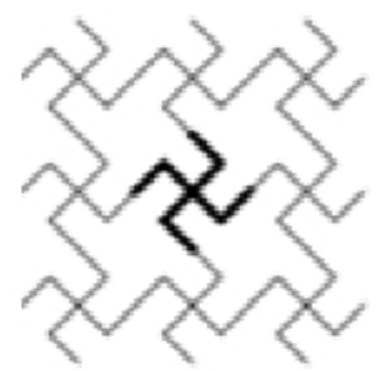

(d)

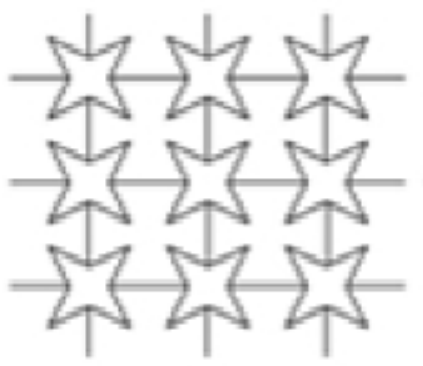

(b)

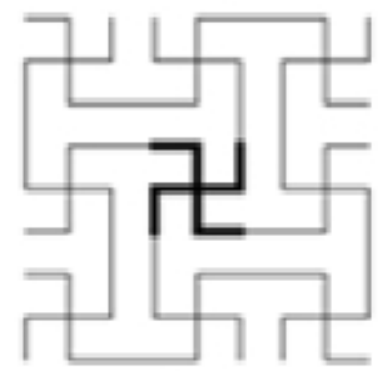

(e)

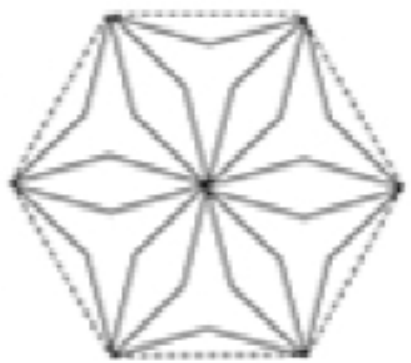

(c)

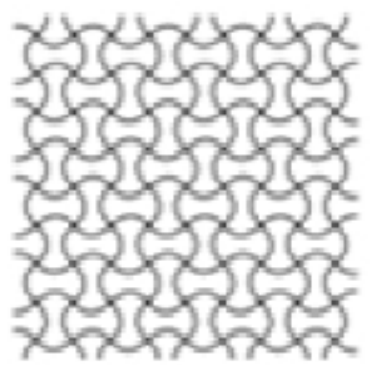

(f)

Figura 6. Otros tipos de estructuras reentrantes (a) estructura de doble punta de flecha (b) estructura de panal de abeja en forma de estrella (c) estructura reentrante hexagonal de panal de abeja (d) estructura formada por mallas romboidales (e) estructura formada por mallas cuadradas ( $f$ ) estructura formada por ligamentos sinusoidales

Además de las estructuras 2D mostradas anteriormente también se puede encontrar estructuras tridimensionales reentrantes auxéticas. Un ejemplo es la estructura auxética generada a partir del tetracaidecaedro (figura 7), también uno de los modelos más clásicos.

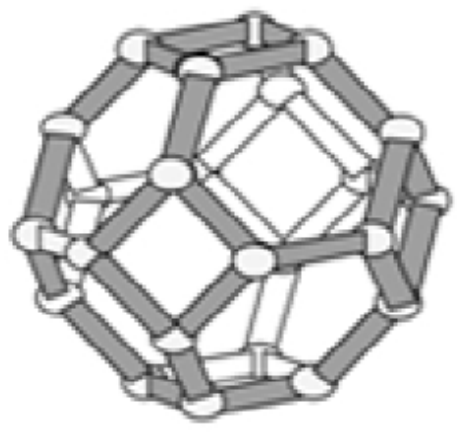

(a)

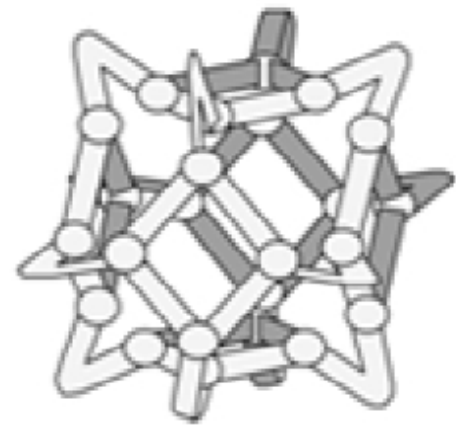

(b)

Figura 7 Estructura tridimensional (a) convencional (b) auxética

- Estructuras quirales. Están formadas básicamente por un núcleo central al que están unidos una serie de ligamentos (figura 8). Para alcanzar el comportamiento auxético dichos ligamentos se enrollan o se desenrollan alrededor del núcleo central. El coeficiente 
de Poisson alcanzado por este tipo de estructuras se encuentra alrededor de -1 (igual deformación transversal que longitudinal). Hay que tener en cuenta que para formar este tipo de estructuras solo serán admisibles núcleos con 3, 4 ó 6 ligamentos, ya que con otro número de estos no es posible repetir la estructura quiral de forma periódica.

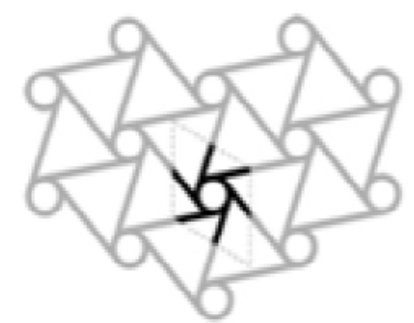

(a)

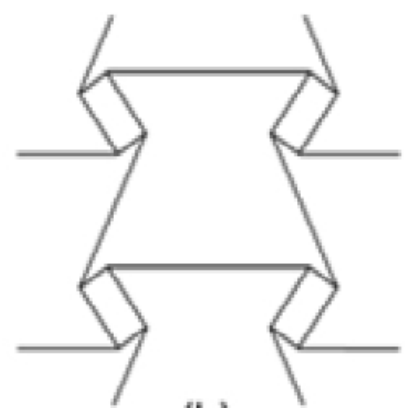

(b)

Figura 8 Estructuras quirales de panal de abeja (a) formada por las mismas unidades quirales (b) formadas por unidades quirales simétricas

- Unidades rotatorias rígidas o semirrígidas. Este tipo de estructuras han sido diseñadas para exhibir comportamiento auxético fundamentalmente en espumas. Se producen por la repetición de polígonos o figuras sencillas unidas mediante bisagras o uniones caracterizadas por su rigidez al movimiento (figura 9). Por ejemplo, se pueden repetir rectángulos, cuadrados, triángulos o tetraedros. El comportamiento auxético se produce por la rotación de las distintas unidades alrededor de las uniones, de tal manera que se produce un empaquetamiento o desempaquetamiento, en función del sentido del movimiento.

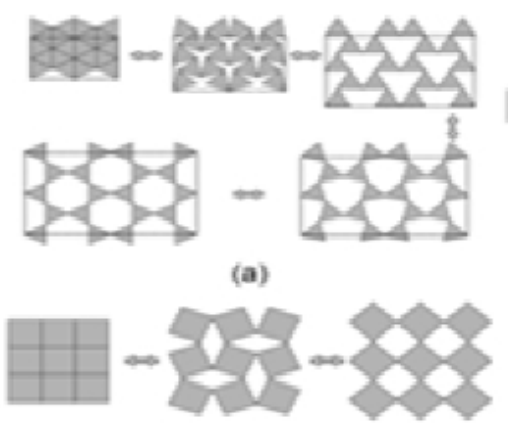

(b)

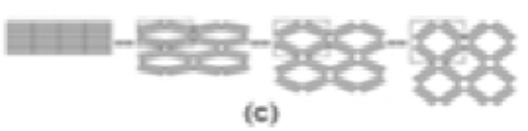

(c)

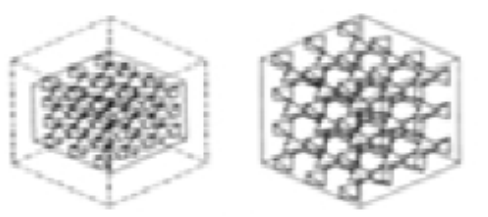

(d)

Figura 9 Unidades rotatorias (a) unidades triangulares (b) unidades cuadradas (c) unidades rectangulares (d) unidades tetraédricas 
- Capas angulares laminadas. Este tipo de composites han sido diseñados para manifestar un comportamiento auxético en función de unos ángulos $\theta 1$ y $\theta 2$ (figura 10).

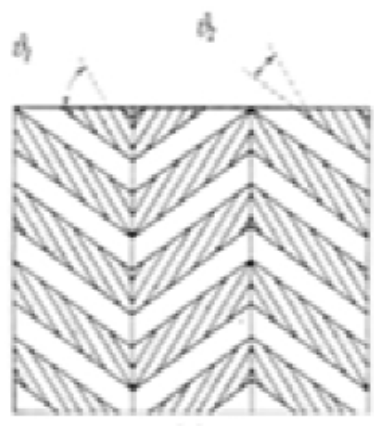

(a)

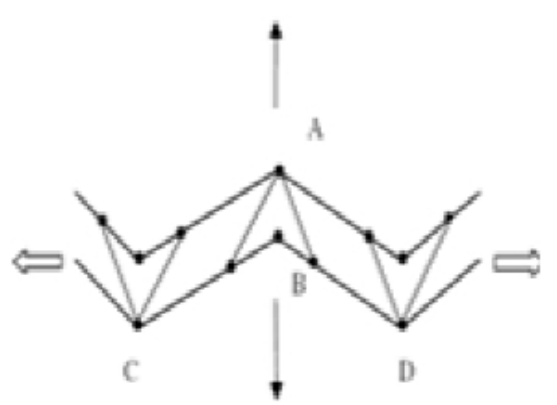

(b)

Figura 10 Composite auxético (a) estructura (b) modelo

- Hard molecules. Se trata de modelos moleculares basados en la interacción molecular, de tal manera que se obtenga un estado termodinámicamente estable y elásticamente isotrópico en el que se manifieste el comportamiento auxético (figura 11).

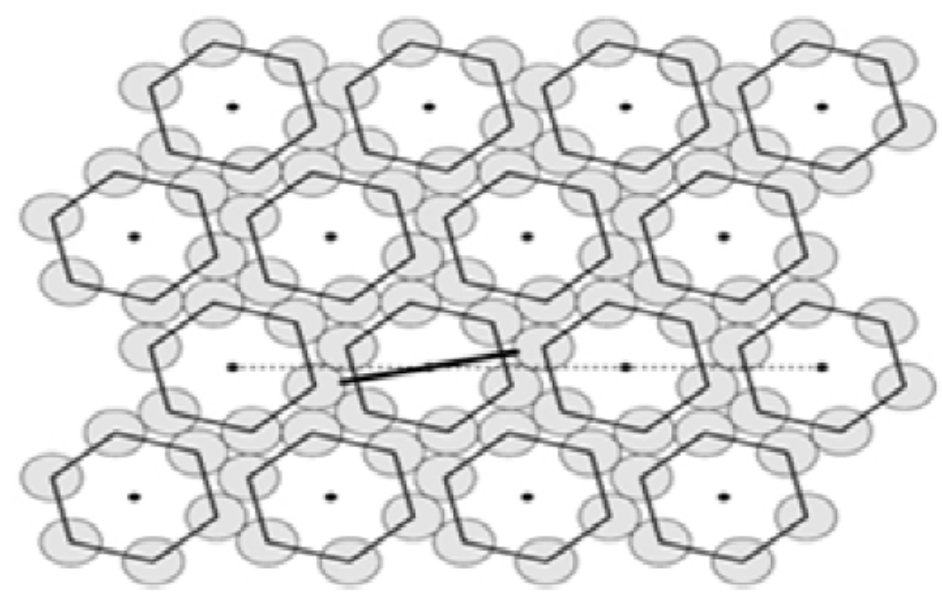

Figura 11 Geometría de hexámeros cíclicos

- Polímeros microporosos. Sus características pueden ser interpretadas como un modelo bidimensional simple, el cual está basado en una red interconectada de núcleos y fibras de manera que al producirse una compresión se produce un movimiento de traslación lateral de los núcleos (figura 12). 


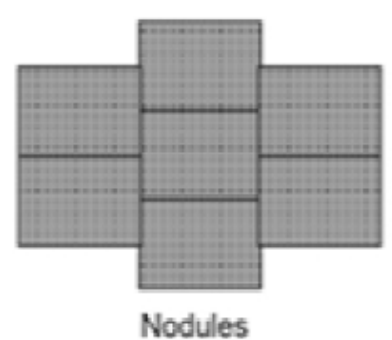

(a)

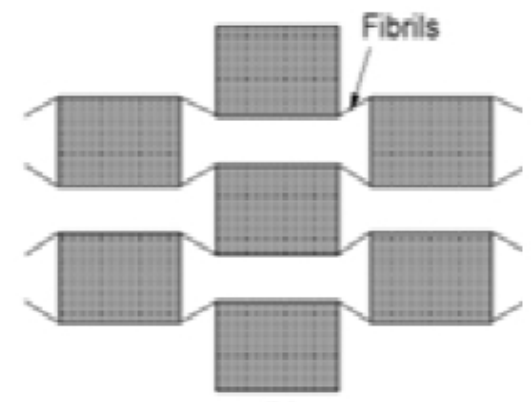

(b)

Figura 12 Esquema de un modelo de nódulos y fibras representando el típico polímero auxético microporoso (a) polímero en reposo (b) polímero bajo carga de tracción

- Polímeros líquidos cristalinos. Este tipo de estructuras se basa en una cadena de moléculas rígidas conectadas por otras cadenas flexibles de tal manera que uno de los extremos de estas últimas está unida a la parte más estrecha de la cadena molecular rígida, y lo otra al punto medio del lateral de dicha cadena molecular. En estado de reposo, todas las moléculas rígidas se encuentran dispuestas en la misma dirección que las flexibles, pero al ejercerse un esfuerzo de tracción esto varía, de tal manera que se orientan alternativamente en direcciones perpendiculares (figura 13).

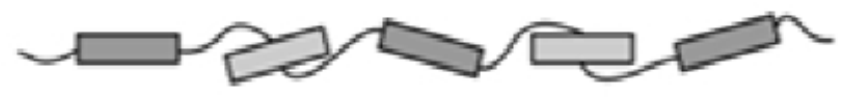

(a)

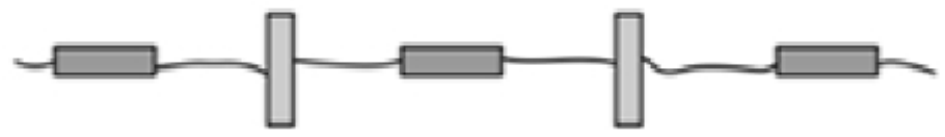

(b)

Figura 13 Polímero líquido cristalino teórico (a) sin deformar (b) deformado 


\subsubsection{Propiedades}

Debido el efecto que el coeficiente de Poisson negativo tiene en las estructuras que lo presentan, estas desarrollan una serie propiedades que las hacen únicas y extremadamente versátiles. A continuación se presentan las características citadas por Yanping Liu \& Hong $\mathrm{Hu}(2010)$.

- Porosidad (>40\% salvo que el comportamiento auxético se presente a nivel molecular). Requisito imprescindible. A mayor porosidad peores propiedades mecánicas en general, con menor rigidez y estabilidad estructural.

Cortadura. A la vista de las ecuaciones de elasticidad, si mantenemos constante el módulo de elasticidad y se consigue un coeficiente de Poisson negativo, se pueden variar las propiedades del material. Por ejemplo, con un coeficiente de Poisson de -1, se obtendría un material muy difícil de deformar a cortadura, pero muy fácil de deformar volumétricamente.

Resistencia a la penetración por indentación. La dureza, entendida como la resistencia a la penetración superficial por un objeto, puede ser mejorada notablemente mediante un coeficiente de Poisson negativo. Esto se explica teniendo en cuanta que este tipo de materiales, al ser deformados por la presión de un objeto, tienden a contraerse hacia ese objeto, de tal manera, que en la vecindad de la penetración el material se vuelve más denso y, por tanto, más duro.

- Resistencia a la fractura. Comparados con materiales no auxéticos, los materiales con coeficiente de Poisson negativo presentan una elevada resistencia a la fractura. Los materiales auxéticos tienen, también, una alta resistencia a la formación de grietas.

Curvatura sinclástica. Al ser deformados por un momento fuera del plano del material, la curvatura toma el mismo signo en las dos direcciones, adoptando la estructura una forma de cúpula, a diferencia de los materiales convencionales, que adoptan una forma de silla de montar.

Absorción de energía. Los materiales auxéticos muestran mayor absorción de energía que los materiales convencionales, ya sea esta ultrasónica, acústica o de amortiguamiento. 
- $\quad$ Permeabilidad variable. Los materiales auxéticos son capaces de abrir los poros cuando son sometidos a tracción, lo cual abre un gran abanico de posibilidades de cara a aplicaciones de filtración.

\subsubsection{Definición de las escalas}

El comportamiento auxético es independiente de la escala, con lo cual puede ser alcanzado desde niveles moleculares hasta niveles macroscópicos. A continuación se muestran las escalas de auxeticidad que, según Alderson (1999), han sido usadas hasta la actualidad (figura 14), más la nueva escala de la arquitectura (en rojo):

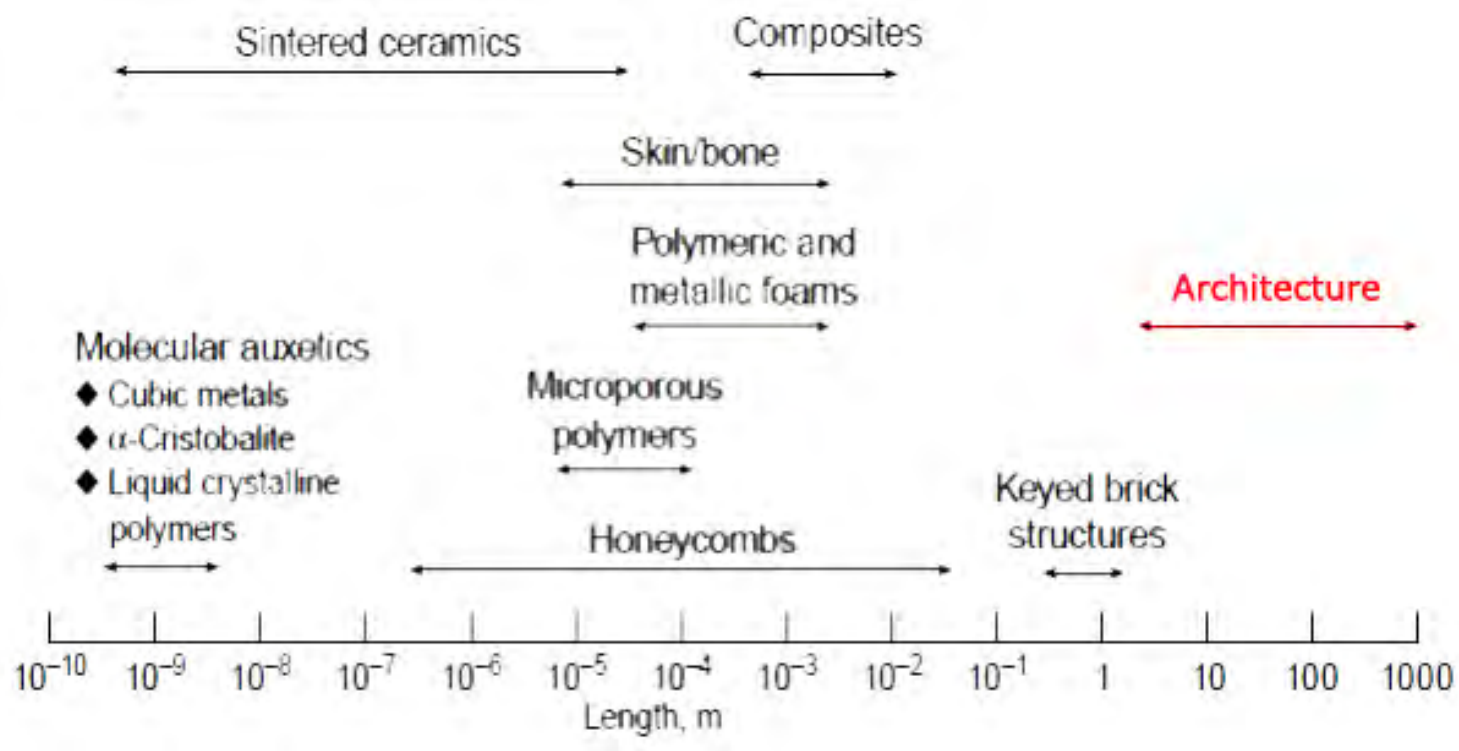

Figura 14 Escalas de auxeticidad según Alderson (1999) + la escala de la arquitectura

Se puede apreciar que estamos en una escala totalmente novedosa, ya que hasta ahora, las estructuras auxéticas más grandes realizadas se medían con unidades inferiores al metro, con lo que el paso a la medición en metros llevará un proceso físico y matemático (además de geométrico) detrás muy importante. 


\subsection{Antecedentes relacionados con arquitectura}

La arquitectura actual se caracteriza por estar concretando nuevas tipologías no experimentadas hasta este momento en el ámbito de la ingeniería y la arquitectura.

Durante los años 50 y 60 se empezaron a desarrollar nuevas tipologías desplegables, generando formas transformables a partir del estudio de la geometría (Puertas, 1989). Geometría, estructura y forma van a coincidir, entendiendo esta última como un concepto fluido y en movimiento, donde es más importante disponer los vacíos en la estructura que disponer las masas. Es el futuro de la arquitectura: la liviandad. Se buscan soluciones para la creación de un espacio arquitectónico transformable a la vez que funcional, ya que son soluciones caracterizadas por su fácil almacenaje, practicidad y polivalencia.

Dado su carácter temporal o itinerante en muchos de los casos, el diseño deberá tener en cuenta la facilidad de transporte, montaje y desmontaje y deberá valorar la sostenibilidad de la propuesta así como la utilización de materiales duraderos a la intemperie. Se valorará su flexibilidad y adaptabilidad con el menor coste y complejidad posible.

Como exponentes de este campo de las estructuras en los años $50-60$ se puede citar a Stephane du Chateau, R. Buckminster Fuller, R. Le Ricolais y el gran animador Z. S. Makowski. Más adelante tendremos exponentes como Florencio del Pozo, Pablo Bueno, José Calavera, Álvarez Castelao y Francisco Rius, Juan Margarit y Carlos Buxadé, Félix Candela, Emilio Pérez Piñero, Escrig, Sánchez y Valcárcel, Chuck Hoberman, Carlos Henrique Hernandez, Luis Sanchez Cuenca...

Por otra parte, este inicio de siglo XXI está inmerso en una segunda revolución postindustrial, la era digital (Anaya, 2014). La sociedad está sufriendo los cambios de adaptación a los nuevos sistemas de producción, al aumento exponencial de disponibilidad de la información y la accesibilidad a la tecnología. La arquitectura está experimentando nuevos procesos de adaptación con el uso de las herramientas digitales, tras la incorporación de software informáticos al campo del diseño industrial con tecnologías avanzadas a sus medios de producción y edición, desarrollando formas libres arquitectónicas con geometrías no euclidianas, lógicas del análisis y diseño paramétrico y tendentes a la mímesis de comportamientos con la naturaleza, de una forma económica y accesible (Fraile, 2014).

La utilización del diseño paramétrico ha revelado ser una experiencia innovadora y enriquecedora del proyecto arquitectónico. Se generan nuevas y novedosas estructuras, de gran riqueza espacial, donde gracias a una serie de algoritmos generativos, las formas 
"crecen" y se interrelacionan en complejos patrones topológicos, de acuerdo con parámetros ajustados por el diseñador (Fraile, 2014). Conducir esta teorización es la noción de que el "parametricismo" (un estilo de curvar las formas cristalinas biomórficas o angulares generadas por ordenador con el software paramétrico) es el inevitable sucesor estilístico a largo plazo de la arquitectura moderna (Buchanan, 2011).

Innovadoras investigaciones están desarrollando avanzadas construcciones de geometrías complejas y formas libres en manos de arquitectos como Yushang Zhang, Rajiv Sewtahal, Riemer Postma and Qianqian Cai, Kahn, grupo Matsys, Acadia, AKT, Adler, Karan y Taylor, Emmanuel Ruffo... Xefirotarch, Menges, Wanders, Kudless, Faulders, Testa, Arad, Oxman, Hadid, Schumacher, Menges, Goulthorpe, Greg Lynn, Rahim, Asymptote, CAP, Foreign Office y UN Studio entre otros, ingenieros como Schlaich, Boelinger, Sasaki, Sobek, Arup, Balmond, Kara, AKT y Hunt entre otros y grupos de investigación como los Media Lab y Digital Design and Fabrication Group, ambos del MIT de Massachusetts.

En los siguientes apartados se aborda el estudio analítico del conjunto de las soluciones técnicas de diseño de arquitecturas basadas en estructuras geométricas desplegables y en la producción de estructuras geométricas paramétricas basadas en la naturaleza que se aplicarán en la construcción de edificios, generando formas transformables y complejas cuyas condiciones de manufacturación y edición caracterizarán los sistemas innovadores de producción de la arquitectura contemporánea. Este estudio constituye, por tanto, un fundamento de la base documental para la investigación sobre la significación de los nuevos sistemas estructurales y constructivos en la producción de la arquitectura en la actualidad.

\subsubsection{Formas libres y su simbiosis con la naturaleza}

En esta sección se estudian arquitecturas experimentales que siguen caminos novedosos a partir de estructuras encontradas en la naturaleza o con propiedades y geometrías estructurales innovadoras diferentes a las habituales. Es la escala en la que la estructura es igual a la forma. Aplicable en edificios como rascacielos, en los que los sistemas ya no son de flexión o de cortante. Para abordar el tema se buscan ejemplos de arquitecturas relevantes en este sentido. 
Para empezar, se tienen en cuenta las ideas de Robert Le Ricolais (1894-1977), quien cuestionaba la noción de forma como algo estático, entendiendo ésta como un concepto fluido y en movimiento. Mimram (1983) realiza un estudio sobre la estructura y la forma aplicada a la obra de Robert le Ricolais. El citado Ricolais intenta descubrir la relación existente entre las estructuras extraídas de la propia naturaleza (donde encuentra sobre todo modelos complejos de organización), y las estructuras de la forma construidas por el ser humano (lo cual corrobora que la hipótesis del cambio de escala es viable). En sus nuevos conceptos estructurales aparece la idea de que es más importante disponer los vacíos en la estructura que disponer las masas. El arte de la estructura consiste en cómo y dónde colocar los agujeros: es una idea tremendamente ligada con toda forma construida, ya que implica construir con agujeros, construir con material hueco y con estructuras huecas y resistentes pero sin peso.

Debido a que vamos a desarrollar una estructura a partir de otra que conocemos a escala nanotécnica, también se tienen en cuenta las reflexiones de Darcy Thomson (2003), en su libro "El crecimiento de la forma", donde nos expone que no se puede crecer de la misma manera en una escala que en otra, explicando del crecimiento y forma biológicos en términos físico-matemáticos. La estructura ha aparecido a causa de fuerzas físicas, moleculares en estructuras muy pequeñas, y mecánicas en estructuras grandes (es decir, "adaptaciones directas"), teniendo la forma un aspecto funcional y mecánicamente eficiente, generada a partir del poder formativo de las fuerzas físicas.

Las velocidades, tensiones y condiciones de equilibrio de las moléculas que forman parte de la materia se abordan mediante la mecánica molecular con los métodos de las matemáticas. Nada más introducirnos en los caminos de la física, aprendemos a pesar y medir, a tratar con el tiempo, el espacio, la masa y otros conceptos, como el número, que nos da una precisión numérica, que permite explicar mediante la geometría o la mecánica las cosas. La causa final es un proceso mecánico, que tiene una unidad de principios o de similitudes esenciales entre los fenómenos orgánicos e inorgánicos, siendo los problemas de morfología problemas del sistema material de fuerzas mecánicas.

Las formas materiales de los seres vivos se mueven, moldean y configuran obedeciendo a las leyes de la física, por lo que, en última instancia, sus problemas de forma son problemas matemáticos. Para una morfología dinámica tenemos leyes físicas y matemáticas. Los principios matemáticos y leyes físicas se relacionan con algunos de los más sencillos fenómenos de construcción de Crecimiento, Estructura y Forma de los organismos, 
entendiendo la formación del organismo como una configuración material y mecánica. Las formas pueden explicarse bajo consideraciones físicas de acuerdo con las leyes físicas y matemáticas, relacionando el Crecimiento con la Forma, tanto si aparece por simple aumento de tamaño sin alteraciones aparentes de la forma, como si aparece como un gradual cambio en la forma y un lento desarrollo de una estructura más o menos complicada.

Si se tienen en cuenta los conceptos de física elemental, la fuerza es la acción para producir o cambiar el movimiento, o para impedir el cambio del movimiento o mantener el reposo. La energía bajo sus diversas formas actúa sobre la materia. Pero cuando abstraemos nuestros pensamientos de la materia a su forma, o de la cosa movida a sus movimientos, si tratamos con el concepto subjetivo de forma, o movimiento o movimientos que implican cambios de forma, entonces el término apropiado para nuestro concepto de las causas por las que estas formas y cambios de forma tienen lugar es Fuerza. Cuando usamos el término fuerza lo usamos, al igual que los físicos, en aras de la brevedad, usando un símbolo o diagrama de una cosa material. Es un término tan subjetivo y simbólico como la forma misma, y de este modo se usa apropiadamente en conexión con ella. Así pues, la forma de cualquier porción de materia tanto viva como inerte, y los cambios de forma que se manifiestan en su crecimiento y sus movimientos, pueden en todos los casos describirse como debidos a la acción de una fuerza. En resumen, la forma de un objeto es un "diagrama de fuerza" en el sentido, al menos, de que a partir de él podemos juzgar o deducir las fuerzas que están actuando o han actuado sobre él.

La Conformación del organismo se consigue mediante la permanencia o equilibrio explicados por la interacción o equilibrio de las fuerzas, como describe la estática. La forma y el movimiento se investigan con los métodos físicos, y se explican invocando al concepto matemático de la Fuerza. El estado de una porción de materia, incluyendo su aspecto o forma, es el resultado de un cierto número de fuerzas que representan o simbolizan la manifestación de ciertos tipos de energía. El asiento de fuerzas moleculares se manifiesta en forma de tensión superficial que afecta considerablemente a la forma de la superficie fluida. La morfología nos permite interpretar en términos de fuerza, el funcionamiento de la energía.

Tomando referencias de una de las publicaciones más innovadoras en esta época, "La singularidad está cerca" de Ray Kurzweil (2005), éste plantea "la ley de los rendimientos 
acelerados". Esta ley analiza la futura aparición de una inteligencia de nivel más elevado con base no biológica que proporcionará un cambio de paradigma en la evolución humana. Las tres tecnologías que darán lugar a esta singularidad son la genética, la nanotecnología y la robótica (GNR). Kurzweil fecha la Singularidad tecnológica en el 2045.

Tras estas premisas de partida, la era computacional acaba de lanzarse a un amplio campo por explorar. No sólo la era computacional ha influenciado activamente en el diseño sino también en la producción, todos los avances realizados en la última década en las herramientas y metodologías de ambas actividades, se muestran en los nuevos programas de CAD/CAM (Computer Aid Design and Manufacturer), según Kolarevic (2001), favoreciendo la obtención de formas libres y formas editables.

Las superficies topológicas, isomórficas, la inclusión de la cinemática y la dinámica, las arquitecturas metamórficas, paramétricas y evolucionarias permiten el descubrimiento de múltiples y variadas soluciones formales desconocidas hasta la fecha, y aplicables en diversas actuaciones artísticas observables en exposiciones internacionales, grupos de investigación y laboratorios universitarios, destacando MIT Media Lab, Digital Design o ETALAB (2002), que ha diseñado una interfaz interactiva para experimentar la forma cambiante de su propuesta de "Tate in Space".

La propuesta "Tate in Space" contiene un modelo tridimensional al que se puede acceder en línea y modificarse en tiempo real. Permitirá a los artistas y curadores de Tate definir, visualizar y trabajar dentro de numerosas nuevas configuraciones de forma y gravedad, ya sean fijas o cambiantes, aleatorias o prescritas. Estas características se pueden aplicar a la Tate física en el espacio. A su debido tiempo, la interfaz se desarrollaría utilizando la programación avanzada de computadoras.

A medida que el proyecto evoluciona, esta herramienta de curadoría podría proporcionar la base para una interfaz personalizada para todos los usuarios de la web. Las preferencias se pueden almacenar como archivos de datos que permiten a los visitantes cambiar rápidamente entre diferentes versiones de su propia "personalidad".

ETALAB considera a "Tate in Space" como un proyecto de potencial sin par, que se desarrolla orgánicamente de acuerdo con la nueva tecnología y horizontes artísticos sin restricciones, las posibilidades son tan infinitas como el espacio mismo. 


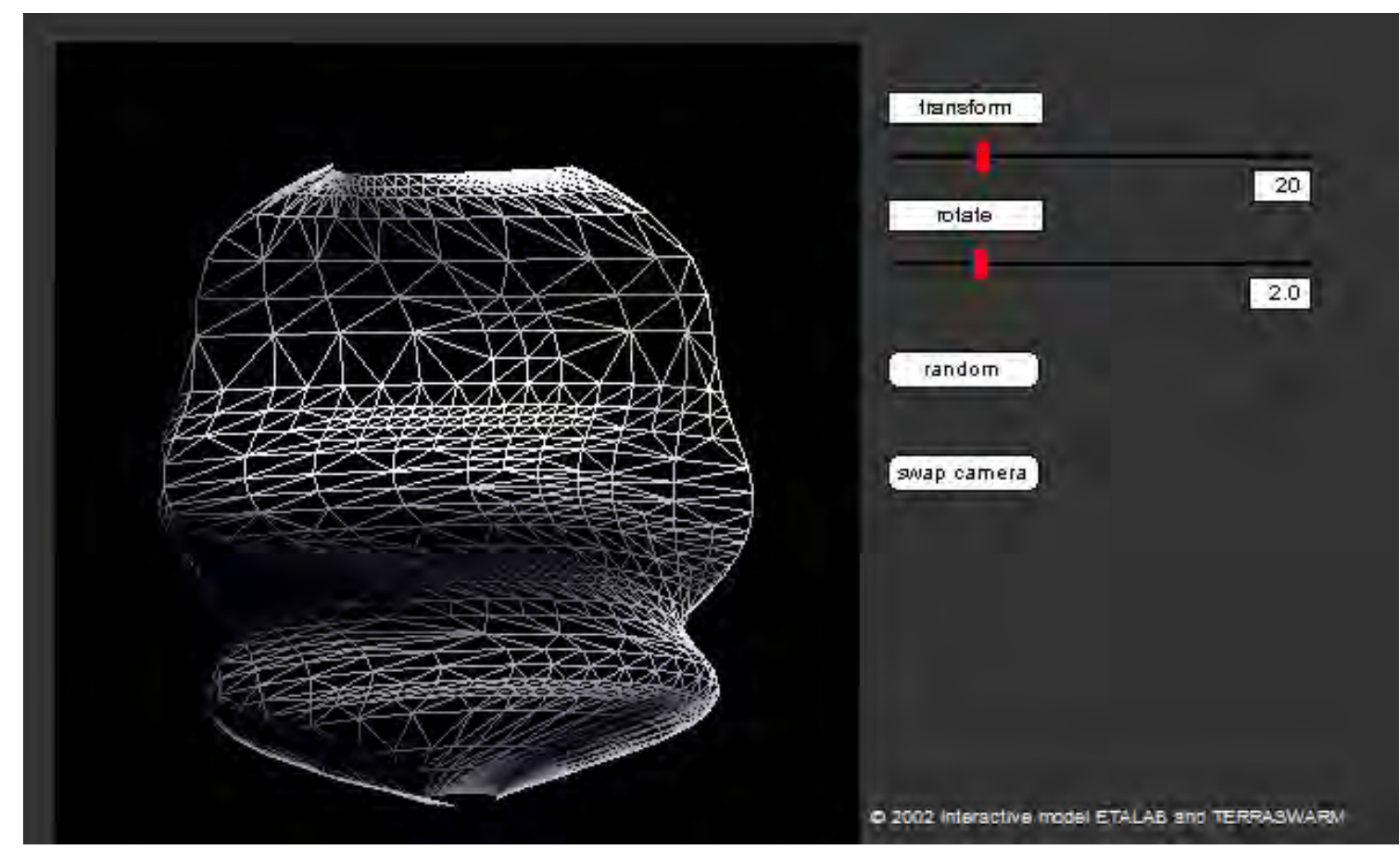

Figura 15 ETALAB interactive model. 2002.

La inclusión de nuevas disciplinas en el campo arquitectónico, o la necesidad de incorporar soluciones pluridisciplinares en el diseño, convergen en la creación de nuevas formas dominadas por el naturalismo. La exploración de los principios evolutivos de las formas existentes en el mundo, y su simulación con herramientas computacionales, nos brindan investigaciones formales que usan una nueva fórmula de hibridación entre naturaleza y artificio.

Siguiendo con las arquitecturas que buscan una mímesis con la naturaleza, se descubrió que la estructura ósea del cerebro responde a polígonos de Voronoy, siendo una estructura absolutamente estable, en la que en todo instante existe una relación de equilibrio, de tal forma que si se mueve algo se redireccionan las tensiones para volver al equilibrio: esto puede producirse porque hay una continuidad estructural. Esta estructura se ha aplicado a la arquitectura en el proyecto "Vertical Village: A Sustainable Way of Village-Style Living" (Charles, 2012), realizado por Yushang Zhang, Rajiv Sewtahal, Riemer Postma y Qianqian Cai (with studio tutor Alexander Sverdlov, at The Why Factory of professor Winy Maas (MVRDV) at the TU Delft que distribuye las tensiones en el espacio con la misma estructura estable, geometrizada a partir de dichos polígonos de Voronoy presentes en la naturaleza. 

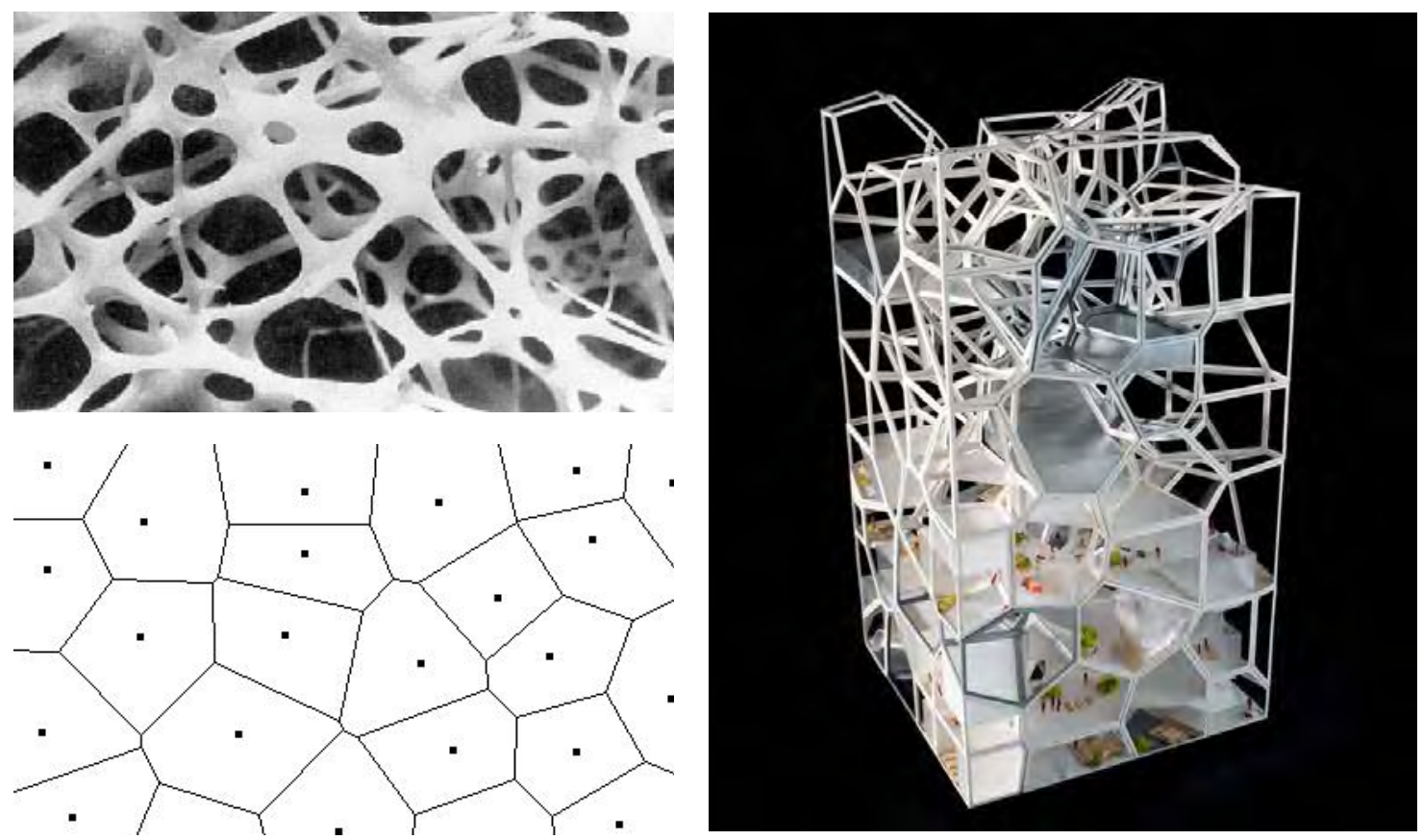

Figura 16 Izquierda arriba: Estructura ósea de cráneo humano. Izquierda abajo: Polígonos de Voronoy. Derecha: Vertical Village: A Sustainable Way of Village - Style Living

De Neri Oxman es el Silk Pavilion (Brayer et al., 2013), en el cual la estructura primaria fue creada a partir de 26 paneles poligonales hechos de hilos de seda establecidos por una máquina CNC (Computer-Numerically Controlled). Inspirado en la capacidad del gusano de seda de generar un capullo 3D de un solo hilo de seda multi-propiedad (1km de longitud), la geometría general del pabellón fue creada usando un algoritmo que asigna un único hilo continuo entre parches que proporciona varios grados de densidad. Los investigadores siguieron el movimiento en 3D para observar gusanos de seda construyendo capullos y traducir el proceso en un modelo digital. Esto se convirtió en la base para una gran estructura - el pabellón - construida a partir de paneles planos, tejidos con un único hilo continuo. Los gusanos de seda fueron desplegados de nuevo, para llenar aún más los espacios negativos. 


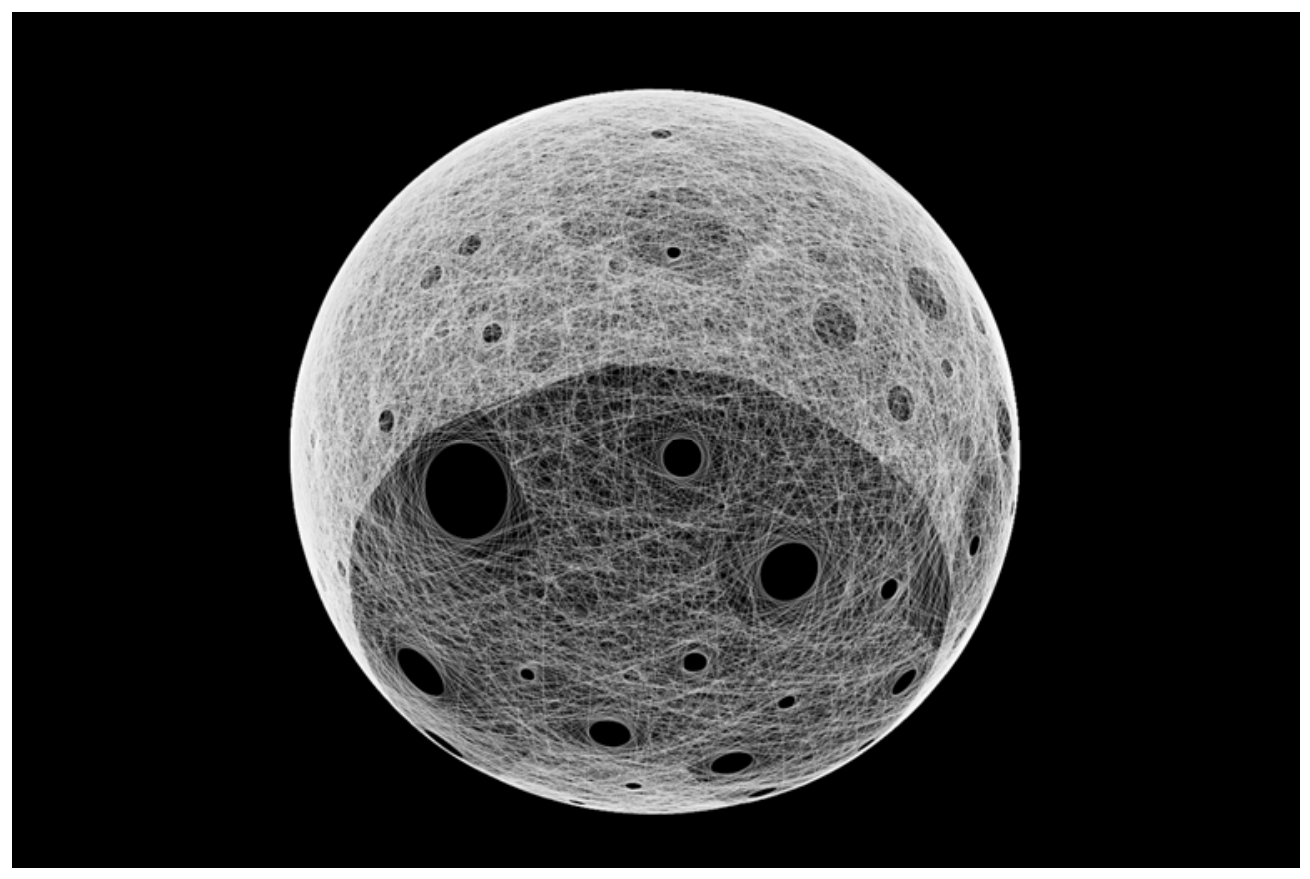

Figura 17 Silk Pavilion, 2013. Neri Oxman.

La City Tower (Bostjan, 2017), diseñada por Louis Kahn con Anne Tyng en Filadelfia (19521957) y nunca construida, es un rascacielos geodésico, estabilizado por un crecimiento desplegable de tetraedros de hormigón postesado, en donde la forma es puro resultado de la estructura. El Proyecto City Tower es importante como parte del desarrollo más amplio de las estructuras espaciales y la noción de crecimiento.
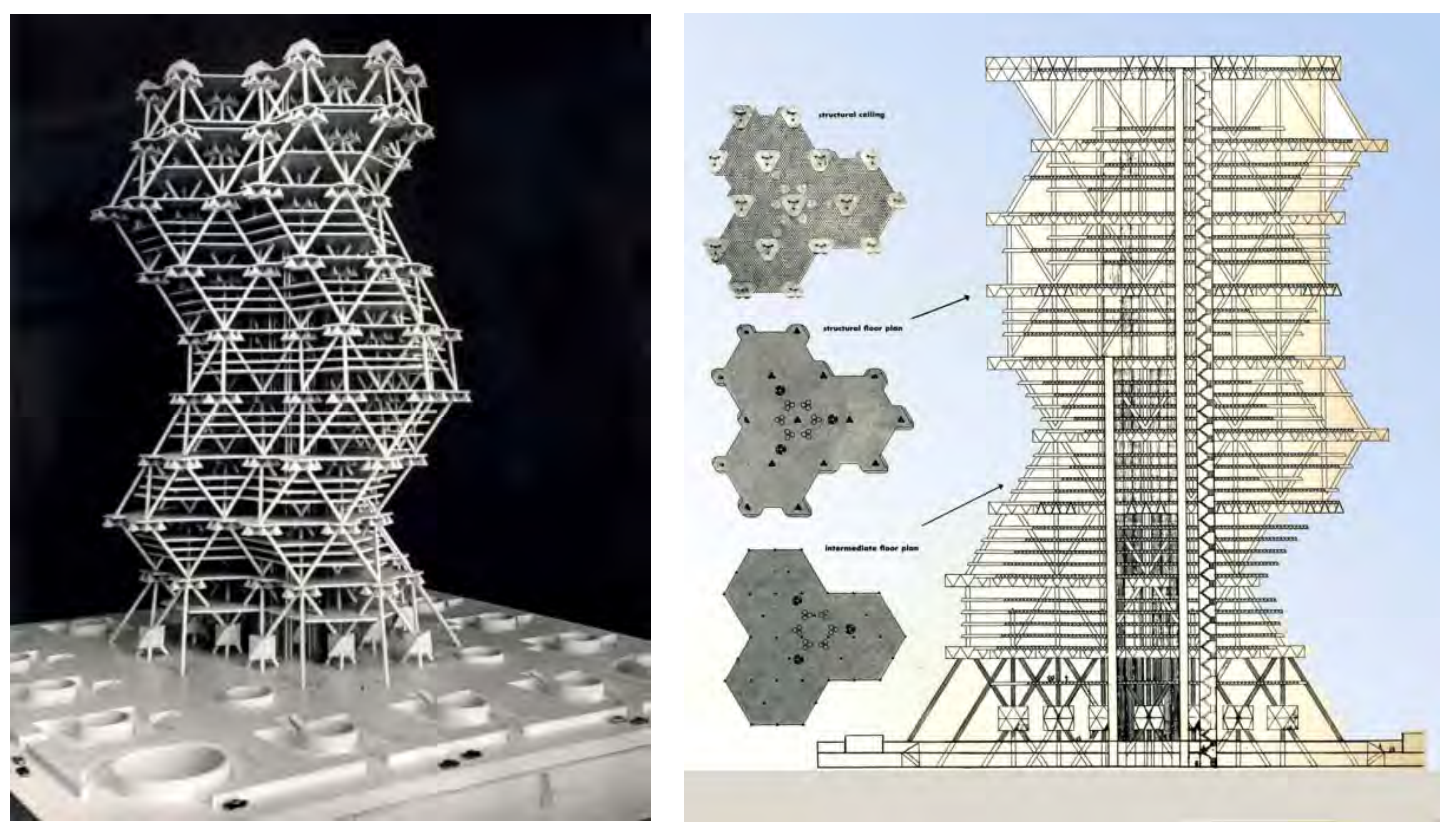

Figura 18 City Tower, Louis I Kahn. Izquierda: Maqueta. Derecha: Sección y plantas 
Estudios del grupo Matsys ${ }^{5}$ reflejan soluciones de trazados geométricos que tienen que ver con los que se están estudiando. La serie de la lámpara diploide explora múltiples patrones inspirados en la naturaleza como escalas, paneles y percebes. Usando modelos paramétricos, secuencias de comandos y fabricación digital, la geometría de la luz se crea, refina y produce.

Este grupo también estudia morfologías de panal de abeja, cuyo objetivo central de la investigación es el desarrollo de un sistema material con un alto grado de integración entre su diseño y rendimiento. Esta integración es inherente a los sistemas de materiales naturales para la que han sido desarrollados a través de medios evolutivos que íntimamente unen a la forma, el crecimiento y el comportamiento del organismo.

El proyecto C_WALL del grupo Matsys ${ }^{5}$ es un desarrollo también en esta línea: es el último desarrollo en una zona en curso de la investigación sobre las estructuras celulares de agregado que se han examinado de nido de abeja y las geometrías de Voronoi y su capacidad para producir interesantes actuaciones estructurales, térmicas y visuales.

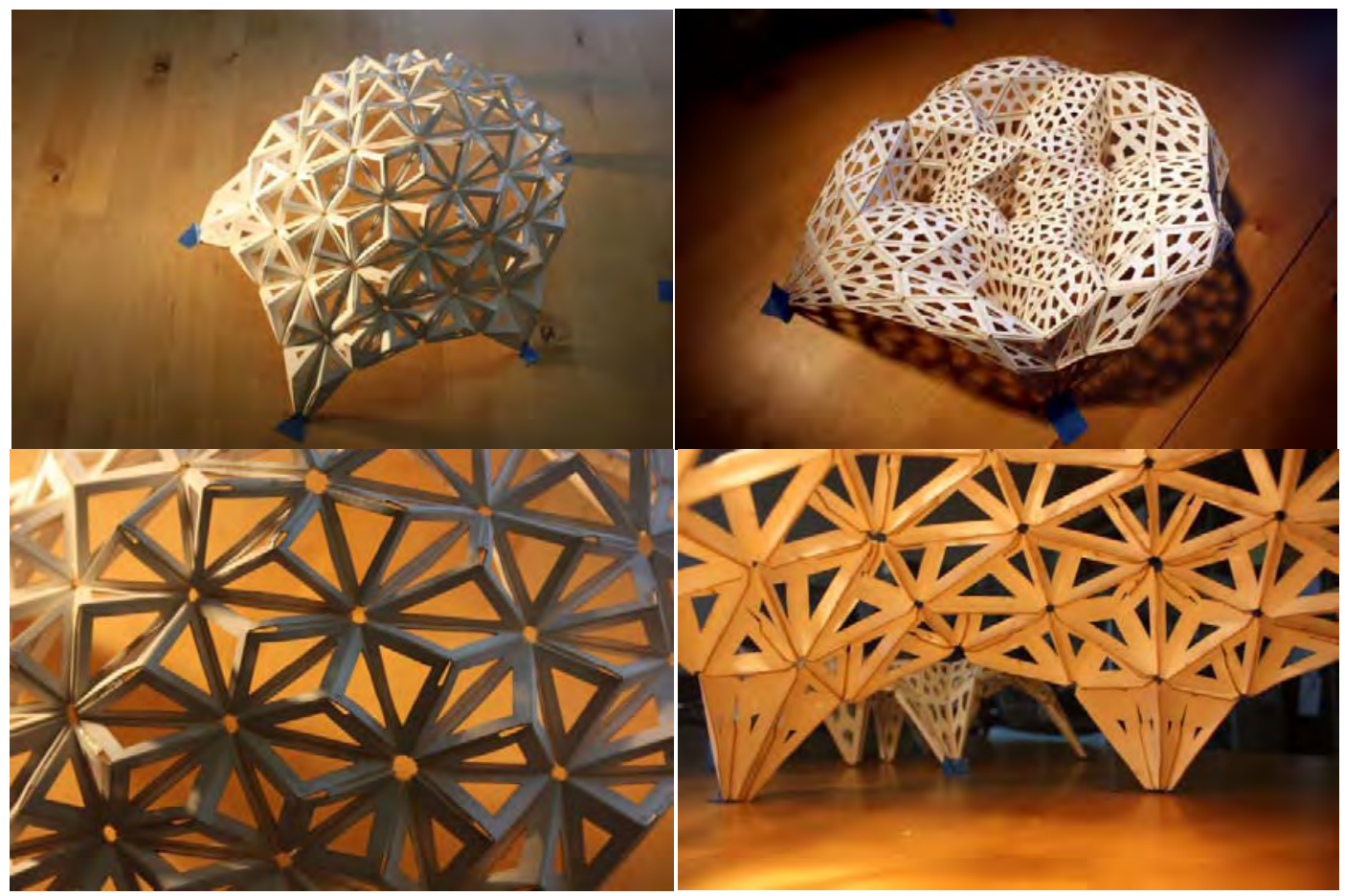

Figura 19 Trabajos realizados en el workshop Cross-Fabricated Scales

\footnotetext{
${ }^{5}$ Ver web "http://matsysdesign.com/"
} 


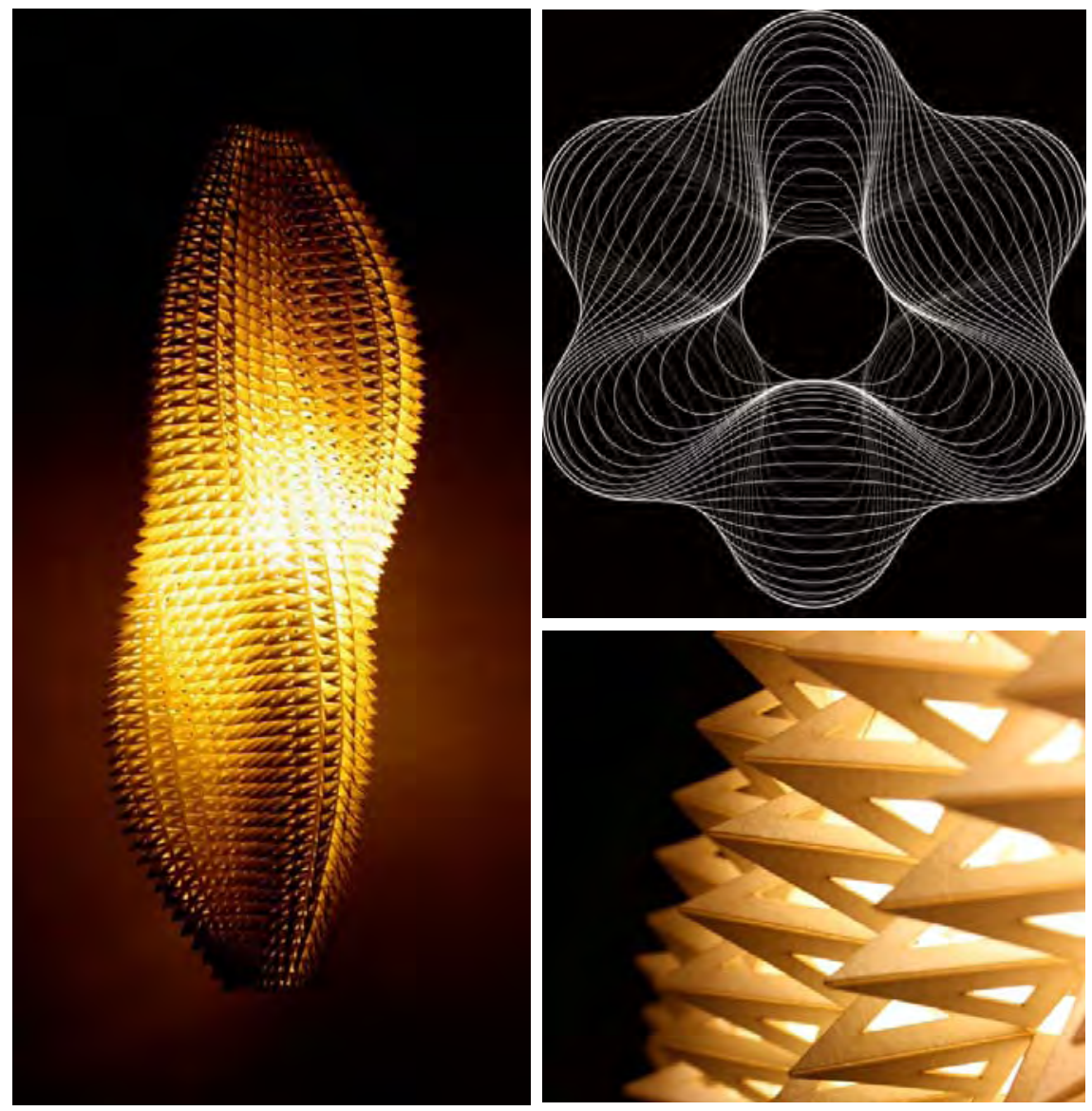

Figura 20 Lámpara diploide, grupo Matsys

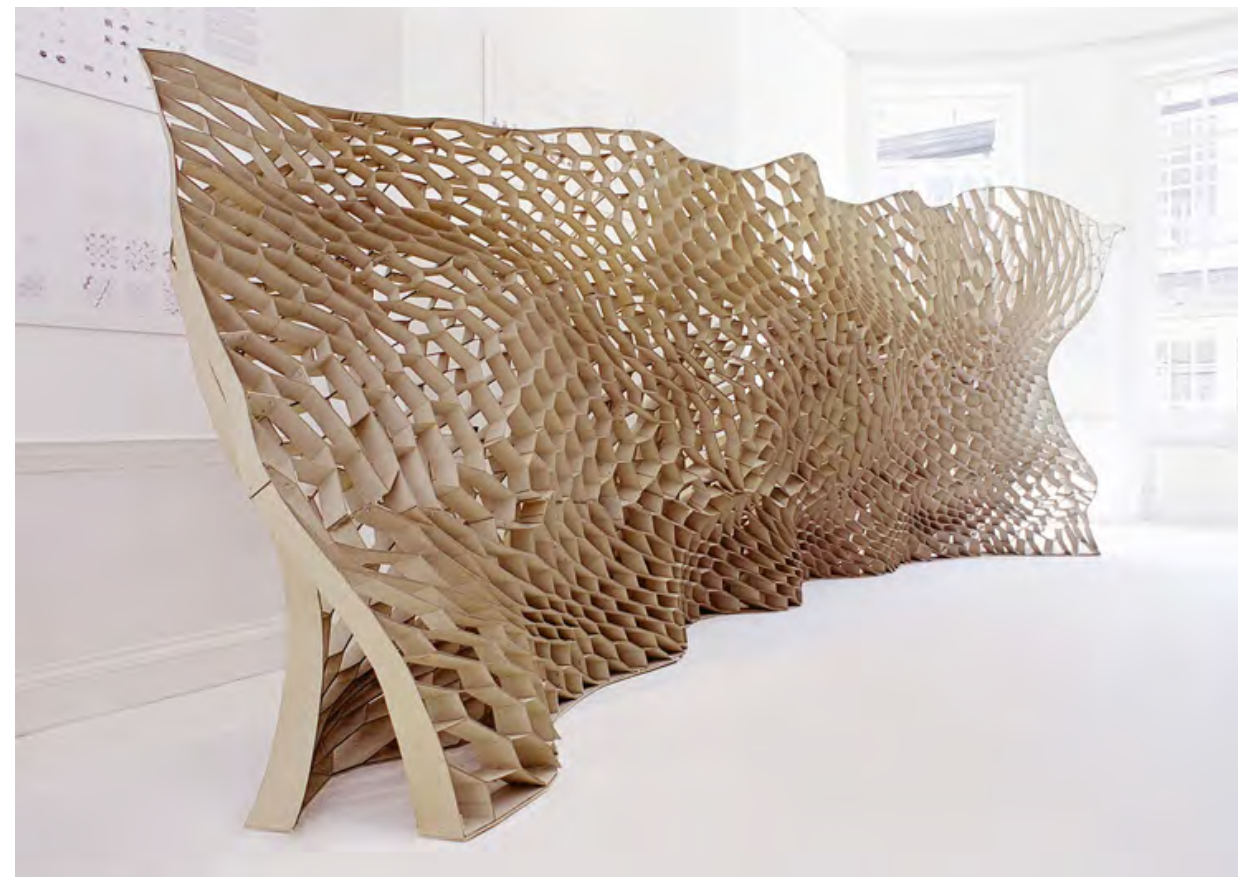

Figura 21 Honeycomb Morphologies 
No debe quedar sin mencionar el grupo ACADIA, de cuyo miembro Dave Pigram, junto con Roland Snooks, se expone a continuación un desarrollo creado a partir de comportamientos de la naturaleza. Este proyecto es un experimento en los afectos creados por algoritmos morfogenéticos. Estos algoritmos están diseñados para generar distorsiones ornamentales dentro de la geometría a través de la lógica interna de la automatización celular. Una técnica donde un elemento en el espacio cambia continuamente su estado basado en los estados de los que lo rodean, dando lugar a patrones emergentes.

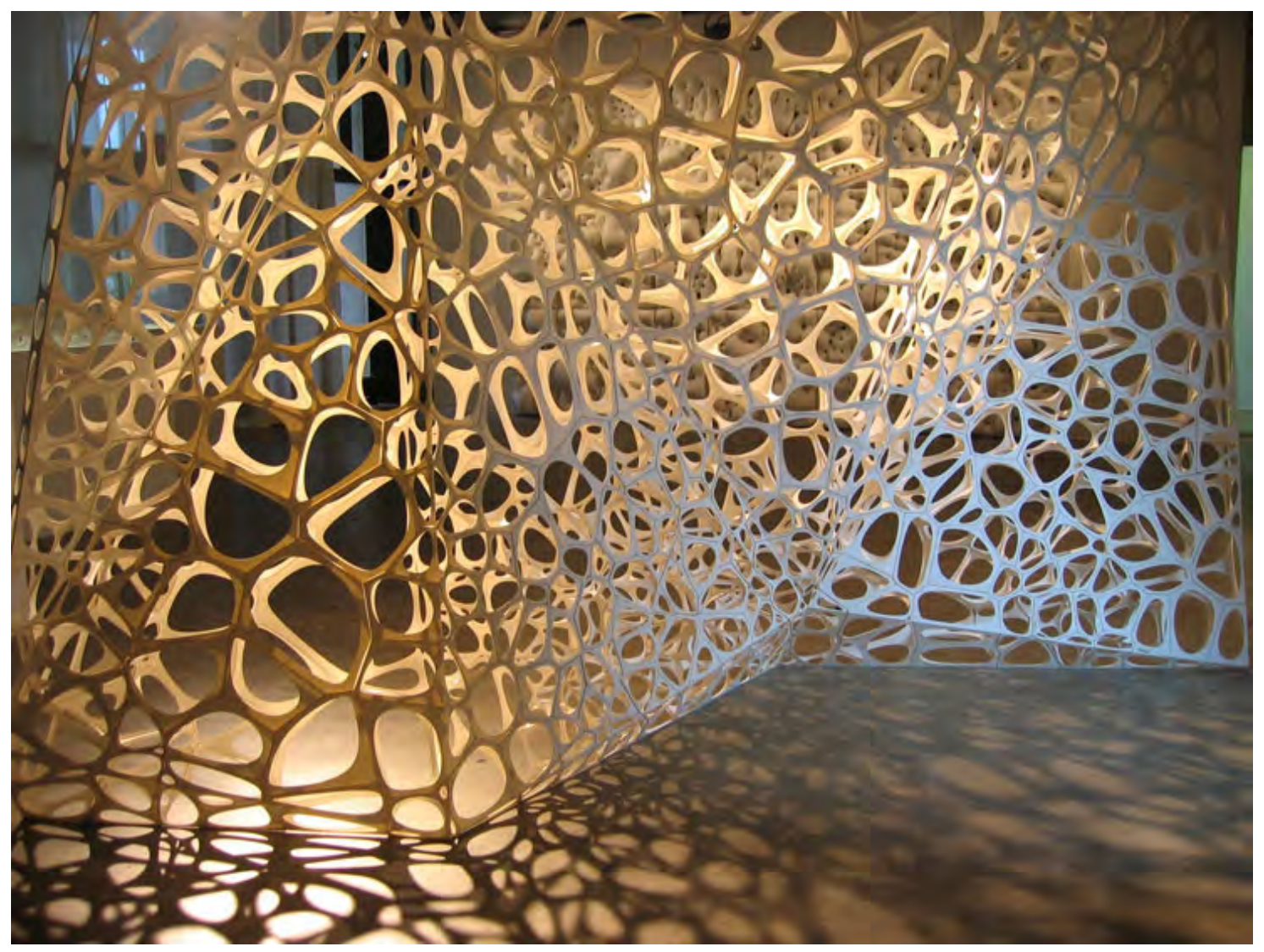

Figura 22 Proyecto C_WALL, grupo Matsys

El proyecto está impulsado por una serie de scripts que construyen un autómata celular de red hexagonal y una red de resortes que impulsan la distorsión de la pantalla más geométricamente compleja. Los muelles están respondiendo a los estados $\mathrm{CA}^{6}$ cambiantes

\footnotetext{
${ }^{6}$ Software y experiencia para alimentar la transformación digital - CA Technologies
} 
y permiten una distorsión no jerárquica de la red mediante el uso de un solucionador de física no lineal. Por consiguiente, la influencia de una célula CA individual fluye a través de sus vecinos influyendo en la geometría más allá de sus contigüidades inmediatas. Los autómatas celulares funcionan en una matriz $2 \mathrm{~d}$ y por lo tanto los patrones que emergen son más evidentes a través del tiempo. En consecuencia, la pantalla es accionada por 3 generaciones consecutivas de la CA para registrar este cambio dentro de la geometría final.

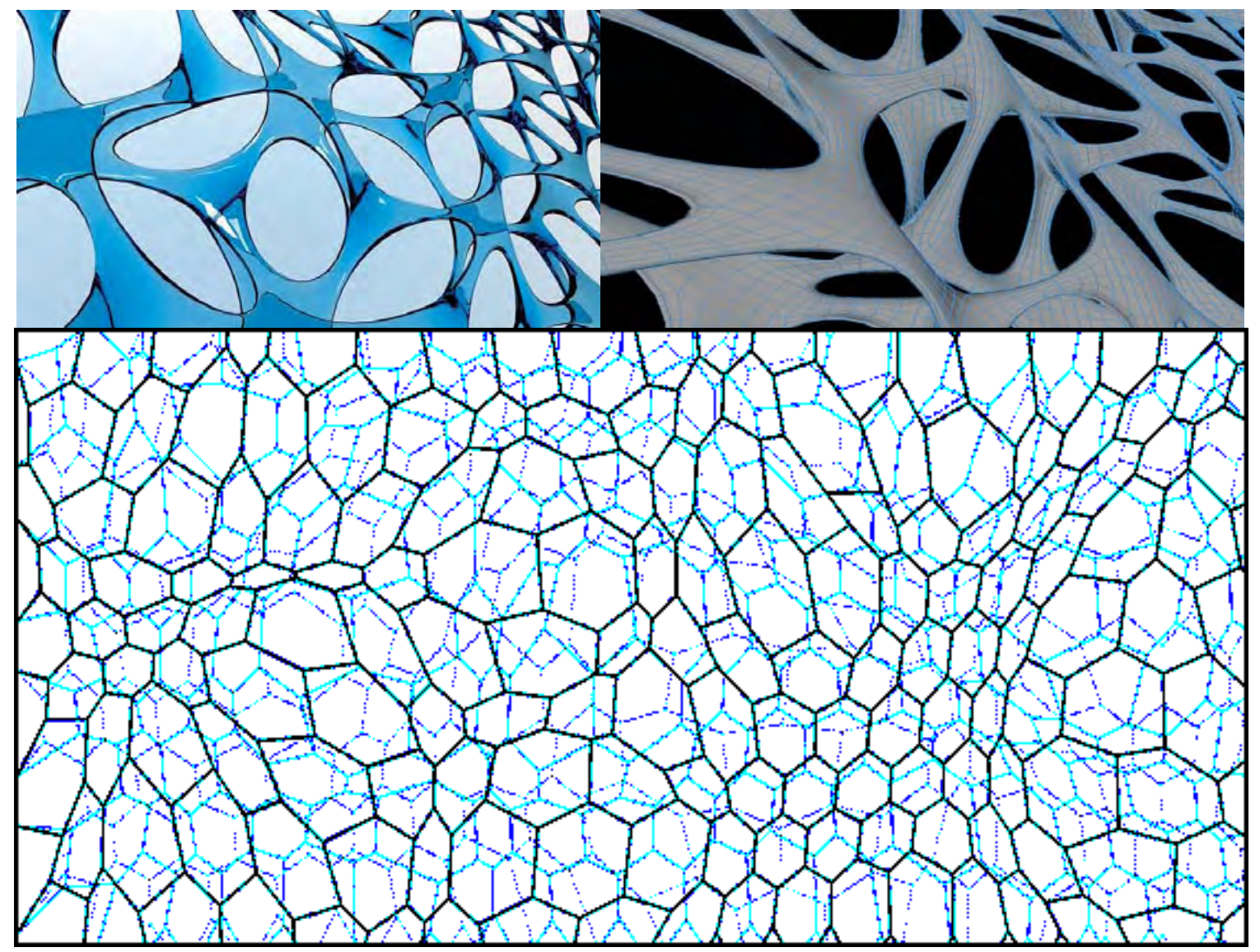

Figura 23 Celosía morfogenética, Dave Pigram y Roland Snooks

Otro ejemplo de arquitectura realizada a partir de crecimientos encontrados en la naturaleza son los fractales, que no mantienen las mismas propiedades en todas las escalas. En los desarrollos de AKT (2008), grupo formado por Adams, Kara y Taylor, nos encontramos unas estructuras realizadas para el "Fibrous Concrete Istambul Workshop" que tienen este comportamiento fractal.

Los workshops revelaron que la interacción entre tubos de hormigón era la clave para fabricar unas estructuras útiles con esta idea. Siempre y cuando los tubos se unen en puntos de máximo esfuerzo, pueden separarse en los tendones de diámetro muy estrecho; 
Aplicaciones de las propiedades auxéticas en la arquitectura

ANTECEDENTES

un efecto que va en contra de la intuición en el hormigón. Está claro que algo parecido a un compuesto de plástico y hormigón podría trabajar.

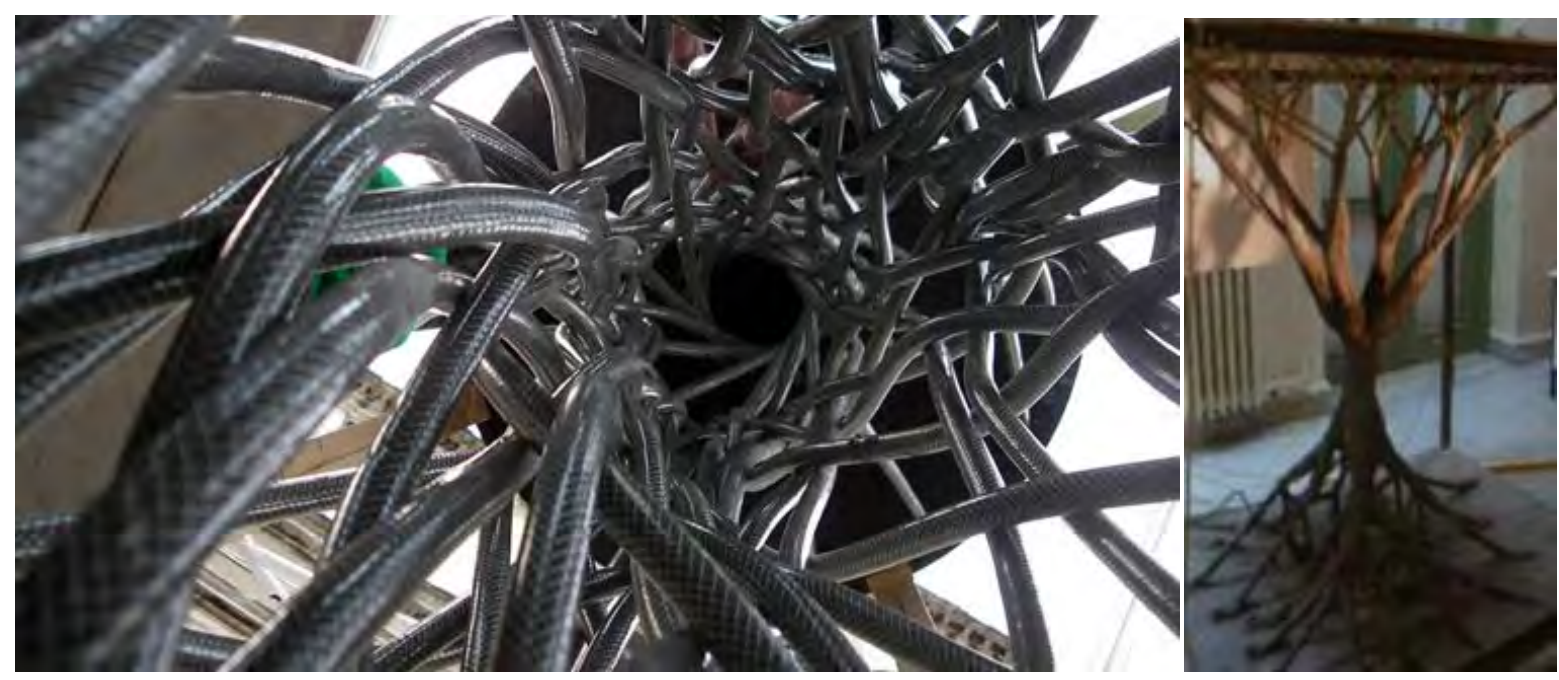

Figura 24 Fibrous Concrete Istambul Workshop, AKT. Izquierda: Enlace entre plástico y hormigón para crear un material compuesto. Derecha: Tubos delgados de hormigón que pueden torsionarse y moverse independientemente, pero a pesar de todo interactúan entre sí para asegurar la estabilidad.
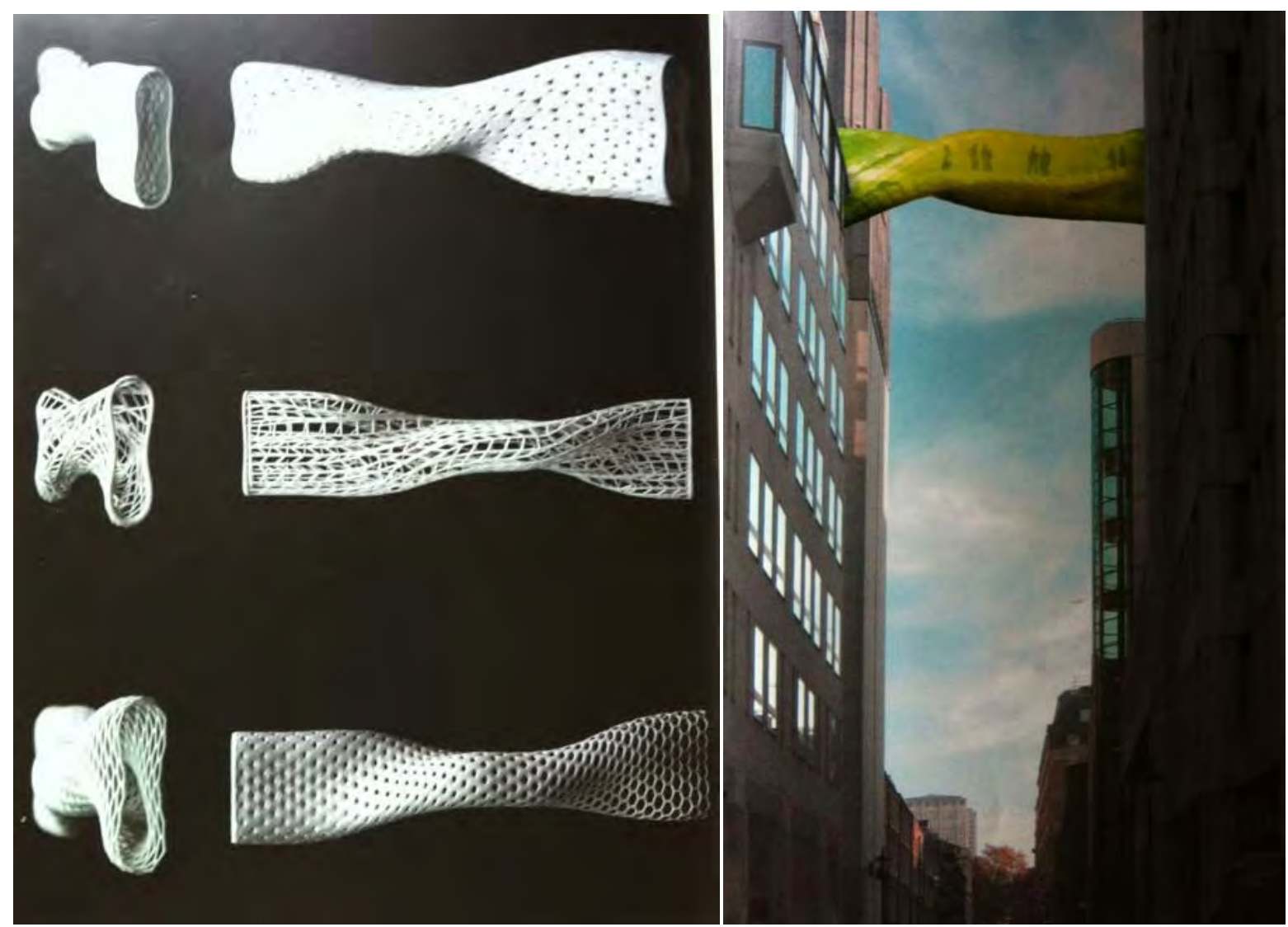

Figura 25 Hexagonal Panelization Strand Link Bridge 
La relación que se trata de establecer con la Arquitectura, se centra también en arquitecturas que desarrollan soluciones de tramas y geometrías espaciales innovadoras, como algunas de las soluciones que están estudiando AKT (2008). Adams, Kara y Taylor estudiaron un puente de panelización hexagonal mediante el cual los arquitectos Future Systems querían conectar dos edificios a través una superficie muy libre. Concibieron la estructura con una serie de componentes hexagonales y triangulares. Trabajaron con diseño computacional para calibrar los diferentes tamaños de estas formas simples para llegar a una forma compleja, hasta llegar a crear el módulo óptimo.

Toyo Ito \& Associates diseñaron el "Parque de la relajación" en Torrevieja, siguiendo la estructura de una caracola (desarrollo a partir de un elemento de la naturaleza). La palabra clave del proyecto fue la "espiral", constando el proyecto de cinco espirales apoyadas en una estructura de hormigón, que se cubren con listones y contrachapados de madera sosteniendo una plataforma colgante en su interior.

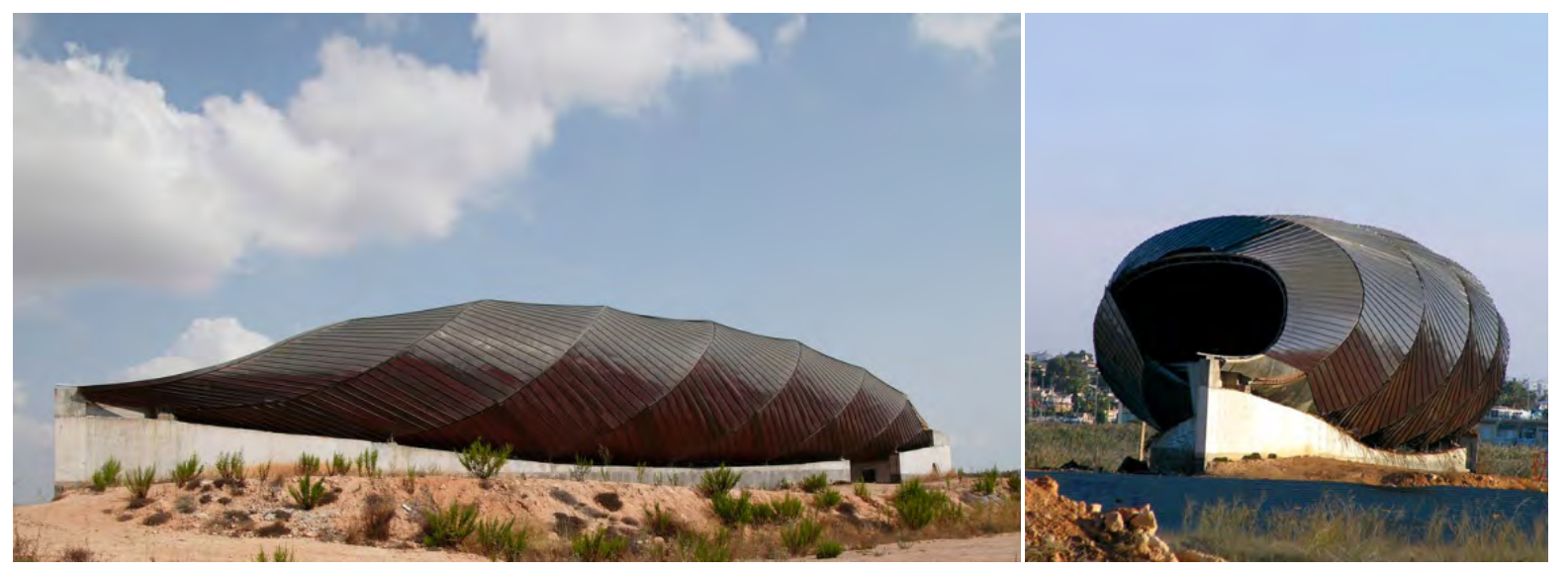

Figura 26 Parque de la relajación, Torrevieja, Toyo Ito

Siguiendo con los desarrollos basados en la naturaleza, las superficies curvas anticipan también las soluciones de Franken para el pabellón BMW 1999 en la feria de Frankfurt, donde la superficie de vidrio acrílico diseñada y producida digitalmente construirá el "Bubble", una doble gota de agua con doble curvatura. Debido a la influencia de la tensión superficial, la gota tiene como objetivo lograr una forma esférica. Sin embargo, su viscosidad, torpidez, fricción atmosférica y otras fuerzas externas impiden esto, de modo que se deforma a través de una gota ligeramente oscilante en una forma esférica. Esta burbuja fue una de las primeras estructuras en el mundo que fue completamente creada con medios digitales, desde el diseño hasta la construcción. 


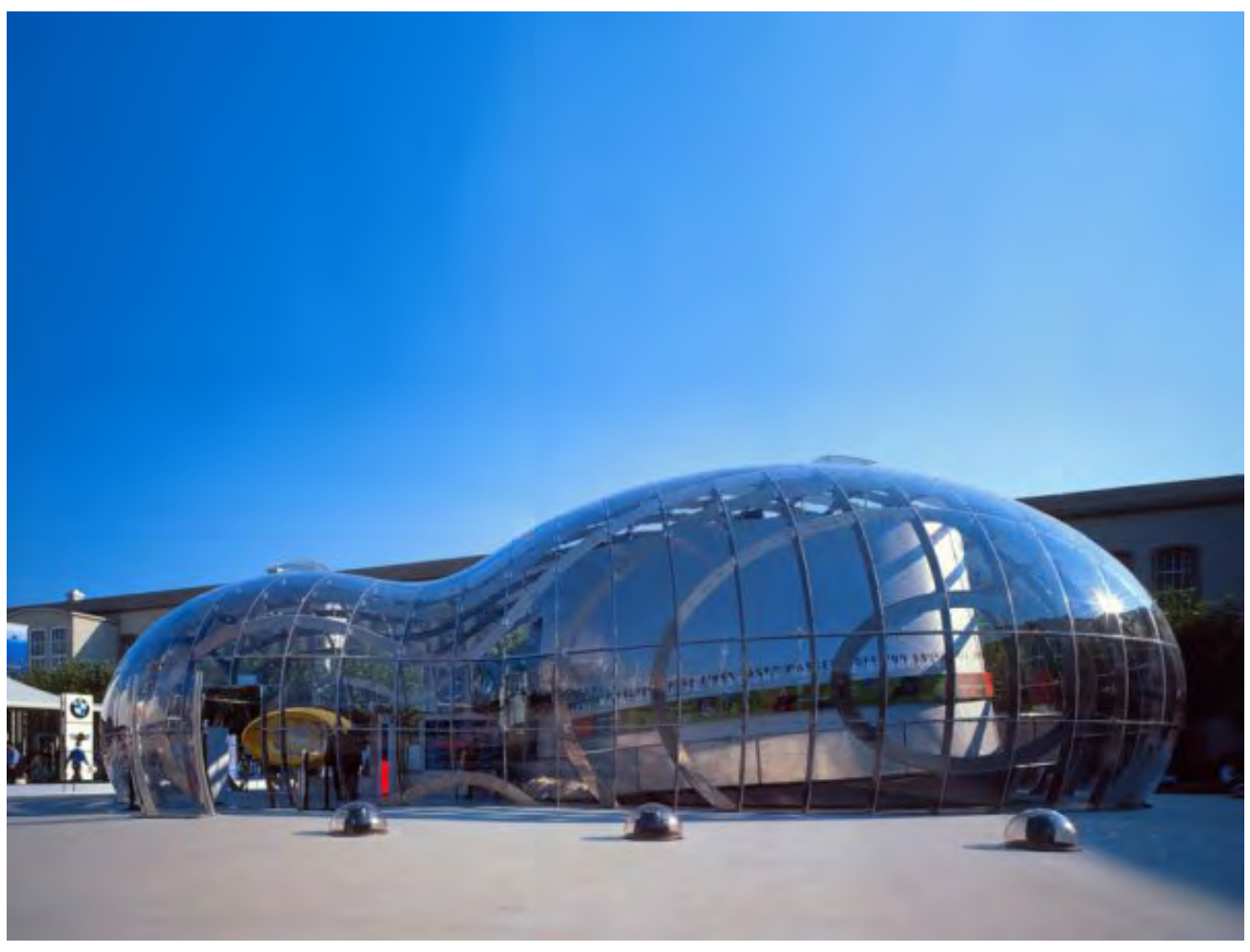

Figura 27 "Bubble" para BMV group, B. Franken

También se cita a Emmanuel Ruffo por sus estudios geométricos relacionados con arquitectura. El arquitecto Emmanuel Ruffo fue galardonado con el "Premio Mejor Presentación“, en la Bienal de Investigación Científica CAAD Futures, que se llevó a cabo en Liege, Bélgica del 6 al 8 de Julio de 2011.

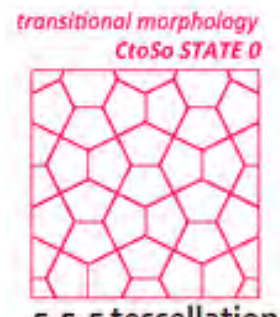

5-5-5 tessellation

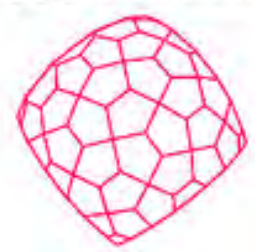

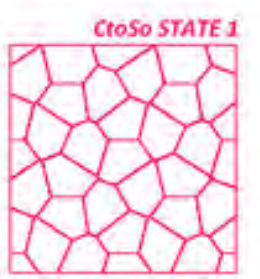
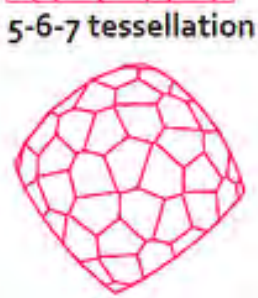
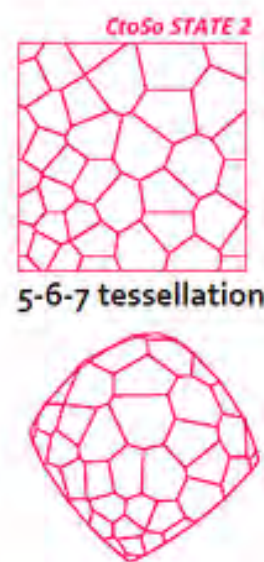

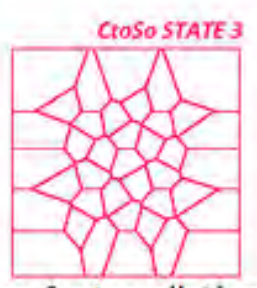

5-6-7 tessellation

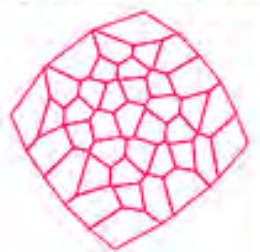

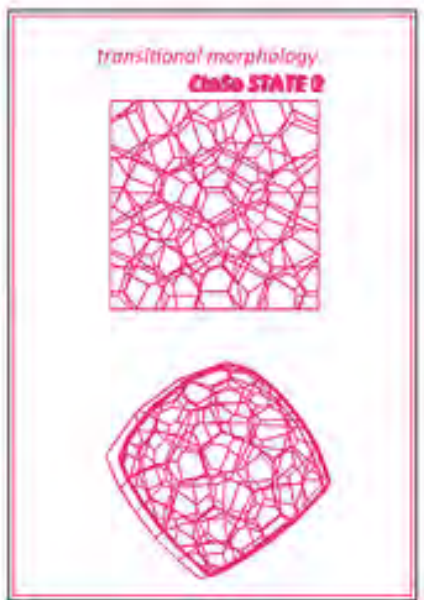

Figura 28 Diseño de geometrías arquitectónicas mediante diseño computacional 
Cristina Doumpioti, miembro de ACADIA, a través de la investigación del comportamiento de materiales y nuevas tecnologías de fabricación, tiene como objetivo explorar los métodos de diseño y modos de pensar influenciada por la inteligencia integrada de los materiales.

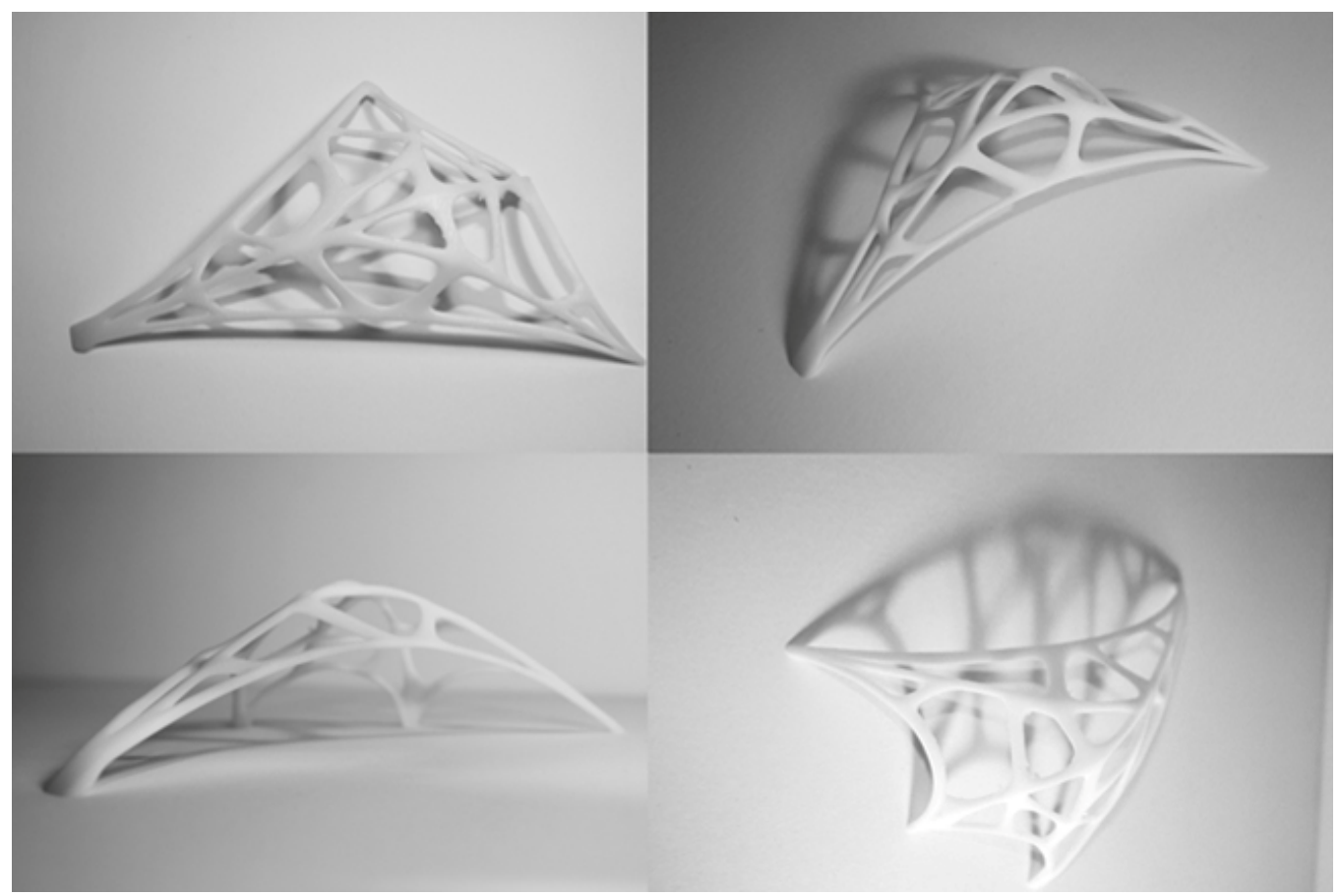

Figura 29 Catenaria o forma suspendida, Cristina Doumpioti

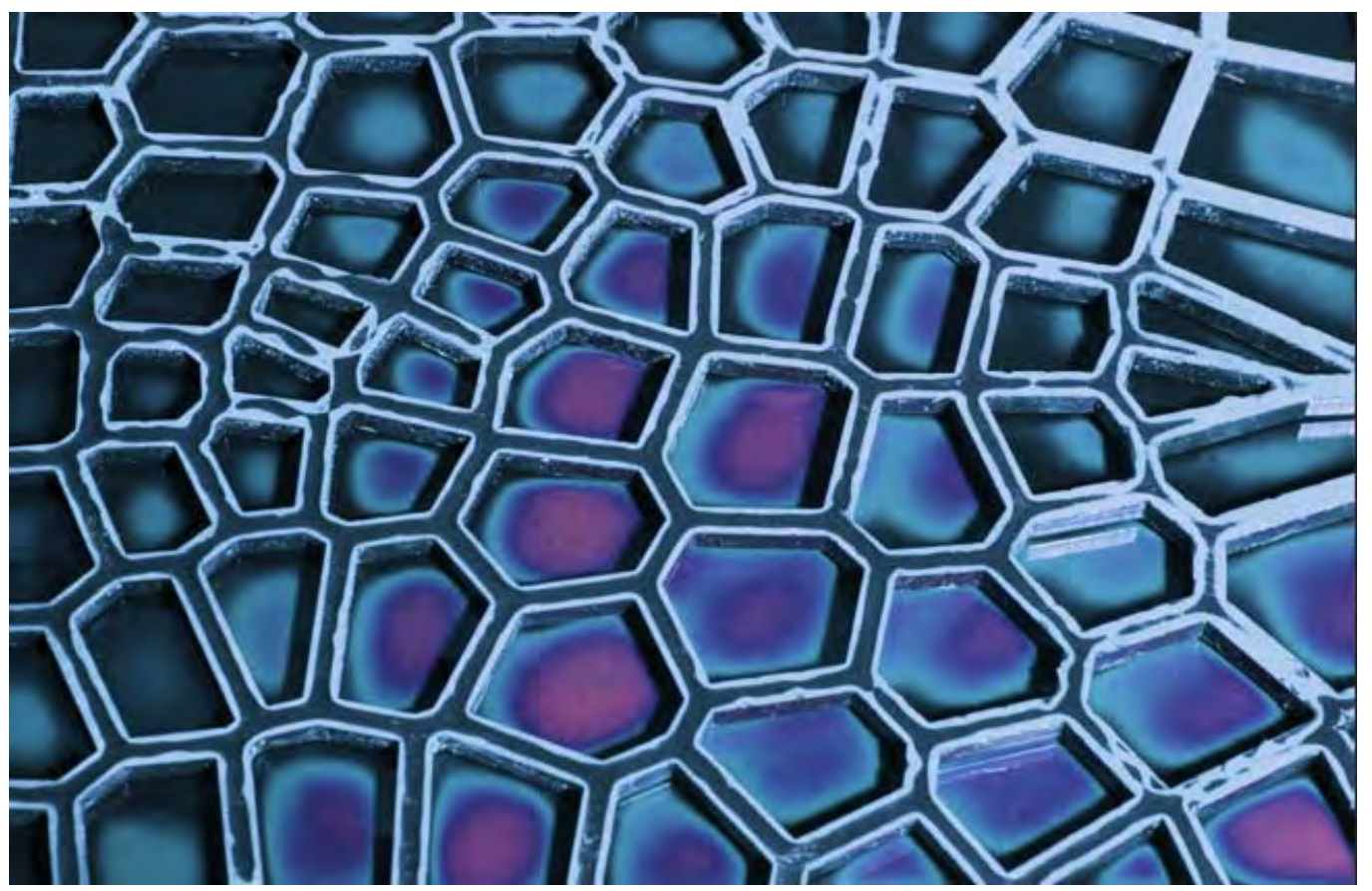

Figura 30 Polímero sensible al calor basado en cristales termocrómicos, Cristina Doumpioti 
Neri Oxman, como arquitecto perteneciente al grupo de investigación MEDIA LAB del MIT, investiga en una línea similar a la de Menges. Explica cómo las formas generadas por la naturaleza son sostenibles y logran una máxima actuación con mínimos recursos. La observación de la misma permitirá experimentar con el artificio y ofrecer soluciones estructurales, dinámicas y con posibilidad de crecimiento.

De igual manera la observación de los materiales y de sus propiedades, nos conduce a priorizar ciertas cualidades anisótropas de los materiales naturales y su fabricación de una forma artificial. Oxman (2010) investiga la obtención de soluciones formales que responden a diversos parámetros como es el entorno, la estructura, el material, todo ello programado mediante soluciones digitales.

Un ejemplo de esta fórmula de diseño de Oxman (2004) es The Vertical Helix en Londres, donde cinco curvas geométricas básicas fueron guiadas para producir variaciones geométricas por unión y/o cambio de datos matemáticos en un comportamiento sistemático.
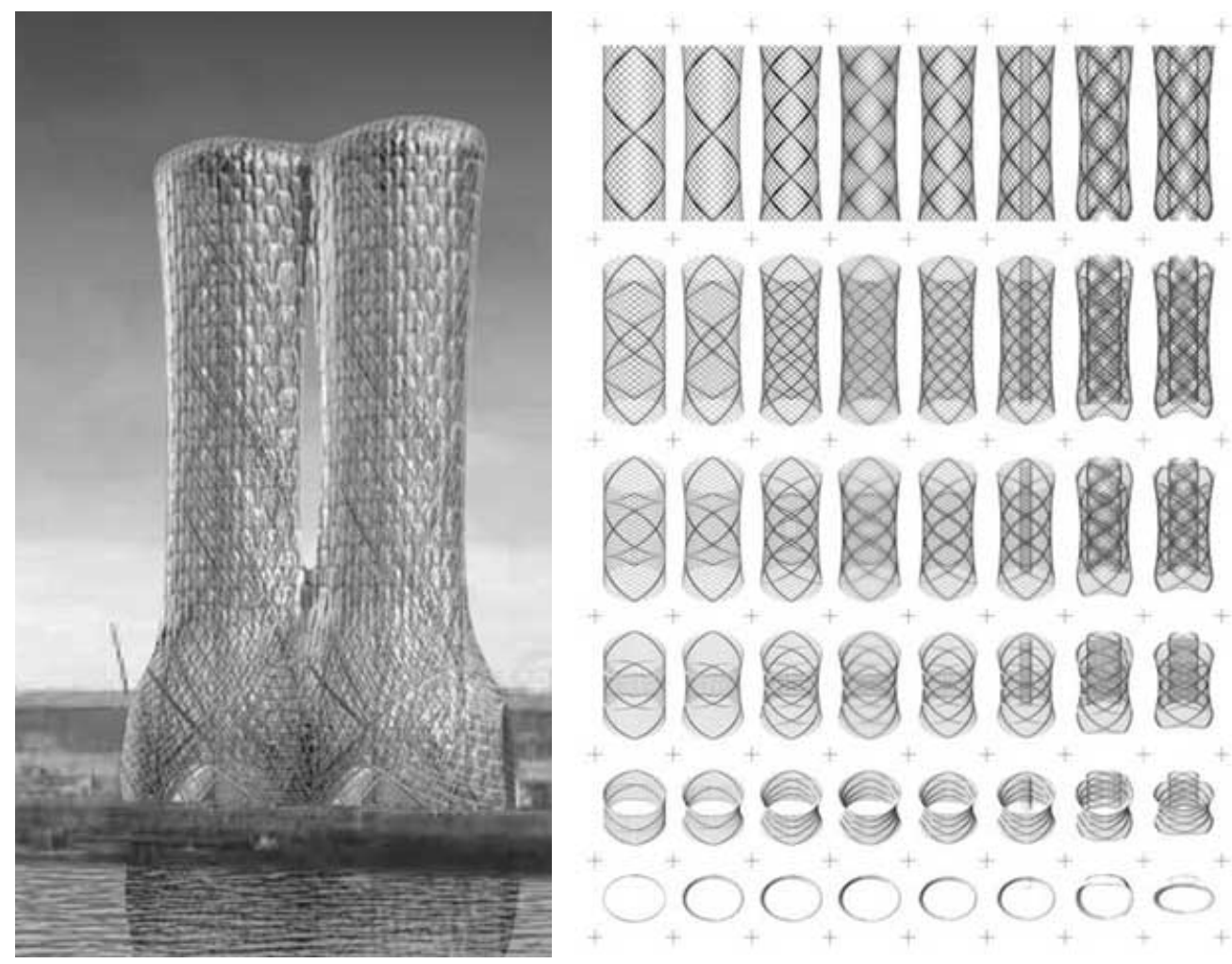

Figura 31 Dublin Landmark Tower. Achim Menges. Emergence and Design Group. 


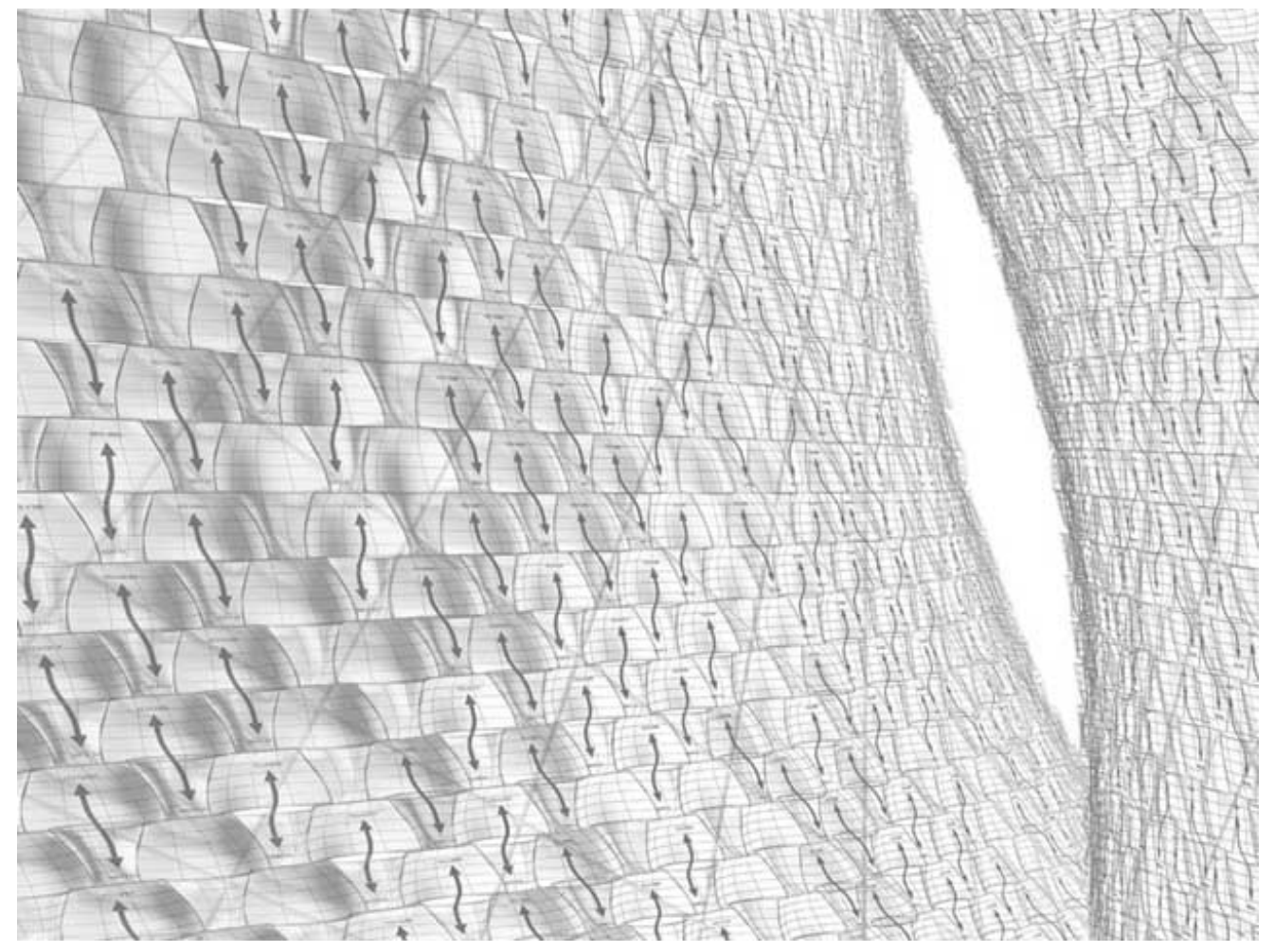

Figura 32 Teselas Dublín Landmark Tower. Achim Menges.
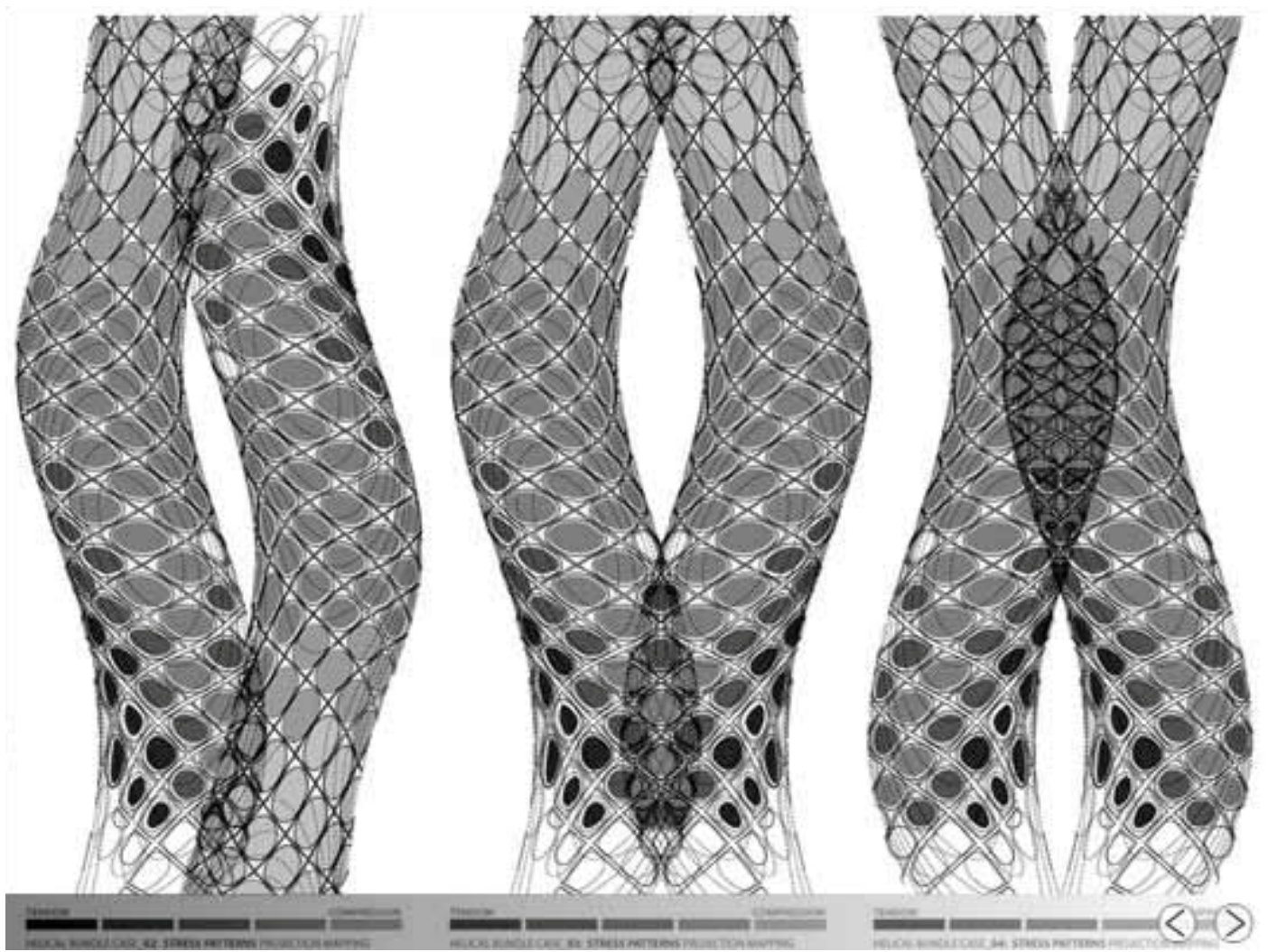

Figura 33 The Vertical Helix,2004. London. Neri Oxman 
Se destaca también a Lisa Iwamoto por sus soluciones de tramas geométricas espaciales. Jellyfish House incorpora materiales emergentes y tecnologías digitales, teniendo una piel que muta. Esta piel es diseñada con una malla paramétrica que usa geometrías eficientes lógicas de la triangulación de Delauney y del diagrama de Voronoy.

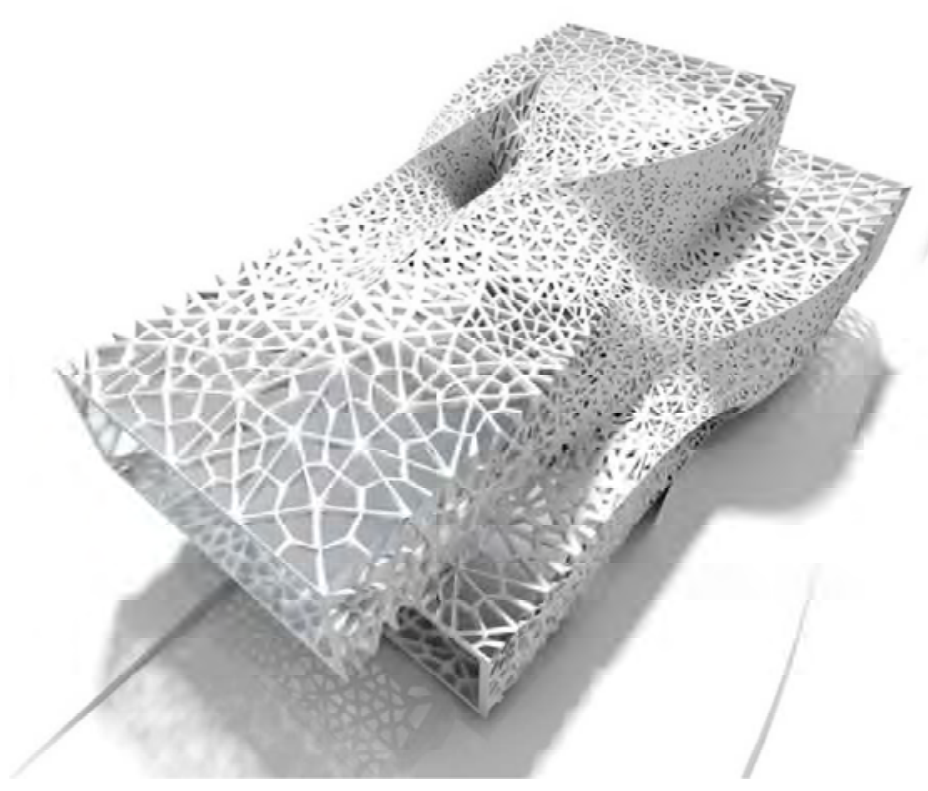

Figura 34 Jellyfish, L Iwamoto

La viabilidad de estas propuestas queda demostrada con los avances en automovilística. En 2008 se presentó el coche "Exaxis" (figura 35), que tiene un chasis de aluminio y está cubierto por un plástico transparente llamado Makrolon, el cual es desarrollado a base de policarbonato que tiene alta densidad, lo que lo hace muy resistente y a la vez es extremadamente liviano. Logra equilibrar muy bien el peso, la forma y la eficiencia, cualidades buscadas continuamente en la arquitectura.

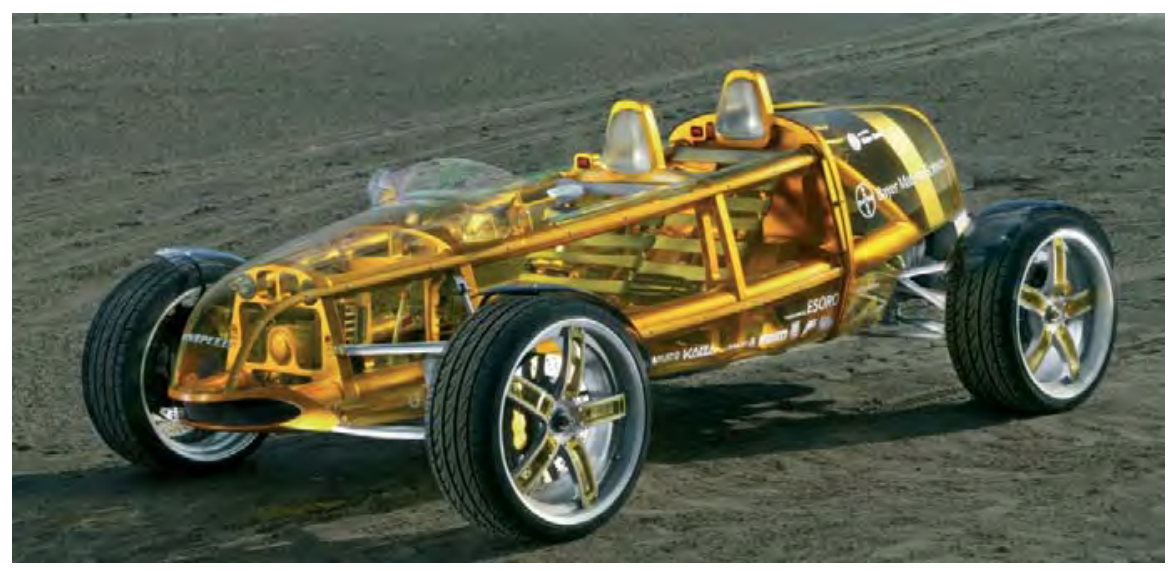

Figura 35 Coche plástico Exaxis, Bayer 
Por otra parte son visibles los avances en impresión en 3D ofrecidos en el año 2014 por la empresa automovilística EDAG (figura 36), presentando su automóvil EDAG Génesis-08 como la solución más avanzada y de última generación de automóvil producido mediante impresión de plástico ABS con impresora 3D. El diseño incluye un chasis diseñado como un exoesqueleto formado por un diagrid espacial y un canopy definido mediante superficies de geometrías complejas y paneles constituidos a la manera del hueso del cráneo humano por dos láminas unidas mediante una estructura espacial ósea impresa mediante impresora 3D, formulación que resolvería la producción de exoesqueletos de construcción, transformando los propios sistemas de producción de la futura Arquitectura.

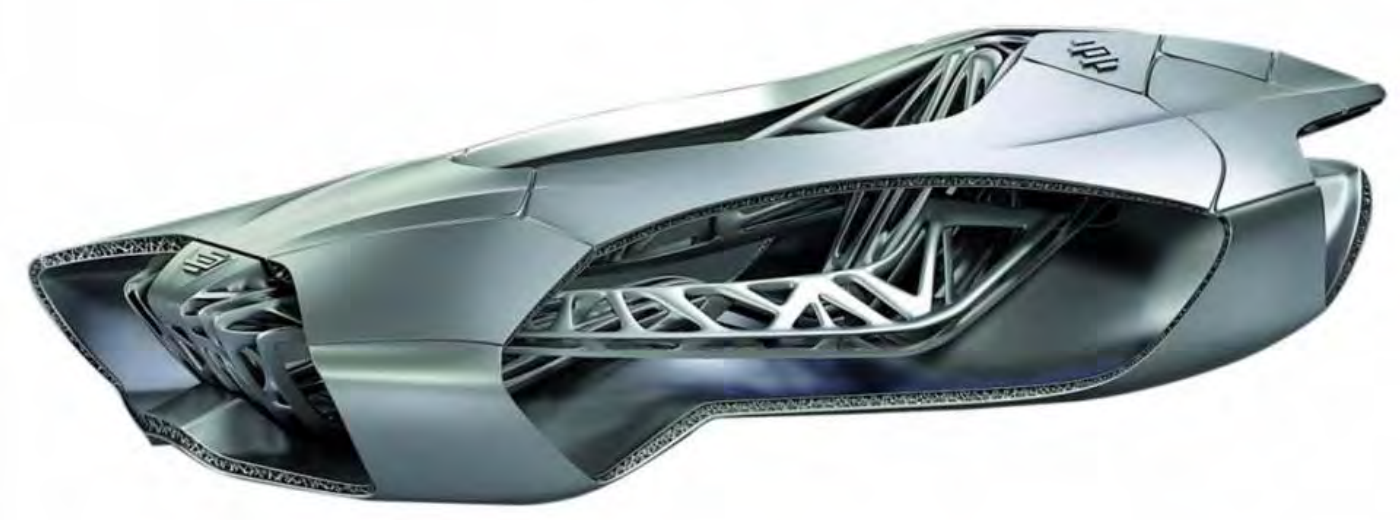

Figura 36 Edag Génesis 8, 2014, EDAG.

Para finalizar se presenta el Gaudi Stool (figura 37), diseñado por Bram Geenen, un taburete súper ligero con una estructura impresa en 3D y concha de fibra de carbono. La forma del Taburete de Gaudí fue creada de la misma manera que el arquitecto Antoni Gaudí español diseñó la estructura de sus iglesias, haciendo un modelo de cadenas colgantes, dejando así que la gravedad determinara la forma más fuerte y lógica para soportar fuerzas. La fibra de carbono y la impresión 3D se utilizaron para poder aplicar los métodos de Gaudí en muebles ligeros. Cuando una cadena cuelga entre dos soportes, seguirá una línea definida por la gravedad. Esta es la catenaria. Cuando esta línea se invierte, surge una forma fuerte para tomar fuerzas de compresión. Al igual que buscamos en arquitectura, geometría, estructura $y$ forma van a coincidir. 


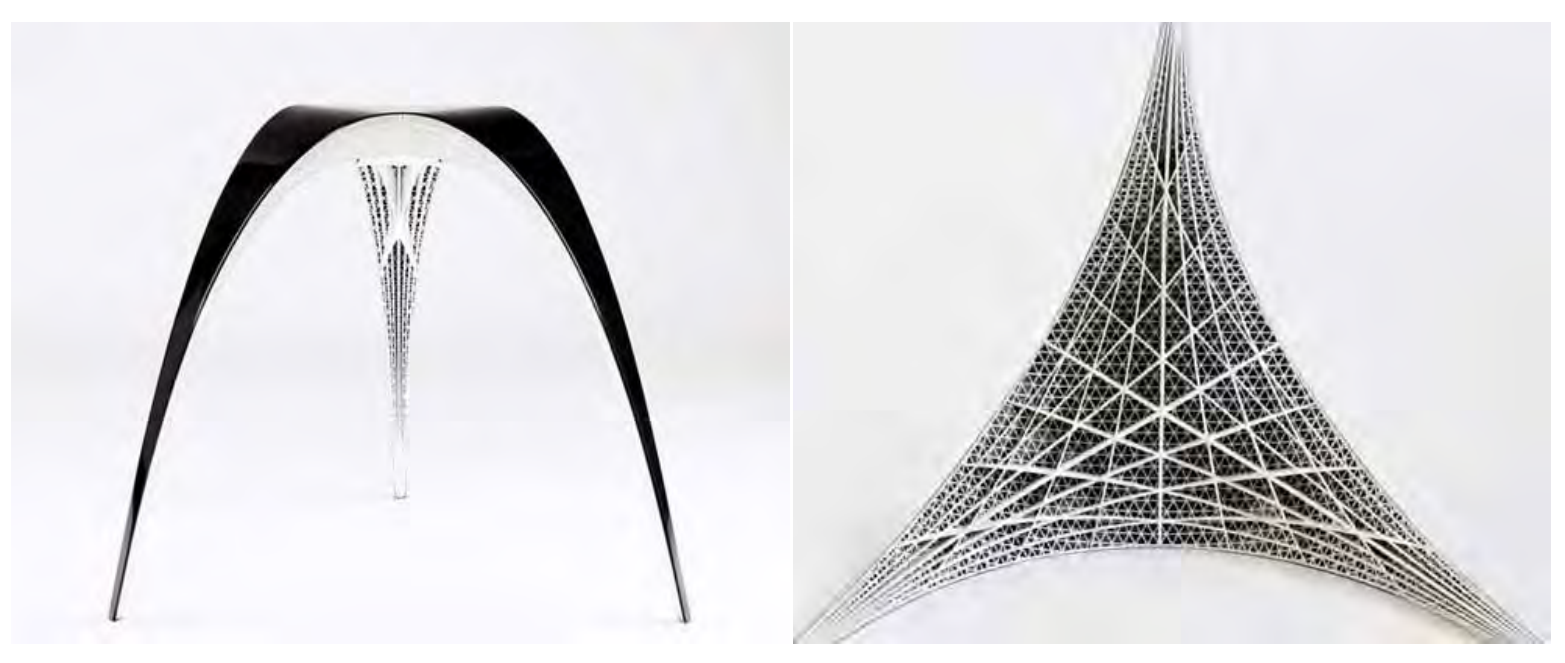

Figura 37 Gaudí Stool, Furnistructures, Bram Geenen

También es presentada la bota motociclista PUMA (figura 38), cuya geometría interna del polímero plástico que la compone tiene forma tetraédrica al carbono, con lo que genera una estructura plana que al ser doblada consigue su resistencia estructural: la unión no tiene una rotura física (bisagra), sino que el empeine puede doblarse gracias a la geometría interna del material. Nuevamente, nos hallamos en la tesitura de que geometría, estructura y forma van a coincidir.

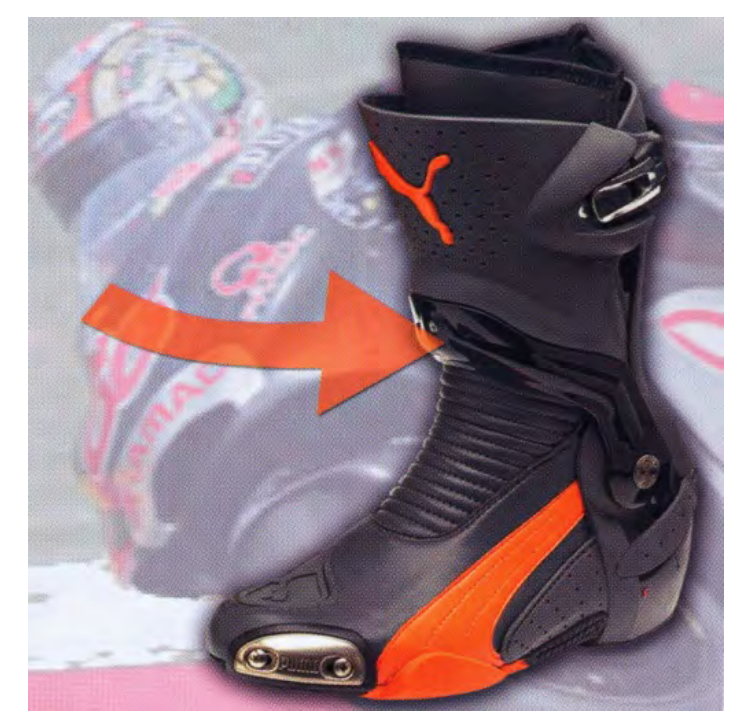

Figura 38 Bota motociclista PUMA 


\subsubsection{Estructuras desplegables}

Consciente de la importancia del desarrollo de la arquitectura social y soluciones de arquitectura de emergencia (como hospitales de campaña), así como de la necesidad de trabajar en la materialización de nuevos espacios expositivos temporales, este artículo presenta una serie de arquitecturas transformables pensadas para este mundo que requiere de soluciones arquitectónicas rápidas en el que vivimos, cuyo objetivo es estudiar las diversas manifestaciones contemporáneas para acercarlas a diversos espacios y lugares que carecen de una infraestructura arquitectónica temporal o de rápido montaje adecuada mediante estructuras transformables, proponiendo una alternativa a los espacios convencionales, tanto en el ámbito rural, barrios deprimidos o centros de ciudades, así como espacios expositivos o para el arte. Se busca garantizar el acercamiento de estas arquitecturas transformables a arquitectos, artistas e ingenieros, así como al público en general, fomentando las conexiones entre prácticas artísticas y arquitectónicas, incitando al debate y la reflexión sobre los límites entre lo temporal o efímero y lo duradero en la creación arquitectónica contemporánea.

A la gran diversidad de tamaños posibles se añade la multiplicidad de morfologías, que nos da un amplio abanico de opciones con las que trabajar y aplicar a la arquitectura, lo que genera arquitecturas dinámicas con forma variable y con multitud de nuevas posibilidades. La formación de las estructuras ordenadas con las que se trabaja es resultado de procesos colectivos de repetición de una unidad. En estos sistemas, se hallan involucradas escalas que van de la dimensión de una sola unidad a la que caracteriza a todo el conglomerado; en estos casos el comportamiento individual nada indica -o indica muy poco- de lo que sucede con la colectividad. Estas estructuras ordenadas, de manera genérica, reciben el nombre de patrones.

En las arquitecturas estudiadas se siguen reglas matemáticas y geométricas sencillas, en las que los problemas de forma son en primera instancia, problemas matemáticos y geométricos, y los problemas de crecimiento son, esencialmente, problemas físicos, ya que la materia obedece leyes físicas. Por ende, la emergencia de estructuras ordenadas es consecuencia de procesos fisicoquímicos, y de ser así, dado que algunas de las leyes que rigen a éstos se expresan en términos matemáticos, entonces, en última instancia, las matemáticas se hallan en la base de los mecanismos subyacentes que están detrás de la emergencia de las estructuras. 
Se va a estudiar la evolución de las estructuras transformables de barras para conocer las innovaciones que se han ido creando. Todo esto es posible gracias al estudio de las patentes que existen.

Durante los años 50 y 60 se empezaron a investigar y trabajar las estructuras transformables para la arquitectura. Hubo una verdadera fiebre en patentar soluciones correspondientes a disposiciones geométricas, sistemas constructivos y diseño de componentes (sobre todo piezas de nudo) cada vez más complejos de ejecución pero de uso más racional y versátil.

La primera patente de estructura desplegable la encontramos en 1944 (Rodríguez, 2005), con la patente "Improvements in supports for tents, marquees, temporary bridges and other portable structure", que consistía en una bóveda de cañón largo compuesta por una sucesión de arcos rebajados y que eran plegables cada uno de los arcos que componían la bóveda; lo cual nos da a entender que hablando de estructuras desplegables estamos hablando de un campo relativamente novedoso.

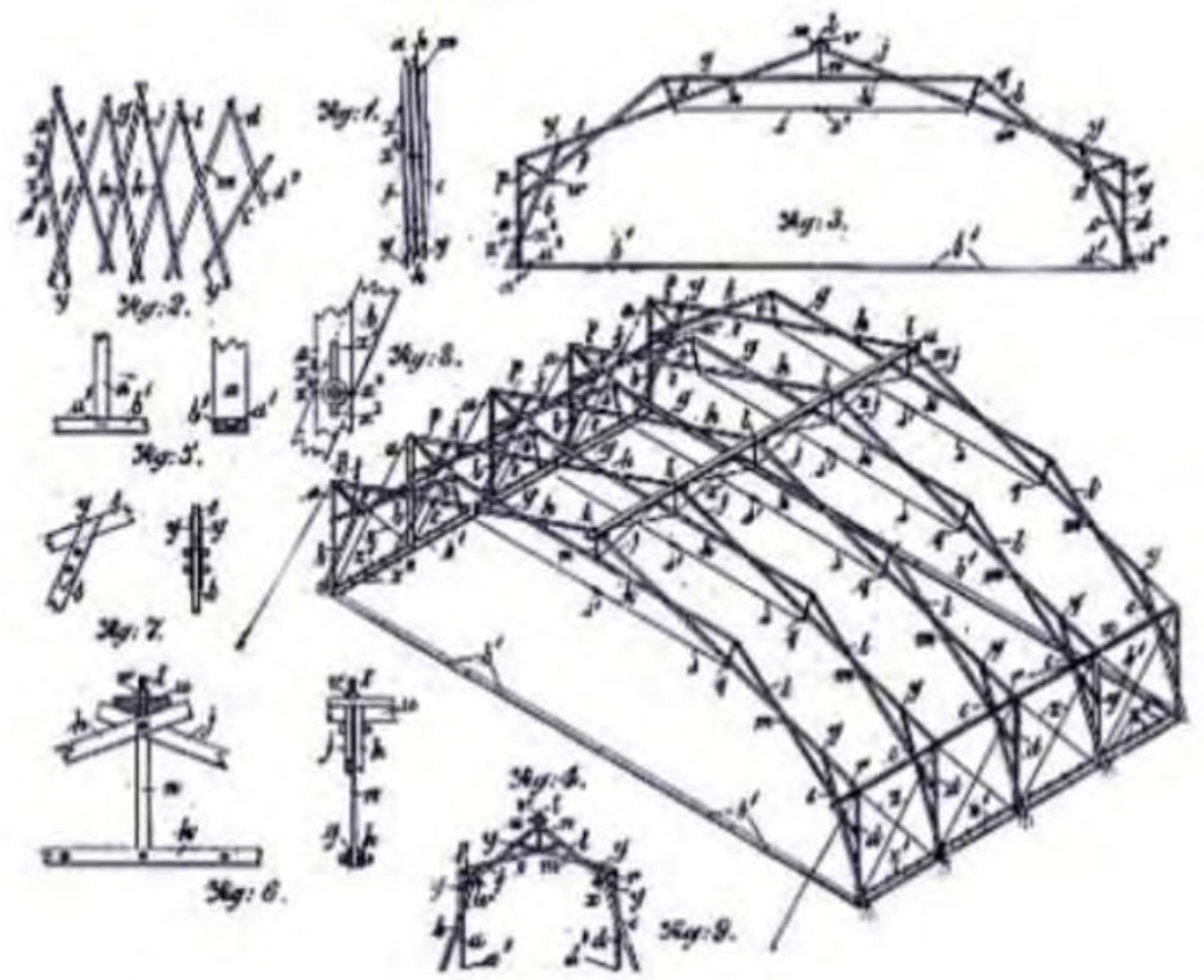

Figura 39 Patente Barde Salden Watkins 
Como gran exponente de este campo de las estructuras en esos años se puede citar a R. Buckminster Fuller, quien desarrolla su primera patente de cúpula geodésica en 1951, y que seguirá estudiando este tipo de estructuras a lo largo de su carrera profesional.

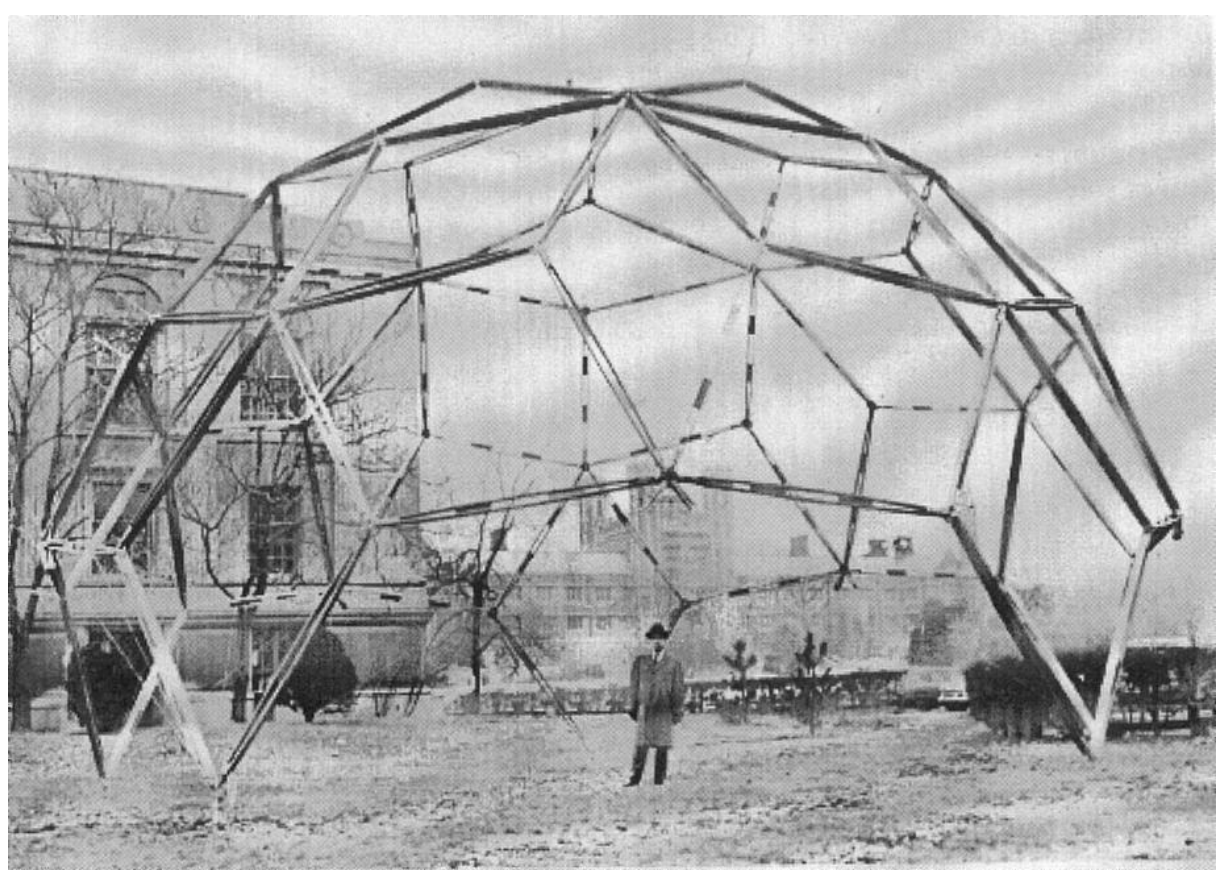

Figura 40 Sistema geodésico, 1954, Buckminster Füller

La cúpula geodésica puede sonar a receta de alquimista, pero es necesario para obtener una estructura completamente triangulada y, por tanto, evitar los esfuerzos de flexión en las barras: la innovación consiste en el desarrollo de estructuras que funcionan a trabajo simple. Parte de dividir en triángulos más pequeños cada triángulo de un icosaedro en función de un orden (más o menos subtriangulaciones) y proyectar sus vértices sobre una esfera, definiendo un número determinado de barras.
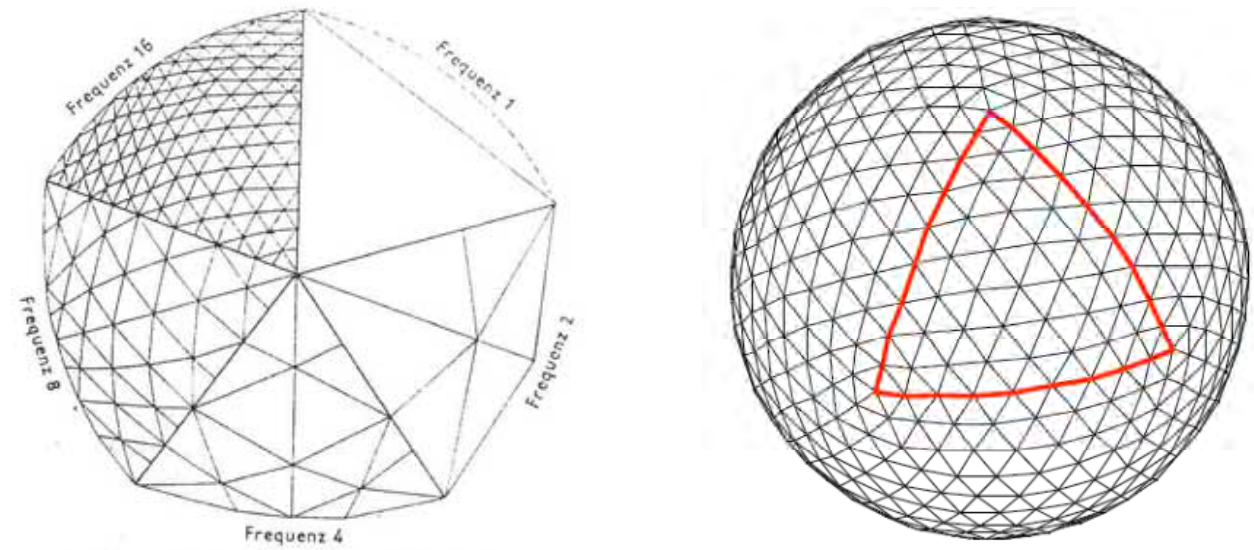

Figura 41 División del icosaedro en patentes (izquierda) y división del icosaedro en construcciones (derecha), R. Buckminster Fuller 
Hubiera sido en principio más sencillo proyectar directamente cada lado del icosaedro sobre la esfera y dividir la curva resultante, que es un círculo máximo, en partes iguales. Pero haciendo las cosas así, los círculos máximos no se encuentran de tres en tres en los nodos, con lo que la estructura no queda completamente triangulada, produciéndose esfuerzos de flexión y además un número de nodos y barras mayor.
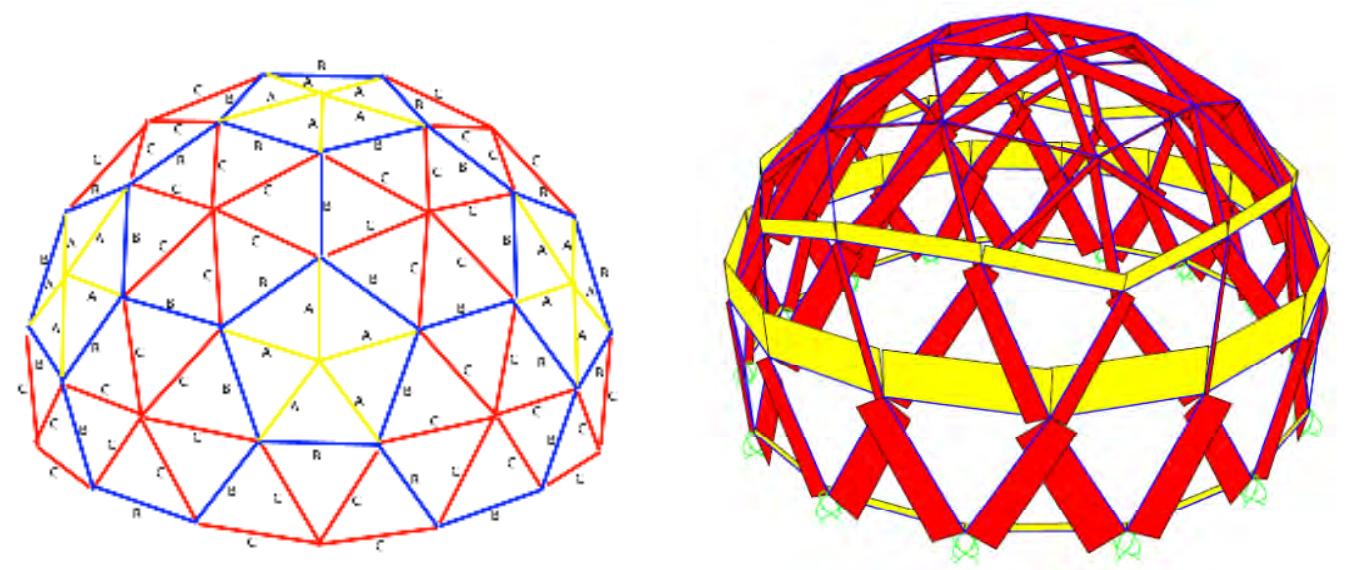

Figura 42 Cúpula geodésica realizada con 3 dimensiones diferentes de barras (izquierda) y esfuerzos simples de tracción (amarillo) y compresión (rojo) en una cúpula geodésica (derecha), elaboración propia

Con R. Buckminster Fuller encontramos, de este modo, una nueva forma de pensar: examinando la construcción tradicional, había descubierto que la mayoría de las construcciones se enfocaban en los ángulos rectos, configuraciones cuadradas, y entendió que los primeros humanos desarrollaron ese modo de construcción sin mucha ciencia, simplemente apilando piedra sobre piedra. Tal sistema tan simple era aceptable para estructuras pequeñas.

Pero Fuller encontró que la fuerza de compresión que causaba la falla de paredes pesadas siempre estaba balanceada por una cantidad igual de fuerza de tensión en la estructura. De hecho descubrió que si la tensión y la compresión no están perfectamente balanceadas en una estructura, esta se colapsará. Siempre buscando la máxima eficiencia, Fuller trató de emplear las fuerzas de tensión en su nueva idea de construcción. El resultado fueron las estructuras geodésicas.

Su propósito declarado es el de cubrir la mayor cantidad de superficie de terreno con el menor peso. Fuller afirmó haberlo logrado con menos de $4 \mathrm{Kg} / \mathrm{m}^{2}$ mediante la construcción de una armazón de forma generalmente esférica cuyos elementos estructurales principales se interconectaban en un diseño geodésico de arcos de círculos máximos formando una retícula triangular y cubriéndola con lámina de plástico. Corresponden a una de las 
estructuras más grandes que se pueden construir con la menor cantidad de material posible. Además económico y rápido de construir.

Fuller era un visionario, que promovió proyectos que replantearon por completo los parámetros de la vida cotidiana. Las cúpulas geodésicas nacieron de su pasión por crear un sistema alternativo de geometría. Tenía capacidad para forjar ideas inspiradoras y transformadoras: dos de los conceptos más contemporáneos de nuestro tiempo, "sostenibilidad" e "innovación", no hubieran existido sin su influencia. Planteó que el mejor maestro de los creadores debía ser la naturaleza.

Un tipo de molécula formada exclusivamente por átomos de carbono (carbono C60) lleva su nombre, los fullerenos, y se conocen así por el parecido de estas moléculas con las cúpulas que diseñó Fuller (desarrollo igual a lo que hay en la naturaleza). La estructura geodésica encontrada dentro del citoesqueleto es un ejemplo clásico de un patrón que se halla en toda la naturaleza, a muchas y diferentes escalas. Los grupos esféricos de átomos de carbono, llamados "buckminsterfullerenos" o "buckybolas", junto con los virus, enzimas, organelos, células y aun pequeños organismos, exhiben formas geodésicas. Todas esas entidades se estabilizan a sí mismas en tres dimensiones, de forma similar al arreglar sus partes para minimizar la energía y la masa a través de una tensión continua y una compresión local.

Los beneficios de la estructura geodésica son:

- Menores costes iniciales:

- Reducción en costos de materiales

- Reducción en costo de energía

- Reducción en costos de mano de obra (más rápido, más fácil, más simple).

- Seguridad: resistencia a vientos, tormentas, sismos y nieve. Cuanto más sopla el viento, al no tener superficies de succión este lo rodea y lo tiende a afirmar más al suelo. Ninguna estructura cubierta es tan estable y fuerte.

- Resistencia estructural: La forma geodésica optimiza la carga desplazando las fuerzas a lo largo de toda la estructura.

- Concentrador de la luz y el calor.

- Menor superficie de pared expuesta al exterior en relación a la superficie cubierta.

- Interiores diáfanos. 
No pueden quedar sin mencionar las ideas de Robert Le Ricolais (1894-1977), quien cuestionaba la noción de forma como algo estático, entendiendo ésta como un concepto fluido y en movimiento. Ricolais (Mimram, 1983) intenta descubrir la relación existente entre las estructuras extraídas de la propia naturaleza (donde encuentra sobre todo modelos complejos de organización), y las estructuras de la forma construidas por el ser humano. En sus nuevos conceptos estructurales aparece la idea de que es más importante disponer los vacíos en la estructura que disponer las masas. El arte de la estructura consiste en cómo y dónde colocar los agujeros: es una idea tremendamente ligada con toda forma construida, ya que implica construir con agujeros, construir con material hueco y con estructuras huecas y resistentes pero sin peso. Es el futuro de la arquitectura: la liviandad.
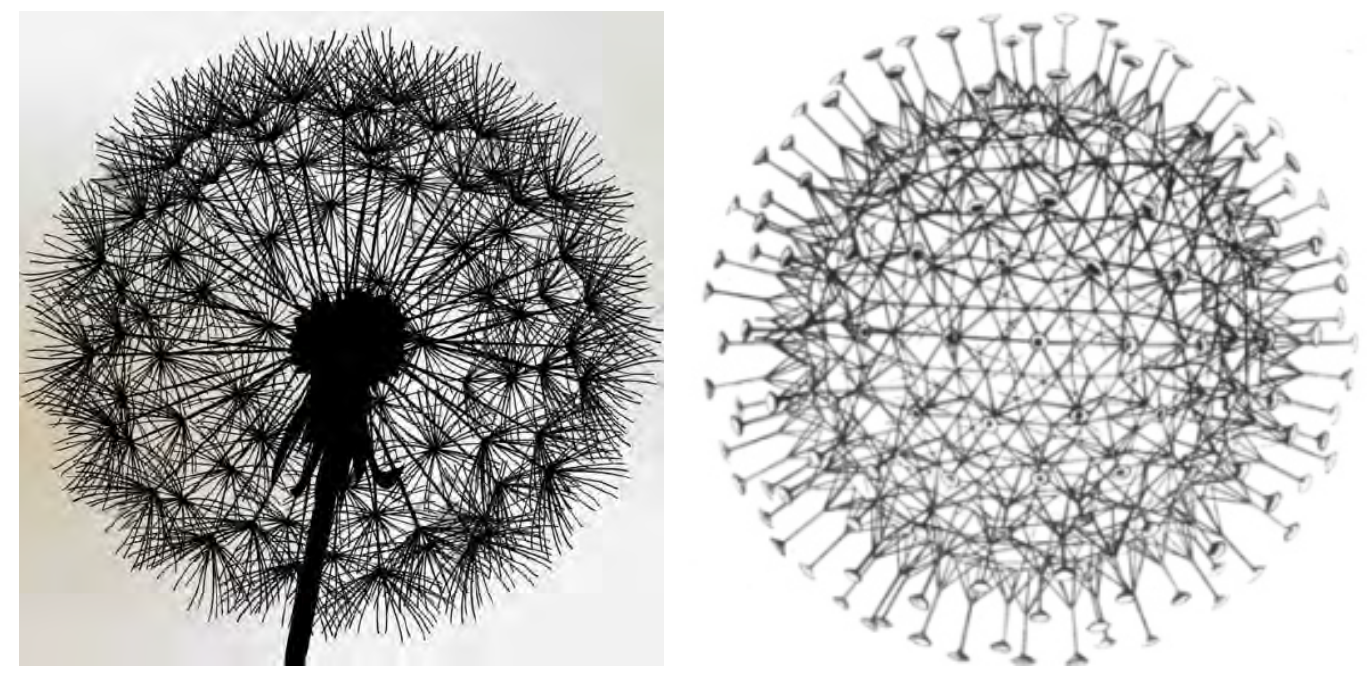

Figura 43 Flor de diente de león (izquierda) y 3 Lattice System, R. Le Ricolais (derecha)

En España, Florencio del Pozo como enseñante y proyectista fue el introductor de este campo de las estructuras. Pablo Bueno remató sus estudios de ingeniería con una investigación sobre mallas planas; después junto con José Calavera proyectó y construyó varias de estas placas. También Ignacio Álvarez Castelao y Francisco Rius fueron pioneros en dar soluciones de estructuras espaciales en sus proyectos. A principios de los años 70 aparecen las mallas espaciales en arquitectura, de Juan Margarit y Carlos Buxadé, y Félix Candela desde México y USA, siempre ejerció influencia sobre los estudiosos españoles. Todos estos iniciadores están ligados al mundo académico y contrastan o aprenden de él sus soluciones.

Emilio Pérez Piñero (Puertas, 1989) no parte de investigar modelos teóricos tanto hablando de diseño como de cálculo. De principio los fabrica, en parte porque no dispone de bagaje aportado por otros en que apoyarse, ya que su diseño es completamente nuevo. También 
se puede decir que no le es una tarea difícil: construye sus diseños aprovechando que tiene tanto habilidad manual como visión espacial. Desarrolló su trabajo en solitario, protegiendo sus hallazgos mediante patentes, intentando comercializar sus estructuras, dedicando por entero su vida profesional a esto.

De sus realizaciones, la información que se suele plasmar en planos, no es abundante ni precisa. Existen, sin embargo, maquetas y modelos a escala o trozos de ellos. Para poder hacer transmisibles sus realizaciones es necesario dibujarlas y definirlas en gran parte pues, aunque se pudieran manejar las maquetas y modelos, es la mejor forma de hacerlo con

Sus inventos característicos son:

- Estructuras desplegables de barras rectas formadas por módulos de haces.

- Estructuras desplegables de barras de directriz quebrada formadas por módulos de haces.

- Cúpulas reticulares desmontables.

- Cúpulas autodesplegables.

- Cúpulas retráctiles.

- Estructuras desplegables con cubierta rígida autoplegable.

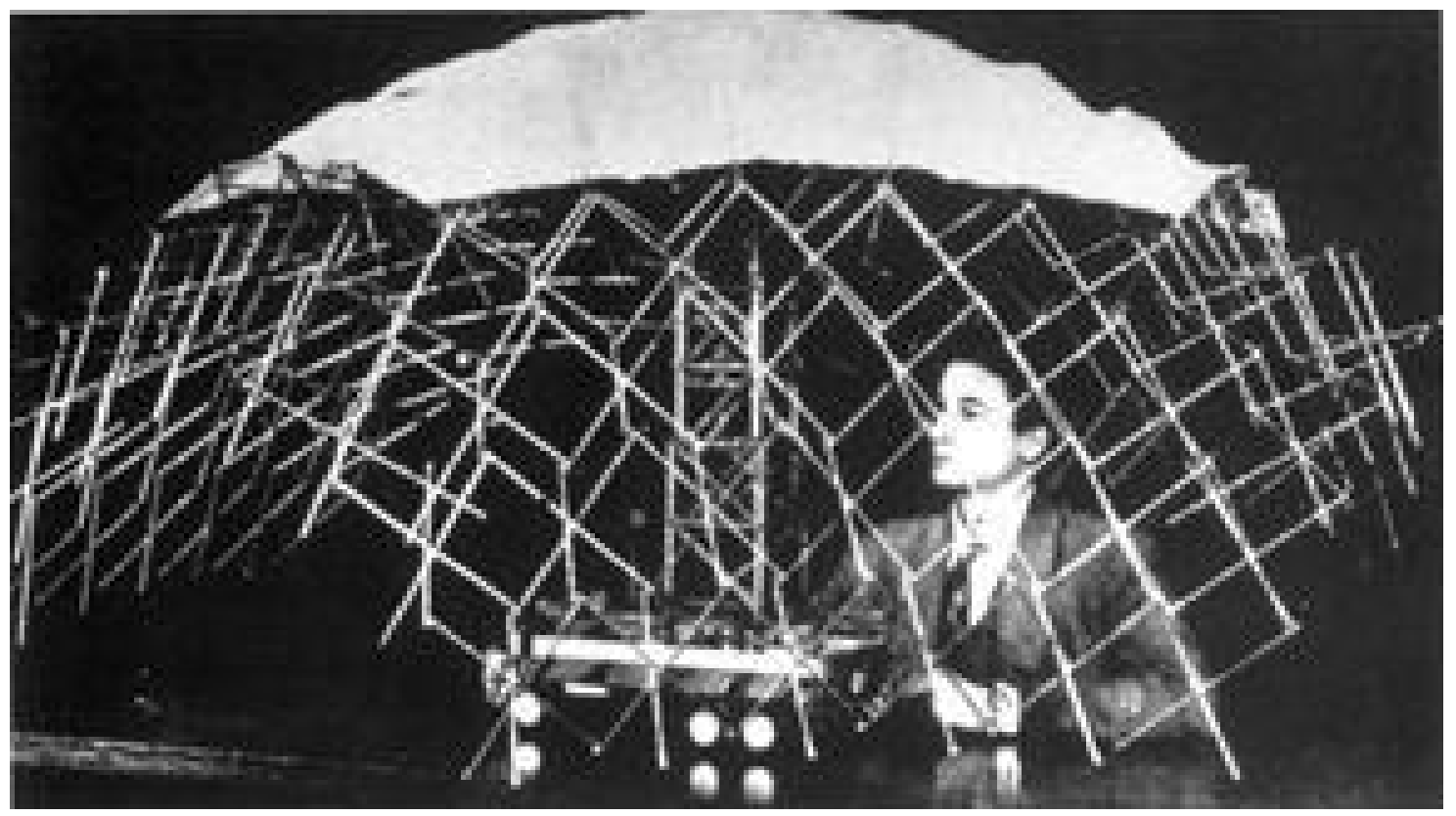

Figura 44 Pantograph, 1963, Pérez Piñero 
Emilio Pérez Piñero y Félix Candela (Churtichaga) se unen profesionalmente hacia un camino prometedor, buscando siempre la forma de los problemas resistentes: ellos buscaron toda su vida la forma de los problemas, y no los problemas de las formas, en un escurridizo y extraordinario juego con las leyes de la gravitación. En el texto "Estructuras Reticulares", publicado por Emilio Pérez Piñero en 1968, aparecen las siguientes palabras:

[...] Resulta premisa inicial la necesidad de adaptar y hermanar en lazo insoluble la forma $y$ el material. [...] La forma ha de estudiarse para conseguir la más adecuada distribución de tensiones. En el material serán sus cualidades mecánicas y su densidad, en corcondancia con la forma elegida y las tensiones que en ella se produzcan, lo que nos fijará su elección. La estructura en la forma es lo que hace posible su subsistencia como tal. En el concepto primero estructura y forma se identifican. [...] La retícula aparece como esqueleto de la forma general, que se supone determinada y fijada previamente, la barra es una condensación de masa en la línea de fuerza y los huecos son una supresión de masa inerte.

En este mismo texto (Pérez, 1968) también enmarca y analiza las características, evolución, tipos y futuro del sistema reticular. En él se lee:

[...] en la concepción, proyecto y ejecución de una estructura reticular aparecen las siguientes fases:

1. Determinación de la forma general del conjunto.

2. Determinación de la retícula, disposición y longitud de las barras. Esto puede llamarse "cálculo geométrico de la estructura.

3. Cálculo mecánico y dimensionamiento de las barras.

4. Resolución constructiva de la conexión de las distintas barras.

5. Formación efectiva de la estructura en su emplazamiento con el montaje de sus elementos.

Este es el proceso que se pretende seguir en la posterior evaluación geométrica de las estructuras desplegables estudiadas.

Se puede decir que Emilio Pérez Piñero es el inventor de la desplegabilidad, basada en los conceptos de modularidad, ligereza y transformabilidad. Su principal innovación son las estructuras espaciales desplegables de barras y nudos pasantes articulados a partir del mecanismo de tijeras formadas por tres o cuatro barras unidas en un punto interior. Este sistema no había sido documentado hasta entonces y él lo protege en patentes entre 1961 y 
1972. Hoy día hay soluciones suyas que no han sido comprendidas ni superadas por investigadores posteriores.

Las estructuras desplegables investigadas se caracterizan por el empleo de barras dispuestas en " $x$ " en el espesor de la estructura, con generación de superficies tanto planas como curvas. En ambos casos se produce la movilidad en fase de mecanismo, teniendo que estabilizarlas posteriormente.

El teatro ambulante desplegable consta de una estructura plana de cubierta, la cual es plegable con todas sus barras, soportes perimetrales abiertos de sección triangular y arriostramientos, y cuatro soportes especiales de sección cuadrada.

En 1964 se le confió un pabellón transportable para celebrar los Veinticinco Años de Paz franquistas. En las antípodas del modelo presentado en Londres, lo resolvió con una estructura plana de doble capa. El nudo articulado facilitaba en gran medida el transporte, pero además el pabellón podía cambiar no sólo de emplazamiento, sino de forma: mientras que en Madrid tenía patios para aprovechar el clima de la primavera y el verano, en San Sebastián y Barcelona presentaba una forma compacta (Pérez, 1968). La envolvente para la exposición al aire libre "25 años de paz" tiene un sistema de estabilización en el cual, una vez desplegada la estructura, se añaden barras en las caras superior e inferior hasta completar cinco parejas de cordones en una dirección y dos más, ocupando los bordes extremos, en la otra, que también recibe montantes hasta que todo el canto de esos bordes queda triangulado.

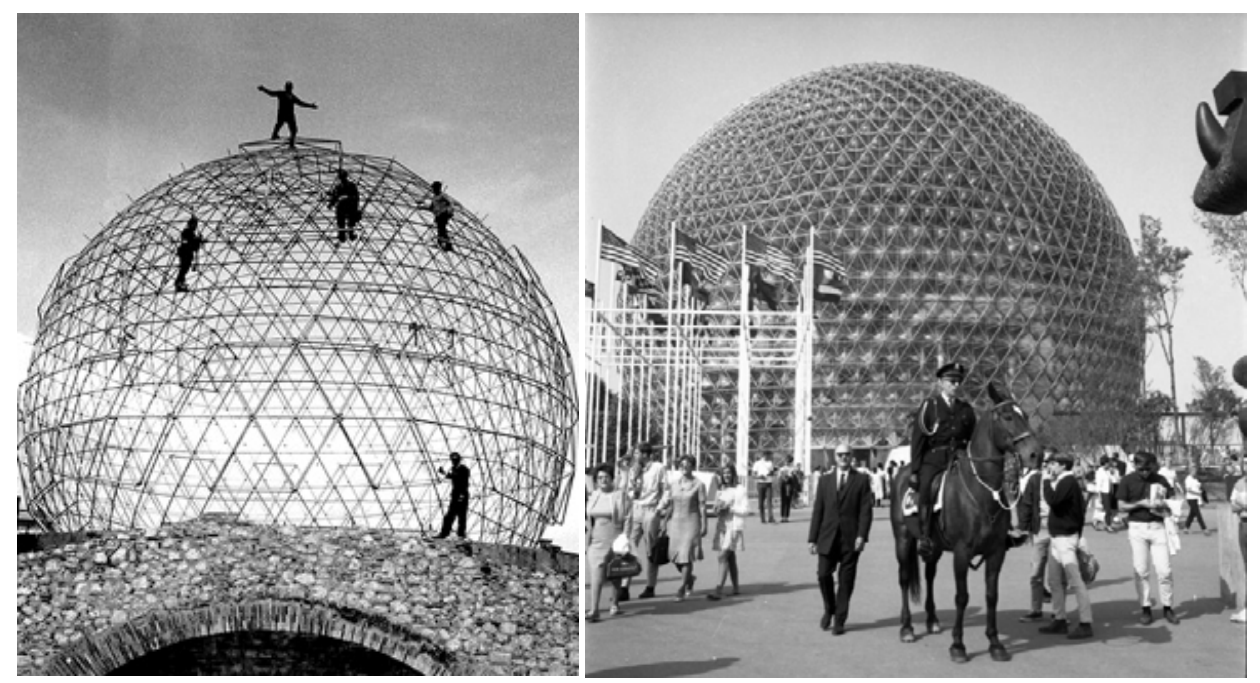

Figura 45 Cúpula del teatro del museo Dalí de Figueres, Gerona, Emilio Pérez Piñero (izquierda) y USA Montreal Pavilion EXPO1967, Richard Buckminster Fuller (derecha) 
También encontramos entre sus obras la cúpula del teatro del museo Dalí de Figueres (Gerona) y el USA Montreal Pavilion en la EXPO1968.

Lina Puertas, en su tesis sobre Emilio Pérez Piñero, aporta la solución matemática y un programa de ordenador para la definición geométrica completa del reticulado empleado a la hora de modelizar estas estructuras desplegables.

Albert Moore aparece como inventor de la patente "Marco estructural preensamblado" concedida en 1967, cuya innovación es la bóveda triangulada de doble curvatura.
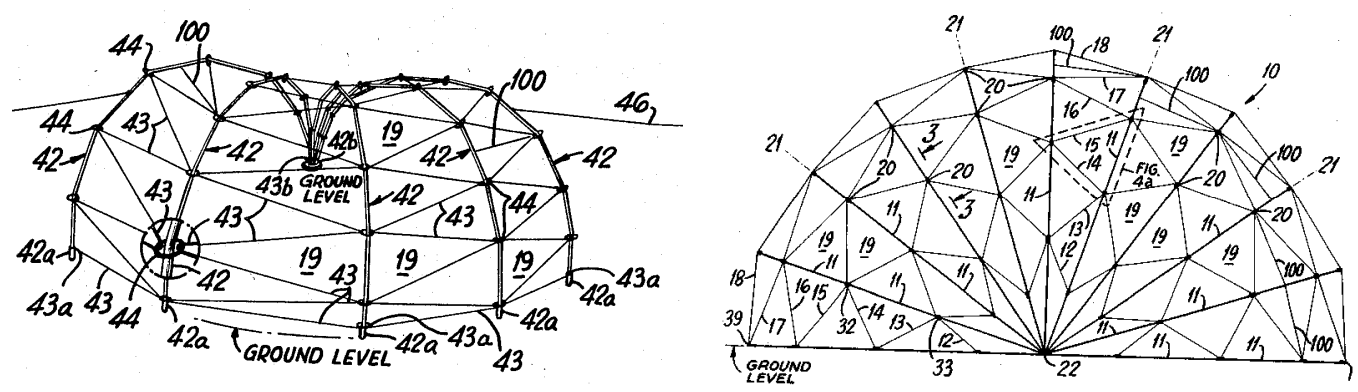

Figura 46 Marco estructural preensamblado, Albert Moore

Teodoro Zeigler desarrolla patentes de estructuras desplegables a partir de 1977, cuya innovación son los nudos pasantes articulados con sistema tipo tijera formando una cúpula triangulada por las barras sin arriostre, como puede verse en la patente denominada "Estructuras autoportantes plegables".
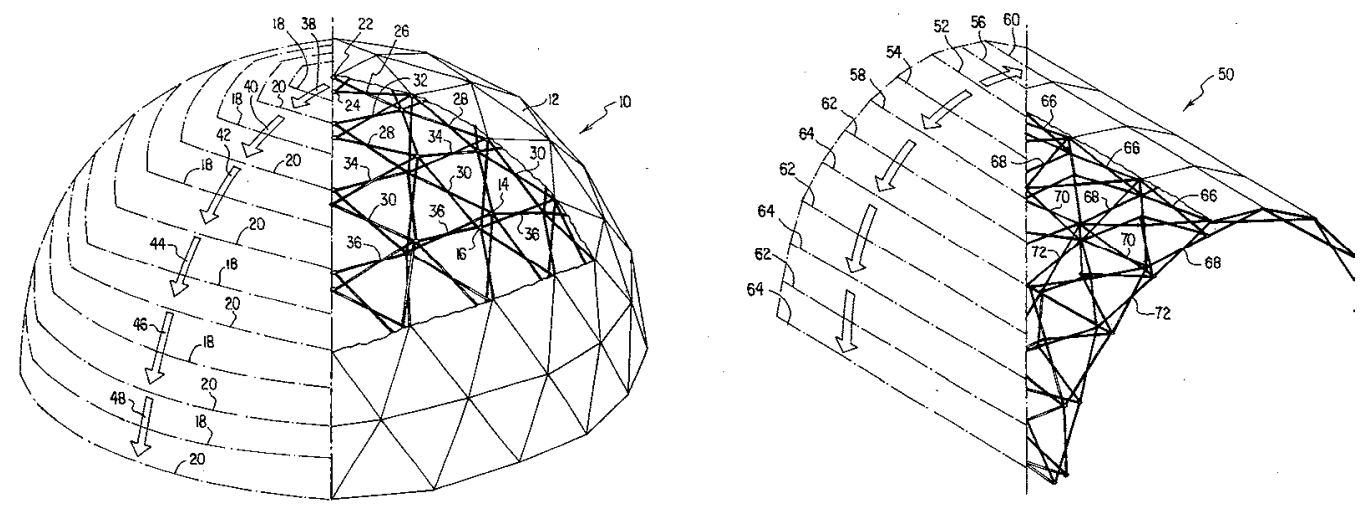

Figura 47 Estructuras autoportantes plegables, Teodoro Zeigler

Más recientemente, en 1981, Santiago Calatrava presenta su tesis "Sobre la plegabilidad de los entramados", en la que realiza un estudio geométrico de las estructuras desplegables a 
partir de sus módulos romboidales, poliédricos, cúbicos y esféricos. Santiago Calatrava prefirió usar brazos articulados en lugar de tijeras en propuestas que lo hicieron famoso como la entrada plegable para la tienda Ernsting, en 1983, y muchas otras. Y más tarde diseñó una gran cantidad de tejados móviles y voladizos basados en un solo brazo articulado.
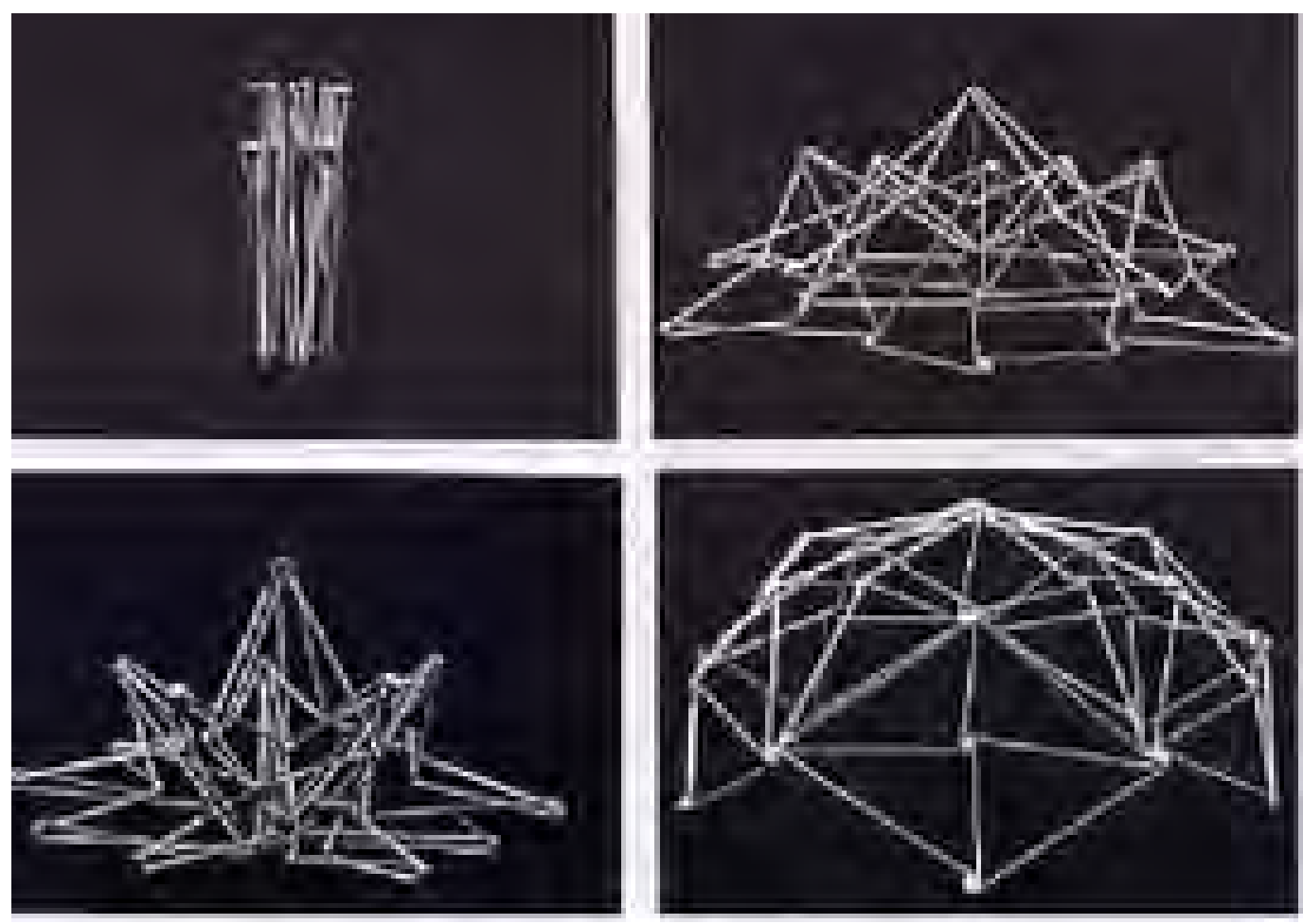

Figura 48 Imágenes de la tesis de Santiago Calatrava

Carlos Henrique Hernández (continuador de los trabajos de W. Zalezwky), entre 1987 y 1992, diseñó y construyó el pabellón de Venezuela en la EXPO 92 de Sevilla, basado en el sistema de acordeón, desarrollando el nudo tipo bisagra y resolviendo problemas constructivos, de montaje y de cerramientos rígidos. También desarrolló estructuras basadas en mallas cuadradas como el STRAN 1 Y STRAN 2, en las que desarrolló el nudo tipo tijera y la bóveda de cañón largo. 


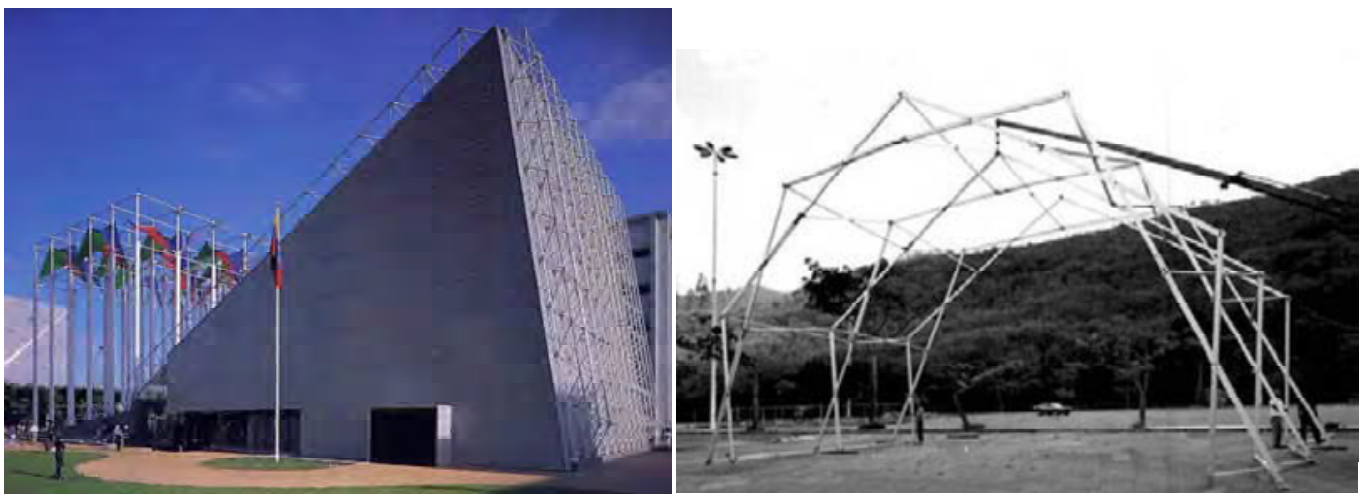

Figura 49 Pabellón de Venezuela en la EXPO 92 de Sevilla (izquierda) y STRAN 1 (derecha), Carlos Henrique Hernández

Actualmente nos podemos encontrar con seguidores de Emilio Pérez Piñero como Escrig, Sánchez y Valcárcel, cuya base de sus diseños son las tijeras de dos brazos. Su principal logro ha sido la piscina cubierta en el área de deportes de San Pablo de Sevilla.

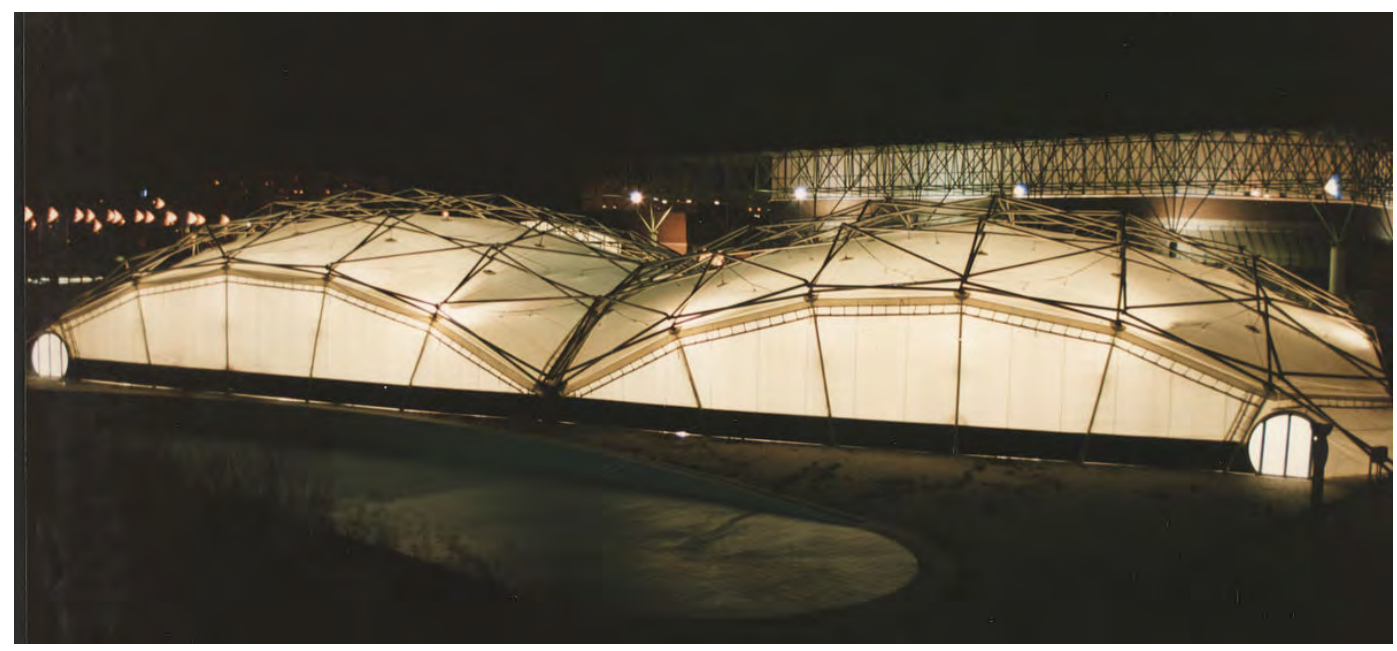

Figura 50 Piscina cubierta en el área de deportes de San Pablo de Sevilla, Escrig, Sánchez y Valcárcel

Chuck Hoberman es el inventor de las tijeras excéntricas y los trenes de tijeras, los cuales permiten hacer más compacta la madeja cuando se pliega y crear poliedros completamente cerrados. 


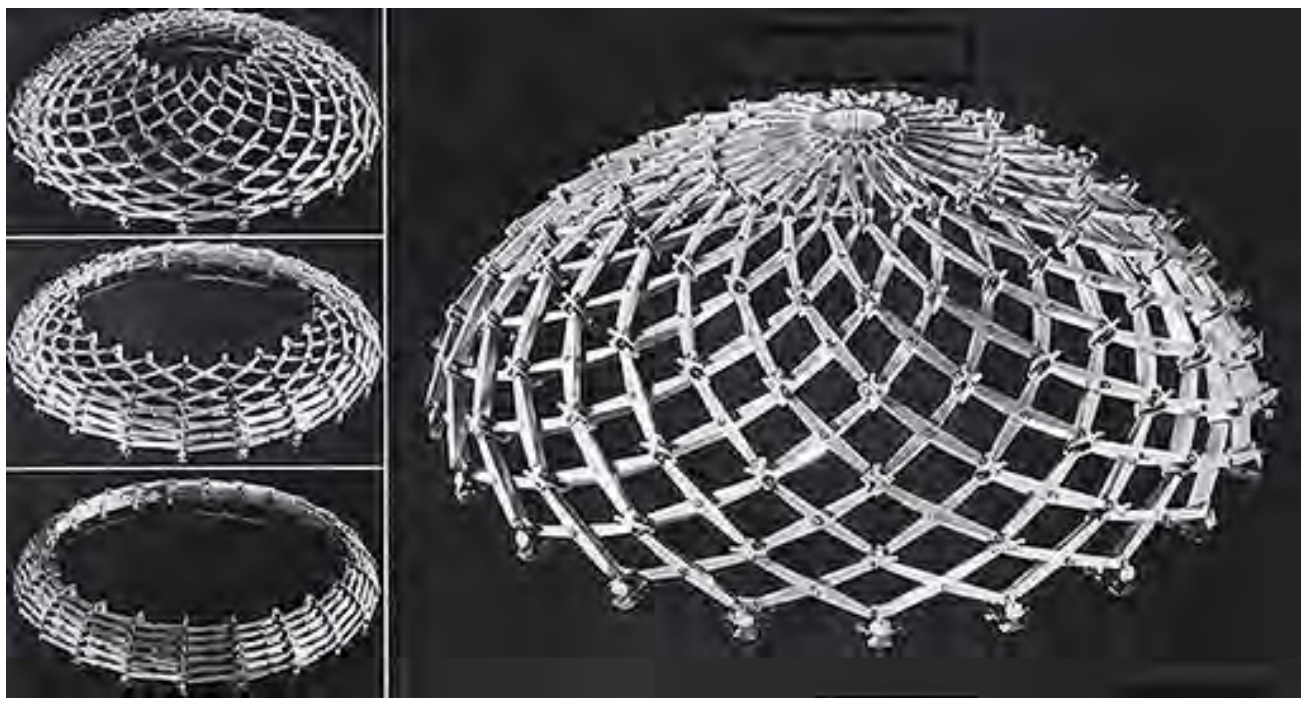

Figura 51 Esfera de Hoberman

N. K. Burford y F. W. Smith desarrollaron un sistema de refugio ligero y rápido que usa una nueva combinación de materiales compuestos y diafragmas de tela en un sistema de soporte de viga en respuesta a los cambios en las necesidades militares. Los autores se centran en los problemas encontrados en el programa de desarrollo y en el proceso de innovación, destacando cómo se superaron estos problemas y detallando los beneficios que se crearon. En particular, la carpa resultante incorpora vigas compuestas reforzadas con vidrio elástico ligero, post-tensionadas por un diafragma de tela. El nuevo refugio utiliza un número mínimo de estos componentes ligeros y rígidos y, en consecuencia, logra una reducción en el peso, los tiempos de erección y de huelga, y empaquetado a través de sus innovaciones.

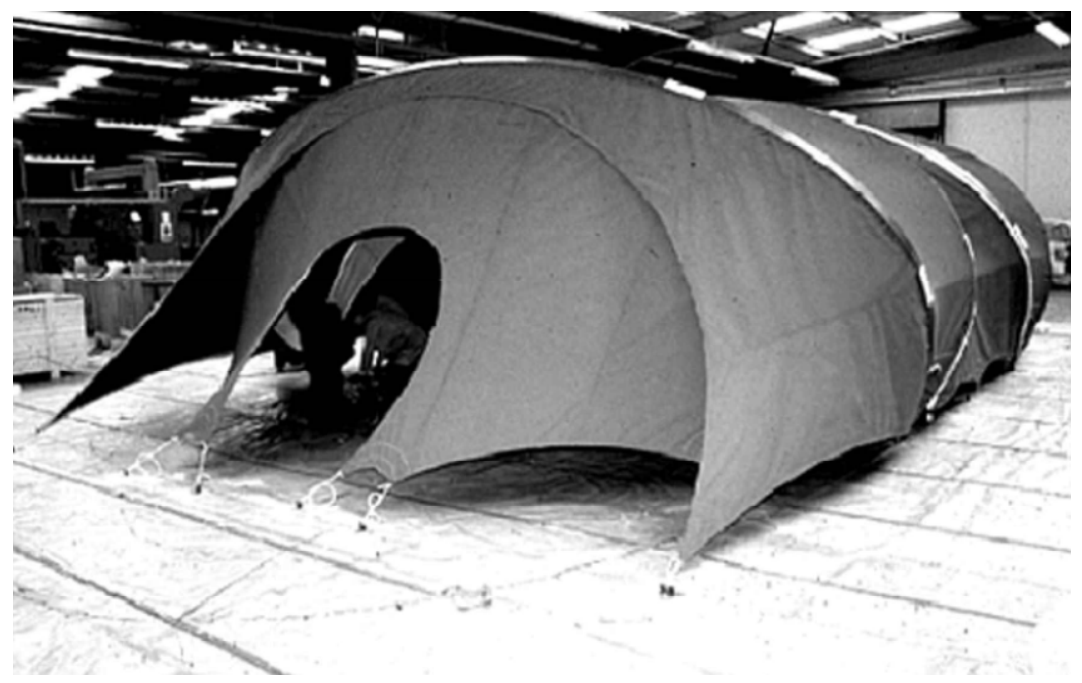

Figura 52 Configuración estructural revisada del refugio de prototipo a escala completa,

N. K. Burford y F. W. Smith

51 
Marta Balaguer Sala y Ramón Sastre i Sastre investigan los sistemas de barras en x con rótulas intermedias, también llamados tijeras con elementos, con el objetivo de obtener diferentes alternativas formales con una única solución estructural mediante la modificación de los grados de libertad en tipologías de barras telescópicas articuladas intermedias, también llamadas de tijeras con elementos.
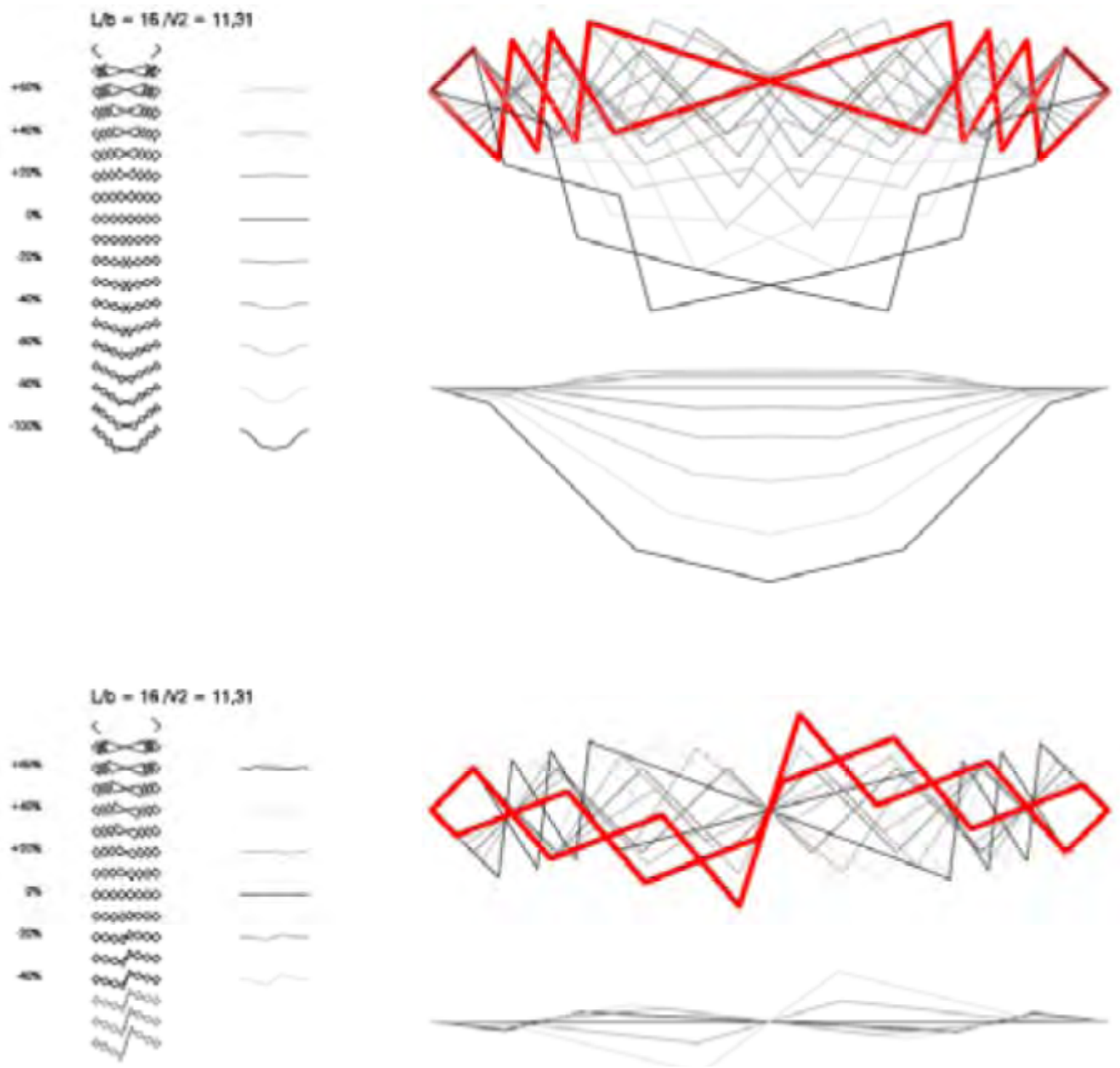

Figura 53 Proceso de transformación en sistema transformable de barras telescópicas y articuladas en $x$ 
Luis Sánchez Cuenca desarrolló una teoría de geometrías complejas para construir algunos tipos de superficies desplegables.

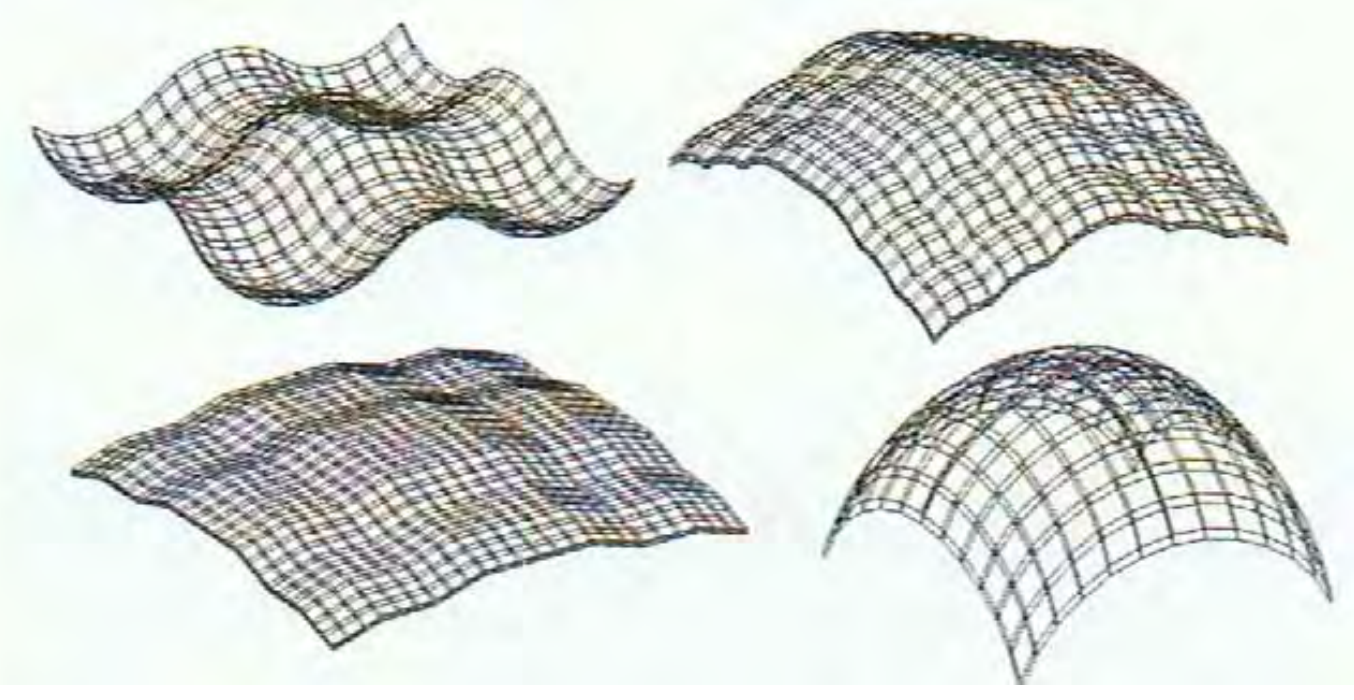

Figura 54 Propuesta de Luis Sánchez Cuenca para generar formas arbitrarias

Daniel Enrique Gómez Lizcano desarrolla sistemas móviles con un grado de libertad, generando dos tipos de polígonos: cuadriláteros y triángulos. El primero es el resultado de tijeras articuladas como elementos, transmitiendo los esfuerzos de un módulo a otro uniformemente. El segundo consiste en la combinación de sistemas articulados y por deslizamiento, incorporando un elemento guía en el cual son inscritos triángulos deformables con una operación de compresión.
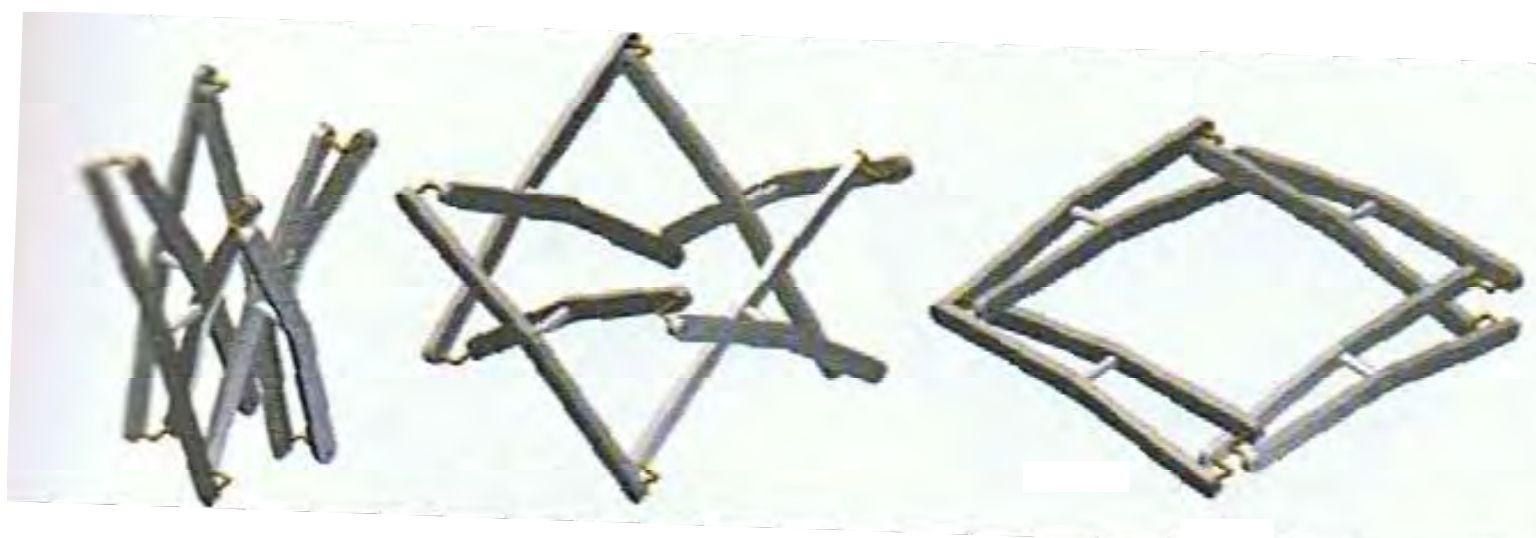

Figura 55 Movimiento de un cuadrilátero truncado de base piramidal, Daniel Enrique Gómez Lizcano 


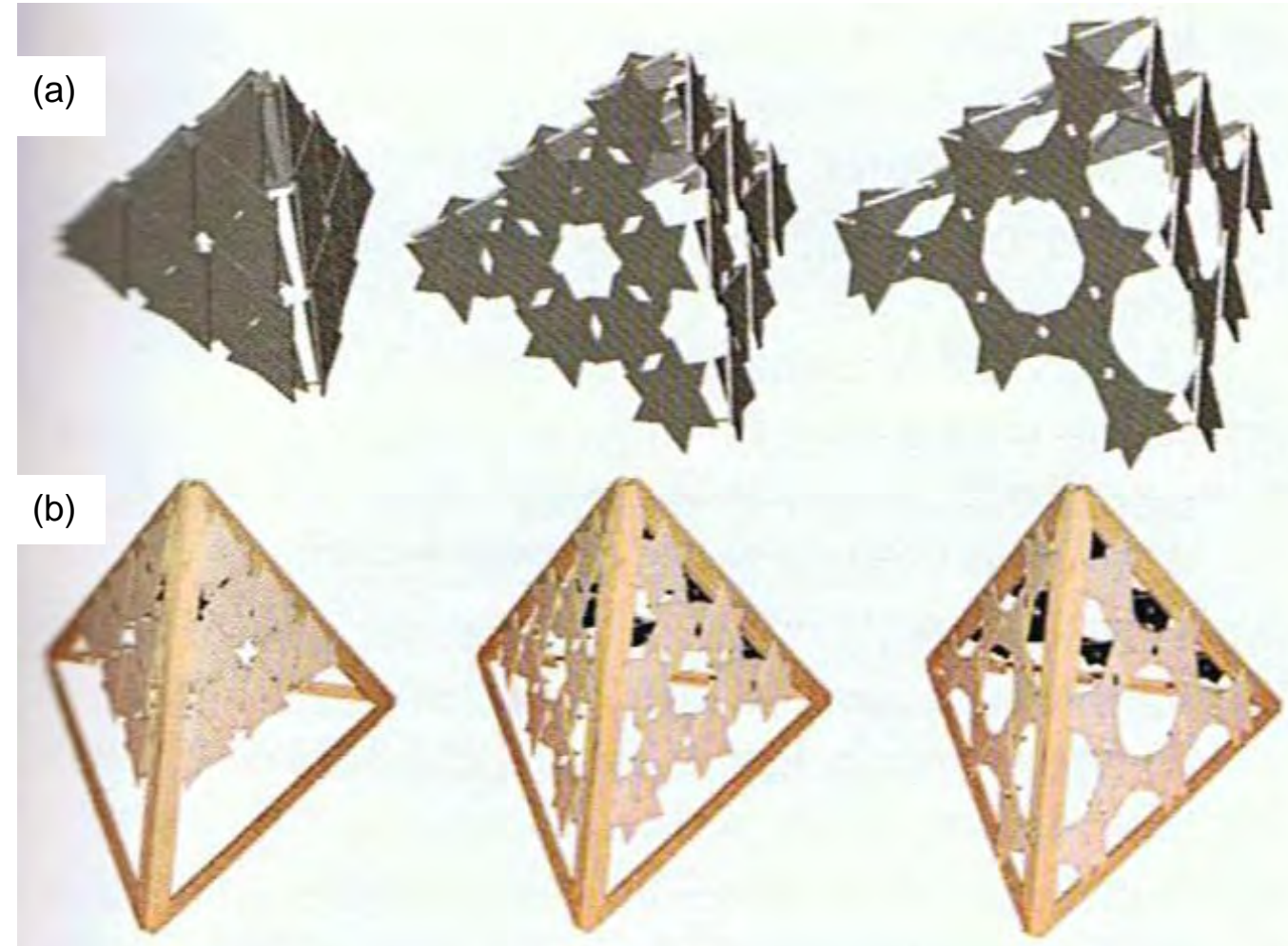

Figura 56 Análisis de la transmisión de movimientos entre caras: (a) Uniones articuladas, (b) Marco deslizable. Daniel Enrique Gómez Lizcano

Koray Korkmaz, Gözde Susam y Yenal Akgün desarrollan el nuevo mecanismo reconfigurable 8R, el cual puede generar diferentes superficies de paraboloides hiperbólicos. El nuevo diseño parte de las super restringidas articulaciones Bennett y la producción principal de superficies regladas, mejorando estos sistemas con su nuevo mecanismo.

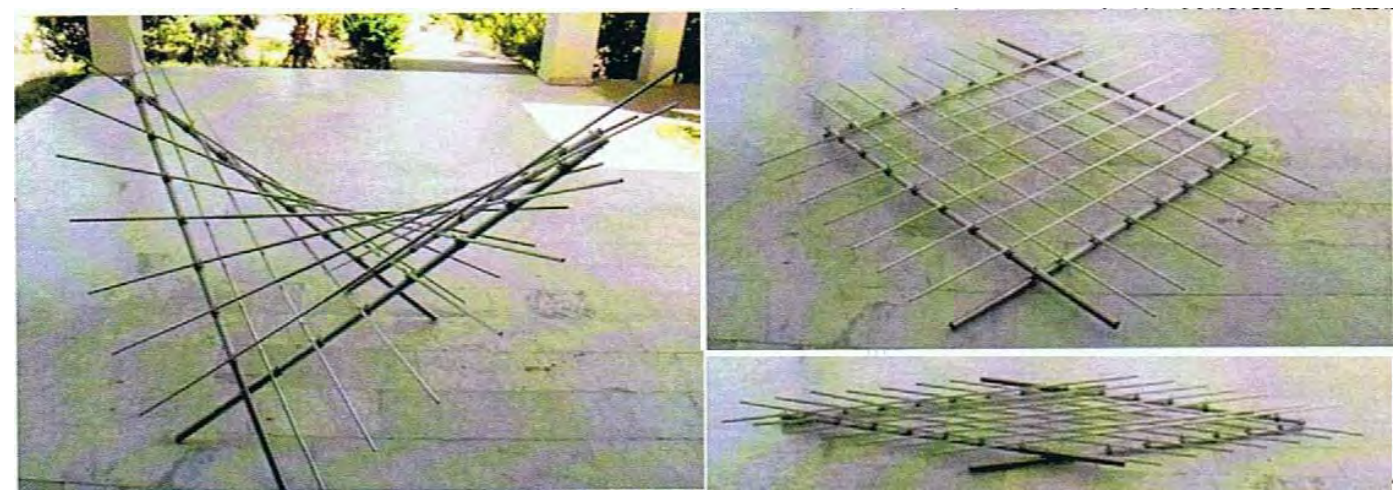

Figura 57 Modelo que muestra la capacidad de transformación del nuevo mecanismo con catorce enlaces intermedios, Koray Korkmaz, Gözde Susam y Yenal Akgün 
Antonio Ponce García y José Sánchez Sánchez generan superficies curvas mediante mecanismos de tijeras en forma de x. Estas superficies que pueden ser curvadas sólo en una dirección dan lugar a superficies cilíndricas, mientras que si son curvadas en dos direcciones dan lugar a superficies de doble curvatura. En su trabajo se busca generar mallas rectangulares como superficies regulares troncocónicas.

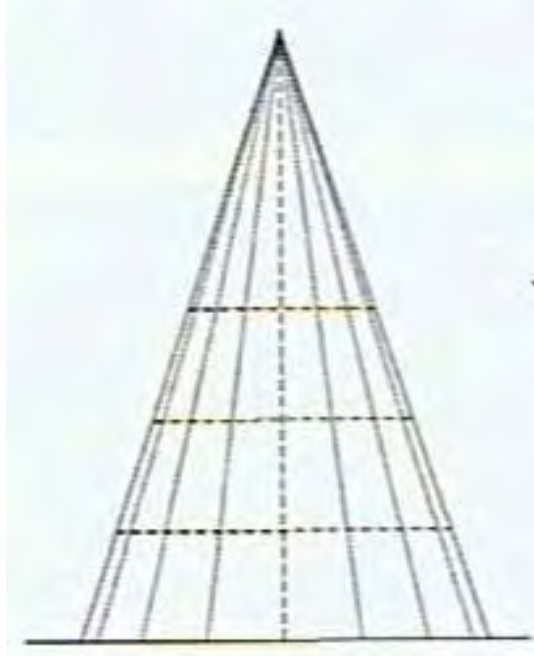

a

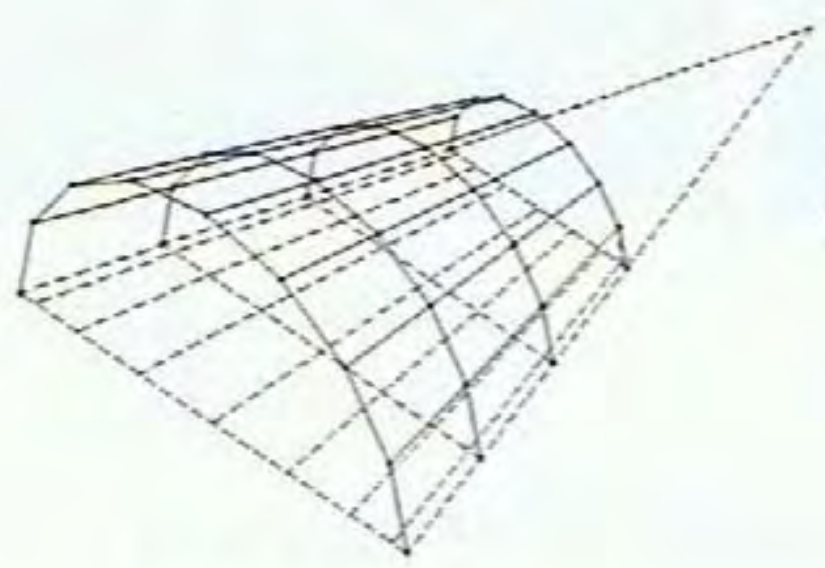

c

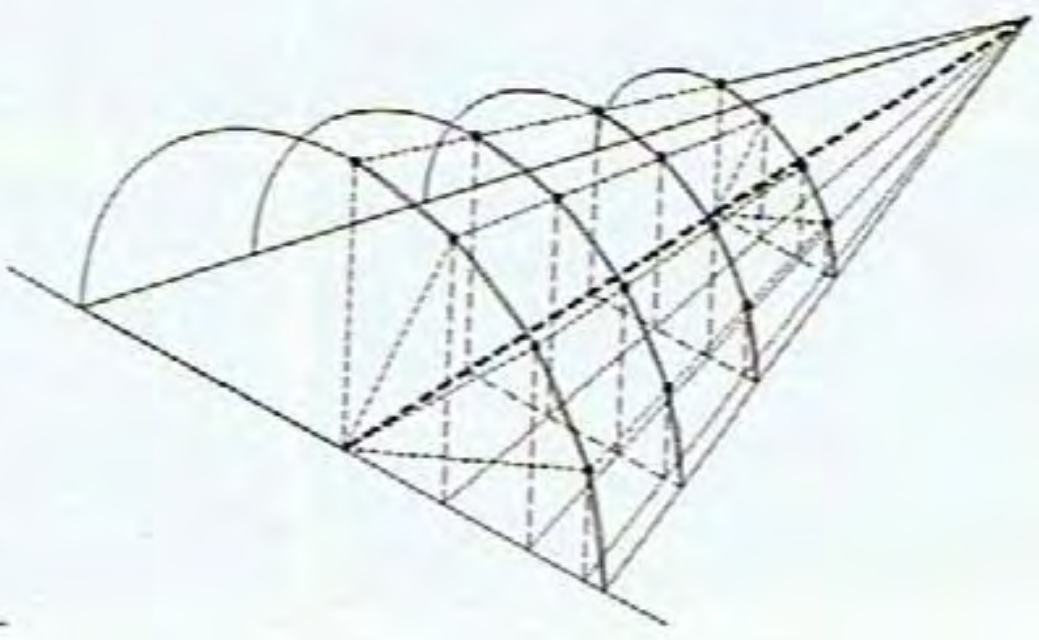

b

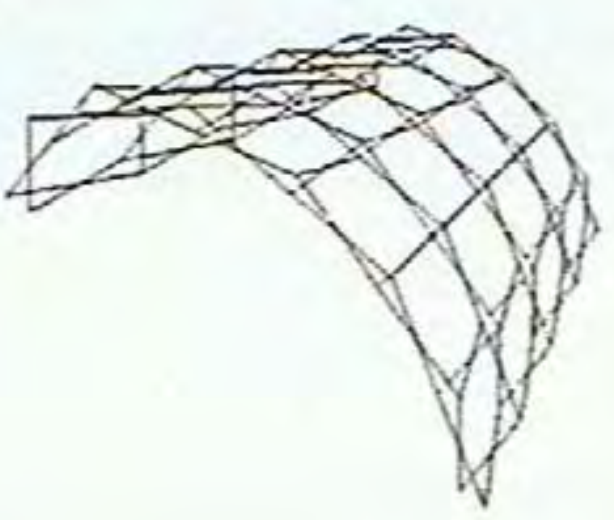

d

Figura 58 Generación de mallas troncocónicas, Antonio Ponce García y José Sánchez Sánchez 
Cristina Ramos Jaime, Antonio Maciá Mateu y José Luis Oliver Ramírez se focalizan en el desarrollo de una solución para lograr la curvatura para mallas esféricas desplegables, con el objetivo de simplificar el proceso constructivo. Se propone un sistema de barras rectas con articulaciones centrales y que tiene en cuenta el tamaño de las articulaciones. Los nudos entre piezas que se cruzan se forman por dos anillos con diferente diámetro de acuerdo al ángulo requerido en cada conexión.
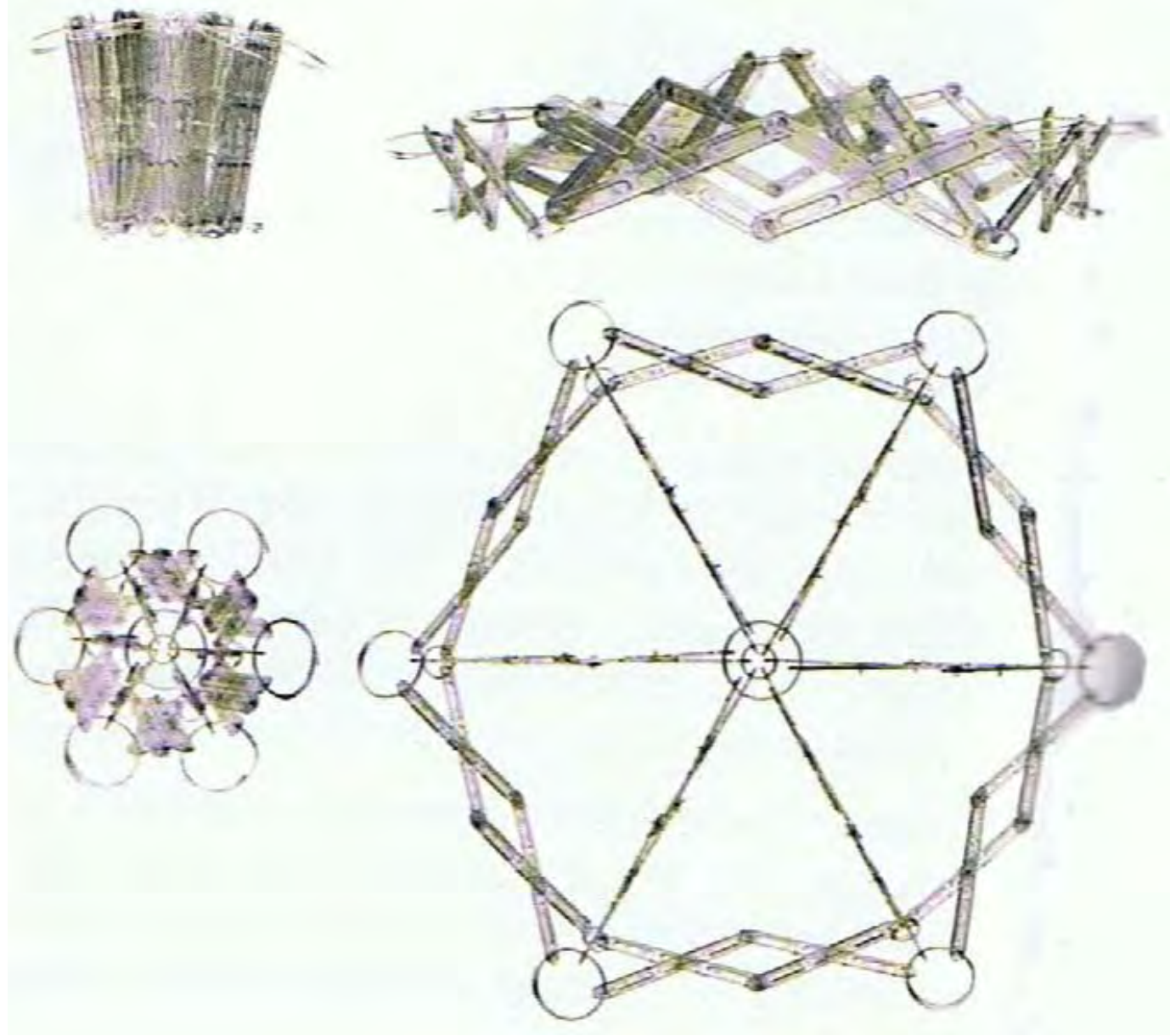

Figura 59 Red unitaria curva, Cristina Ramos Jaime, Antonio Maciá Mateu y José Luis Oliver Ramírez

Omar F. Avellaneda L. investiga el problema de estructuras dinámicas vistas desde su morfología estructural y función en el campo de la arquitectura. El objetivo de su investigación es el estudio de soluciones de recintos para estructuras desplegables, adoptando sistemas textiles y relacionando en el diseño estructura y forma. 

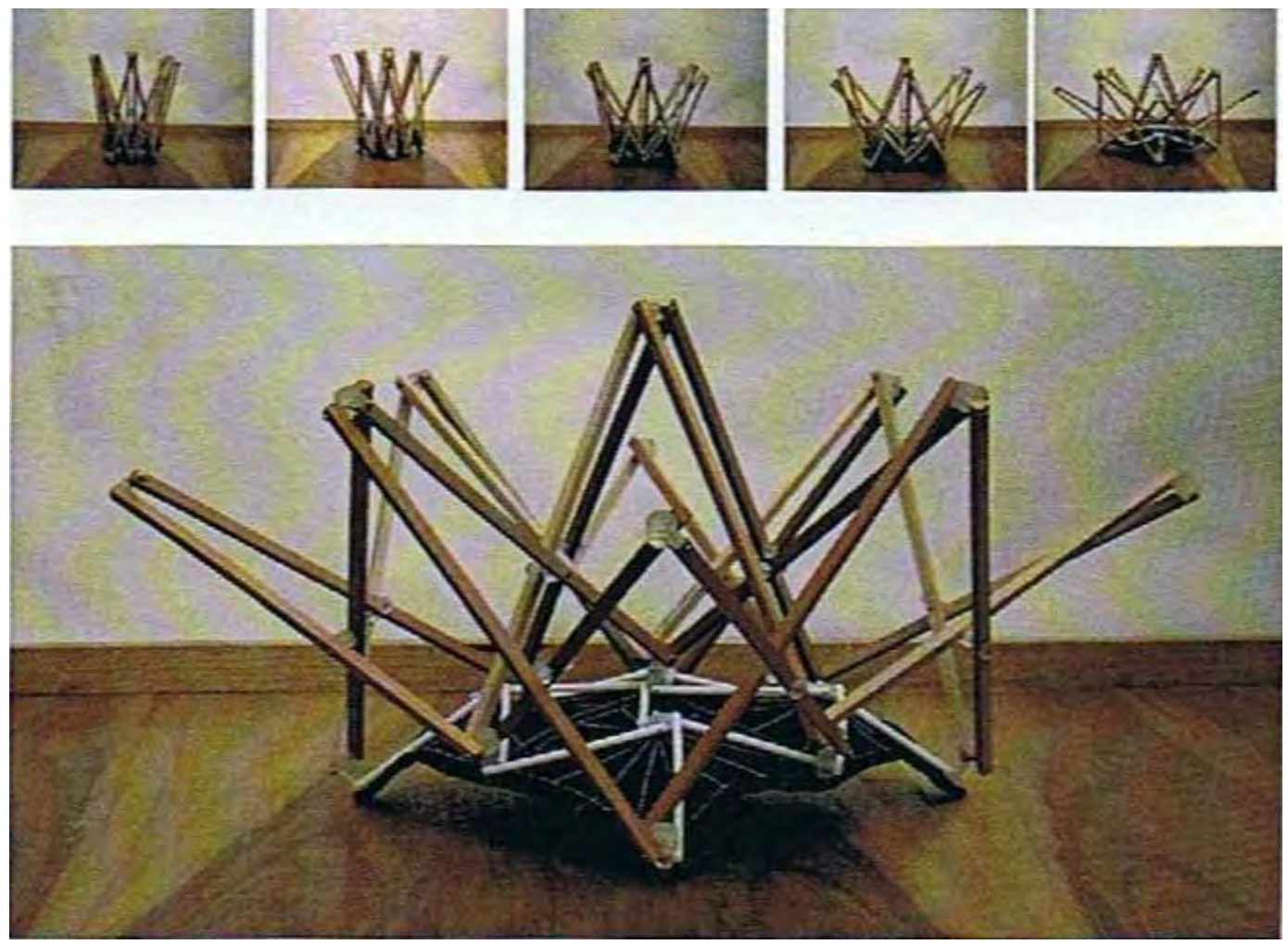

Figura 60 Modelo con sistema de membrana rigidizada sinclástica, Omar F. Avellaneda L.

Yohei Yokosuka y Teruo Matsuzawa presentan un sistema de unión llamado "articulación esférica multiunión", el cual es un novedoso mecanismo que permite la rotación triaxial de los miembros. Se forman sistemas de estructuras ideales de geometría variable a partir de desplazamientos pequeños con el centro de rotación de las uniones.

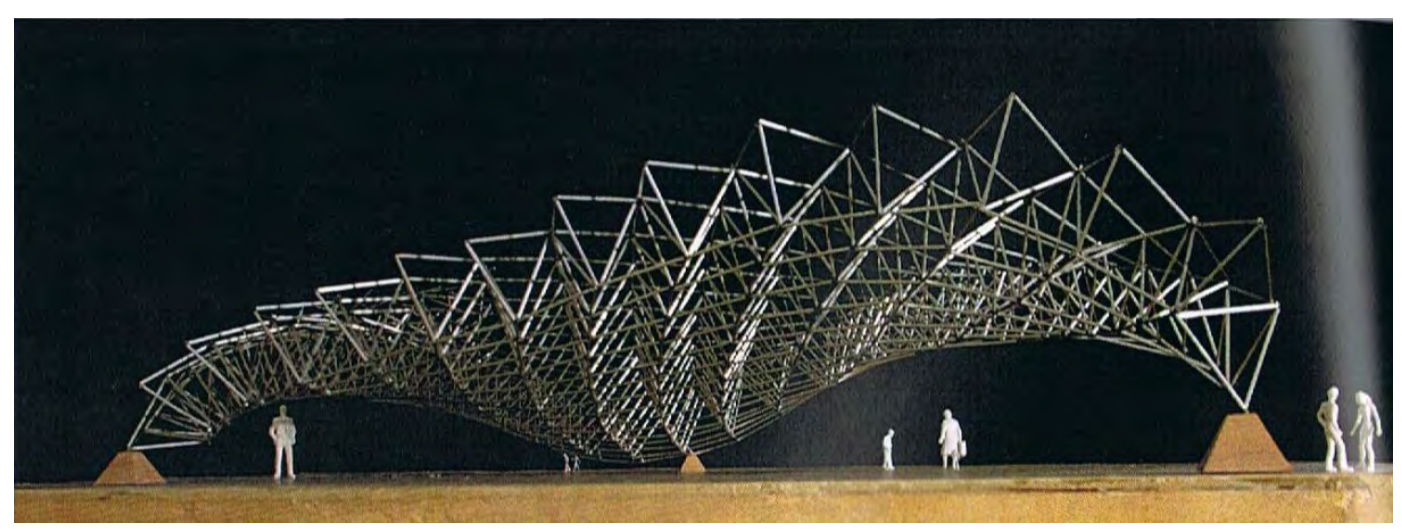

Figura 61 Modelo de estudio de estructura de geometría variable, Yohei Yokosuka y Teruo Matsuzawa 
Rodrigo Ramos Jiménez busca la geometría apropiada para una estructura desplegable de barras en $x$ y un sistema de apertura que permita instalar una cubrición en unos pocos minutos. Se busca ser modular en longitud, llegando a la conclusión de que las geometrías que mejor funcionan son las formadas por troncos de cono formados por trapezoides y filas de triángulos en la base.

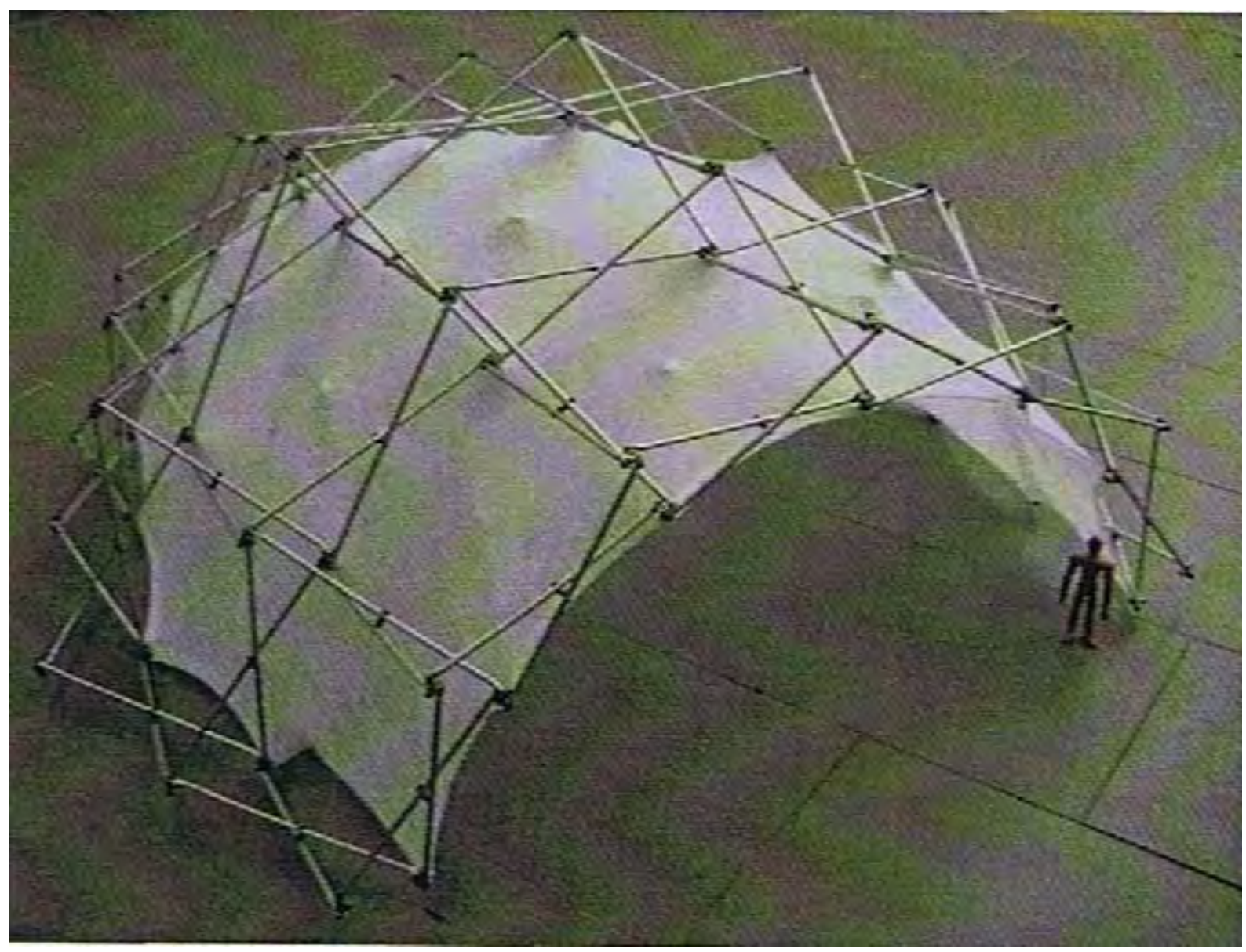

Figura 62 Modelo de cúpula hecha de dos troncos de cono, Rodrigo Ramos Jiménez

Lara Alegria Mira, Niels De Temmerman y Ashley P. Thrall desarrollan albergues temporales que pueden ser desplegados rápidamente y reconfigurados después basados en los sistemas de elementos de tijera, que son ligeros y generan una gran expansión de su volumen después de ser desplegados. 


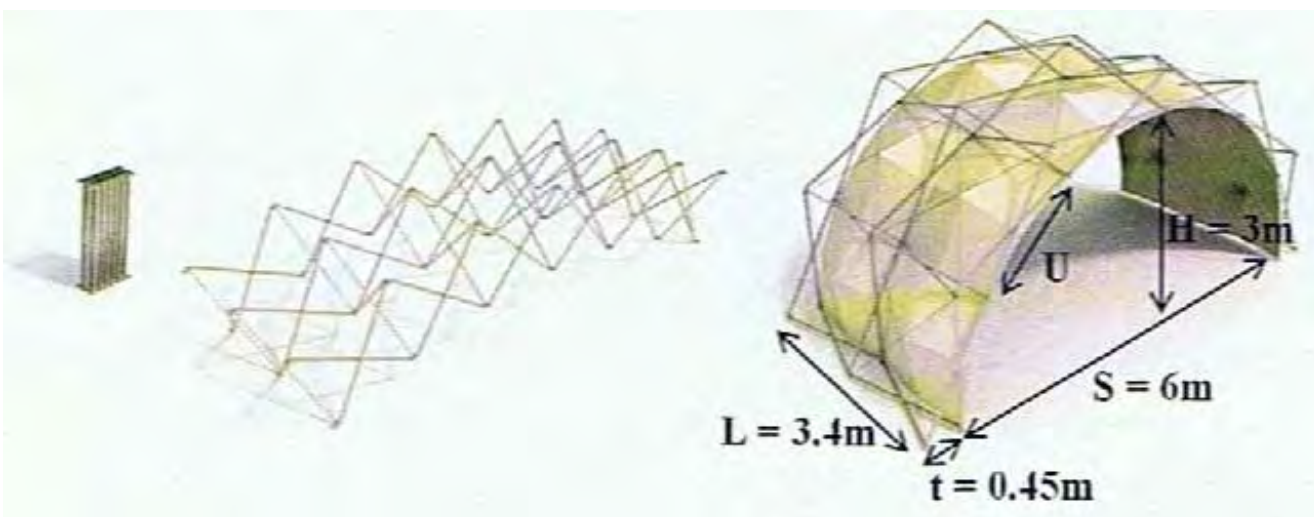

Figura 63 Concepto para un uso de albergue desplegable de arcos de tijera con una membrana. Las dimensiones son indicadas a la derecha, Lara Alegria Mira, Niels De Temmerman y Ashley P. Thrall

Daniel S-H Lee, Olga Popovic Larsen y Seung-Deog Kim investigan para obtener un diseño más efectivo para la conexión de las uniones para las estructuras desplegables tipo tijera, con el principal objetivo de obtener un diseño que minimice la deformación estructural y por tanto las tensiones inducidas durante el despliegue. También buscan la solución más simple para la práctica del análisis y construcción.

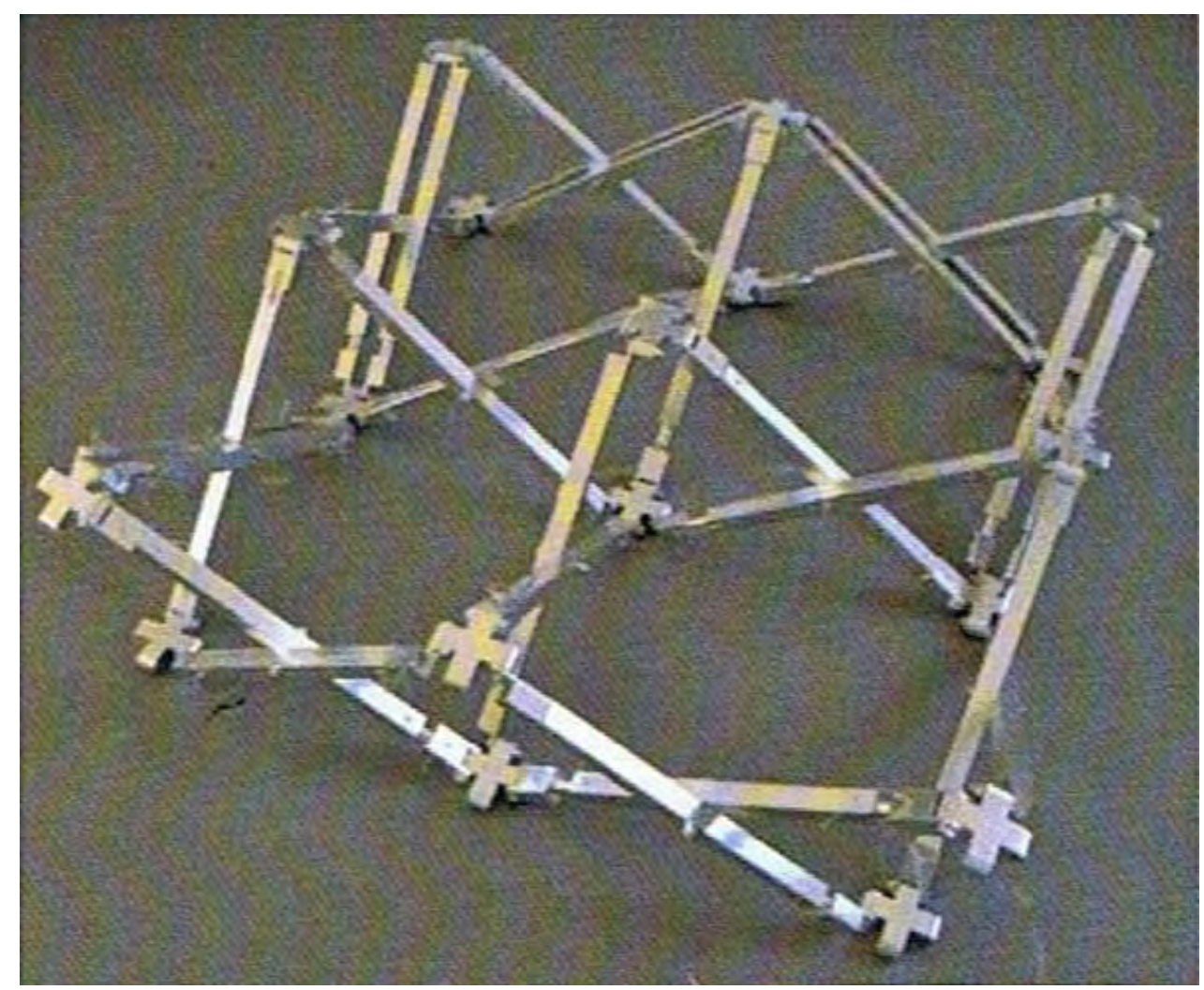

Figura 64 Prototipo físico, Daniel S-H Lee, Olga Popovic Larsen y Seung-Deog Kim 
Carlos Cesar Morales Guzman desarrolla una investigación experimental de geometrías orgánicas en la arquitectura, con referencias consecutivas de geometrías fractales. Del mismo modo que esto ayuda a formar estructuras flexibles y adaptables en la naturaleza, esto genera estructuras versátiles que se adaptan a una gran variedad de contextos, dentro de unas estructuras ligeras y retráctiles.

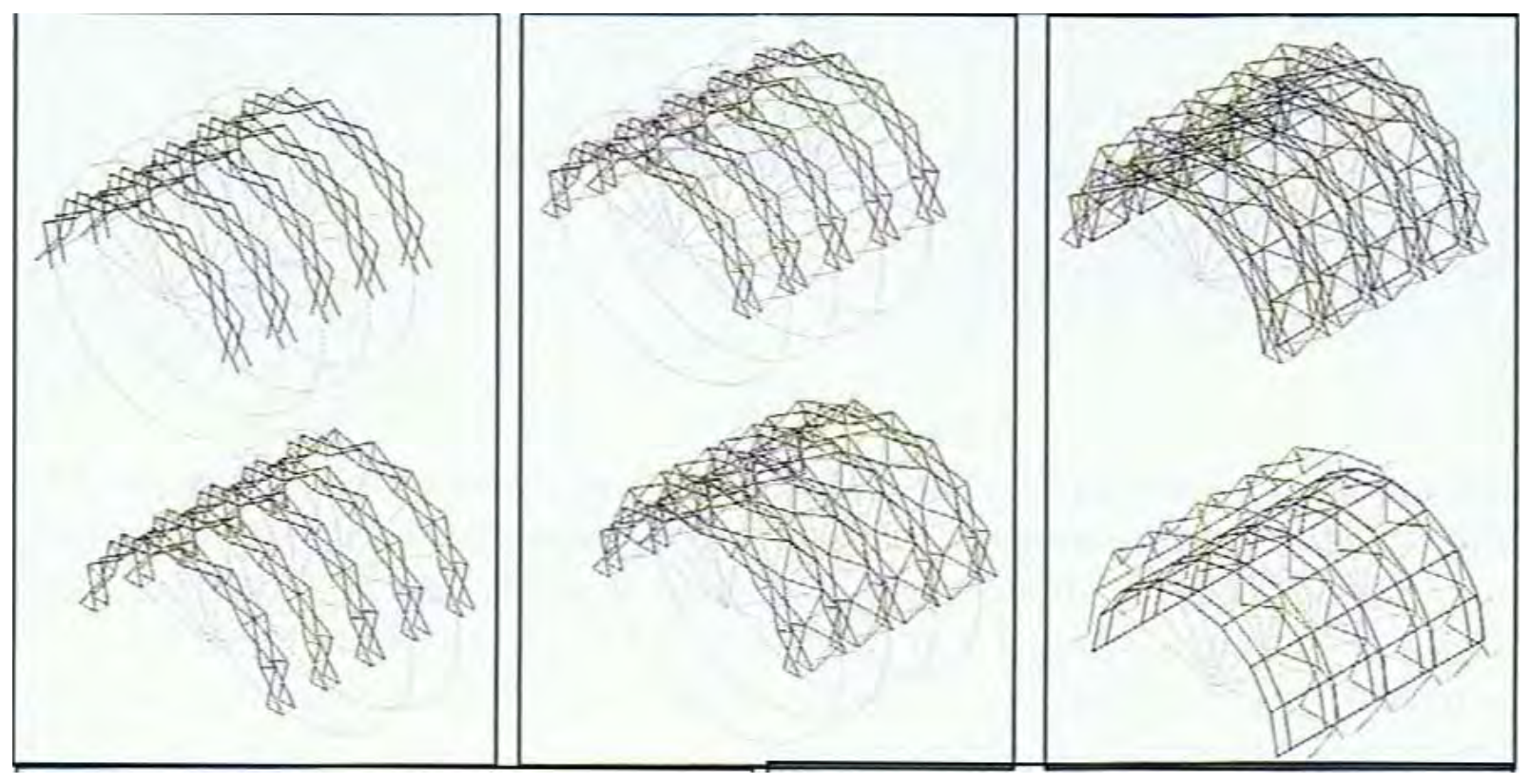

Figura 65 Desarrollo orgánico de acuerdo a la geometría generada por formas y membranas modulares para su estandarización e iteración. Morales, 2010.

Natalia Paola Torres Londoño desarrolla un escenario desplegable y móvil que puede ser adaptado a diferentes espacios y usos. La configuración de la estructura es desarrollada mediante el análisis de varios sistemas estructurales claves que permiten ser abiertos, cerrados y transportados sin la necesidad de desmontarlos. Su investigación está basada en el estudio de los sistemas de tijera, plegables y en el diseño de membranas de estructuras desplegables. 


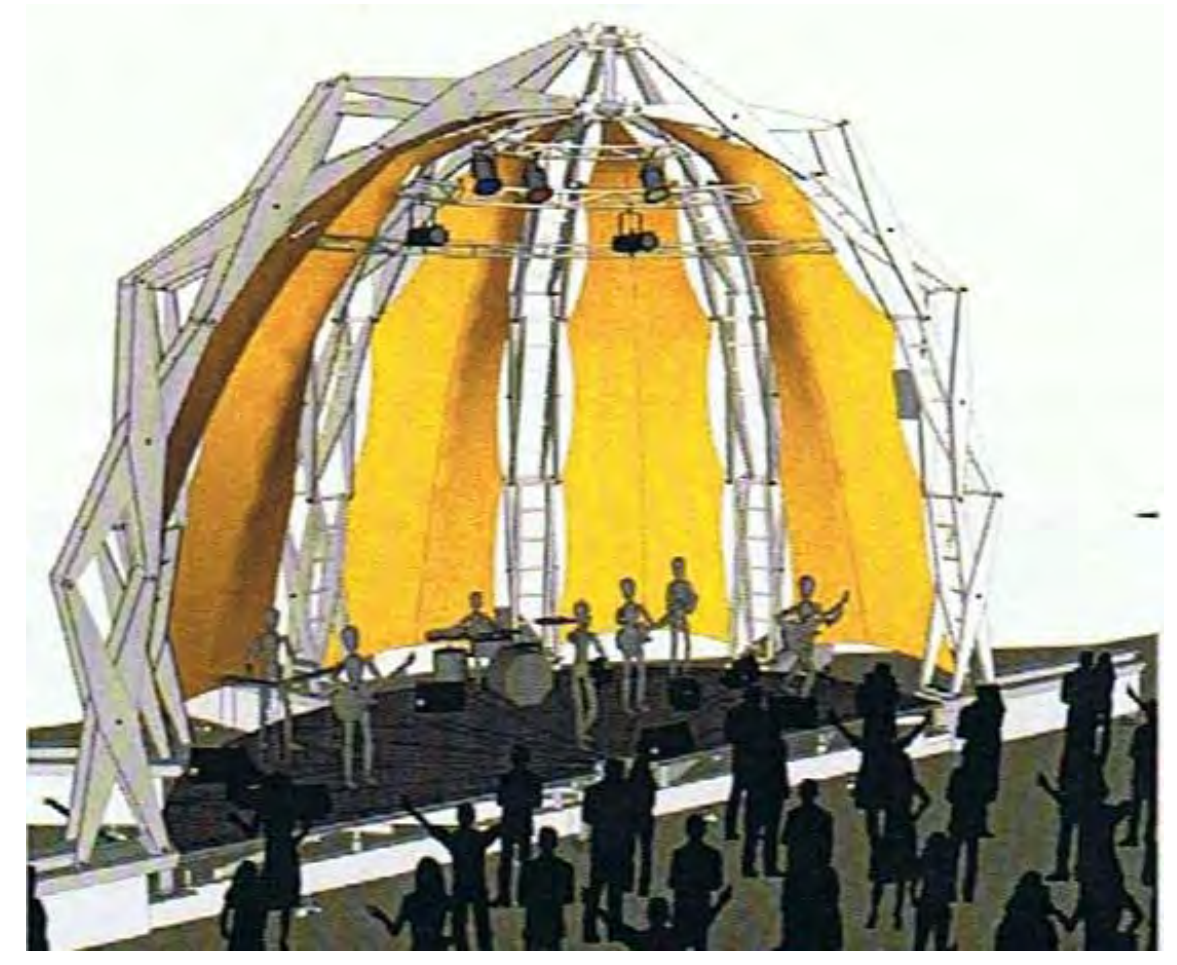

Figura 66 Escenario plegable para eventos culturales, Natalia Paola Torres Londoño

Rodrigo García González innova rigidizando la estructura gracias a su propia configuración geométrica una vez desplegada sin requerir elementos externos. Se puede usar para edificios en altura. Incorpora el concepto de fractalidad a las estructuras desplegables.
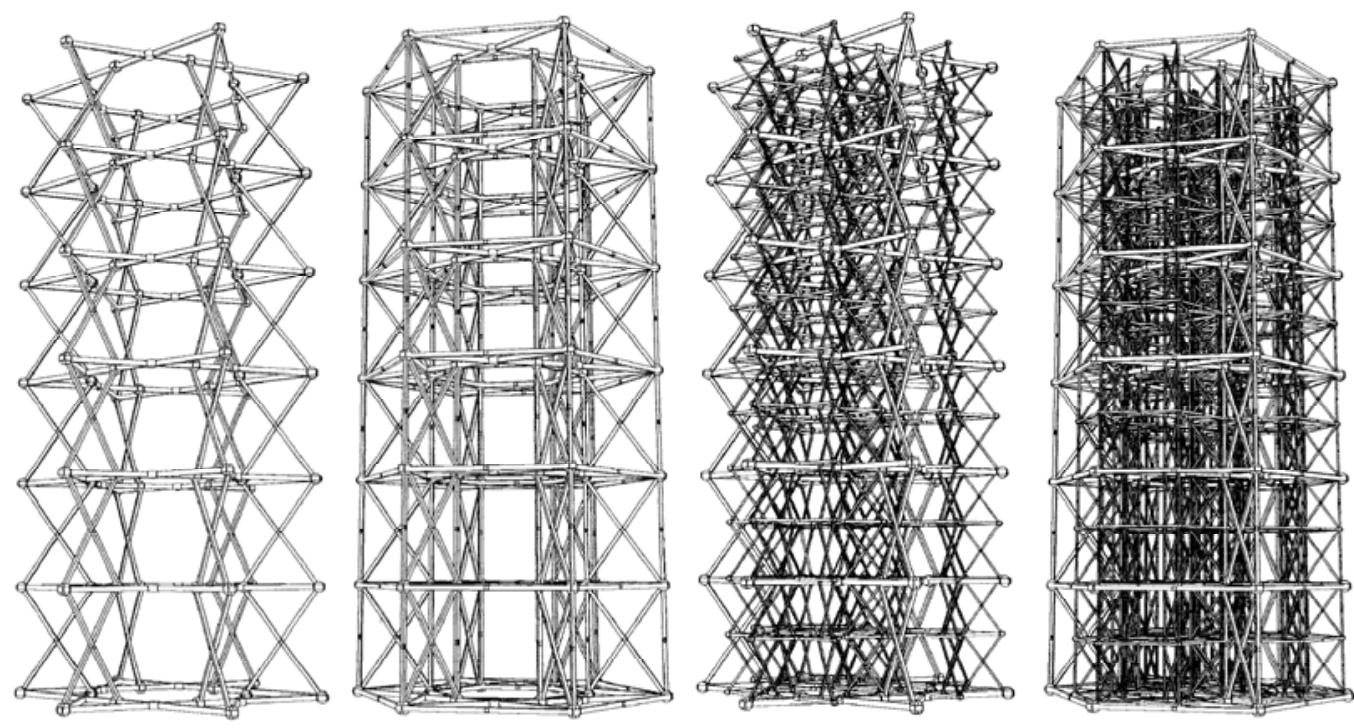

Figura 67 Sistema estructural desplegable fractal, Rodrigo García González 
Recientemente, AKT, Adams, Kara y Taylor (2008), estudian el proyecto que FOA desarrolló basado en piezas hexagonales para una idea de prototipo. Se desarrollaron varios tamaños de paneles hexagonales provistos de paredes internas curvas y planas. El problema eran las uniones, que se resolvieron llevándolas lejos de los nodos.

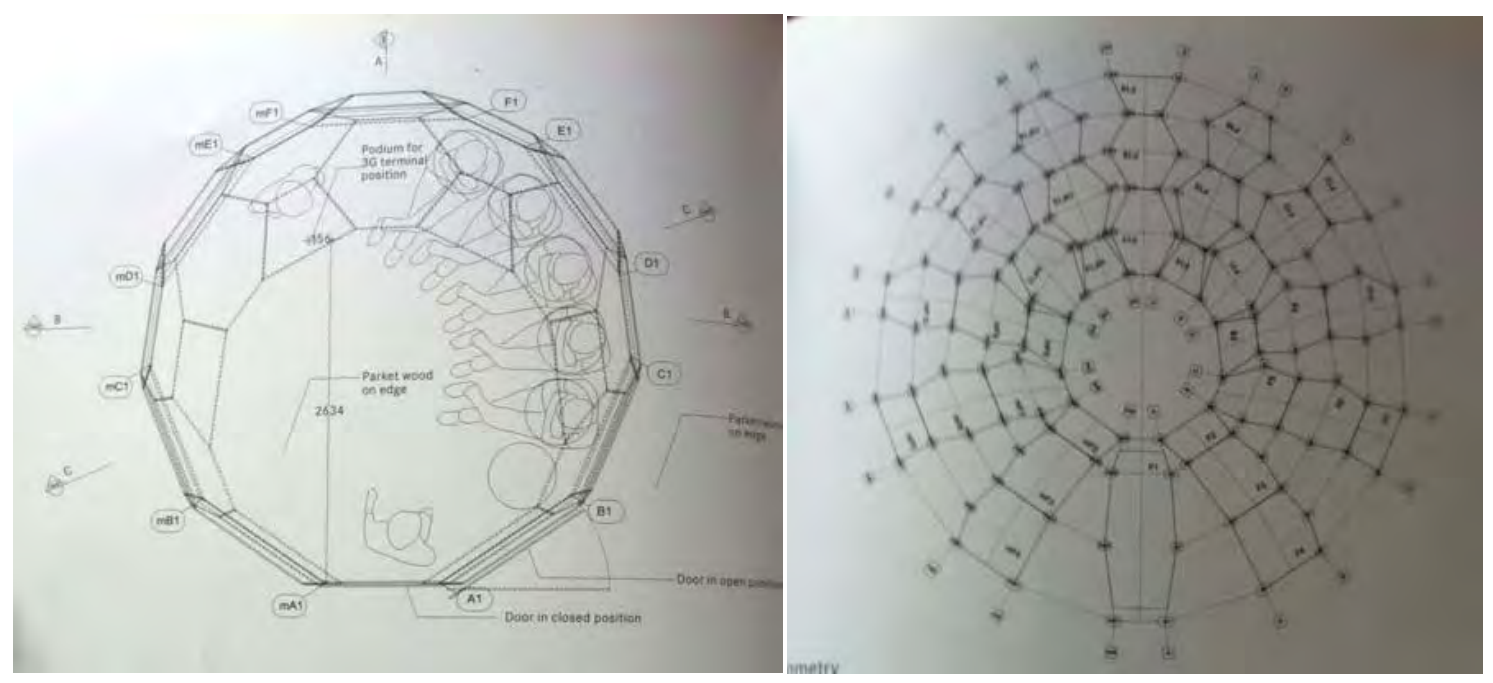

Figura 68 Pods, Hexagonal Glass and Glass Joint HUTCHINSON 3G, AKT

Charis J. Gantes, Konstantinos E. Kalochairetis y Yenal Akgün desarrollan estructuras desplegables que pueden ser definidas como estructuras que pueden ser transformadas desde una configuración cerrada compacta a una forma predeterminada expandida, la cual es estable y capaz de soportar cargas. Para lograr la desplegabilidad son impuestas restricciones significantes sobre las posibles formas geométricas así como la disposición de las membranas estructurales.

Lisa Iwamoto también desarrolla alguna estructura desplegable, como la que se observa en la "Digital Weave". La exploración de las superficies expansibles y las cuestiones sociales de los sin techo se experimentaron en el diseño de una actuación de centro de arte. La idea del mecanismo extensible era capaz de proporcionar una superficie multifuncional que permitía que varios programas diferentes sucedieran. Parte de la fachada podría estar abierta durante cierto período de tiempo para crear un área de actuación al aire libre. Cuando la fachada estaba cerrada, se podía utilizar como sala de ensayo y también como espacio de exposición. Este evento transitorio fue la clave para crear conciencia pública sobre la falta de vivienda en la comunidad circundante. 

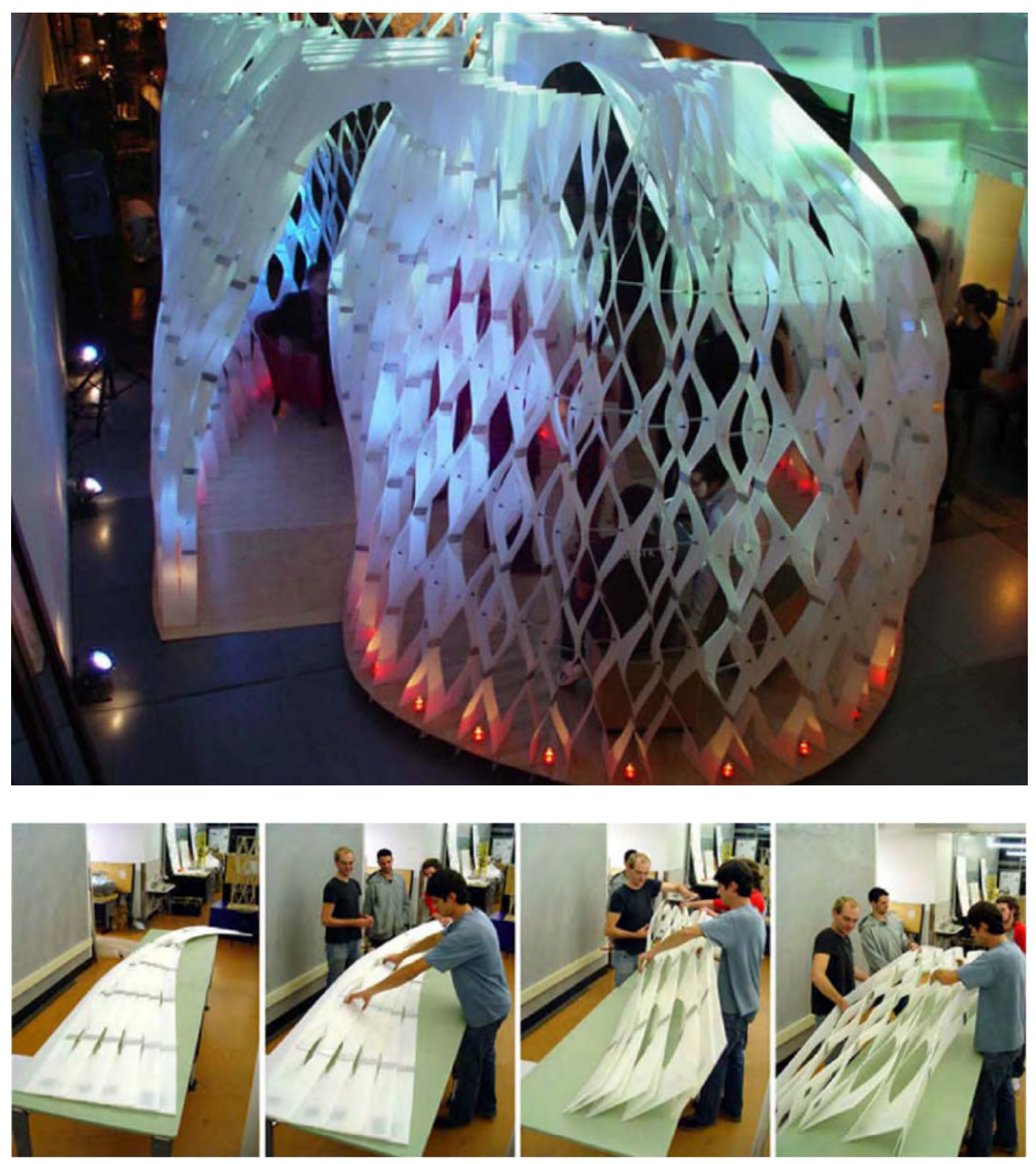

Figura 69 Digital Weave, Lisa Iwamoto 


\subsubsection{Tensegrities y estructuras tensionadas}

Hay que enfatizar que la mayor parte de estas estructuras desplegables están basadas en sistemas tensegríticos. Los tensegrities son estructuras de barras y cables que sólo trabajan a compresión y tracción respectivamente, en las que dichas barras y cables se equilibran, pero aparentemente el crecimiento es desordenado. Debido a que el soporte principal de estas estructuras objeto de estudio es la tensión continua, la investigación de materiales adecuados para los esfuerzos de tracción ha sido crucial.

Las estructuras "push-and-pull" eficaces hubieran sido inconcebibles antes del siglo XVIII debido a la incapacidad para obtener un comportamiento efectivo del material bajo tensión. Edmonson (1987) afirma que hasta ese momento sólo se había explotado la resistencia a la tracción de la madera (principalmente en la construcción de los buques), pero su tracción no era comparable con la compresión de la mampostería de piedra.

Sin embargo, la primera producción masiva de acero, en 1851, cambió mucho esta situación. Ese acero fue capaz de alcanzar resistencias similares a la piedra de mampostería, tanto en compresión como en tracción, dando lugar a muchas nuevas posibilidades y, de acuerdo con Edmonson (1987), la construcción del Puente de Brooklyn abrió una era innovadora de diseño tensional. "La tensión es algo muy nuevo", dijo Fuller (Edmonson, 1987).

Es evidente que el desarrollo de aceros y otras aleaciones dio lugar a resultados impredecibles en términos de resistencia, peso y rendimiento de los materiales, lo que permitió a ingenieros y arquitectos crear nuevos diseños y nuevos conceptos estructurales. Estos nuevos materiales no sólo sirvieron para aumentar la resistencia de los componentes, sino también para disminuir su sección transversal y, en consecuencia, su peso.

Sin embargo, el comportamiento de los elementos bajo una carga es diferente dependiendo del tipo de carga. Cuando un elemento lineal se comprime a lo largo de su eje principal, tiene la tendencia a aumentar su sección transversal (debido al efecto de la relación de Poisson) y a alabearse, lo que significa que pierde su forma recta. Por el contrario, cuando el mismo elemento está tensado en la misma dirección, tiende a volverse más delgado y, más importante aún, "reafirma" su eje recto. Por esta razón, la innovación en materiales es esencial para el futuro de estructuras pretensadas, cuyos elementos comprimidos deben ser más resistentes al pandeo, y cuyos elementos tensados tienen que resistir mejor las fuerzas de tracción. 
Algunas obras fueron concebidas para adoptar los recursos más recientes y aprovechar sus propiedades más privilegiadas, especialmente su resistencia a la tracción. Según Tibert (1999), los primeros tejados de cable fueron diseñados por V. G. Shookhov en 1896. Este ingeniero ruso construyó cuatro pabellones con techos colgantes en una exposición en Nizjny-Novgorod (Rusia). Después de este primer intento, algunas otras estructuras se propusieron durante la década de 1930, pero no eran ejemplos muy importantes.

Aparte de los puentes de suspensión, algunos otros tipos de puentes elevaron la importancia de la tensión al mismo nivel que la compresión había tenido durante los siglos anteriores. Este es el caso de los puentes atirantados, que hacen uso de los cables traccionados para soportar la cubierta y también la ponen bajo compresión. Así, la cubierta es pretensada y puesta en equilibrio. Un buen ejemplo es el puente Barrios de Luna en Asturias (España), de Javier Manterola, que muestra este principio perfectamente en sus dos torres y en el tramo principal de $440 \mathrm{~m}$.

En 1951, apenas tres años después del descubrimiento oficial de la tensegridad, el Festival South Bank Exhibition de Gran Bretaña tuvo lugar en Londres. En esa ocasión, se organizó un concurso para erigir un "Vertical Feature", un elemento básico de las exposiciones internacionales. Philip Powell e Hidalgo Moya (ayudados e inspirados por su formador Felix Samuely) diseñaron el Skylon, que fue seleccionado como la mejor propuesta y construido cerca de la Cúpula del Descubrimiento.

Algunos autores (Burstow, 1996; Cruickshank, 1995) afirman que esta estructura de agujas era un monumento sin ningún propósito funcional, pero se convirtió en un símbolo para el festival, un faro de potencialidades tecnológicas y sociales y, finalmente, una referencia para futuros ingenieros y arquitectos. La aguja de 300 pies de altura era un cuerpo revestido de aluminio con forma de cigarro suspendido por sólo tres cables casi invisibles, y parecía flotar a 40 pies sobre el suelo. La estructura estaba compuesta por una cuna de cables de acero pretensado y tres pilones abatidos.

Según Moya, el padre de la idea: "Por un asombroso golpe de genio (Felix Samuely) organizó un sistema de gatos hidráulicos debajo de los tres pilones más pequeños. Una vez que toda la estructura fue montada, bombeó estos gatos y levantó los pilones. Esto puso tensiones o tracciones en todos los cables e hizo que todo se convirtiera en una estructura tensionada. Esto redujo el número de alambres necesarios para anclar el Skylon y redujo a 
la mitad la cantidad de oscilación en la estructura. Esta falta de apoyo hizo que la estructura se viera tremendamente peligrosa. Parecía que no había suficientes cables para sostenerlo, lo que lo hacía tremendamente emocionante." (Cruickshank, 1995). La causa de la sensación de no tener suficientes cables para sostener el elemento de forma similar a un dirigible se debía al equilibrio estable obtenido por medio de su configuración particular.

Francis (1980) presentó un diagrama que explica la condición de estabilidad de un poste soportado por cables traccionados. Si uno de los cables está unido al suelo, el equilibrio del puntal dependerá de la posición donde se mantenga la otra cuerda. Si se fija en un punto por debajo del nivel del poste, se derrumba. Si lo hace al mismo nivel, el poste está en un equilibrio inestable (cualquier movimiento lo llevará a caer). Por el contrario, si se mantiene en un punto por encima del nivel del suelo, el sistema se encuentra en un equilibrio estable. En otras palabras, cuando hay alguna perturbación de esta situación, tiende a volver a la posición vertical. El diagrama de Skylon es similar. Como consecuencia, se ha demostrado que las condiciones para el equilibrio de un puntal en un espacio tridimensional son susceptibles al punto de aplicación de los extremos de los cables que lo fijan.

Durante los años cincuenta, no sólo se mejoró la explotación de cables en tracción, sino también la de otros elementos como membranas, materiales y tejidos. En 1950, el State Fair Arena, en Raleigh (Carolina del Norte) fue diseñado por Matthew Nowicki siguiendo sus intuitivos conceptos de techos suspendidos. Ese mismo año, un estudiante alemán de arquitectura tuvo una breve mirada a los dibujos y planos durante un viaje de intercambio a los EE.UU., y quedó completamente fascinado por la idea innovadora. Como resultado, inició una investigación sistemática que fue presentada como su tesis doctoral en 1952. Su nombre era Frei Otto y esa fue la primera documentación completa sobre los techos suspendidos (Tibert, 1999; Drew, 1976).

El Centro de Desarrollo para la Construcción Ligera fue fundado por él cinco años más tarde en Berlín, y en 1964 fue incluido en el Instituto de Estructuras de Superficie Ligera en la Universidad de Stuttgart, para aumentar aún más la investigación en la arquitectura de tracción. Por lo tanto, se desarrollaron algunas obras importantes que explotan las propiedades de tracción de materiales, especialmente acero, pero también poliuretano, poliéster, PVC, fibra de vidrio, mezcla de algodón-poliéster, paneles acrílicos, etc. Entre estos proyectos había una tienda de cuatro apoyos como Pabellón de Música del Bundesgartenschau, Kassel (Alemania) en 1955, la primera gran malla de cables con 
revestimiento de tela, el pabellón alemán en la Feria Mundial de Montreal 1967 y el célebre Estadio Olímpico de Munich en 1972, cuya estructura fue calculada por Jörg Schlaich.

Por ejemplo, Pugh (1976) construyó una cúpula hecha de puntales de madera y piel plástica, siendo esta última el componente en tensión que soportaba los elementos de compresión de la estructura.

Como señala W. O. Williams (2003), la denominación de "tensegridad" se ha extendido para incluir cualquier tipo de estructura conectada con pasadores en la que algunos de los miembros del bastidor sean cables en tensión o barras sólo en compresión. Este es el caso de las "Cúpulas de cables" o las "Cúpulas de rueda de bicicleta", inventadas por David Geiger (1988). Desde entonces, se han construido varias cúpulas siguiendo esta técnica, donde un grupo de vigas de tensegridad radial está unido a un anillo externo en compresión, y converge a un anillo interno para unirlas todas.

A pesar de que algunos arquitectos e ingenieros consideran estas estructuras de techos como tensegrities, Motro (2003) es rápido para identificarlos como tensegrities falsos, ya que tienen un miembro comprimido en el límite. De hecho, aunque Geiger no se refirió directamente a Buckminster Fuller, debe recordarse que Fuller (1964) patentó un tipo similar de estructura, que más tarde llamó "Aspension".

Las primeras cúpulas de cable fueron diseñadas por Geiger para las Olimpiadas de Seúl (1986), seguidas por la Redbird Arena en Illinois, la primera cúpula de cable ovalada (1988), la Florida Suncoast Dome en San Petersburgo (1988) y El Tayouan Arena en Taiwán (1993). De hecho, la cúpula más grande del mundo hasta la fecha, que es una de este tipo, es el Georgia Dome en Atlanta (1992) de Levy y Weidlinger Associates.

Habría que puntualizar sobre la definición de "tensegrity", esencial para la consideración de algunas estructuras como reales o falsos tensegrities. Gómez (2004) define los tensegrities como un principio estructural basado en el uso de componentes aislados en compresión dentro de un conjunto de tensión continua, en los cuales los miembros a compresión (usualmente barras o puntales) no se tocan entre ellos y los miembros tensionados (usualmente cables o tendones) delinean el sistema espacial.

Una estructura tenségrida es un sistema estructural cerrado en que tres o más elementos se comprimen entre elementos traccionarios, que los distancian, generando un sistema 
triangulado que anula las fuerzas manteniéndolo en un perfecto equilibrio. Es decir, que en lugar de emplear una estrategia de peso y empuje, está basado en un sistema de tensiones equilibradas, que no depende de esfuerzos externos: peso ni gravedad.

Tienen la capacidad de responder globalmente como un todo, por lo que cualquier carga puntual a la que se les someta es transmitida uniformemente y absorbida por toda la estructura. Además, su rigidez aumenta a medida que la carga aumenta.

En cuanto a sus propiedades estructurales, las tensegridades destacan por su ligereza en comparación a otras estructuras de similar resistencia o, si se prefiere, tienen una gran capacidad portante si se comparan a otras estructuras de peso análogo.

Poseen auto-equilibrio, no requieren de ningún anclaje o fijación para mantener su forma o geometría, estables en cualquier posición.

Cuanto mayor sea el pretensado de un sistema tensegrítico, mayor será su capacidad portante o resistente.

Debido a que los elementos a compresión son discontinuos, sólo trabajan localmente, además debido a la reducida sección de sus elementos comprimidos, son resistentes a la torsión y al pandeo.

Poseen la propiedad de la sinergia, donde el comportamiento de todo el conjunto no es predecible a partir del comportamiento de sus componentes considerados individualmente.

La rigidez de la estructura depende de la materialidad y uniones.

Estas estructuras tensegríticas se relacionan con principios de la naturaleza. La célula puede considerarse un sistema de tensegridad. El citoesqueleto de las células tiene el mismo papel que las barras y los cables en las estructuras de tensegridad: equilibrar los esfuerzos que dan forma y rigidez a la célula.

Las estructuras tensegríticas tienen una serie de ventajas e inconvenientes.

Las VENTAJAS de las estructuras tensegríticas son:

- No presenta puntos de debilidad local.

- Resulta factible el empleo de materiales de forma económica y rentable.

- Las tensegridades no sufren a torsión y el pandeo es un fenómeno raramente presente en ellas. 
- Se tiene la capacidad de crear sistemas más complejos mediante el ensamblaje de otros más simples.

- Para estructuras a gran escala, el proceso constructivo se vería facilitado al no necesitar de andamiajes adicionales. La propia estructura sirve de andamio para sí misma.

- En sistemas plegables, sólo se necesita una pequeña cantidad de energía para cambiar su configuración.

Los INCONVENIENTES de las estructuras tensegríticas son:

- Las agrupaciones tensegríticas aún han de resolver el problema de congestión de barras. A medida que crece el tamaño, sus montajes empiezan a interferirse entre ellos.

- Se constata un relativamente alto grado de deformaciones y una escasa eficiencia del material, en comparación con estructuras convencionales geométricamente rígidas.

- La compleja fabricación de estas construcciones es una barrera para el desarrollo de las mismas.

- Para mantener el estado de auto-tensión, es necesario someterlas a un estado de pretensado que requeriría de fuerzas muy elevadas para su estabilidad, especialmente para aquellas de grandes dimensiones.

Según Gómez (2004), tres hombres han sido considerados los inventores de los tensegrities: Richard Buckminster Fuller, David Georges Emmerich and Kenneth D. Snelson?. Emmerich reportó el primer sistema de proto-tensegrity, llamado "Equilibrio Elemental" o "Simplex", con tres barras y nueve cables. R. B. Fuller y K. D. Snelson, independientemente de David Georges Emmerich, estudiaron diferentes tipos de modelos geométricos considerados estructuras tensegríticas.

\footnotetext{
${ }^{7}$ Como precaución, estos nombres han sido mencionados en orden cronológico de sus patentes concedidas: Fuller-13 Nov 1962; Emmerich-28 Sep 1964; Snelson-16 Feb 1965.
} 


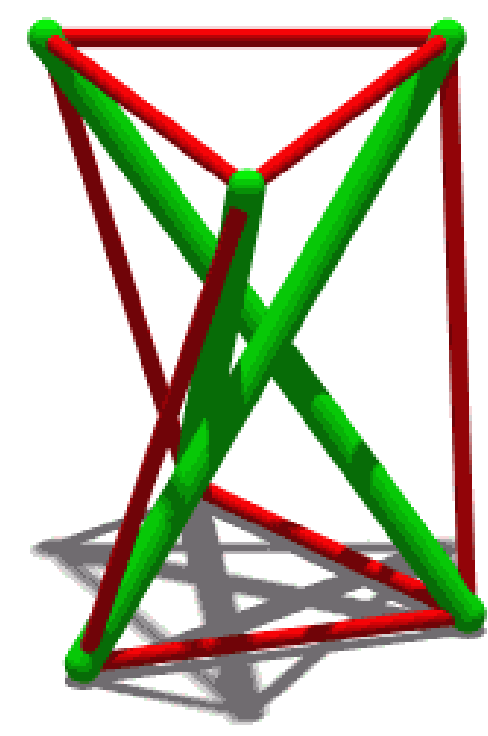

Figura 70 "Elementary Equilibrium" or "Simplex", David Georges Emmerich

Snelson focalizó su trabajo en el aspecto escultural y estético, por lo que evitó muchas complicaciones con la física y las matemáticas, debido a su bagaje artístico y su opinión en relación a la difícil aplicación de los sistemas tensegríticos. Este proceso le facilitó desarrollar muy diversas configuraciones, asimétricas y no convencionales8. Además, la construcción de sistemas tensegríticos requiere una fina y delicada técnica que él ha estado mejorando durante años. El proceso actual mediante el cual Snelson erige sus trabajos es una ciencia y un arte en sí mismo. Actualmente, como estableció Fox (1981), él es la única persona capaz de ingeniar estas construcciones.

\footnotetext{
${ }^{8}$ Ver página web de Kenneth Snelson (www.kennethsnelson.net)
} 


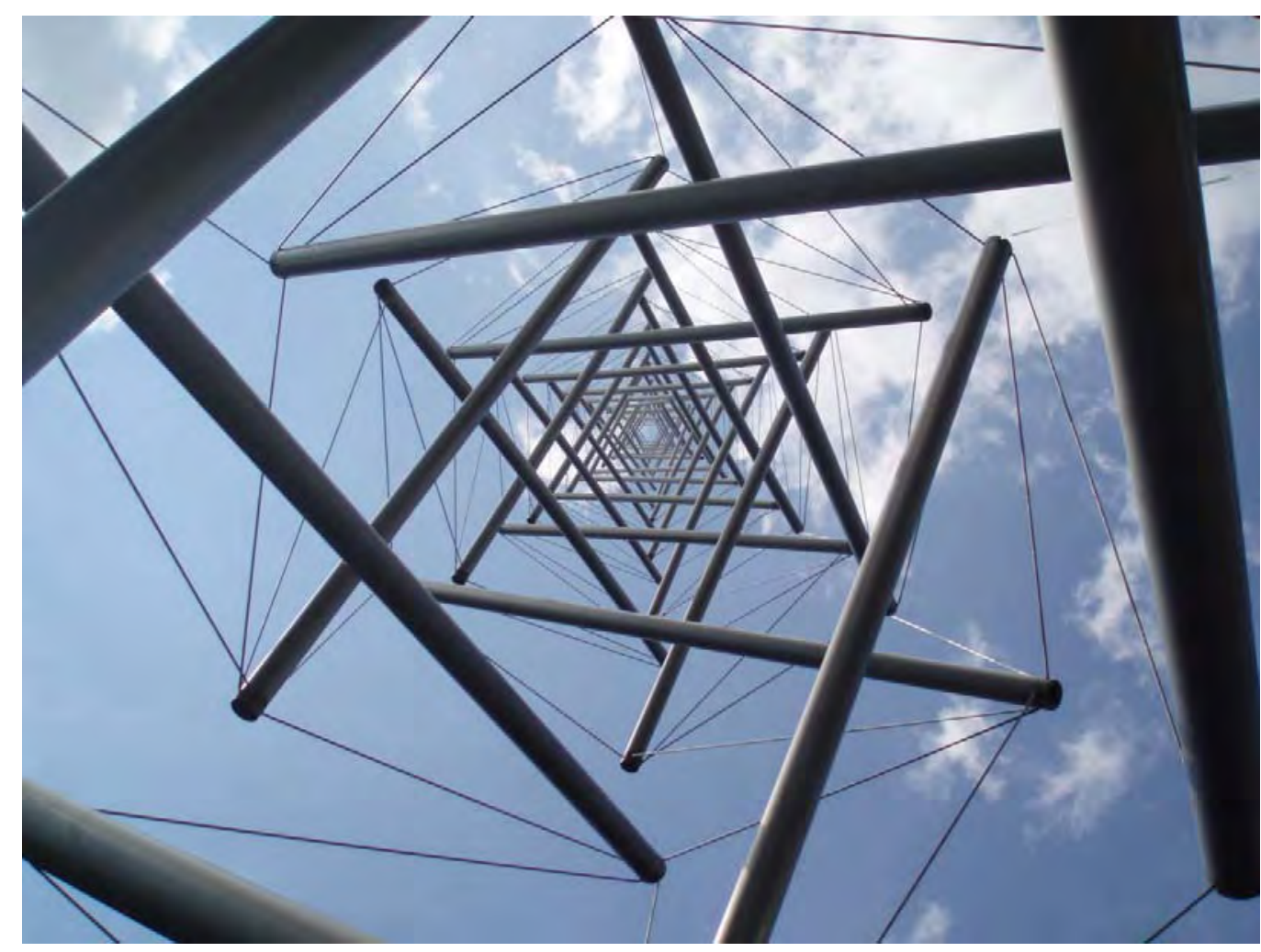

Figura 71 Needle Tower II en el Kröller-Müller Museum en Holanda, Kenneth Snelson (1969)

Por otra parte, Fuller y Emmerich tomaron diferentes caminos, estudiando las diferentes posibles tipologías de tensegrity, principalmente esféricas y sistemas unidimensionales como mástiles. Ellos lo hicieron usando modelos y experimentos empíricos como principales herramientas, y en contraste con Snelson, ellos buscaron las posibles aplicaciones en la arquitectura y la ingeniería.

Justo después, viendo la escultura de Snelson, el inventor de Massachusetts estudió algunas composiciones simples y produjo una familia para mástiles tensegríticos, caracterizada por caras verticales de tres, cuatro, cinco y seis lados respectivamente (Fuller 1961). Él también descubrió el "icosaedro de seis barras aisladas" (octaedro expandido). Consecuentemente, este trabajo fue desarrollado por otras personas creando sistemas tensegríticos como el "vector equilibrio" (cuboctaedro), la "esfera tensegrítica de 30 barras aisladas" (icosaedro), el "tetraedro de seis barras aisladas" (tetraedro truncado) y el "octaTensegrity de tres barras aisladas". Consecuentemente, una jerarquía de primeras

\footnotetext{
${ }^{9}$ Entre comillas, denominación de Fuller
} 
Aplicaciones de las propiedades auxéticas en la arquitectura

ANTECEDENTES

estructuras tensegríticas fue creada, y las leyes de comprensión de las estructuras universales tensegríticas fueron completadas.

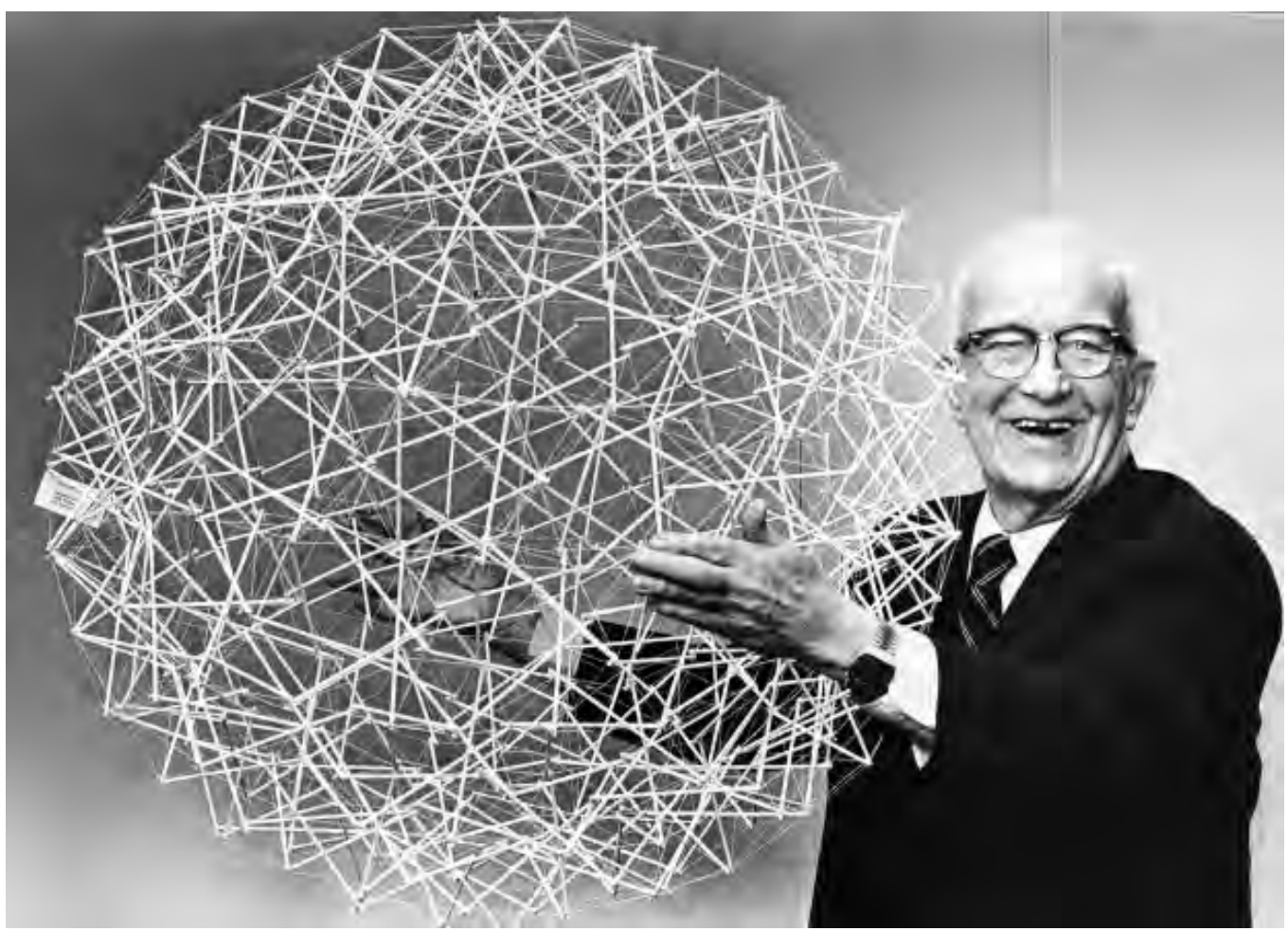

Figura 72 Buckminister Fuller sosteniendo una esfera geodésica tensegrítica

Así, Bucky (como Buckminster Fuller era también conocido), se mantuvo buscando nuevos diseños, aplicaciones y métodos de construcción. Él realizó varios intentos de diseñar cúpulas geodésicas tensegríticas (figura 72) (aunque a ellas les faltaba estabilidad debido a la ausencia de triangulación), y patentó ${ }^{10}$ algunos de sus trabajos en relación con este tema (Fuller, 1967, 1975). Sin embargo, la aplicación final de los tensegrities no fue tan satisfactoria como se pensaba que sería; él nunca fue capaz de producir la cúpula tensegrítica que pudiera cubrir una gran ciudad, como él se había propuesto; y, además, él fue forzado a construir la burbuja de Montreal en la Expo del 67 como una cúpula geodésica pero sin usar principios tensegríticos debido al tiempo y razones de presupuestos.

De aquí en adelante, alguna gente que fue influenciada por el trabajo de Fuller, empezó a explorar su nuevo sistema estructural, buscando alguna aplicación en la arquitectura y la

\footnotetext{
${ }^{10}$ Por coincidencia, mientras Fuller patentaba sus "cúpulas geodésicas" en 1954 (US 2,682,235), Emmerich patentaba las "cúpulas estereométricas" en 1967 (US 3,341,989).
} 
ingeniería. René Motro, probablemente uno de los especialistas más importantes en tensegrities en el presente empezó a publicar sus estudios en este tema en 1973: Topologie des structures discrètes. Incidence sur leur comportement mécanique. Autotendant icosaédrique (Gómez, 2004). Fue una nota interna para el Laboratorio de Ingeniería Civil de la Universidad de Montpellier (Francia) sobre el comportamiento mecánico de este tipo de estructuras. De aquí en adelante, este laboratorio e ingeniería llegó a ser la referencia en términos de investigación sobre tensegrities.

Algunos años después, Pugh y Kenner (1976), ambos de la universidad de California (Berkeley), continuaron su trabajo con diferentes líneas de ataque. Por una parte, Pugh escribió "An Introduction to Tensegrity", el cual es interesante por la variedad de modelos que esboza y su estricta clasificación y tipología. Por otra parte, Kenner desarrolló el útil "Geodesic Math and How to Use It", el cual muestra cómo calcular "para cualquier grado de exactitud" los pertinentes detalles de la geometría de las estructuras geodésicas y tensegríticas (longitudes y ángulos del sistema de barras), y explora su potencial. Incluso aunque este último trabajo es más explícito en temas geométricos y matemáticos, también carece del tratamiento del comportamiento de la tensegridad bajo carga.

Durante los años 80, algunos autores hicieron el esfuerzo de desarrollar el campo abierto de sus predecesores. Robert Burkhardt (figura 73) empezó una exhaustiva investigación y mantuvo correspondencia con Fuller (1982) para obtener más detalles sobre la geometría y las matemáticas de los tensegrities. El resultado final, 20 años después, es una completa, útil y continuamente revisada "Guía Práctica para el diseño de tensegrities" (Burkhardt, 1994-2004). Otros investigadores importantes han sido Ariel Hanaor (1987, 1992), quien definió los principales conjuntos bidimensionales de células elementales auto-equilibradas, y Nestorovic (1987), quien propuso una cúpula metálica de tensión integrada. Recientemente, algunos trabajos han sido añadidos a este campo del conocimiento. 


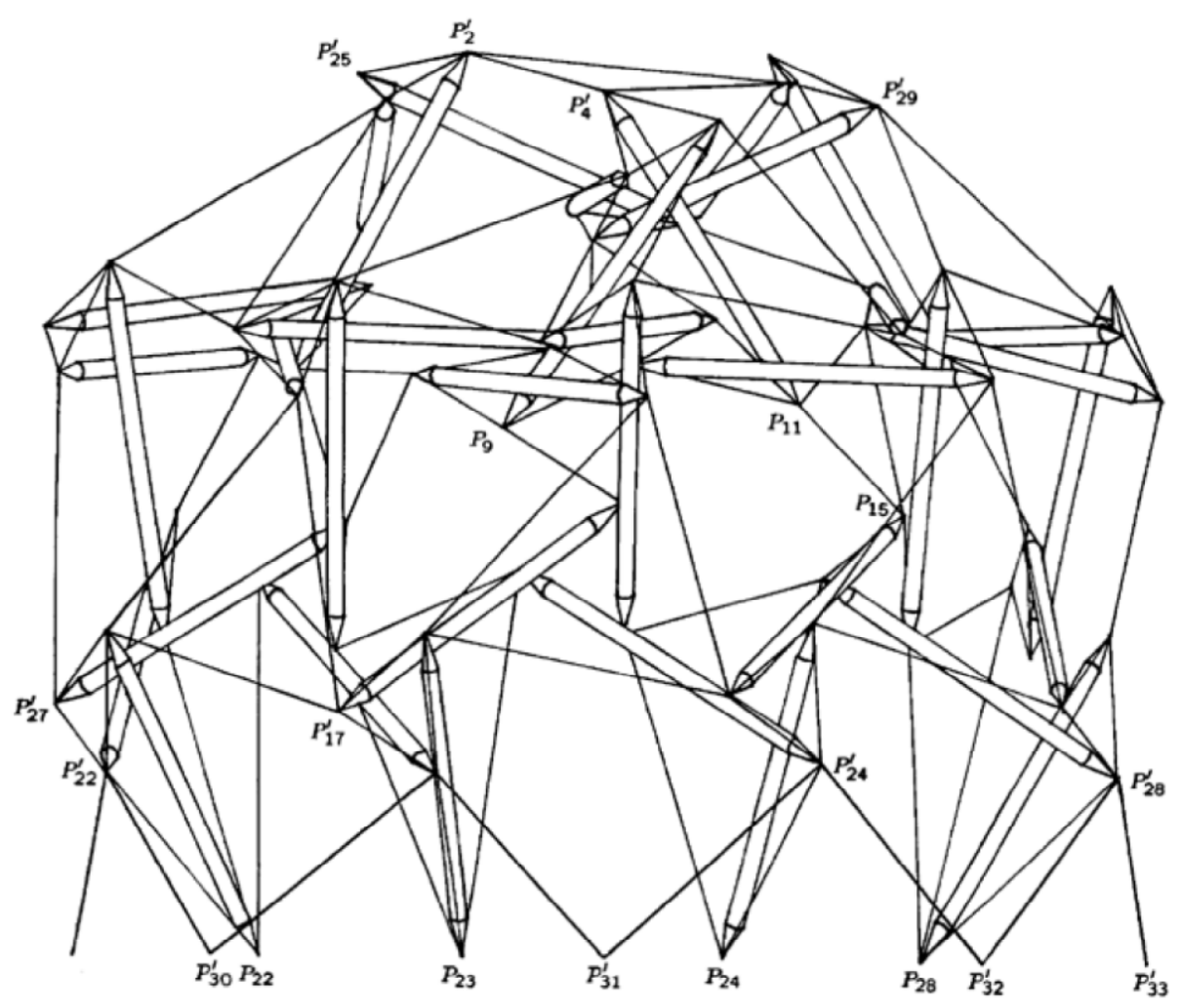

Figura 73 T-Octahedron Dome (vista lateral), Burkhardt

Connelly y Back (1998a, 1998b) han buscado encontrar una adecuada relación tridimensional generalizada para tensegrities. Usando las herramientas matemáticas de teoría de grupos y teoría de la representación y las capacidades de las computadoras, ellos han dibujado un completo catálogo de tensegrities con detalladas normas tipológicas de estabilidad y simetría, incluyendo algunos que no habían sido vistos antes.

Otros autores (S. Pellegrino, A.G. Tibert, A.M. Watt, W.O. Williams, D. Williamson, R.E. Skelton, Y. Kono, Passera, M. Pedretti, etc.) han estudiado también la física, matemáticas (desde un punto de vista geométrico, topológico y algebraico) y mecanismos de las estructuras tensegríticas. Sin embargo, aparte de los autores mencionados anteriormente, y Motro y su grupo en Montpellier, no ha habido muchos trabajos buscando aplicar este nuevo conocimiento a cualquier campo en particular.

Recientemente Peter Testa ha desarrollado la Carbon Tower (figura 74), primera torre de fibra de carbono a partir del concepto de tensegrity: es un desarrollo interesante con elementos a tracción y compresión, pero metiendo una precompresión basándose en el concepto de la madeja para hacer la estructura más resistente. 


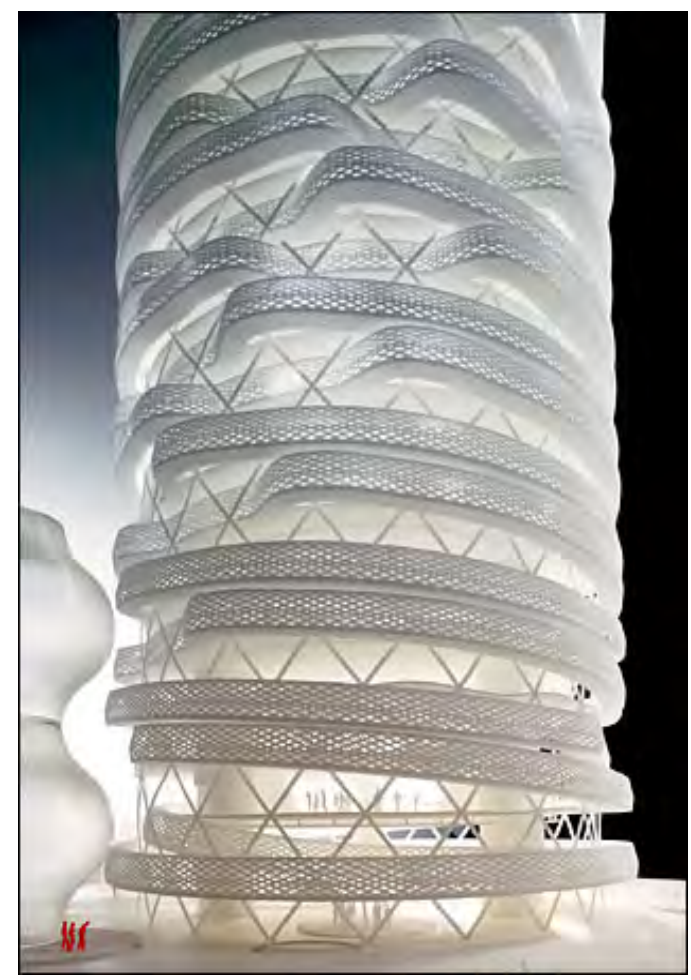

Figura 74 Carbon Tower, Testa

El estadio Arena (figura 75) cambia también el concepto estructural, al meter una estructura de rueda de bicicleta como cubierta, en donde el borde exterior está comprimido, y el anillo central y los radios están traccionados.

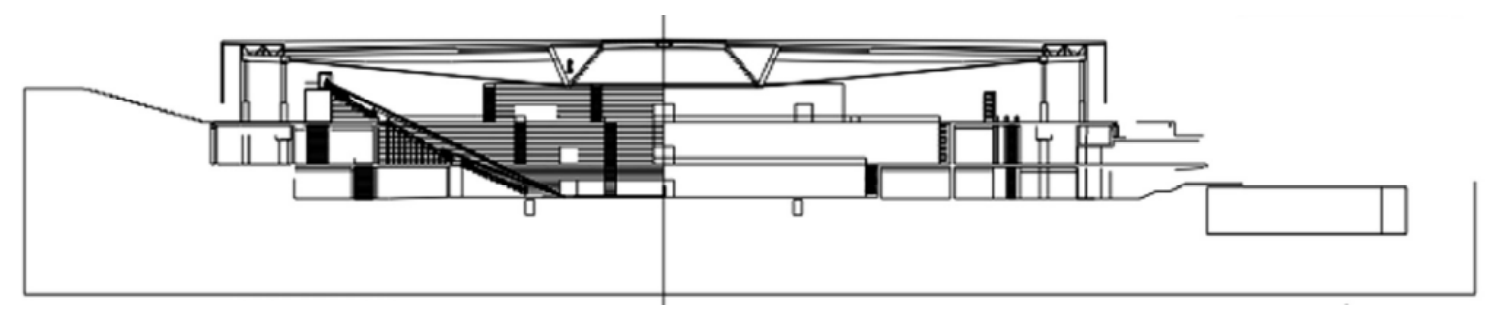

Figura 75 Estadio Madrid Arena, Estudio Cano Lasso,

Estructura de Cubierta diseñada por Julio Martínez Calzón

En estructuras de barras, además de las fuerzas, tenemos que prestar atención a las deformaciones: la solución de deformación angular que tiene la cubierta del Banco de Berlín de Ghery (figura 76) consiste en un sistema de barras tensadas. 


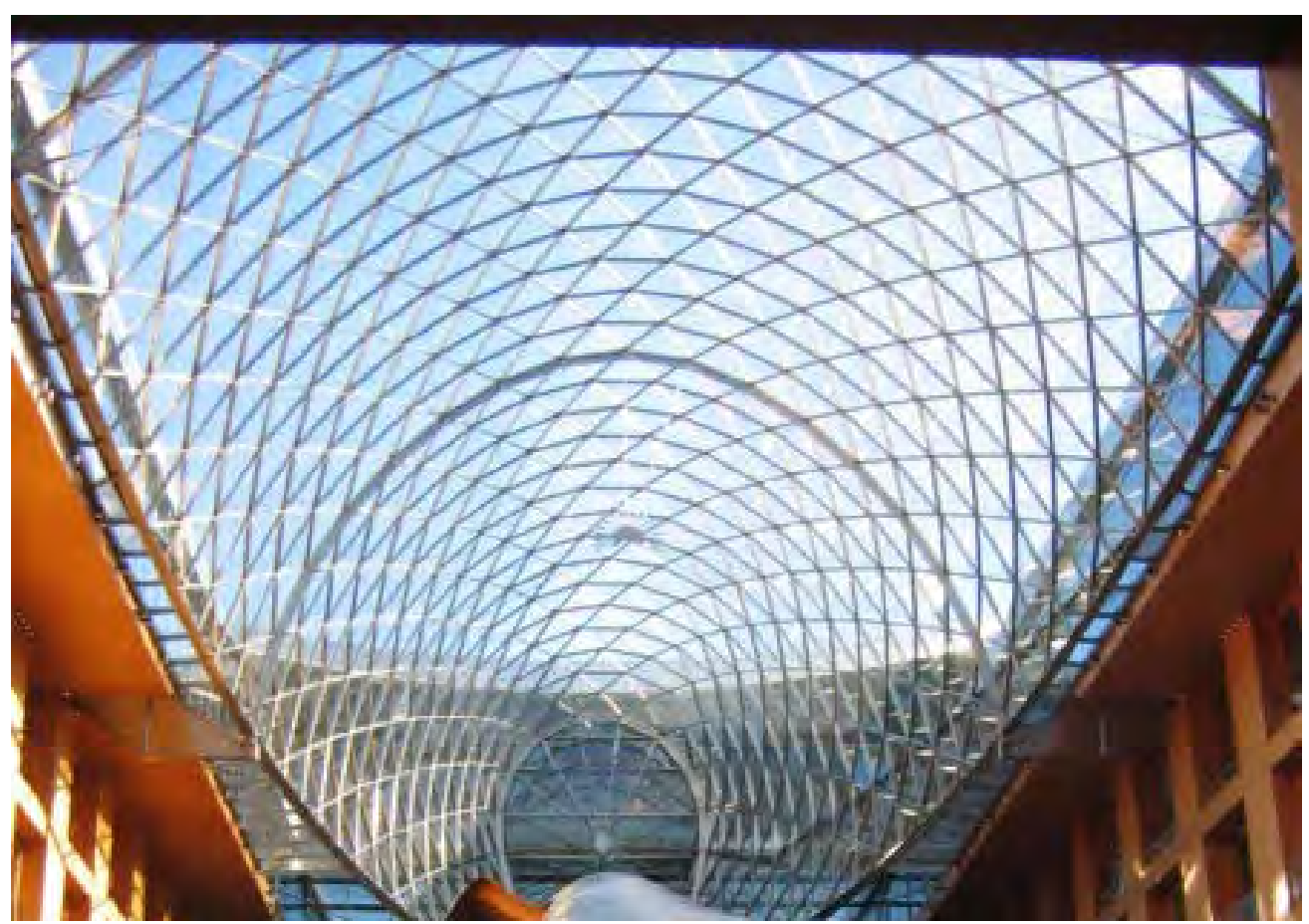

Figura 76 Banco DZ, Pariser Platz, Berlín, Frank O Gehry

Landolf Rhode-Barbarigos, Nicolas Veuve, Nizar Bel Hadj Ali, René Motro e Ian F. C. Smith desarrollan un sistema tensegrítico de puente para peatones, cuyo despliegue requiere emplear cables activos para ajustar simultáneamente los grados de libertad de la estructura.

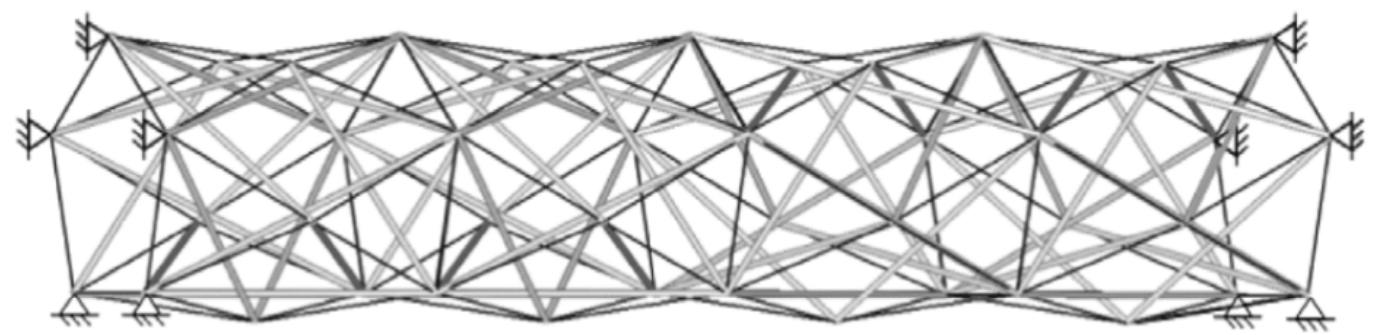

Figura 77 Condiciones de los límites del puente de tensegridad, Landolf Rhode-Barbarigos, Nicolas Veuve, Nizar Bel Hadj Ali, René Motro e lan F. C.

Investigadores que actualmente están interesados en las estructuras tensegríticas son: Josep Llorens, V. Gómez-Jauregui, C. Manchado y C. Otero, Paolo Beccarelli, Guglielmo Carra y Roberto Maffei, Carolina M. Stevenson Rodríguez, Ana Cocho-Bermejo, InA Sin y SeungDeog Kim. Todos ellos realizan investigaciones teóricas en un contexto académico. 


\subsubsection{Nudos}

Un nudo es el lugar de encuentro entre dos o más elementos constructivos en un entramado o estructura. Tienen una importancia fundamental en la estructura, ya que según su diseño serán capaces de dar una configuración geométrica u otra al sistema y además absorberán unos esfuerzos determinados u otros. Según los movimientos que permiten, existen nudos rígidos, nudos articulados y nudos deslizantes.

Los nudos objeto de esta tesis serán aquellos utilizados por los sistemas estructurales transformables, ya que toda estructura transformable precisa de mecanismos en las uniones para realizar el proceso de pliegue, despliegue, abertura, cerrado o deformado. Primeramente, se puede determinar que los movimientos en las uniones pueden ser en el plano o en el espacio. Los movimientos de una barra en el plano son tres: un giro y dos desplazamientos "u" y "v". Mientras que en el espacio una barra tiene seis posibles movimientos: 3 giros y 3 desplazamientos.

Según construpedia ${ }^{11}$, un nudo articulado es aquel tipo de nudo que permite el giro pero no el desplazamiento de los elementos. También son llamados articulaciones. Un nudo deslizante es aquel tipo de nudo que impide el movimiento en uno de los tres ejes del sistema de referencia, pero no en los otros, ni en el giro entre los elementos.

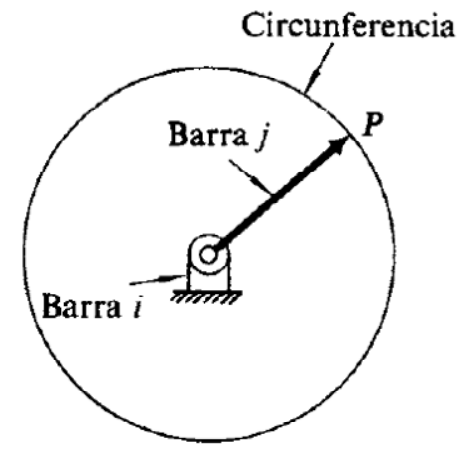

Par lineal

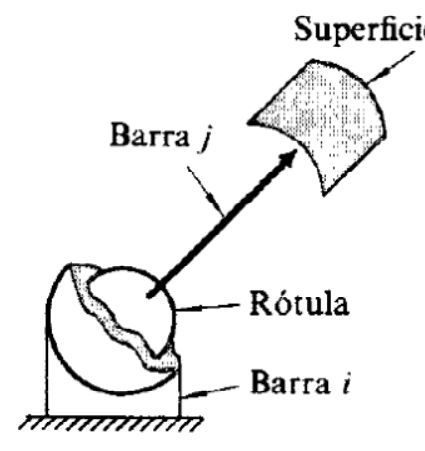

Par superficial

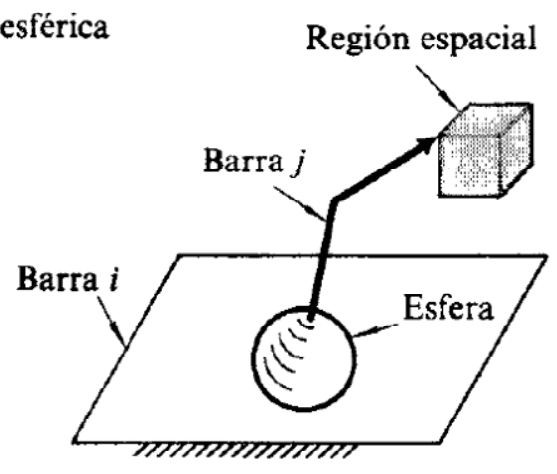

Par espacial

Figura 78 Clasificación pares cinématicos, Nieto (1978)

11 Enciclopedia de la construcción (http://www.construmatica.com/construpedia) 
Aplicaciones de las propiedades auxéticas en la arquitectura

ANTECEDENTES

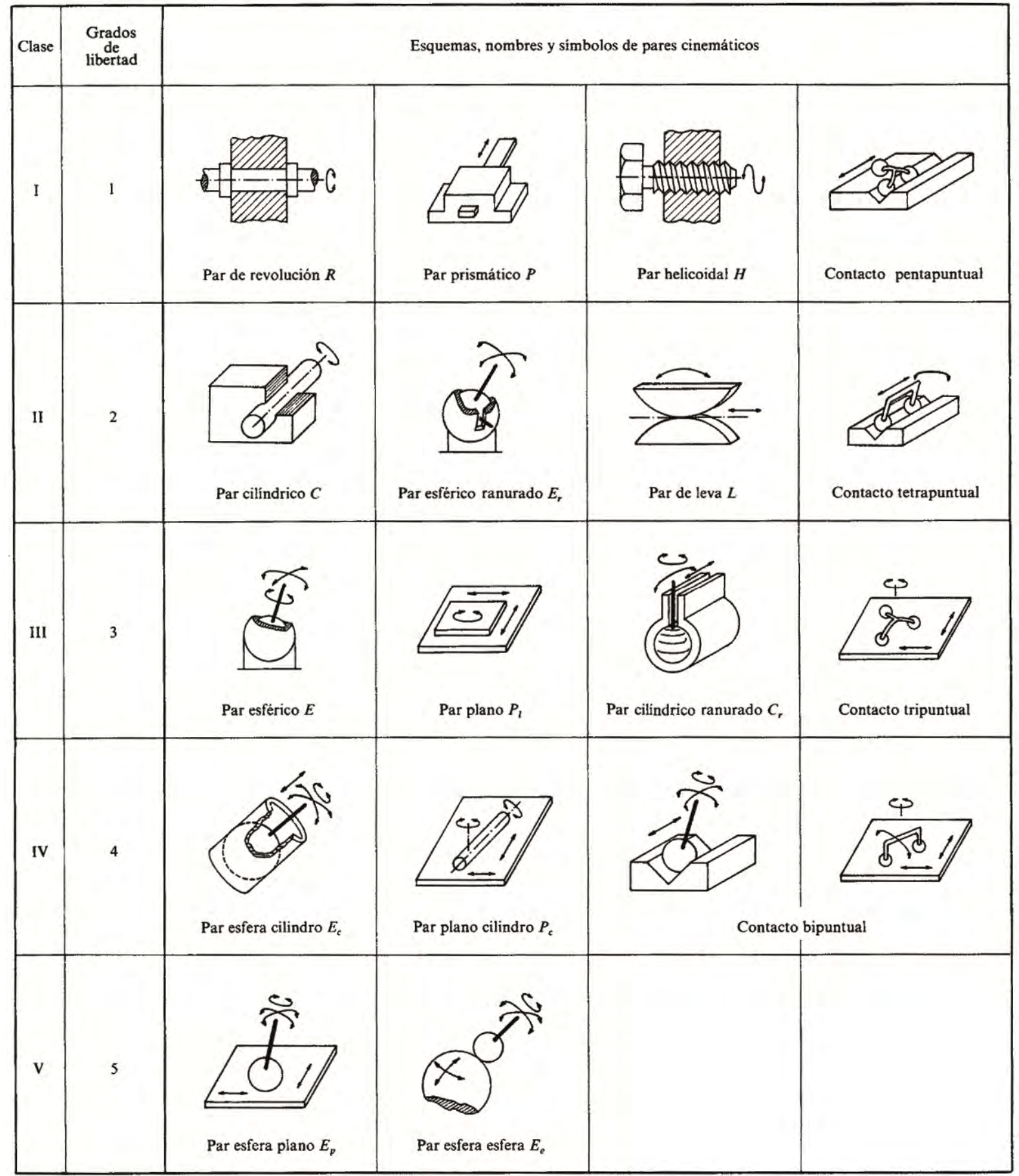

Figura 79 Clasificación de pares cinématicos según grados de libertad, Nieto (1978)

Revisando el libro "Síntesis de mecanismos", de Nieto (1978), se puede decir que se llama par cinemático a la unión, con facultad de movimiento, de dos barras, de forma que las barras presentan un movimiento relativo de unas determinadas características debido a las 
constricciones que impone esta unión. Según el lugar geométrico ${ }^{12}$ descrito por un punto cualquiera de una barra en el movimiento relativo de ambas, se clasifican en: pares de primer grado o lineales, si el lugar geométrico es una línea; pares de segundo grado o superficiales, si el lugar geométrico es una superficie; y pares de tercer grado o espaciales, si el lugar geométrico es una región del espacio (figura 78).

Según el número de grados de libertad que posea el movimiento relativo de las dos barras que forman el par, se clasifican en: pares de uno, dos, tres, cuatro y cinco grados de libertad, o pares de clase I, II, III, IV y V, respectivamente (figura 79).

Rodríguez (2005), intenta resumir los tipos de nudos independientemente de las condiciones de las barras (figura 80).

\begin{tabular}{|l|l|l|}
\hline TIPO DE NODO & G R A F I C O & CONDICIONES \\
\hline Por Rotaclón de la \\
A a r i s a g r a d o
\end{tabular}

Figura 80 Clasificación de los nudos de las estructuras transformables, Rodríguez (2005)

\footnotetext{
${ }^{12}$ Un lugar geométrico es un conjunto de puntos que cumplen determinadas condiciones o propiedades geométricas.
} 
Los dos primeros, nudos por rotación y abisagrado, son soluciones simples que pueden estar ubicados en el centro de la barra o en sus extremos. Los dos últimos casos, nudo pasador y por rodamiento, son más complejos. Además de rotar la barra, cambia de posición toda la estructura. En estos tipos de nudo las holguras son un requerimiento importante para permitir el paso de la barra por sus diferentes etapas.

A continuación se expondrán, de manera cronológica, los nudos que han ido surgiendo y que han sido objeto de patentes desde que comenzaron a desarrollarse las estructuras desplegables de barras.

Como gran exponente de este campo de las estructuras en esos años se puede citar a R. Buckminster Fuller, quien desarrolla su primera patente de cúpula geodésica "Building construction" en 1951, y donde se puede encontrar un nudo con una configuración de puño tipo bola. Las piezas se sujetan juntas por medio de un perno, estando previsto un muelle helicoidal para proporcionar una cierta cantidad de elasticidad en la fijación, lo cual es particularmente útil durante la erección de la estructura (figura 81).
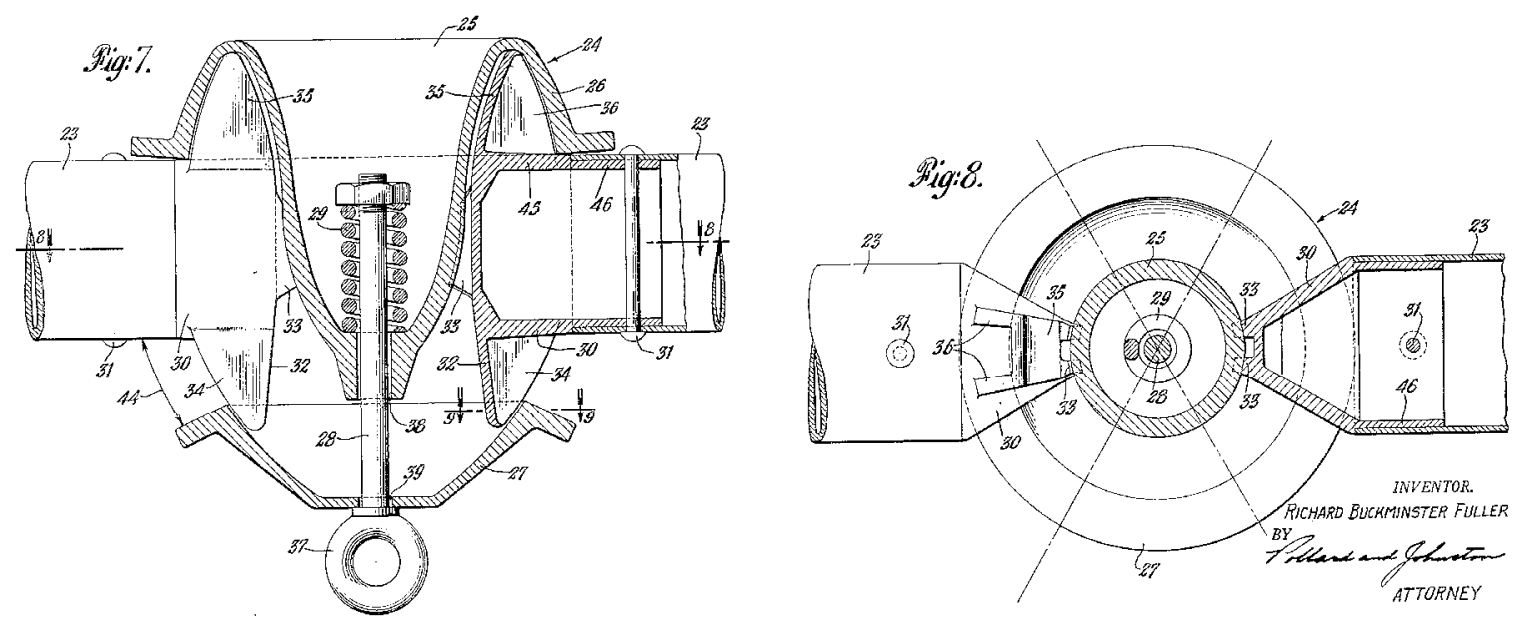

Figura 81 Nudo cúpula geodésica "Building construction" (Fuller, 1951)

En 1953 Fuller diseña un trípode para sus cúpulas geodésicas conectadas por nudos articulados y que se llamaba Flying Seedpot (figura 82). 


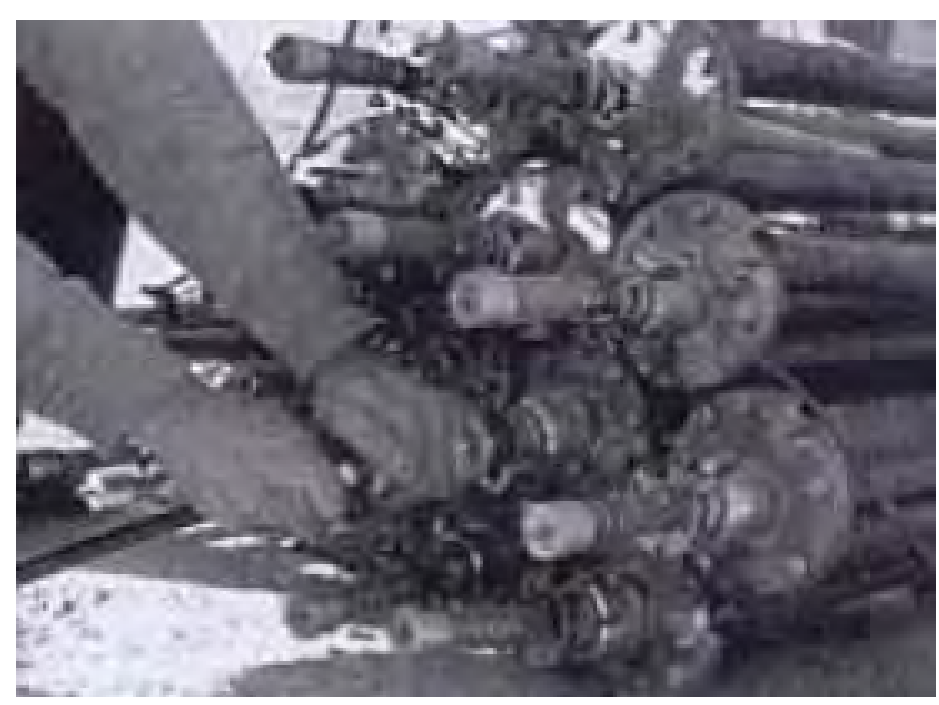

Figura 82 Flying Seedpot (Fuller, 1953)

En 1961 Pérez Piñero presenta su diseño de una bóveda reticular que se despliega siendo completamente prefabricada en su patente ES-0266801_A1. Emilio Pérez Piñero acopla tres barras deslizantes en un nudo intermedio (figura 83).

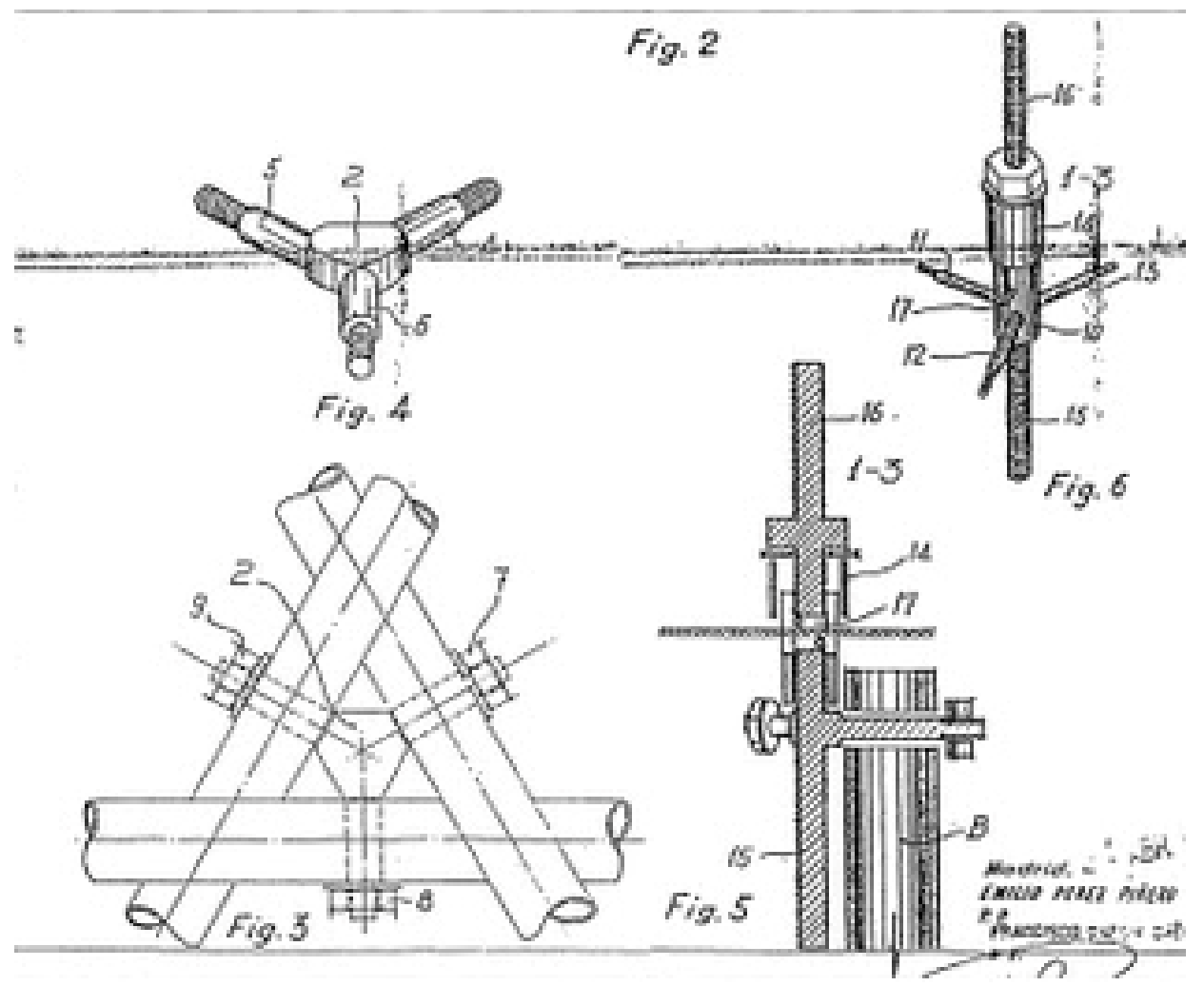

Figura 83 Nudo de patente ES-0266801_A1, Emilio Pérez Piñero (1961) 
Posteriormente, en 1967 Albert Moore patenta un sistema de cúpula llamado "Preassambled structural framework" que consiste en una bóveda triangulada de doble curvatura con un nudo formado por un aro al cuál llegan todas las barras.

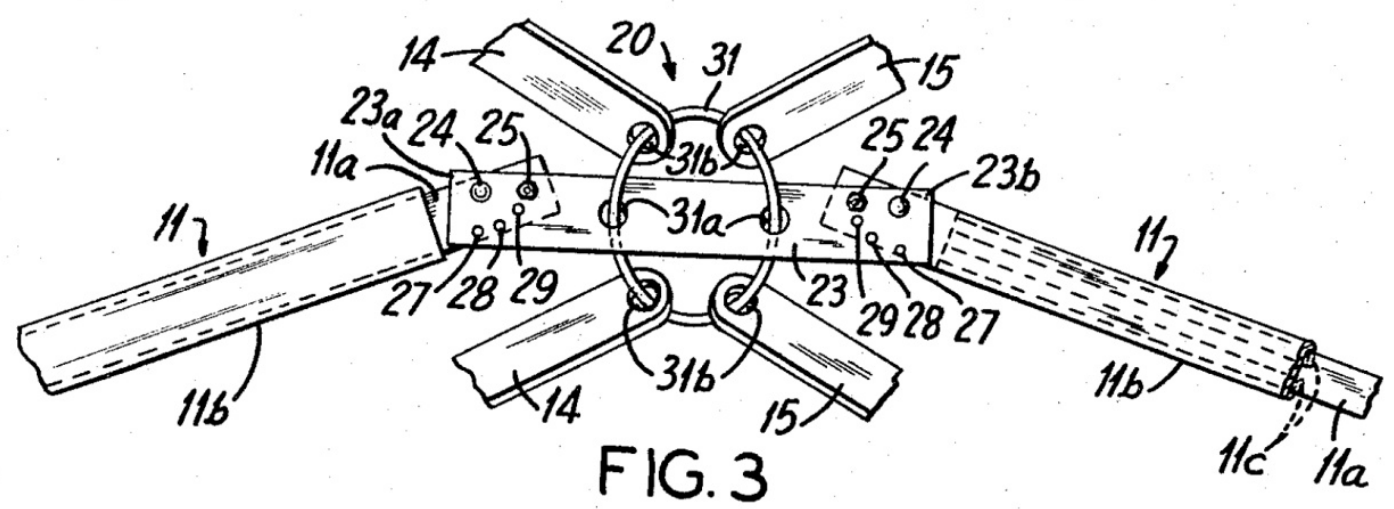

Figura 84 Nudo de patente US3325958, Albert Moore (1967)

En 1977 se publica la patente de Zeigler en la que los puntos de cruce de elementos de varilla cruzados en la estructura implicada pueden incluir conexiones deslizantes limitadas que efectúan la transferencia de la fuerza de contracción a otros puntos de cruce que están unidos de forma pivotante (figura 85).
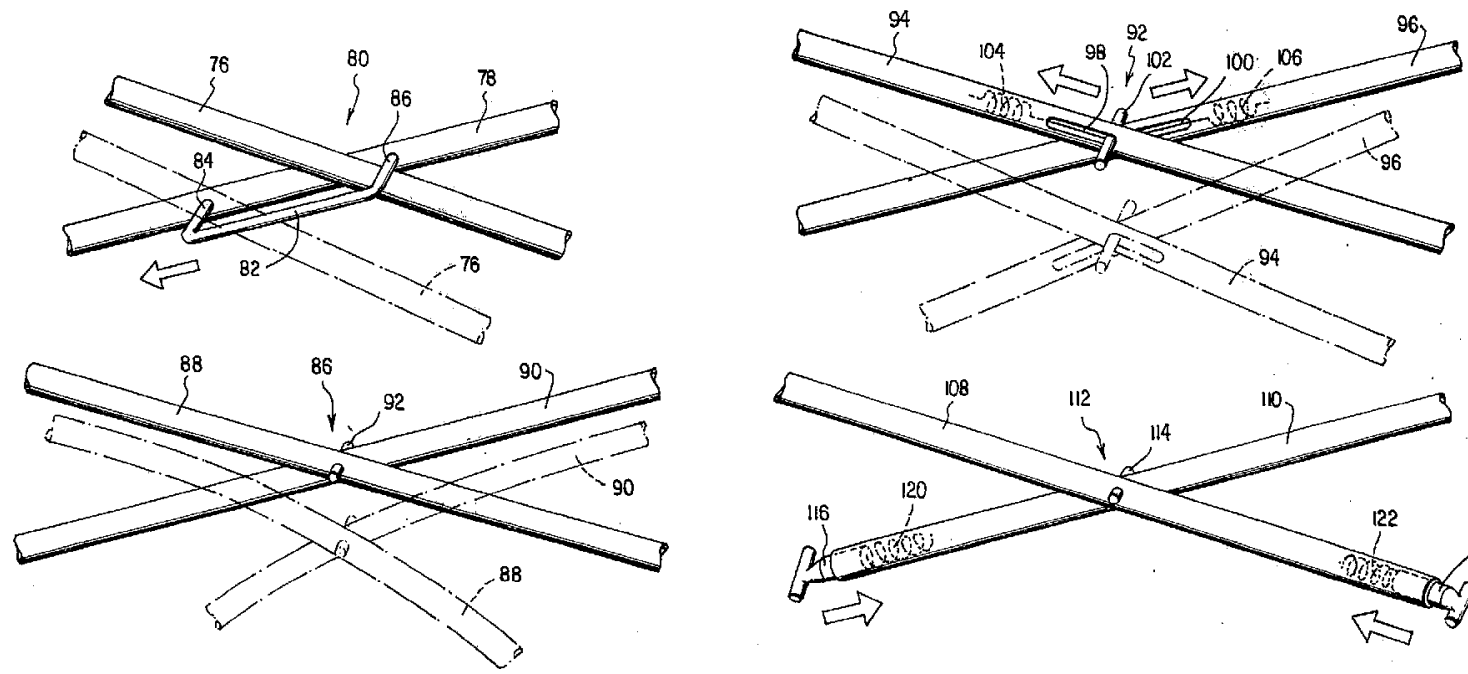

Figura 85 Nudos de barras deslizantes, patente US4026313, Zeigler (1977) 
En 1984 y basado en el trabajo de Piñero, Zeigler patenta una estructura auto portante en su forma desplegada sin necesidad de elementos rigidizadores (figura 86).
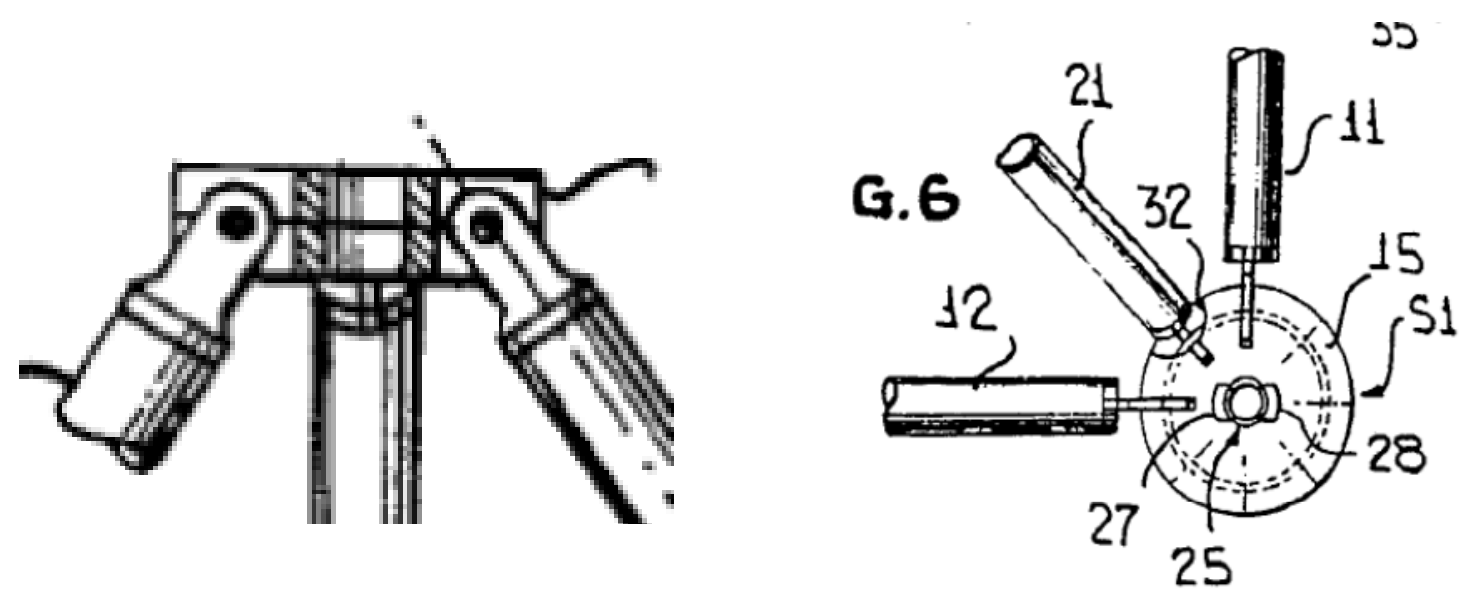

Figura 86 Nudo de patente US4473986A, Zeigler (1984)

Swetish y Baumann (2003) diseñan unas articulaciones pivotantes entre polos de soporte adyacentes para rotación alrededor de un eje paralelo a los polos de soporte. Cada polo de soporte se mueve entre una posición extendida en la que el polo de soporte se extiende perpendicularmente a los polos transversales y una posición colapsada en la que el polo de soporte se extiende a lo largo de los polos transversales.

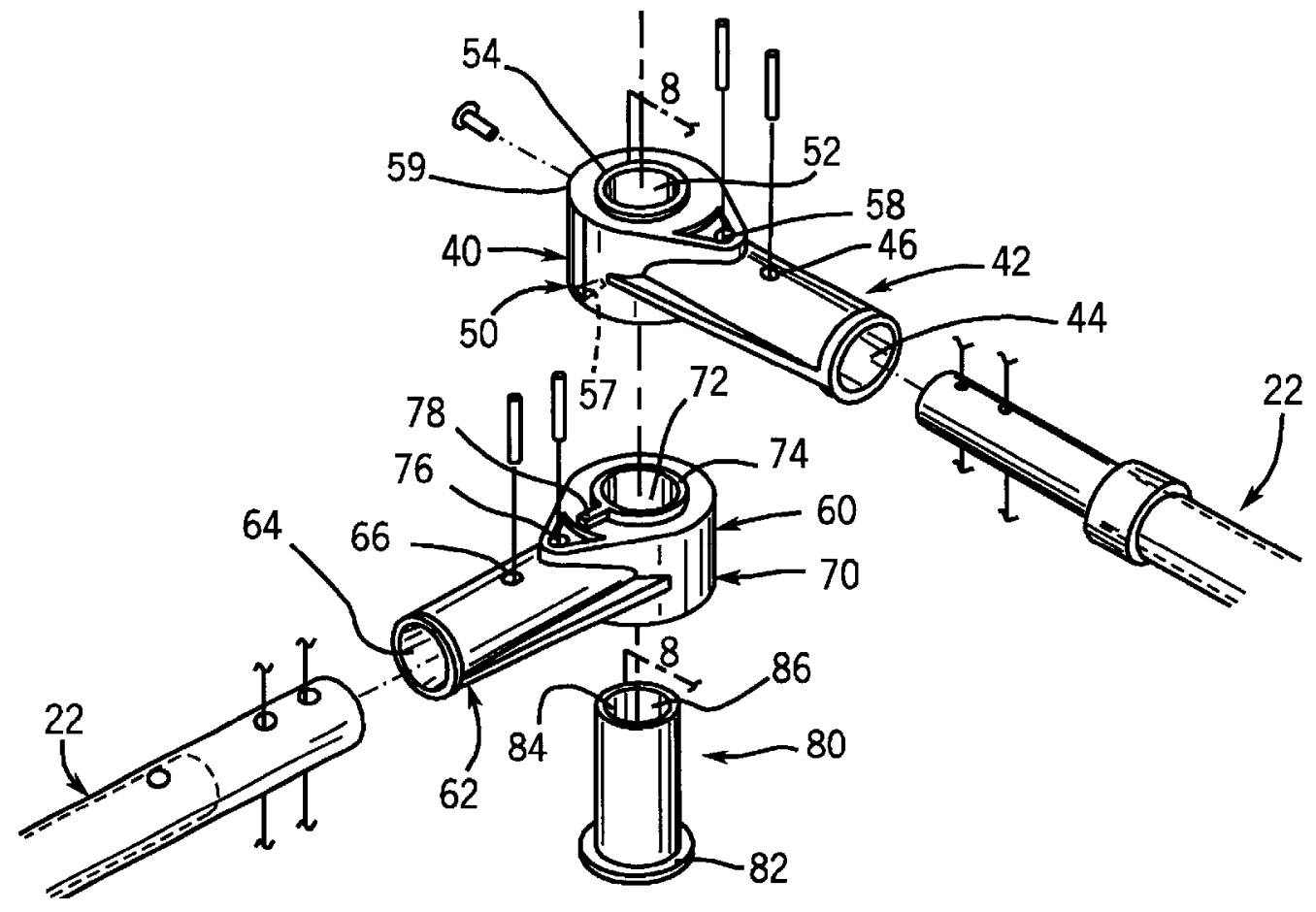

Figura 87 Nudo de patente US 6591849 B1, Swetish y Baumann (2003) 
Daniel S-H Lee, Olga Popovic Larsen y Seung-Deog Kim (2013) desarrollan un nudo con dos conexiones abisagradas que permiten la rotación horizontal y vertical (figura 88).

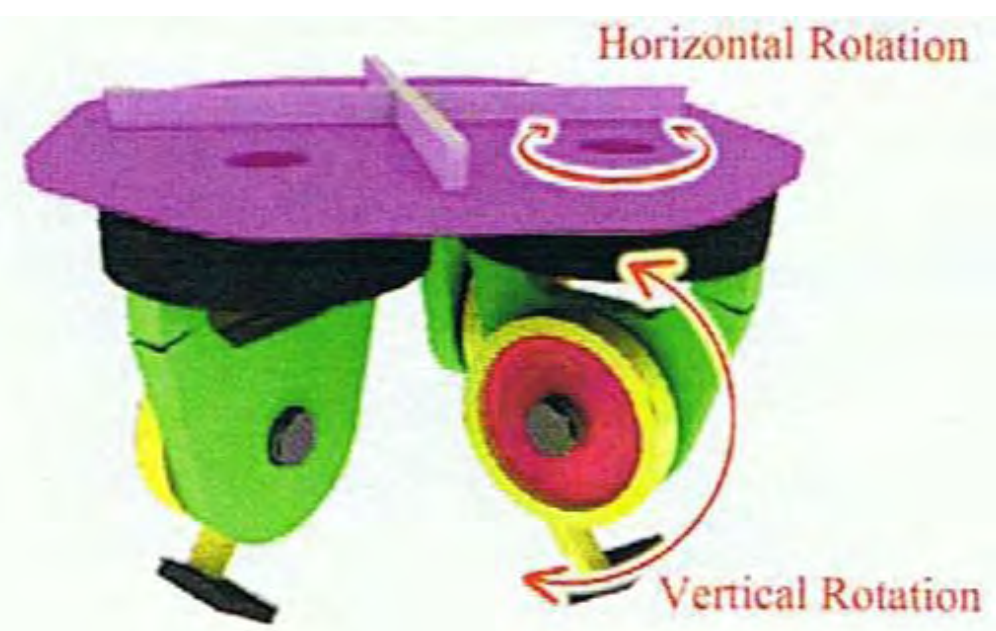

Figura 88 Nudo diseñado y construido por la Universidad de Semyung

SeungDeog KIM, SunKyeong PARK, JePil JANG, InA SIN, JangBog LEE, ChangWoo HA y SeungTeak JUNG (2013) estudian casos de articulaciones y ejes ya desarrolladas para estructuras desplegables y sugieren nuevas uniones y ejes a partir de maquetas (figura 89).

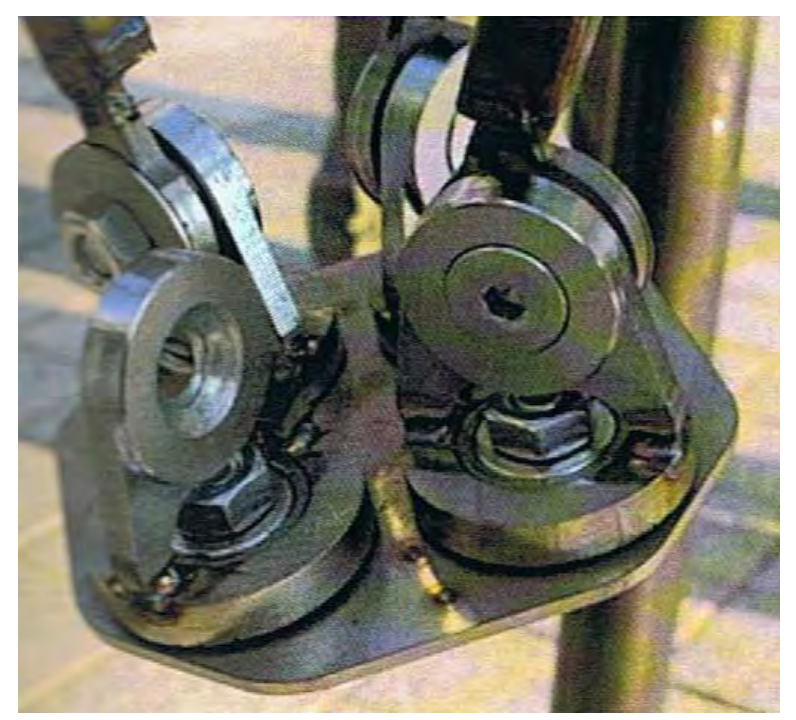

Figura 89 Nudo de maqueta para modelo de prueba 
Una evolución de los nudos esféricos rígidos es la "articulación esférica multiunión" de Yohei Yokosuka y Teruo Matsuzawa (2013), el cual es un novedoso mecanismo que permite la rotación triaxial de los miembros (figura 90).

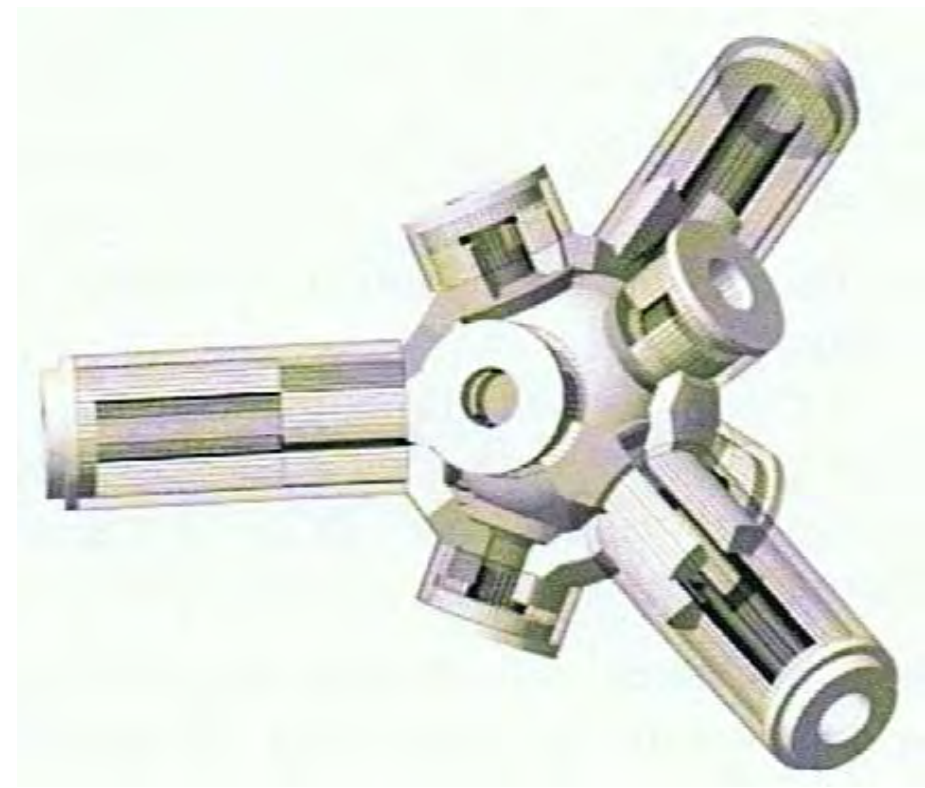

Figura 90 Articulación esférica multiunión, Yohei Yokosuka y Teruo Matsuzawa 


\section{ESTUDIO DE ESTRUCTURAS AUXÉTICAS}

Según Yanping Liu \& Hong Hu (2010), las estructuras auxéticas se clasifican en varios grupos en función de sus configuraciones geométricas: estructuras reentrantes, quirales, unidades rotatorias rígidas o semirrígidas, capas angulares laminadas, hard molecules, polímeros microporosos y polímeros líquidos cristalinos. De cara a utilizarlas como elementos estructurales arquitectónicos para estructuras desplegables nos quedaríamos con las estructuras reentrantes, las quirales, las unidades rotatorias y los polímeros microporosos, ya que son los patrones aptos para la arquitectura, desarrollando las geometrías de 22 modelos aptos para ser desplegables dentro de cada grupo.

Estas 22 estructuras se han modelizado en autocad primeramente como patrón individual, para combinarlas posteriormente entre sí y ver las condiciones geométricas de plegado según las configuraciones grupales escogidas. Se han estudiado los modelos auxéticos existentes, que tienen nudos rígidos y funcionan por flexión de sus barras, para transformarlos en estructuras articuladas capaces de ser desplegables.

Se proponen tres tipos de patrones conjunto:

- El patrón conjunto 2D, que engloba las combinaciones posibles del patrón unidad repitiéndose para formar una estructura plana. Dependiendo de la geometría que se repita esta trama generará formas que crezcan de forma cuadrada o circular.

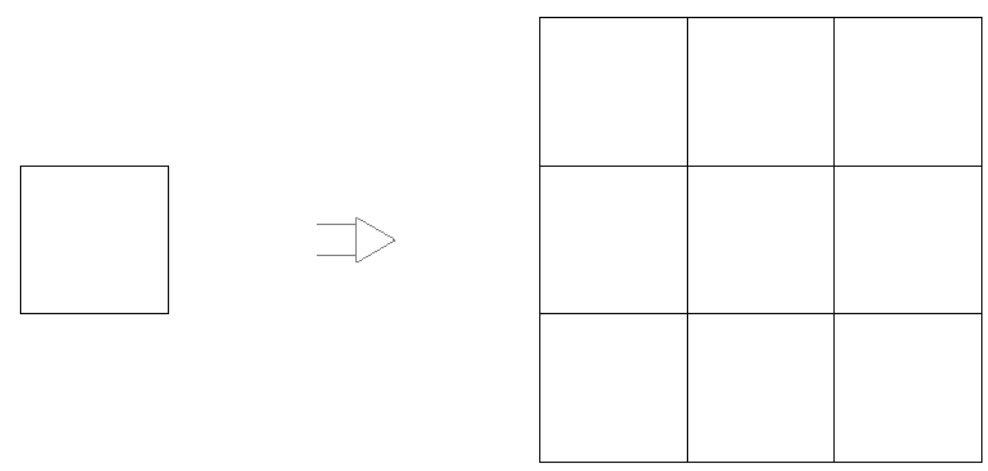

Figura 91, generación de patrón 2D a partir de patrón unidad, elaboración propia

- El patrón conjunto 3D, que engloba las combinaciones posibles del patrón unidad repitiéndose para formar una estructura tridimensional en los ejes x, y, z. Generalmente funciona combinando dos patrones individuales girados $90^{\circ}$ uno sobre el otro en su eje vertical central. Estos patrones combinados se repiten en dirección horizontal y vertical, generando una estructura 3D. 


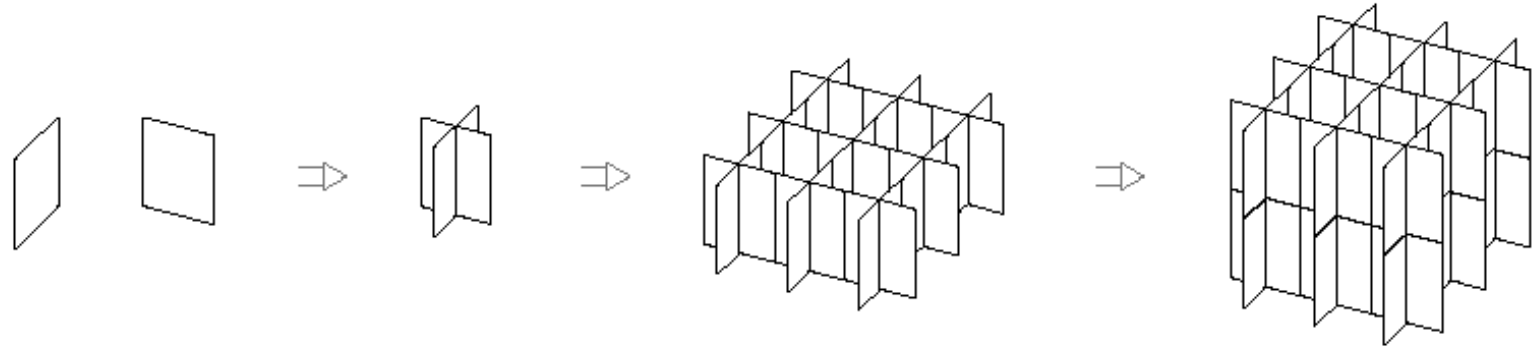

Figura 92, generación de patrón 3D a partir de patrón unidad, elaboración propia

- El patrón conjunto torre, que engloba las combinaciones posibles del patrón unidad repitiéndose para formar una estructura plana que gracias a su giro y unión forma una estructura en 3D.
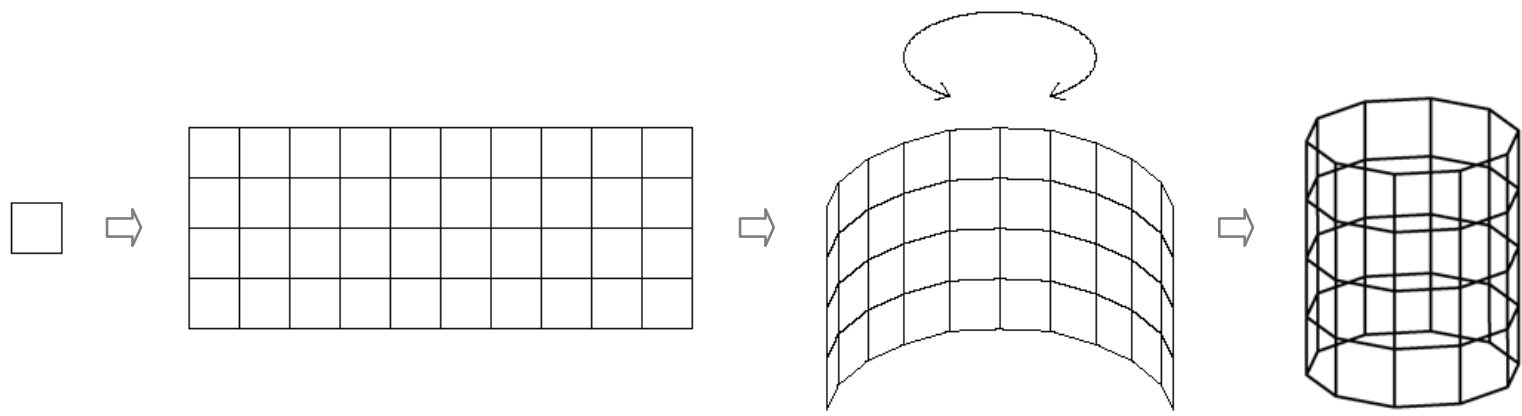

Figura 93, generación de patrón 3D a partir de patrón unidad, elaboración propia

De este modo, después de combinar cada una de las 22 estructuras individuales, desarrolladas en 2D, 3D y tipo torre, se obtienen un total de 88 tipologías de estructuras auxéticas para estudiar geométricamente (tabla 1).

Después se realiza el cálculo estructural de la estructura reentrante hexagonal. El objetivo es comprobar de forma matemática cómo funcionan estas geometrías estructuralmente en la escala de la arquitectura, y compararlas con los comportamientos de estructuras tradicionales. Para ello, se tendrá atención a los desplazamientos horizontales y verticales en articulaciones, rotaciones en articulaciones, reacciones en apoyos, esfuerzos axiles, cortantes y momentos que se generan en cada una de las estructuras comprobadas, para ver si conservan su comportamiento auxético y si, en caso de conservarlo, resulta útil para estructuras de arquitectura.

Para finalizar se estudian las condiciones necesarias para el desarrollo constructivo de las estructuras auxéticas, para determinar las cuestiones necesarias para ser capaces de llevar estas estructuras de forma real a la escala de arquitectura. 


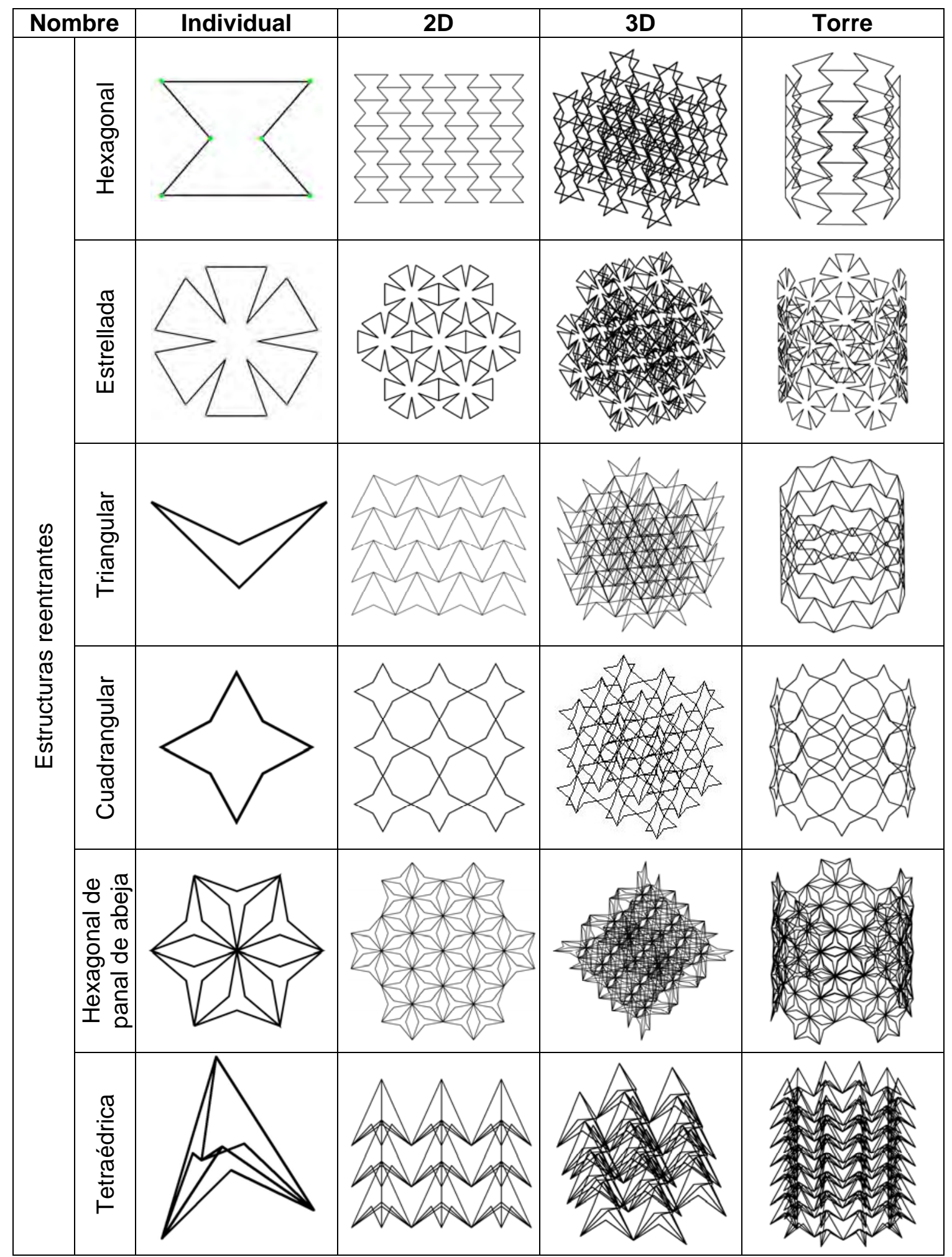

Tabla 1 (I). Patrones auxéticos y sus diferentes combinaciones, elaboración propia 


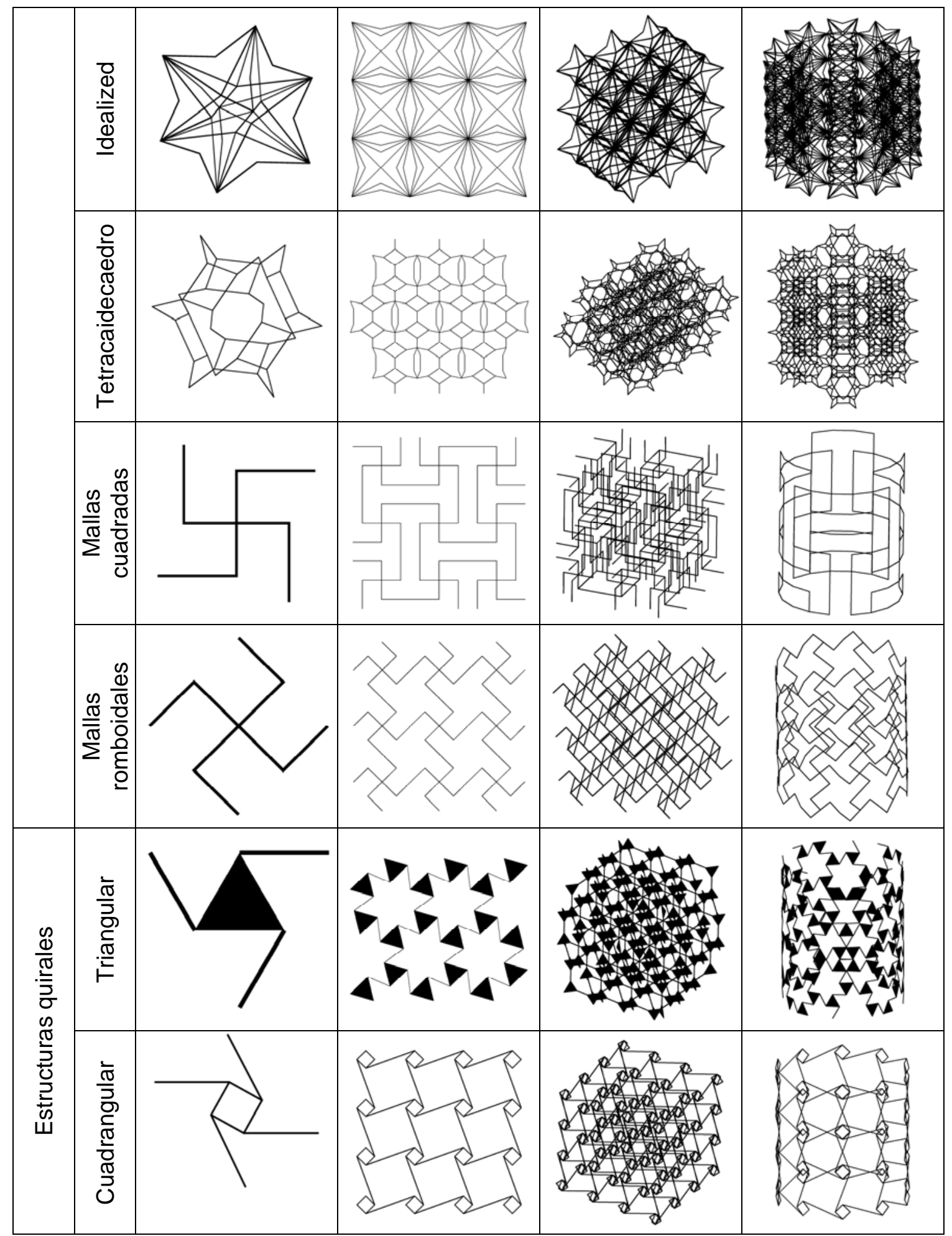

Tabla 1 (II). Patrones auxéticos y sus diferentes combinaciones, elaboración propia 


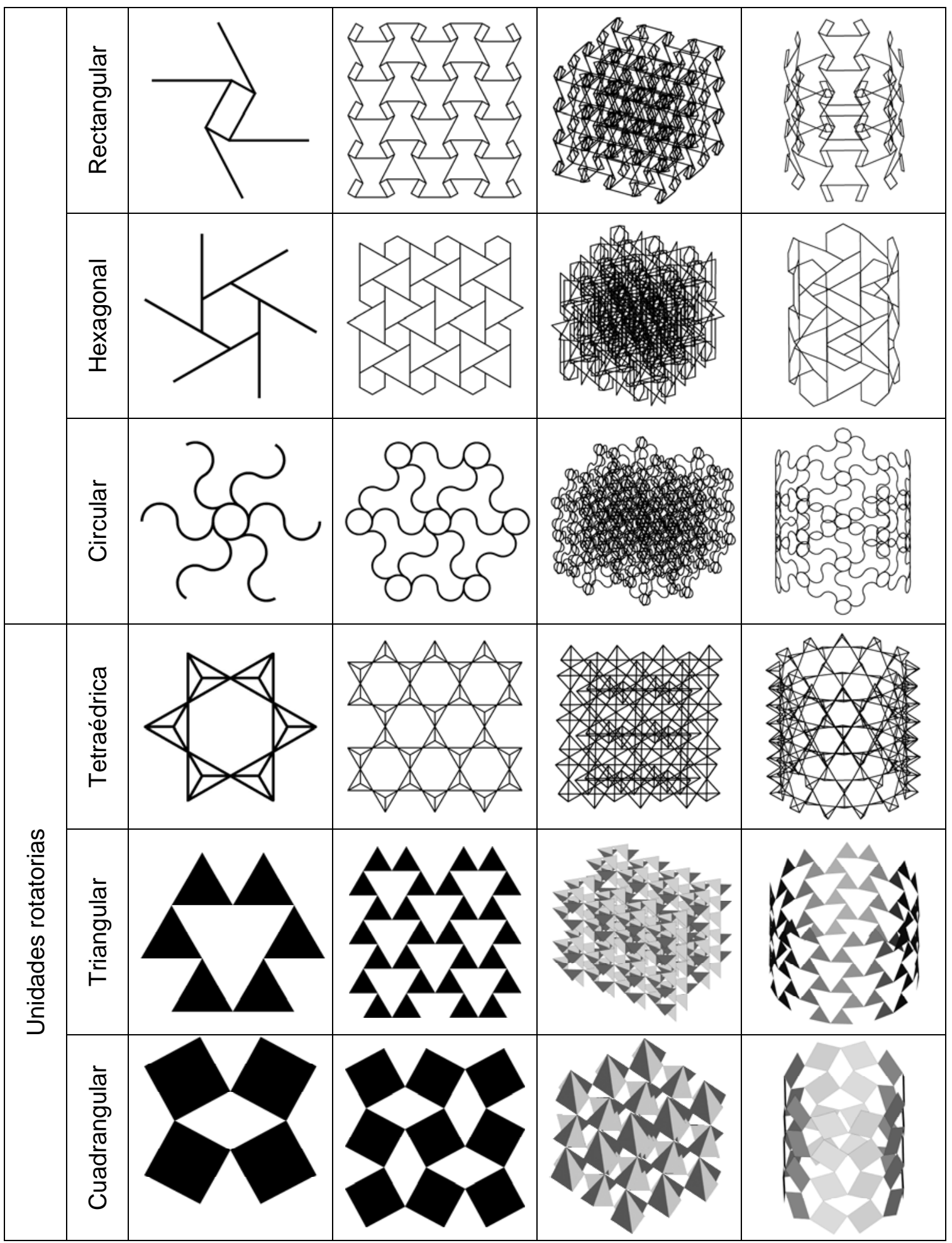

Tabla 1 (III). Patrones auxéticos y sus diferentes combinaciones, elaboración propia 


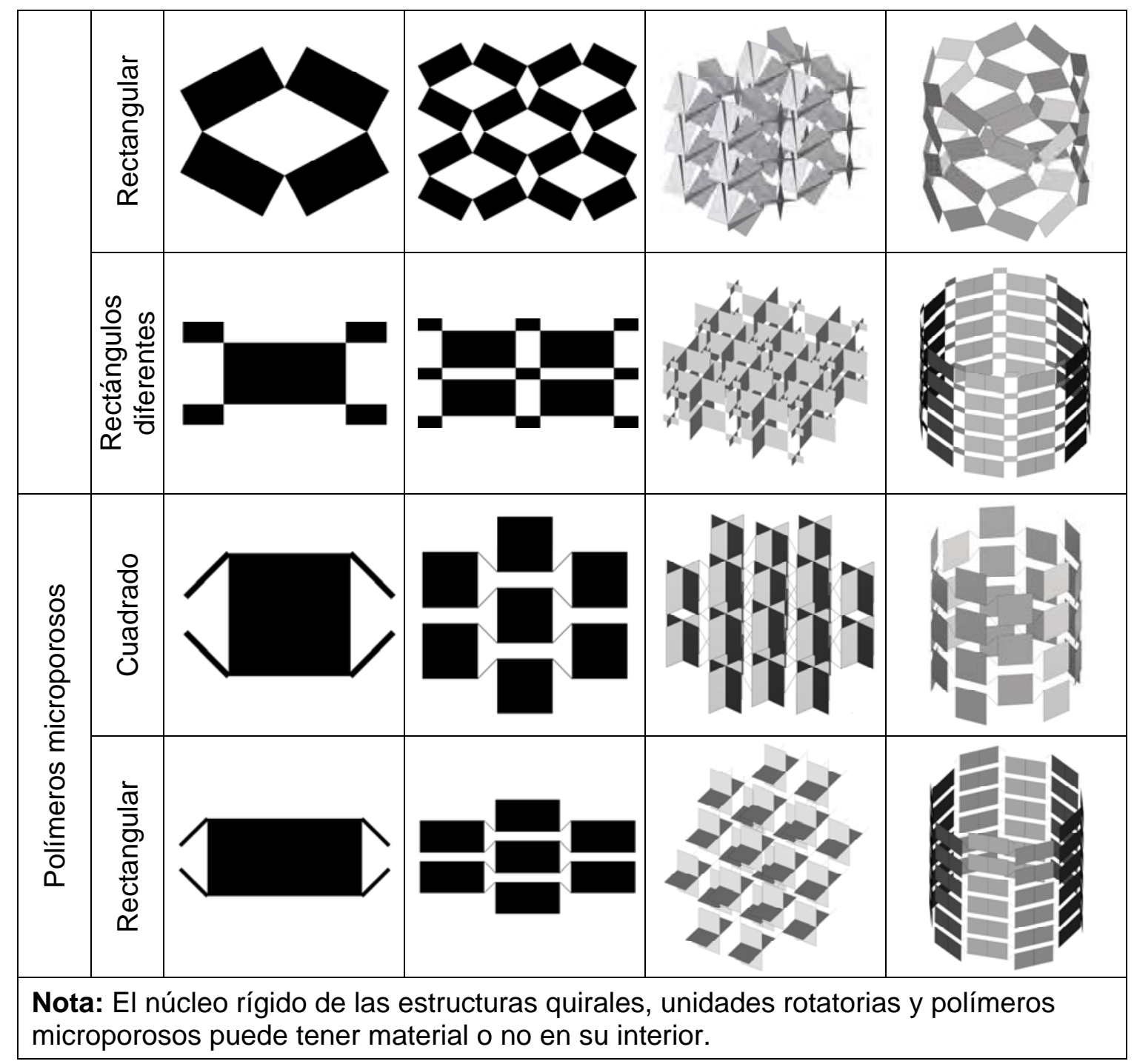

Tabla 1 (IV). Patrones auxéticos y sus diferentes combinaciones, elaboración propia 


\subsection{Estudio geométrico de estructuras auxéticas. Patrones auxéticos desarrollados y su plegabilidad}

En este apartado de la Tesis, se han generado en el programa de dibujo asistido por ordenador Autocad las geometrías transformables auxéticas en varias posiciones para entender su comportamiento geométrico. Al igual que expone Darcy Thomson (2003), en su libro "El crecimiento de la forma", todos nuestros conceptos de Forma deben estar referidos a términos de magnitud y de dirección. Esto es así porque la forma de un objeto sólo puede definirse cuando conocemos su magnitud, real o relativa, en varias direcciones; y el Crecimiento implica los mismos conceptos de magnitud y dirección, en relación con un concepto de dimensión más: el Tiempo.

En este sentido habría que desarrollar el concepto de estabilización en un determinado momento de apertura, tema que únicamente se tocará de forma sucinta en el apartado 3.3. Cálculo estructural de estructuras auxéticas, y que es totalmente imprescindible al hablar de arquitectura, ya que el estudio geométrico se desarrollará sobre los puntos de apertura y cierre de los mecanismos que habría que estabilizar para convertir en estructuras de arquitectura.

En las figuras similares la superficie aumenta con el cuadrado, y el volumen con el cubo, de las dimensiones lineales. Habiendo calculado que una pequeña ave zancuda, la cigoñuela, pesaba $120 \mathrm{~g}$. y que sus patas medían $20 \mathrm{~cm}$, supuso que un flamenco, que pesa más de 2 $\mathrm{kg}$, debería tener patas de $3 \mathrm{~m}$ de largo, para guardar la misma proporción. Pero es obvio que, estando los pesos de ambas aves en la proporción de 1:15, la longitud de las patas (o cualquier otra dimensión lineal) variará como la raíz cúbica de dichos números, aproximadamente en la proporción 1:2.5. Y según esta escala, las patas del flamenco deberían ser como realmente son, de unos $50 \mathrm{~cm}$ de longitud.

Aunque el crecimiento en longitud y el crecimiento en volumen (que suele ser equivalente a la masa o al peso) son partes del mismo proceso o fenómeno, el crecimiento de uno atrae mucho más nuestra atención que el del otro. Por ejemplo, un pez al doblar su longitud multiplica su peso al menos por ocho; para doblar su peso le basta con pasar de 10 a $12 \mathrm{~cm}$ de longitud. En segundo lugar, podemos observar que comprender la correlación entre longitud y peso en cualquier especie animal, en otras palabras, determinar el valor de k en la fórmula $\mathrm{W}=\mathrm{kL} 3$, nos permite traducir en cualquier momento una magnitud a la otra. 
El efecto de la escala no depende de una cosa en sí misma sino de su relación con todo su ambiente o medio. Uno de los efectos más comunes de la escala se debe al hecho de que algunas fuerzas físicas actúan directamente en la superficie de un cuerpo, fuerzas que se tendrán en cuenta en el apartado 3.3. Cálculo estructural de estructuras auxéticas.

Existe un principio de similitud dinámica por el cual las "dimensiones" siguen siendo las mismas en nuestras ecuaciones de equilibrio, pero los valores relativos se alteran con la escala.

De este modo, han sido modelizadas posibles posiciones en el espacio de diferentes tipologías auxéticas desde que están totalmente plegadas hasta que se consigue su máxima apertura, consiguiendo con la misma masa una variación de su superficie o volumen. El objetivo es conocer las condiciones de apertura y cierre de los ángulos generados en los nudos, para determinar si estos giros son superficiales o espaciales y en qué direcciones se generan según las condiciones geométricas de la estructura impuestas.

También se analiza la relación entre la cantidad de material usado y la superficie o volumen conseguido, según estemos analizando estructuras en 2 o 3 dimensiones. Para ello se contabilizará la longitud total de barras usadas en la construcción de cada estructura, como analogía a la cantidad de material, ya que para conocer esas cantidades de dicho material en unidades de masa tendríamos que definir secciones concretas de barras y materiales concretos. En este estudio se busca un comportamiento teórico general, por lo que la longitud identifica perfectamente esos elementos lineales usados. La relación entre el área $(A)$ o el volumen $(V)$ con la longitud $(L)$ nos dará una relación $(K)$ entre dichas unidades, ayudándonos a comprender los valores de crecimiento de estas estructuras tan particulares. El área de cada figura corresponderá al cuadrado, circunferencia o polígono (según corresponda) donde se inscriba la figura; y el volumen corresponderá al cubo o cilindro que contenga la estructura. De la división y la resta de $\mathrm{K}_{\text {máx }}$ y $\mathrm{K}_{\text {mín }}$ se obtendrán unos factores de crecimiento FC (:) y FC (-) de cada estructura.

Se estudian los patrones aplicables de manera individual y sus posibles combinaciones, para poder establecer desarrollos estructurales en función del tamaño, así como transformar arquitecturas que siguen desarrollos geométricos novedosos en arquitecturas auxéticas desplegables. Los modelos auxéticos que serán estudiados geométricamente serán los siguientes: 
- Estructuras reentrantes. Como ha sido comentado en los antecedentes los modelos auxéticos pueden generarse a partir de polígonos (regulares o irregulares) dividiendo sus caras en dos y plegándolas hacia el interior (hacia el exterior el comportamiento no es auxético). También pueden ser generados a partir de poliedros (regulares: sólidos platónicos y arquimedianos, o irregulares: prismas y pirámides) dividiendo las aristas de los polígonos de sus caras en dos y plegándolas hacia el interior (hacia el exterior el comportamiento no es auxético). Además de los polígonos o poliedros este tipo de estructura pueden ser desarrolladas en estrella, panal de abeja, ligamentos sinusoidales o con forma de esvástica.

- Estructuras quirales. Están formadas básicamente por un núcleo central al que están unidos una serie de ligamentos. Para alcanzar el comportamiento auxético dichos ligamentos se enrollan o se desenrollan alrededor del núcleo central. Hay que tener en cuenta que para formar este tipo de estructuras solo serán admisibles núcleos con 3, 4 ó 6 ligamentos, ya que con otro número de estos no es posible repetir la estructura quiral de forma periódica.

- $\quad$ Unidades rotatorias. Se producen por la repetición de polígonos o figuras sencillas unidas mediante bisagras. Por ejemplo, se pueden repetir rectángulos, cuadrados, triángulos o tetraedros. El comportamiento auxético se produce por la rotación de las distintas unidades alrededor de las uniones, de tal manera que se produce un empaquetamiento 0 desempaquetamiento, en función del sentido del movimiento.

- Polímeros microporosos. Sus características pueden ser interpretadas como un modelo bidimensional simple, el cual está basado en una red interconectada de núcleos y fibras de manera que al producirse una compresión se produce un movimiento de traslación lateral de los núcleos.

Las variaciones geométricas sobre estos modelos son infinitas, ya que podríamos comprobar multitud de comportamientos variando el tamaño de cada barra de la estructura individual que afecta al conjunto. Sin embargo, este estudio de variaciones geométricas para un mismo patrón se desarrollará únicamente para la estructura reentrante hexagonal, que será objeto de estudio a lo largo de esta tesis.

El resto de estructuras serán estudiadas para patrones totalmente regulares, con el objetivo de realizar un estudio comparativo entre todas ellas donde se pueda visualizar cómo afecta la forma a la capacidad de crecimiento de la estructura de forma auxética. Además, con los 
patrones estudiados se realizará una clasificación tipológica de nudos, para clasificar las estructuras en función de los mismos, y poder realizar un desarrollo constructivo tipo de estas articulaciones que afectan a las estructuras objeto de estudio.

\subsubsection{Estructura reentrante hexagonal}

Conocida comúnmente como Master-Evans, se trata de una de las estructuras auxéticas más clásicas. Se analiza su comportamiento en función de los parámetros geométricos, ya que dependiendo de la longitud de las barras conseguimos unas propiedades diferentes. De este modo se han considerado las barras fijas (las que no giran) de longitud igual a la unidad, y se han ido variando las longitudes del resto de barras.

\subsubsection{Patrón unidad}

Se aprecian los comportamientos siguientes:

\section{b $\leq 1 / 2 B$}
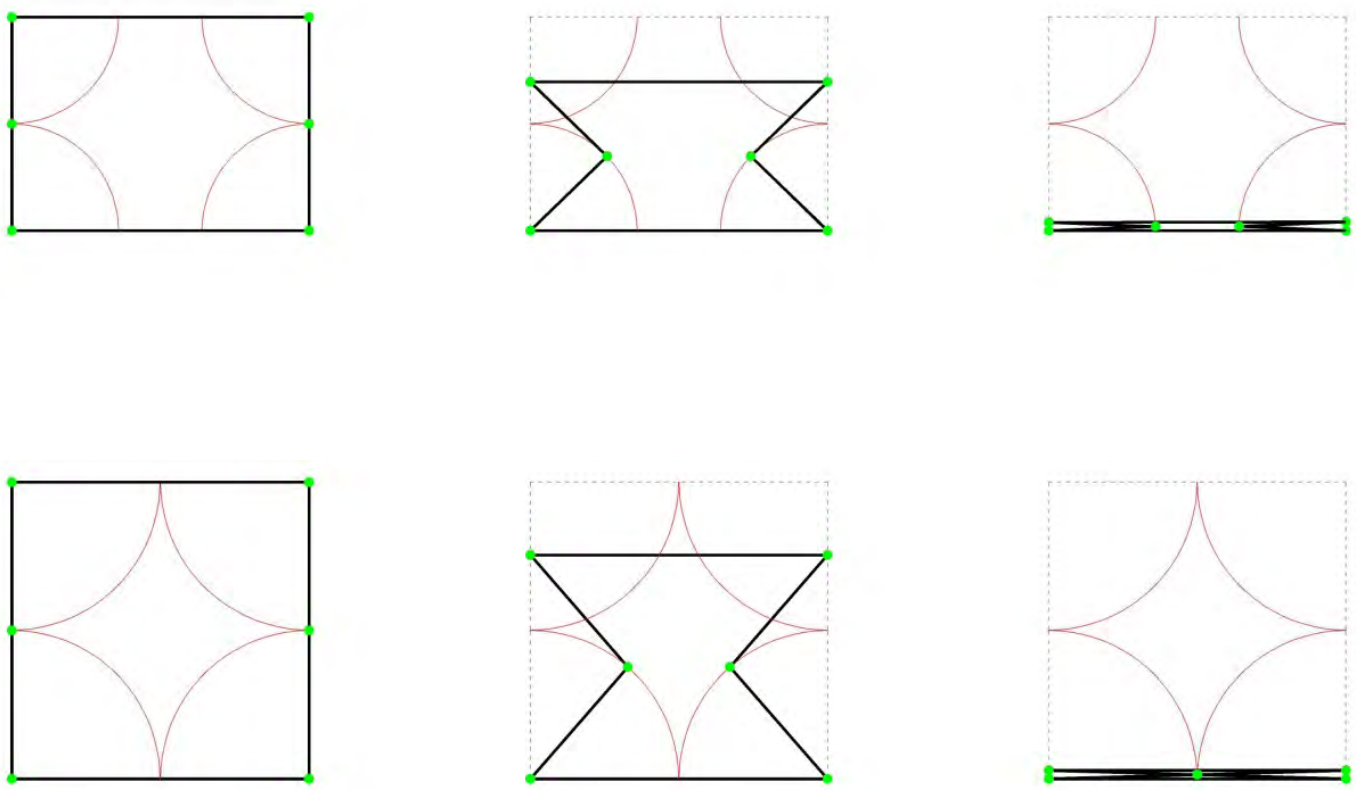

Figura 94 Estructura reentrante hexagonal $b \leq 1 / 2$ B, elaboración propia

\section{b $>1 / 2$ B}
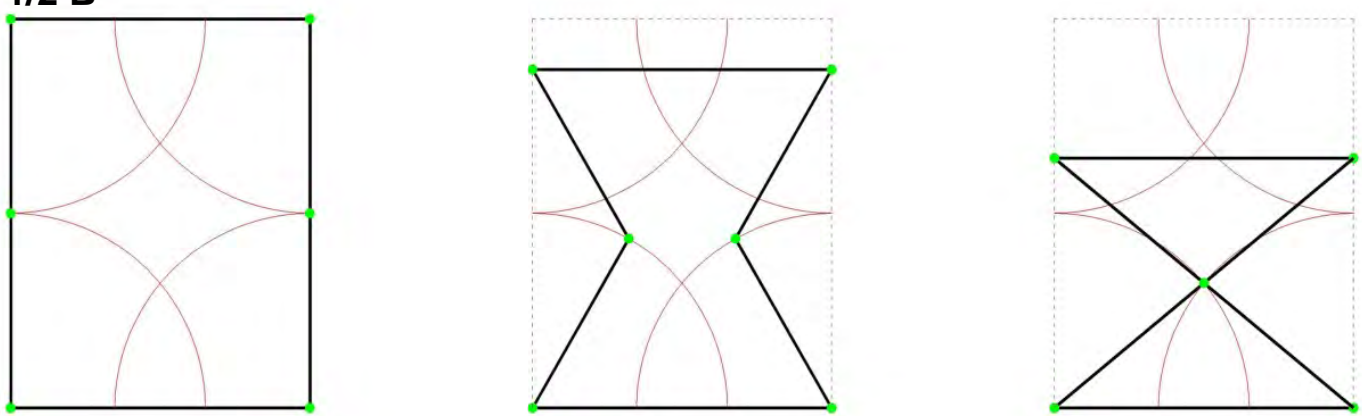

Figura 95 Estructura reentrante hexagonal $b>1 / 2$ B, elaboración propia 
donde:

$B=$ barra fija

b = barra móvil

Se percibe a simple vista que cuando $b \leq 1 / 2$ B la estructura varía desde una línea (comportamiento teórico, porque habría que tener en cuenta que la materia ocupa un lugar y que realmente no se podría plegar hasta la totalidad) hasta una estructura 2D, en la que la máxima apertura que se considera para obtener un comportamiento auxético son $90^{\circ}$, ya que con aperturas mayores tendríamos un comportamiento tradicional de la estructura.

Las estructuras en las que $b>1 / 2$ B las consideramos para macroestructuras como rascacielos, o estructuras internas para materiales (por ejemplo, podríamos diseñar un vidrio auxético que no rompiese por compresión de los elementos estructurales), pero nunca las tendríamos en cuenta para estructuras plegables.

Por tanto, como condiciones de plegabilidad necesitamos que $b_{\text {lateral }} \leq 1 / 2 B$ sup e inf

En concreto, los datos numéricos obtenidos han sido los siguientes:

\begin{tabular}{|c|c|c|c|c|c|c|c|}
\hline & $\mathbf{L}$ & $\mathbf{A}_{\text {mín }}$ & $\mathbf{A}_{\text {máx }}$ & $\mathbf{K}_{\text {mín }}$ & $\mathbf{K}_{\text {máx }}$ & $\mathbf{F C}(:)$ & $\mathbf{F C}(-)$ \\
\hline $\mathbf{b} \leq \mathbf{1 / 2} \mathbf{B}$ & 3,44 & 0,00 & 0,72 & 0,00 & 0,21 & $\#_{i} \mathrm{DIV} / 0 !$ & 0,21 \\
\hline $\mathbf{b}=\mathbf{1 / 2} \mathbf{B}$ & 4,00 & 0,00 & 1,00 & 0,00 & 0,25 & $\#_{i} \mathrm{DIV} / 0 !$ & 0,25 \\
\hline $\mathbf{b}>\mathbf{1 / 2} \mathbf{\mathbf { B }}$ & 4,60 & 0,42 & 1,30 & 0,09 & 0,28 & 3,10 & 0,19 \\
\hline
\end{tabular}

Tabla 2. Relación entre áreas mínimas $\left(A_{\text {minn }}\right.$ y máximas $\left(A_{m a ́ x}\right)$ con la longitud total de barras de la estructura, elaboración propia

Puede observarse que al aumentar la longitud de las barras que se pliegan, el área y, por tanto, la relación "K" buscada aumentan. Los factores de crecimiento generados a partir de la división no son calculables, ya que, al haber considerado el área mínima de forma teórica con un valor igual a 0 , dicha división da error. Sí se puede apreciar que el factor de crecimiento generado a partir de la resta nos indica que el máximo factor se da cuando $b=$ $1 / 2 \mathrm{~B}$.

Del análisis de esta figura también se puede ver que todos sus nudos son articulados en el plano, y confluyen dos barras en los mismos, permitiéndose giros en el eje xy que van de $0^{\circ}$ a $90^{\circ}$ o de $0^{\circ}$ a $180^{\circ}$ según barra. 


\subsubsection{Estructura en 2 dimensiones}

Se analiza el comportamiento geométrico combinando el patrón unidad de forma plana, teniendo como resultado que este patrón conjunto se pliega desde una línea hasta una superficie (figura 96).
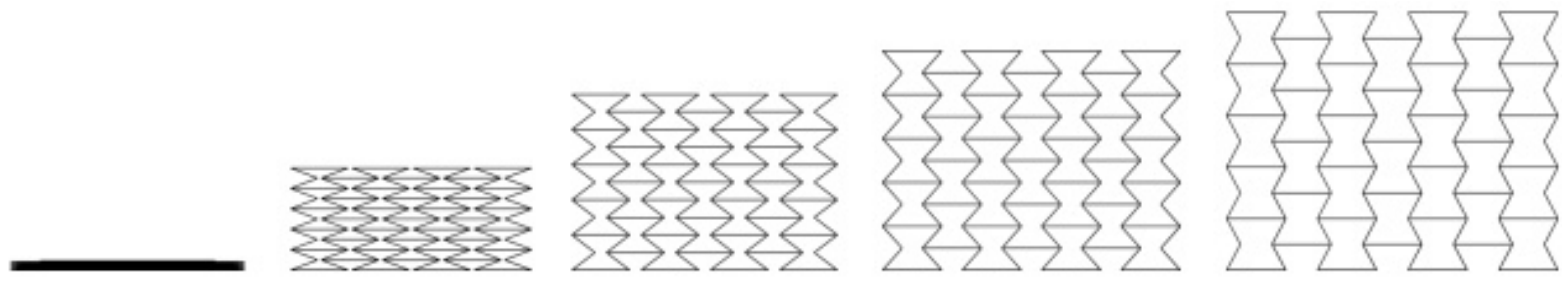

Figura 96 Estructura reentrante hexagonal, elaboración propia

En este caso, al igual que para la estructura individual, del análisis de esta figura mediante repetición en un plano, también se puede ver que todos sus nudos son articulados únicamente en el plano, con la diferencia de que, al estar agrupado el platrón unidad, generalmente confluyen tres barras cada nudo, y no dos como cuando el comportamiento es individual, permitiéndose giros en el eje xy que van de $0^{\circ}$ a $90^{\circ}$ o de $0^{\circ}$ a $180^{\circ}$ según barra.

La estructura reentrante hexagonal 2D que se estudia es la de FC (-) mayor, teniendo una longitud total de sus barras de 79,00m. Es capaz de plegarse totalmente, siendo su superficie mínima nula (genera una línea), y su superficie máxima de $35 \mathrm{~m}^{2}$ (área del cuadrado que genera), por lo que se aprecian unas constantes "K" en función de la superficie entre la longitud de líneas que van de 0,00 como mínimo a 0,44 como máximo. Esto nos da un factor de crecimiento FC (-) de 0,44.

\subsubsection{Estructura en 3 dimensiones}

Existen infinidad de combinaciones posibles, yendo todas ellas de una superficie a un volumen o entramado espacial, de las cuales se han analizado las que aparecen en las figuras 97, 98 y 99. El primer (figura 97) y el segundo caso (figura 98) se han generado de la manera explicada en la página 87, siendo la diferencia que en el primer caso sólo cruzamos superficies perpendiculares cada dos estructuras individuales auxéticas, mientras que en el segundo tenemos un entramado cruzado para todas y cada una de las estructuras individuales auxéticas. El tercer caso, se genera mediante cruce perpendicular en los vértices (y no en el centro de las aristas) generando formas cúbicas, de tal forma, que el patrón individual que se repite, pasa a tener volumen 3D. 


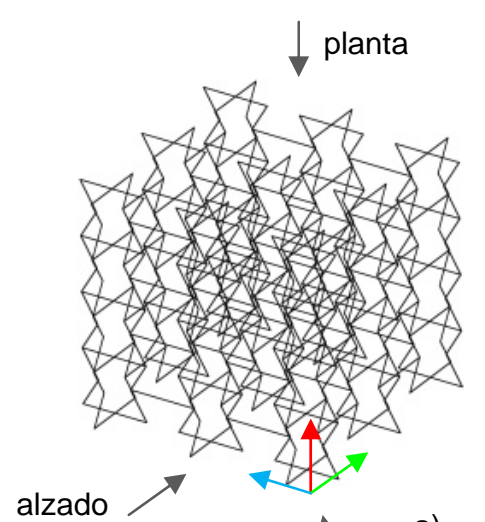

Perfil diagonal

e)

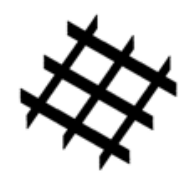

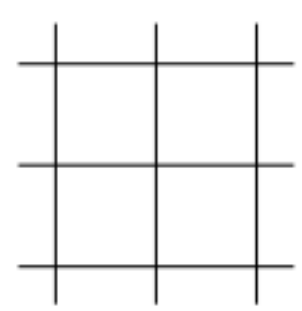

b)

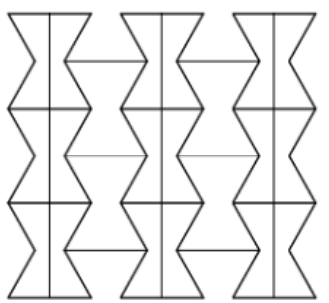

c)

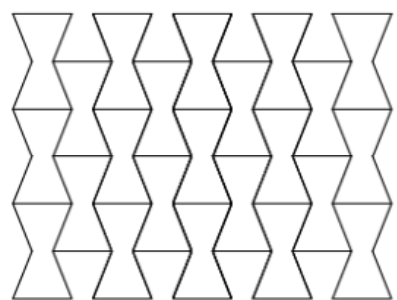

d)

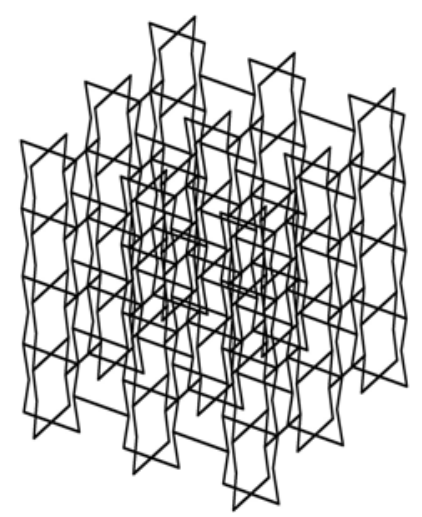

Figura 97 Primera combinación de estructura reentrante hexagonal, elaboración propia: a) vista 3D, b) planta, c) alzado, d) perfil, e) desarrollo desplegable auxético.

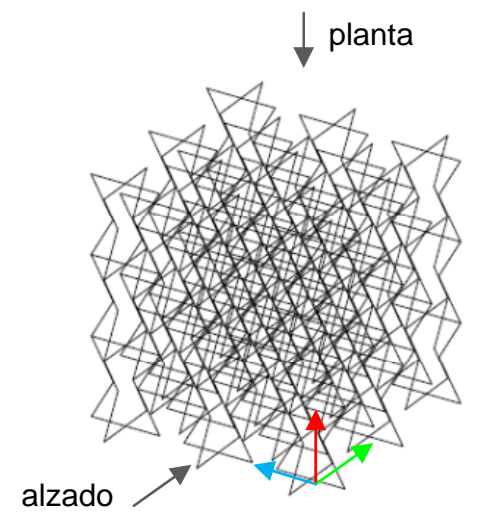

a)

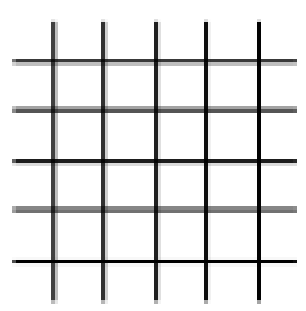

b)

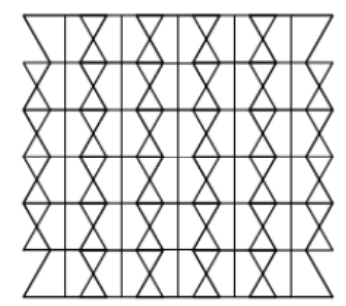

c)

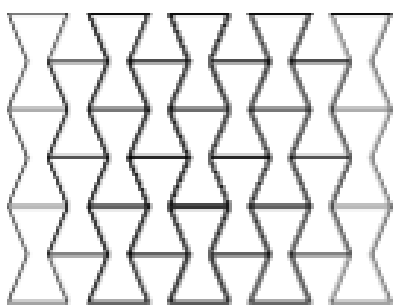

d)

e)
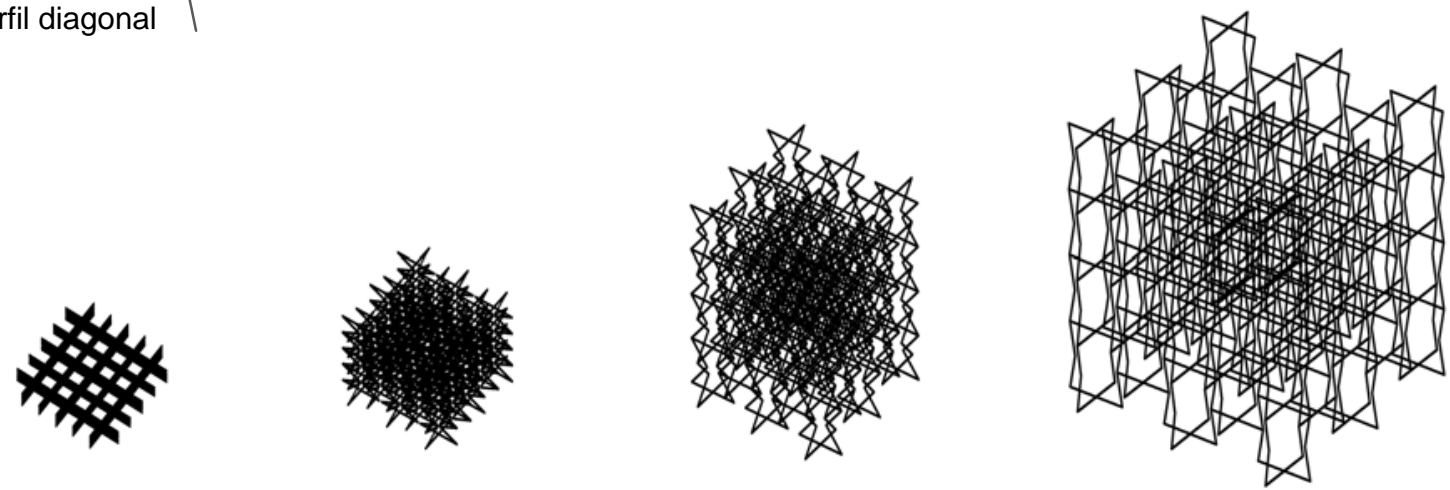

Figura 98 Segunda combinación de estructura reentrante hexagonal, elaboración propia: a) vista 3D, b) planta, c) alzado, d) perfil, e) desarrollo desplegable auxético. 


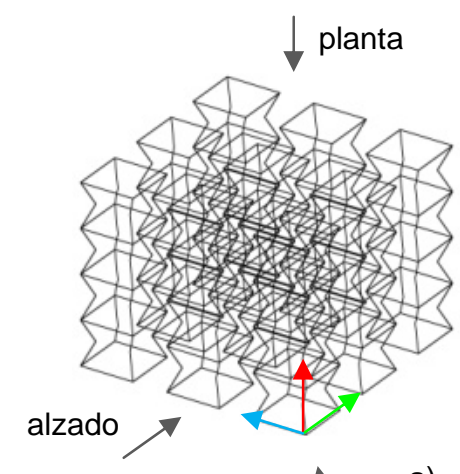

Perfil diagonal

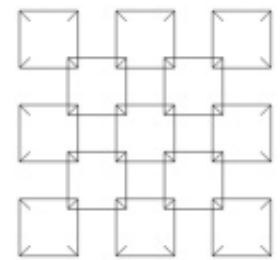

b)

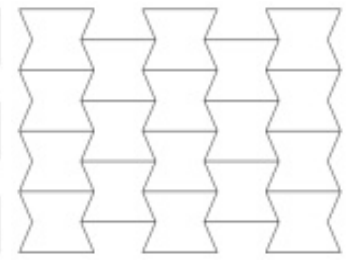

c)

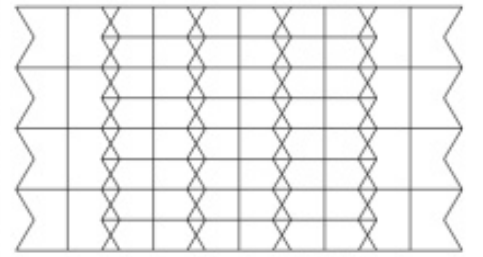

d)

e)
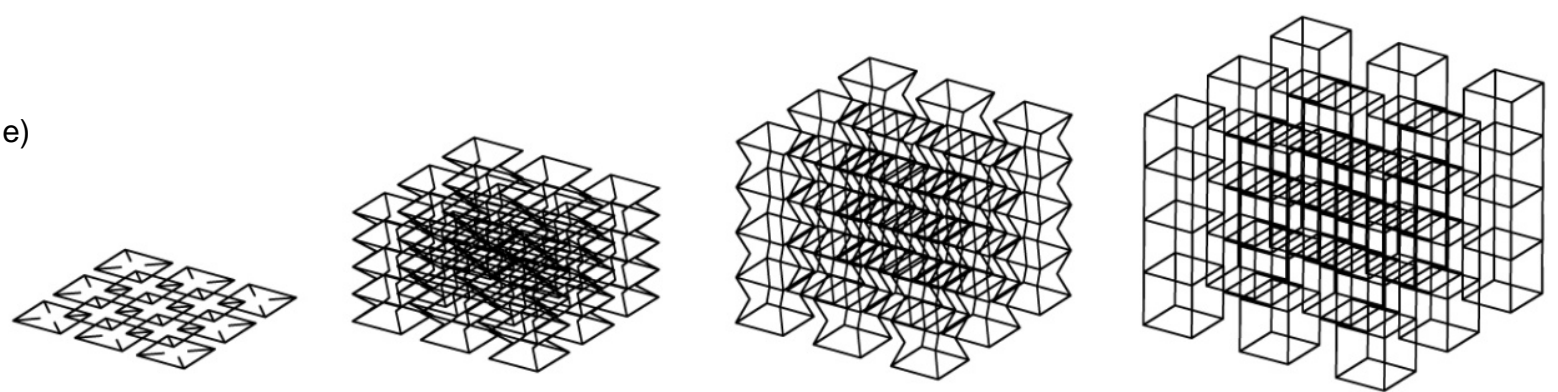

Figura 99 Tercera combinación de estructura reentrante hexagonal, elaboración propia: a) vista 3D, b) planta, c) alzado, d) perfil, e) desarrollo desplegable auxético.

Las figuras 97 y 98 han sido diseñados para $b=1 / 2 B$, ya que siguen las mismas reglas geométricas que el patrón individual y el patrón 2D, y se ha querido testear para el patrón conjunto aquel patrón unidad con mayor factor de crecimiento. Las estructuras generadas permiten giros en el eje xy que van de $0^{\circ}$ a $90^{\circ}$ o de $0^{\circ}$ a $180^{\circ}$ según barra, ya que se trata de combinaciones de la estructura reentrante hexagonal 2D. Sin embargo, las barras horizontales para estos supuestos (figuras 97 y 98) sufren una discontinuidad, ya que hay que combinarlas con la estructura girada $90^{\circ}$. Si quisiéramos que esta estructura funcionara de forma auxética únicamente, estas barras podrían ir soldadas en forma de cruz.

La figura 99 ha sido diseñada también para $b=1 / 2 \mathrm{~B}$, aunque en este caso también podría ser $b>1 / 2 B$, ya que las barras no son coplanarias. Aparecen articulaciones en tres planos, con confluencia de tres o más barras. Los giros en sentido vertical siguen yendo de $0^{\circ}$ a $90^{\circ}$ o de $0^{\circ}$ a $180^{\circ}$ según barra.

Los datos numéricos obtenidos en relación al crecimiento de la estructura y su relación masa-volumen han sido los siguientes: 


\begin{tabular}{|l|c|c|c|c|c|c|c|}
\hline & $\mathbf{L}$ & $\mathbf{V}_{\text {mín }}$ & $\mathbf{V}_{\text {máx }}$ & $\mathbf{K}_{\text {mín }}$ & $\mathbf{K}_{\text {máx }}$ & FC (:) & FC (-) \\
\hline Caso A & 277,06 & 0,00 & 80,50 & 0,00 & 0,29 & $\#_{i} \mathrm{DIV} / 0 !$ & 0,29 \\
\hline Caso B & 418,60 & 0,00 & 80,50 & 0,00 & 0,19 & $\#_{i} \mathrm{DIV} / 0 !$ & 0,19 \\
\hline Caso C & 383,06 & 0 & 96,57 & 0,00 & 0,25 & $\#_{i} \mathrm{DIV} / 0 !$ & 0,25 \\
\hline
\end{tabular}

Tabla 3. Relación de volúmenes mínimos $\left(V_{\text {mín }}\right)$ y máximos $\left(V_{\text {máx }}\right)$ con la longitud total de barras de la estructura, elaboración propia

Se puede apreciar que el factor de crecimiento generado a partir de la resta nos indica que el máximo factor de crecimiento se da para el caso A. Los factores de crecimiento generados a partir de la división no son calculables, ya que, al haber considerado el área mínima de forma teórica con un valor igual a 0, dicha división da error.

\subsubsection{Estructura torre (por giro de la estructura 2D)}

A continuación se expone el desarrollo desplegable auxético, de la estructura torre reentrante hexagonal (figura 100).
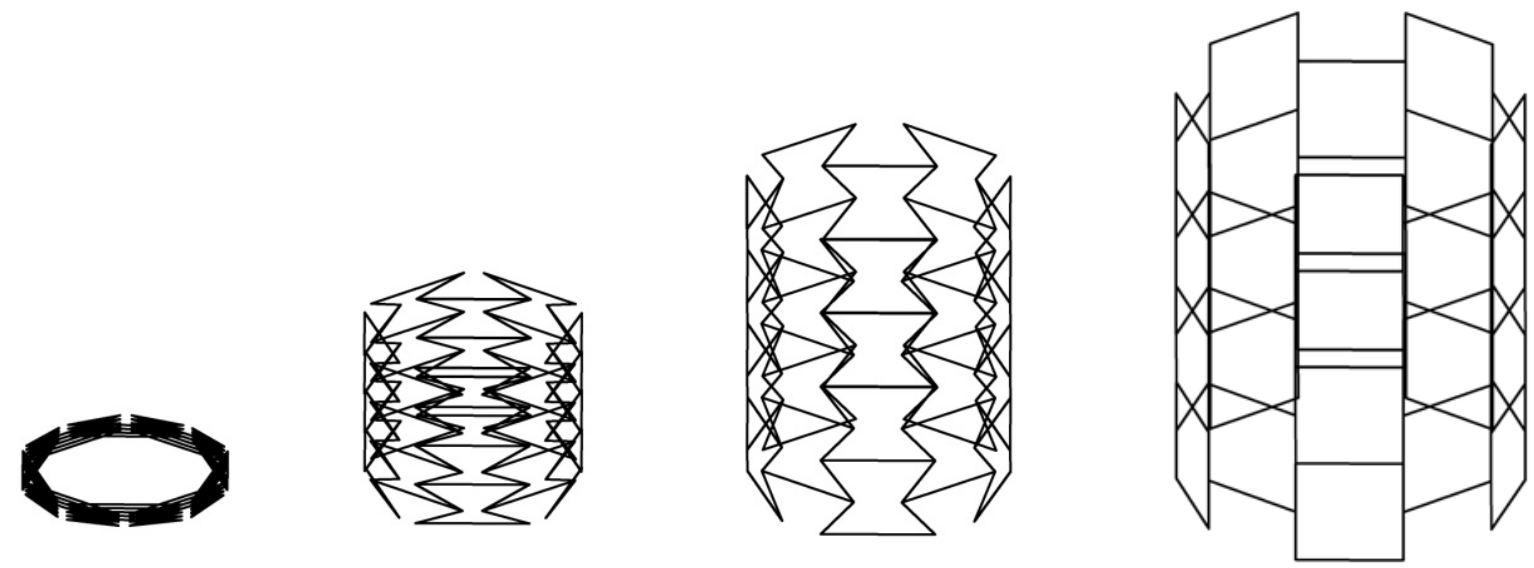

Figura 100 Desarrollo desplegable auxético de estructurra reentrante hexagonal torre, elaboración propia

La estructura ha sido modelizada, como en todas las combinaciones de estructura reentrante hexagonal, para $b=1 / 2 B$, pero en este caso también podría ser $b>1 / 2 B$, ya que las barras no son coplanarias. Se producen giros en el eje vertical de $90^{\circ}$ o $180^{\circ}$ según barra (al igual que en la estructura 2D). Además, para conseguir la máxima compactación de forma auxética se puede colocar una articulación en el centro de las barras horizontales, que puede abarcar giros de hasta $180^{\circ}$.

La estructura reentrante hexagonal tipo torre que se estudia es la de FC (-) mayor para el patrón individual, teniendo una longitud total de sus barras de $82,84 \mathrm{~m}$. Es capaz de plegarse 
totalmente, siendo su volumen mínimo nulo (genera una superficie), y su volumen máximo de $31,12 \mathrm{~m}^{3}$ (volumen del cilindro que genera), por lo que se aprecian unas constantes "K" en función del volumen entre la longitud de líneas que van de 0,00 como mínimo a 0,38 como máximo. Esto nos da un factor de crecimiento FC (-) de 0,38. Los factores de crecimiento generados a partir de la división no son calculables, ya que, al haber considerado el volumen mínimo de forma teórica con un valor igual a 0 , dicha división da error.

\subsubsection{Estructura reentrante estrellada}

Esta estructura nunca se pliega totalmente de forma auxética. Se analiza su comportamiento en función de los parámetros geométricos, para ello se ha variado el número de vértices que atacan el núcleo central en el patrón individual y 2D, consiguiendo unas propiedades diferentes. De este modo se han considerado 3, 4 y 6 puntas, de tal forma que se aprecian los comportamientos siguientes:

\subsubsection{Patrón unidad}

\section{3 puntas}
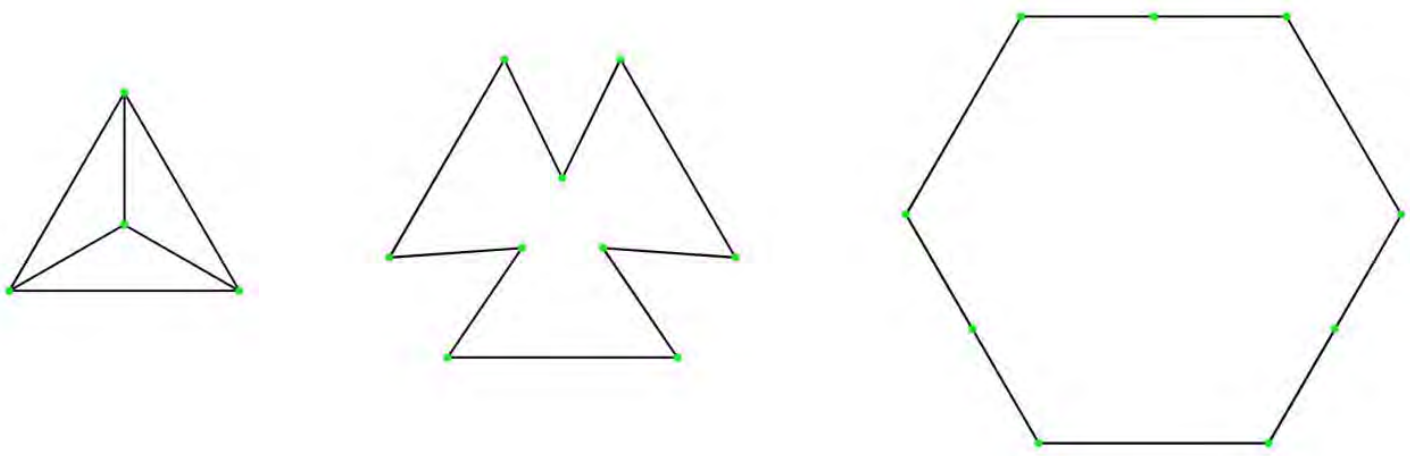

Figura 101 Unidad de estructura reentrante estrellada de tres puntas, elaboración propia

\section{4 puntas}
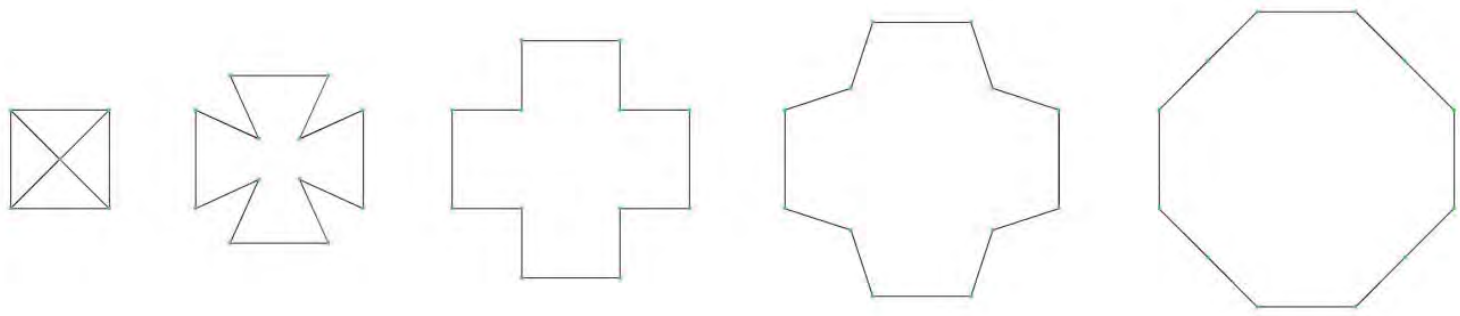

Figura 102 Unidad de estructura reentrante estrellada de cuatro puntas, elaboración propia 


\section{$\underline{6 \text { puntas }}$}
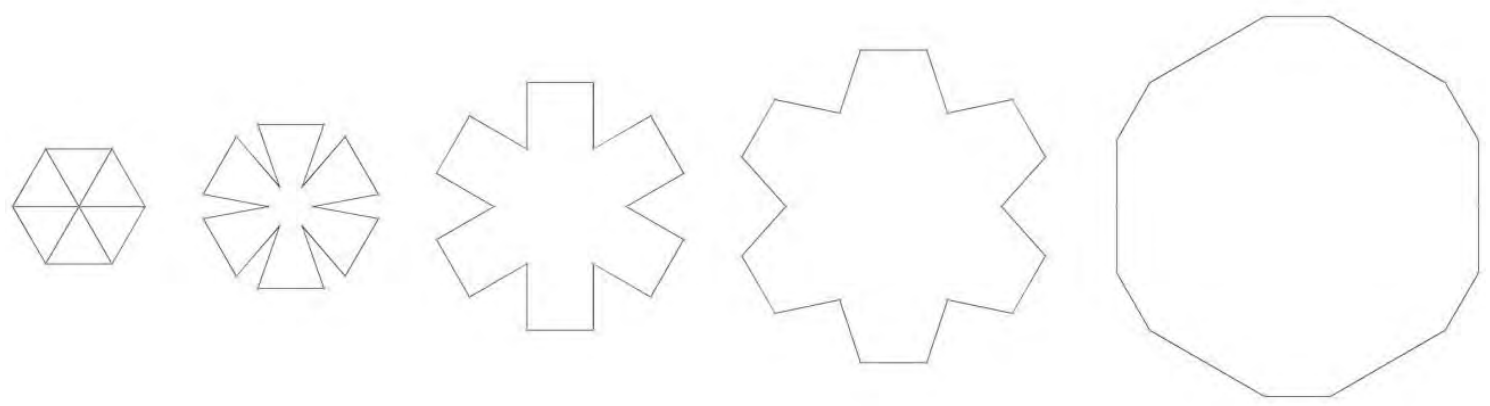

Figura 103 Unidad de estructura reentrante estrellada de seis puntas, elaboración propia

Se ha analizado de forma gráfica el factor de crecimiento de cada unidad de las tres estructuras analizadas, llegando a la conclusión de que el crecimiento es proporcional al número de lados, es decir, a mayor cantidad de lados más crece la estructura al desplegarla. Y parece un crecimiento exponencial.

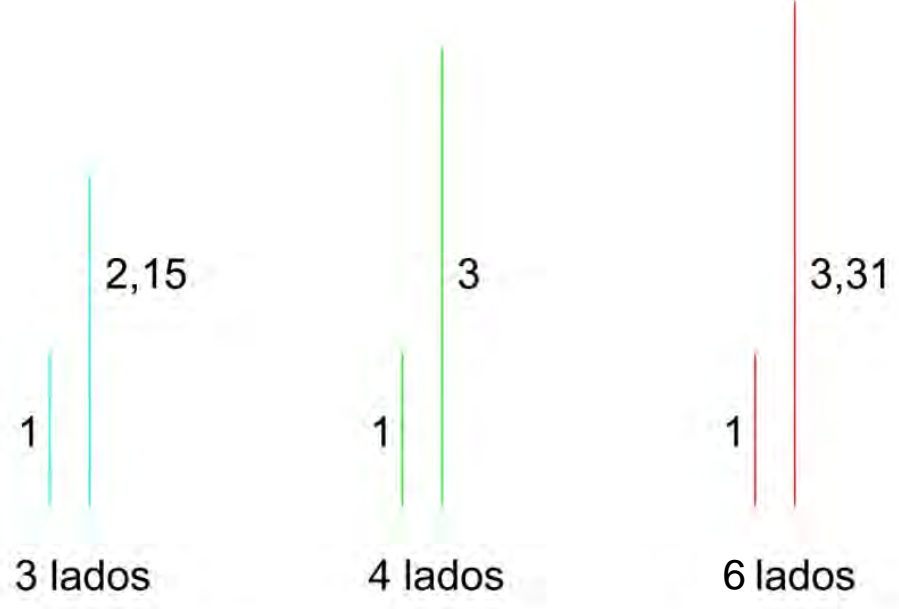

Figura 104 Factores de crecimiento de estructuras reentrantes estrelladas, elaboración propia

También se han analizado de forma numérica los factores de crecimiento de estas tres estructuras estrelladas analizadas. Los datos numéricos obtenidos en relación al crecimiento de dichas estructuras y su relación masa-volumen han sido los siguientes:

\begin{tabular}{|c|c|c|c|c|c|c|c|}
\hline & $\mathbf{L}$ & $\mathbf{A}_{\text {mín }}$ & $\mathbf{A}_{\text {máx }}$ & $\mathbf{K}_{\text {mín }}$ & $\mathbf{K}_{\text {máx }}$ & $\mathbf{F C}(:)$ & $\mathbf{F C}(-)$ \\
\hline 3 puntas & 7,46 & 0,43 & 3,01 & 0,06 & 0,40 & 7,00 & 0,35 \\
\hline 4 puntas & 9,66 & 1,00 & 7,00 & 0,10 & 0,72 & 7,00 & 0,62 \\
\hline 6 puntas & 18,00 & 2,60 & 24,99 & 0,14 & 1,39 & 9,61 & 1,24 \\
\hline
\end{tabular}

Tabla 4. Relación entre áreas mínimas $\left(A_{\min }\right)$ y máximas $\left(A_{\text {máx }}\right)$ con la longitud total de barras de la estructura, elaboración propia 
Se puede apreciar que numéricamente también los factores de crecimiento van aumentando con el número de vértices que atacan al núcleo central de la estrella, obteniendo los mayores factores de crecimiento la estructura auxética individual estrellada de 6 puntas, con lo que se corrobora el análisis gráfico.

Del análisis de estas figuras también se puede ver que todos sus nudos son articulados en el plano, y confluyen dos barras en los mismos, permitiéndose giros en el eje xy que van de $0^{\circ}$ a $90^{\circ}$ o de $0^{\circ}$ a $120^{\circ}$ según barra para la estrella de 3 puntas, de $0^{\circ}$ a $90^{\circ}$ o de $0^{\circ}$ a $135^{\circ}$ según barra para la estrella de 4 puntas y de $0^{\circ}$ a $90^{\circ}$ o de $0^{\circ}$ a $150^{\circ}$ según barra para la estrella de 6 puntas. Es decir, a mayor número de vértices que atacan al núcleo central, las aperturas máximas entre las barras aumentan.

\subsubsection{Estructura en 2 dimensiones}

\section{3 puntas}
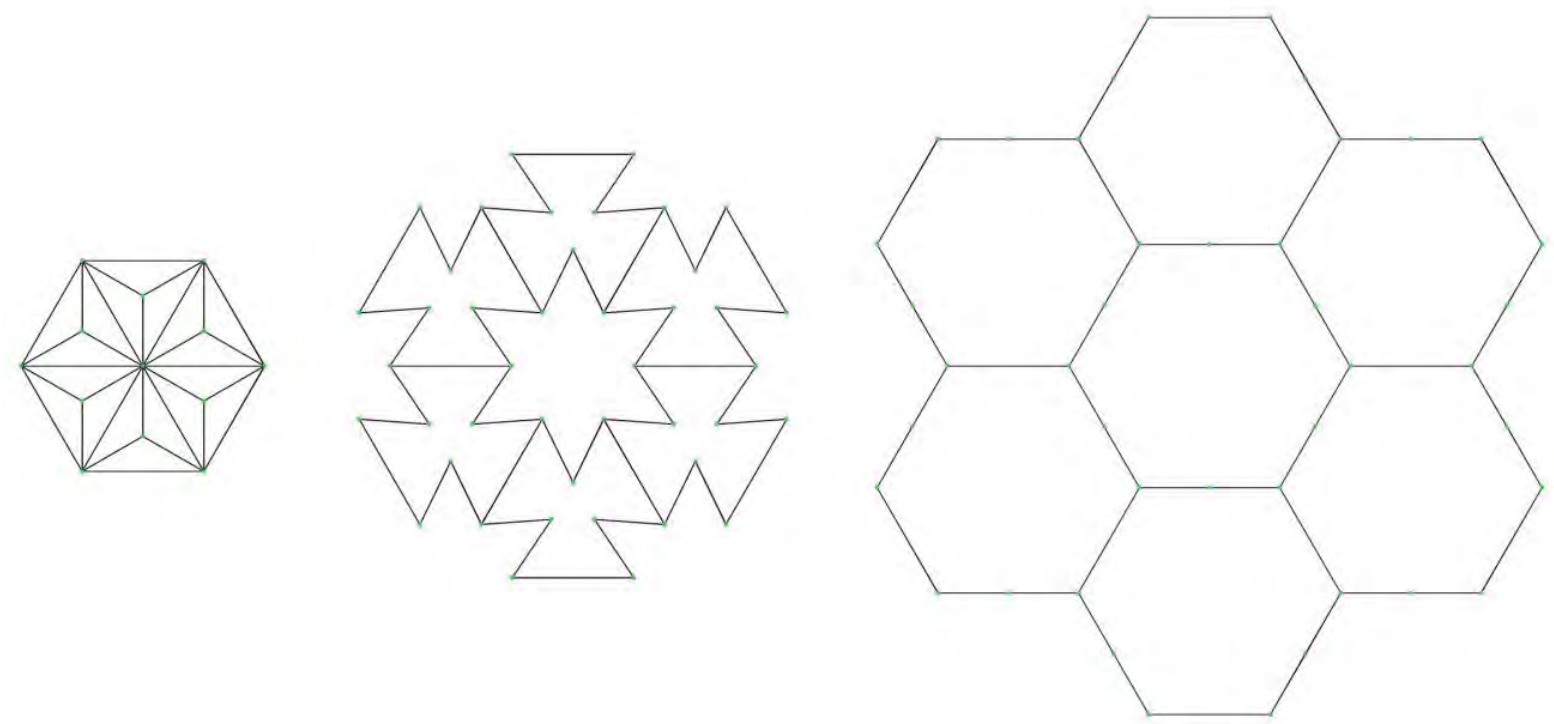

Figura 105 Conjunto de estructura reentrante estrellada de tres puntas, elaboración propia

\section{4 puntas}

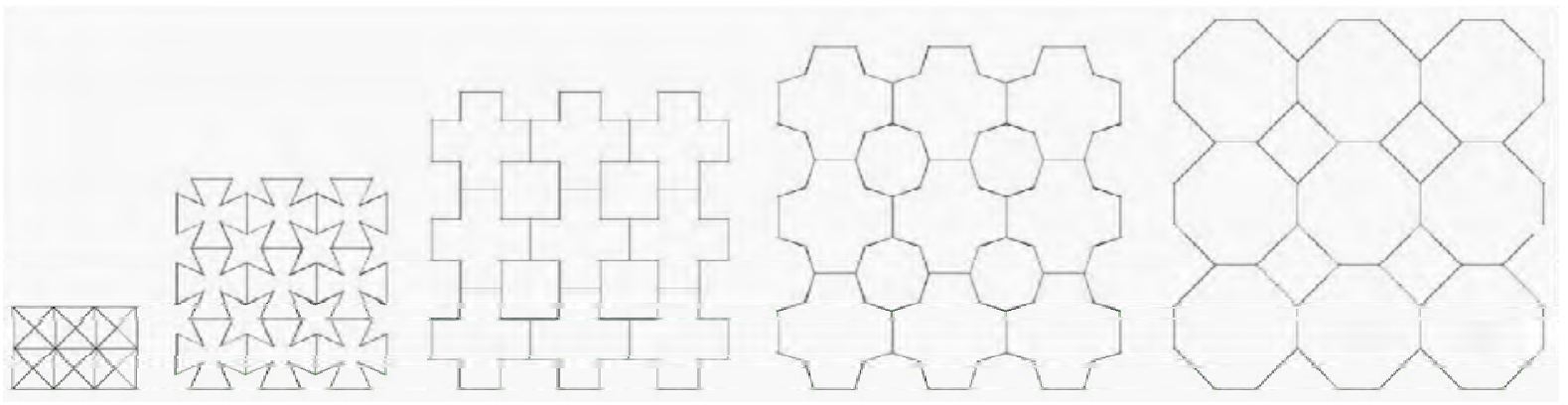

Figura 106 Conjunto de estructura reentrante estrellada de cuatro puntas, elaboración propia 


\section{$\underline{6 \text { puntas }}$}
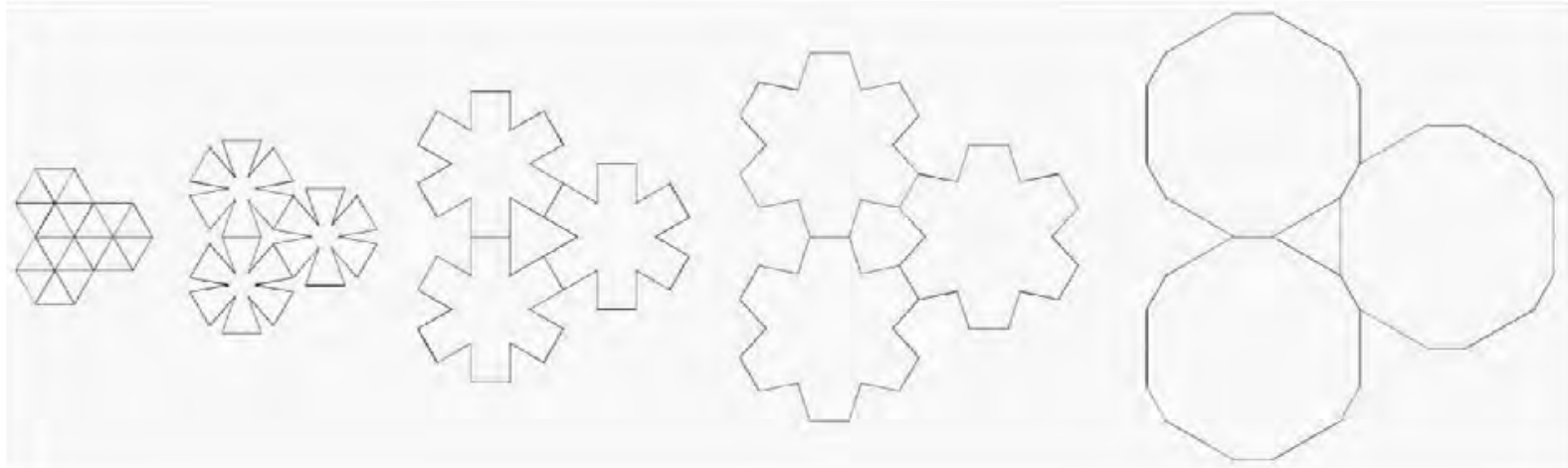

Fig 107 Conjunto de estructura reentrante estrellada de seis puntas, elaboración propia

Al igual que para el patrón unidad, a mayor número de lados en la estrella generada, también crece más esta estructura al desplegarla, lo que aumenta el factor de crecimiento en la estructura conjunto. Por lo que se puede establecer que dicha estructura conjunto crece más cuántos más lados tiene el polígono que la genera.

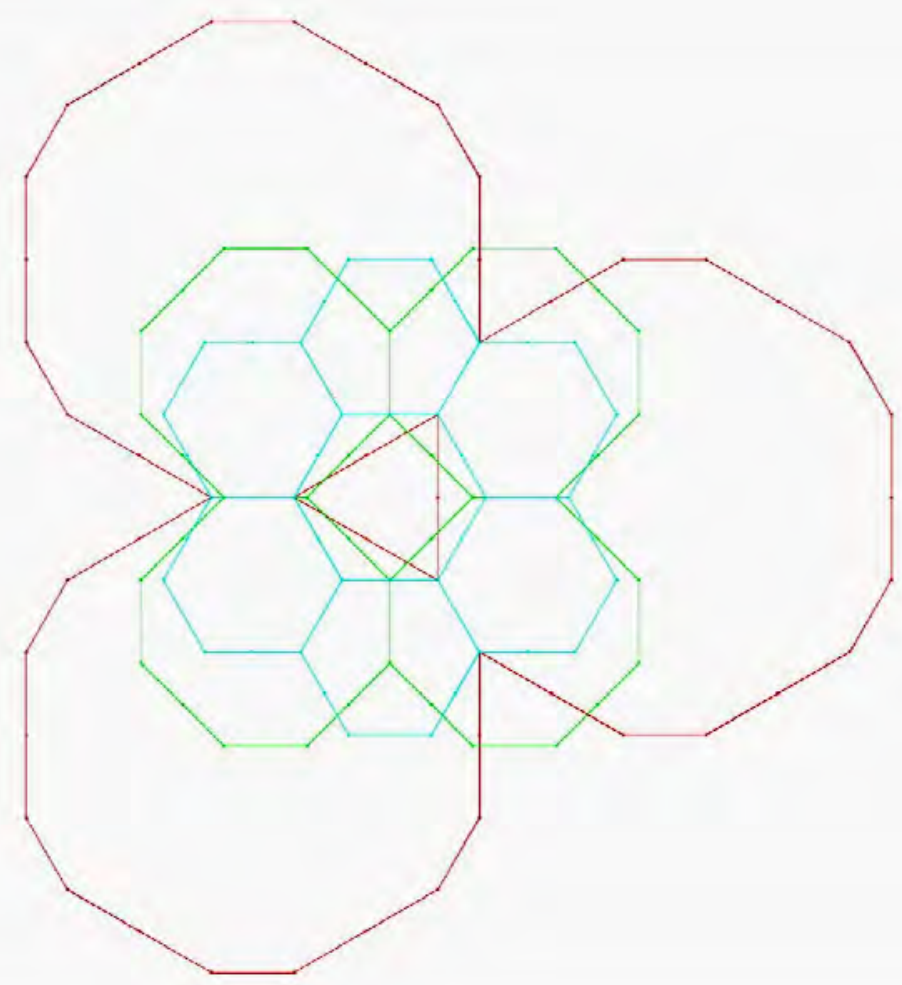

Figura 108 Superposición de estructuras reentrantes estrelladas de tres, cuatro y seis puntas, elaboración propia 
También se han analizado de forma numérica los factores de crecimiento de estas tres estructuras estrelladas 2D analizadas. Los datos numéricos obtenidos en relación al crecimiento de dichas estructuras y su relación masa-volumen han sido los siguientes:

\begin{tabular}{|c|c|c|c|c|c|c|c|}
\hline & $\mathbf{L}$ & $\mathbf{A}_{\text {mín }}$ & $\mathbf{A}_{\text {máx }}$ & $\mathbf{K}_{\text {mín }}$ & $\mathbf{K}_{\text {máx }}$ & $\mathbf{F C}(:)$ & $\mathbf{F C}(-)$ \\
\hline 3 puntas & 32,78 & 2,6 & 21,53 & 0,08 & 0,66 & 8,28 & 0,58 \\
\hline 4 puntas & 74,91 & 9,00 & 80,89 & 0,12 & 1,08 & 8,99 & 0,96 \\
\hline 6 puntas & 114,00 & 21,99 & 233,03 & 0,19 & 2,04 & 10,60 & 1,85 \\
\hline
\end{tabular}

Tabla 5. Relación entre áreas mínimas $\left(A_{\min }\right)$ y máximas $\left(A_{\text {máx }}\right)$ con la longitud total de barras de la estructura, elaboració propia

Se puede apreciar que numéricamente también los factores de crecimiento van aumentando con el número de vértices que atacan al núcleo central de la estrella, obteniendo los mayores factores de crecimiento la estructura auxética conjunto 2D estrellada de 6 puntas, con lo que se corrobora el análisis gráfico.

Del análisis de estas combinaciones de estructuras reentrantes estrelladas 2D también se puede ver que todos sus nudos son articulados en el plano, y confluyen dos o tres barras en los mismos, permitiéndose giros en el eje xy que van de $0^{\circ}$ a $90^{\circ}$ ( 2 barras) o de $0^{\circ}$ a $120^{\circ}(3$ barras, salvo que pertenezca al perímetro exterior del conjunto) para la estrella de 3 puntas, de $0^{\circ}$ a $90^{\circ}$ ( 2 barras) o de $0^{\circ}$ a $135^{\circ}$ ( 3 barras, salvo que pertenezca al perímetro exterior del conjunto) para la estrella de 4 puntas y de $0^{\circ}$ a $90^{\circ}$ ( 2 barras) o de $0^{\circ}$ a $150^{\circ}$ (3 barras, salvo que pertenezca al perímetro exterior del conjunto) para la estrella de 6 puntas. Es decir, se conservan las propiedades del patrón individual para estructuras reentrantes estrelladas.

\subsubsection{Estructura en 3 dimensiones}

En 3 dimensiones sólo se representa la estructura reentrante estrellada de 6 puntas, ya que es la que tiene mejores propiedades de cara a utilizarla como estructura arquitectónica. La estructura se ha generado de la manera explicada en la página 96, teniendo un entramado cruzado de superficies perpendiculares para todas y cada una de las estructuras individuales auxéticas (figura 109). 


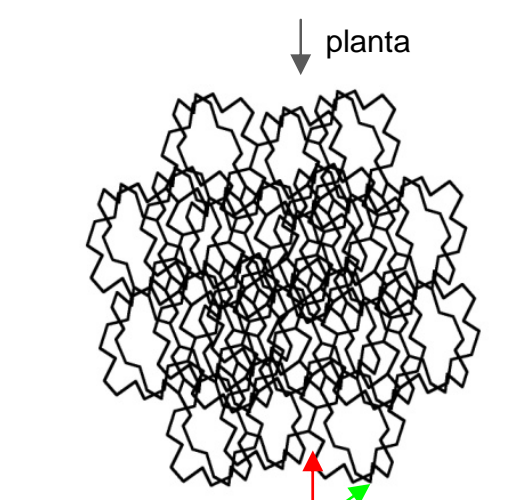

alzado

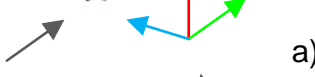

a)

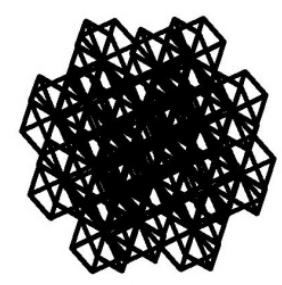

Perfil diagonal $\uparrow$

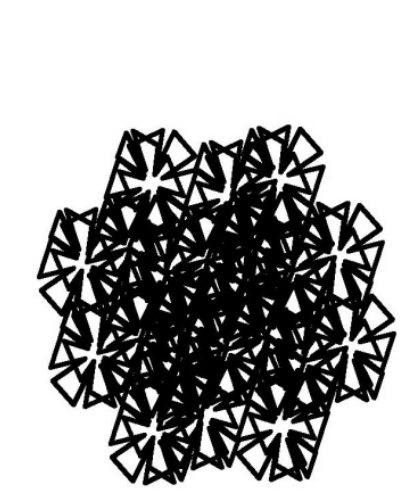

b)

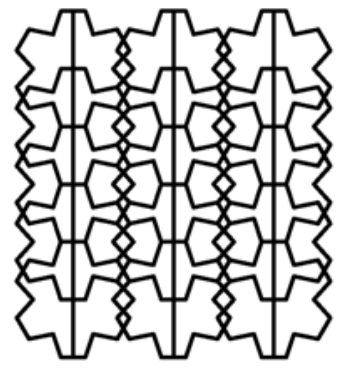

c)

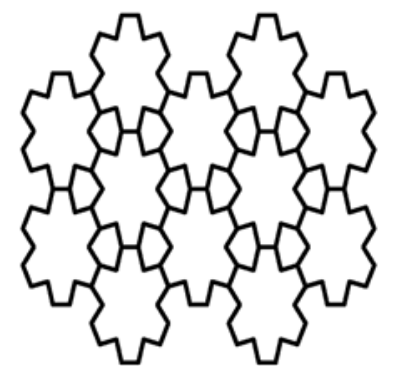

d)

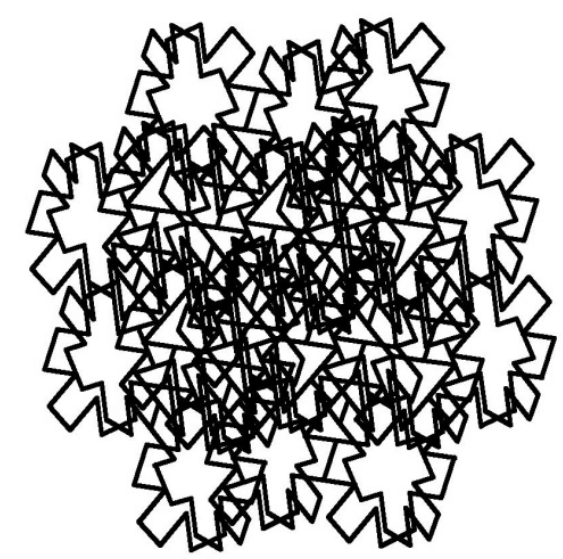

e)
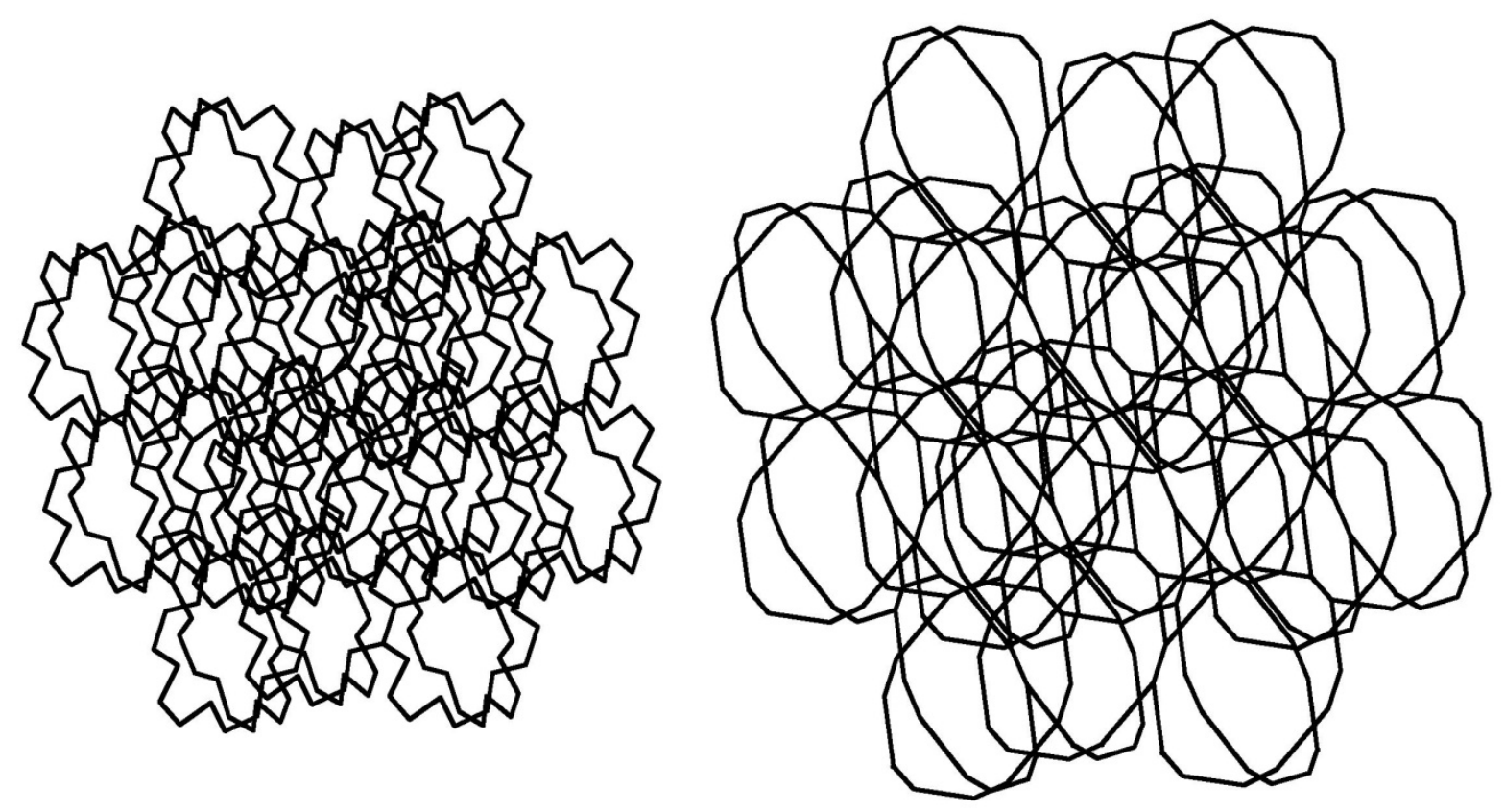

Figura 109 Estructura reentrante estrellada de 6 puntas 3D, elaboración propia: a) vista 3D, b) planta, c) alzado, d) perfil, e) desarrollo desplegable auxético. 
La estructura ha sido modelizada para barras que atacan al centro del polígono iguales a la dimensión del radio de la circunferencia en que se inscribe el polígono correspondiente (que es la máxima longitud que pueden tener estas barras interiores), ya que las barras son coplanarias. Todos sus nudos son articulados en el plano, y confluyen dos o tres barras en los mismos, permitiéndose giros en el eje xy que van de $0^{\circ}$ a $90^{\circ}$ ( 2 barras) o de $0^{\circ}$ a $120^{\circ}$ ( 3 barras, salvo que pertenezca al perímetro exterior del conjunto) para la estrella de 3 puntas, de $0^{\circ}$ a $90^{\circ}$ ( 2 barras) o de $0^{\circ}$ a $135^{\circ}$ ( 3 barras, salvo que pertenezca al perímetro exterior del conjunto) para la estrella de 4 puntas y de $0^{\circ}$ a $90^{\circ}$ ( 2 barras) o de $0^{\circ}$ a $150^{\circ}$ (3 barras, salvo que pertenezca al perímetro exterior del conjunto) para la estrella de 6 puntas. Es decir, se conservan las propiedades del patrón individual y patrón 2D para estructuras reentrantes estrelladas. Sin embargo, las barras horizontales donde se produce el cruce entre planos sufren una discontinuidad, ya que hay que combinarlas con la estructura girada $90^{\circ}$. Si quisiéramos que esta estructura funcionara de forma auxética únicamente, estas barras podrían ir soldadas en forma de cruz.

La estructura reentrante estrellada de 6 puntas en 3 dimensiones por generada por cruce perpendicular de estructuras en 2 dimensiones, tiene una longitud total de sus barras de $718,00 \mathrm{~m}$. El volumen mínimo que genera de forma auxética es de $129,90 \mathrm{~m}^{3}$, y su volumen máximo de $4077,96 \mathrm{~m}^{3}$ (en ambos casos volumen del cubo que genera), por lo que se aprecian unas constantes " $K$ " en función del volumen entre la longitud de líneas que van de 0,18 como mínimo a 5.68 como máximo. Esto nos da un factor de crecimiento FC (:) de 31,39 y un factor de crecimiento FC (-) de 5,50. Estos factores son muy elevados, por lo que se puede apreciar a simple vista que podemos cubrir un gran espacio con muy poca cantidad de material, y que además, esa gran estructura podría ser transportada en muy poco espacio en comparación al resultado final de dimensiones que se tiene. Sería muy interesante estudiar una forma de compactación máxima (aunque para ello entrásemos en plegabilidad sin auxeticidad), de cara a generar estructuras muy útiles para arquitecturas de rápido montaje. 


\subsubsection{Estructura torre (por giro de la estructura 2D)}

Para esta combinación tipo torre sólo se representa la estructura reentrante estrellada de 6 puntas, al igual que para la combinación 3D, ya que es la que tiene mejores propiedades de cara a utilizarla como estructura arquitectónica. La estructura se ha generado de la manera explicada en la página 87, mediante giro de la estructura 2D generada por combinación de patrones individuales (figura 110).
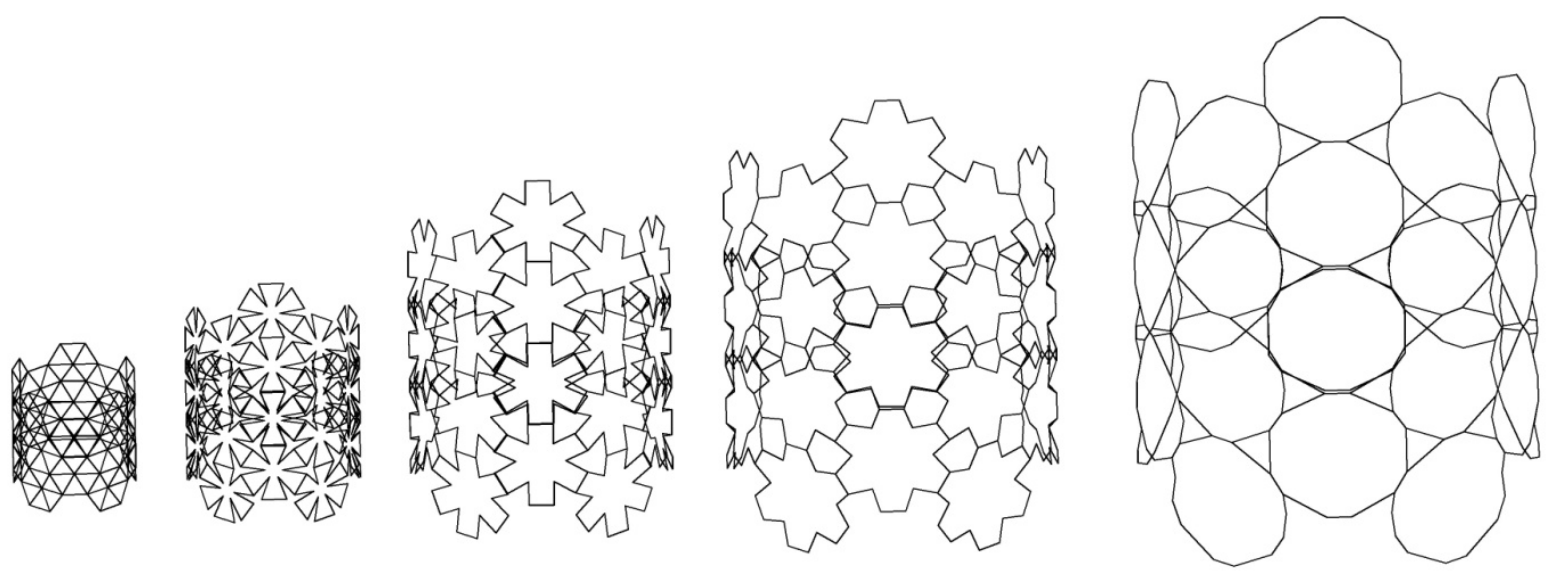

Figura 110 Estructura reentrante estrellada de 6 puntas tipo torre: desarrollo desplegable auxético. Elaboración propia

La estructura ha sido modelizada para para barras que atacan al núcleo central de la dimensión del radio del hexágono que se describe cuando la estructura está cerrada. Esta dimensión máxima no puede verse alterada, pues aunque las barras dejen de ser coplanarias, siguen confluyendo en el centro del polígono cuando la estructura se pliega al máximo. Todos sus nudos son articulados en el espacio, y confluyen dos o tres barras en los mismos, permitiéndose giros en el eje xy que van de $0^{\circ}$ a $90^{\circ}$ ( 2 barras) o de $0^{\circ}$ a $120^{\circ}$ ( 3 barras) para la estrella de 3 puntas, de $0^{\circ}$ a $90^{\circ}$ ( 2 barras) o de $0^{\circ}$ a $135^{\circ}$ ( 3 barras) para la estrella de 4 puntas y de $0^{\circ}$ a $90^{\circ}$ ( 2 barras) o de $0^{\circ}$ a $150^{\circ}$ (3 barras) para la estrella de 6 puntas. Es decir, se conservan las aperturas de los nudos del patrón individual, patrón 2D y patrón 3D para estructuras reentrantes estrelladas, pero pasando a estar en distintos planos.

La estructura reentrante estrellada de 6 puntas tipo torre que se estudia es la de mayor factor de crecimiento para los patrones individual y 2D, teniendo una longitud total de sus barras de $395 \mathrm{~m}$. Su volumen mínimo es de $95,54 \mathrm{~m}^{3}$, y su volumen máximo de $3804,44 \mathrm{~m}^{3}$ (siendo ambos los volúmenes de los cilindros que generan), por lo que se aprecian unas constantes "K" en función del volumen entre la longitud de líneas que van de 0,24 como mínimo a 9,63 como máximo. Esto nos da un factor de crecimiento FC (:) de 39,82 y un 
factor de crecimiento FC (-) de 9,39. Estos factores son muy elevados, por lo que se puede apreciar a simple vista que podemos cubrir un gran espacio con muy poca cantidad de material, y que además, esa gran estructura podría ser transportada en muy poco espacio en comparación al resultado final de dimensiones que se tiene. Sería muy interesante estudiar una forma de compactación máxima (aunque para ello entrásemos en plegabilidad sin auxeticidad), de cara a generar estructuras muy útiles para arquitecturas de rápido montaje.

\subsubsection{Estructura reentrante triangular}

Se analiza su comportamiento en función de los parámetros geométricos, variando las longitudes de las barras para el patrón individual y el patrón conjunto 2D, ya que dependiendo de la longitud de las barras se consiguen unas propiedades diferentes.

\subsubsection{Patrón unidad}

Para la estructura reentrante triangular individual, se han considerado las barras exteriores de longitud igual a la unidad, y se han ido variando las longitudes del resto de barras, de tal forma que se aprecian diversos comportamientos (tabla 6).

Se han analizado de forma numérica los factores de crecimiento de siete estructuras reentrantes triangulares individuales, variando la longitud de sus barras internas. Los datos numéricos obtenidos en relación al crecimiento de dichas estructuras y su relación masavolumen han sido los siguientes:

\begin{tabular}{|c|c|c|c|c|c|c|c|}
\cline { 2 - 8 } \multicolumn{1}{c|}{} & $\mathbf{L}$ & $\mathbf{A}_{\text {mín }}$ & $\mathbf{A}_{\text {máx }}$ & $\mathbf{K}_{\text {mín }}$ & $\mathbf{K}_{\text {máx }}$ & FC (:) & FC (-) \\
\hline a) & 4,00 & 0,00 & 0,00 & 0,00 & 0,00 & $\#_{i D I V / 0 !}$ & 0,00 \\
\hline b) & 3,85 & 0,00 & 0,35 & 0,00 & 0,09 & $\#_{i D I V / 0 !}$ & 0,09 \\
\hline c) & 3,72 & 0,00 & 0,45 & 0,00 & 0,12 & $\#_{i D I V / 0 !}$ & 0,12 \\
\hline d) & 3,58 & 0,00 & 0,48 & 0,00 & 0,13 & $\#_{i D I V / 0 !}$ & 0,13 \\
\hline e) & 3,41 & 0,00 & 0,50 & 0,00 & 0,15 & $\#_{i D I V / 0 !}$ & 0,15 \\
\hline f) & 3,00 & 0,00 & 0,43 & 0,00 & 0,14 & $\#_{i D I V / 0 !}$ & 0,14 \\
\hline g) & 2,50 & 0,00 & 0,24 & 0,00 & 0,10 & $\#$ iDIV/0! & 0,10 \\
\hline
\end{tabular}

Tabla 6. Relación entre áreas mínimas $\left(A_{\min }\right)$ y máximas $\left(A_{m a ́ x}\right)$ con la longitud total de barras de la estructura, elaboración propia

La estructura reentrante triangular individual es capaz de plegarse totalmente, siendo su superficie mínima nula (genera una línea) para todos los casos, y su superficie máxima 
(área del triángulo que genera) mayor para estructuras con barras interiores de aproximadamente la séptima parte de la longitud de las exteriores, generando los factores de crecimiento mayores, lógicamente, también para este caso, disminuyendo de forma gradual según nos acercamos a las barras iguales a la unidad o a barras teóricas nulas.

a)
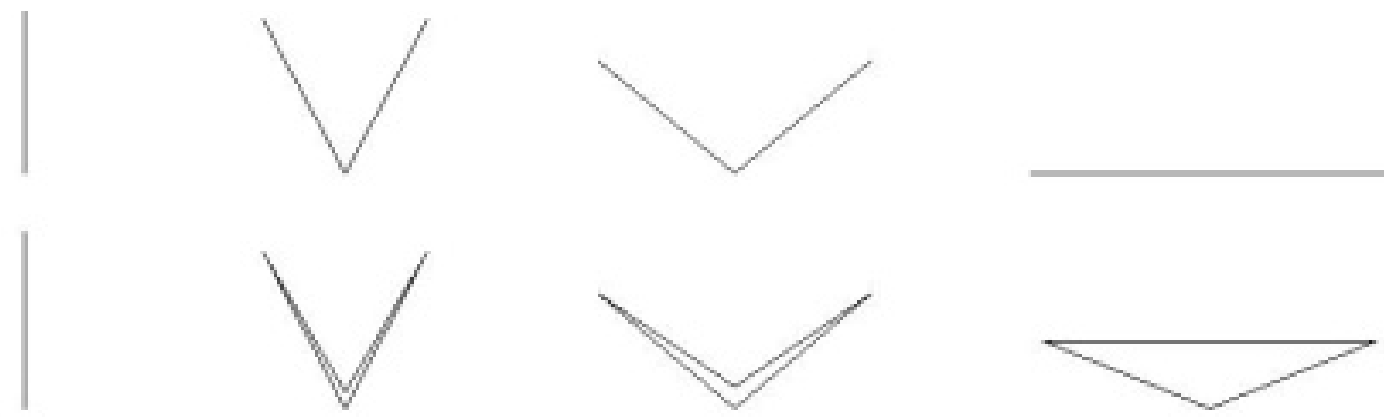

c)
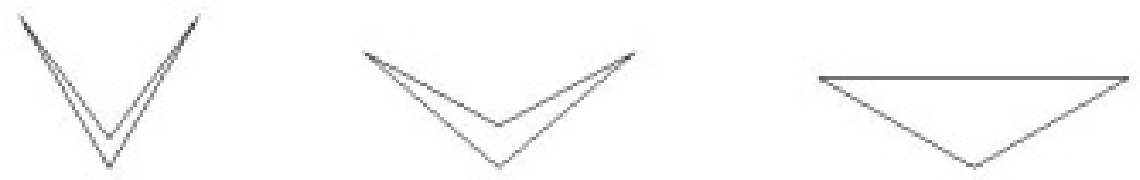

d)
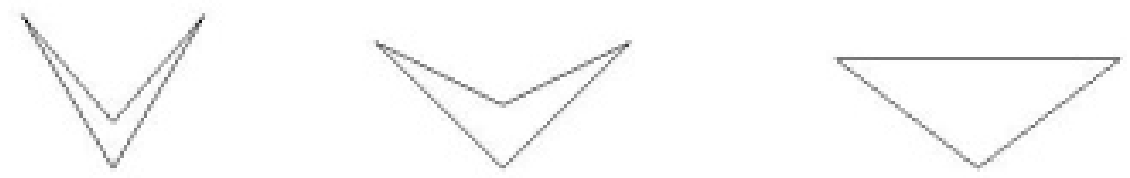

e)
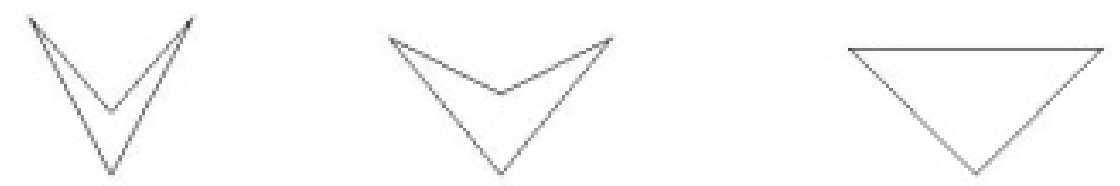

f)
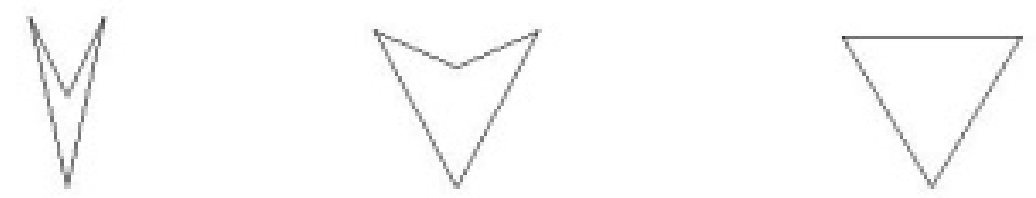

g)
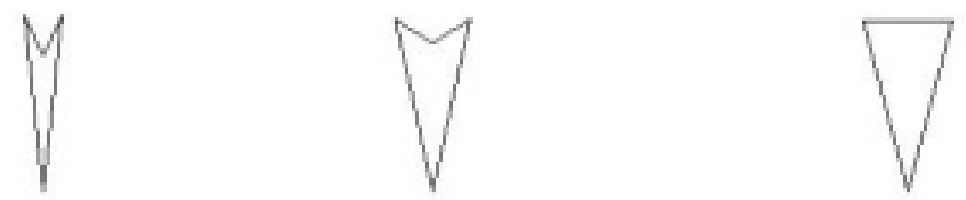

Figura 111 Comportamientos geométricos de estructuras reentrantes triangulares unitarias en función de la longitud de sus barras, elaboración propia 
Gráficamente se puede apreciar que ningún patrón individual es auxético: al desplegarse la línea mínima que genera esta estructura cuando es unitaria aumenta su volumen lateral, pero disminuye su altura ${ }^{15}$, de lo que se puede deducir que la estructura reentrante triangular consigue este comportamiento auxético al agruparse.

Del análisis de esta figura también se puede ver que todos sus nudos son articulados en el plano, y confluyen dos barras en los mismos, permitiéndose giros en el eje xy que van de $0^{\circ}$ a $180^{\circ}$ para un comportamiento teórico en el que todas las barras tienen la misma longitud. Para el comportamiento real los ángulos máximos a formar entre barras serán variables, teniendo en cuenta que la suma total de los ángulos de un triángulo es $180^{\circ}$, y que las bases plegables siempre se abrirán de $0^{\circ}$ a $180^{\circ}$.

\subsubsection{Estructura en 2 dimensiones}

Para la estructura reentrante triangular 2D, se han establecido los mismos supuestos que para la estructura reentrante triangular individual, considerando las barras exteriores de longitud igual a la unidad, y variando las longitudes del resto de barras, de tal forma que se aprecian diversos comportamientos (tabla 7).

Se han analizado de forma numérica los factores de crecimiento de siete estructuras reentrantes triangulares 2D, variando la longitud de sus barras internas. Los datos numéricos obtenidos en relación al crecimiento de dichas estructuras y su relación masavolumen se presentan en la tabla 7.

\begin{tabular}{|c|c|c|c|c|c|c|c|}
\hline & $\mathbf{L}$ & $A_{\text {mín }}$ & $A_{\text {máx }}$ & $\mathrm{K}_{\text {mín }}$ & $\mathrm{K}_{\text {máx }}$ & FC (:) & FC (-) \\
\hline a) & 8,00 & 0,00 & 0,00 & 0,00 & 0,00 & $\#_{i} \mathrm{DIV} / 0 !$ & 0,00 \\
\hline b) & 32,65 & 0,00 & 5,63 & 0,00 & 0,17 & $\#_{i \mathrm{DIV} / 0 !}$ & 0,17 \\
\hline c) & 31,48 & 0,00 & 7,02 & 0,00 & 0,22 & $\#_{i} \mathrm{DIV} / 0 !$ & 0,22 \\
\hline d) & 30,22 & 0,00 & 7,75 & 0,00 & 0,26 & $\#_{i \mathrm{DIV} / 0 !}$ & 0,26 \\
\hline e) & 28,65 & 0,00 & 8,00 & 0,00 & 0,28 & $\#_{i \mathrm{DIV} / 0 !}$ & 0,28 \\
\hline f) & 25,00 & 0,00 & 6,93 & 0,00 & 0,28 & $\#_{i \mathrm{DIV} / 0 !}$ & 0,28 \\
\hline g) & 20,50 & 0,00 & 3,87 & 0,00 & 0,19 & $\#_{i} D I V / 0 !$ & 0,19 \\
\hline
\end{tabular}

Tabla 7. Relación entre áreas mínimas $\left(A_{\min }\right)$ y máximas $\left(A_{m a ́ x}\right)$ con la longitud total de barras de la estructura, elaboración propia

\footnotetext{
${ }^{15}$ Ver introducción: ¿Qué es un material auxético?
} 
a)

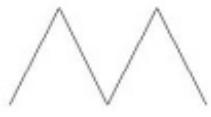

b)

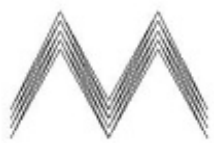

c)

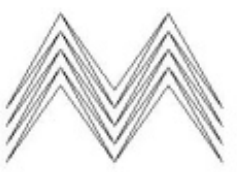

d)

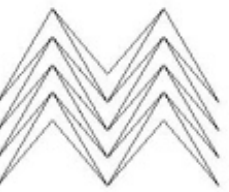

e)

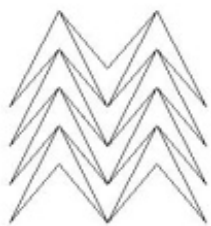

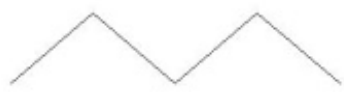
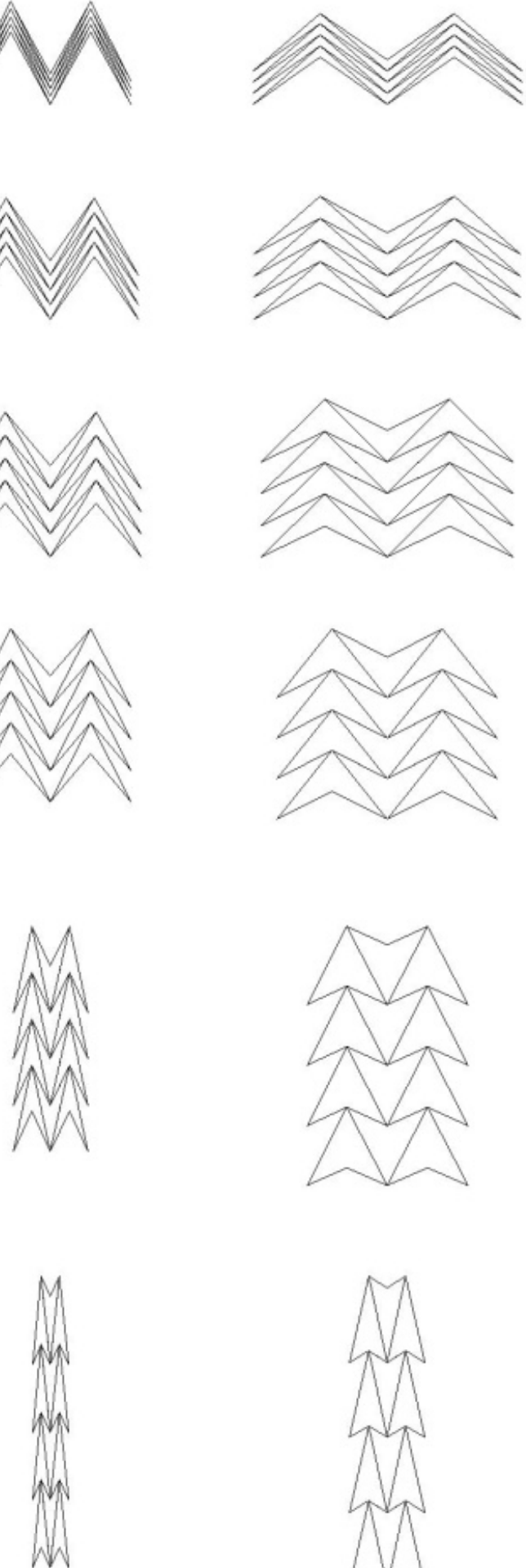
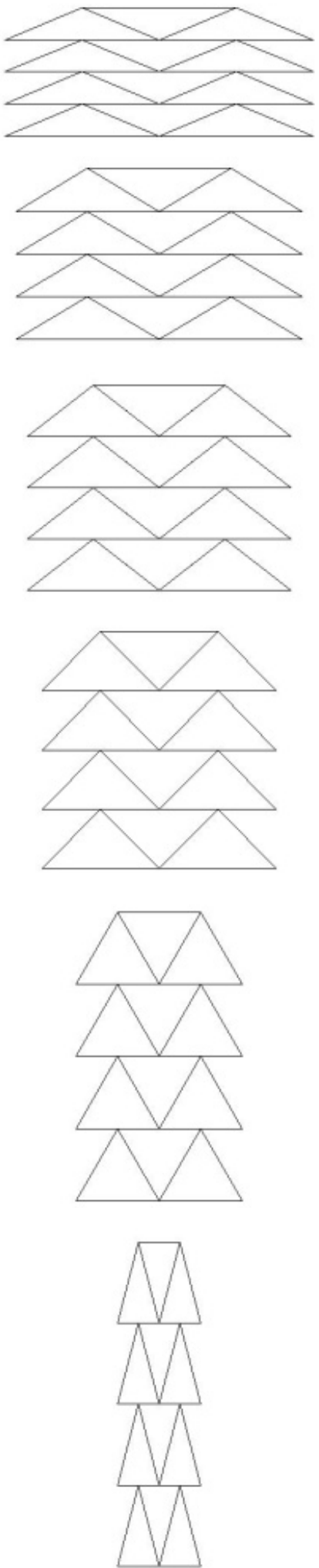

Figura 112 Comportamientos geométricos de estructuras reentrantes triangulares unitarias en función de la longitud de sus barras, elaboración propia 
Se percibe a simple vista que la estructura varía desde una línea (comportamiento teórico, porque habría que tener en cuenta que la materia ocupa un lugar y que realmente no se podría plegar hasta la totalidad) hasta una estructura 2D. El grado de auxeticidad depende tanto de la longitud de las barras consideradas, como del número de unidades que se repiten: cuando las barras interiores comienzan a tener una longitud cercana a las barras exteriores dejamos de tener comportamiento auxético, y a mayor número de repeticiones mayor coeficiente auxético.

La superficie máxima (área del cuadrado que genera la estructura reentrante triangular 2D) mayor se encuentra para estructuras con patrones individuales con barras interiores de aproximadamente la séptima parte de la longitud de las exteriores, generando los factores de crecimiento mayores, lógicamente, también para este caso, disminuyendo de forma gradual según nos acercamos a las barras iguales a la unidad o a barras teóricas nulas.

Gráficamente se puede apreciar que las estructuras a, b y c no son auxéticas: al desplegarse la línea mínima que genera estas estructuras aumenta su volumen lateral, pero disminuye su altura ${ }^{16}$, de lo que se puede deducir que con barras interiores demasiado grandes obtenemos estructuras desplegables, pero que no cumplen con el comportamiento auxético.

Del análisis de esta figura también se puede ver que todos sus nudos son articulados en el plano, y confluyen cuatro barras en los mismos (salvo las excepciones del perímetro exterior, donde únicamente confluyen dos), permitiéndose giros en el eje xy que van de $0^{\circ} \mathrm{a}$ $180^{\circ}$ para un comportamiento teórico en el que todas las barras tienen la misma longitud y la estructura no es auxética. Para el comportamiento real y auxético los ángulos máximos a formar entre barras serán variables, teniendo en cuenta que la suma total de los ángulos de un triángulo es $180^{\circ}$, y que las bases plegables siempre se abrirán de $0^{\circ}$ a $180^{\circ}$.

\footnotetext{
${ }^{16}$ Ver introducción: ¿Qué es un material auxético?
} 


\subsubsection{Estructura en 3 dimensiones}

De acuerdo a las mismas leyes funciona la estructura reentrante triangular 3D, más comúnmente conocida como "Pirámide US Patent".

La estructura reentrante triangular 3D estudiada se ha modelizado como conjunto de estructuras unitarias de barras exteriores de $1 \mathrm{~m}$ e interiores de $0,5 \mathrm{~m}$, teniendo una longitud total de sus barras de 290,00m. Es capaz de plegarse totalmente, siendo su volumen mínimo nulo (genera una superficie), y su volumen máximo de $23,40 \mathrm{~m}^{3}$ (volumen del cubo que genera), por lo que se aprecian unas constantes "K" en función de la superficie entre la longitud de líneas que van de 0,00 como mínimo a 0,08 como máximo. Esto nos da un factor de crecimiento FC (-) de 0,08.

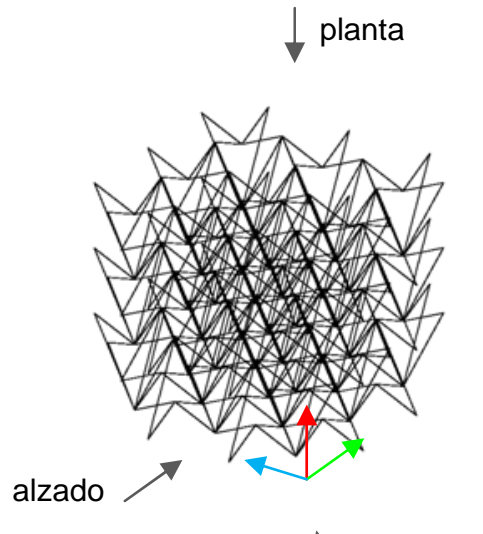

Perfil diagonal a)

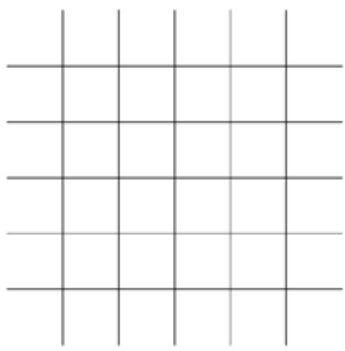

b)

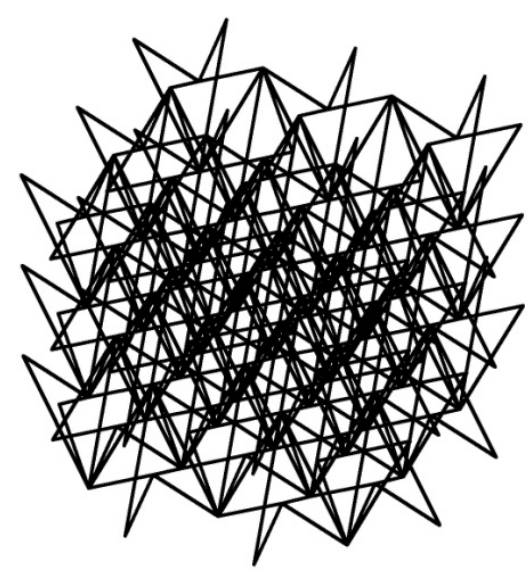

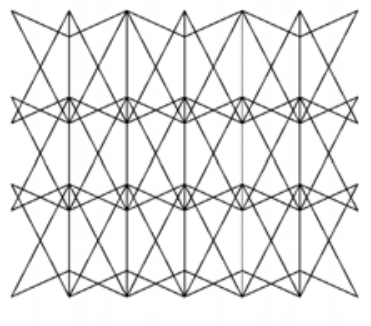

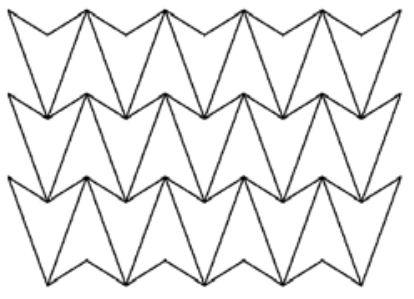

c)

d)

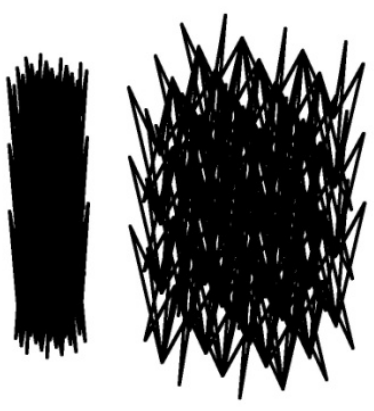

e)

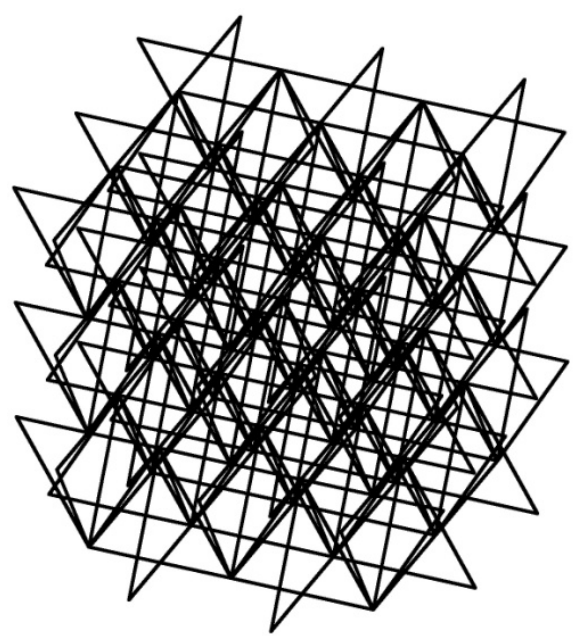

Figura 113 Estructura reentrante triangular 3D, elaboración propia: a) vista 3D, b) planta, c) alzado, d) vista oblicua, e) desarrollo desplegable auxético. 
Del análisis de esta figura se puede ver que todos sus nudos son articulados en los planos verticales, y confluyen cuatro barras en los mismos (salvo las excepciones del perímetro exterior, donde únicamente confluyen dos), permitiéndose giros en los ejes xz e yz que van de $0^{\circ}$ a $60^{\circ}$, ya que se generan triángulos equiláteros, teniendo en cuenta que la suma total de los ángulos de un triángulo es $180^{\circ}$, y que las bases plegables siempre se abrirán de $0^{\circ} \mathrm{a}$ $180^{\circ}$. Sin embargo, las barras horizontales para este supuesto de estructura sufren una discontinuidad, ya que hay que combinarlas con la estructura girada $90^{\circ}$. Si quisiéramos que esta estructura funcionara de forma auxética únicamente, estas barras podrían ir soldadas en forma de cruz.

\subsubsection{Estructura torre (por giro de la estructura 2D)}

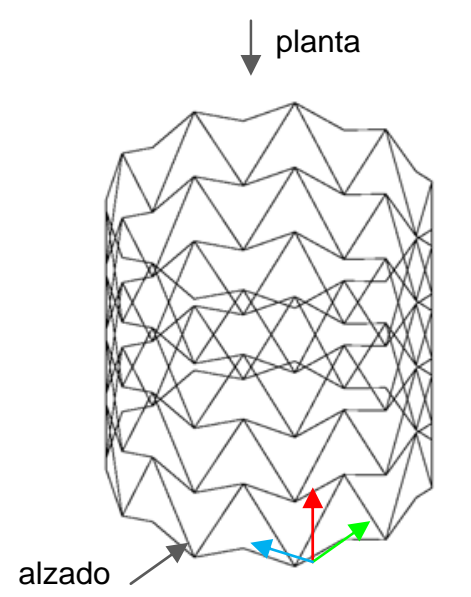

a)

Perfil diagonal

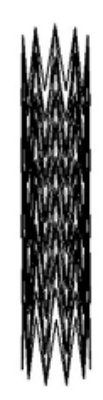

e)

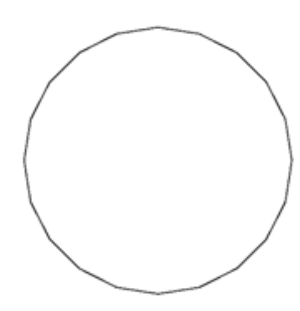

b)

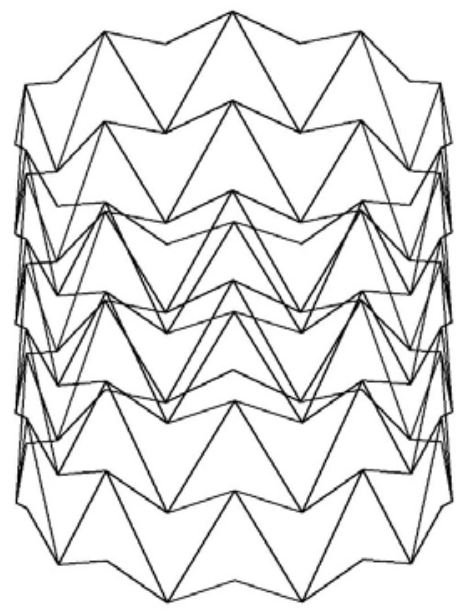

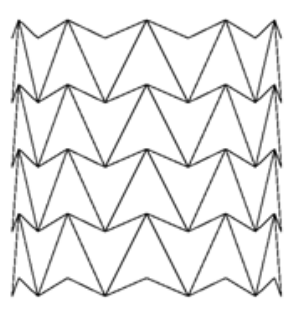

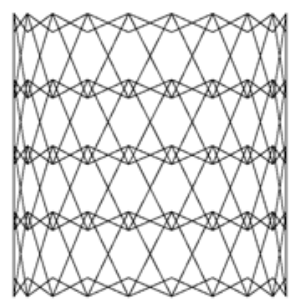

c)

d)

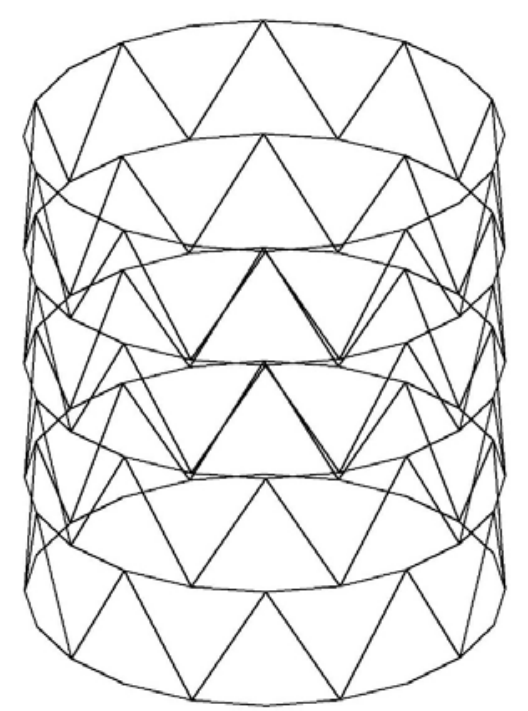

Figura 114 Estructura reentrante triangular torre, elaboración propia: a) vista 3D, b) planta, c) alzado, d) vista oblicua, e) desarrollo desplegable auxético. 
La estructura reentrante triangular 3D estudiada se ha modelizado como conjunto de estructuras unitarias de barras exteriores de $1 \mathrm{~m}$ e interiores de $0,5 \mathrm{~m}$, teniendo una longitud total de sus barras de $130,00 \mathrm{~m}$. Es capaz de plegarse totalmente, siendo su volumen mínimo nulo (genera una superficie), y su volumen máximo de $27,79 \mathrm{~m}^{3}$ (volumen del cilindro que genera), por lo que se aprecian unas constantes "K" en función de la superficie entre la longitud de líneas que van de 0,00 como mínimo a 0,21 como máximo. Esto nos da un factor de crecimiento FC (-) de 0,21.

Las barras de la estructura tipo torre producida por giro de estructura conjunto en 2 dimensiones no son coplanarias, atacando 4 barras a cada articulación. Se producen giros que van de $0^{\circ}$ a $60^{\circ}$, ya que se generan triángulos equiláteros, teniendo en cuenta que la suma total de los ángulos de un triángulo es $180^{\circ}$, y que las bases plegables siempre se abrirán de $0^{\circ}$ a $180^{\circ}$.

\subsubsection{Estructura reentrante cuadrangular}

Esta estructura se genera mediante subdivisión en dos partes iguales de los lados de un cuadrado. Una vez divididos, el cuadrado es la máxima apertura, y llevando las articulaciones generadas mediante la subdivisión al centro del polígono obtenemos el comportamiento auxético, generando una cruz como máximo plegado.

\subsubsection{Patrón unidad}

La estructura reentrante cuadrangular individual estudiada tiene una longitud total de sus barras de $8,00 \mathrm{~m}$. Aunque al plegarse las barras se junten entre ellas, genera una superficie cuadrangular mínima de $2 \mathrm{~m}^{2}$ y no una línea. Su superficie máxima es de $0,43 \mathrm{~m}^{2}$ (área del cuadrado que genera), por lo que se aprecian unas constantes "K" en función de la superficie entre la longitud de líneas que van de 0,25 como mínimo a 0,50 como máximo. Esto nos da un factor de crecimiento FC (:) de 2,00 y un factor de crecimiento FC (-) de 0,25.

Del análisis de esta figura también se puede ver que todos sus nudos son articulados en el plano, y confluyen dos barras en los mismos, permitiéndose giros en el eje xy que van de $0^{\circ}$ a $45^{\circ}$. 

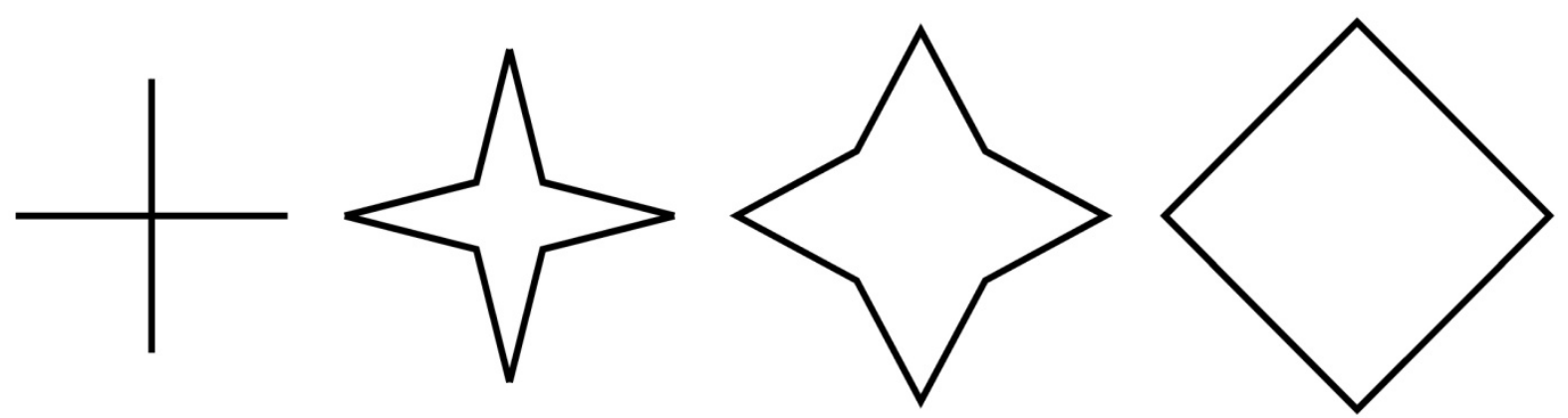

Figura 115 Desarrollo desplegable de estructura reentrante cuadrangular unidad, elaboración propia

\subsubsection{Estructura en 2 dimensiones}

La estructura reentrante cuadrangular 2D estudiada tiene una longitud total de sus barras de $72,00 \mathrm{~m}$. No es capaz de plegarse totalmente, siendo su superficie mínima de $36,00 \mathrm{~m}^{2}$, y su superficie máxima de $72,00 \mathrm{~m}^{2}$ (área del cuadrado que genera), por lo que se aprecian unas constantes "K" en función de la superficie entre la longitud de líneas que van de 0,50 como mínimo a 1,00 como máximo. Esto nos da un factor de crecimiento FC (-) de 0,50 y un factor de crecimiento FC (:) de 2,00.
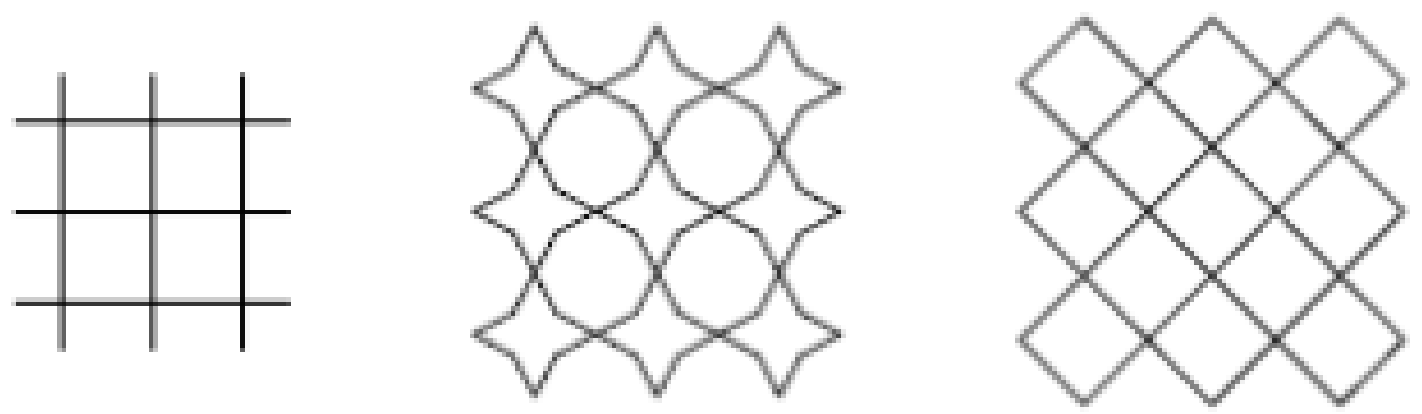

Figura 116 Desarrollo desplegable de estructura reentrante cuadrangular de 2 dimensiones, elaboración propia

Del análisis de esta figura también se puede ver que todos sus nudos son articulados en el plano, y confluyen dos o cuatro barras en los mismos, permitiéndose giros en el eje xy que van de $0^{\circ}$ a $45^{\circ}$.

\subsubsection{Estructura en 3 dimensiones}

La estructura reentrante cuadrangular 3D estudiada tiene una longitud total de sus barras de $432,00 \mathrm{~m}$. No es capaz de plegarse totalmente, siendo su volumen mínimo de $216,00 \mathrm{~m}^{3}$, y su volumen máximo de $509,61 \mathrm{~m}^{3}$ (volumen del cubo que genera), por lo que se aprecian unas 
constantes "K" en función de la superficie entre la longitud de líneas que van de 0,50 como mínimo a 1,18 como máximo. Esto nos da un factor de crecimiento FC (-) de 0,68 y un factor de crecimiento FC (:) de 2,36.

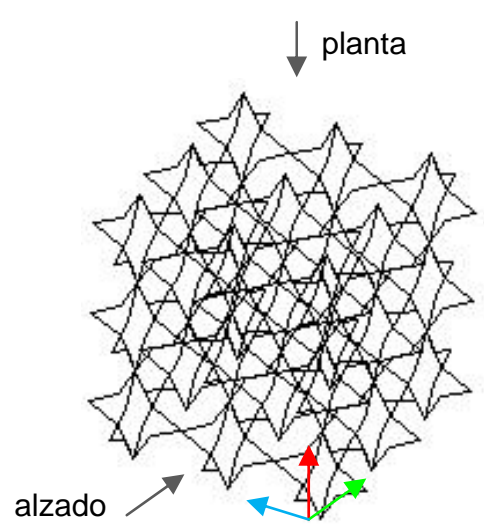

Perfil diagonal

a)

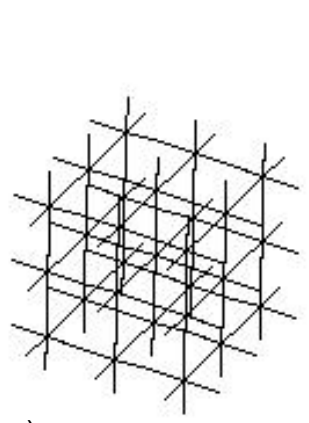

e)

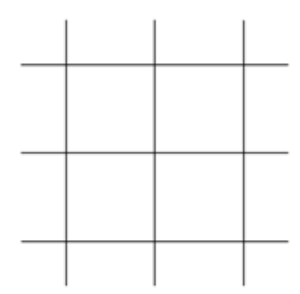

b)

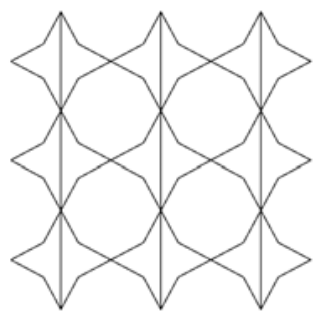

c)

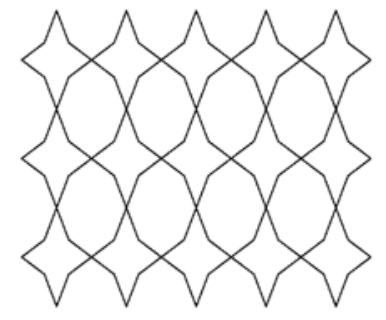

d)
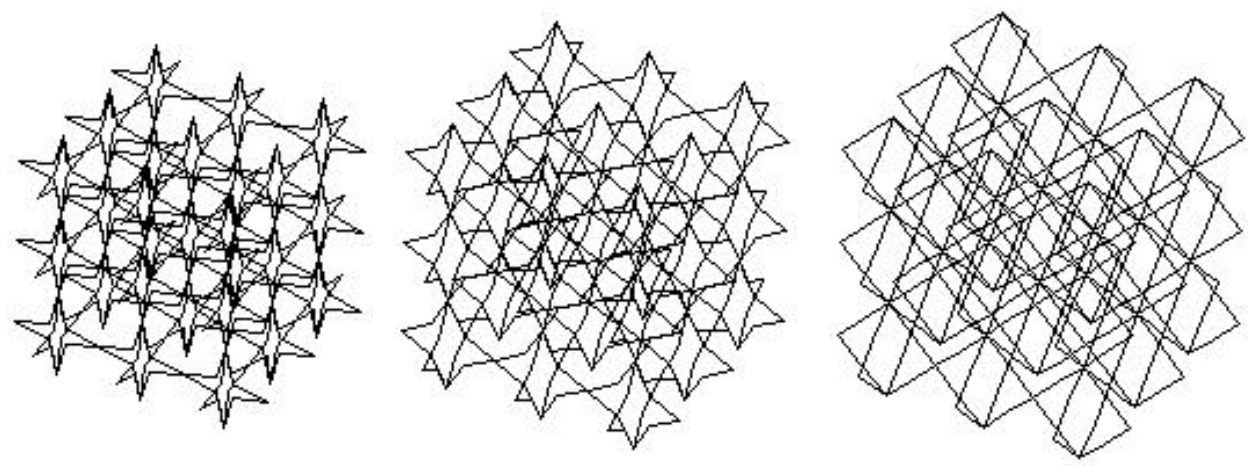

Figura 117 Estructura reentrante cuadrangular 3d, elaboración propia: a) vista 3D, b) planta, c) alzado, d) vista oblicua, e) desarrollo desplegable auxético.

Del análisis de esta figura también se puede ver que algunos nudos son articulados en el plano, confluyendo 4 barras en los mismos (salvo en los casos del perímetro exterior, que confluyen 2); y otros (aquellos donde confluyen dos planos) son articulados en el espacio (confluyendo 8 barras en los mismos salvo en los casos del perímetro exterior, que confluyen 4), permitiéndose giros que van de $0^{\circ}$ a $45^{\circ}$.

\subsubsection{Estructura torre (por giro de la estructura 2D)}

La estructura reentrante cuadrangular torre estudiada tiene una longitud total de sus barras de 240,00m. No es capaz de plegarse totalmente, siendo su volumen mínimo de $197,40 \mathrm{~m}^{3}$, y su volumen máximo de $558,32 \mathrm{~m}^{3}$ (volumen del cilindro que genera), por lo que se aprecian 
unas constantes "K" en función de la superficie entre la longitud de líneas que van de 0,82 como mínimo a 2,33 como máximo. Esto nos da un factor de crecimiento FC (-) de 1,50 y un factor de crecimiento FC (:) de 2,83.

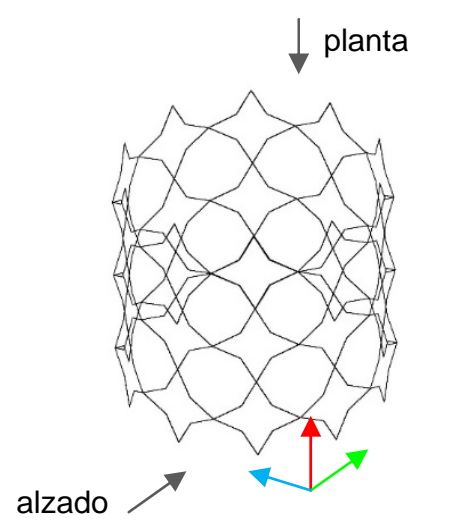

Perfil diagonal $\uparrow$

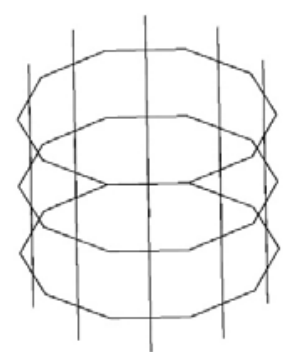

e)

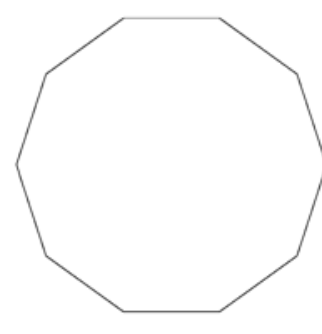

b)

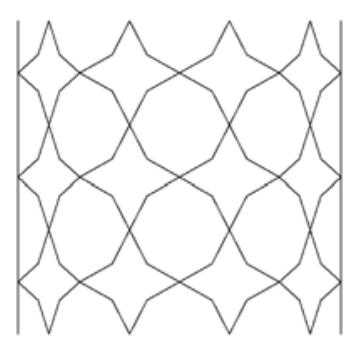

c)

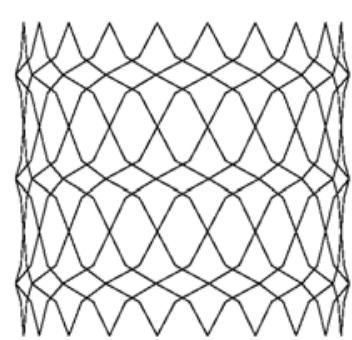

d) a)

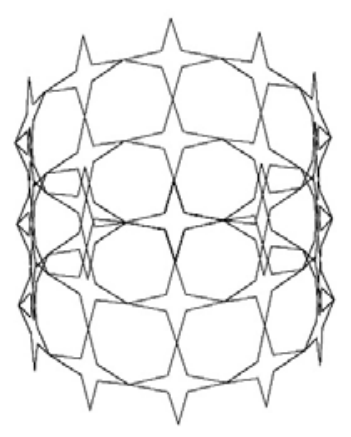

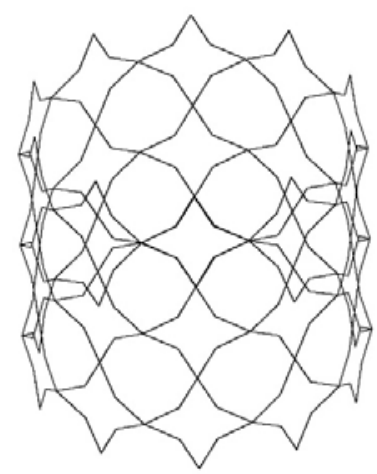

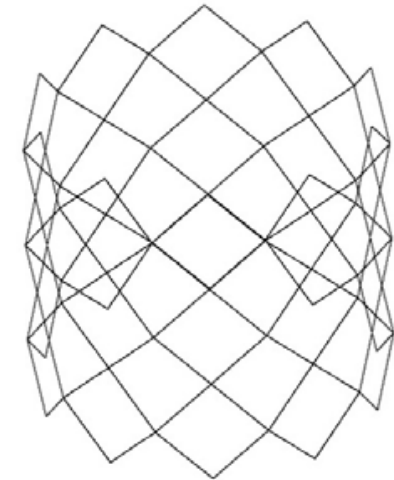

Figura 118 Estructura reentrante cuadrangular torre, elaboración propia: a) vista 3D, b) planta, c) alzado, d) vista oblicua, e) desarrollo desplegable auxético.

Las barras de la estructura tipo torre producida por giro de estructura conjunto en 2 dimensiones no son coplanarias, atacando 4 barras a cada articulación. Se producen giros que van de $0^{\circ}$ a $45^{\circ}$ por barra.

\subsubsection{Panal de abeja}

Esta estructura tiene la particularidad de que tiene barras internas, que son las que hacen que se genere un desarrollo auxético específico en función de dicha forma, pero siempre siguiendo los criterios de estructuras auxéticas reentrantes. 


\subsubsection{Patrón unidad}

La estructura reentrante hexagonal de panal de abeja individual estudiada tiene una longitud total de sus barras de $18,00 \mathrm{~m}$. No es capaz de plegarse totalmente, siendo su superficie mínima de $1,82 \mathrm{~m}^{2}$, y su superficie máxima de $2,60 \mathrm{~m}^{2}$ (área del hexágono que genera), por lo que se aprecian unas constantes "K" en función de la superficie entre la longitud de líneas que van de 0,10 como mínimo a 0,14 como máximo. Esto nos da un factor de crecimiento FC (-) de 0,04 y un factor de crecimiento FC (:) de 1,43.
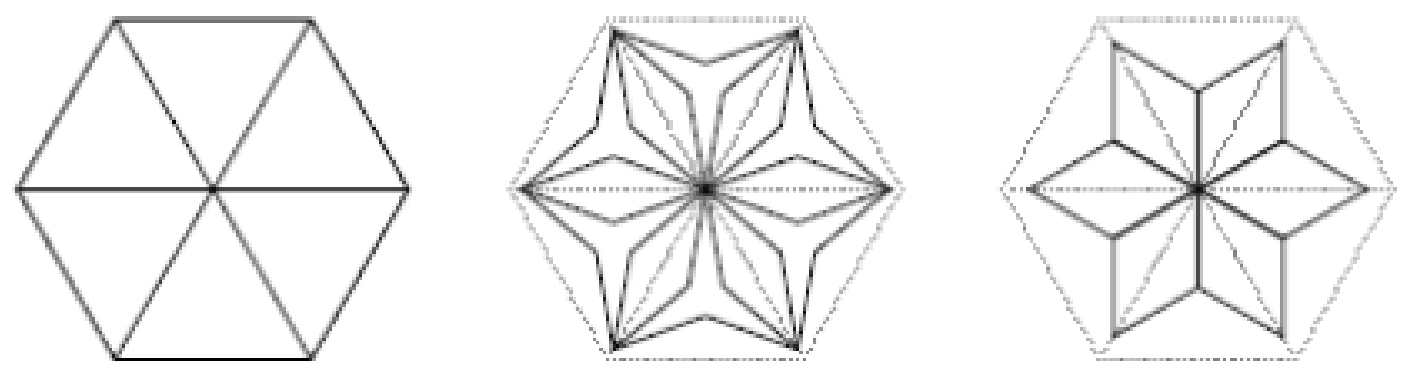

Figura 119 Desarrollo desplegable de estructura reentrante hexagonal de panal de abeja, elaboración propia

Del análisis de esta figura también se puede ver que todos sus nudos son articulados en el plano, y confluyen dos, cuatro o doce barras en los mismos, permitiéndose giros en el eje xy que van de $0^{\circ}$ a $30^{\circ}$.

\subsubsection{Estructura en 2 dimensiones}

La estructura reentrante hexagonal de panal de abeja 2D estudiada tiene una longitud total de sus barras de $126,00 \mathrm{~m}$. No es capaz de plegarse totalmente, siendo su superficie mínima de $16,49 \mathrm{~m}^{2}$, y su superficie máxima de $21,99 \mathrm{~m}^{2}$ (área de la circunferencia que genera), por lo que se aprecian unas constantes "K" en función de la superficie entre la longitud de líneas que van de 0,13 como mínimo a 0,17 como máximo. Esto nos da un factor de crecimiento FC (-) de 0,04 y un factor de crecimiento FC (:) de 1,33.

Del análisis de esta figura también se puede ver que todos sus nudos son articulados en el plano, y confluyen dos, cuatro (sólo en los nudos que se hallan en el perímetro) o doce barras en los mismos, permitiéndose giros en el eje xy que van de $0^{\circ}$ a $30^{\circ}$. 

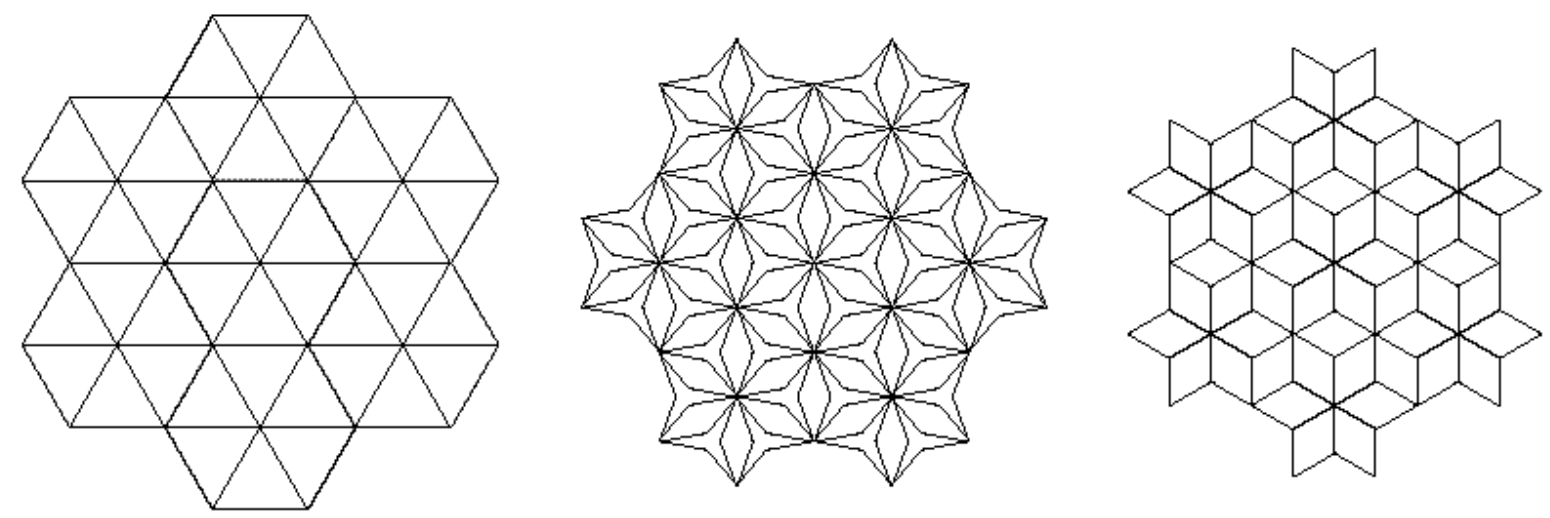

Figura 120 Desarrollo desplegable de estructura reentrante de panal de abeja 2D, elaboración propia

\subsubsection{Estructura en 3 dimensiones}

La estructura reentrante hexagonal de panal de abeja 3D estudiada tiene una longitud total de sus barras de $612,00 \mathrm{~m}$. No es capaz de plegarse totalmente, siendo su volumen mínimo de $43,76 \mathrm{~m}^{3}$, y su volumen máximo de $67,34 \mathrm{~m}^{3}$ (volumen del cubo que genera), por lo que se aprecian unas constantes "K" en función de la superficie entre la longitud de líneas que van de 0,07 como mínimo a 0,11 como máximo. Esto nos da un factor de crecimiento FC (-) de 0,04 y un factor de crecimiento FC (:) de 1,54.
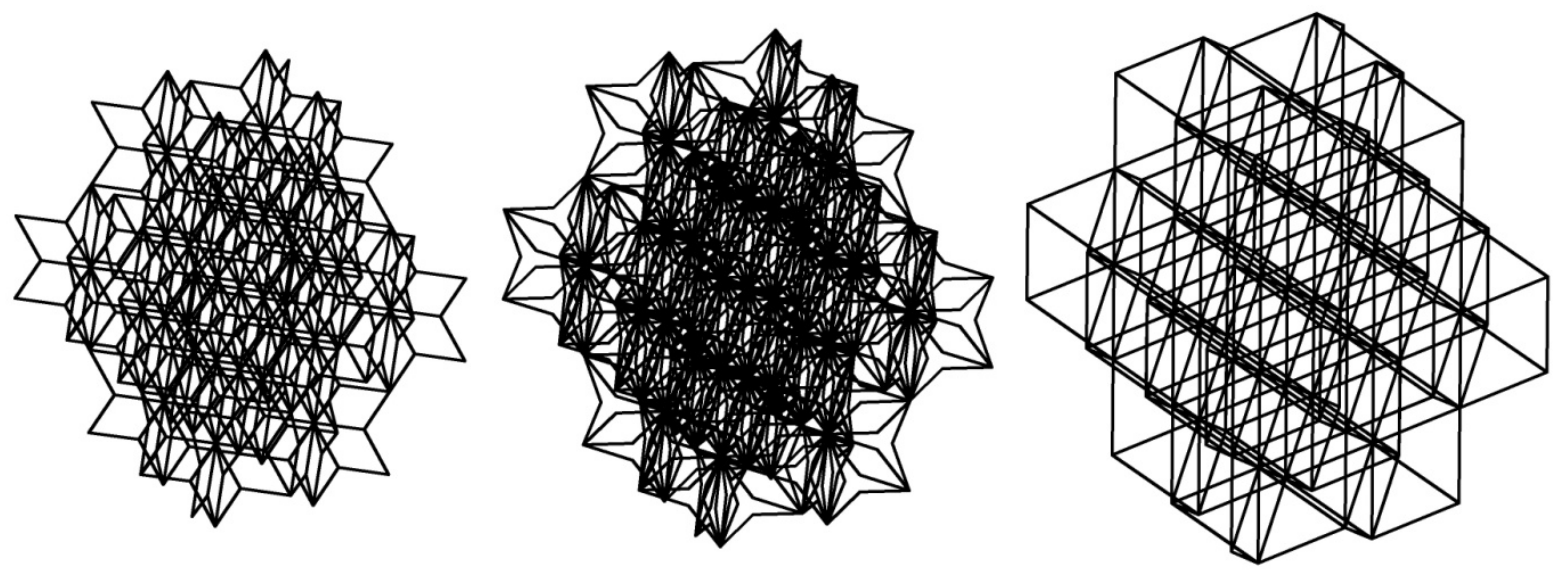

Figura 121 Desarrollo desplegable de estructura reentrante de panal de abeja 3D, elaboración propia

Del análisis de esta figura también se puede ver que algunos de sus nudos son articulados en el plano y otros en el espacio, y confluyen hasta 24 barras por nudo, permitiéndose giros en el eje xy que van de $0^{\circ}$ a $30^{\circ}$. Esta excesiva confluencia de barras dificultaría la construcción real de este patrón como estructura arquitectónica. 


\subsubsection{Estructura torre (por giro de la estructura 2D)}

La estructura reentrante hexagonal de panal de abeja torre estudiada tiene una longitud total de sus barras de $630,00 \mathrm{~m}$. No es capaz de plegarse totalmente, siendo su volumen mínimo de $85,31 \mathrm{~m}^{3}$, y su volumen máximo de $131,26 \mathrm{~m}^{3}$ (volumen del cilindro que genera), por lo que se aprecian unas constantes " $K$ " en función del volumen entre la longitud de líneas que van de 0,14 como mínimo a 0,21 como máximo. Esto nos da un factor de crecimiento FC (-) de 0,07 y un factor de crecimiento FC (:) de 1,54.

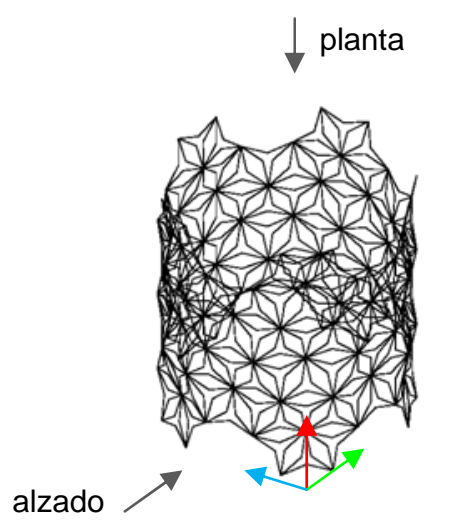

Perfil diagonal

e)

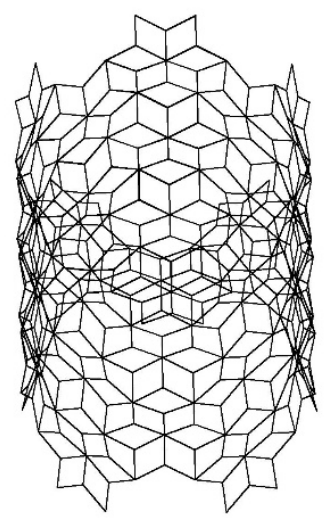

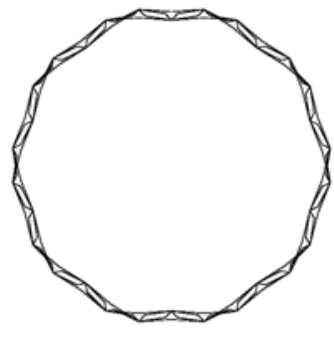

b)

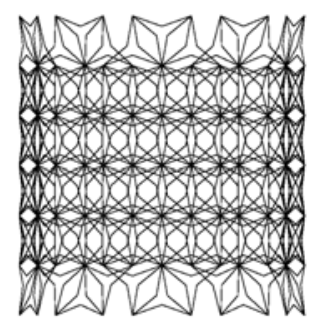

c)

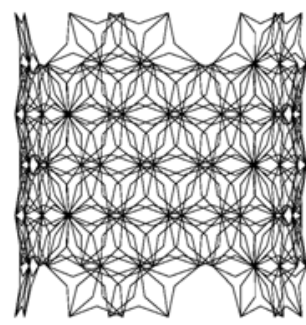

d)
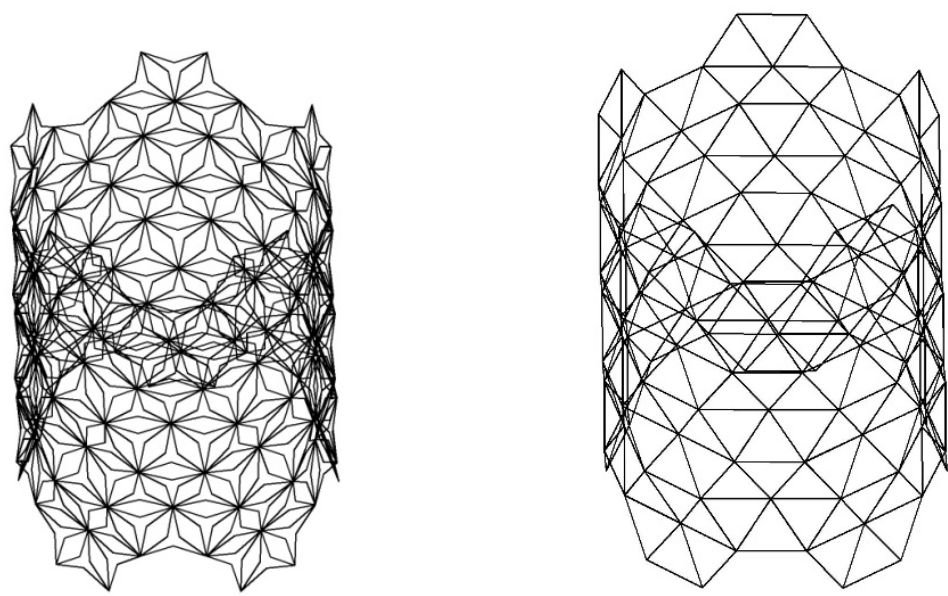

Figura 122 Estructura reentrante de panal de abeja tipo torre, elaboración propia: a) vista 3D, b) planta, c) alzado, d) perfil, e) desarrollo desplegable auxético.

Del análisis de esta figura también se puede ver que todos sus nudos son articulados en el espacio, ya que aunque el dibujo siga siendo el mismo, las barras dejan de ser coplanarias. Confluyen dos, cuatro (sólo en los nudos que se hallan en el perímetro) o doce barras en los nudos, permitiéndose giros que van de $0^{\circ}$ a $30^{\circ}$. 


\subsubsection{Estructura reentrante tetraédrica}

Esta estructura es generada mediante la división en dos partes iguales de cada una de las aristas de la base de un tetraedro, así como por generación de sus medianas ${ }^{17}$ en la base. Mediante plegado de todo lo que se ha generado en la base hacia el interior conseguimos el comportamiento auxético de esta estructura. Hay que puntualizar que esta estructura individual genera un volumen y no una superficie, pero de cara al estudio y sus posteriores combinaciones se cogerá como dato la superficie equivalente que genera en alzado.

\subsubsection{Patrón unidad}

La estructura reentrante tetraédrica individual estudiada tiene una longitud total de sus barras de 23,20m. Es capaz de plegarse totalmente, siendo su superficie mínima nula (genera una línea), y su superficie máxima de $3,67 \mathrm{~m}^{2}$ (área del triángulo que genera en su vista en alzado), por lo que se aprecian unas constantes "K" en función de la superficie entre la longitud de líneas que van de 0,00 como mínimo a 0,14 como máximo. Esto nos da un factor de crecimiento FC (-) de 0,14.
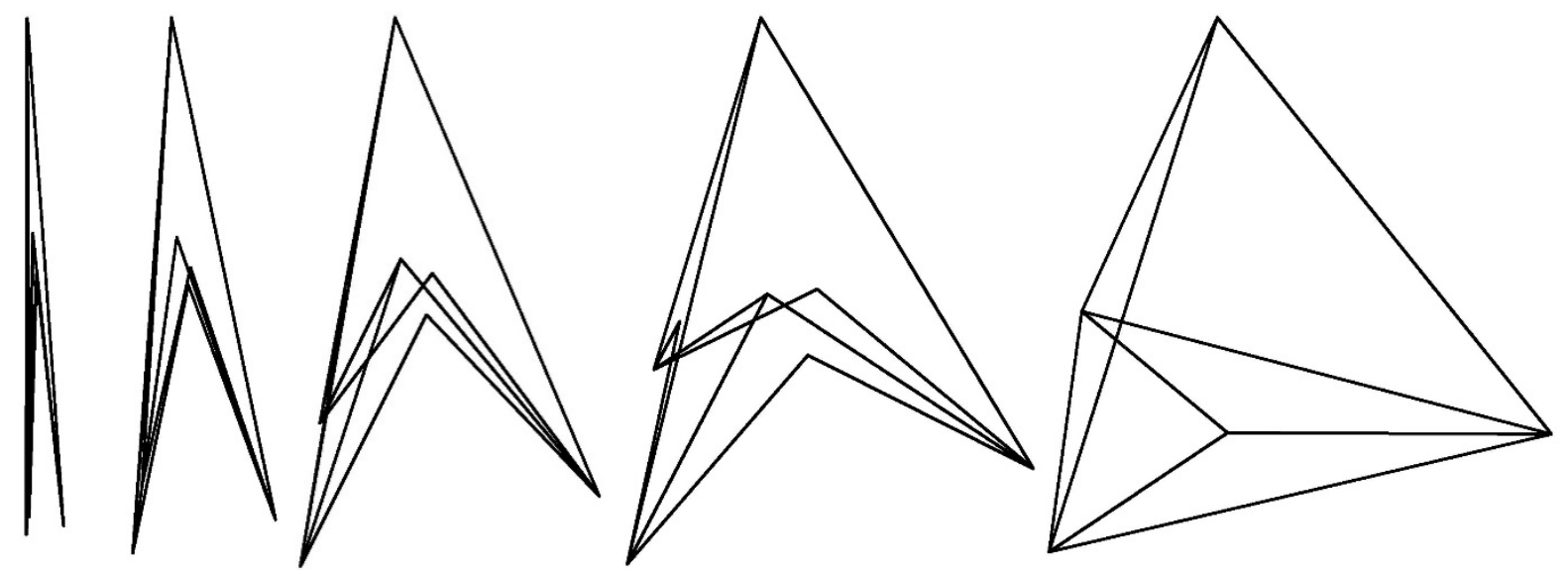

Figura 123 Desarrollo desplegable de estructura reentrante tetraédrica individual, elaboración propia

${ }^{17}$ En geometría las medianas o transversales de gravedad de un triángulo son cada uno de los tres segmentos que unen cada vértice con el punto medio de su lado opuesto. 
Del análisis de esta figura también se puede ver que todos sus nudos son articulados en el espacio. Esto es debido a que la estructura es un poliedro ${ }^{18}$ y no un polígono ${ }^{19}$. Confluyen siempre tres barras en los nudos, permitiéndose giros que van de $0^{\circ}$ a $60^{\circ}$, excepto en los vértices donde además confluyen las medianas de la base triangular, donde se juntan cuatro barras en el nudo, plegándose las que pertenecen a las medianas de $0^{\circ}$ a $90^{\circ}$.

\subsubsection{Estructura en 2 dimensiones}

La estructura reentrante tetraédrica 2D estudiada tiene una longitud total de sus barras de 241,76m. Es capaz de plegarse totalmente, siendo su superficie mínima nula (genera una línea), y su superficie máxima de $66,14 \mathrm{~m}^{2}$ (área del cuadrado que genera en alzado), por lo que se aprecian unas constantes "K" en función de la superficie entre la longitud de líneas que van de 0,00 como mínimo a 0,27 como máximo. Esto nos da un factor de crecimiento FC (-) de 0,27 .

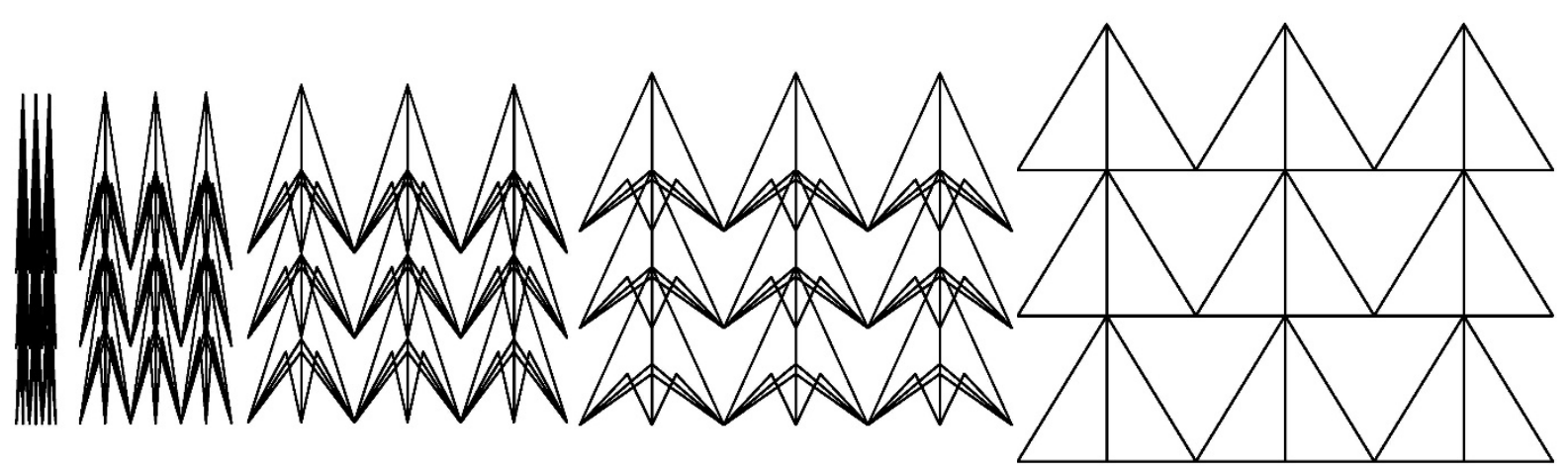

Figura 124 Desarrollo desplegable de estructura reentrante tetraédrica 2d, elaboración propia

Del análisis de esta figura también se puede ver que todos sus nudos son articulados en el espacio. Esto es debido a que la estructura unitaria que se repite es un poliedro ${ }^{2}$ y no un polígono ${ }^{3}$. Confluyen seis barras en los nudos que unen el centro de la base de la pirámide con la punta de la misma, permitiéndose giros que van de $0^{\circ}$ a $60^{\circ}$ (aristas tetraedro) o de $0^{\circ}$ a $90^{\circ}$ (centro base), excepto en los vértices donde además confluyen las medianas de la

\footnotetext{
${ }^{18}$ Un poliedro es, en el sentido dado por la geometría clásica al término, un cuerpo geométrico cuyas caras son planas y encierran un volumen finito.

${ }^{19}$ En geometría, un polígono es una figura geométrica plana compuesta por una secuencia finita de segmentos rectos consecutivos que encierran una región en el plano.
} 
base triangular, donde se juntan ocho barras en el nudo (cuatro de cada tetraedro), plegándose las barras de $0^{\circ}$ a $90^{\circ}$.

\subsubsection{Estructura en 3 dimensiones}

La estructura reentrante tetraédrica 3D estudiada tiene una longitud total de sus barras de $626,30 \mathrm{~m}$. Es capaz de plegarse totalmente, siendo su volumen mínimo nulo (genera una línea), y su volumen máximo de $372,35 \mathrm{~m}^{3}$ (volumen del poliedro que genera), por lo que se aprecian unas constantes " $K$ " en función del volumen entre la longitud de líneas que van de 0,00 como mínimo a 0,59 como máximo. Esto nos da un factor de crecimiento FC (-) de 0,59 . Hay que señalar que esta estructura 3D no se genera como lo explicado en la página 96, ya que al tener volumen por sí mismo el patrón individual, lo único que hay que hacer es ir agrupándolo.

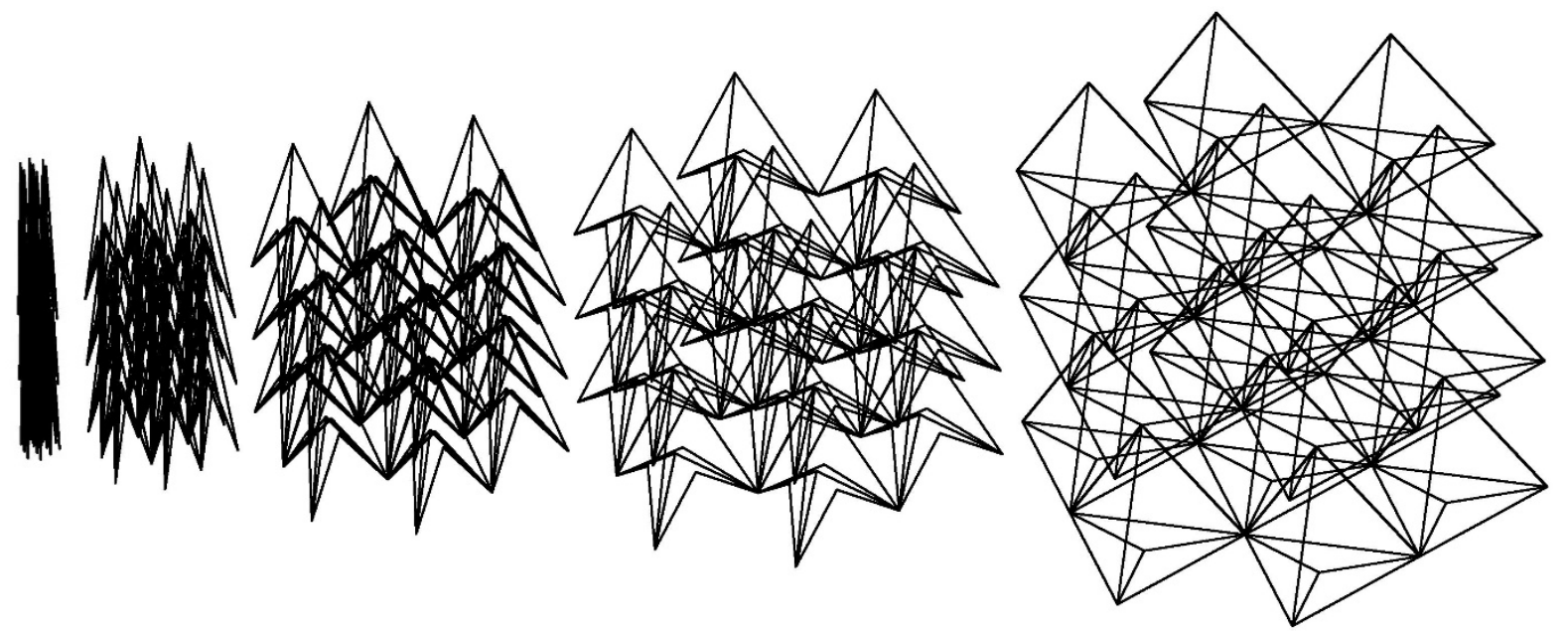

Figura 125 Desarrollo desplegable de estructura reentrante tetraédrica 3d, elaboración propia

Del análisis de esta figura también se puede ver que todos sus nudos son articulados en el espacio. Confluyen seis barras en los nudos que unen el centro de la base de la pirámide con la punta de la misma, permitiéndose giros que van de $0^{\circ}$ a $60^{\circ}$ (aristas tetraedro) o de $0^{\circ}$ a $90^{\circ}$ (centro base), excepto en los vértices donde además confluyen las medianas de la base triangular, donde se juntan doce barras en el nudo (cuatro de cada tetraedro), plegándose las barras de $0^{\circ}$ a $90^{\circ}$. 


\subsubsection{Estructura torre (por giro de la estructura 2D)}

La estructura reentrante tetraédrica torre estudiada tiene una longitud total de sus barras de $1623,73 \mathrm{~m}$. Es capaz de plegarse totalmente, siendo su volumen mínimo nulo (genera una línea), y su volumen máximo de $2803,81 \mathrm{~m}^{3}$ (volumen del cilindro que genera), por lo que se aprecian unas constantes "K" en función del volumen entre la longitud de líneas que van de 0,00 como mínimo a 1,73 como máximo. Esto nos da un factor de crecimiento FC (-) de 1,73 .

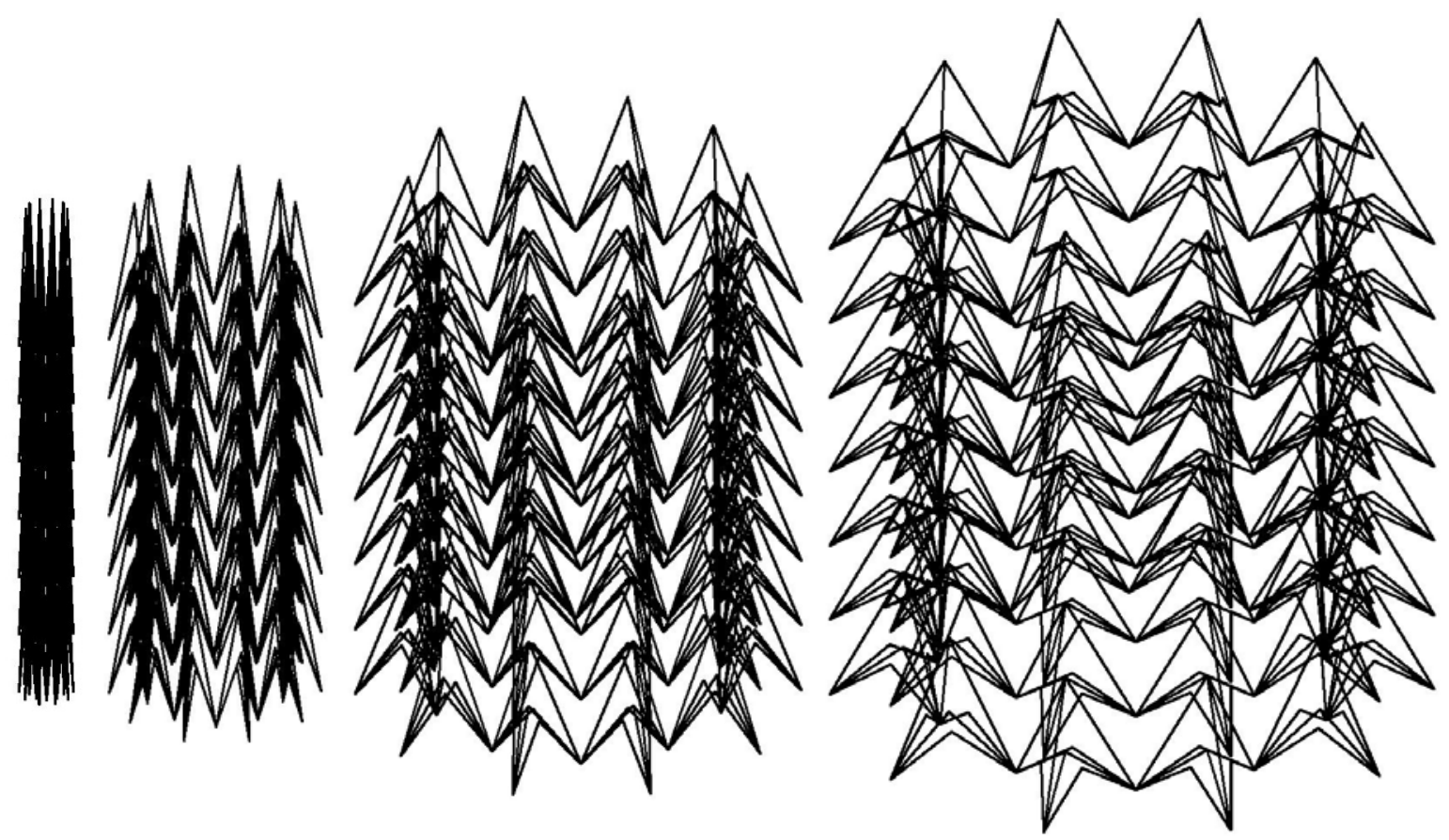

Figura 126 Desarrollo desplegable de estructura reentrante tetraédrica torre, elaboración propia

Del análisis de esta figura también se puede ver que todos sus nudos son articulados en el espacio. Esto es debido a que la estructura unitaria que se repite es un poliedro ${ }^{20}$ y no un polígono $^{21}$. Confluyen seis barras en los nudos que unen el centro de la base de la pirámide con la punta de la misma, permitiéndose giros que van de $0^{\circ}$ a $60^{\circ}$ (aristas tetraedro) o de $0^{\circ}$ a $90^{\circ}$ (centro base), excepto en los vértices donde además confluyen las medianas de la base triangular, donde se juntan ocho barras en el nudo (cuatro de cada tetraedro), plegándose las barras de $0^{\circ}$ a $90^{\circ}$.

\footnotetext{
${ }^{20}$ Ver nota 18 página 124

${ }^{21}$ Ver nota 19 página 124
} 


\subsubsection{Estructura reentrante hexatruss (idealized)}

La estructura reentrante hexatruss, también conocida como estructura reentrante idealized, se genera mediante la división en dos partes iguales de cada una de las aristas de un cubo, así como por generación de sus diagonales en todos los lados que lo componen. Mediante plegado de todo lo que se ha generado hacia el interior conseguimos el comportamiento auxético de esta estructura. Hay que puntualizar que esta estructura individual genera un volumen y no una superficie, pero de cara al estudio y sus posteriores combinaciones se cogerá como dato la superficie equivalente que genera.

\subsubsection{Patrón unidad}

La estructura reentrante idealized individual estudiada tiene una longitud total de sus barras de $57,94 \mathrm{~m}$. No es capaz de plegarse totalmente, siendo su superficie mínima de $1,84 \mathrm{~m}^{2}$, y su superficie máxima de $4,00 \mathrm{~m}^{2}$ (área del cuadrado que genera), por lo que se aprecian unas constantes "K" en función de la superficie entre la longitud de líneas que van de 0,00 como mínimo a 0,14 como máximo. Esto nos da un factor de crecimiento FC (-) de 0,13 y un factor de crecimiento FC (:) de 38,10.
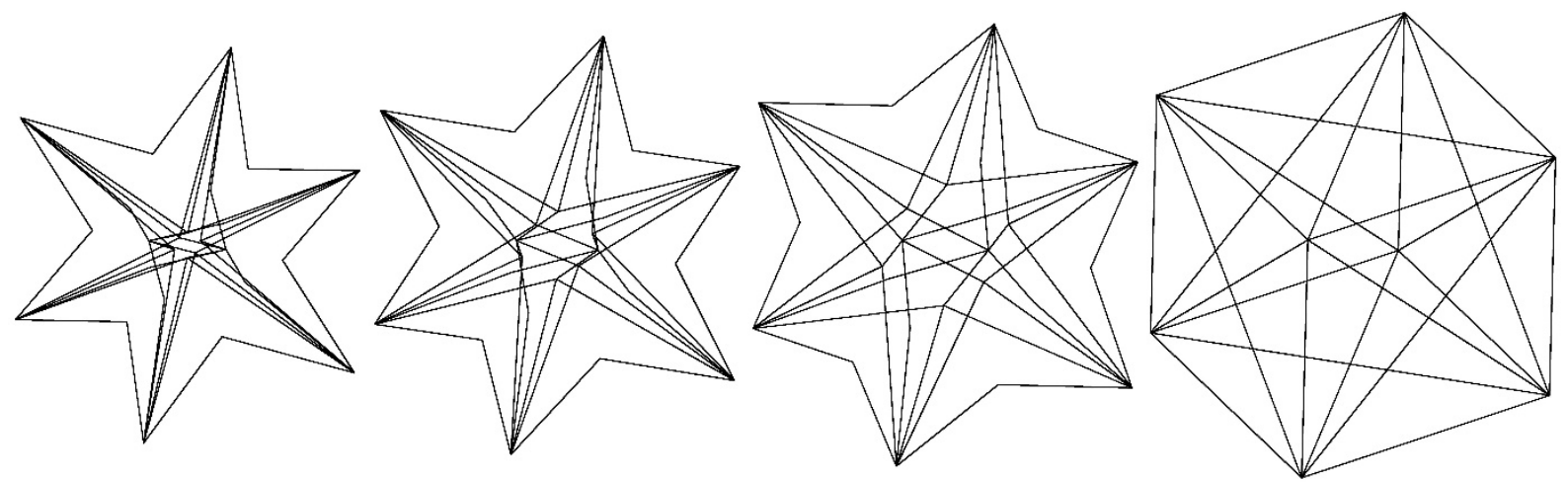

Figura 127 Desarrollo desplegable de estructura reentrante idealized hexatruss individual, elaboración propia

Del análisis de esta figura también se puede ver que todos sus nudos son articulados en el espacio. Esto es debido a que la estructura es un poliedro ${ }^{22}$ y no un polígono ${ }^{23}$. Confluyen

\footnotetext{
${ }^{22}$ Ver nota 18 página 124

${ }^{23}$ Ver nota 19 página 124
} 
cuatro barras en los nudos en el centro de las caras del cubo, permitiéndose giros que van de $0^{\circ}$ a $45^{\circ}$; y seis barras en los vértices del cubo, plegándose también de $0^{\circ}$ a $45^{\circ}$.

\subsubsection{Estructura en 2 dimensiones}

La estructura reentrante idealized 2D estudiada tiene una longitud total de sus barras de $521,47 \mathrm{~m}$. No es capaz de plegarse totalmente, siendo su superficie mínima de $23,30 \mathrm{~m}^{2}$, y su superficie máxima de $36,00 \mathrm{~m}^{2}$ (área del cuadrado que genera), por lo que se aprecian unas constantes "K" en función de la superficie entre la longitud de líneas que van de 0,04 como mínimo a 0,07 como máximo. Esto nos da un factor de crecimiento FC (-) de 0,02 y un factor de crecimiento FC (:) de 1,55.
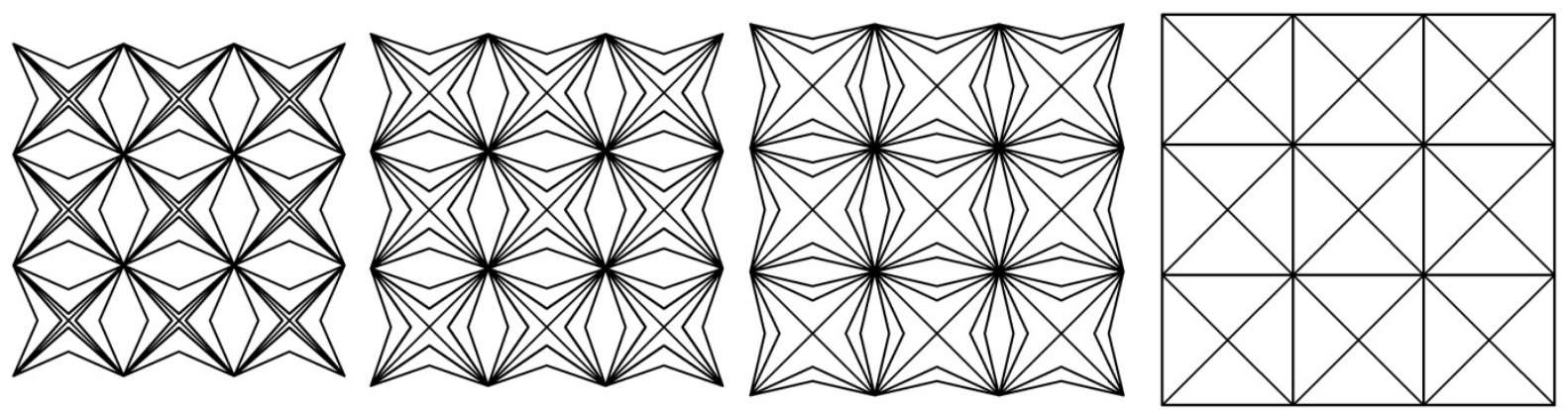

Figura 128 Desarrollo desplegable de estructura reentrante idealized hexatruss 2d, elaboración propia

Del análisis de esta figura también se puede ver que todos sus nudos son articulados en el espacio. Esto es debido a que la estructura es un poliedro ${ }^{24}$ y no un polígono ${ }^{25}$. Confluyen cuatro barras en los nudos en el centro de las caras del cubo, permitiéndose giros que van de $0^{\circ}$ a $45^{\circ}$; y once barras en los vértices del cubo (salvo que pertenezcan al perímetro), plegándose también de $0^{\circ}$ a $45^{\circ}$.

\footnotetext{
${ }^{24}$ Ver nota 18 página 124

${ }^{25}$ Ver nota 19 página 124
} 


\subsubsection{Estructura en 3 dimensiones}

La estructura reentrante idealized 3D estudiada tiene una longitud total de sus barras de $1542,95 \mathrm{~m}$. No es capaz de plegarse totalmente, siendo su volumen mínimo de $264,38 \mathrm{~m}^{3}$, y su volumen máximo de $432,48 \mathrm{~m}^{3}$ (volumen del cubo que genera), por lo que se aprecian unas constantes " $K$ " en función del volumen entre la longitud de líneas que van de 0,17 como mínimo a 0,8 como máximo. Esto nos da un factor de crecimiento FC (-) de 0,11 y un factor de crecimiento FC (:) de 1,64.
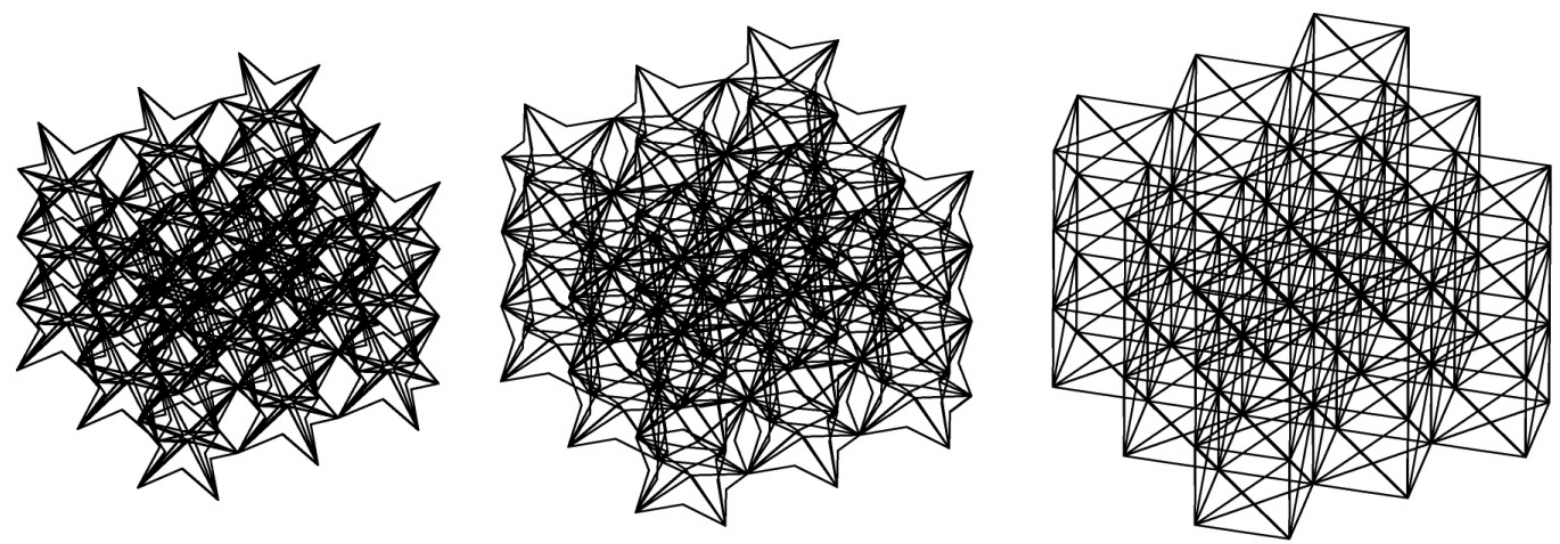

Figura 129 Desarrollo desplegable de estructura reentrante idealized hexatruss 3d, elaboración propia

Del análisis de esta figura también se puede ver que todos sus nudos son articulados en el espacio. Esto es debido a que la estructura es un poliedro ${ }^{26}$ y no un polígono ${ }^{27}$. Confluyen cuatro barras en los nudos en el centro de las caras del cubo, permitiéndose giros que van de $0^{\circ}$ a $45^{\circ}$; y once barras en los vértices del cubo (salvo que pertenezacan al perímetro), plegándose también de $0^{\circ}$ a $45^{\circ}$.

\subsubsection{Estructura torre (por giro de la estructura 2D)}

La estructura reentrante idealized torre estudiada tiene una longitud total de sus barras de $2317,65 \mathrm{~m}$. No es capaz de plegarse totalmente, siendo su volumen mínimo de $413,38 \mathrm{~m}^{3}$, y su volumen máximo de $673,13 \mathrm{~m}^{3}$ (volumen del cilindro que genera), por lo que se aprecian

\footnotetext{
${ }^{26}$ Ver nota 18 página 124

${ }^{27}$ Ver nota 19 página 124
} 
unas constantes "K" en función del volumen entre la longitud de líneas que van de 0,18 como mínimo a 0,29 como máximo. Esto nos da un factor de crecimiento FC (-) de 0,11 y un factor de crecimiento FC (:) de 1,63.
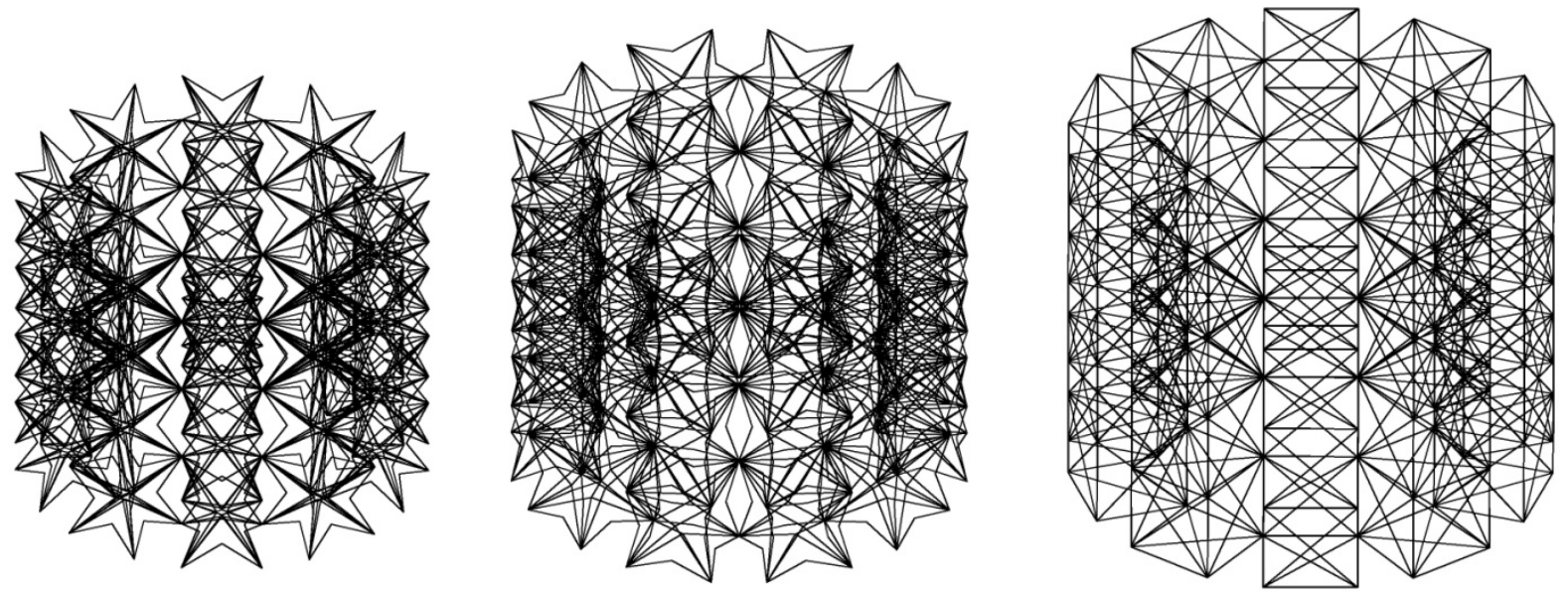

Figura 130 Desarrollo desplegable de estructura reentrante idealized hexatruss torre, elaboración propia

\subsubsection{Tetracaidecaedro}

El Octaedro truncado es un sólido de Arquímedes que se obtiene truncando cada vértice de un octaedro o también se puede conseguir truncando los vértices de un cubo. También es denominado tetracaidecaedro o poliedro de Kelvin, por ser éste el que demostró la singularidad de que es el único poliedro semirregular que puede llenar el espacio por repetición de sí mismo. Para generar el comportamiento auxético se dividen todas las aristas que no pertenecen a los cuadrados existentes en la superficie en dos partes iguales, para que sus barras puedan ser plegadas.

\subsubsection{Patrón unidad}

La estructura reentrante tetracaidecaedro individual estudiada tiene una longitud total de sus barras de 56,97m. No es capaz de plegarse totalmente, siendo su superficie mínima de $2,00 \mathrm{~m}^{2}$, y su superficie máxima de $9,82 \mathrm{~m}^{2}$ (área del polígonos que genera en su proyección en alzado), por lo que se aprecian unas constantes "K" en función de la superficie entre la longitud de líneas que van de 0,04 como mínimo a 0,17 como máximo. Esto nos da un factor de crecimiento FC (-) de 0,14 y un factor de crecimiento FC (:) de 4,91. 

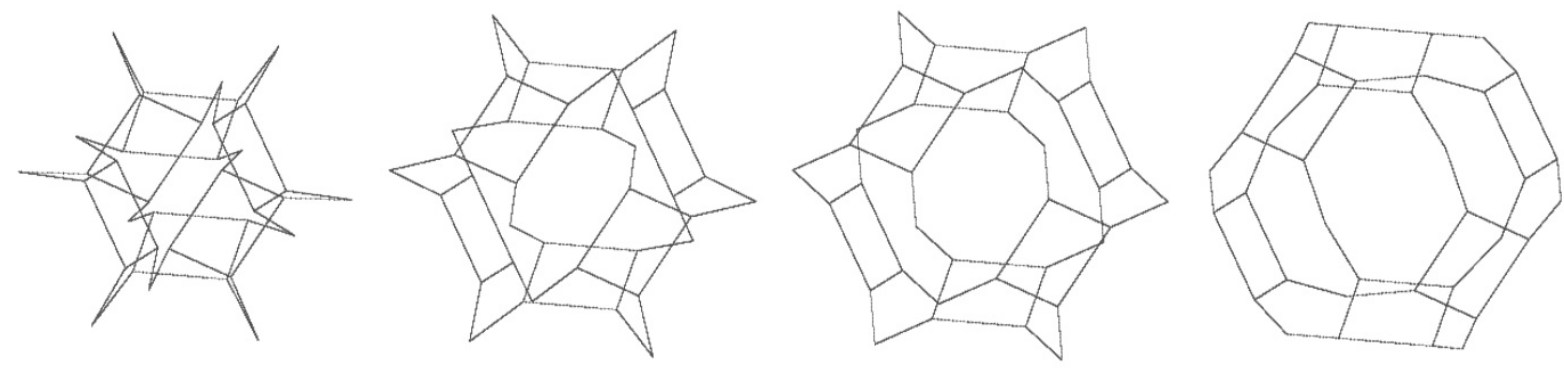

Figura 131 Desarrollo desplegable de estructura reentrante tetracaidecaedro individual, elaboración propia

Del análisis de esta figura también se puede ver que todos sus nudos son articulados en el espacio. Esto es debido a que la estructura es un poliedro ${ }^{28}$ y no un polígono ${ }^{29}$. Confluyen dos barras en los nudos formados por división de aristas, permitiéndose giros que van de $0^{\circ}$ a $180^{\circ}$; y tres barras en los vértices propios del tetracaidecaedro, plegándose de $0^{\circ}$ a $90^{\circ}$.

\subsubsection{Estructura en 2 dimensiones}

La estructura reentrante tetracaidecaedro 2D estudiada tiene una longitud total de sus barras de 569,71m. No es capaz de plegarse totalmente, siendo su superficie mínima de $50,97 \mathrm{~m}^{2}$, y su superficie máxima de $76,37 \mathrm{~m}^{2}$ (área del cuadrado que genera), por lo que se aprecian unas constantes "K" en función de la superficie entre la longitud de líneas que van de 0,09 como mínimo a 0,13 como máximo. Esto nos da un factor de crecimiento FC (-) de 0,04 y un factor de crecimiento FC (:) de 1,50.

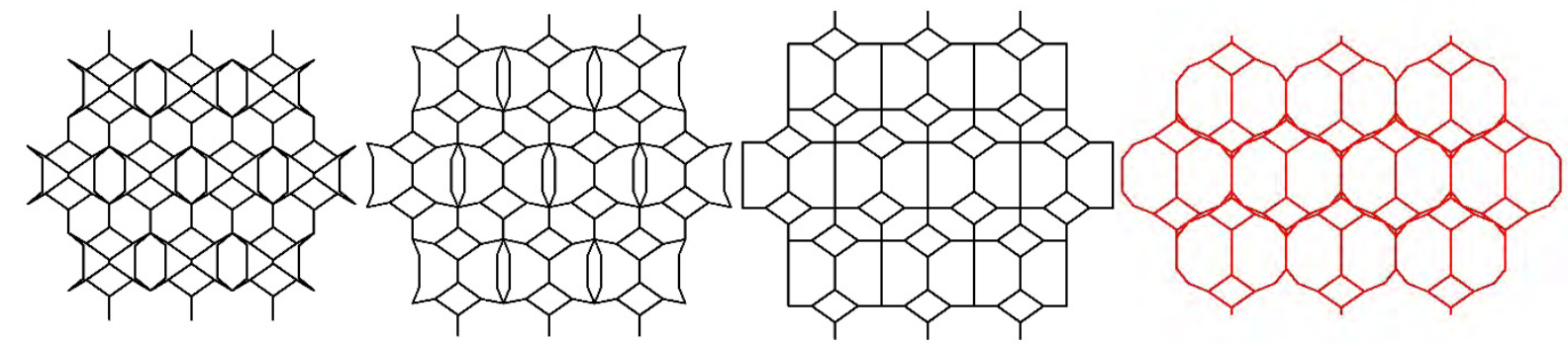

Figura 132 Desarrollo desplegable de estructura reentrante tetracaidecaedro 2d, elaboración propia

\footnotetext{
${ }^{28}$ Ver nota 18 página 124

${ }^{29}$ Ver nota 19 página 124
} 
Puede apreciarse (figura 132) que con el tetracaidecaedro desplegado totalmente (rojo) el comportamiento deja de ser auxético. Del análisis de esta figura también se puede ver que todos sus nudos son articulados en el espacio. Esto es debido a que la estructura unitaria que la genera es un poliedro ${ }^{30}$ y no un polígono ${ }^{31}$. Confluyen dos barras en los nudos formados por división de aristas que no forman parte de las uniones entre patrones individuales y cuatro barras en los nudos formados por división de aristas que forman parte de las uniones entre patrones individuales, permitiéndose giros que van de $0^{\circ}$ a $180^{\circ}$. En los vértices propios del tetracaidecaedro confluyen tres barras, plegándose de $0^{\circ}$ a $90^{\circ}$.

\subsubsection{Estructura en 3 dimensiones}

La estructura reentrante tetracaidecaedro 3D estudiada tiene una longitud total de sus barras de 696,50m. No es capaz de plegarse totalmente, siendo su volumen mínimo de $283,59 \mathrm{~m}^{3}$, y su volumen máximo de $611,96 \mathrm{~m}^{3}$ (volumen del cubo que genera), por lo que se aprecian unas constantes " $K$ " en función del volumen entre la longitud de líneas que van de 0,41 como mínimo a 0,88 como máximo. Esto nos da un factor de crecimiento FC (-) de 0,47 y un factor de crecimiento FC (:) de 2,16.

Del análisis de esta figura también se puede ver que todos sus nudos son articulados en el espacio. Esto es debido a que la estructura unitaria que la genera es un poliedro ${ }^{32}$ y no un polígono $^{33}$. Confluyen dos barras en los nudos formados por división de aristas que no forman parte de las uniones entre patrones individuales y cuatro barras en los nudos formados por división de aristas que forman parte de las uniones entre patrones individuales, permitiéndose giros que van de $0^{\circ}$ a $180^{\circ}$. En los vértices propios del tetracaidecaedro confluyen tres barras, plegándose de $0^{\circ}$ a $90^{\circ}$.

\footnotetext{
${ }^{30}$ Ver nota 18 página 124

${ }^{31}$ Ver nota 19 página 124

32 Ver nota 18 página 124

${ }^{33}$ Ver nota 19 página 124
} 


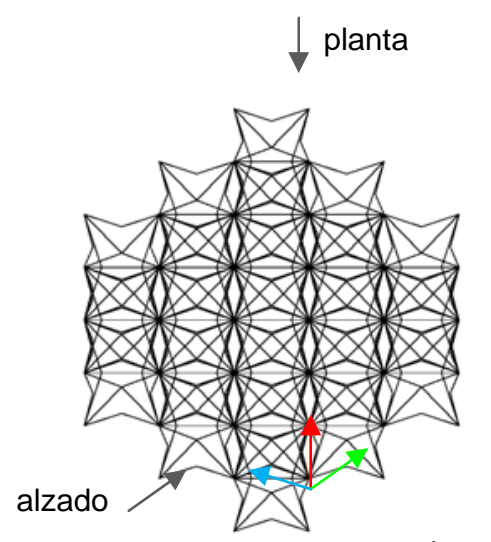

a)

Perfil diagonal

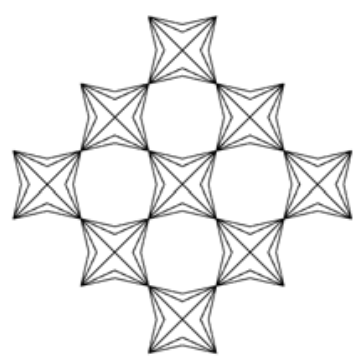

b)

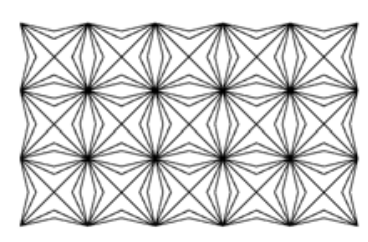

c)

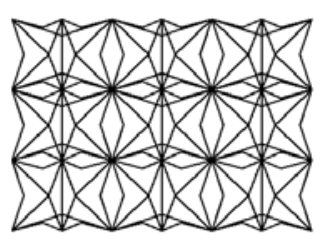

d)
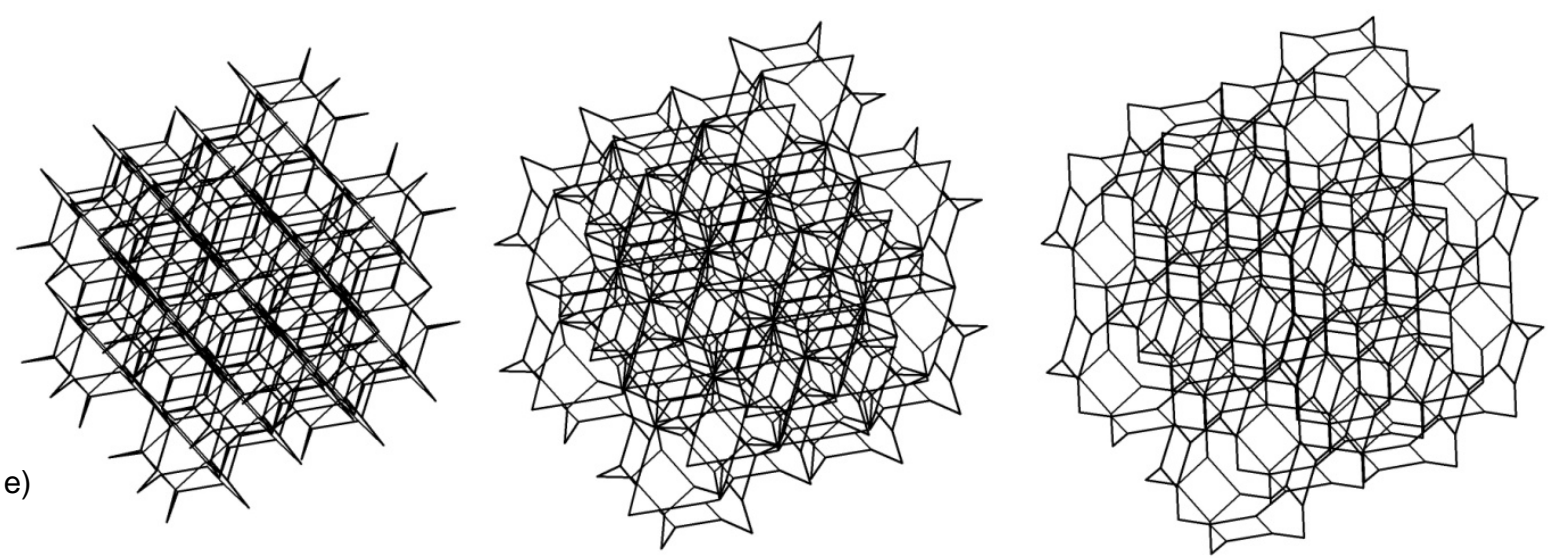

Figura 133 Estructura reentrante tetracaidecaedro 3d, elaboración propia: a) vista 3D, b) planta, c) alzado, d) perfil, e) desarrollo desplegable auxético.

\subsubsection{Estructura torre (por giro de la estructura 2D)}

La estructura reentrante tetracaidecaedro torre estudiada tiene una longitud total de sus barras de $1147,18 \mathrm{~m}$. No es capaz de plegarse totalmente, siendo su volumen mínimo de $599,43 \mathrm{~m}^{3}$, y su volumen máximo de $1279,55 \mathrm{~m}^{3}$ (volumen del cilindro que genera), por lo que se aprecian unas constantes " $K$ " en función del volumen entre la longitud de líneas que van de 0,52 como mínimo a 1,12 como máximo. Esto nos da un factor de crecimiento FC (-) de 0,59 y un factor de crecimiento FC (:) de 2,13.

Al igual que en la estructura 2D, para el tetracaidecaedro desplegado totalmente el comportamiento deja de ser auxético, ya que la forma de combinar los tetracaidecaedros entre sí es idéntica. Del análisis de esta figura también se puede ver que todos sus nudos son articulados en el espacio. Esto es debido a que la estructura unitaria que la genera es 
un poliedro ${ }^{34}$ y no un polígono ${ }^{35}$. Confluyen dos barras en los nudos formados por división de aristas que no forman parte de las uniones entre patrones individuales y cuatro barras en los nudos formados por división de aristas que forman parte de las uniones entre patrones individuales, permitiéndose giros que van de $0^{\circ}$ a $180^{\circ}$. En los vértices propios del tetracaidecaedro confluyen tres barras, plegándose de $0^{\circ}$ a $90^{\circ}$.
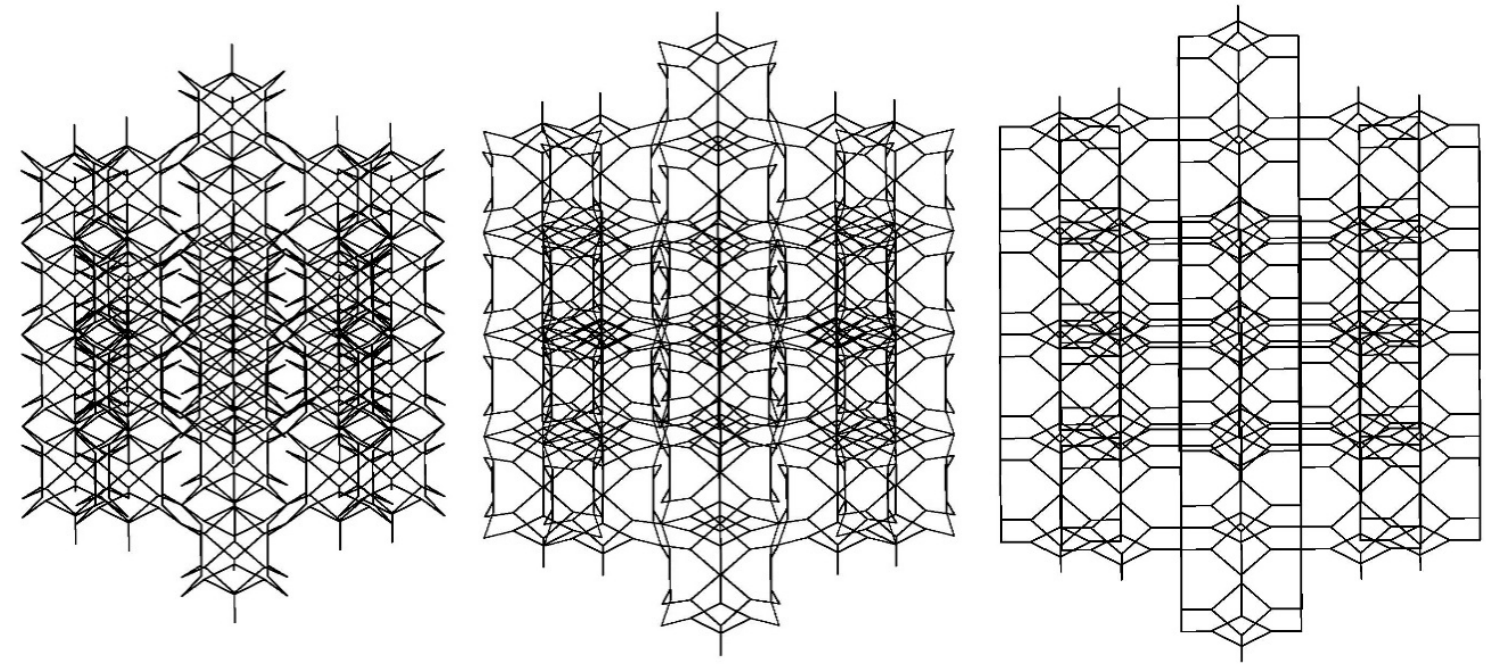

Figura 134 Desarrollo desplegable de estructura reentrante tetracaidecaedro torre, elaboración propia

\subsubsection{Mallas cuadradas}

Consisten en la formación de unas mallas mediante barras unitarias unidas a lo largo entre dos o tres de ellas. Después se combinan de forma perpendicular hasta llegar a la formación de la malla cuadrada buscada. Para estudiar su comportamiento geométrico pormenorizado se podría variar el ángulo que forman los distintos brazos de la estructura.

\subsubsection{Patrón unidad}

La estructura reentrante de mallas cuadradas individual estudiada tiene una longitud total de sus barras de 10,00m. No es capaz de plegarse totalmente, siendo su superficie mínima de $4,00 \mathrm{~m}^{2}$, y su superficie máxima de $6,50 \mathrm{~m}^{2}$ (área del cuadrado que genera), por lo que se

\footnotetext{
${ }^{34}$ Ver nota 18 página 124

${ }^{35}$ Ver nota 19 página 124
} 
aprecian unas constantes "K" en función de la superficie entre la longitud de líneas que van de 0,40 como mínimo a 0,65 como máximo. Esto nos da un factor de crecimiento FC (-) de 0,25 y un factor de crecimiento FC (:) de 1,63.
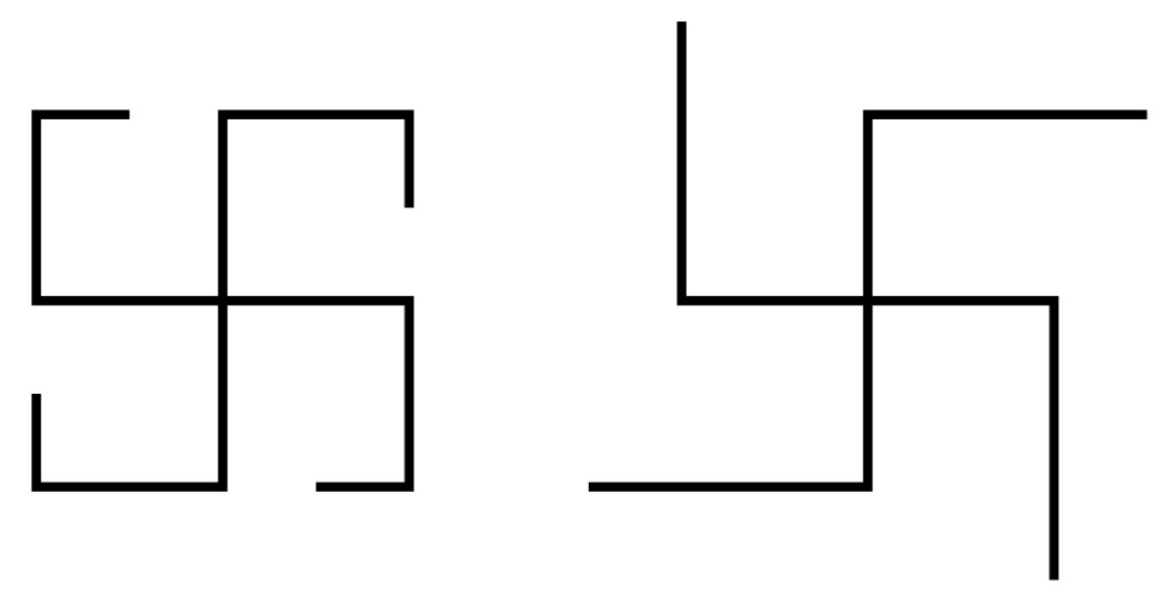

Figura 135 Desarrollo desplegable de estructura reentrante de mallas cuadradas individual, elaboración propia

Del análisis de esta figura también se puede ver que tiene un nudo rígido en el plano y que el resto de sus nudos son articulados en dicho plano, confluyendo dos barras en los mismos, permitiéndose giros en el eje xy que van de $0^{\circ}$ a $90^{\circ}$.

\subsubsection{Estructura en 2 dimensiones}

La estructura reentrante de mallas cuadradas 2D estudiada tiene una longitud total de sus barras de 152,00m. No es capaz de plegarse totalmente, siendo su superficie mínima de $88,20 \mathrm{~m}^{2}$, y su superficie máxima de $121,00 \mathrm{~m}^{2}$ (área del cuadrado que genera), por lo que se aprecian unas constantes "K" en función de la superficie entre la longitud de líneas que van de 0,58 como mínimo a 0,80 como máximo. Esto nos da un factor de crecimiento FC (-) de 0,22 y un factor de crecimiento FC (:) de 1,37.

Del análisis de esta figura también se puede ver que tiene un nudo rígido en el plano y que el resto de sus nudos son articulados en dicho plano, confluyendo dos barras en los mismos, permitiéndose giros en el eje xy que van de $0^{\circ}$ a $90^{\circ}$. 

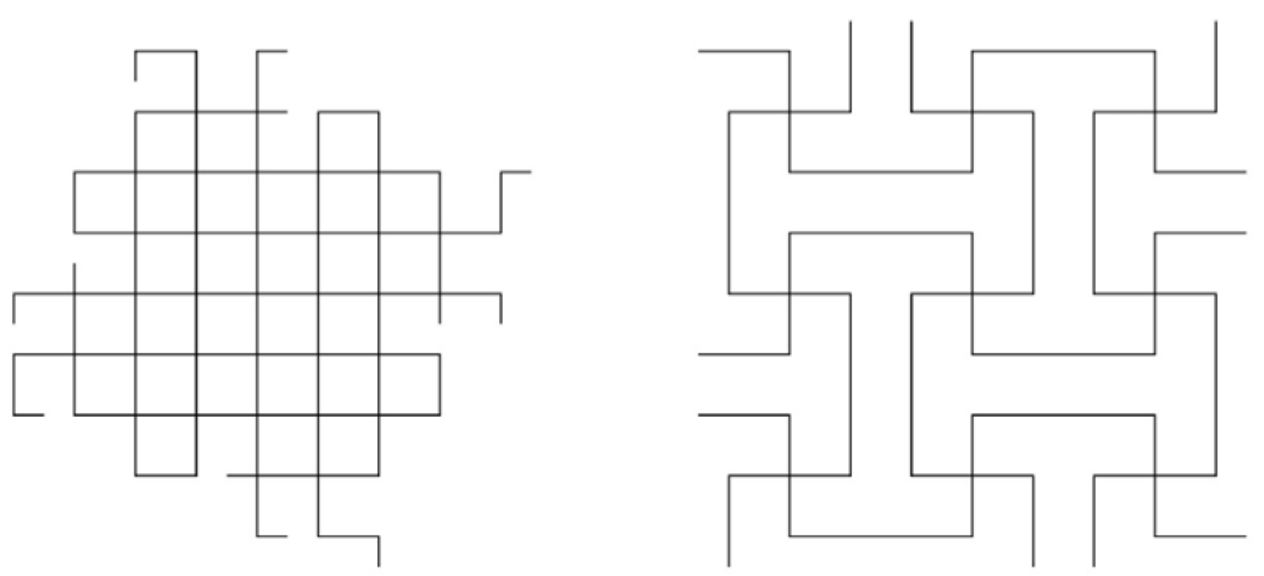

Figura 136 Desarrollo desplegable de estructura de malla cuadrada en forma de esvástica, elaboración propia

\subsubsection{Estructura en 3 dimensiones}

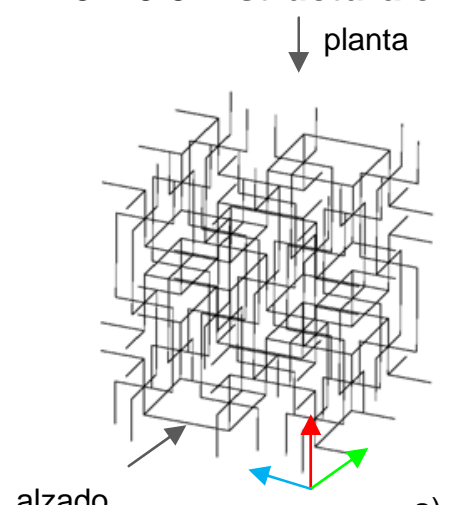

a)

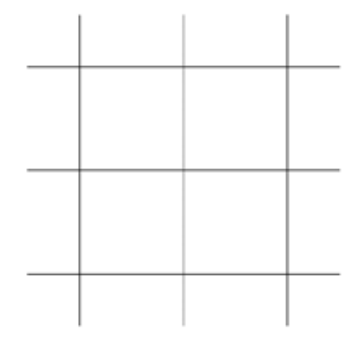

b)

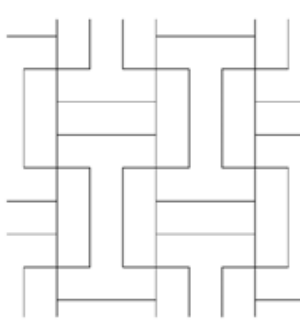

c)

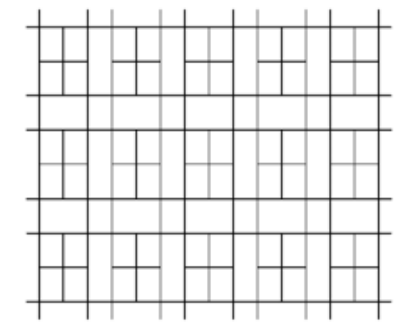

d)
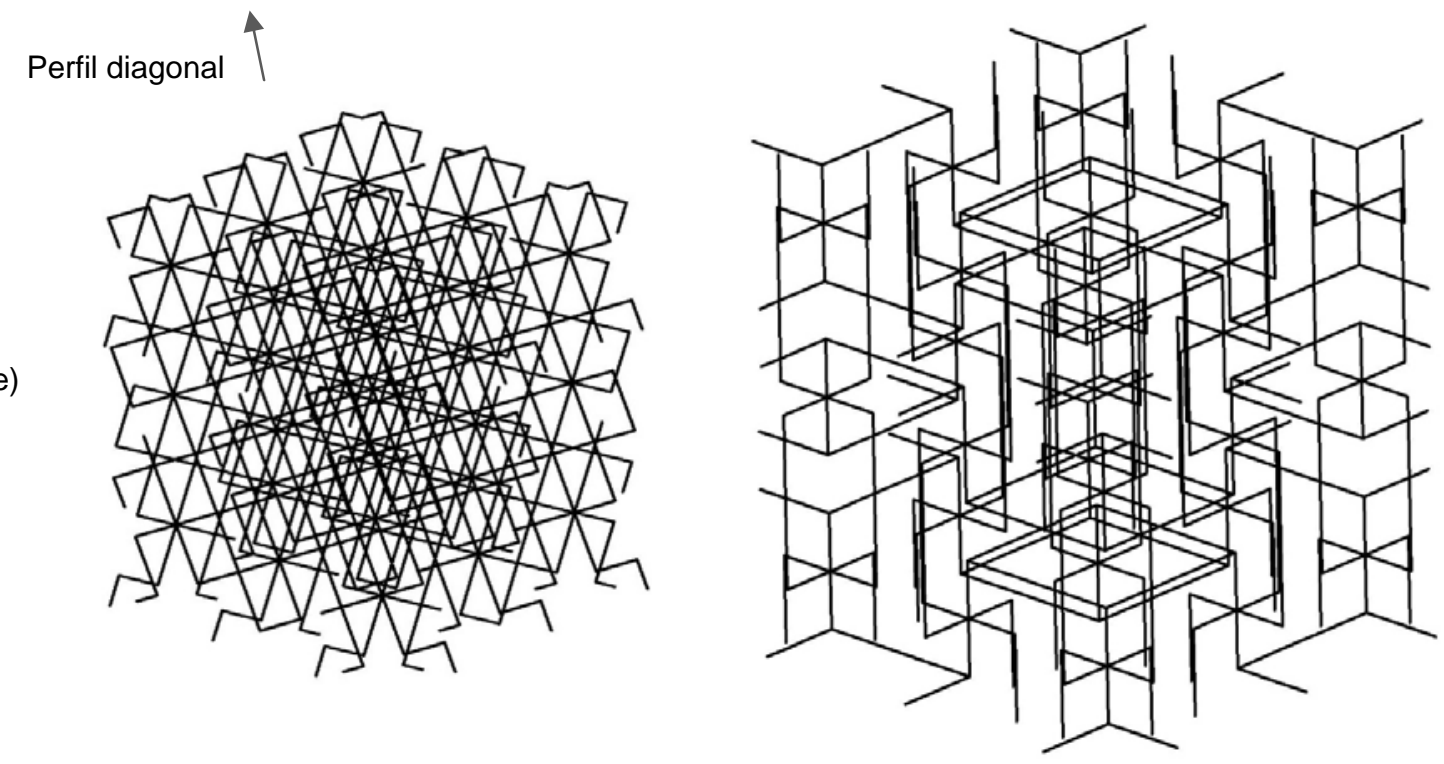

Figura 137 Estructura reentrante de mallas cuadradas 3d, elaboración propia: a) vista 3D, b) planta, c) alzado, d) perfil, e) desarrollo desplegable auxético. 
La estructura reentrante de mallas cuadradas 3D estudiada tiene una longitud total de sus barras de 540,00m. No es capaz de plegarse totalmente, siendo su volumen mínimo de $401,95 \mathrm{~m}^{3}$, y su volumen máximo de $729,00 \mathrm{~m}^{3}$ (volumen del cubo que genera), por lo que se aprecian unas constantes " $K$ " en función del volumen entre la longitud de líneas que van de 0,74 como mínimo a 1,35 como máximo. Esto nos da un factor de crecimiento FC (-) de 0,61 y un factor de crecimiento FC (:) de 1,81.

Del análisis de esta figura también se puede ver que los nudos rígidos en el plano que tenían la estructura individual y la estructura 2D se convierten en nudos espaciales con confluencia de ocho barras, en las que se permite el giro. Los nudos que eran articulados en el plano, confluyendo dos barras en los mismos, siguen conservando sus propiedades en la estructura 3D, permitiéndose giros en los planos que van de $0^{\circ}$ a $90^{\circ}$.

\subsubsection{Estructura torre (por giro de la estructura 2D)}

La estructura reentrante de mallas cuadradas torre estudiada tiene una longitud total de sus barras de $153,00 \mathrm{~m}$. No es capaz de plegarse totalmente, siendo su volumen mínimo de $108,20 \mathrm{~m}^{3}$, y su volumen máximo de $182,33 \mathrm{~m}^{3}$ (volumen del cilindro que genera), por lo que se aprecian unas constantes "K" en función del volumen entre la longitud de líneas que van de 0,58 como mínimo a 1,19 como máximo. Esto nos da un factor de crecimiento FC (-) de 0,62 y un factor de crecimiento FC (:) de 2,07.

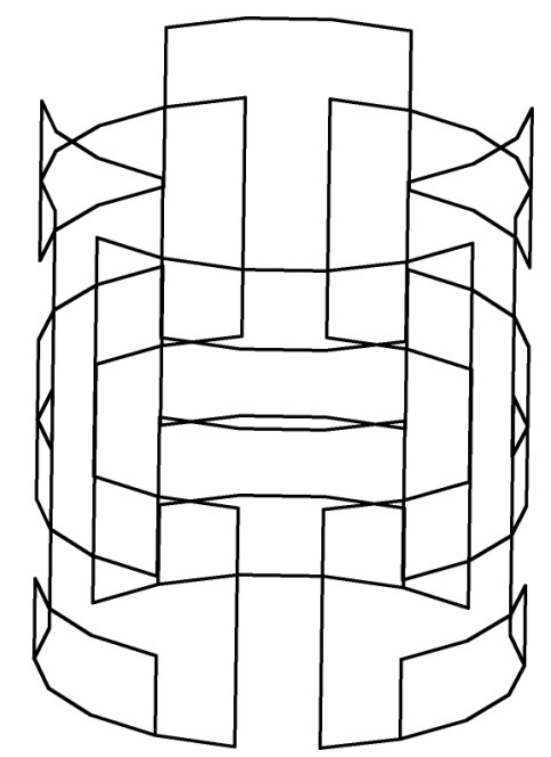

Figura 138 Estructura de malla cuadrada en forma de esvástica tipo torre, elaboración propia 


\subsubsection{Mallas romboidales}

Consisten en la formación de unas mallas mediante barras unitarias unidas a lo largo entre dos o tres de ellas. Después se combinan de forma perpendicular hasta llegar a la formación de la malla cuadrada buscada. Para estudiar su comportamiento geométrico pormenorizado se podría variar el ángulo que forman los distintos brazos de la estructura.

\subsubsection{Patrón unidad}

La estructura reentrante de mallas romboidales individual estudiada tiene una longitud total de sus barras de $8,00 \mathrm{~m}$. No es capaz de plegarse totalmente, siendo su superficie mínima de $4,00 \mathrm{~m}^{2}$, y su superficie máxima de $8,00 \mathrm{~m}^{2}$ (área del cuadrado que genera), por lo que se aprecian unas constantes " $K$ " en función de la superficie entre la longitud de líneas que van de 0,50 como mínimo a 1,00 como máximo. Esto nos da un factor de crecimiento FC (-) de 0,50 y un factor de crecimiento FC (:) de 2,00.
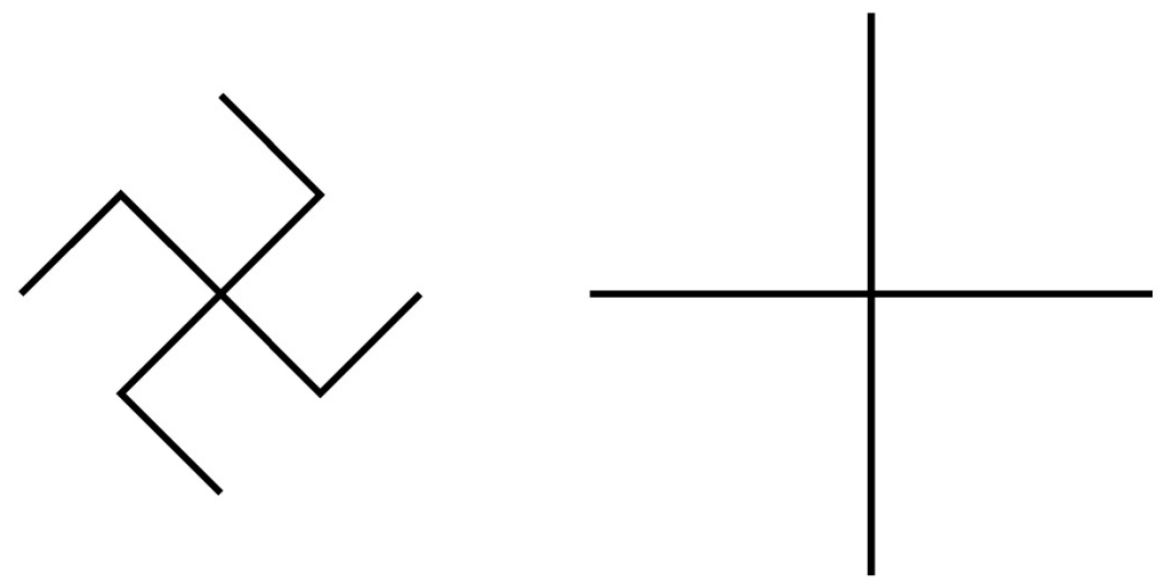

Figura 139 Desarrollo desplegable de estructura reentrante de mallas romboidales individual, elaboración propia

Del análisis de esta figura también se puede ver que tiene un nudo rígido en el plano y que el resto de sus nudos son articulados en dicho plano, confluyendo dos barras en los mismos, permitiéndose giros en el eje xy que van de $0^{\circ}$ a $90^{\circ}$. 


\subsubsection{Estructura en 2 dimensiones}

La estructura reentrante de mallas romboidales 2D estudiada tiene una longitud total de sus barras de 72,00m. No es capaz de plegarse totalmente, siendo su superficie mínima de $72,00 \mathrm{~m}^{2}$, y su superficie máxima de $144,00 \mathrm{~m}^{2}$ (área del cuadrado que genera), por lo que se aprecian unas constantes "K" en función de la superficie entre la longitud de líneas que van de 1,00 como mínimo a 2,00 como máximo. Esto nos da un factor de crecimiento FC (-) de 1,00 y un factor de crecimiento FC (:) de 2,00.
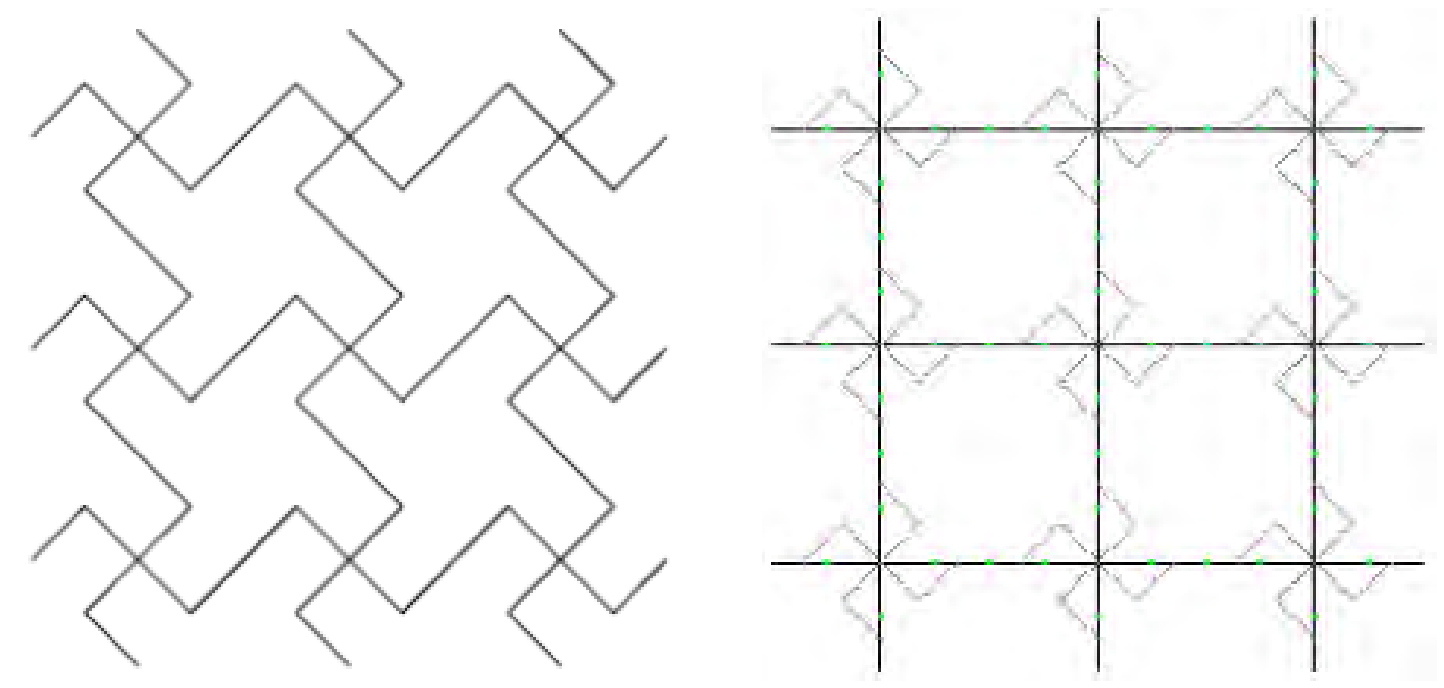

Figura 140 Desarrollo desplegable de estructura de malla romboidal en forma de esvástica, elaboración propia

Del análisis de esta figura también se puede ver que tiene un nudo rígido en el plano y que el resto de sus nudos son articulados en dicho plano, confluyendo dos barras en los mismos, permitiéndose giros en el eje xy que van de $0^{\circ}$ a $90^{\circ}$.

\subsubsection{Estructura en 3 dimensiones}

La estructura reentrante de mallas romboidales 3D estudiada tiene una longitud total de sus barras de 432,00m. No es capaz de plegarse totalmente, siendo su volumen mínimo de $611,96 \mathrm{~m}^{3}$, y su volumen máximo de $1728,00 \mathrm{~m}^{3}$ (volumen del cubo que genera), por lo que se aprecian unas constantes "K" en función del volumen entre la longitud de líneas que van de 1,42 como mínimo a 4,00 como máximo. Esto nos da un factor de crecimiento FC (-) de 2,58 y un factor de crecimiento FC (:) de 2,82. 


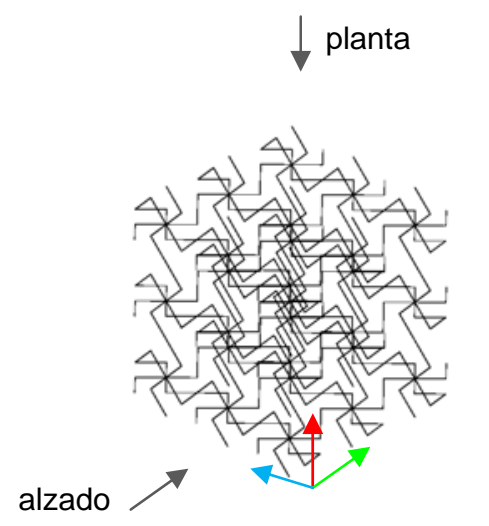

a)

Perfil diagonal

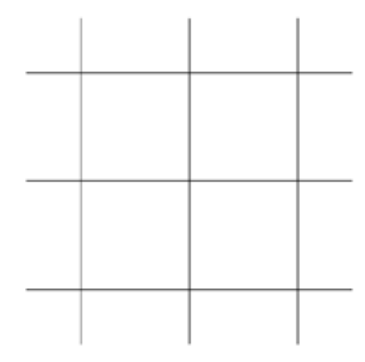

b)

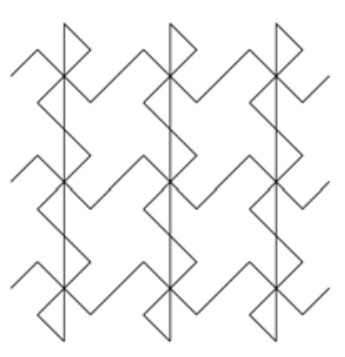

c)

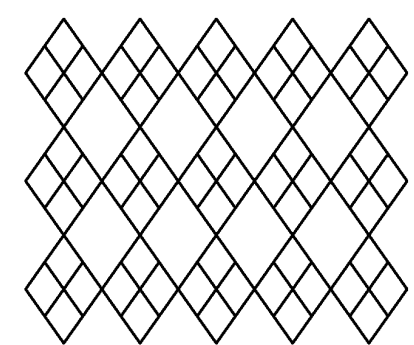

d)
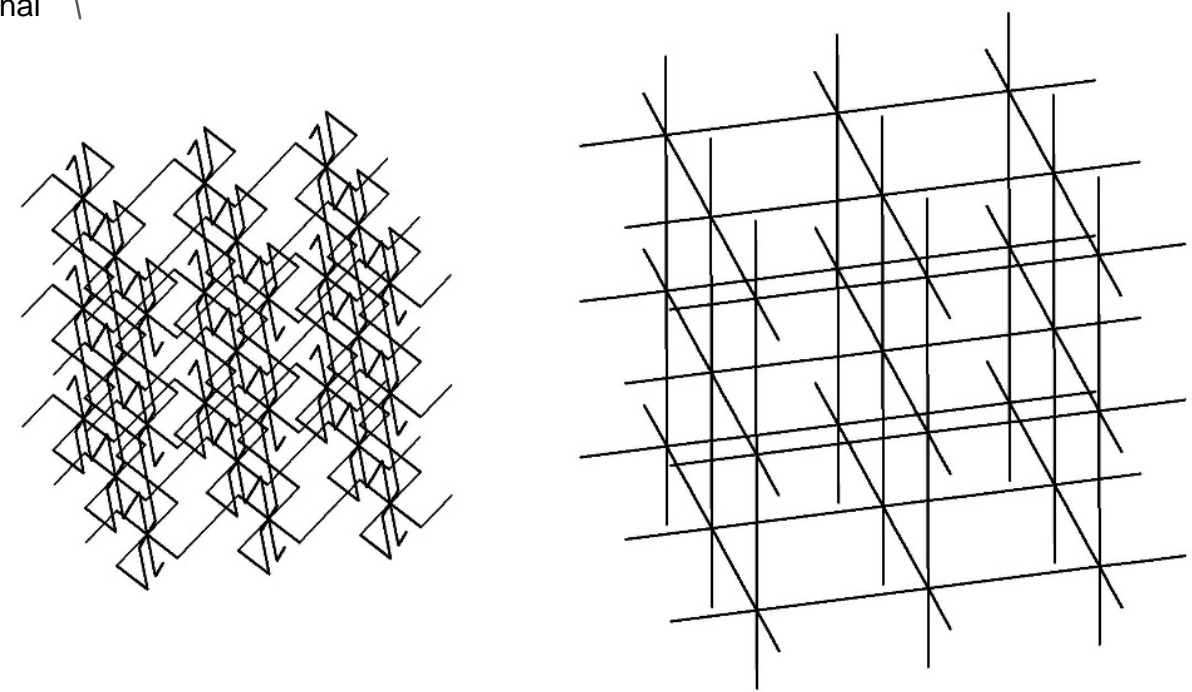

Figura 141 Estructura reentrante de mallas romboidales 3d, elaboración propia: a) vista 3D, b) planta, c) alzado, d) perfil, e) desarrollo desplegable auxético.

Del análisis de esta figura también se puede ver que los nudos rígidos que tenía en el plano la estructura 2D se convierten en nudos articulados en los que confluyen ocho barras. El resto de los nudos son articulados en un determinado plano, confluyendo dos o cuatro barras en los mismos, permitiéndose giros que van de $0^{\circ}$ a $90^{\circ}$.

\subsubsection{Estructura torre (por giro de la estructura 2D)}

La estructura reentrante de mallas romboidales torre estudiada tiene una longitud total de sus barras de $98,99 \mathrm{~m}$. No es capaz de plegarse totalmente, siendo su volumen mínimo de $28,79 \mathrm{~m}^{3}$, y su volumen máximo de $81,42 \mathrm{~m}^{3}$ (volumen del cilindro que genera), por lo que se aprecian unas constantes "K" en función del volumen entre la longitud de líneas que van de 
0,29 como mínimo a 1,45 como máximo. Esto nos da un factor de crecimiento FC (-) de 1,16 y un factor de crecimiento FC (:) de 5,00.

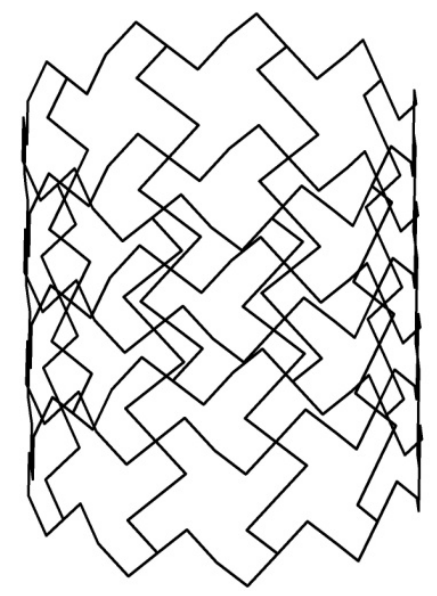

Figura 142 Estructura reentrante de mallas romboidales tipo torre, elaboración propia

Del análisis de esta figura también se puede ver que tiene un nudo rígido en el plano y que el resto de sus nudos son articulados en dicho plano, confluyendo dos barras en los mismos, permitiéndose giros en el eje xy que van de $0^{\circ}$ a $90^{\circ}$.

\subsubsection{Quiral triangular}

La estructura quiral triangular se forma mediante la unión de unas barras a los vértices de un triángulo equilátero. Mediante la rotación en el mismo sentido de todas estas barras se consigue el comportamiento auxético.

\subsubsection{Patrón unidad}

La estructura quiral triangular individual estudiada tiene una longitud total de sus barras de $6,00 \mathrm{~m}$. No es capaz de plegarse totalmente, siendo su superficie mínima de $0,43 \mathrm{~m}^{2}$, y su superficie máxima de $3,23 \mathrm{~m}^{2}$ (área del triángulo que genera), por lo que se aprecian unas constantes "K" en función de la superficie entre la longitud de líneas que van de 0,07 como mínimo a 0,54 como máximo. Esto nos da un factor de crecimiento FC (-) de 0,47 y un factor de crecimiento FC (:) de 7,51. 


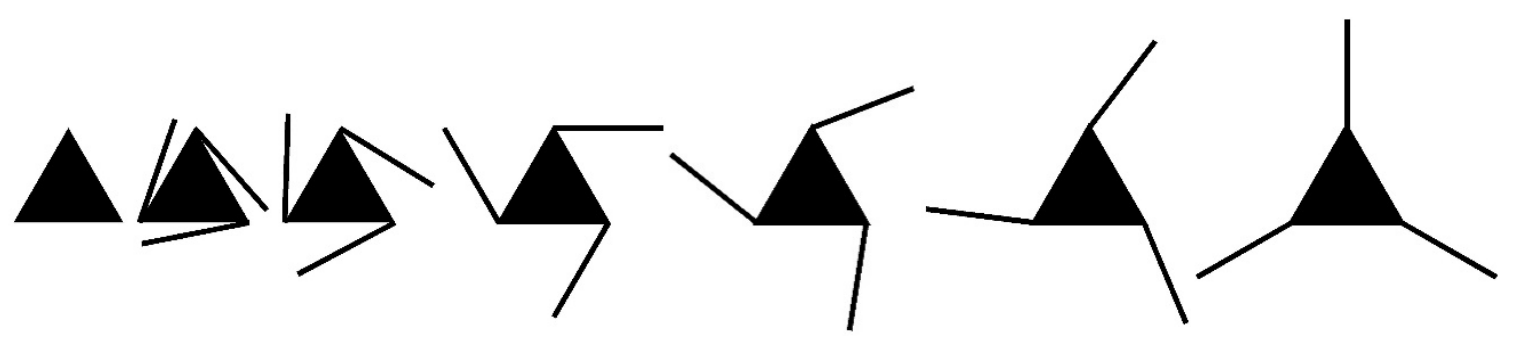

Figura 143 Desarrollo desplegable de estructura quiral triangular individual, elaboración propia

Del análisis de esta figura también se puede ver que tiene una barra articulada a un nudo rígido en el plano que corresponde al vértice del triángulo. Los giros permitidos en el eje xy van de $0^{\circ}$ a $150^{\circ}$.

\subsubsection{Estructura en 2 dimensiones}
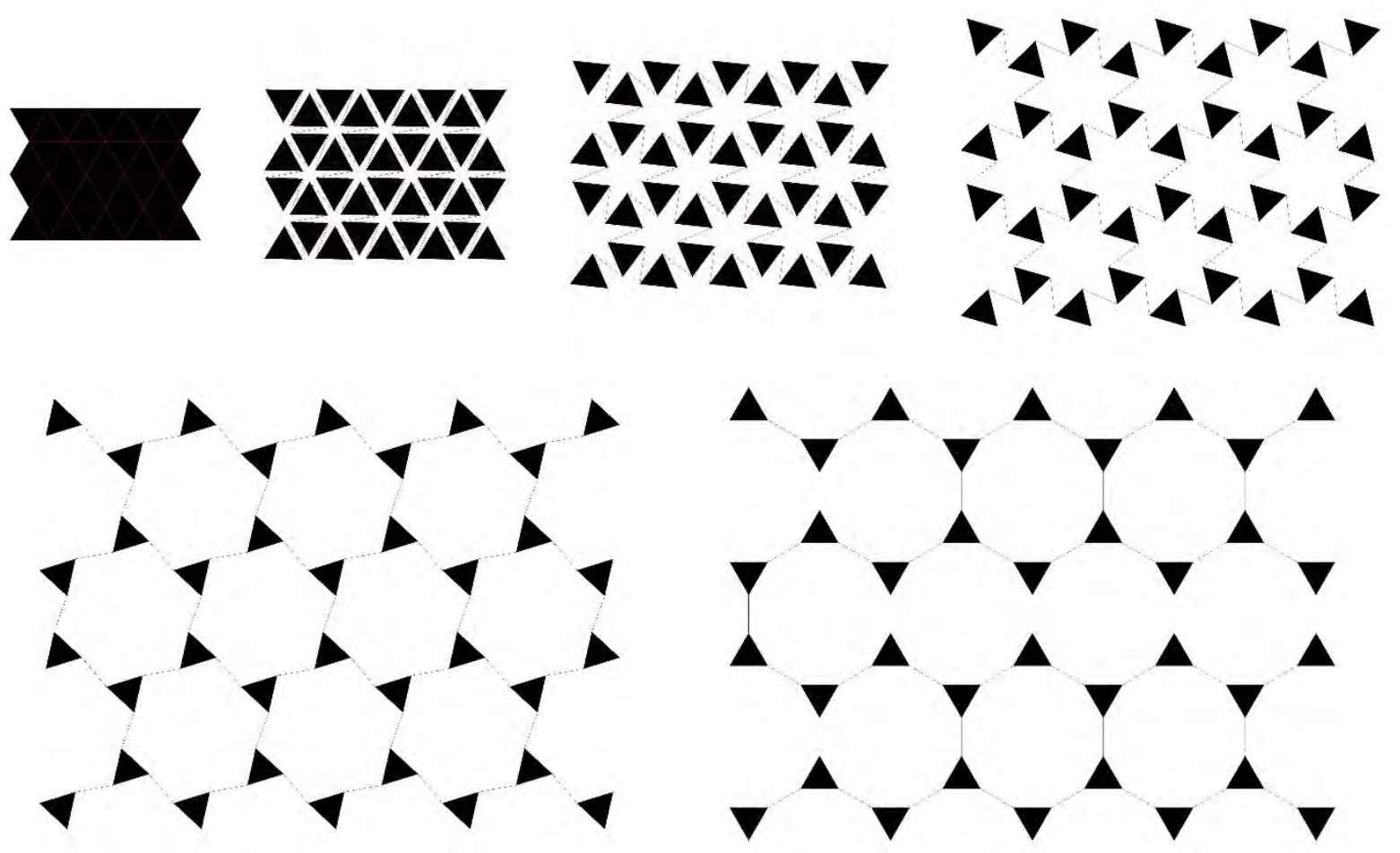

Figura 144 Desarrollo desplegable de estructura quiral triangular 2d, elaboración propia

La estructura quiral triangular 2D estudiada tiene una longitud total de sus barras de $216,00 \mathrm{~m}$. No es capaz de plegarse totalmente, siendo su superficie mínima de $17,32 \mathrm{~m}^{2}$, y su superficie máxima de $189,99 \mathrm{~m}^{2}$ (área del cuadrado que genera), por lo que se aprecian unas constantes "K" en función de la superficie entre la longitud de líneas que van de 0,08 como 
mínimo a 0,88 como máximo. Esto nos da un factor de crecimiento FC (-) de 0,80 y un factor de crecimiento FC (:) de 10,97.

Del análisis de esta figura también se puede ver que tiene una barra articulada a un nudo rígido en el plano que corresponde al vértice del triángulo. Los giros permitidos en el eje xy van de $0^{\circ}$ a $150^{\circ}$.

\subsubsection{Estructura en 3 dimensiones}

La estructura quiral triangular 3D estudiada tiene una longitud total de sus barras de $1005,00 \mathrm{~m}$. No es capaz de plegarse totalmente, siendo su volumen mínimo de $129,78 \mathrm{~m}^{3}$, y su volumen máximo de $1427,63 \mathrm{~m}^{3}$ (volumen del cubo que genera), por lo que se aprecian unas constantes "K" en función de la superficie entre la longitud de líneas que van de 0,02 como mínimo a 1,42 como máximo. Esto nos da un factor de crecimiento FC (-) de 1,40 y un factor de crecimiento FC (:) de 82,43.

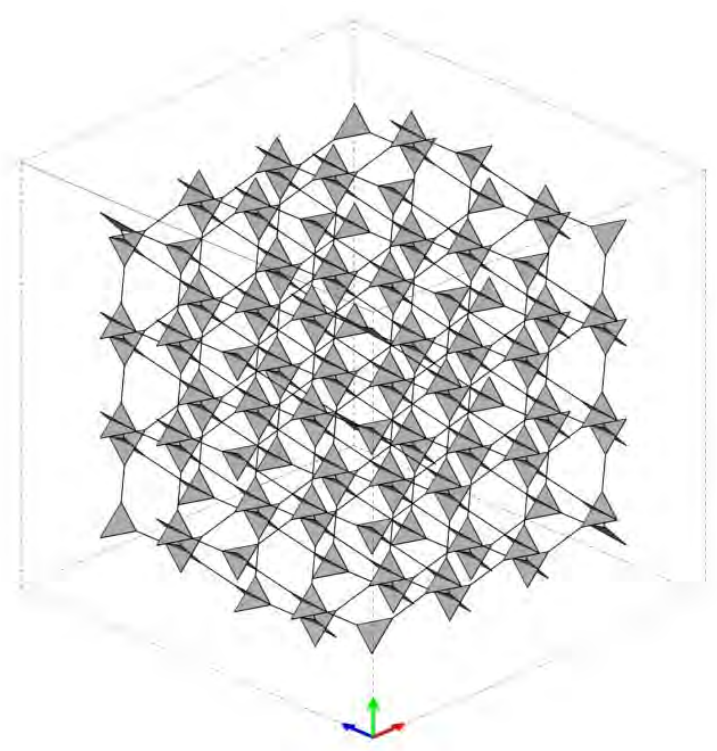

Figura 145 Estructura quiral triangular 3D, elaboración propia

Del análisis de esta figura también se puede ver que tiene una barra articulada en el espacio a un nudo rígido que corresponde al vértice del triángulo. Los giros permitidos van de $0^{\circ} \mathrm{a}$ $150^{\circ}$. 


\subsubsection{Estructura torre (por giro de la estructura 2D)}

La estructura quiral triangular torre estudiada tiene una longitud total de sus barras de $637,00 \mathrm{~m}$. No es capaz de plegarse totalmente, siendo su volumen mínimo de $53,63 \mathrm{~m}^{3}$, y su volumen máximo de $189,99 \mathrm{~m}^{3}$ (volumen del cilindro que genera), por lo que se aprecian unas constantes "K" en función de la superficie entre la longitud de líneas que van de 0,03 como mínimo a 0,30 como máximo. Esto nos da un factor de crecimiento FC (-) de 0,27 y un factor de crecimiento FC (:) de 10,97.

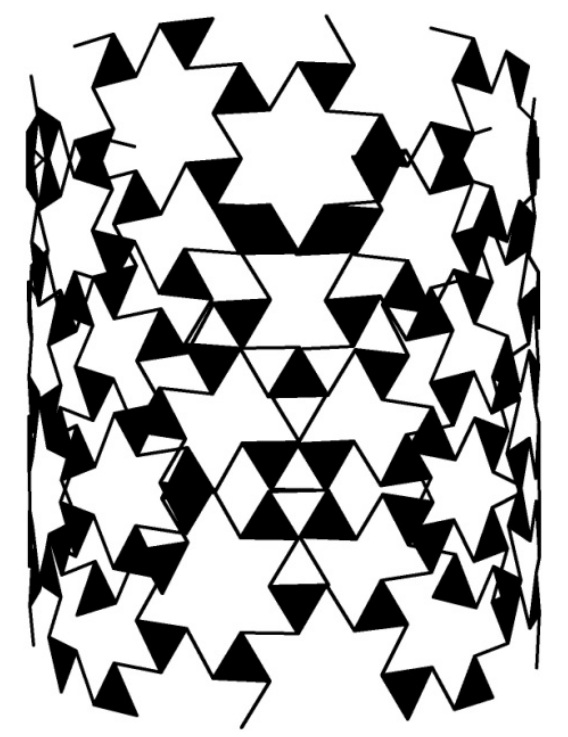

Figura 146 Estructura quiral triangular tipo torre, elaboración propia

Del análisis de esta figura también se puede ver que tiene una barra articulada en el espacio a un nudo rígido que corresponde al vértice del triángulo. Los giros permitidos van de $0^{\circ} \mathrm{a}$ $150^{\circ}$.

\subsubsection{Quiral cuadrangular}

La estructura quiral cuadrangular se forma mediante la unión de unas barras a los vértices de un cuadrado. Mediante la rotación en el mismo sentido de todas estas barras se consigue el comportamiento auxético. 


\subsubsection{Patrón unidad}

La estructura quiral cuadrangular individual estudiada tiene una longitud total de sus barras de $8,00 \mathrm{~m}$. No es capaz de plegarse totalmente, siendo su superficie mínima de $1,00 \mathrm{~m}^{2}$, y su superficie máxima de $5,83 \mathrm{~m}^{2}$ (área del cuadrado que genera), por lo que se aprecian unas constantes "K" en función de la superficie entre la longitud de líneas que van de 0,13 como mínimo a 0,73 como máximo. Esto nos da un factor de crecimiento FC (-) de 0,60 y un factor de crecimiento FC (:) de 5,83.

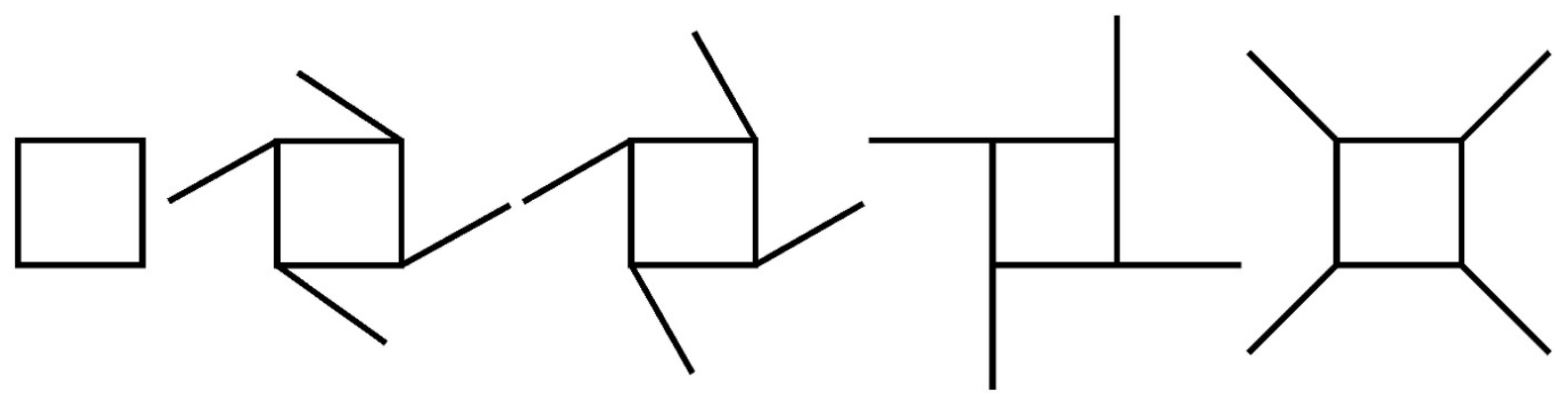

Figura 147 Desarrollo desplegable de estructura quiral cuadrada individual, elaboración propia

Del análisis de esta figura también se puede ver que tiene una barra articulada a un nudo rígido en el plano que corresponde al vértice del cuadrado. Los giros permitidos en el eje xy van de $0^{\circ}$ a $135^{\circ}$.

\subsubsection{Estructura en 2 dimensiones}

La estructura quiral cuadrangular 2D estudiada tiene una longitud total de sus barras de $64,00 \mathrm{~m}$. No es capaz de plegarse totalmente, siendo su superficie mínima de $14,00 \mathrm{~m}^{2}$, y su superficie máxima de $55,46 \mathrm{~m}^{2}$ (área del cuadrado que genera), por lo que se aprecian unas constantes "K" en función de la superficie entre la longitud de líneas que van de 0,22 como mínimo a 0,87 como máximo. Esto nos da un factor de crecimiento FC (-) de 0,65 y un factor de crecimiento FC (:) de 3,96.

Del análisis de esta figura también se puede ver que tiene una barra articulada a un nudo rígido en el plano que corresponde al vértice del cuadrado. Los giros permitidos en el eje xy van de $0^{\circ}$ a $135^{\circ}$. 


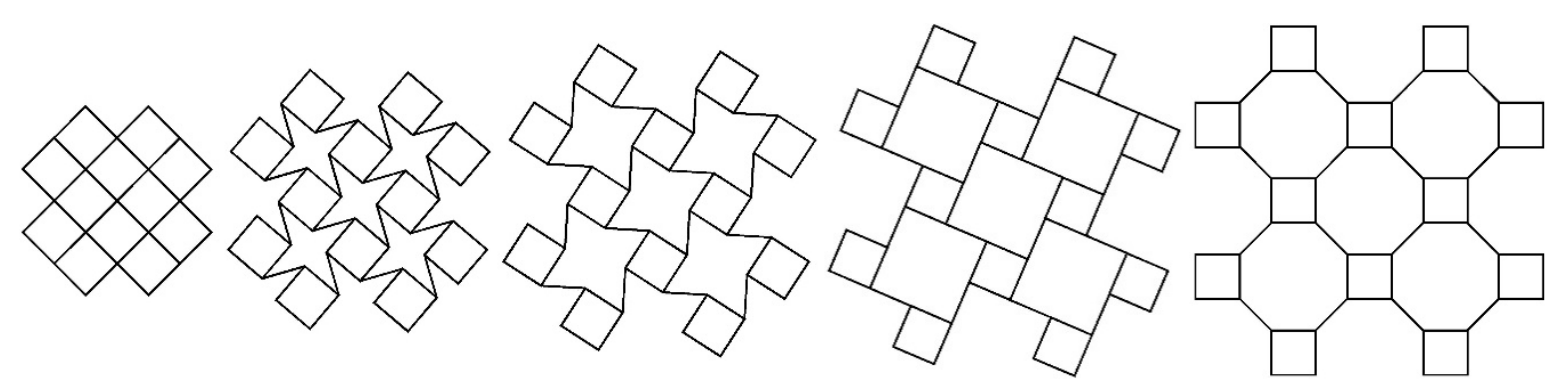

Figura 148 Desarrollo desplegable de estructura quiral cuadrada 2d, elaboración propia

\subsubsection{Estructura en 3 dimensiones}

La estructura quiral cuadrangular 3D estudiada tiene una longitud total de sus barras de $1312,05 \mathrm{~m}$. No es capaz de plegarse totalmente, siendo su volumen mínimo de $571,08 \mathrm{~m}^{3}$, y su volumen máximo de $2284,32 \mathrm{~m}^{3}$ (volumen del cubo que genera), por lo que se aprecian unas constantes "K" en función de la superficie entre la longitud de líneas que van de 0,01 como mínimo a 1,74 como máximo. Esto nos da un factor de crecimiento FC (-) de 1,73 y un factor de crecimiento FC (:) de 163,17.

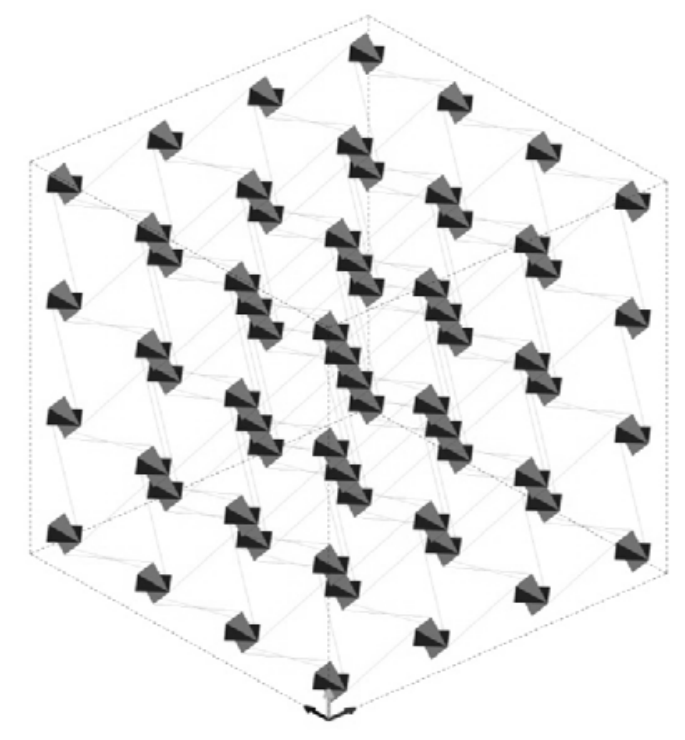

Figura 149 Estructura quiral cuadrangular 3d, elaboración propia

Del análisis de esta figura también se puede ver que tiene una barra articulada en el espacio a un nudo rígido que corresponde al vértice del cuadrado. Los giros permitidos van de $0^{\circ} \mathrm{a}$ $135^{\circ}$. 


\subsubsection{Estructura torre (por giro de la estructura 2D)}

La estructura quiral cuadrangular torre estudiada tiene una longitud total de sus barras de $451,69 \mathrm{~m}$. No es capaz de plegarse totalmente, siendo su volumen mínimo de $188,86 \mathrm{~m}^{3}$, y su volumen máximo de $55,46 \mathrm{~m}^{3}$ (volumen del cilindro que genera), por lo que se aprecian unas constantes "K" en función de la superficie entre la longitud de líneas que van de 0,03 como mínimo a 0,12 como máximo. Esto nos da un factor de crecimiento FC (-) de 0,09 y un factor de crecimiento FC (:) de 3,96.

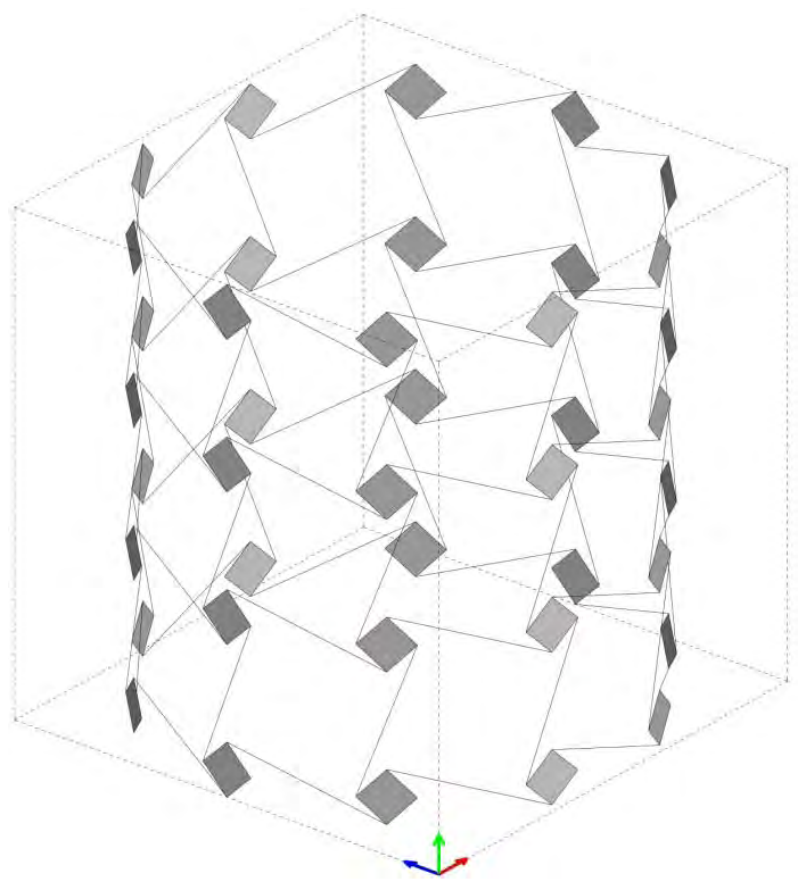

Figura 150 Estructura quiral cuadrangular tipo torre, elaboración propia

Del análisis de esta figura también se puede ver que tiene una barra articulada en el espacio a un nudo rígido que corresponde al vértice del triángulo. Los giros permitidos van de $0^{\circ} \mathrm{a}$ $135^{\circ}$.

\subsubsection{Quiral rectangular}

La estructura quiral rectangular se forma mediante la unión de unas barras a los vértices de un cuadrado. Mediante la rotación en el mismo sentido de todas estas barras se consigue el comportamiento auxético. 


\subsubsection{Patrón unidad}

La estructura quiral rectangular individual estudiada tiene una longitud total de sus barras de $12,00 \mathrm{~m}$. No es capaz de plegarse totalmente, siendo su superficie mínima de $2,00 \mathrm{~m}^{2}$, y su superficie máxima de $11,00 \mathrm{~m}^{2}$ (área del paralelepípedo que genera), por lo que se aprecian unas constantes "K" en función de la superficie entre la longitud de líneas que van de 0,17 como mínimo a 0,92 como máximo. Esto nos da un factor de crecimiento FC (-) de 0,75 y un factor de crecimiento FC (:) de 5,50.
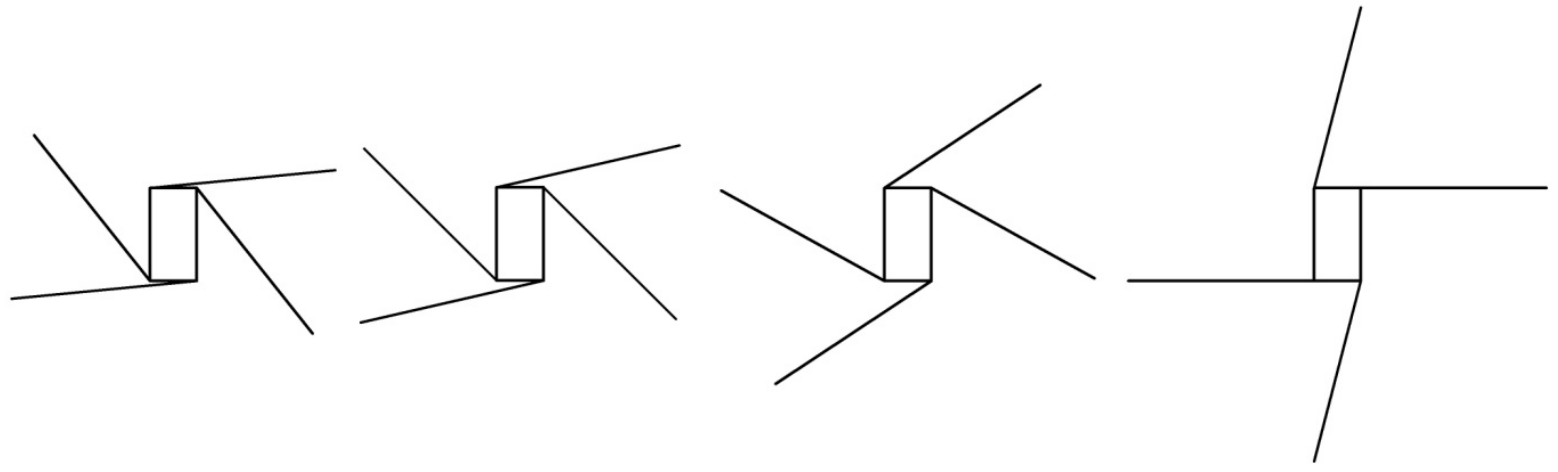

Figura 151 Desarrollo desplegable de estructura quiral rectangular individual, elaboración propia

Del análisis de esta figura también se puede ver que tiene una barra articulada a un nudo rígido en el plano que corresponde al vértice del rectángulo. Los giros permitidos en el eje xy van de $0^{\circ}$ a $90^{\circ}$.

\subsubsection{Estructura en 2 dimensiones}

La estructura quiral rectangular 2D estudiada tiene una longitud total de sus barras de $376,00 \mathrm{~m}$. No es capaz de plegarse totalmente, siendo su superficie mínima de $302,44 \mathrm{~m}^{2}$, y su superficie máxima de $662,79 \mathrm{~m}^{2}$ (área del rectángulo que genera), por lo que se aprecian unas constantes "K" en función de la superficie entre la longitud de líneas que van de 0,80 como mínimo a 1,76 como máximo. Esto nos da un factor de crecimiento FC (-) de 0,96 y un factor de crecimiento FC (:) de 2,19.

Del análisis de esta figura también se puede ver que tiene una barra articulada a un nudo rígido en el plano que corresponde al vértice del rectángulo. Los giros permitidos en el eje xy van de $0^{\circ}$ a $76^{\circ}$. 

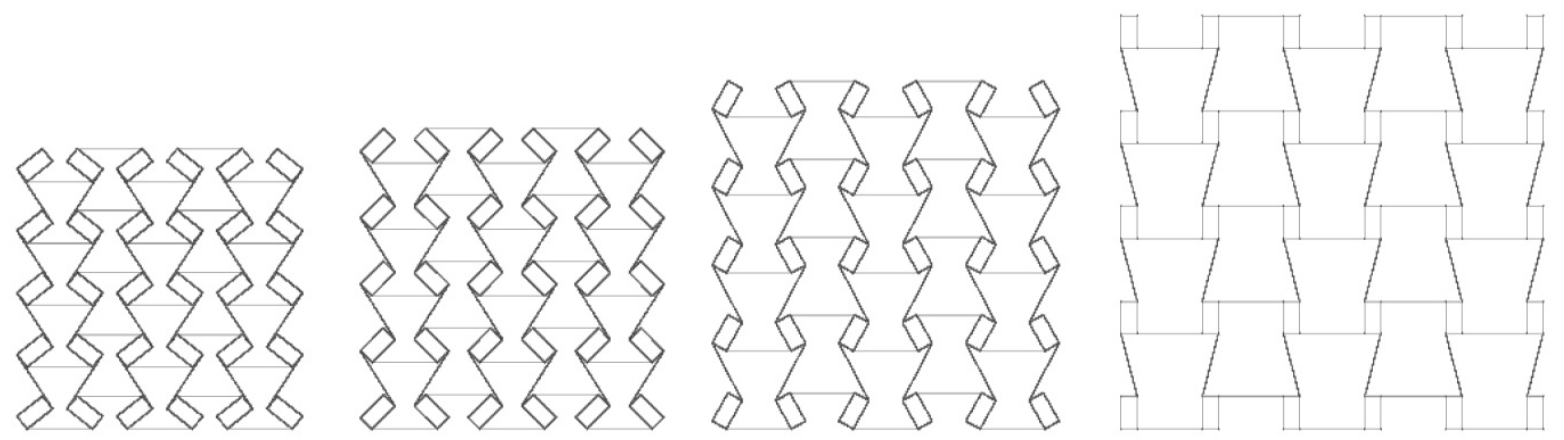

Figura 152 Desarrollo desplegable de estructura quiral rectangular simétrica 2d, elaboración propia

\subsubsection{Estructura en 3 dimensiones}

La estructura quiral rectangular 3D estudiada tiene una longitud total de sus barras de $2455,03 \mathrm{~m}$. No es capaz de plegarse totalmente, siendo su volumen mínimo de $2802,44 \mathrm{~m}^{3}$, y su volumen máximo de $5484,67 \mathrm{~m}^{3}$ (volumen del cubo que genera), por lo que se aprecian unas constantes "K" en función de la superficie entre la longitud de líneas que van de 0,12 como mínimo a 2,23 como máximo. Esto nos da un factor de crecimiento FC (-) de 2,11 y un factor de crecimiento FC (:) de 18,13.

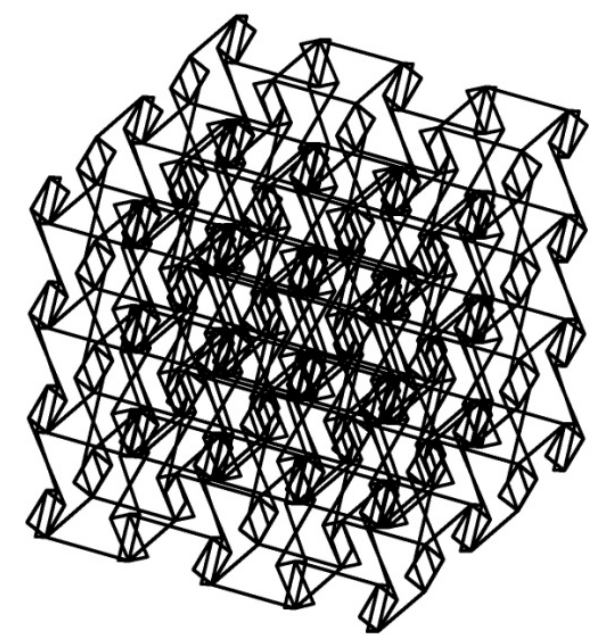

Figura 153 Estructura quiral rectangular simétrica 3d, elaboración propia

Del análisis de esta figura también se puede ver que tiene una barra articulada a un nudo rígido en el espacio que corresponde al vértice del rectángulo. Los giros permitidos van de $0^{\circ}$ a $76^{\circ}$. 


\subsubsection{Estructura torre (por giro de la estructura 2D)}

La estructura quiral rectangular simétrica tipo torre estudiada tiene una longitud total de sus barras de $480,34 \mathrm{~m}$. No es capaz de plegarse totalmente, siendo su volumen mínimo de $802,44 \mathrm{~m}^{3}$, y su volumen máximo de $1662,79 \mathrm{~m}^{3}$ (volumen del cilindro que genera), por lo que se aprecian unas constantes "K" en función de la superficie entre la longitud de líneas que van de 0,63 como mínimo a 1,38 como máximo. Esto nos da un factor de crecimiento FC (-) de 0,75 y un factor de crecimiento FC (:) de 2,19.

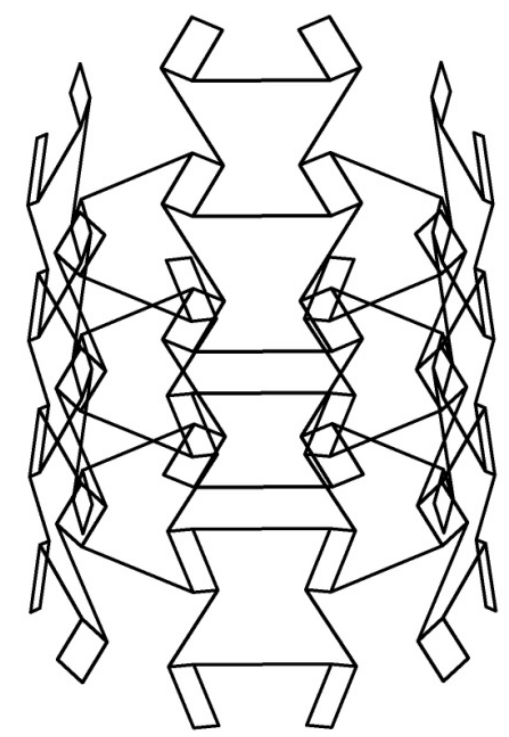

Figura 154 Estructura quiral rectangular simétrica tipo torre, elaboración propia

\subsubsection{Quiral hexagonal}

La estructura quiral hexagonal se forma mediante la unión de unas barras a los vértices de un hexágono. Mediante la rotación en el mismo sentido de todas estas barras se consigue el comportamiento auxético.

\subsubsection{Patrón unidad}

La estructura quiral hexagonal individual estudiada tiene una longitud total de sus barras de $12,00 \mathrm{~m}$. No es capaz de plegarse totalmente, siendo su superficie mínima de $2,60 \mathrm{~m}^{2}$, y su superficie máxima de $10,39 \mathrm{~m}^{2}$ (área del hexágono que genera), por lo que se aprecian unas constantes "K" en función de la superficie entre la longitud de líneas que van de 0,22 como mínimo a 0,87 como máximo. Esto nos da un factor de crecimiento FC (-) de 0,65 y un factor de crecimiento FC (:) de 4,00. 


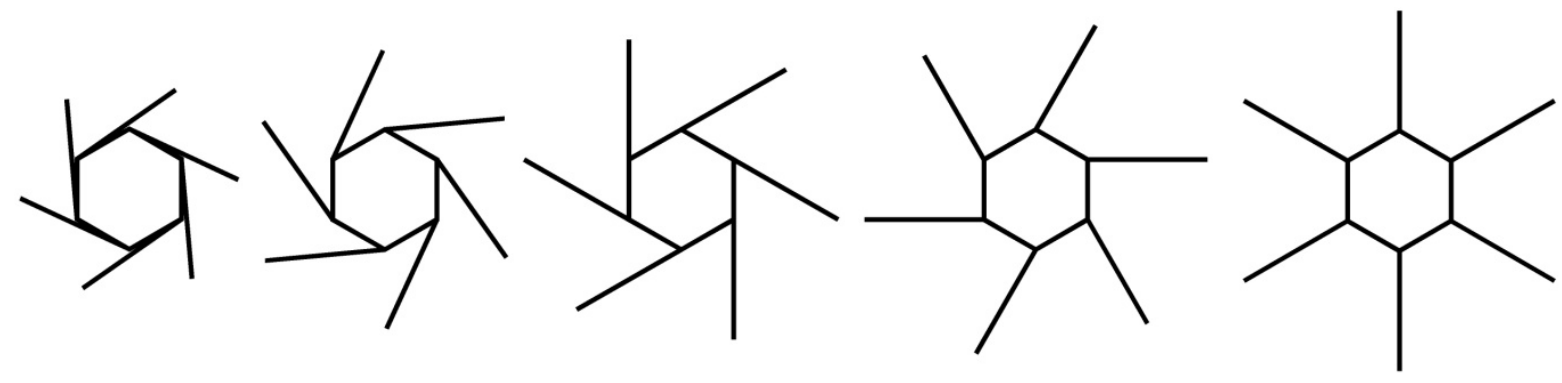

Figura 155 Desarrollo desplegable de estructura quiral hexagonal individual, elaboración propia

Del análisis de esta figura también se puede ver que tiene una barra articulada a un nudo rígido en el plano que corresponde al vértice del hexágono. Los giros permitidos en el eje xy van de $0^{\circ}$ a $150^{\circ}$.

\subsubsection{Estructura en 2 dimensiones}

La estructura quiral hexagonal 2D estudiada tiene una longitud total de sus barras de $141,96 \mathrm{~m}$. No es capaz de plegarse totalmente, siendo su superficie mínima de $45,74 \mathrm{~m}^{2}$, y su superficie máxima de $157,62 \mathrm{~m}^{2}$ (área del cuadrado que genera), por lo que se aprecian unas constantes "K" en función de la superficie entre la longitud de líneas que van de 0,32 como mínimo a 1,11 como máximo. Esto nos da un factor de crecimiento FC (-) de 0,79 y un factor de crecimiento FC (:) de 3,45.
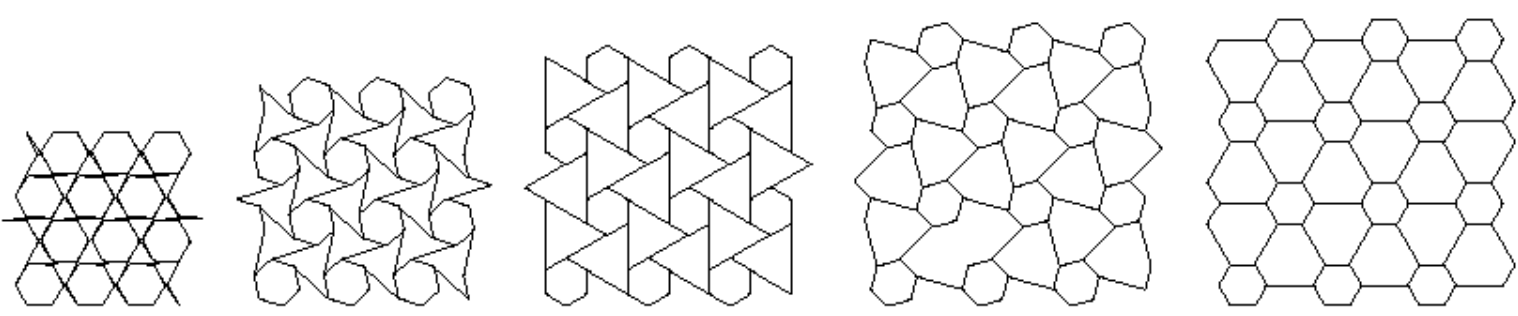

Figura 156 Desarrollo desplegable de estructura quiral hexagonal 2d, elaboración propia

Del análisis de esta figura también se puede ver que tiene una barra articulada a un nudo rígido en el plano que corresponde al vértice del hexágono. Los giros permitidos en el eje xy van de $0^{\circ}$ a $150^{\circ}$. 


\subsubsection{Estructura en 3 dimensiones}

La estructura quiral hexagonal 3D estudiada tiene una longitud total de sus barras de $1728,00 \mathrm{~m}$. No es capaz de plegarse totalmente, siendo su volumen mínimo de $645,74 \mathrm{~m}^{3}$, y su volumen máximo de $1615,84 \mathrm{~m}^{3}$ (volumen del cubo que genera), por lo que se aprecian unas constantes "K" en función de la superficie entre la longitud de líneas que van de 0,03 como mínimo a 0,94 como máximo. Esto nos da un factor de crecimiento FC (-) de 0,91 y un factor de crecimiento FC (:) de 35,33.

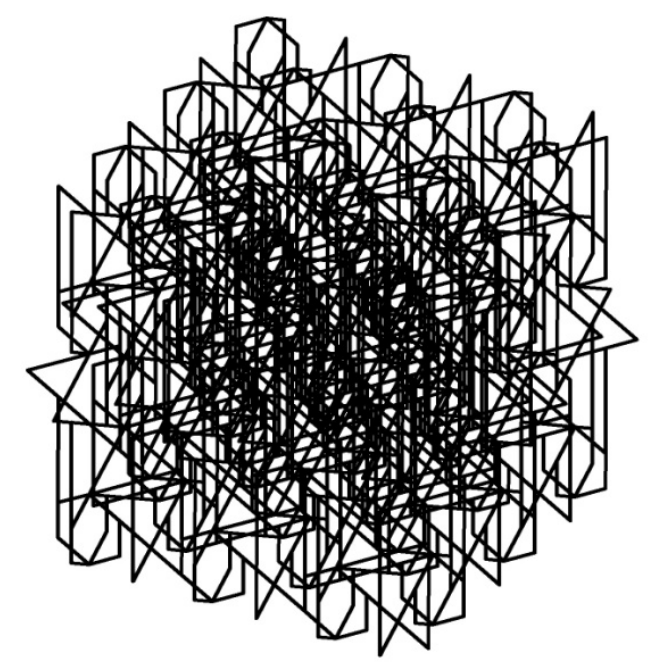

Figura 157 Estructura quiral hexagonal 3d, elaboración propia

Del análisis de esta figura también se puede ver que tiene una barra articulada a un nudo rígido en los planos que corresponden al vértice del hexágono: cuando se juntan dos de estos dos planos en perpendicular aparecen dos barras articuladas en el mismo nudo, produciéndose las rotaciones en el espacio. Los giros permitidos van de $0^{\circ}$ a $150^{\circ}$.

\subsubsection{Estructura torre (por giro de la estructura 2D)}

La estructura quiral hexagonal torre estudiada tiene una longitud total de sus barras de $159,27 \mathrm{~m}$. No es capaz de plegarse totalmente, siendo su volumen mínimo de $263,05 \mathrm{~m}^{3}$, y su volumen máximo de $657,62 \mathrm{~m}^{3}$ (volumen del cilindro que genera), por lo que se aprecian unas constantes "K" en función de la superficie entre la longitud de líneas que van de 0,29 como mínimo a 0,99 como máximo. Esto nos da un factor de crecimiento FC (-) de 0,70 y un factor de crecimiento FC (:) de 3,45. 


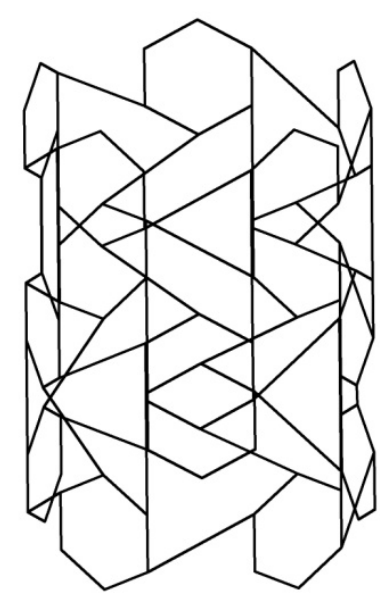

Figura 158 Estructura quiral hexagonal tipo torre, elaboración propia

Del análisis de esta figura también se puede ver que tiene una barra articulada a un nudo rígido en el espacio que corresponde al vértice del hexágono. Los giros permitidos van de $0^{\circ}$ a $150^{\circ}$.

\subsubsection{Quiral circular}

La estructura quiral circular se forma mediante la unión de unas barras con forma de arco de circunferencia al perímetro de una circunferencia. Mediante la rotación en el mismo sentido de todas estas barras se consigue el comportamiento auxético.

\subsubsection{Patrón unidad}

La estructura quiral circular individual estudiada tiene una longitud total de sus barras de $25,13 \mathrm{~m}$. No es capaz de plegarse totalmente, siendo su superficie mínima de $18,31 \mathrm{~m}^{2}$, y su superficie máxima de $28,27 \mathrm{~m}^{2}$ (área del círculo que genera), por lo que se aprecian unas constantes "K" en función de la superficie entre la longitud de líneas que van de 0,73 como mínimo a 1,12 como máximo. Esto nos da un factor de crecimiento FC (-) de 0,40 y un factor de crecimiento FC (:) de 1,54.

Del análisis de esta figura también se puede ver que tiene una barra articulada a un nudo rígido en el plano que corresponde a un punto de la longitud de una circunferencia. Los giros permitidos van de $0^{\circ}$ a $90^{\circ}$. 

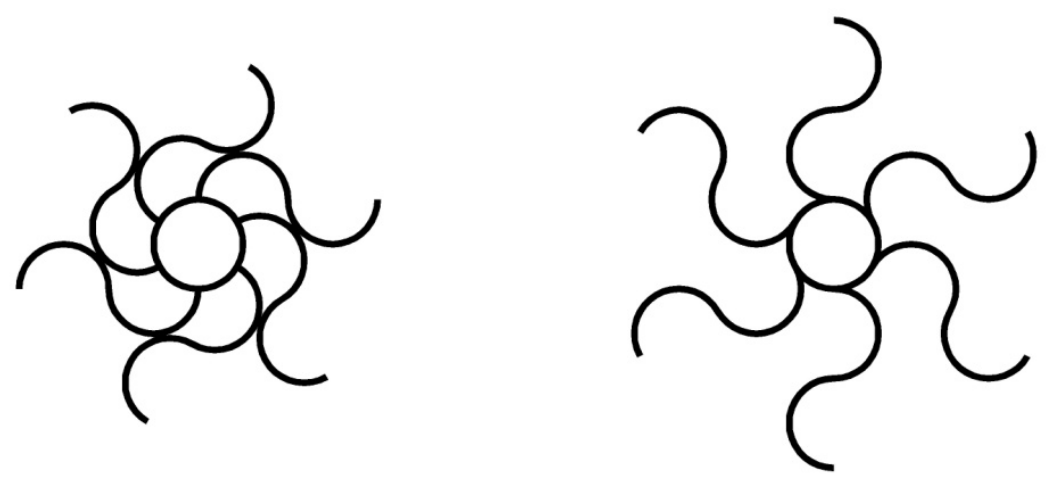

Figura 159 Desarrollo desplegable de estructura quiral circular individual, elaboración propia

\subsubsection{Estructura en 2 dimensiones}

La estructura quiral circular 2D estudiada tiene una longitud total de sus barras de $119,32 \mathrm{~m}$. No es capaz de plegarse totalmente, siendo su superficie mínima de $94,07 \mathrm{~m}^{2}$, y su superficie máxima de $153,94 \mathrm{~m}^{2}$ (área de la circunferencia que genera), por lo que se aprecian unas constantes " $\mathrm{K}$ " en función de la superficie entre la longitud de líneas que van de 0,79 como mínimo a 1,29 como máximo. Esto nos da un factor de crecimiento FC (-) de 0,50 y un factor de crecimiento FC (:) de 1,64.
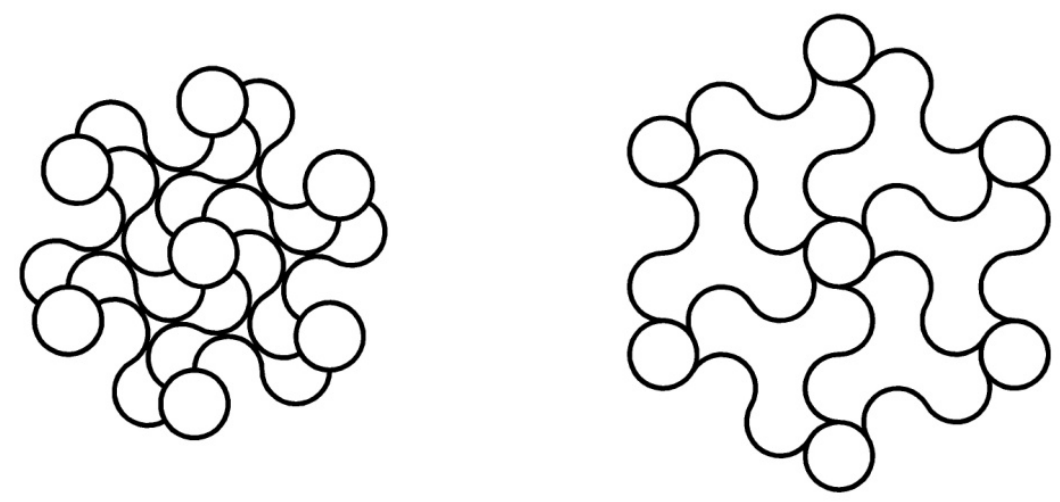

Figura 160 Desarrollo desplegable de estructura quiral circular 2D, elaboración propia

Del análisis de esta figura también se puede ver que tiene una barra articulada a un nudo rígido en el plano que corresponde a un punto de la longitud de una circunferencia. Los giros permitidos van de $0^{\circ}$ a $90^{\circ}$. 


\subsubsection{Estructura en 3 dimensiones}

La estructura quiral circular 3D estudiada tiene una longitud total de sus barras de $3328,40 \mathrm{~m}$. No es capaz de plegarse totalmente, siendo su volumen mínimo de $5198,56 \mathrm{~m}^{3}$, y su volumen máximo de $10313,55 \mathrm{~m}^{3}$ (volumen del cubo que genera), por lo que se aprecian unas constantes "K" en función de la superficie entre la longitud de líneas que van de 0,79 como mínimo a 1,29 como máximo. Esto nos da un factor de crecimiento FC (-) de 0,50 y un factor de crecimiento FC (:) de 1,64.
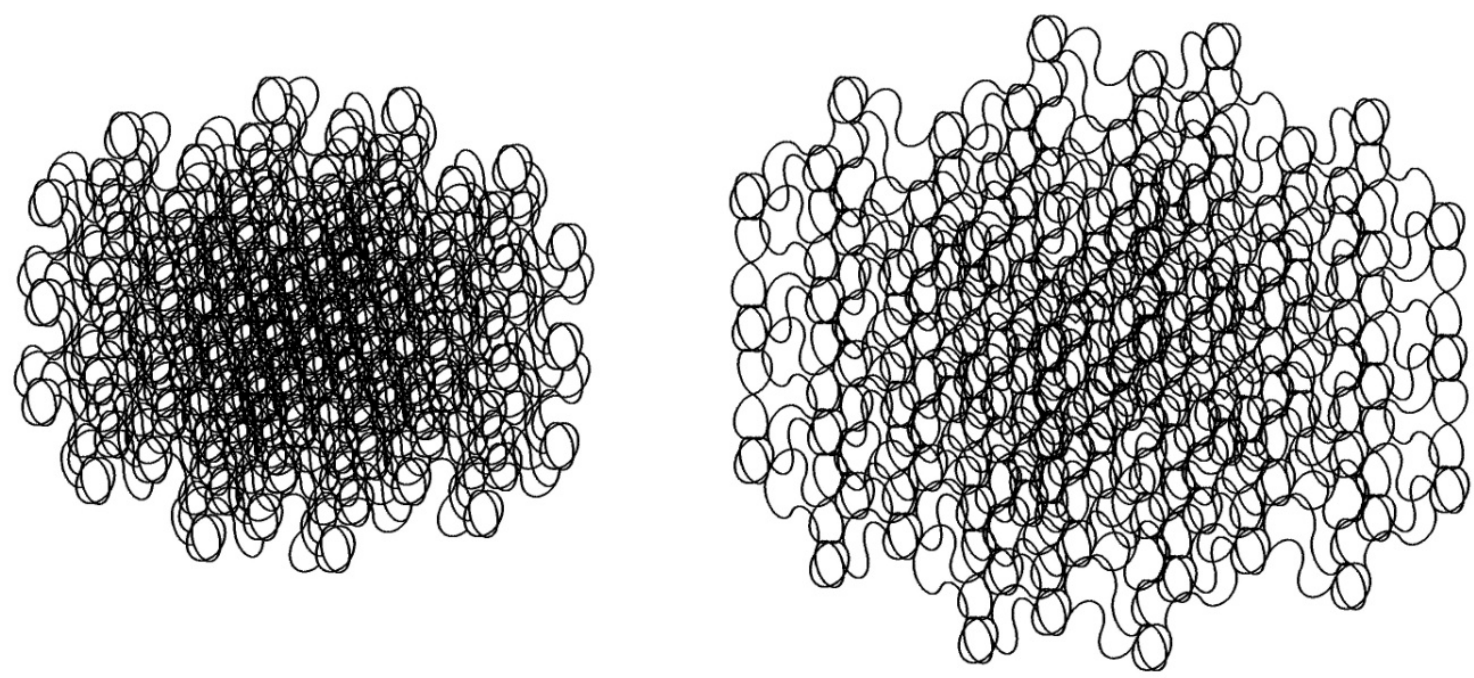

Figura 161 Desarrollo desplegable de estructura quiral circular 3D, elaboración propia

Del análisis de esta figura también se puede ver que tiene una barra articulada a un nudo rígido en el plano que corresponde a un punto de la longitud de una circunferencia. Cuando los planos se cruzan pasan a ser dos barras articuladas las que atacan a un mismo punto del perímetro de la circunferencia. Los giros permitidos van de $0^{\circ}$ a $90^{\circ}$.

\subsubsection{Estructura torre (por giro de la estructura 2D)}

La estructura quiral circular torre estudiada tiene una longitud total de sus barras de $200,00 \mathrm{~m}$. No es capaz de plegarse totalmente, siendo su volumen mínimo de $1894,07 \mathrm{~m}^{3}$, y su volumen máximo de $3828,59 \mathrm{~m}^{3}$ (volumen del cilindro que genera), por lo que se aprecian unas constantes "K" en función de la superficie entre la longitud de líneas que van de 0,79 como mínimo a 32,09 como máximo. Esto nos da un factor de crecimiento FC (-) de 31,30 y un factor de crecimiento FC (:) de 40,70. 


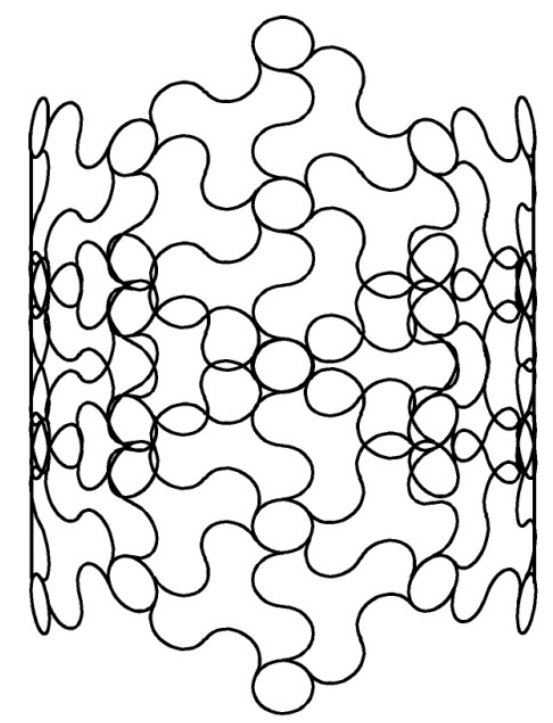

Figura 162 Estructura quiral circular tipo torre, elaboración propia

\subsubsection{Unidad rotatoria tetraédrica}

Se produce por la repetición tetraedros unidos mediante bisagras. El comportamiento auxético se produce por la rotación de las distintas unidades alrededor de las uniones, de tal manera que se produce un empaquetamiento o desempaquetamiento, en función del sentido del movimiento.

\subsubsection{Patrón unidad}

La unidad rotatoria tetraédrica individual estudiada tiene una longitud total de sus barras de $36,00 \mathrm{~m}$. No es capaz de plegarse totalmente, siendo su superficie mínima de $2,60 \mathrm{~m}^{2}$, y su superficie máxima de $7,79 \mathrm{~m}^{2}$ (área del hexágono que genera), por lo que se aprecian unas constantes "K" en función de la superficie entre la longitud de líneas que van de 0,07 como mínimo a 0,22 como máximo. Esto nos da un factor de crecimiento FC (-) de 0,14 y un factor de crecimiento FC (:) de 3,00 .
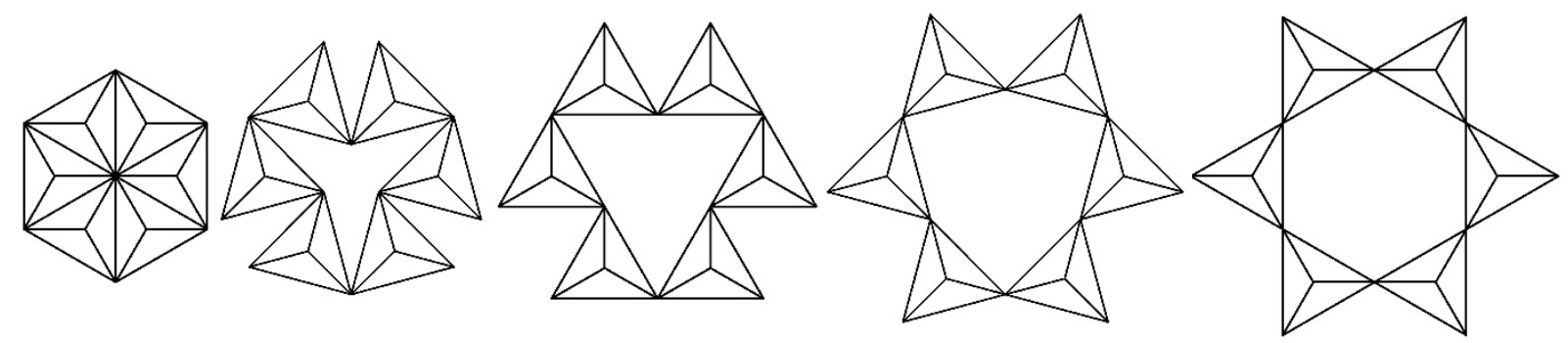

Figura 163 Desarrollo desplegable de unidad rotatoria tetraédrica individual, elaboración propia 
Del análisis de esta figura también se puede ver que los paquetes de 3 barras rígidas de dos tetraedros se articulan entre sí en un nudo que permite las rotaciones en el plano. Los giros permitidos van de $0^{\circ}$ a $60^{\circ}$.

\subsubsection{Estructura en 2 dimensiones}

La unidad rotatoria tetraédrica 2D estudiada tiene una longitud total de sus barras de $168,00 \mathrm{~m}$. No es capaz de plegarse totalmente, siendo su superficie mínima de $13,86 \mathrm{~m}^{2}$, y su superficie máxima de $48,50 \mathrm{~m}^{2}$ (área del cuadrilátero que genera), por lo que se aprecian unas constantes " $K$ " en función de la superficie entre la longitud de líneas que van de 0,08 como mínimo a 0,29 como máximo. Esto nos da un factor de crecimiento FC (-) de 0,21 y un factor de crecimiento FC (:) de 3,50.

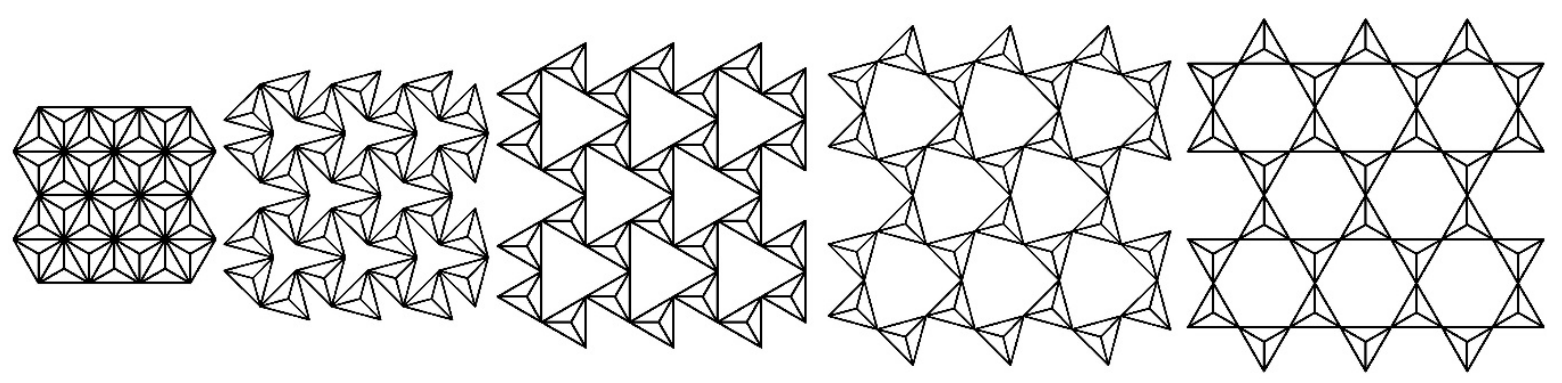

Figura 164 Desarrollo desplegable de unidad rotatoria tetraédrica 2d, elaboración propia

Del análisis de esta figura también se puede ver que los paquetes de 3 barras rígidas de dos tetraedros se articulan entre sí en un nudo que permite las rotaciones en el plano. Los giros permitidos van de $0^{\circ}$ a $60^{\circ}$.

\subsubsection{Estructura en 3 dimensiones}

La unidad rotatoria tetraédrica 3D estudiada tiene una longitud total de sus barras de $1845,00 \mathrm{~m}$. No es capaz de plegarse totalmente, siendo su volumen mínimo de $65,21 \mathrm{~m}^{3}$, y su volumen máximo de $228,24 \mathrm{~m}^{3}$ (volumen del cubo que genera), por lo que se aprecian unas constantes "K" en función de la superficie entre la longitud de líneas que van de 0,01 como mínimo a 0,03 como máximo. Esto nos da un factor de crecimiento FC (-) de 0,02 y un factor de crecimiento FC (:) de 3,50. 


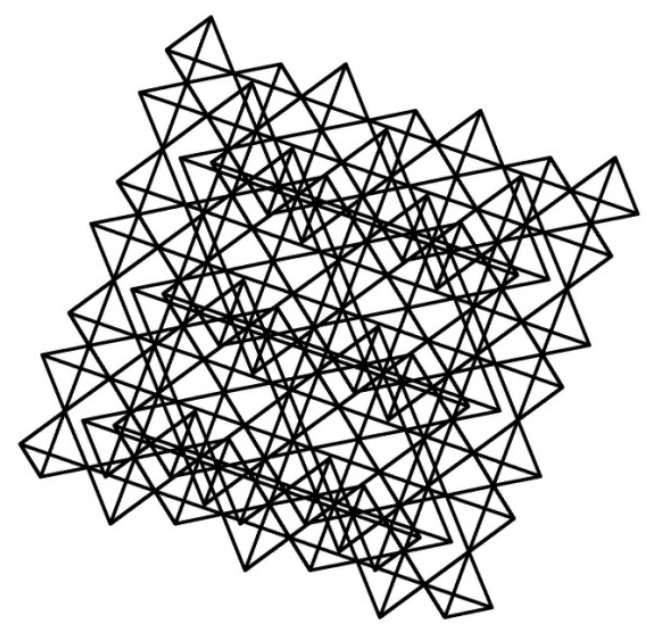

Figura 165 Unidad rotatoria tetraédrica 3D, elaboración propia

Del análisis de esta figura también se puede ver que los paquetes de 3 barras rígidas de dos tetraedros se articulan entre sí en un nudo que permite las rotaciones en el plano. Los giros permitidos van de $0^{\circ}$ a $60^{\circ}$.

\subsubsection{Estructura torre (por giro de la estructura 2D)}

La unidad rotatoria tetraédrica torre estudiada tiene una longitud total de sus barras de $2160,00 \mathrm{~m}$. No es capaz de plegarse totalmente, siendo su volumen mínimo de $4413,86 \mathrm{~m}^{3}$, y su volumen máximo de $15641,19 \mathrm{~m}^{3}$ (volumen del cilindro que genera), por lo que se aprecian unas constantes "K" en función de la superficie entre la longitud de líneas que van de 0,01 como mínimo a 7,24 como máximo. Esto nos da un factor de crecimiento FC (-) de 7,23 y un factor de crecimiento FC (:) de 1128,51.

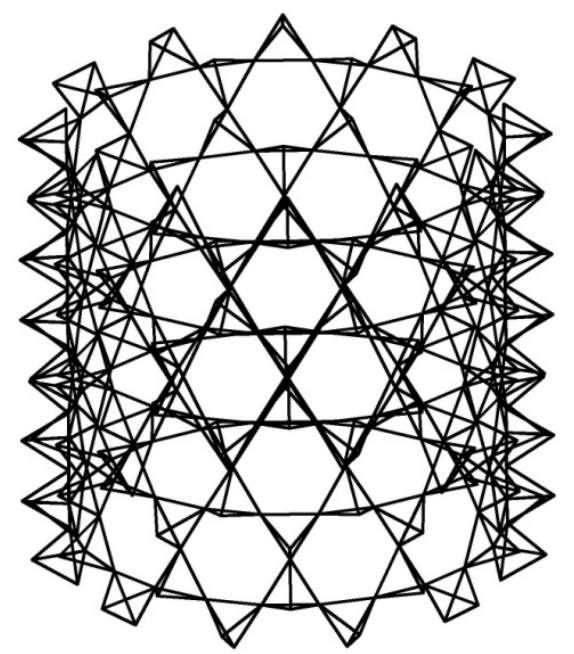

Figura 166 Unidad rotatoria tetraédrica tipo torre, elaboración propia 


\subsubsection{Unidad rotatoria triangular}

Se produce por la repetición triángulos unidos mediante bisagras. El comportamiento auxético se produce por la rotación de las distintas unidades alrededor de las uniones, de tal manera que se produce un empaquetamiento o desempaquetamiento, en función del sentido del movimiento.

\subsubsection{Patrón unidad}

La unidad rotatoria triangular individual estudiada tiene una longitud total de sus barras de $18,00 \mathrm{~m}$. No es capaz de plegarse totalmente, siendo su superficie mínima de $2,60 \mathrm{~m}^{2}$, y su superficie máxima de $7,79 \mathrm{~m}^{2}$ (área del hexágono que genera), por lo que se aprecian unas constantes "K" en función de la superficie entre la longitud de líneas que van de 0,14 como mínimo a 0,43 como máximo. Esto nos da un factor de crecimiento FC (-) de 0,29 y un factor de crecimiento FC (:) de 3,00.
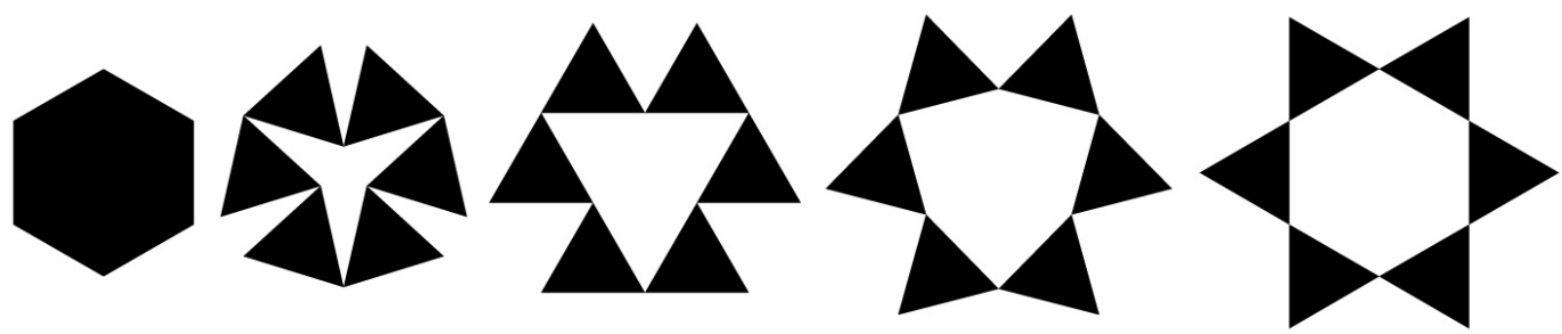

Figura 167 Desarrollo desplegable de unidad rotatoria triangular individual, elaboración propia

Del análisis de esta figura también se puede ver que los paquetes de 2 barras rígidas de dos triángulos se articulan entre sí en un nudo que permite las rotaciones en el plano. Los giros permitidos van de $0^{\circ}$ a $60^{\circ}$.

\subsubsection{Estructura en 2 dimensiones}

La unidad rotatoria triangular 2D estudiada tiene una longitud total de sus barras de $84,00 \mathrm{~m}$. No es capaz de plegarse totalmente, siendo su superficie mínima de $13,86 \mathrm{~m}^{2}$, y su superficie máxima de $48,50 \mathrm{~m}^{2}$ (área del cuadrilátero que genera), por lo que se aprecian unas constantes "K" en función de la superficie entre la longitud de líneas que van de 0,17 como mínimo a 0,58 como máximo. Esto nos da un factor de crecimiento FC (-) de 0,41 y un factor de crecimiento FC (:) de 3,50. 

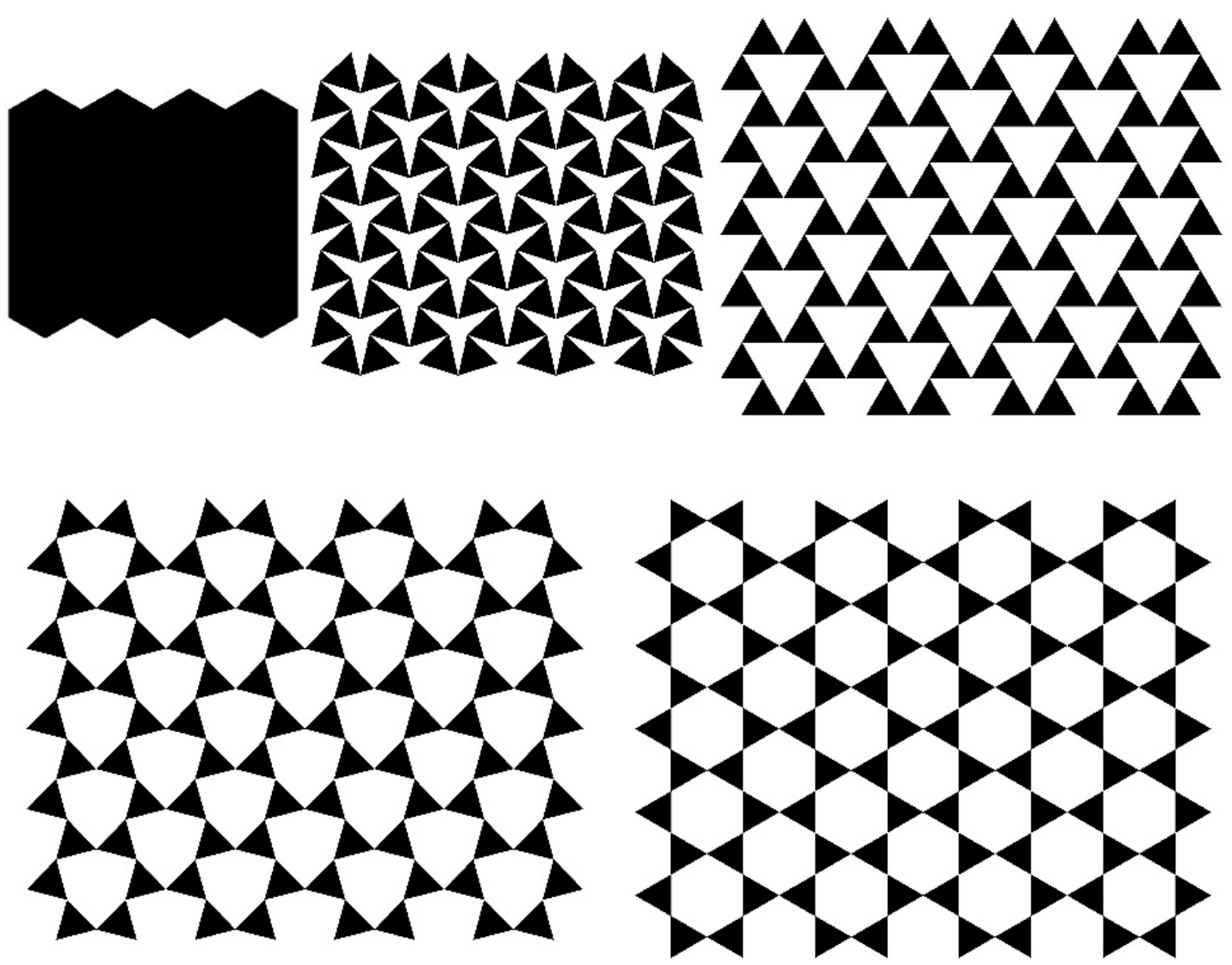

Figura 168 Desarrollo desplegable de unidad rotatoria triangular 2d, elaboración propia

Del análisis de esta figura también se puede ver que los paquetes de 2 barras rígidas de dos triángulos se articulan entre sí en un nudo que permite las rotaciones en el plano. Los giros permitidos van de $0^{\circ}$ a $60^{\circ}$.

\subsubsection{Estructura en 3 dimensiones}

La unidad rotatoria triangular 3D estudiada tiene una longitud total de sus barras de $672,00 \mathrm{~m}$. No es capaz de plegarse totalmente, siendo su volumen mínimo de $65,21 \mathrm{~m}^{3}$, y su volumen máximo de $228,24 \mathrm{~m}^{3}$ (volumen del cubo que genera), por lo que se aprecian unas constantes "K" en función de la superficie entre la longitud de líneas que van de 0,02 como mínimo a 0,34 como máximo. Esto nos da un factor de crecimiento FC (-) de 0,32 y un factor de crecimiento FC (:) de 16,47. 


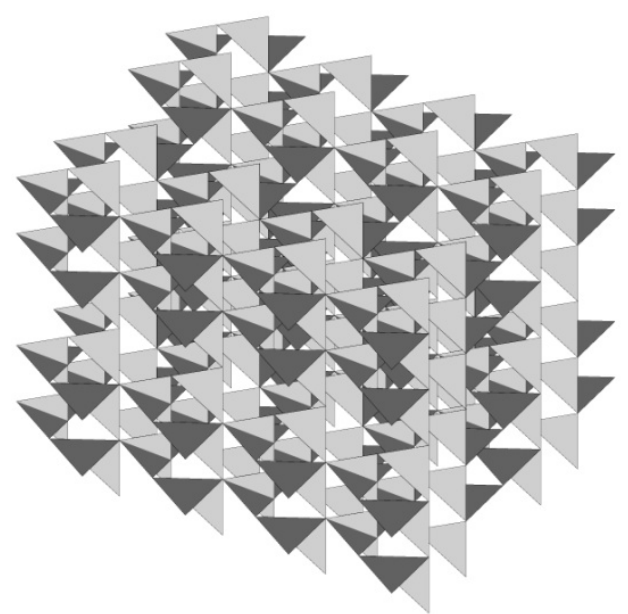

Figura 169 Unidad rotatoria triangular 3D, elaboración propia

Del análisis de esta figura también se puede ver que los paquetes de 2 barras rígidas de dos o tres triángulos se articulan entre sí en un nudo que permite las rotaciones en el espacio. Los giros permitidos van de $0^{\circ}$ a $60^{\circ}$.

\subsubsection{Estructura torre (por giro de la estructura 2D)}

La unidad rotatoria triangular torre estudiada tiene una longitud total de sus barras de $336,00 \mathrm{~m}$. No es capaz de plegarse totalmente, siendo su volumen mínimo de $68,86 \mathrm{~m}^{3}$, y su volumen máximo de $240,65 \mathrm{~m}^{3}$ (volumen del cilindro que genera), por lo que se aprecian unas constantes "K" en función de la superficie entre la longitud de líneas que van de 0,04 como mínimo a 0,72 como máximo. Esto nos da un factor de crecimiento FC (-) de 0,67 y un factor de crecimiento FC (:) de 17,36.

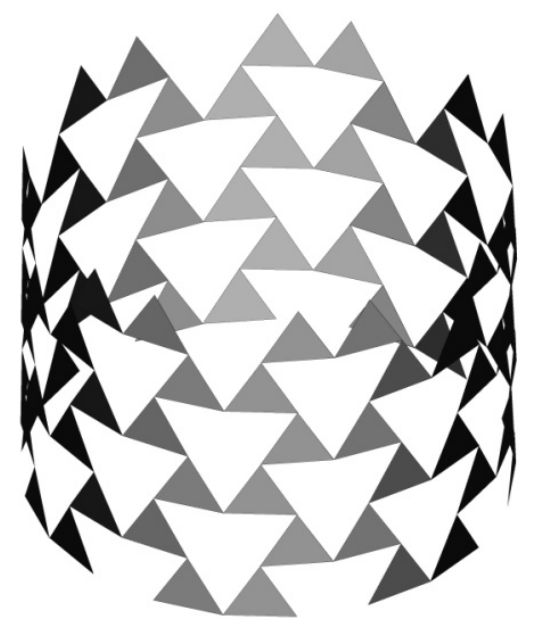

Figura 170 Unidad rotatoria triangular tipo torre, elaboración propia 


\subsubsection{Unidad rotatoria cuadrangular}

Se produce por la repetición cuadrados unidos mediante bisagras en sus vértices. El comportamiento auxético se produce por la rotación de las distintas unidades alrededor de las uniones, de tal manera que se produce un empaquetamiento o desempaquetamiento, en función del sentido del movimiento.

\subsubsection{Patrón unidad}

La unidad rotatoria cuadrangular individual estudiada tiene una longitud total de sus barras de $16,00 \mathrm{~m}$. No es capaz de plegarse totalmente, siendo su superficie mínima de $4,00 \mathrm{~m}^{2}$, y su superficie máxima de $7,00 \mathrm{~m}^{2}$ (área del cuadrado que genera), por lo que se aprecian unas constantes "K" en función de la superficie entre la longitud de líneas que van de 0,25 como mínimo a 0,44 como máximo. Esto nos da un factor de crecimiento FC (-) de 0,19 y un factor de crecimiento FC (:) de 1,75.
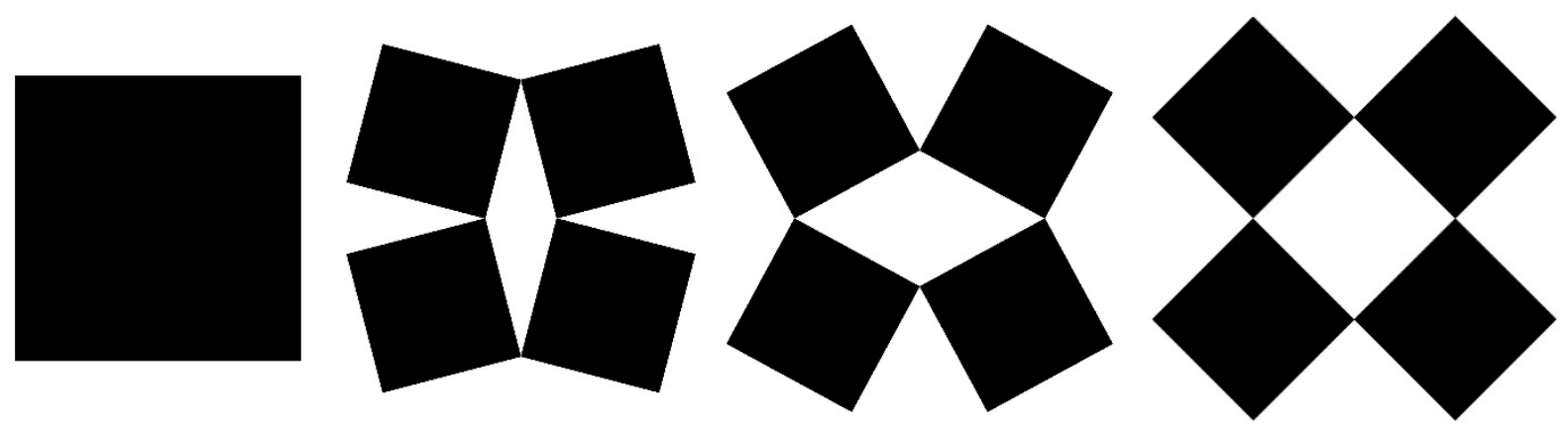

Figura 171 Desarrollo desplegable de unidad rotatoria cuadrada individual, elaboración propia

Del análisis de esta figura también se puede ver que los paquetes de 2 barras rígidas de dos cuadrados se articulan entre sí en un nudo que permite las rotaciones en el plano. Los giros permitidos van de $0^{\circ}$ a $45^{\circ}$.

\subsubsection{Estructura en 2 dimensiones}

La unidad rotatoria cuadrangular 2D estudiada tiene una longitud total de sus barras de $100,00 \mathrm{~m}$. No es capaz de plegarse totalmente, siendo su superficie mínima de $25,00 \mathrm{~m}^{2}$, y su superficie máxima de $50,00 \mathrm{~m}^{2}$ (área del cuadrado que genera), por lo que se aprecian unas constantes "K" en función de la superficie entre la longitud de líneas que van de 0,25 como 
mínimo a 0,50 como máximo. Esto nos da un factor de crecimiento FC (-) de 0,25 y un factor de crecimiento FC (:) de 2,00.

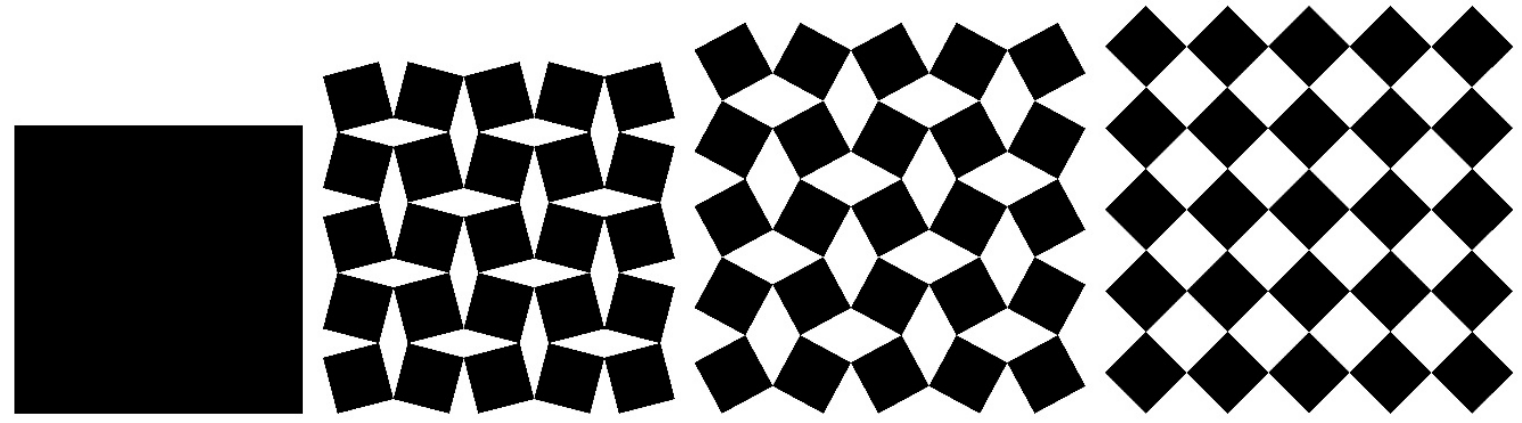

Figura 172 Desarrollo desplegable de unidad rotatoria cuadrada 2d, elaboración propia

Del análisis de esta figura también se puede ver que los paquetes de 2 barras rígidas de dos cuadrados se articulan entre sí en un nudo que permite las rotaciones en el plano. Los giros permitidos van de $0^{\circ}$ a $45^{\circ}$.

\subsubsection{Estructura en 3 dimensiones}

La unidad rotatoria cuadrangular 3D estudiada tiene una longitud total de sus barras de $254,18 \mathrm{~m}$. No es capaz de plegarse totalmente, siendo su volumen mínimo de $38,18 \mathrm{~m}^{3}$, y su volumen máximo de $76,37 \mathrm{~m}^{3}$ (volumen del cubo que genera), por lo que se aprecian unas constantes "K" en función de la superficie entre la longitud de líneas que van de 0,10 como mínimo a 0,30 como máximo. Esto nos da un factor de crecimiento FC (-) de 0,15 y un factor de crecimiento FC (:) de 2,00.
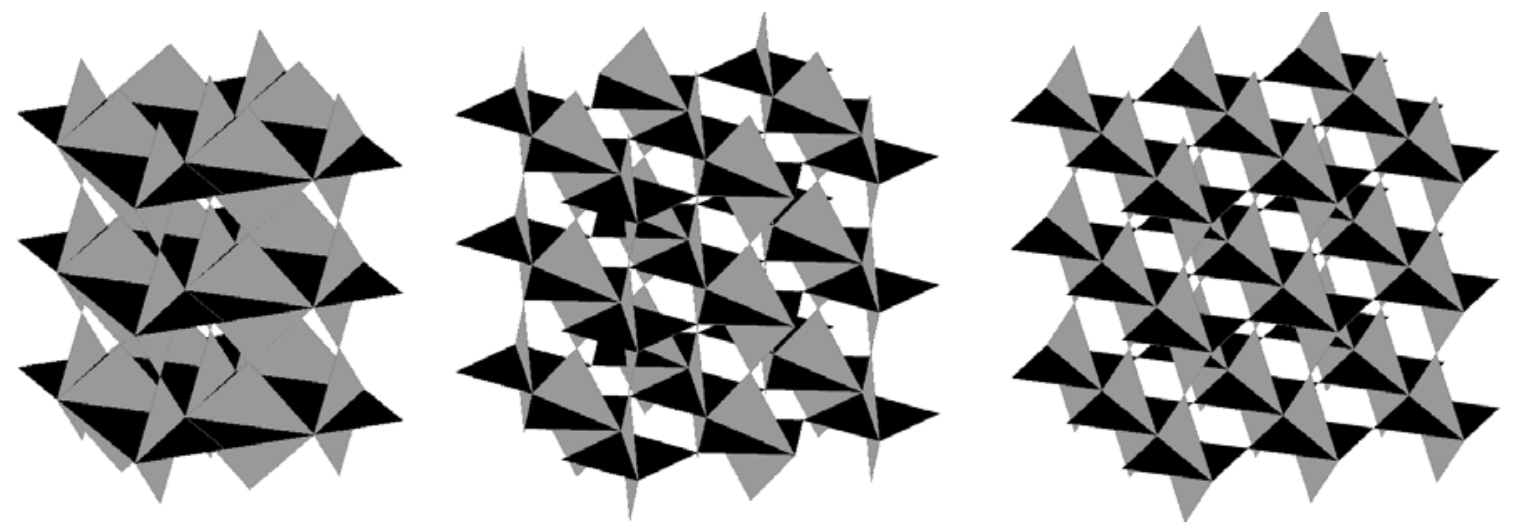

Figura 173 Desarrollo desplegable de unidad rotatoria cuadrada 3d, elaboración propia 
Del análisis de esta figura también se puede ver que los paquetes de 2 barras rígidas de dos cuadrados que se articulaban entre sí en un nudo que permitía las rotaciones en el plano para la estructura 2D, pasan a ser paquetes de 5 barras rígidas de dos cuadrados que generan un nudo que permite las rotaciones en el espacio. Los giros permitidos van de $0^{\circ} \mathrm{a}$ $45^{\circ}$.

\subsubsection{Estructura torre (por giro de la estructura 2D)}

La unidad rotatoria cuadrangular torre estudiada tiene una longitud total de sus barras de $120,00 \mathrm{~m}$. No es capaz de plegarse totalmente, siendo su volumen mínimo de $34,00 \mathrm{~m}^{3}$, y su volumen máximo de $68,00 \mathrm{~m}^{3}$ (volumen del cilindro que genera), por lo que se aprecian unas constantes "K" en función de la superficie entre la longitud de líneas que van de 0,21 como mínimo a 0,42 como máximo. Esto nos da un factor de crecimiento $\mathrm{FC}(-)$ de 0,21 y un factor de crecimiento FC (:) de 2,00.

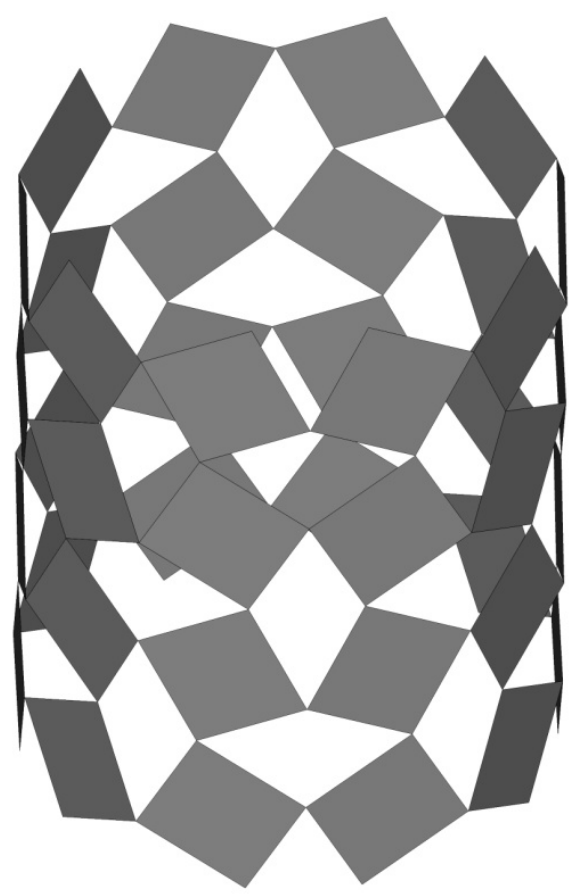

Figura 174 Unidad rotatoria cuadrangular tipo torre, elaboración propia

Del análisis de esta figura también se puede ver que los paquetes de 2 barras rígidas de dos cuadrados se articulan entre sí en un nudo que permite las rotaciones en el espacio. Los giros permitidos van de $0^{\circ}$ a $45^{\circ}$. 


\subsubsection{Unidad rotatoria rectangular}

Se produce por la repetición rectángulos unidos mediante bisagras en sus vértices. El comportamiento auxético se produce por la rotación de las distintas unidades alrededor de las uniones, de tal manera que se produce un empaquetamiento o desempaquetamiento, en función del sentido del movimiento.

\subsubsection{Patrón unidad}

La unidad rotatoria rectangular individual estudiada tiene una longitud total de sus barras de $24,00 \mathrm{~m}$. No es capaz de plegarse totalmente, siendo su superficie mínima de $12,00 \mathrm{~m}^{2}$, y su superficie máxima de $13,00 \mathrm{~m}^{2}$ (área del rectángulo que genera), por lo que se aprecian unas constantes "K" en función de la superficie entre la longitud de líneas que van de 0,50 como mínimo a 0,54 como máximo. Esto nos da un factor de crecimiento FC (-) de 0,04 y un factor de crecimiento FC (:) de 1,08.
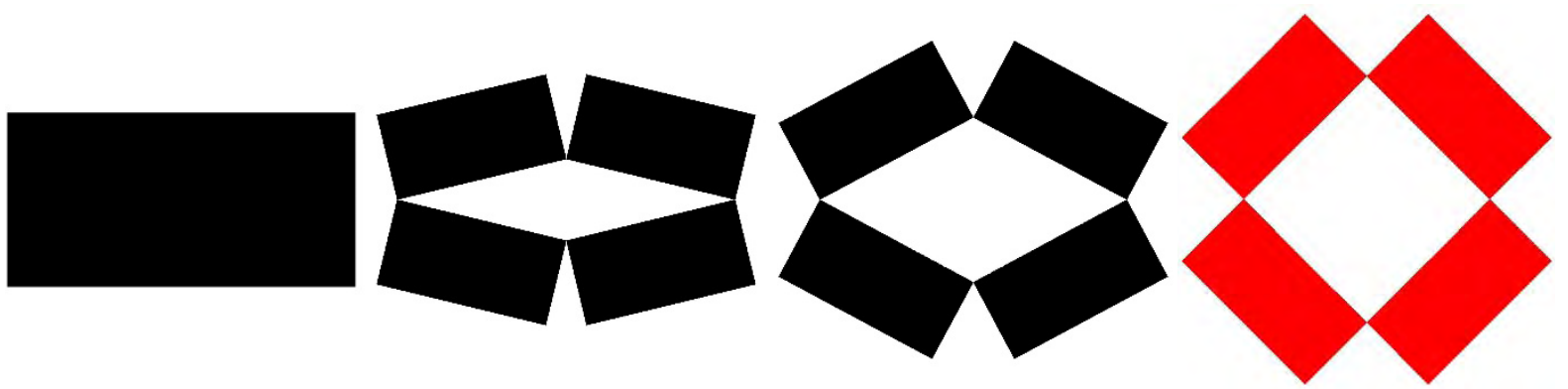

Figura 175 Desarrollo desplegable de unidad rotatoria rectangular individual, elaboración propia

Del análisis de esta figura también se puede ver que los paquetes de 2 barras rígidas de dos rectángulos se articulan entre sí en un nudo que permite las rotaciones en el plano. Los giros permitidos van de $0^{\circ}$ a $45^{\circ}$, pero sin embargo, al llegar a su máxima apertura $\left(45^{\circ}\right)$ el comportamiento deja de ser auxético (se aprecia que la dimensión lateral disminuye al aumentar la vertical).

\subsubsection{Estructura en 2 dimensiones}

La unidad rotatoria rectangular 2D estudiada tiene una longitud total de sus barras de $288,00 \mathrm{~m}$. No es capaz de plegarse totalmente, siendo su superficie mínima de $96,00 \mathrm{~m}^{2}$, y su superficie máxima de $195,96 \mathrm{~m}^{2}$ (área del rectángulo que genera), por lo que se aprecian unas constantes "K" en función de la superficie entre la longitud de líneas que van de 0,33 
como mínimo a 0,68 como máximo. Esto nos da un factor de crecimiento FC (-) de 0,35 y un factor de crecimiento FC (:) de 2,04.
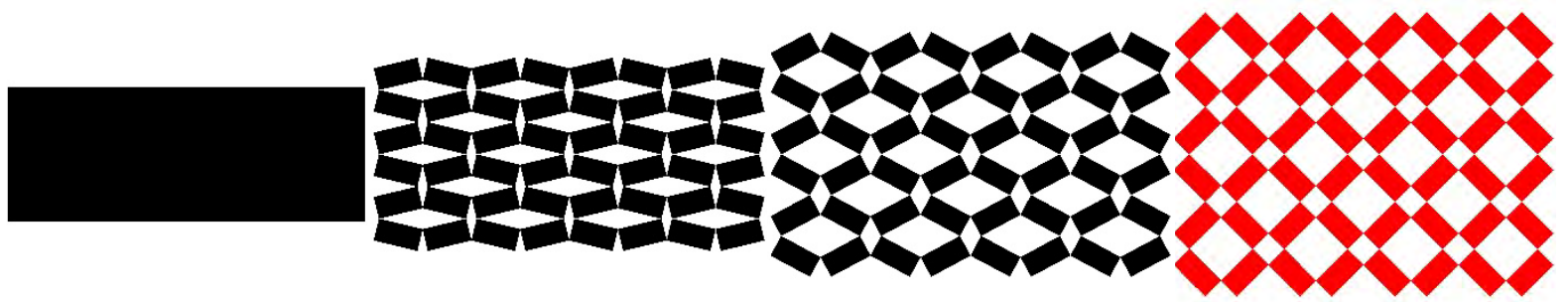

Figura 176 Desarrollo desplegable de unidad rotatoria rectangular 2d, elaboración propia

Del análisis de esta figura también se puede ver que los paquetes de 2 barras rígidas de dos rectángulos se articulan entre sí en un nudo que permite las rotaciones en el plano. Los giros permitidos van de $0^{\circ}$ a $45^{\circ}$, pero sin embargo, al llegar a su máxima apertura $\left(45^{\circ}\right)$ el comportamiento deja de ser auxético (se aprecia que la dimensión lateral disminuye al aumentar la vertical).

\subsubsection{Estructura en 3 dimensiones}

La unidad rotatoria rectangular 3D estudiada tiene una longitud total de sus barras de $576,00 \mathrm{~m}$. No es capaz de plegarse totalmente, siendo su volumen mínimo de $146,61 \mathrm{~m}^{3}$, y su volumen máximo de $301,36 \mathrm{~m}^{3}$ (volumen del cubo que genera), por lo que se aprecian unas constantes "K" en función de la superficie entre la longitud de líneas que van de 0,17 como mínimo a 0,34 como máximo. Esto nos da un factor de crecimiento FC (-) de 0,17 y un factor de crecimiento FC (:) de 2,04.

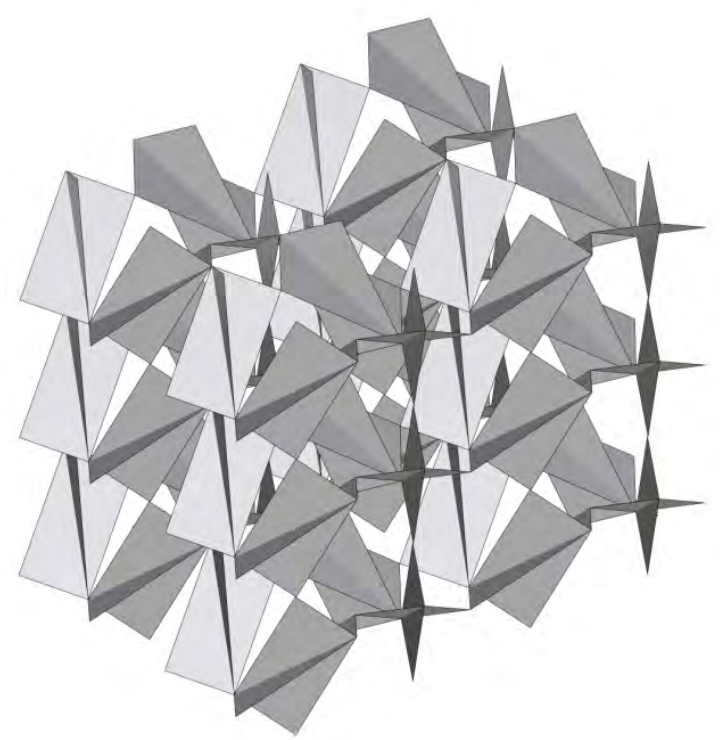

Figura 177 Unidad rotatoria rectangular 3d, elaboración propia 
Del análisis de esta figura también se puede ver que los paquetes de 2 barras rígidas de dos rectángulos se articulaban entre sí en un nudo que permitía las rotaciones en el plano, pasan a ser 2 barras rígidas de 4 rectángulos que se articulan entre sí en el espacio, permitiendo giros que van de $0^{\circ}$ a $45^{\circ}$.

\subsubsection{Estructura torre (por giro de la estructura 2D)}

La unidad rotatoria rectangular torre estudiada tiene una longitud total de sus barras de $240,00 \mathrm{~m}$. No es capaz de plegarse totalmente, siendo su volumen mínimo de $146,00 \mathrm{~m}^{3}$, y su volumen máximo de $295,96 \mathrm{~m}^{3}$ (volumen del cilindro que genera), por lo que se aprecian unas constantes "K" en función de la superficie entre la longitud de líneas que van de 0,40 como mínimo a 0,82 como máximo. Esto nos da un factor de crecimiento FC (-) de 0,42 y un factor de crecimiento FC (:) de 2,04.

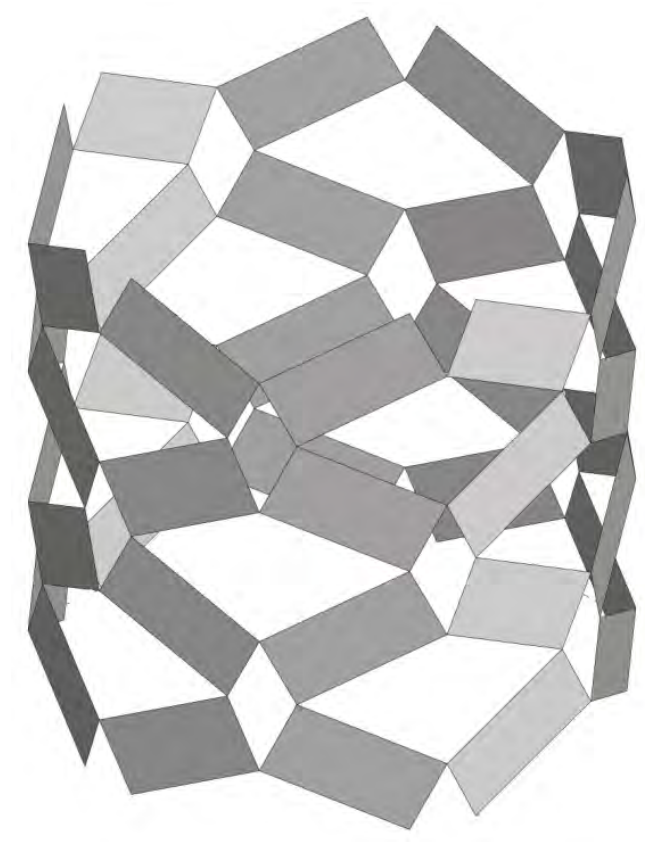

Figura 178 Unidad rotatoria rectangular tipo torre, elaboración propia

Del análisis de esta figura también se puede ver que los paquetes de 2 barras rígidas de dos rectángulos se articulan entre sí en un nudo que permite las rotaciones en el plano. Los giros permitidos van de $0^{\circ}$ a $45^{\circ}$, pero sin embargo, al llegar a su máxima apertura $\left(45^{\circ}\right)$ el comportamiento deja de ser auxético (se aprecia que la dimensión lateral disminuye al aumentar la vertical). 


\subsubsection{Unidad rotatoria de rectángulos diferentes}

Se produce por la repetición rectángulos de diferente tamaño unidos mediante bisagras en sus vértices. El comportamiento auxético se produce por la rotación de las distintas unidades alrededor de las uniones, de tal manera que se produce un empaquetamiento o desempaquetamiento, en función del sentido del movimiento.

\subsubsection{Patrón unidad}

La unidad rotatoria de rectángulos diferentes individual estudiada tiene una longitud total de sus barras de $42,00 \mathrm{~m}$. No es capaz de plegarse totalmente, siendo su superficie mínima de $41,00 \mathrm{~m}^{2}$, y su superficie máxima de $50,00 \mathrm{~m}^{2}$ (área del rectángulo que genera), por lo que se aprecian unas constantes "K" en función de la superficie entre la longitud de líneas que van de 0,98 como mínimo a 1,19 como máximo. Esto nos da un factor de crecimiento FC (-) de 0,21 y un factor de crecimiento FC (:) de 1,22.

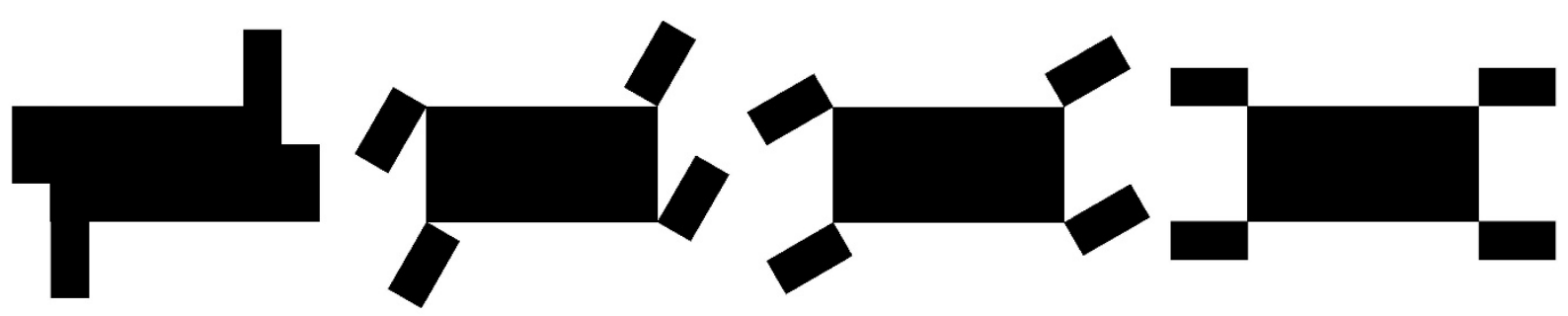

Figura 179 Desarrollo desplegable de unidad rotatoria de rectángulos diferentes individual, elaboración propia

Del análisis de esta figura también se puede ver que los paquetes de 2 barras rígidas de dos rectángulos de diferente tamaño se articulan entre sí en un nudo que permite las rotaciones en el plano. Los giros permitidos van de $0^{\circ}$ a $90^{\circ}$.

\subsubsection{Estructura en 2 dimensiones}

La unidad rotatoria de rectágulos diferentes 2D estudiada tiene una longitud total de sus barras de 432,00m. No es capaz de plegarse totalmente, siendo su superficie mínima de $445,50 \mathrm{~m}^{2}$, y su superficie máxima de $570,00 \mathrm{~m}^{2}$ (área del rectángulo que genera), por lo que se aprecian unas constantes "K" en función de la superficie entre la longitud de líneas que van de 1,03 como mínimo a 1,32 como máximo. Esto nos da un factor de crecimiento FC (-) de 0,29 y un factor de crecimiento FC (:) de 1,28. 

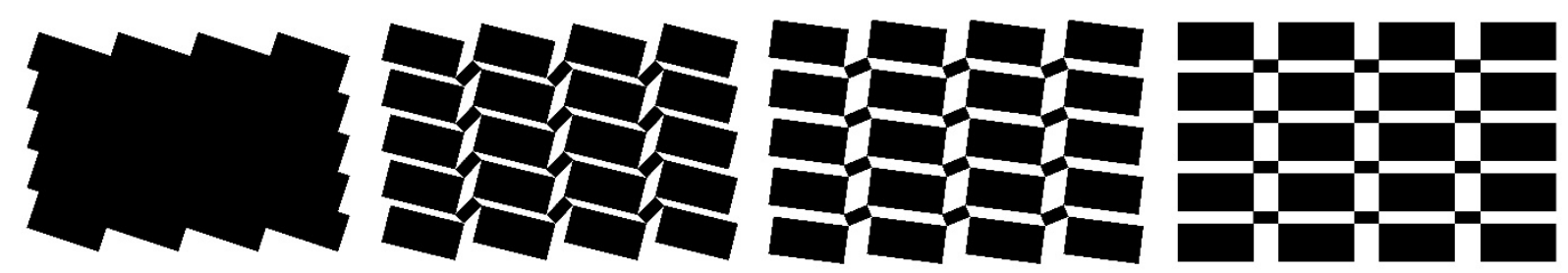

Figura 180 Desarrollo desplegable de unidad rotatoria de rectángulos diferentes 2d, elaboración propia

Del análisis de esta figura también se puede ver que los paquetes de 2 barras rígidas de dos rectángulos de diferente tamaño se articulan entre sí en un nudo que permite las rotaciones en el plano. Los giros permitidos van de $0^{\circ}$ a $90^{\circ}$.

\subsubsection{Estructura en 3 dimensiones}

La unidad rotatoria de rectángulos diferentes 3D estudiada tiene una longitud total de sus barras de $1236,00 \mathrm{~m}$. No es capaz de plegarse totalmente, siendo su volumen mínimo de $3403,12 \mathrm{~m}^{3}$, y su volumen máximo de $4356,00 \mathrm{~m}^{3}$ (volumen del cubo que genera), por lo que se aprecian unas constantes "K" en función de la superficie entre la longitud de líneas que van de 0,36 como mínimo a 3,52 como máximo. Esto nos da un factor de crecimiento FC (-) de 3,16 y un factor de crecimiento FC (:) de 9,78.

Del análisis de esta figura también se puede ver que los paquetes de 2 barras rígidas de dos rectángulos de diferente tamaño se articulan entre sí en un nudo que permite las rotaciones en el plano. Los giros permitidos van de $0^{\circ}$ a $90^{\circ}$.

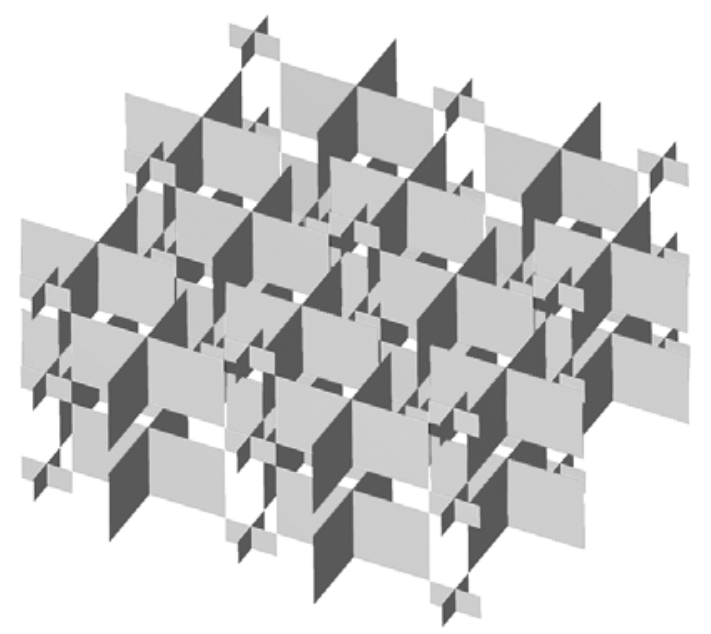

Figura 181 Unidad rotatoria de rectángulos diferentes 3d, elaboración propia 


\subsubsection{Estructura torre (por giro de la estructura 2D)}

La unidad rotatoria de rectángulos diferentes torre estudiada tiene una longitud total de sus barras de $1691,75 \mathrm{~m}$. No es capaz de plegarse totalmente, siendo su volumen mínimo de $10345,50 \mathrm{~m}^{3}$, y su volumen máximo de $13238,21 \mathrm{~m}^{3}$ (volumen del cilindro que genera), por lo que se aprecian unas constantes " $K$ " en función de la superficie entre la longitud de líneas que van de 0,26 como mínimo a 7,83 como máximo. Esto nos da un factor de crecimiento FC (-) de 7,56 y un factor de crecimiento FC (:) de 29,72.

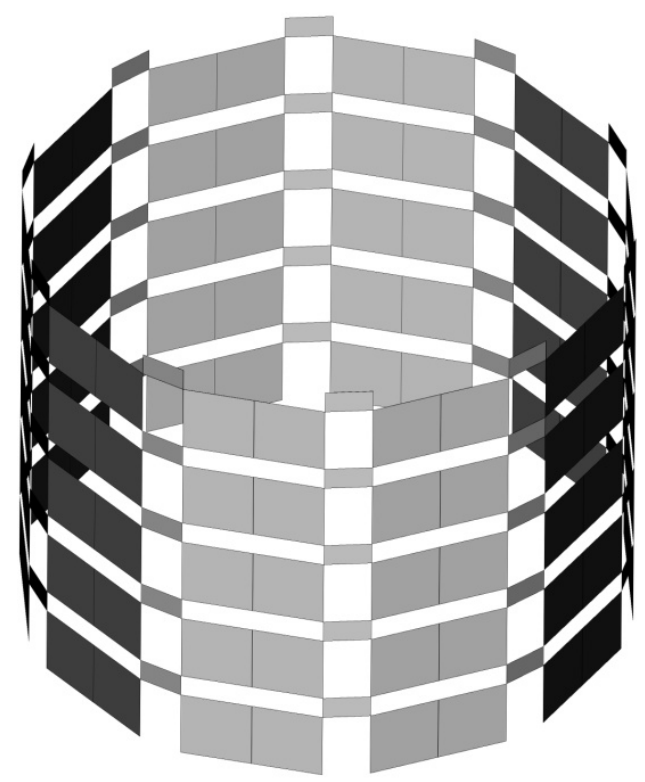

Figura 182 Unidad rotatoria de rectángulos diferentes tipo torre, elaboración propia

Del análisis de esta figura también se puede ver que los paquetes de 2 barras rígidas de dos rectángulos de diferente tamaño se articulan entre sí en un nudo que permite las rotaciones en el espacio. Los giros permitidos van de $0^{\circ}$ a $90^{\circ}$.

\subsubsection{Polímero microporoso cuadrado}

El polímero microporoso cuadrado se forma mediante la unión de unas barras a los vértices de un cuadrado. Mediante la rotación en sentidos opuestos y simétricos de todas estas barras se consigue el comportamiento auxético, de manera que al producirse una compresión se produce un movimiento de traslación lateral de los núcleos. 


\subsubsection{Patrón unidad}

El polímero microporoso cuadrado individual estudiado tiene una longitud total de sus barras de 6,00m. No es capaz de plegarse totalmente, siendo su superficie mínima de $1,00 \mathrm{~m}^{2}$, y su superficie máxima de $2,00 \mathrm{~m}^{2}$ (área del rectángulo que genera), por lo que se aprecian unas constantes "K" en función de la superficie entre la longitud de líneas que van de 0,17 como mínimo a 0,33 como máximo. Esto nos da un factor de crecimiento FC (-) de 0,17 y un factor de crecimiento FC (:) de 2,00.
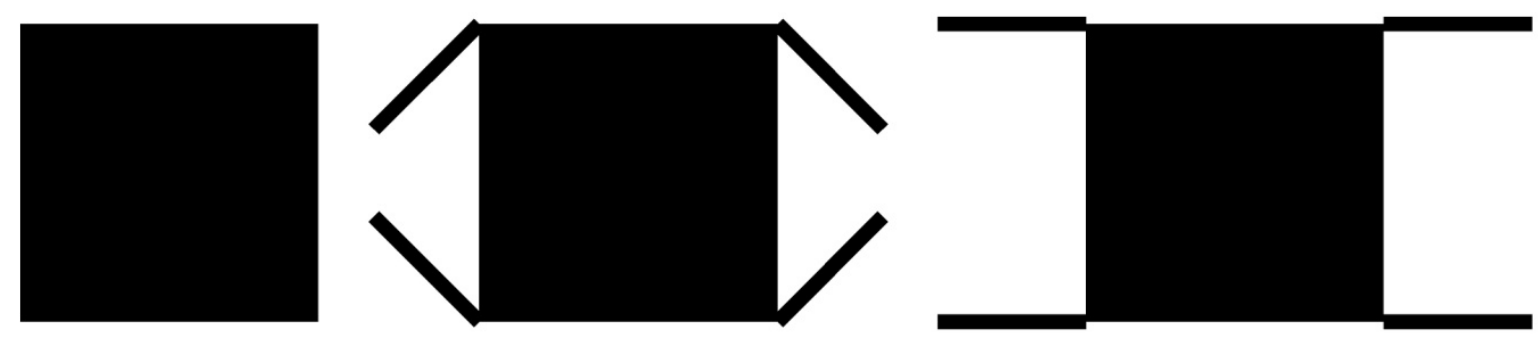

Figura 183 Desarrollo desplegable de polímero microporoso cuadrado individual, elaboración propia

Del análisis de esta figura también se puede ver que tiene una barra articulada a un nudo rígido en el plano que corresponde al vértice del cuadrado. Los giros permitidos en el eje xy van de $0^{\circ}$ a $90^{\circ}$.

\subsubsection{Estructura en 2 dimensiones}

El polímero microporoso cuadrado 2D estudiado tiene una longitud total de sus barras de $84,00 \mathrm{~m}$. No es capaz de plegarse totalmente, siendo su superficie mínima de $20,00 \mathrm{~m}^{2}$, y su superficie máxima de $49,00 \mathrm{~m}^{2}$ (área del cuadrado que genera), por lo que se aprecian unas constantes " $K$ " en función de la superficie entre la longitud de líneas que van de 0,24 como mínimo a 0,58 como máximo. Esto nos da un factor de crecimiento FC (-) de 0,35 y un factor de crecimiento FC (:) de 2,45. 

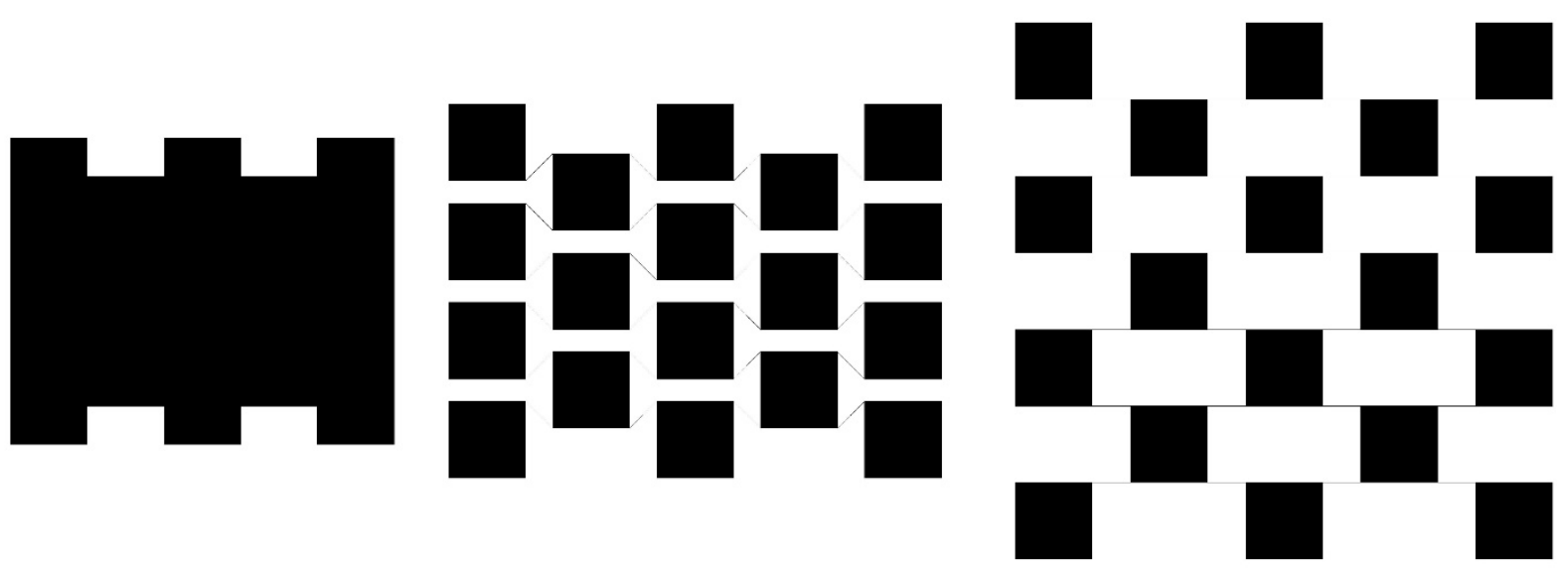

Figura 184 Desarrollo desplegable de polímero microporoso cuadrado 2d, elaboración propia

Del análisis de esta figura también se puede ver que tiene una barra articulada a un nudo rígido en el plano que corresponde al vértice del cuadrado. Los giros permitidos en el eje xy van de $0^{\circ}$ a $90^{\circ}$.

\subsubsection{Estructura en 3 dimensiones}

El polímero microporoso cuadrado 3D estudiado tiene una longitud total de sus barras de $200,00 \mathrm{~m}$. No es capaz de plegarse totalmente, siendo su volumen mínimo de $27,00 \mathrm{~m}^{3}$, y su volumen máximo de $80,00 \mathrm{~m}^{3}$ (volumen del cubo que genera), por lo que se aprecian unas constantes "K" en función de la superficie entre la longitud de líneas que van de 0,14 como mínimo a 0,40 como máximo. Esto nos da un factor de crecimiento FC (-) de 0,27 y un factor de crecimiento FC (:) de 2,96.

Del análisis de esta figura también se puede ver que tiene una barra articulada a un nudo rígido en cada plano que corresponde al vértice del cuadrado. Los giros permitidos en los ejes horizontales van de $0^{\circ}$ a $90^{\circ}$. 

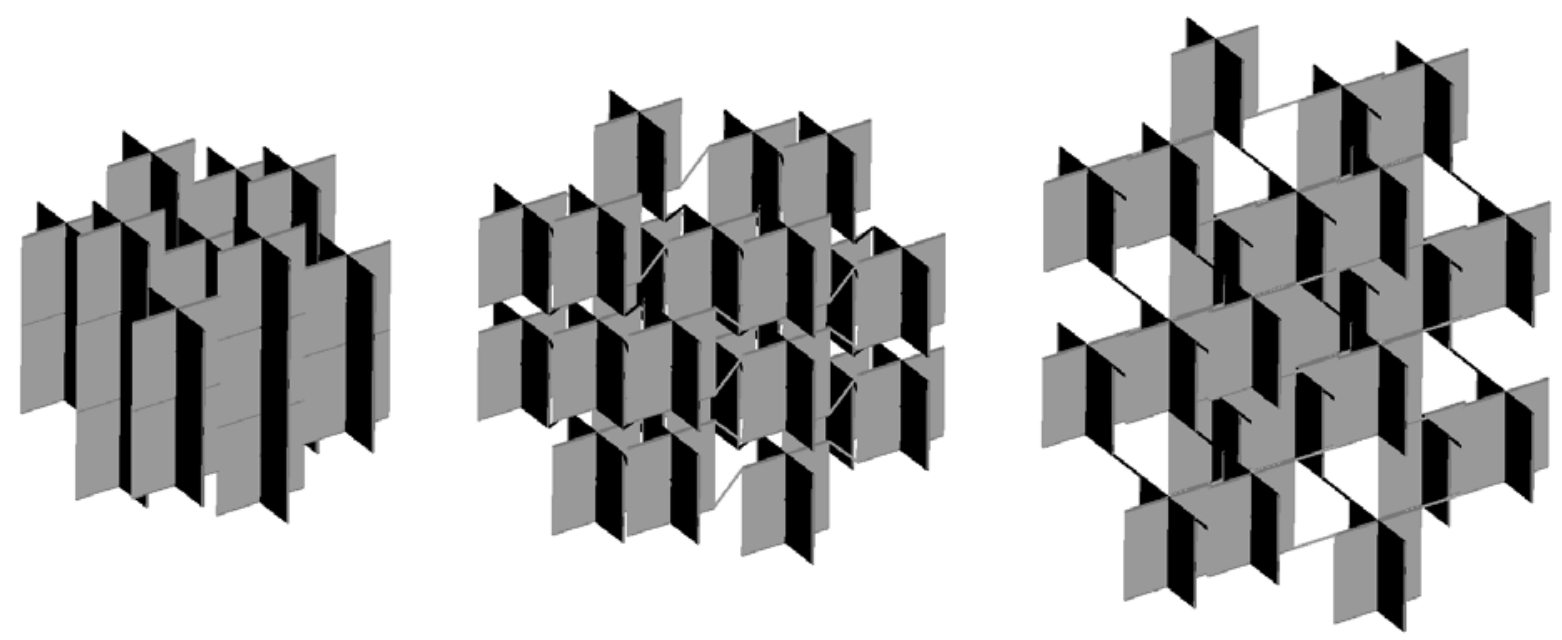

Figura 185 Desarrollo desplegable de polímero microporoso cuadrado 3d, elaboración propia

\subsubsection{Estructura torre (por giro de la estructura 2D)}

El polímero microporoso cuadrado torre estudiado tiene una longitud total de sus barras de $172,42 \mathrm{~m}$. No es capaz de plegarse totalmente, siendo su volumen mínimo de $40,00 \mathrm{~m}^{3}$, y su volumen máximo de $98,00 \mathrm{~m}^{3}$ (volumen del cilindro que genera), por lo que se aprecian unas constantes "K" en función de la superficie entre la longitud de líneas que van de 0,12 como mínimo a 0,28 como máximo. Esto nos da un factor de crecimiento FC (-) de 0,17 y un factor de crecimiento FC (:) de 2,45.

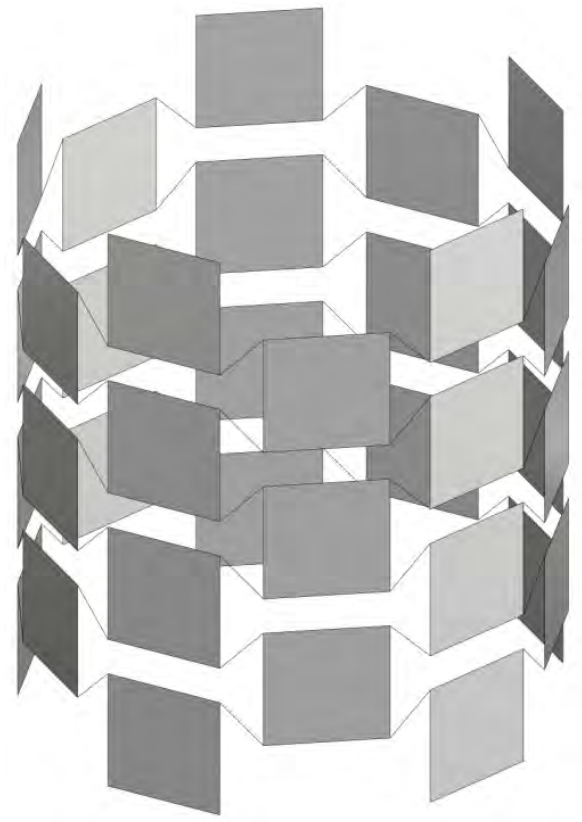

Figura 186 Polímero microporoso cuadrado tipo torre, elaboración propia 
Del análisis de esta figura también se puede ver que tiene una barra articulada a un nudo rígido en cada plano que corresponde al vértice del cuadrado. Los giros permitidos en el espacio van de $0^{\circ}$ a $90^{\circ}$.

\subsubsection{Polímero microporoso rectangular}

El polímero microporoso rectangular se forma mediante la unión de unas barras a los vértices de un rectángulo. Mediante la rotación en sentidos opuestos y simétricos de todas estas barras se consigue el comportamiento auxético, de manera que al producirse una compresión se produce un movimiento de traslación lateral de los núcleos.

\subsubsection{Patrón unidad}

El polímero microporoso rectangular individual estudiado tiene una longitud total de sus barras de 8,00m. No es capaz de plegarse totalmente, siendo su superficie mínima de $2,00 \mathrm{~m}^{2}$, y su superficie máxima de $3,00 \mathrm{~m}^{2}$ (área del rectángulo que genera), por lo que se aprecian unas constantes "K" en función de la superficie entre la longitud de líneas que van de 0,25 como mínimo a 0,38 como máximo. Esto nos da un factor de crecimiento FC (-) de 0,13 y un factor de crecimiento FC (:) de 1,50 .
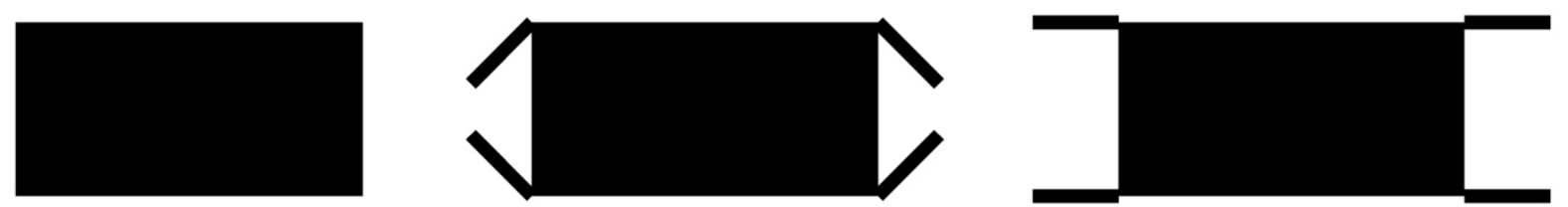

Figura 187 Desarrollo desplegable de polímero microporoso rectangular individual, elaboración propia

Del análisis de esta figura también se puede ver que tiene una barra articulada a un nudo rígido en el plano que corresponde al vértice del rectángulo. Los giros permitidos en el eje xy van de $0^{\circ}$ a $90^{\circ}$.

\subsubsection{Estructura en 2 dimensiones}

El polímero microporoso rectangular 2D estudiado tiene una longitud total de sus barras de $154,00 \mathrm{~m}$. No es capaz de plegarse totalmente, siendo su superficie mínima de $50,00 \mathrm{~m}^{2}$, y su superficie máxima de $108,00 \mathrm{~m}^{2}$ (área del rectángulo que genera), por lo que se aprecian unas constantes "K" en función de la superficie entre la longitud de líneas que van de 0,32 
como mínimo a 0,70 como máximo. Esto nos da un factor de crecimiento FC (-) de 0,38 y un factor de crecimiento FC (:) de 2,16.

Del análisis de esta figura también se puede ver que tiene una barra articulada a un nudo rígido en el plano que corresponde al vértice del rectángulo. Los giros permitidos en el eje xy van de $0^{\circ}$ a $90^{\circ}$.
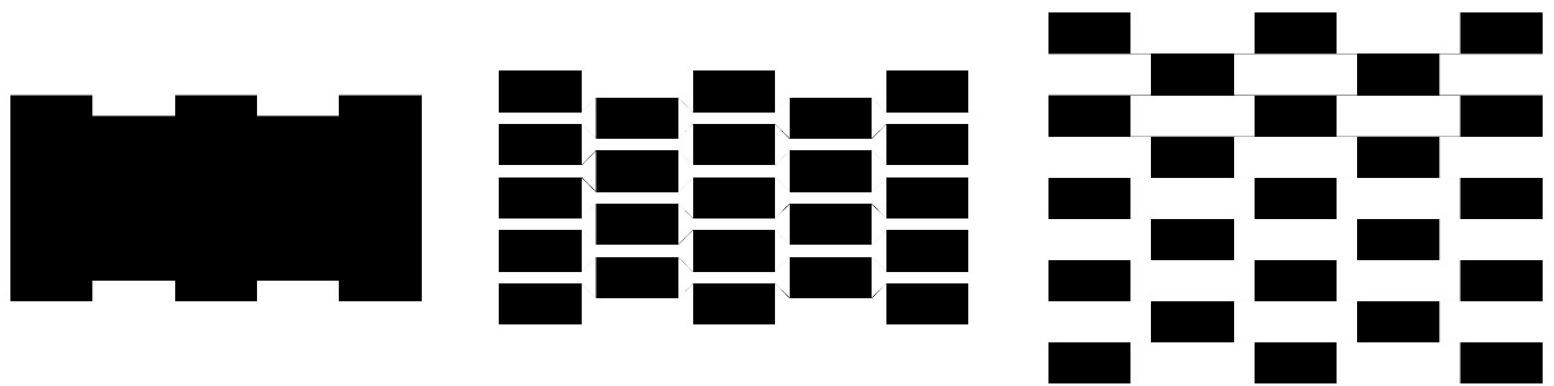

Figura 188 Desarrollo desplegable de polígono microporoso rectangular 2d, elaboración propia

\subsubsection{Estructura en 3 dimensiones}

El polímero microporoso rectangular 3D estudiado tiene una longitud total de sus barras de $288,00 \mathrm{~m}$. No es capaz de plegarse totalmente, siendo su volumen mínimo de $108,00 \mathrm{~m}^{3}$, y su volumen máximo de $245,00 \mathrm{~m}^{3}$ (volumen del cubo que genera), por lo que se aprecian unas constantes "K" en función de la superficie entre la longitud de líneas que van de 0,38 como mínimo a 0,85 como máximo. Esto nos da un factor de crecimiento FC (-) de 0,48 y un factor de crecimiento FC (:) de 2,27.
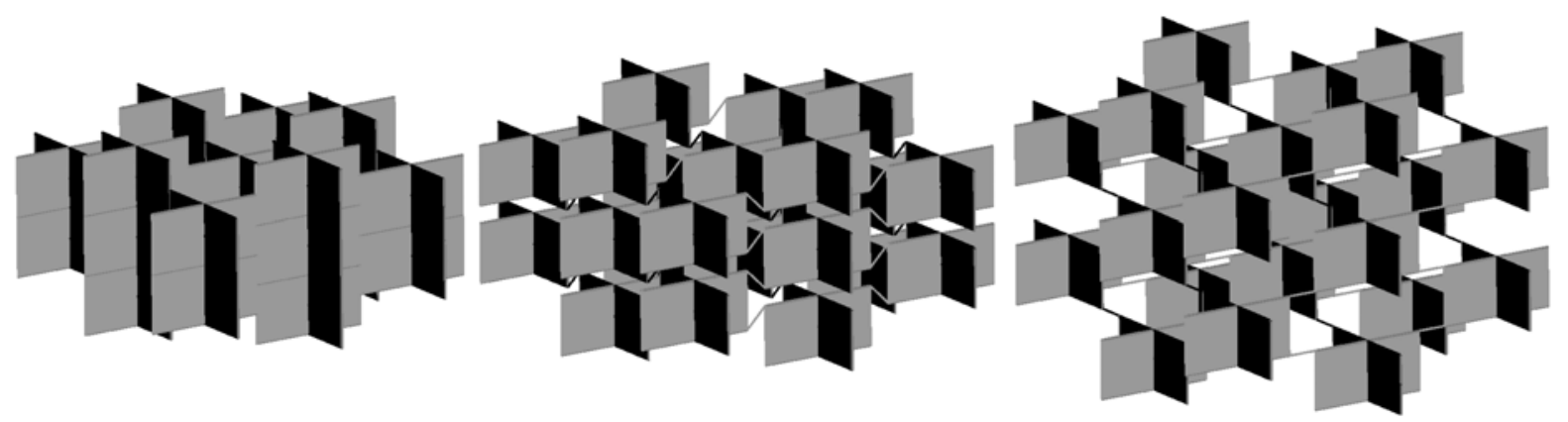

Figura 189 Desarrollo desplegable de polímero microporoso rectangular 3d, elaboración propia

Del análisis de esta figura también se puede ver que tiene una barra articulada a un nudo rígido en cada plano que corresponde al vértice del rectángulo. Los giros permitidos en los ejes horizontales van de $0^{\circ}$ a $90^{\circ}$. 


\subsubsection{Estructura torre (por giro de la estructura 2D)}

El polímero microporoso rectangular torre estudiado tiene una longitud total de sus barras de $396,73 \mathrm{~m}$. No es capaz de plegarse totalmente, siendo su volumen mínimo de $185,00 \mathrm{~m}^{3}$, y su volumen máximo de $400,00 \mathrm{~m}^{3}$ (volumen del cilindro que genera), por lo que se aprecian unas constantes "K" en función de la superficie entre la longitud de líneas que van de 0,13 como mínimo a 0,27 como máximo. Esto nos da un factor de crecimiento $F C$ (-) de 0,015 y un factor de crecimiento FC (:) de 2,16.

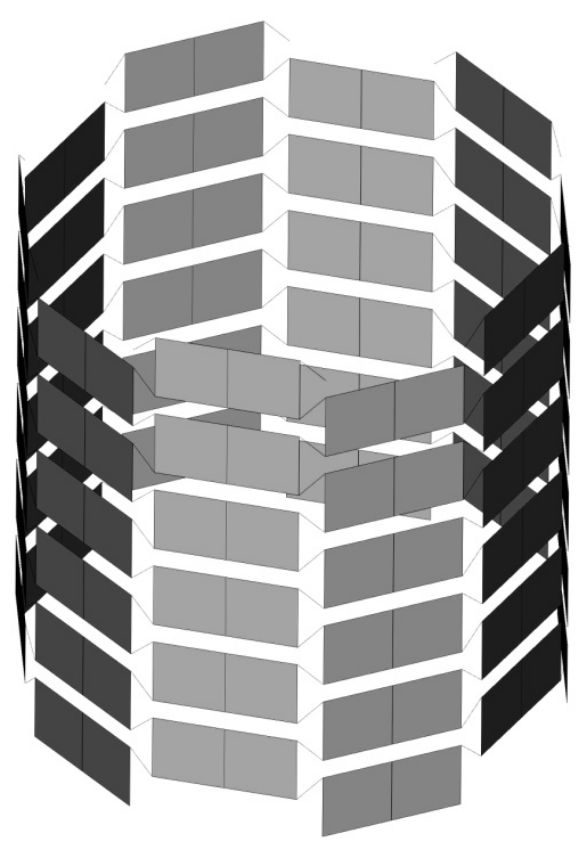

Figura 190 Polímero microporoso rectangular tipo torre, elaboración propia

Del análisis de esta figura también se puede ver que tiene una barra articulada a un nudo rígido en cada plano que corresponde al vértice del rectángulo. Los giros permitidos en el espacio van de $0^{\circ}$ a $90^{\circ}$. 


\subsection{Discusión de resultados}

Después del estudio desarrollado, para las estructuras estudiadas se hace una nueva clasificación en función de sus articulaciones. De este modo tendríamos:

1. Articulaciones en un solo plano de varias barras.

2. Articulaciones en el espacio, con confluencia de tres o más barras.

3. Articulaciones en un solo plano uniendo el vértice de un polígono con el final de una barra.

4. Articulaciones en el espacio uniendo el vértice de un polígono con el final de una barra.

5. Articulaciones en un solo plano uniendo vértices de polígonos.

6. Articulaciones en el espacio uniendo vértices de polígonos.

De tal manera que lo que nos preocupa es cómo resolver constructivamente al nivel escalar de la construcción estas uniones en función de su número de barras, ángulo de rotación y dirección de cada una de esas barras.

Por otra parte, se ha evaluado el factor de crecimiento auxético de cada estructura estudiada. Estos resultados serán comparados entre sí para establecer cuáles de las estructuras que se han desarrollo ofrecen mejores cualidades a la hora de aplicarlas a la arquitectura. Estas comparaciones se establecerán por grupos de estructuras, agrupando entre sí los patrones individuales (tabla 25 o gráficas 01 y 02), los patrones 2D (tabla 26 o gráficas 03 y 04), los patrones 3D (tabla 27 o gráficas 05 y 06) y los patrones tipo torre (tabla 28 o gráficas 07 y 08), generando cuatro grupos comparativos en total.

Para los casos de estructura reentrante hexagonal individual y $2 \mathrm{D}$, se ha comparado únicamente con el resto de estructuras aquella en la que $b=1 / 2 \mathrm{~B}$. Para el caso de la estructura reentrante estrella individual y 2D, el único caso comparado es el de la estrella de 6 puntas, ya que se dedujo que era la que tenía un mejor comportamiento auxético. Y para el caso de la estructura reentrante triangular individual y 2D se compara únicamente aquella en la cual las barras interiores tienen la mitad de dimensión que las barras exteriores.

A continuación se exponen las gráficas comparativas de los resultados obtenidos, cuyos resultados numéricos pueden consultarse en las tablas disponibles en los apéndices a tal efecto. 


\subsubsection{Comparación de patrones individuales}

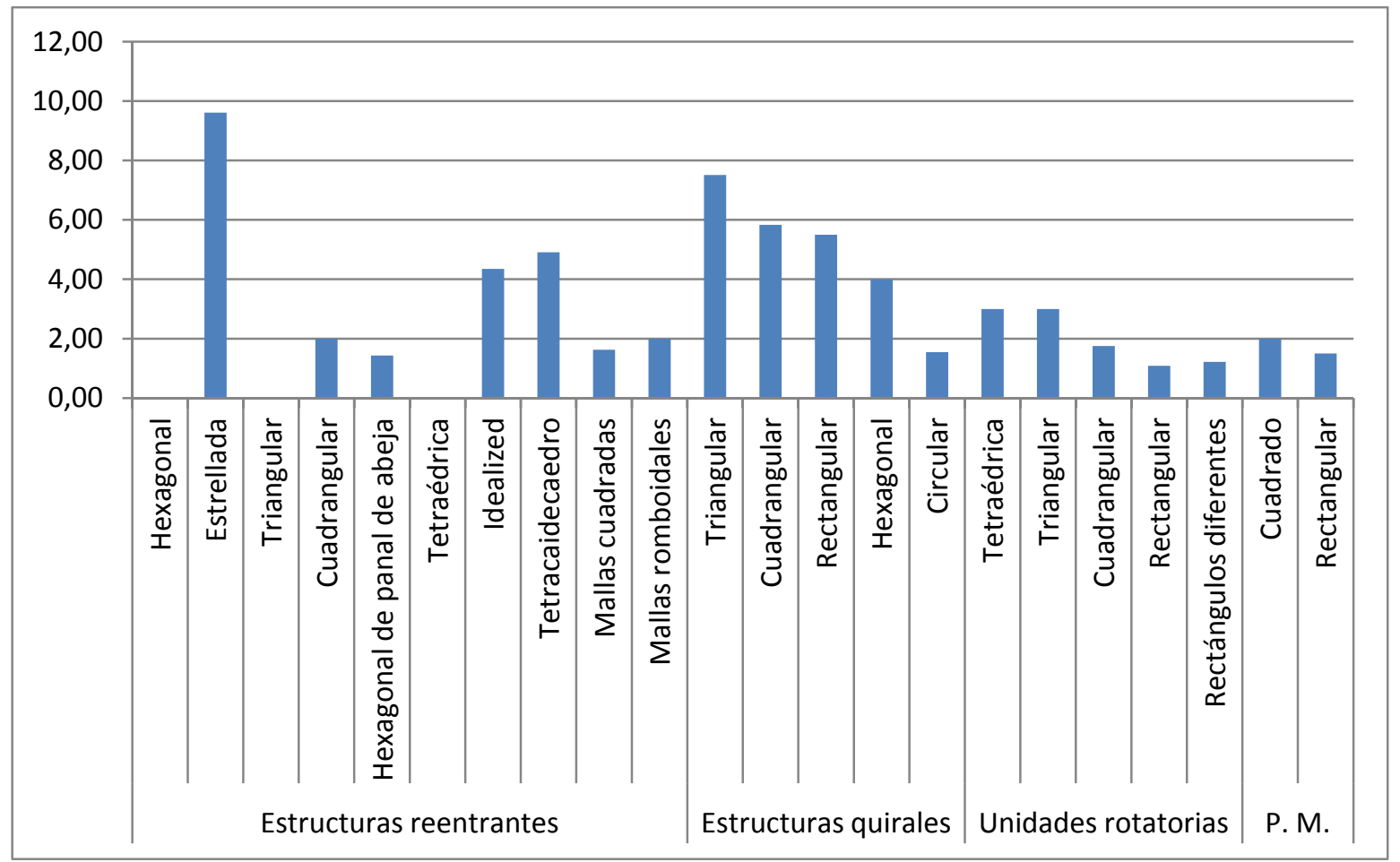

Gráfica 01 Factores de crecimiento de estructuras auxéticas individuales generados por división FC (:), elaboración propia

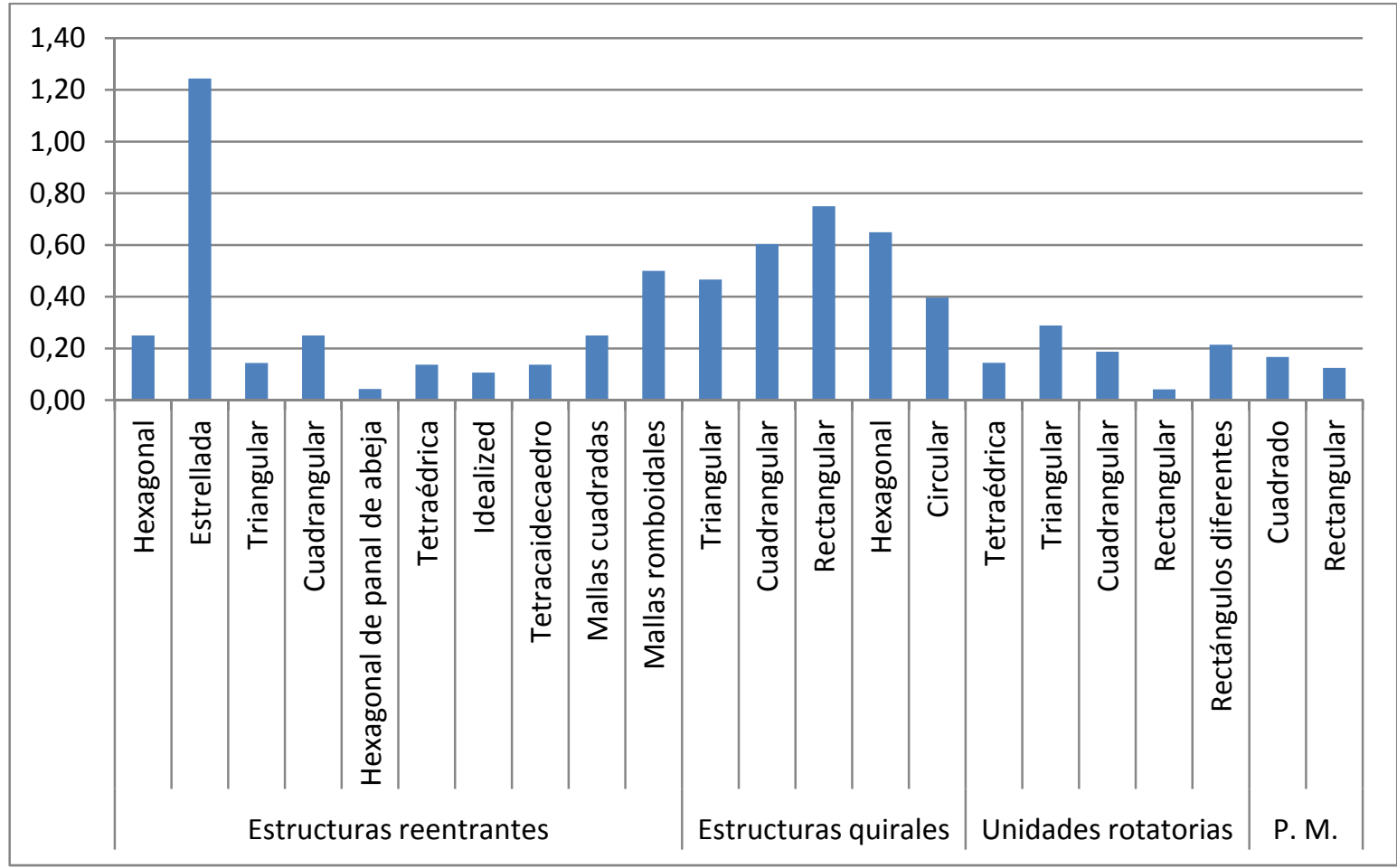

Gráfica 02 Factores de crecimiento de estructuras auxéticas individuales generados por resta FC (-), elaboración propia 
Puede apreciarse que la estructura reentrante estrellada tiene un factor de crecimiento que se halla muy por encima de la media, por lo que sería muy interesante su aplicación como estructura auxética desplegable. Sin embargo, tiene la limitación de que es una de las estructuras que menos se pliega de forma auxética (tabla 25 del apéndice 1 . Tablas de comportamiento geométrico de estructuras auxéticas), por lo que habría que diseñar sus articulaciones de tal forma que permitieran giros que generasen un plegado no auxético. Como la mayoría de las estructuras reentrantes individuales, consta en sus nudos de articulaciones en un solo plano de varias barras (tabla 25 del apéndice 1. Tablas de comportamiento geométrico de estructuras auxéticas).

Los giros que permiten estas articulaciones van de $0^{\circ}$ a $150^{\circ}$. En un principio la solución aparente consistiría en dotar de más amplitud de giro a la articulación, pero si estudiamos la geometría, la única forma de plegado no auxético para el empaquetamiento total de la estructura consiste en desarrollar una articulación intermedia en las barras que quedan en el exterior tras obtener el máximo plegado auxético. Además, sería necesaria, la introducción de un sistema de apertura que permita abrir esta geometría auxética para obtener después su plegado y empaquetamiento aptos para el transporte.

Por otra parte, se observan factores de crecimiento globalmente mayores para las estructuras quirales individuales. El plegado máximo de este tipo de estructuras es el polígono alrededor del cual giran las barras. Si quisiéramos una compactación mayor, al igual que en la estructura anterior, habría que recurrir a plegados finales no auxéticos (y esto contando siempre con que el polígono base no tenga masa en su interior). Para las estructuras quirales el plegado no auxético es más fácil de conseguir, ya que únicamente consiste en abrir uno de los vértices del polígono y dotar de más giro a las articulaciones para que se puedan doblar unas barras sobre otras.

Cabría destacar también que las estructuras individuales reentrante hexagonal, reentrante triangular y reentrante tetraédrica se pliegan totalmente de forma auxética, lo que supone una propiedad excepcional a la hora de trabajar con estas geometrías para estructuras desplegables. 


\subsubsection{Comparación de patrones 2D}

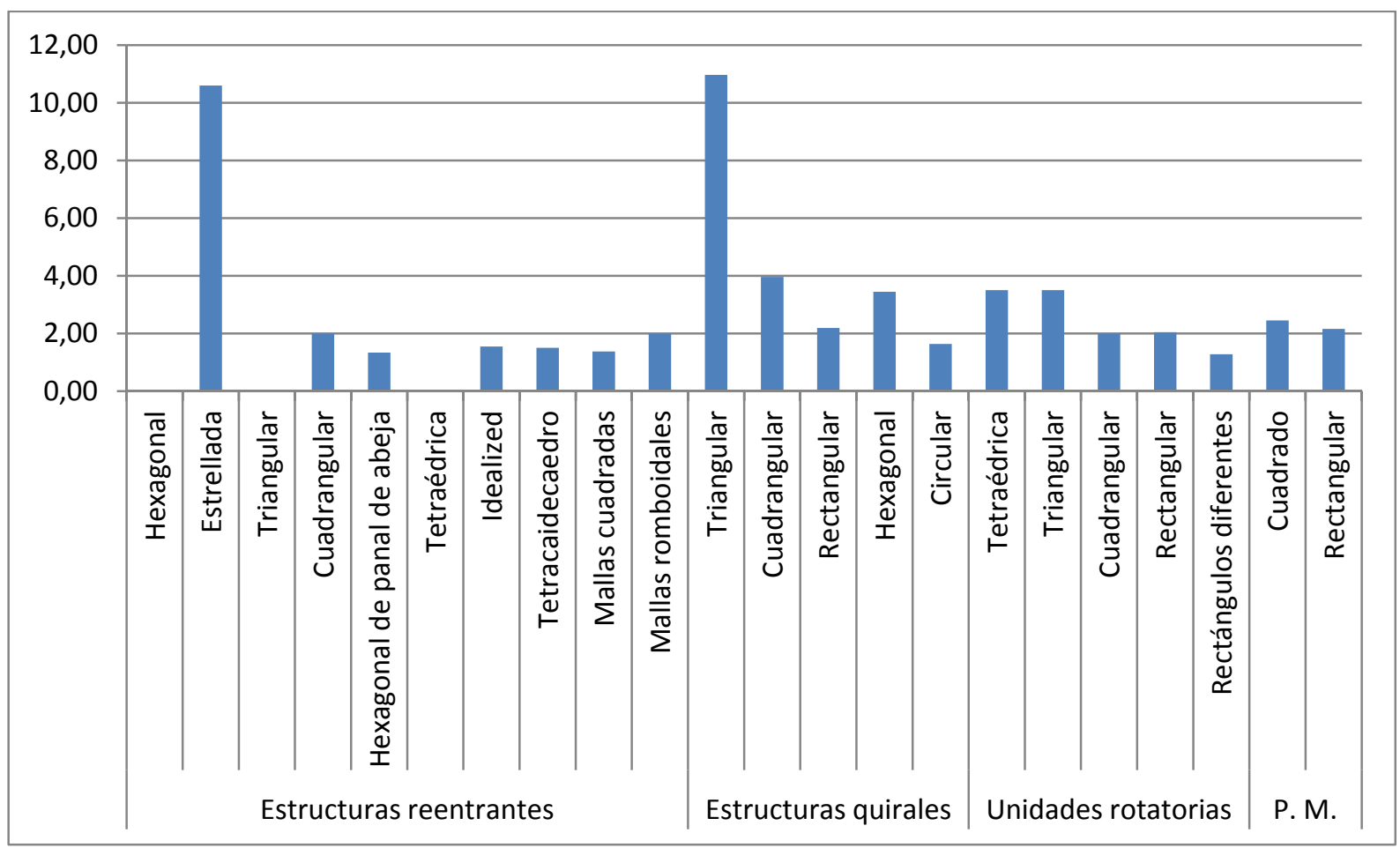

Gráfica 03 Factores de crecimiento de estructuras auxéticas 2D generados por división FC (:), elaboración propia

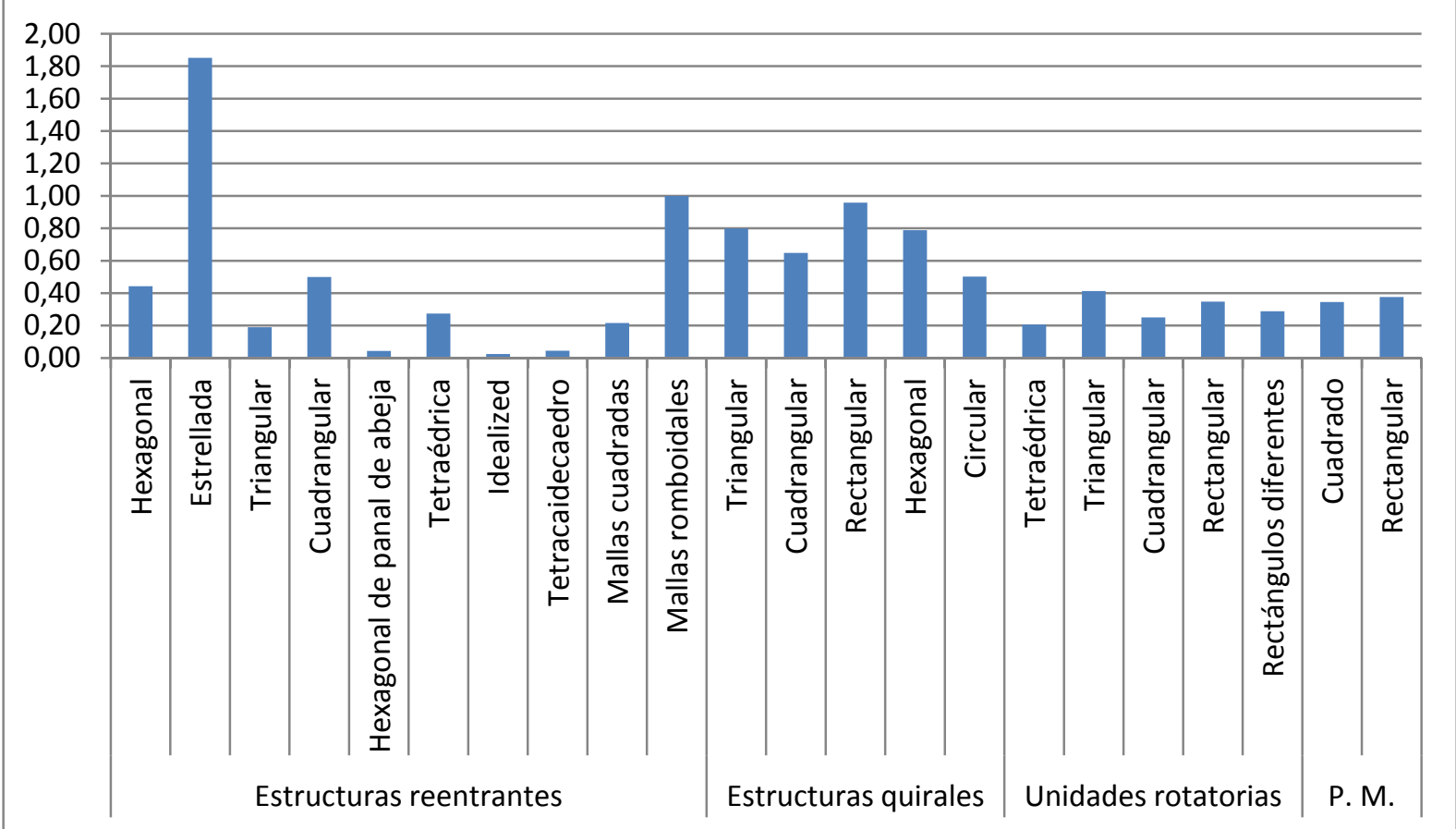

Gráfica 04 Factores de crecimiento de estructuras auxéticas 2D generados por resta FC (-), elaboración propia 
Puede apreciarse nuevamente que la estructura reentrante estrellada tiene un factor de crecimiento que se halla muy por encima de la media, por lo que sería muy interesante su aplicación como estructura auxética desplegable. Sin embargo, tiene la limitación de que es una de las estructuras que menos se pliega de forma auxética (tabla 26 del apéndice 1. Tablas de comportamiento geométrico de estructuras auxéticas), por lo que habría que diseñar sus articulaciones de tal forma que permitieran giros que generasen un plegado no auxético. Como la mayoría de las estructuras reentrantes en dos dimensiones, consta en sus nudos de articulaciones en un solo plano de varias barras (tabla 26 del apéndice 1. Tablas de comportamiento geométrico de estructuras auxéticas).

Los giros que permiten estas articulaciones van de $0^{\circ}$ a $150^{\circ}$. En un principio la solución aparente consistiría en dotar de más amplitud de giro a la articulación, pero si estudiamos la geometría, la única forma de plegado no auxético para el empaquetamiento total de la estructura consiste en desarrollar una articulación intermedia en las barras que quedan en el exterior tras obtener el máximo plegado auxético. Además, sería necesaria, la introducción de un sistema de apertura que permita abrir esta geometría auxética para obtener después su plegado y empaquetamiento aptos para el transporte.

Por otra parte, se observan factores de crecimiento globalmente mayores para las estructuras quirales en dos dimensiones, destacando la estructura quiral triangular por FC (:). El plegado máximo de este tipo de estructuras es la suma de polígonos alrededor de los cuales giran las barras. Si quisiéramos una compactación mayor, al igual que en la estructura anterior, habría que recurrir a plegados finales no auxéticos (y esto contando siempre con que el polígono base no tenga masa en su interior). Para las estructuras quirales el plegado no auxético es más fácil de conseguir, ya que únicamente consiste en abrir uno de los vértices del polígono y dotar de más giro a las articulaciones para que se puedan doblar unas barras sobre otras.

Las estructuras 2D reentrante hexagonal, reentrante triangular y reentrante tetraédrica siguen plegándose totalmente de forma auxética, lo que supone una propiedad excepcional a la hora de trabajar con estas geometrías para estructuras desplegables.

Se puede apreciar que se mantienen los valores aproximados de las geometrías que tienen una mayor auxeticidad, pero sin embargo, al agruparlas, se nota un aumento en sus factores de crecimiento. 


\subsubsection{Comparación de patrones 3D}

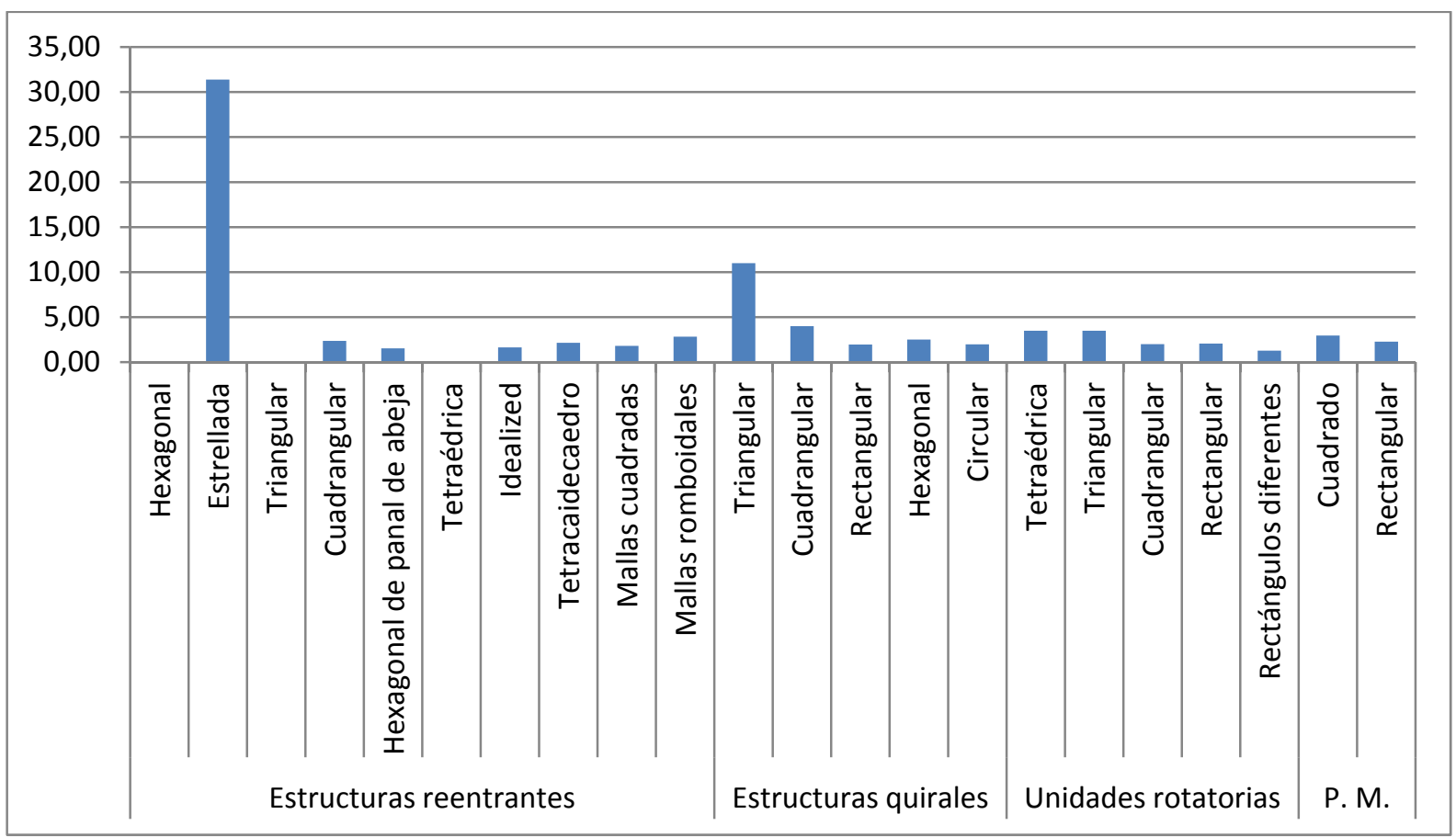

Gráfica 05 Factores de crecimiento de estructuras auxéticas 3D generados por división FC (:), elaboración propia

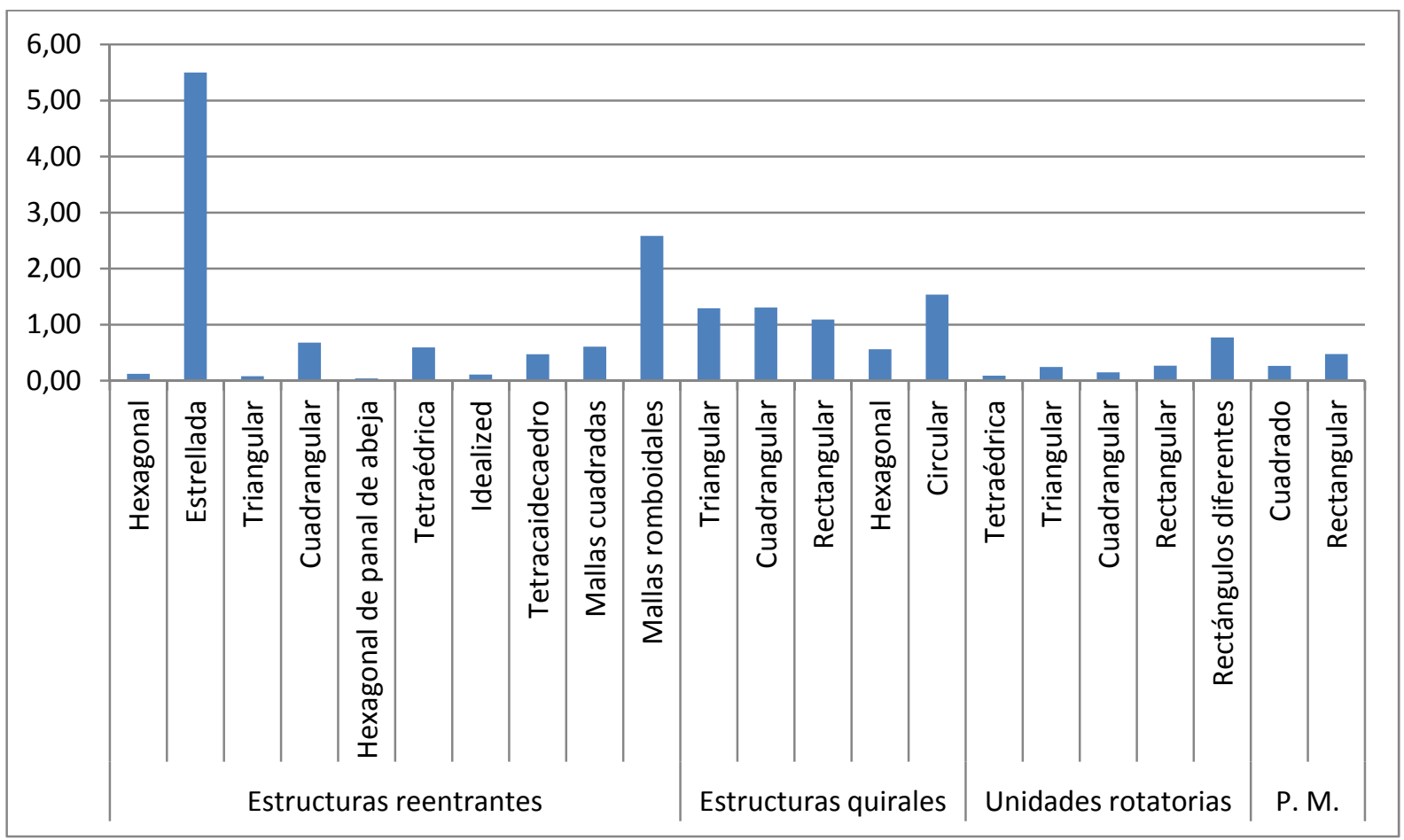

Gráfica 06 Factores de crecimiento de estructuras auxéticas 3D generados por resta FC (-), elaboración propia 
Puede apreciarse nuevamente que la estructura reentrante estrellada tiene un factor de crecimiento que se halla muy por encima de la media, por lo que sería muy interesante su aplicación como estructura auxética desplegable. Sin embargo, tiene la limitación de que es una de las estructuras que menos se pliega de forma auxética (tabla 27 del apéndice 1. Tablas de comportamiento geométrico de estructuras auxéticas), por lo que habría que diseñar sus articulaciones de tal forma que permitieran giros que generasen un plegado no auxético. Como algunas de las estructuras reentrantes en tres dimensiones, consta en sus nudos de articulaciones en un solo plano de varias barras (tabla 27 del apéndice 1. Tablas de comportamiento geométrico de estructuras auxéticas).

Los giros que permiten estas articulaciones van de $0^{\circ}$ a $150^{\circ}$. En un principio la solución aparente consistiría en dotar de más amplitud de giro a la articulación, pero si estudiamos la geometría, la única forma de plegado no auxético para el empaquetamiento total de la estructura consiste en desarrollar una articulación intermedia en las barras que quedan en el exterior tras obtener el máximo plegado auxético. Además, sería necesaria, la introducción de un sistema de apertura que permita abrir esta geometría auxética para obtener después su plegado y empaquetamiento aptos para el transporte.

Por otra parte, se observan factores de crecimiento globalmente mayores para las estructuras quirales en tres dimensiones, destacando la estructura quiral triangular por FC (:). El plegado máximo de este tipo de estructuras es la suma de polígonos alrededor de los cuales giran las barras. Si quisiéramos una compactación mayor, al igual que en la estructura anterior, habría que recurrir a plegados finales no auxéticos (y esto contando siempre con que el polígono base no tenga masa en su interior). Para las estructuras quirales el plegado no auxético es más fácil de conseguir, ya que únicamente consiste en abrir uno de los vértices del polígono y dotar de más giro a las articulaciones para que se puedan doblar unas barras sobre otras.

Las estructuras 2D reentrante hexagonal, reentrante triangular y reentrante tetraédrica se pliegan totalmente de forma auxética hasta conseguir una superficie, lo que supone una propiedad excepcional a la hora de trabajar con estas geometrías para estructuras desplegables. No obstante, para su plegado y empaquetamiento final habría que disponer a la estructura de articulaciones que permitieran el plegado no auxético. Al adquirir volumen, se nota un aumento de auxeticidad en general y un alejamiento entre estructuras en sus factores de crecimiento. 


\subsubsection{Comparación de patrones torre}

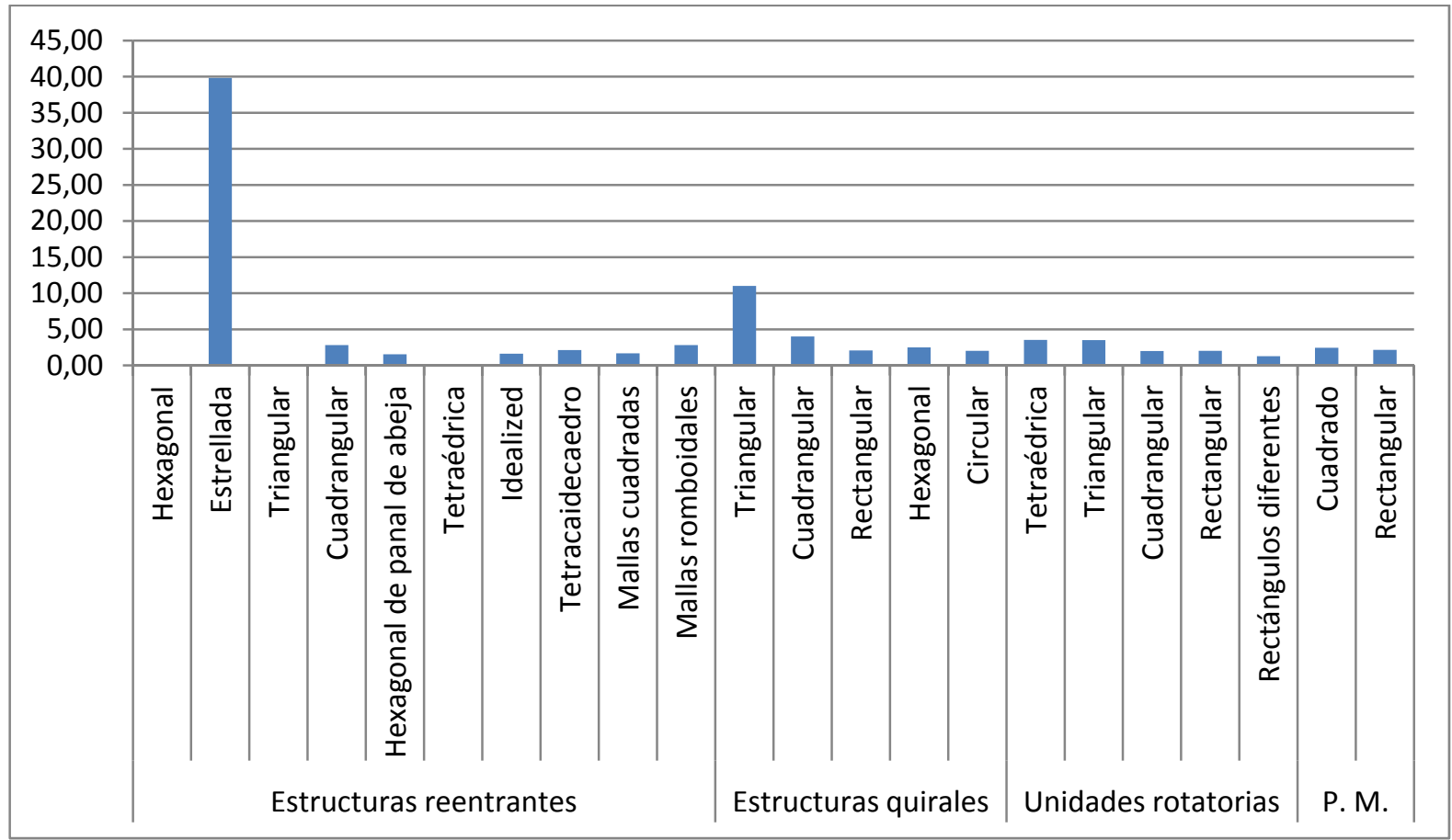

Gráfica 07 Factores crecimiento de estructuras auxéticas torre generados por división FC (:), elaboración propia

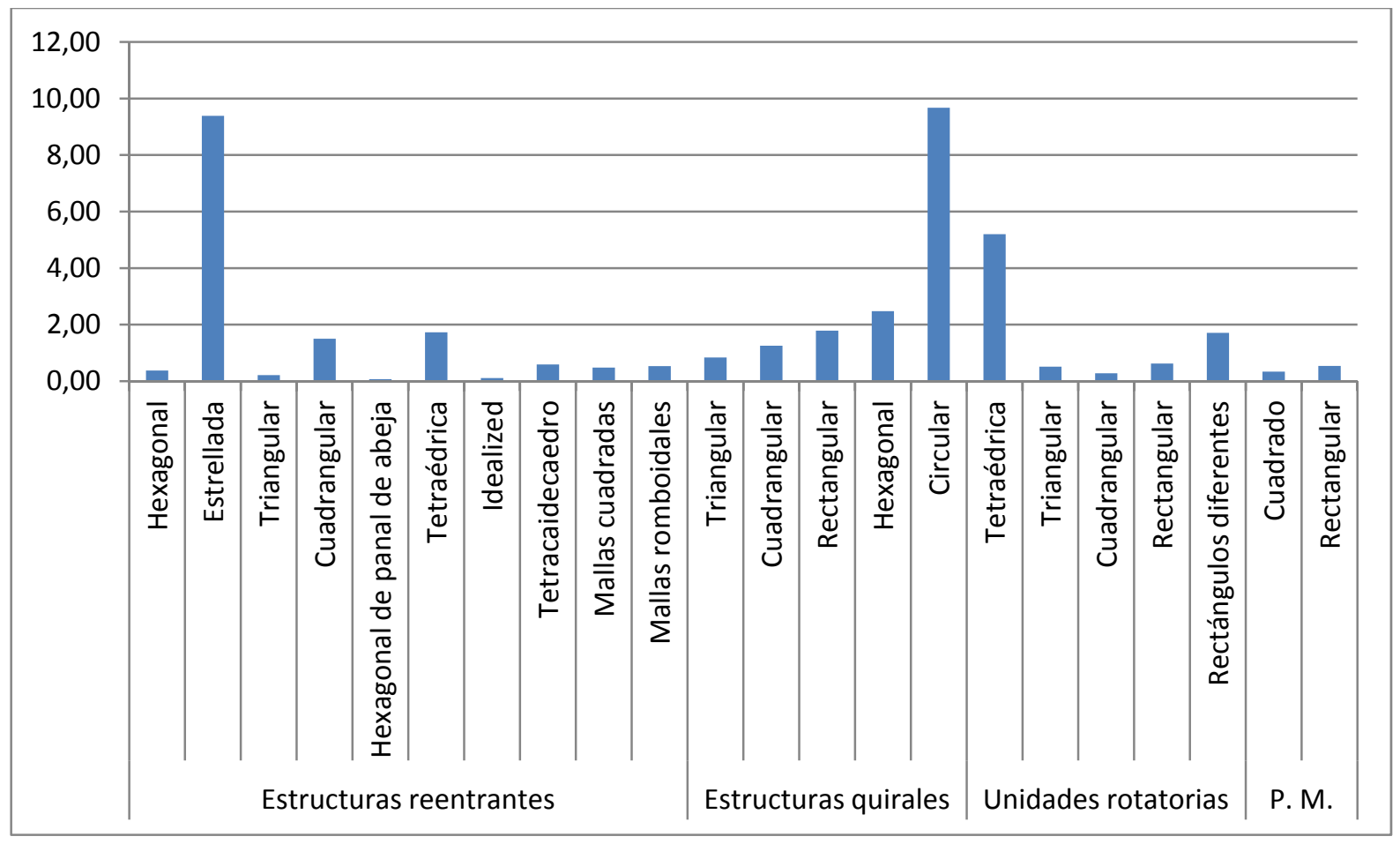

Gráfica 08 Factores crecimiento de estructuras auxéticas torre generados por resta FC (-), elaboración propia 
Puede apreciarse nuevamente que la estructura reentrante estrellada tiene un factor de crecimiento que se halla muy por encima de la media, por lo que sería muy interesante su aplicación como estructura auxética desplegable. Sin embargo, tiene la limitación de que es una de las estructuras que menos se pliega de forma auxética (tabla 28 del apéndice 1. Tablas de comportamiento geométrico de estructuras auxéticas), por lo que habría que diseñar sus articulaciones de tal forma que permitieran giros que generasen un plegado no auxético. Como todas las estructuras reentrantes tipo torre, consta en sus nudos de articulaciones en el espacio de varias barras (tabla 28 del apéndice 1. Tablas de comportamiento geométrico de estructuras auxéticas).

Los giros que permiten estas articulaciones van de $0^{\circ}$ a $150^{\circ}$. En un principio la solución aparente consistiría en dotar de más amplitud de giro a la articulación, pero si estudiamos la geometría, la única forma de plegado no auxético para el empaquetamiento total de la estructura consiste en desarrollar una articulación intermedia en las barras que quedan en el exterior tras obtener el máximo plegado auxético. Además, sería necesaria, la introducción de un sistema de apertura que permita abrir esta geometría auxética para obtener después su plegado y empaquetamiento aptos para el transporte.

Por otra parte, se observan factores de crecimiento globalmente mayores para las estructuras quirales tipo torre, destacando la estructura quiral triangular por FC (:) y la estructura quiral circular por FC (-). El plegado máximo de este tipo de estructuras es la suma de polígonos alrededor de los cuales giran las barras. Si quisiéramos una compactación mayor, al igual que en la estructura anterior, habría que recurrir a plegados finales no auxéticos ( $y$ esto contando siempre con que el polígono base no tenga masa en su interior). Para las estructuras quirales el plegado no auxético es más fácil de conseguir, ya que únicamente consiste en abrir uno de los vértices del polígono y dotar de más giro a las articulaciones para que se puedan doblar unas barras sobre otras.

Las estructuras tipo torre reentrante hexagonal, reentrante triangular y reentrante tetraédrica se pliegan totalmente de forma auxética hasta conseguir una superficie, lo que supone una propiedad excepcional a la hora de trabajar con estas geometrías para estructuras desplegables. No obstante, para su plegado y empaquetamiento final habría que disponer a la estructura de articulaciones que permitieran el plegado no auxético. Con la configuración torre, se nota un aumento de auxeticidad en general y un alejamiento entre estructuras en sus factores de crecimiento. 


\subsection{Cálculo estructural de estructuras auxéticas: estructura reentrante hexagonal}

Con el objetivo de conocer cómo funcionan estructuralmente las estructuras auxéticas respecto a las tradicionales va a realizarse un análisis estructural mediante el programa de cálculo SAP2000 (salvo para un caso concreto, en el cual se hará de forma manual). Se escoge la estructura reentrante hexagonal por ser una de las más estudiadas en otras disciplinas hasta el momento, así como por su sencilla configuración, que permite diseños fáciles que podrían dar mucho juego en la arquitectura. La estructura tradicional con la que se va a comparar el comportamiento corresponde al límite de apertura de la estructura reentrante hexagonal en el cual deja de ser auxética, que se corresponde con estructuras tradicionales de pilares y vigas.

De este modo, calcularemos casos concretos para esta estructura concreta, para comparar su comportamiento estructural en las diferentes hipótesis consideradas, que serán:

$\checkmark$ Estructura auxética individual reentrante hexagonal de acero:

- Estudio comparativo de estructuras con nudos rígidos:

- Cálculo para diversas aperturas sin carga y con carga

- Cálculo para apertura de $63^{\circ}$ y aumento de carga progresiva

- Cálculo para apertura de $90^{\circ}$ (tradicional) y aumento de carga progresiva

- Caso de estudio:

- Estructura auxética con nudos articulados y tendón interno (cálculo manual).

Estructura auxética individual reentrante hexagonal de hormigón:

- Estudio comparativo:

- Pórtico no auxético con tendón continuo en barras verticales y horizontal superior

- Pórtico auxético sin tendón con ángulo de apertura de 75,96

- Pórtico auxético con tendón en barras verticales con ángulo de apertura de 75,96

- Pórtico auxético con tendón continuo en barras vertical y horizontal superior con ángulo de apertura de $75,96^{\circ}$

- Pórtico auxético con tendón continuo en todas sus barras con ángulo de apertura de $75,96^{\circ}$

- Pórtico auxético con tendón en barras verticales con ángulo de apertura de 63,43

- Pórtico auxético con tendón continuo en barras vertical y horizontal superior con ángulo de apertura de $63,43^{\circ}$ 
- Pórtico auxético con tendón en barras verticales con ángulo de apertura de 53,13

- Pórtico auxético con tendón continuo en barras vertical y horizontal superior con ángulo de apertura de 53,13

- Pórtico auxético con tendón en barras verticales con ángulo de apertura de $45^{\circ}$

- Casos de estudio:

- Estructura auxética individual reentrante hexatruss de hormigón.

- Estructura auxética conjunto reentrante hexatruss de hormigón.

El objetivo es comprobar de forma matemática cómo funcionan estas geometrías estructuralmente en la escala de la arquitectura. Para ello, se tendrá atención a los desplazamientos horizontales y verticales en articulaciones, rotaciones en articulaciones, reacciones en apoyos, esfuerzos axiles, cortantes y momentos que se generan en cada una de las estructuras comprobadas, para ver si conservan su comportamiento auxético y si, en caso de conservarlo, resulta útil para estructuras de arquitectura.

\subsubsection{Justificación de las hipótesis de cálculo escogidas}

A continuación se estudia el comportamiento estructural para una estructura auxética plana reentrante hexagonal, escogiendo hipótesis en las que $b \leq 1 / 2 \mathrm{~B}$ y $\mathrm{b}>1 / 2 \mathrm{~B}$, y considerando uniones empotradas y articuladas. Esto se realiza para unas cargas aleatorias, ya que sólo se quiere comprobar la diferencia de comportamiento cuando la estructura es rígida o es articulada. Después de realizar el análisis se observan los siguientes los comportamientos representados en las figuras 191 y 192.
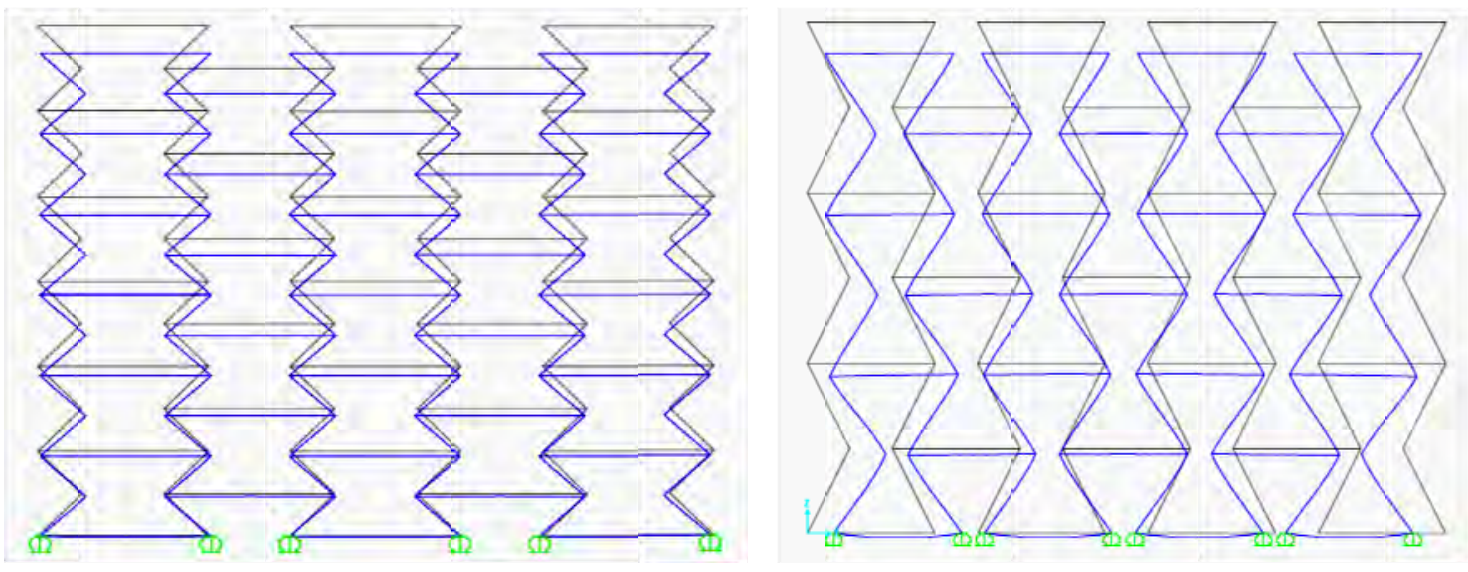

Figura 191Estructuras reentrantes hexagonales de nudos rígidos, elaboración propia 

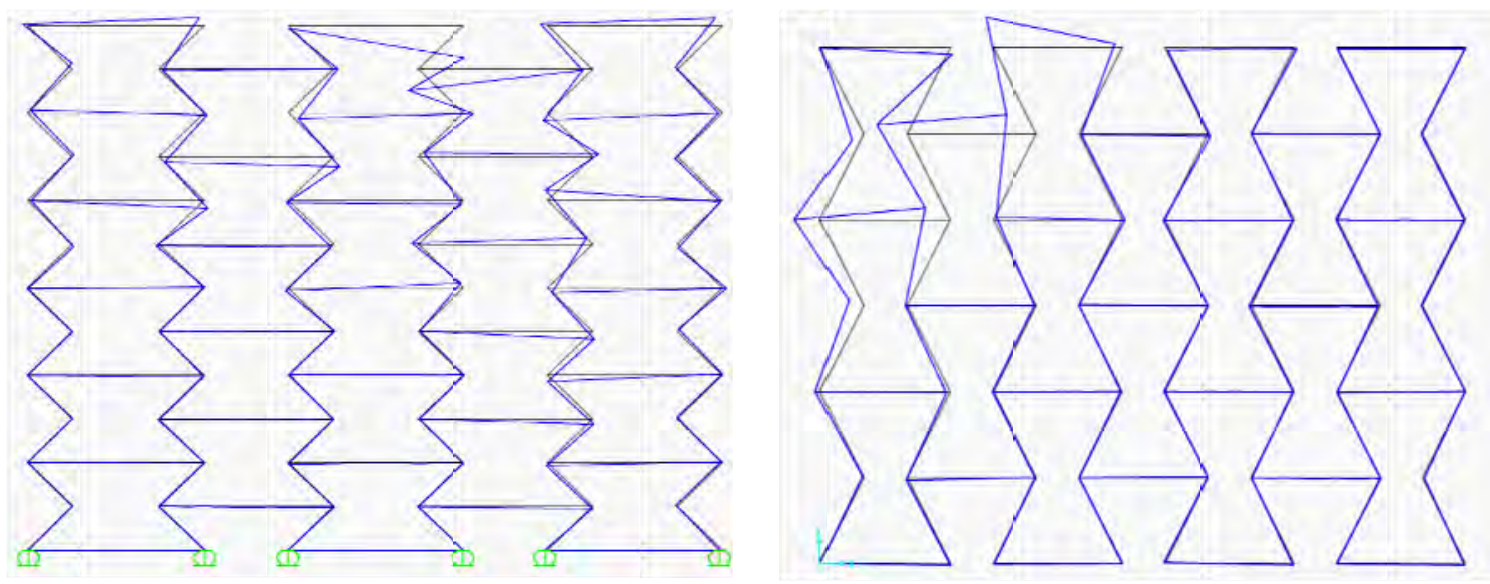

Figura 192 Estructuras reentrantes hexagonales de nudos articulados, elaboración propia

Al meter las estructuras en el programa de cálculo SAP2000 para estudiar su comportamiento nos damos cuenta de que cuando consideramos las uniones rígidas la estructura funciona exactamente igual que como se había previsto, realizando este comportamiento mediante flexión de las barras.

Sin embargo, al considerar sus uniones articuladas pensando en estructuras desplegables nos damos cuenta de que no se mueve como debería: esto es debido a que estas estructuras son mecanismos, y necesitamos una condición de borde que las ate a donde queramos para que tengan un buen comportamiento. Por tanto, este análisis continuará usando estructuras con nudos articulados y fuerzas externas conseguidas mediante el uso de tendones internos que mantienen la estructura estable. Esto es, se usarán estructuras auxéticas que trabajan debido a fuerzas de balance, de forma similar a los tensegrities.

Por eso las estructuras estudiadas comprenderán sistemas rígidos y sistemas articulados autoestabilizados por tendones. Estos dos tipos de estructuras se estudiarán para acero y hormigón, y para diversas cargas. 


\subsubsection{Estructura individual reentrante hexagonal de acero con nudos rígidos}

\subsubsection{Cálculo para diversas aperturas sin carga y con carga}

\subsection{Metodología}

Calcularemos una estructura auxética reentrante hexagonal unitaria sin ningún tipo de carga, tal y como se indica en la figura 193 (izquierda), y otra idéntica con dos cargas verticales de $1 \mathrm{KN}$ y una carga horizontal también de $1 \mathrm{KN}$, distribuidas como se muestra en la figura 193 (derecha). Estas estructuras se modelizarán con nudos rígidos, con diferentes aperturas (ángulo $\alpha=48^{\circ}, 51^{\circ}, 55^{\circ}, 59^{\circ}, 63^{\circ}, 68^{\circ}, 73^{\circ}, 79^{\circ}, 84^{\circ}$ y $90^{\circ}$ ), y con dimensiones de barras "a" y "f" de longitud $1 \mathrm{~m}$ y resto de barras de longitud $0,5 \mathrm{~m}$ cuando $\alpha=90^{\circ}$ y algo más conforme se va cerrando el ángulo de apertura de la estructura, ya que la geometría de dicha estructura responde a una cuadrícula para facilitar la implementación del modelo. Para que dicha estructura esté bien condicionada necesita tener 6 restricciones, repartidas de la siguiente manera: le imponemos en el apoyo de la izquierda 3 restricciones al desplazamiento +1 restricción a la rotación respecto al eje $x, y 2$ restricciones al desplazamiento en los ejes y y $z$ en el apoyo de la derecha.
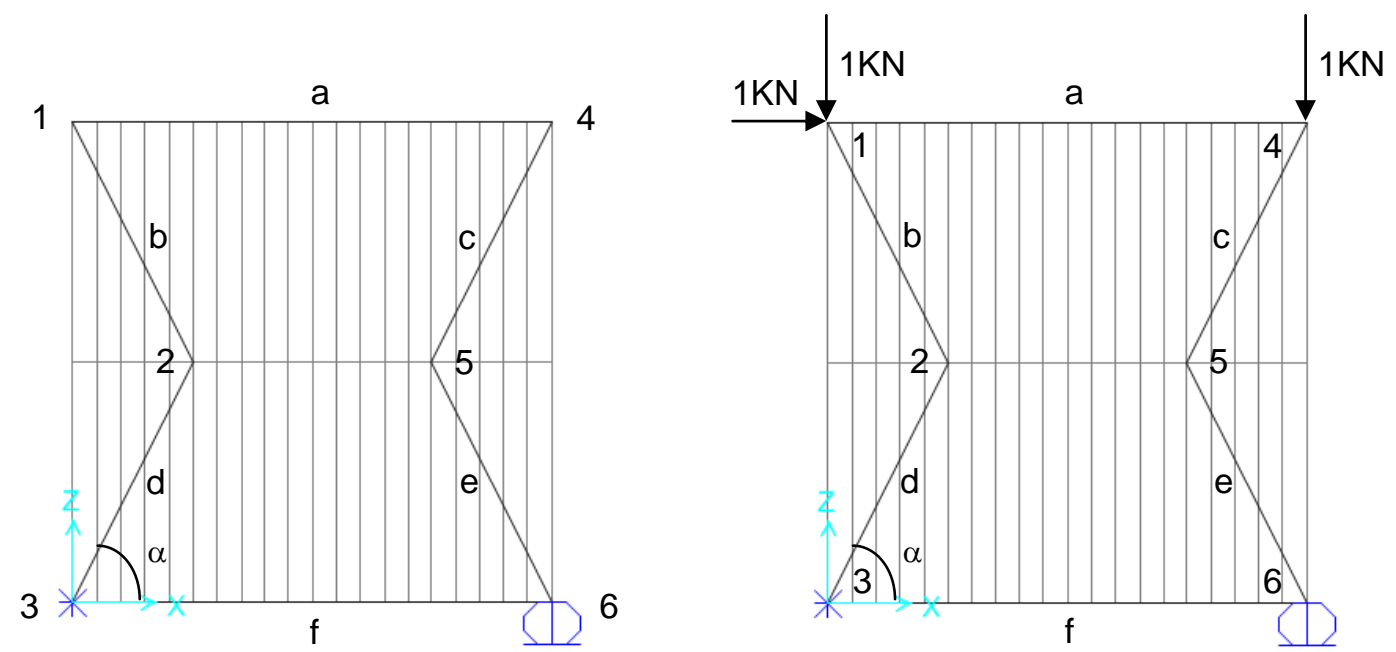

Figura 193 Estructura auxética reentrante hexagonal unitaria, elaboración propia. Izquierda: estructura sin carga. Derecha: estructura con carga 
Las barras son perfiles metálicos, con las características que se indican en la figura 194.

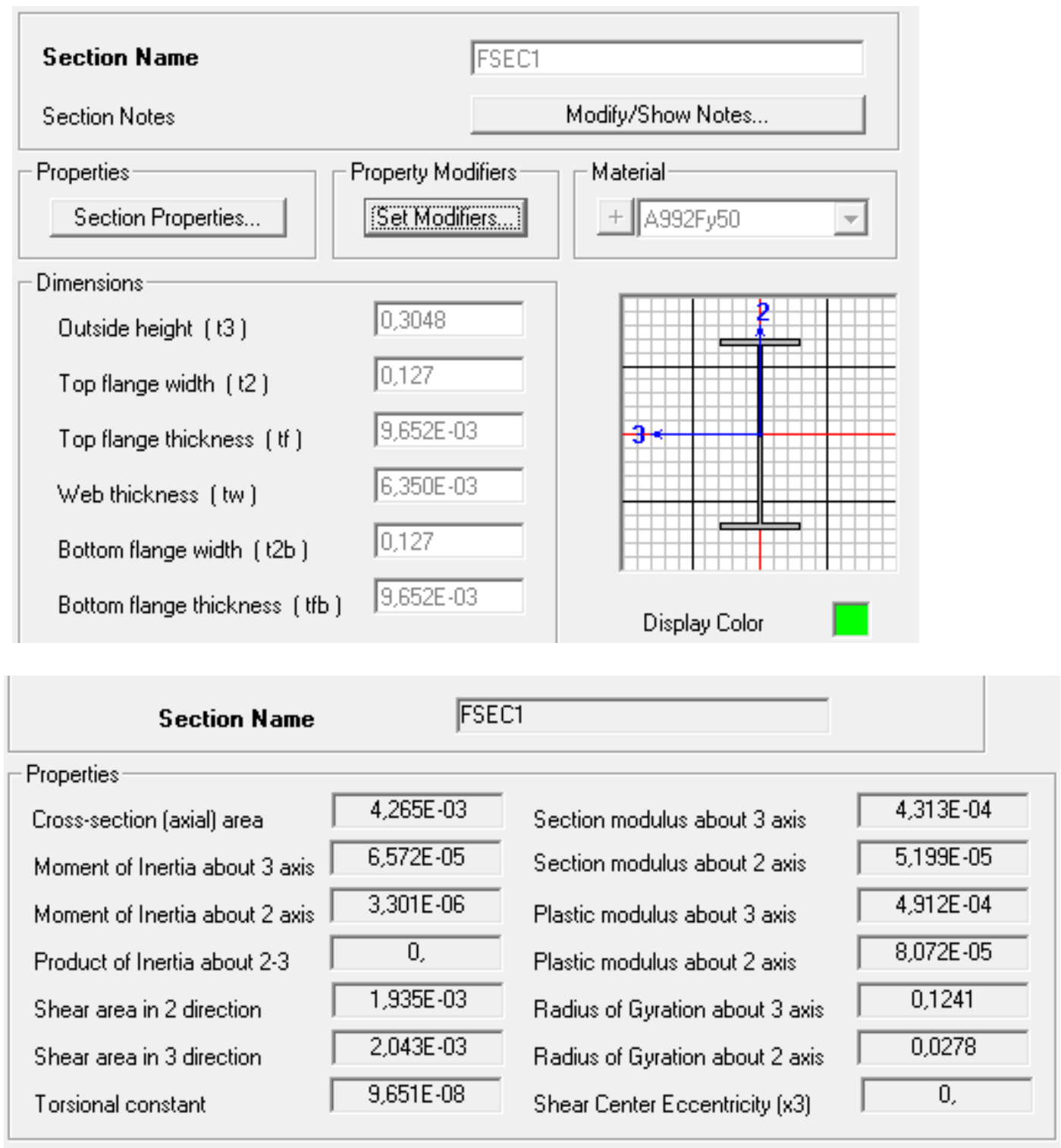

Figura 194 Características de perfil metálico, SAP2000

\subsection{Resultados}

Para las estructuras reentrantes hexagonales metálicas rígidas sin tendones se obtienen los resultados que aparecen en las tablas 29 a 35 del Apéndice 2: tablas de cálculo estructural para las diferentes aperturas y nudos, y que se representan en las gráficas que se presentan a continuación. 
Desplazamientos horizontales

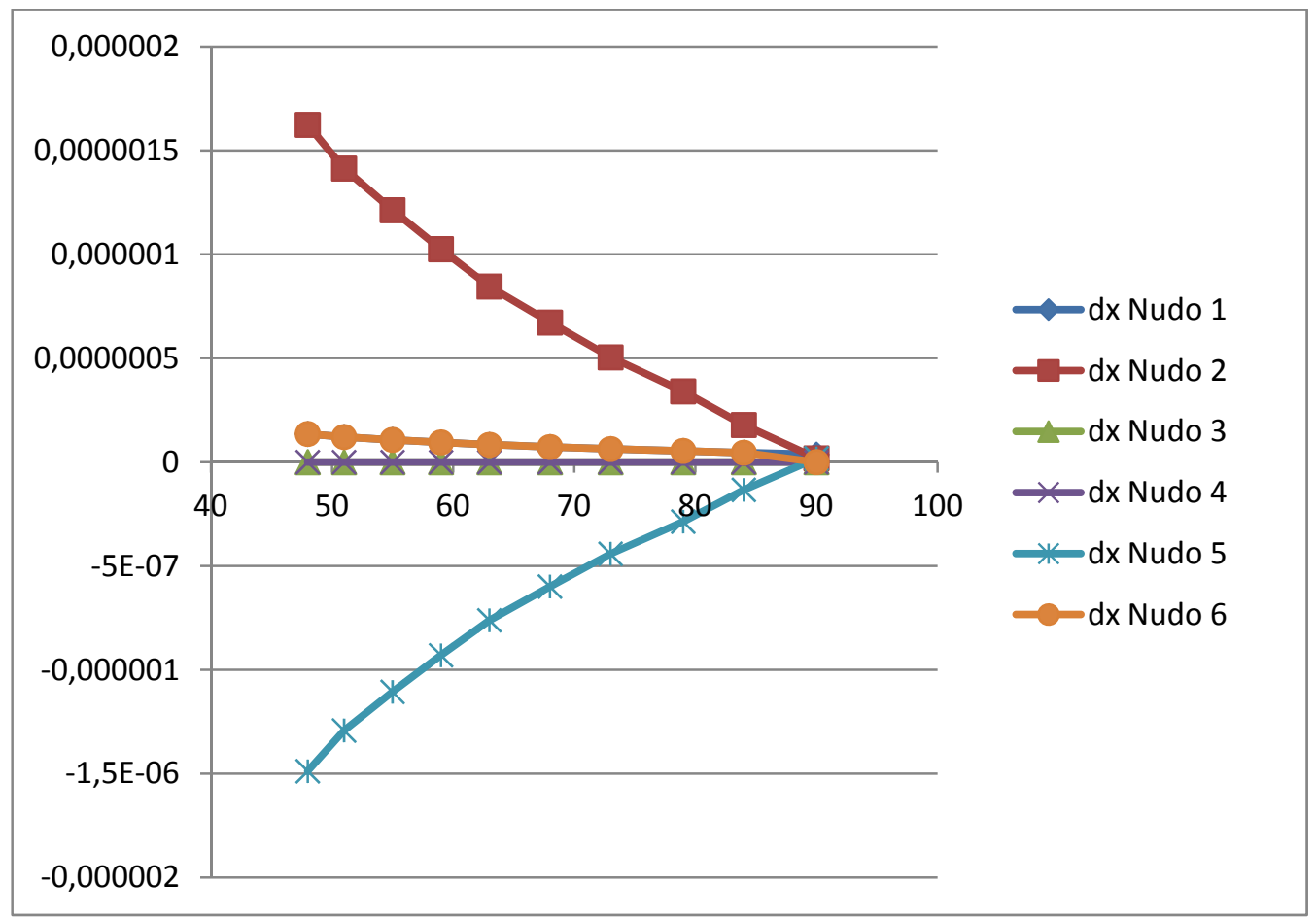

Gráfica 09 Desplazamientos horizontales (KN, eje y) en nudos estructura auxética reentrante hexagonal unitaria sin carga en función de la apertura (grados ${ }^{\circ}$, eje x), elaboración propia

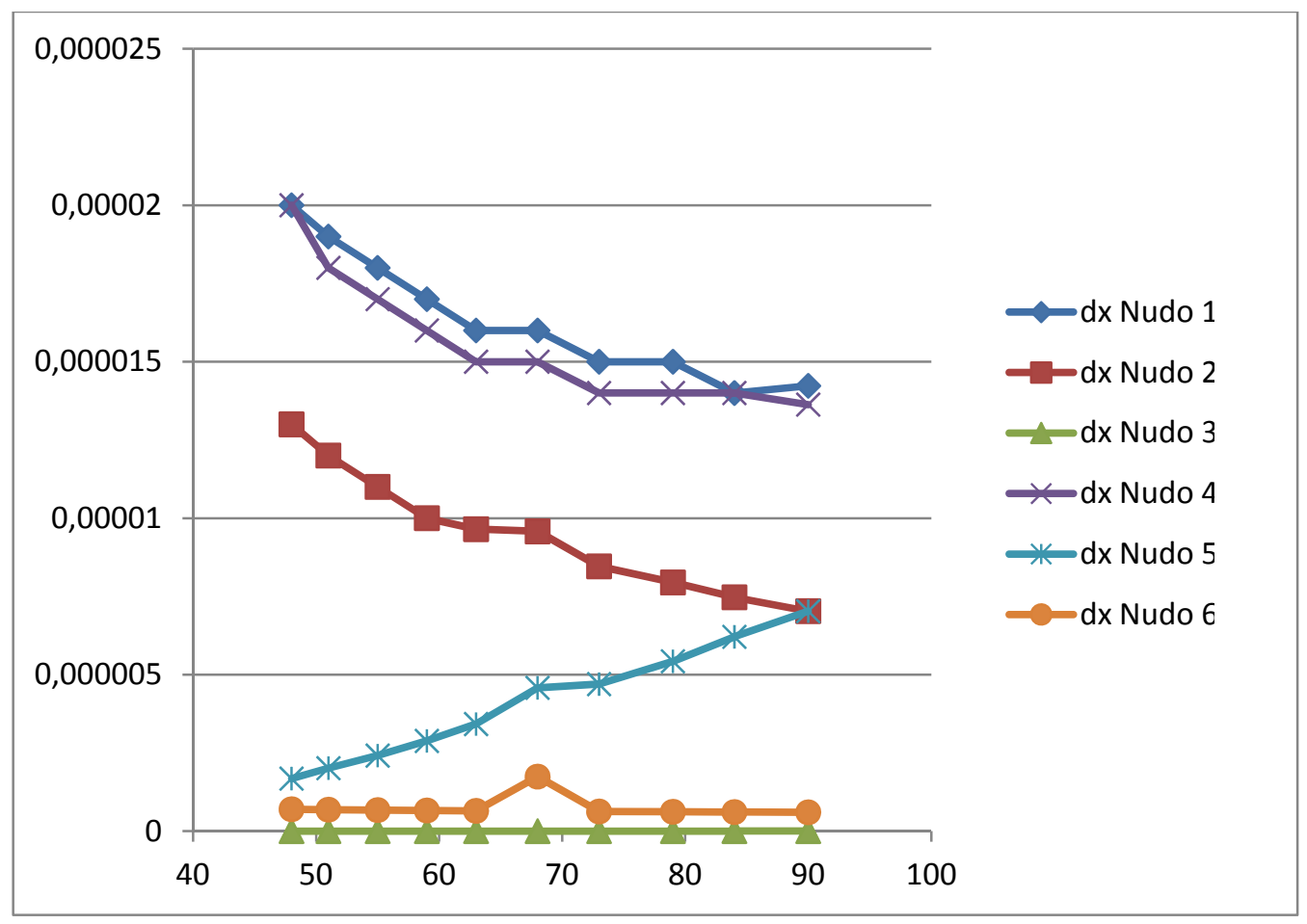

Gráfica 10 Desplazamientos horizontales (KN, eje y) en nudos estructura auxética reentrante hexagonal unitaria con carga en función de la apertura (grados ${ }^{\circ}$, eje x), elaboración propia 
Como puede observarse en las gráficas anteriores, realizadas a partir de la Tabla 29, desplazamientos horizontales estructura reentrante hexagonal metálica rígida para diversas aperturas sin carga y con carga, del Apéndice 2: Tablas de cálculo estructural, se observan unos desplazamientos horizontales con comportamientos muy diversos dependiendo de las aperturas de la estructura y la carga de la misma, así como del nudo a que afectan dichos desplazamientos.

Para el nudo 1 se aprecian unos desplazamientos horizontales que oscilan entre 0,0000000367m y 0,0000001355m cuando la estructura no está cargada. Los desplazamientos horizontales en el nudo 1 para la estructura cargada son mucho mayores, oscilando entre 0,00001423m y 0,00002m. Los desplazamientos mayores en ambos casos corresponden a la menor apertura de la figura (es decir, cuanto más cerrada está, más desplazamientos horizontales se generan en este nudo). Los desplazamientos menores corresponden a la mayor apertura de la figura (es decir, cuanto más abierta está, menos desplazamientos horizontales se generan en este nudo).

Para el nudo 2 se aprecian unos desplazamientos horizontales que oscilan entre 0,00000001835m y 0,000001624m cuando la estructura no está cargada. Los desplazamientos horizontales en el nudo 2 para la estructura cargada son mucho mayores, oscilando entre 0,00000703m y 0,000013m. Los desplazamientos mayores en ambos casos corresponden a la menor apertura de la figura (es decir, cuanto más cerrada está, más desplazamientos horizontales se generan en este nudo). Los desplazamientos menores corresponden a la mayor apertura de la figura (es decir, cuanto más abierta está, menos desplazamientos horizontales se generan en este nudo).

Para el nudo 3 se aprecian unos desplazamientos horizontales nulos en todos los casos. Esto es debido a que este nudo corresponde a uno de los apoyos de la estructura y tiene impuestas restricciones a los desplazamientos en todas las direcciones.

Para el nudo 4 se aprecian unos desplazamientos horizontales nulos cuando la estructura no está cargada. Sin embargo, cuando la estructura está cargada aparecen desplazamientos horizontales en el nudo 4, oscilando sus valores entre 0,00001363m y $0,00002 \mathrm{~m}$. Los desplazamientos mayores en este caso corresponden a la menor apertura de la figura (es decir, cuanto más cerrada está, más desplazamientos horizontales se generan en este nudo). Los desplazamientos menores corresponden a la mayor apertura de la figura (es decir, cuanto más abierta está, menos desplazamientos horizontales se generan en este nudo). 
Para el nudo 5 se aprecian unos desplazamientos horizontales que oscilan entre 0,00000001835m y -0,000001488m cuando la estructura no está cargada. Los desplazamientos horizontales en el nudo 5 para la estructura cargada son mayores, oscilando entre 0,00000703m y 0,00000168m. Los desplazamientos mayores para la estructura sin carga corresponden a la menor apertura de la figura (es decir, cuanto más cerrada está, más desplazamientos horizontales se generan en este nudo), sin embargo, para la estructura cargada ocurre lo contrario, los desplazamientos menores corresponden a la menor apertura de la figura (es decir, cuanto menos abierta está, menos desplazamientos se generan en este nudo).

Para el nudo 6 se aprecian unos desplazamientos horizontales que oscilan entre $0 \mathrm{~m}$ y 0,0000001355m cuando la estructura no está cargada. Los desplazamientos horizontales en el nudo 6 para la estructura cargada son mayores, variando linealmente de 0,0000006024m a 0,0000007019m, con un desplazamiento mayor de valor 0,000001744m para una apertura de $68^{\circ}$. Los desplazamientos mayores en ambos casos (salvo la excepción comentada) corresponden a la menor apertura de la figura (es decir, cuanto más cerrada está, más desplazamientos horizontales se generan en este nudo). Los desplazamientos menores corresponden a la mayor apertura de la figura (es decir, cuanto más abierta está, menos desplazamientos horizontales se generan en este nudo).

De este modo, se puede concluir que los desplazamientos horizontales para una estructura reentrante hexagonal metálica rígida para diversas aperturas aumentan con la carga, siendo mayores cuanto más se cierra la estructura, salvo en la excepción del nudo 5, en el que aparecen mayores desplazamientos cuanto más se abre la estructura. Generalmente se obtiene un comportamiento lineal de desplazamiento horizontal según la apertura o cierre de la estructura, salvo para el caso comentado del nudo 6 cuando la estructura está cargada, en el que para una apertura de $68^{\circ}$ obtenemos los desplazamientos horizontales mayores de dicho nudo. 


\section{Desplazamientos verticales}

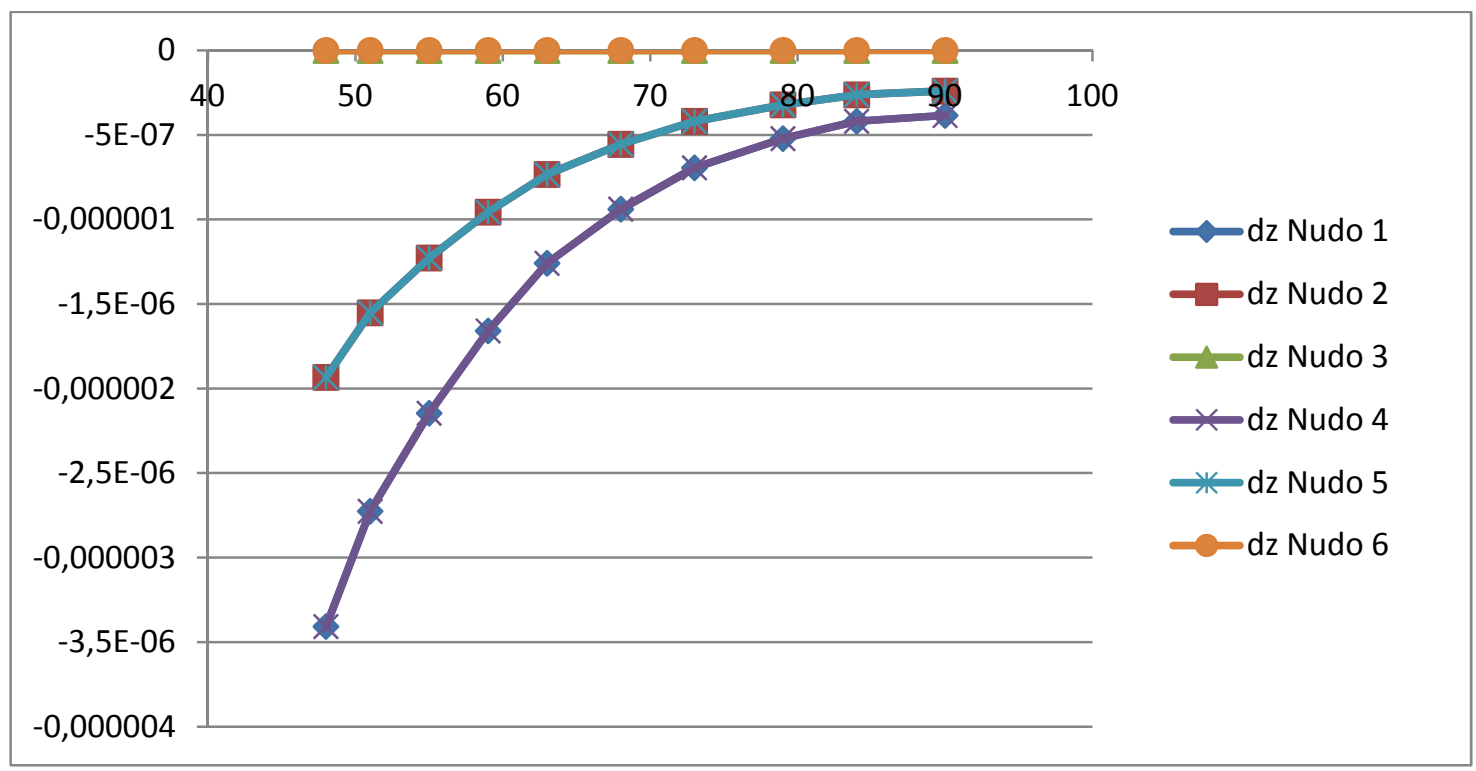

Gráfica 11 Gráfica comparativa de desplazamientos verticales (KN, eje y) para la estructura reentrante hexagonal metálica rígida para diversas aperturas sin carga (grados ${ }^{\circ}$, eje $x$ ), elaboración propia

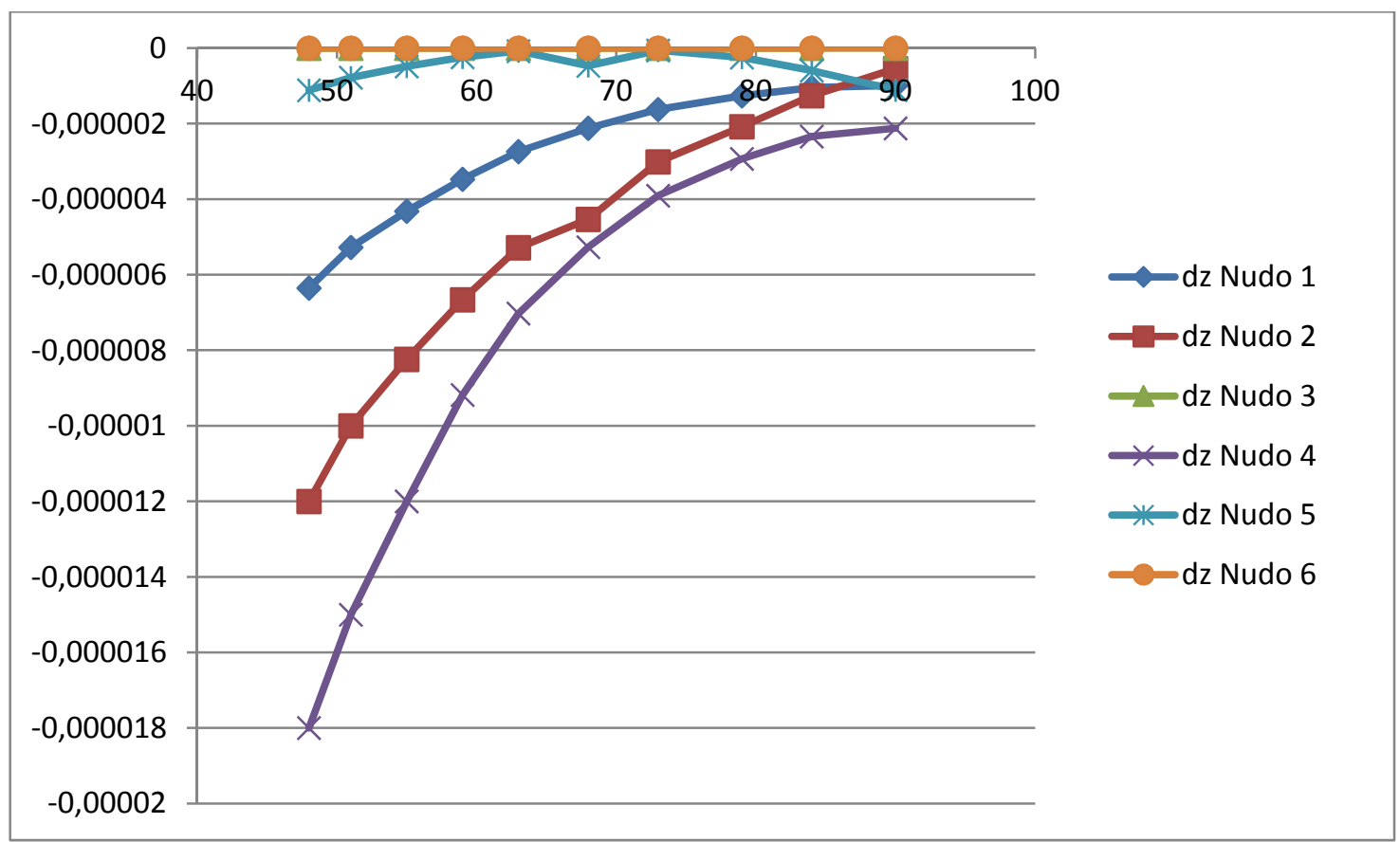

Gráfica 12 Gráfica comparativa de desplazamientos verticales ( $K N$, eje y) para la estructura reentrante hexagonal metálica rígida para diversas aperturas con carga (grados ${ }^{\circ}$, eje $x$ ), elaboración propia 
Como puede observarse en las gráficas anteriores, realizadas a partir de la Tabla 30 , desplazamientos verticales estructura reentrante hexagonal metálica rígida para diversas aperturas sin carga y con carga, del Apéndice 2: Tablas de cálculo estructural, se observan unos desplazamientos verticales con comportamientos muy diversos dependiendo de las aperturas de la estructura y la carga de la misma, así como del nudo a que afectan dichos desplazamientos.

Para el nudo 1 se aprecian unos desplazamientos verticales que oscilan entre $-0,000000385 m$ y $-0,000003408 m$ cuando la estructura no está cargada. Los desplazamientos verticales en el nudo 1 para la estructura cargada son mucho mayores, oscilando entre $-0,000000992 \mathrm{~m}$ y $-0,000006351 \mathrm{~m}$. Los desplazamientos mayores en ambos casos corresponden a la menor apertura de la figura (es decir, cuanto más cerrada está, más desplazamientos verticales se generan en este nudo). Los desplazamientos menores corresponden a la mayor apertura de la figura (es decir, cuanto más abierta está, menos desplazamientos verticales se generan en este nudo).

Para el nudo 2 se aprecian unos desplazamientos verticales que oscilan entre $-0,0000002406 m$ y $-0,000001934 m$ cuando la estructura no está cargada. Los desplazamientos verticales en el nudo 2 para la estructura cargada son mucho mayores, oscilando entre $-0,0000005441 \mathrm{~m}$ y $-0,000012 \mathrm{~m}$. Los desplazamientos mayores en ambos casos corresponden a la menor apertura de la figura (es decir, cuanto más cerrada está, más desplazamientos verticales se generan en este nudo). Los desplazamientos menores corresponden a la mayor apertura de la figura (es decir, cuanto más abierta está, menos desplazamientos verticales se generan en este nudo).

Para el nudo 3 se aprecian unos desplazamientos verticales nulos en todos los casos. Esto es debido a que este nudo corresponde a uno de los apoyos de la estructura y tiene impuestas restricciones a los desplazamientos en todas las direcciones.

Para el nudo 4 se aprecian unos desplazamientos verticales que oscilan entre $-0,000000385 \mathrm{~m}$ y $-0,000003408 \mathrm{~m}$ cuando la estructura no está cargada. Los desplazamientos verticales en el nudo 4 para la estructura cargada son mucho mayores, oscilando entre $-0,000002123 m$ y $-0,000018 m$. Los desplazamientos mayores en ambos casos corresponden a la menor apertura de la figura (es decir, cuanto más cerrada está, más desplazamientos verticales se generan en este nudo). Los desplazamientos menores corresponden a la mayor apertura de la figura (es decir, cuanto más abierta está, menos desplazamientos verticales se generan en este nudo). 
Para el nudo 5 se aprecian unos desplazamientos verticales que oscilan entre $-0,0000002406 m$ y $-0,000001934 m$ cuando la estructura no está cargada, estos máximos y mínimos son iguales que los del nudo 2. Los desplazamientos verticales en el nudo 5 para la estructura cargada son una excepción porque no siguen una distribución lineal sino

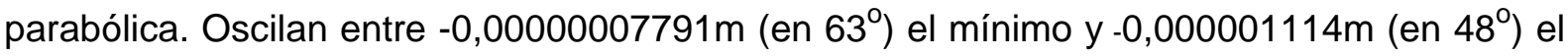
máximo. Los desplazamientos mayores para la estructura sin carga corresponden a la menor apertura de la figura (es decir, cuanto más cerrada está, más desplazamientos verticales se generan en este nudo). Sin embargo, para la estructura cargada el desplazamiento vertical menor para el nudo 5 corresponde a la apertura de $63^{\circ}$, mientras que en los extremos del estudio $\left(48^{\circ}\right.$ y $\left.90^{\circ}\right)$ los desplazamientos verticales son los mayores de este nudo.

Para el nudo 6 se aprecian unos desplazamientos verticales nulos en todos los casos. Esto es debido a que este nudo corresponde a uno de los apoyos de la estructura y tiene impuestas restricciones a los desplazamientos.

De este modo, se puede concluir que los desplazamientos verticales para una estructura reentrante hexagonal metálica rígida para diversas aperturas aumentan con la carga, siendo mayores cuanto más se cierra la estructura, salvo en la excepción del nudo 5, en el que la distribución de desplazamientos verticales no es lineal al variar el ángulo de apertura, sino que dibuja una trayectoria parabólica en la cual los menores desplazamientos corresponden a una apertura intermedia de la figura. Generalmente se obtiene un comportamiento lineal del desplazamiento vertical según la apertura o cierre de la estructura, salvo para el caso comentado del nudo 5 cuando la estructura está cargada, en el que para una apertura de $68^{\circ}$ obtenemos los desplazamientos verticales mayores de dicho nudo. 
Rotaciones en articulaciones

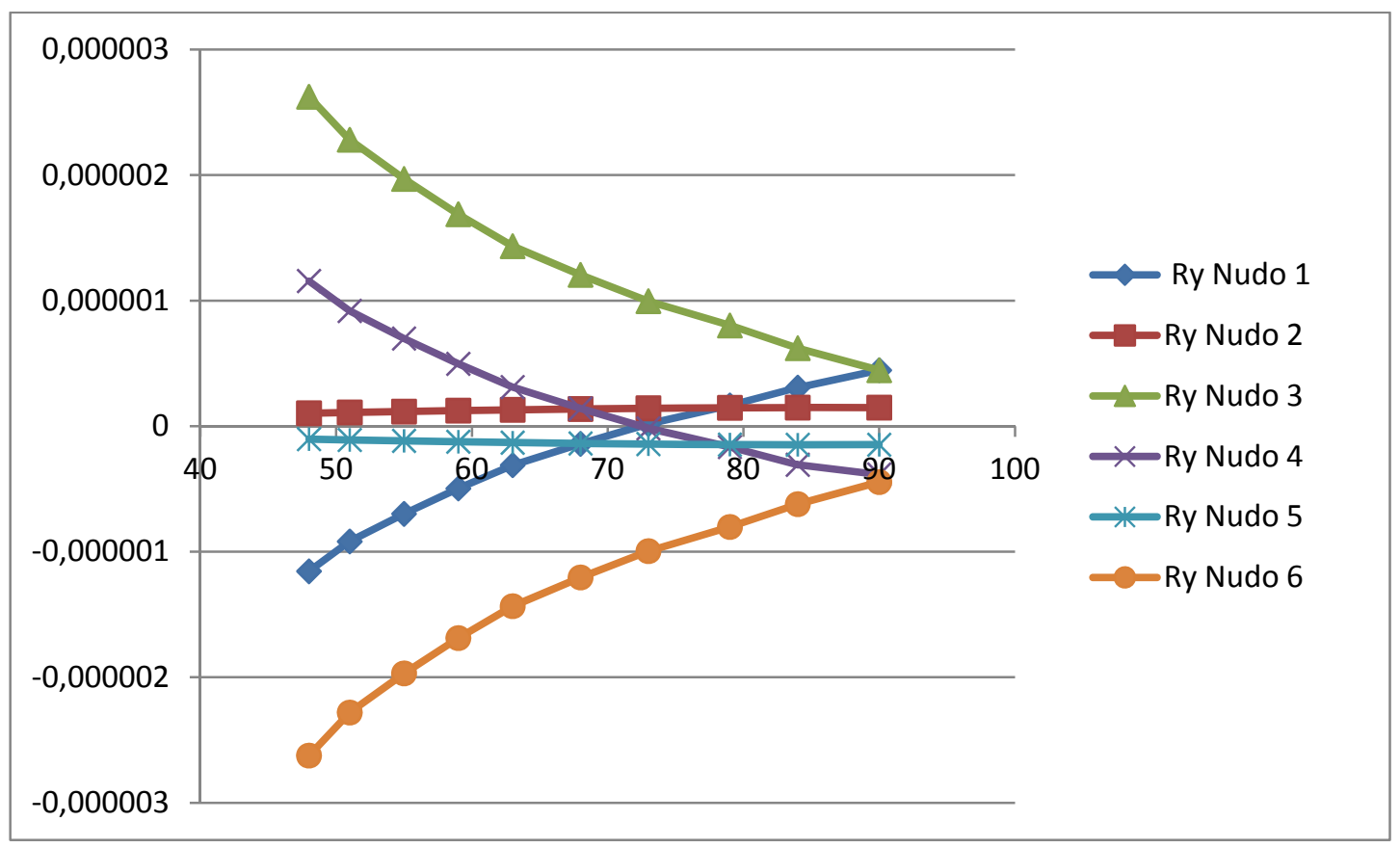

Gráfica 13 Gráfica comparativa de rotaciones ( rad, eje y) en articulaciones para la estructura reentrante hexagonal metálica rígida para diversas aperturas sin carga (grados ${ }^{\circ}$, eje $x$ ), elaboración propia

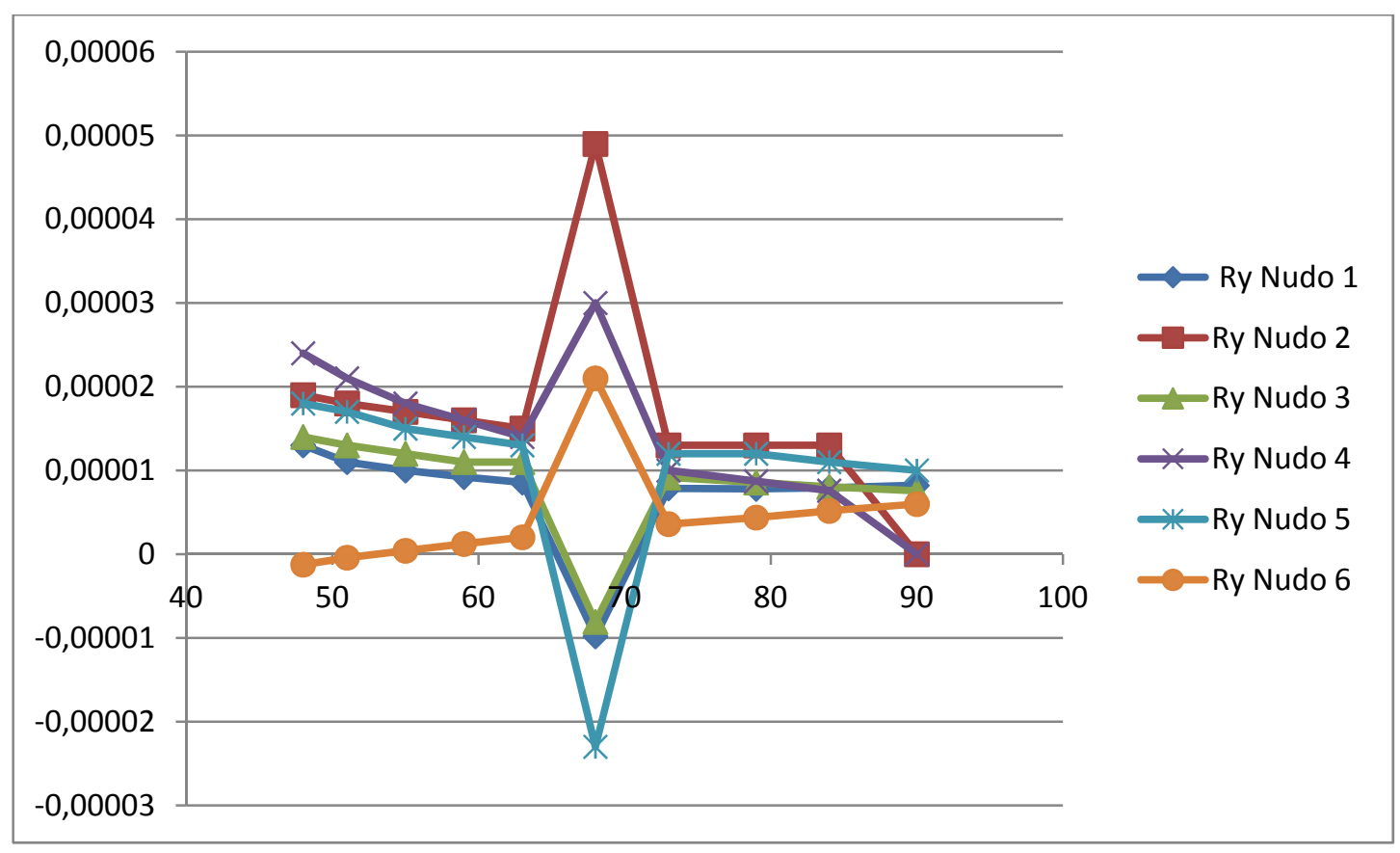

Gráfica 14 Gráfica comparativa de rotaciones (rad, eje y) en articulaciones para la estructura reentrante hexagonal metálica rígida para diversas aperturas con carga (grados ${ }^{\circ}$, eje x), elaboración propia 
Como puede observarse en las gráficas anteriores, realizadas a partir de la Tabla 31, rotaciones en articulaciones estructura reentrante hexagonal metálica rígida para diversas aperturas sin carga y con carga, del Apéndice 2: Tablas de cálculo estructural, se observan unas rotaciones en las articulaciones con comportamientos muy diversos dependiendo de las aperturas de la estructura y la carga de la misma, así como del nudo a que afectan dichas rotaciones.

Para el nudo 1 se aprecian unas rotaciones que oscilan entre $0,00000001758 \mathrm{rad}\left(\mathrm{en} 73^{\circ}\right.$ ) y $-0,000001156$ rad (en $48^{\circ}$ ) cuando la estructura no está cargada. Las rotaciones en el nudo 1 para la estructura cargada son mucho mayores, oscilando entre 0,000007798 rad (en $79^{\circ}$ ) y 0,000013 rad $\left(e n 8^{\circ}\right.$ ). Las rotaciones mayores en ambos casos corresponden a la menor apertura de las estructuras estudiadas (es decir, cuanto más cerrada está, mayores rotaciones se generan en este nudo). Sin embargo, las menores rotaciones corresponden a los ángulos $73^{\circ}$ y $79^{\circ}$ respectivamente y no al ángulo de $90^{\circ}$ como correspondería a una distribución lineal. Es decir, las menores rotaciones se generan en este nudo para un plegado medio de la estructura.

Para el nudo 2 se aprecian unas rotaciones que oscilan entre 0,0000001034 rad (en $48^{\circ}$ ) y $0,0000001482 \mathrm{rad}\left(\mathrm{en} 84^{\circ}\right.$ ) cuando la estructura no está cargada. Las rotaciones en el nudo 2 para la estructura cargada son mucho mayores, oscilando entre 0,00001 rad (en $90^{\circ}$ ) y $0,000049 \mathrm{rad}\left(\mathrm{en} 68^{\circ}\right)$. Las rotaciones mayores en corresponden a las aperturas de $84^{\circ}$ cuando la estructura no está cargada y $68^{\circ}$ cuando sí lo está. En el caso de la estructura sin cargar el comportamiento es bastante lineal. Sin embargo, en la estructura cargada, se observa un pico para una apertura media que rompe este comportamiento lineal, generándose para esta apertura unas rotaciones en esta articulación mucho mayores que las del resto de la gráfica. Las rotaciones menores corresponden a los ángulos extremos del estudio, es decir, a los ángulos muy abiertos o a los ángulos muy cerrados.

Para el nudo 3 se aprecian unas rotaciones que oscilan entre 0,0000004454 rad y 0,000002624 rad cuando la estructura no está cargada. Las rotaciones en el nudo 3 para la estructura cargada son mucho mayores, oscilando entre 0,000007541 rad y 0,000014 rad. Las rotaciones mayores en ambos casos corresponden a la menor apertura de la figura (es decir, cuanto más cerrada está, más rotaciones se generan en este nudo). Las rotaciones menores corresponden a la mayor apertura de la figura (es decir, cuanto más abierta está, menos rotaciones se generan en este nudo). Esto es una percepción a nivel general porque, en el caso con carga, no es una distribución lineal sino que tiene irregularidades. 
Para el nudo 4 se aprecian unas rotaciones que oscilan entre $-0,00000001758 \mathrm{rad}\left(\mathrm{en} 73^{\circ}\right)$ y $0,000001156 \mathrm{rad}$ (en $48^{\circ}$ ) cuando la estructura no está cargada. Las rotaciones en el nudo 4 para la estructura cargada son mucho mayores, oscilando entre $0,0000665 \mathrm{rad}\left(\mathrm{en} 90^{\circ}\right.$ ) y $0,00003 \mathrm{rad}\left(\mathrm{en} 68^{\circ}\right.$ ). Las rotaciones mayores corresponden a las aperturas de $48^{\circ}$ en el caso de la estructura sin carga y $68^{\circ}$ para la estructura cargada. Las rotaciones menores corresponden a los ángulos de $73^{\circ}$ y $90^{\circ}$. Nuevamente podemos encontrar comportamientos lineales en función de la apertura, salvo para el caso de $68^{\circ}$ cuando la estructura está cargada, donde nos encontramos un pico que rompe este comportamiento lineal.

Para el caso del nudo 5, nos encontramos unas rotaciones iguales a las del nudo 2 pero de signo contrario. Esto es debido a su posición equivalente y simétrica en la estructura.

Para el nudo 6 se aprecian unas rotaciones que oscilan entre $-0,0000004454$ rad y $-0,000002624$ rad cuando la estructura no está cargada. Las rotaciones en el nudo 6 para la estructura cargada son mucho mayores, oscilando entre 0,000001223 rad (en 59 ${ }^{\circ}$ y $0,000021 \mathrm{rad}\left(\mathrm{en} 68^{\circ}\right.$ ). En el caso de la estructura sin cargar, las rotaciones mayores se producen en los ángulos más cerrados y las rotaciones menores en los ángulos mas abiertos. En el caso de la estructura cargada, las rotaciones siguen un comportamiento lineal, aumentando de forma no lineal para la apertura de $68^{\circ}$, donde se rompe este patrón y se genera un pico donde aumentan considerablemente dichas rotaciones.

De este modo, se puede concluir que las rotaciones en las articulaciones para una estructura reentrante hexagonal metálica rígida para diversas aperturas siguen una distribución lineal cuando no están cargadas. Pero, sin embargo, al cargarse, esta distribución se transforma en no lineal, debiendo ser concretada siguiendo un estudio exhaustivo de sus esfuerzos. 


\section{Reacciones en apoyos}

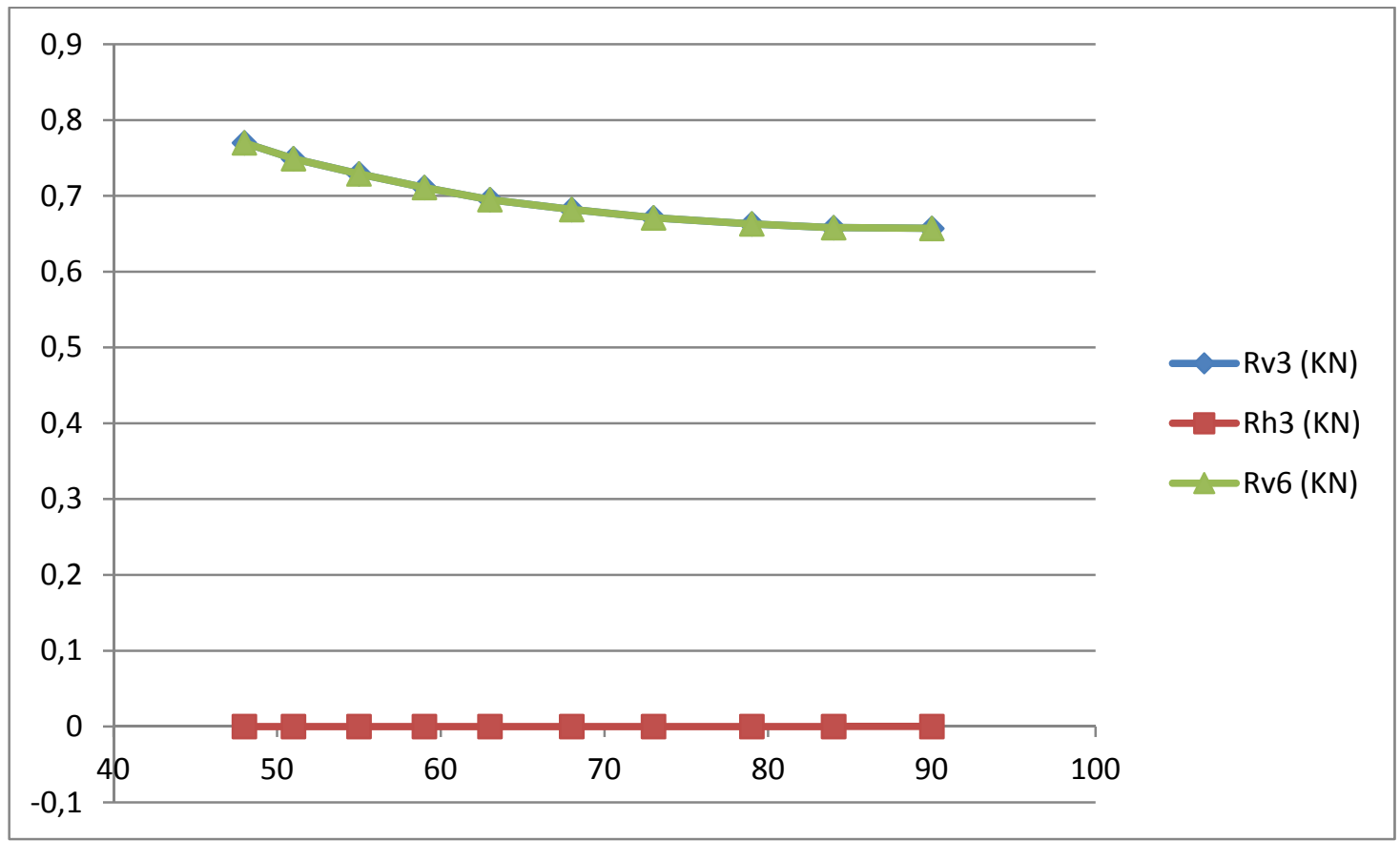

Gráfica 15 Gráfica comparativa de reacciones en apoyos (KN, eje y) para la estructura reentrante hexagonal metálica rígida para diversas aperturas sin carga (grados ${ }^{\circ}$, eje $x$ ), elaboración propia

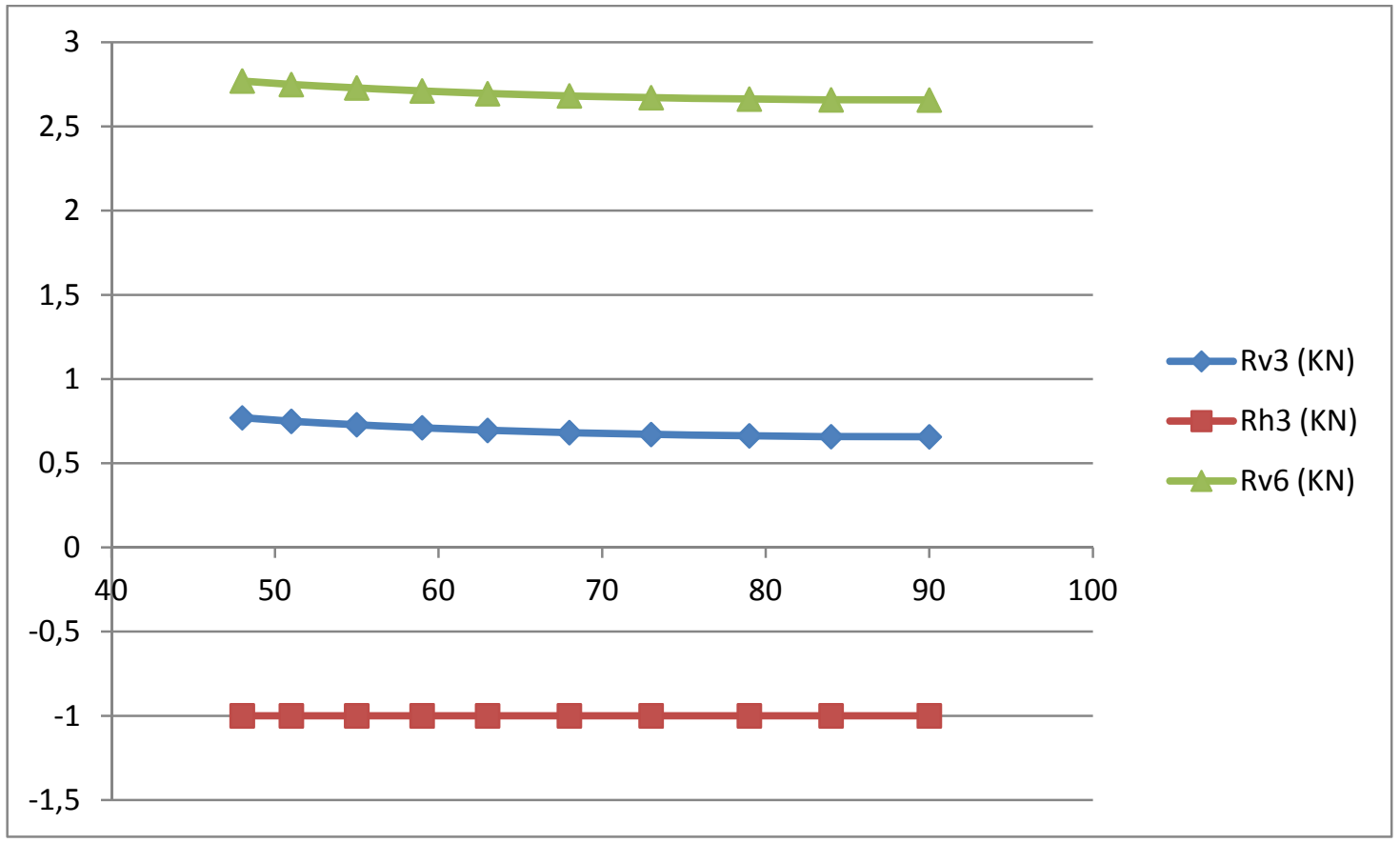

Gráfica 16 Gráfica 15 Gráfica comparativa de reacciones en apoyos (KN, eje y) para la estructura reentrante hexagonal metálica rígida para diversas aperturas con carga (grados ${ }^{\circ}$, eje $x$ ), elaboración propia 
Como puede observarse en las gráficas anteriores, realizadas a partir de la Tabla 32, reacciones en apoyos estructura reentrante hexagonal metálica rígida para diversas aperturas sin carga y con carga, del Apéndice 2: Tablas de cálculo estructural, se observan unas reacciones en apoyos con comportamientos muy diversos dependiendo sobre todo de la carga de la estructura y, en algunos casos, de la apertura de la misma, así como del nudo a que afectan dichas reacciones.

Para el nudo 3 se aprecian unas reacciones verticales que oscilan entre $0,657 \mathrm{KN}$ y $0,77 \mathrm{KN}$ cuando la estructura no está cargada y también cuando lo está. Las reacciones verticales mayores en ambos casos corresponden a la menor apertura de la figura (es decir, cuanto más cerrada está, más reacciones verticales se generan en este nudo). Las reacciones verticales menores corresponden a la mayor apertura de la figura (es decir, cuanto más abierta está, menos reacciones verticales se generan en este nudo).

Para el nudo 3 también se aprecian unas reacciones horizontales que oscilan entre $-6,939 \cdot 10^{-18} \mathrm{KN}$ y $-3,261 \cdot 10^{-16} \mathrm{KN}$ cuando la estructura no está cargada. Las reacciones horizontales en el nudo 3 para la estructura cargada son mucho mayores, siendo iguales a $1 \mathrm{KN}$ (equivalentes a la carga horizontal aplicada). Las reacciones horizontales mayores en el primer caso corresponden a la menor apertura de la figura (es decir, cuanto más cerrada está, más reacciones horizontales se generan en este nudo). Las reacciones horizontales menores corresponden a la mayor apertura de la figura (es decir, cuanto más abierta está, menos reacciones horizontales se generan en este nudo). En cualquier caso, estas reacciones horizontales para este caso concreto pueden considerarse despreciables.

Para el nudo 6 se aprecian unas reacciones verticales que oscilan entre $0,657 \mathrm{KN}$ y $0,77 \mathrm{KN}$ cuando la estructura no está cargada. Cuando dicha estructura tiene carga las reacciones verticales en este apoyo oscilan entre $2,657 \mathrm{KN}$ y $2,77 \mathrm{KN}$. Las reacciones verticales mayores en ambos casos corresponden a la menor apertura de la figura (es decir, cuanto más cerrada está, más reacciones verticales se generan en este nudo). Las reacciones verticales menores corresponden a la mayor apertura de la figura (es decir, cuanto más abierta está, menos reacciones verticales se generan en este nudo). Pero en ambos casos, estas variaciones pueden considerarse despreciables.

De este modo, se puede concluir que los aumentos de reacciones horizontales y verticales son debidos principalmente a la carga, salvo en el caso de las reacciones verticales del nudo 6, que además pueden atribuirse también a la configuración de dicho nudo. 
Esfuerzos axiles

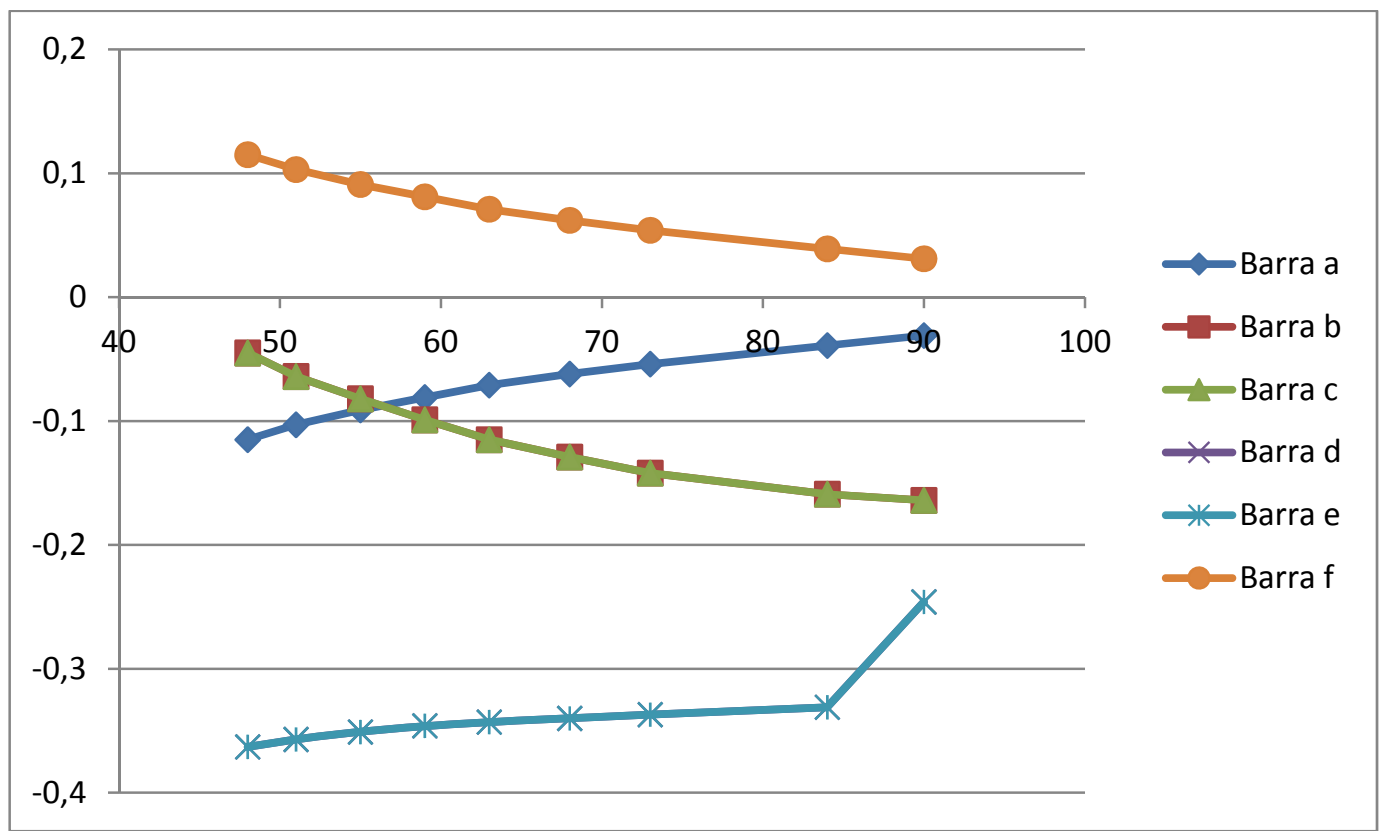

Gráfica 17 Comparación de esfuerzos axiles mínimos ( $K N$, eje y) en barras para la estructura reentrante hexagonal metálica rígida para diversas aperturas sin carga (grados ${ }^{\circ}$, eje $x$ ), elaboración propia

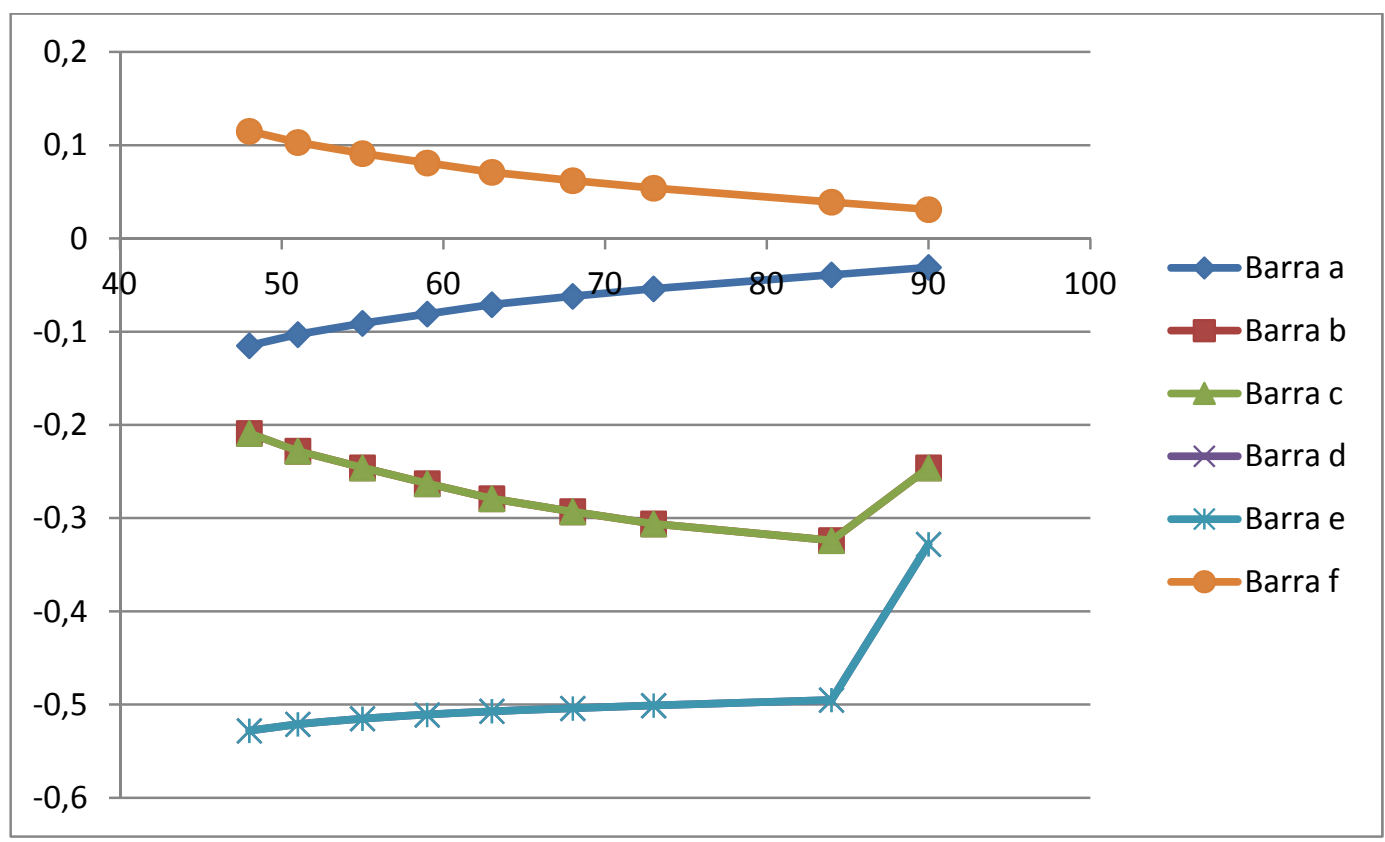

Gráfica 18 Gráfica comparativa de esfuerzos axiles máximos (KN, eje y) en barras para la estructura reentrante hexagonal metálica rígida para diversas aperturas sin carga (grados ${ }^{\circ}$, eje $x$ ), elaboración propia 


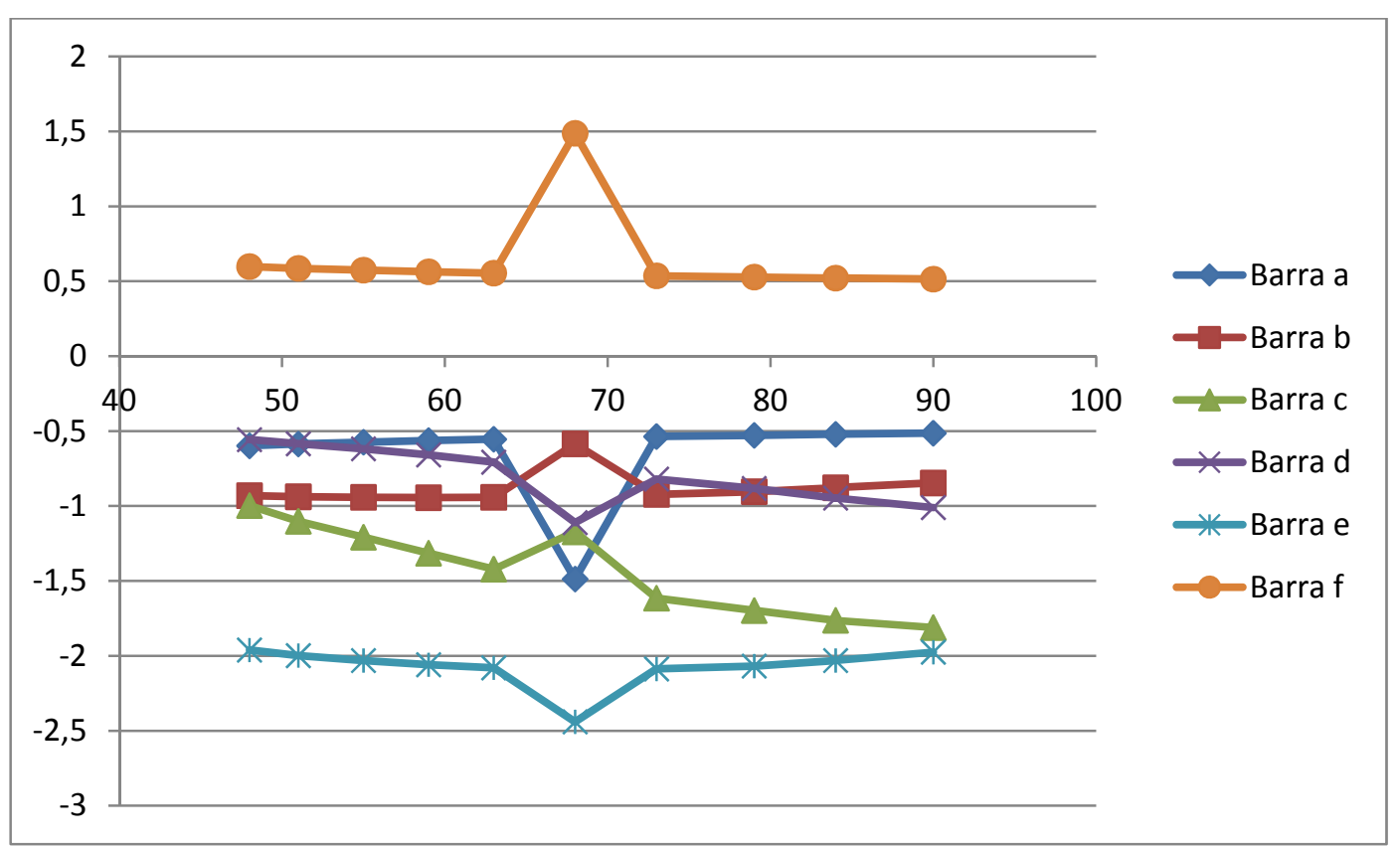

Gráfica 19 Gráfica comparativa de esfuerzos axiles mínimos (KN, eje y) en barras para la estructura reentrante hexagonal metálica rígida para diversas aperturas con carga (grados ${ }^{\circ}$, eje $x$ ), elaboración propia

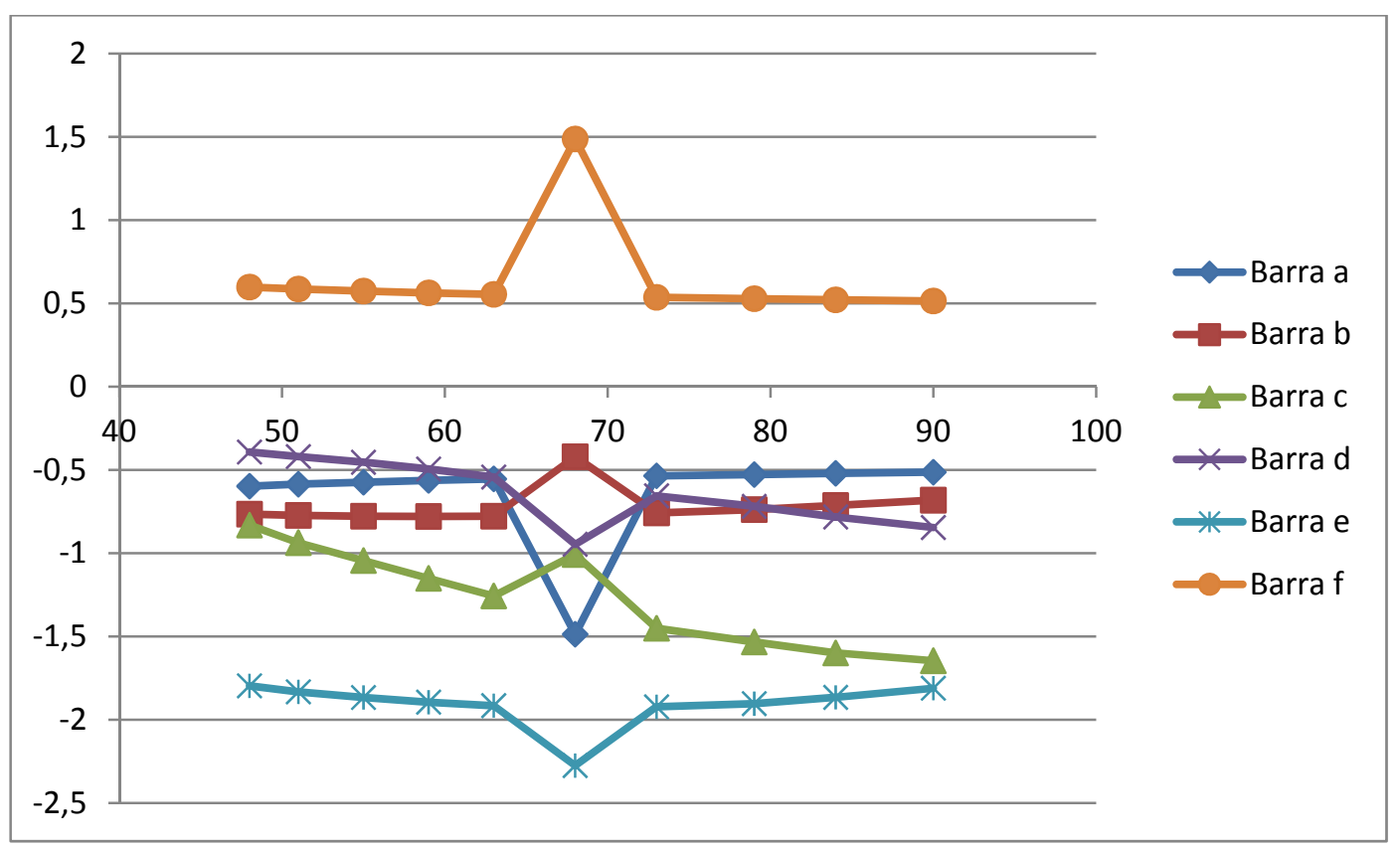

Gráfica 20 Gráfica comparativa de esfuerzos axiles máximos (KN, eje y) en barras para la estructura reentrante hexagonal metálica rígida para diversas aperturas con carga (grados ${ }^{\circ}$, eje x), elaboración propia 
Como puede observarse en las gráficas anteriores, realizadas a partir de la Tabla 33, esfuerzos axiles estructura reentrante hexagonal metálica rígida para diversas aperturas sin carga y con carga, del Apéndice 2: Tablas de cálculo estructural, se observan unos esfuerzos axiles en barras con comportamientos diversos dependiendo de las aperturas de la estructura y la carga de la misma, así como de la barra a que afectan dichos esfuerzos.

Para la barra a se observan unos esfuerzos axiles para la estructura sin carga con un valor mínimo de -0,031 a $90^{\circ}$, siendo el valor máximo -0,115 en $48^{\circ}$. En cuanto a los esfuerzos axiles para la estructura con carga los valores son: mínimo $-0,514$ también para $90^{\circ}, \mathrm{y}$ máximo para $68^{\circ}$ con un valor de $-1,487$. Los esfuerzos axiles mayores en ambos casos corresponden a la menor apertura de la figura (es decir, cuanto más cerrada está, más esfuerzos axiles se generan en esta barra). Los esfuerzos axiles menores corresponden a la mayor apertura de la figura (es decir, cuanto más abierta está, menos esfuerzos axiles se generan en esta barra). En cualquier caso, se aprecia que las diferencias entre los esfuerzos generados según la apertura de la estructura son mucho más apreciables cuando la estructura está sin cargar.

Para la barra b los valores para los esfuerzos axiles para la estructura sin carga son: mínimo para $48^{\circ}$ con un valor de $-0,045$ a $-0,209$ y máximo con un valor de $-0,164$ a -0,248 para $90^{\circ}$. Los valores para los esfuerzos axiles para la estructura con carga son: mínimo de -0,585 a 0,421 para $68^{\circ}$ y máximo de $-0,944$ a $-0,78$ para $59^{\circ}$. Los esfuerzos axiles mayores para la estructura sin cargar corresponden a la mayor apertura de la figura (es decir, cuanto más abierta está, más esfuerzos axiles se generan en esta barra). Los esfuerzos axiles en esta barra para la estructura cargada, al igual que para la estructura sin cargar, siguen una distribución lineal en función de la apertura, pero se observa una ruptura de esta distribución para el caso de $68^{\circ}$.

Para la barra c los valores de los esfuerzos axiles sin cargas son: mínimos de -0,045 a 0,209 para $48^{\circ}$ y máximo de $-0,164$ a 0,246 para $90^{\circ}$. Los valores de los esfuerzos axiles con carga son: mínimo -0,997 a 0,832 para 48 y máximo de -1,811 a -1,648 para $90^{\circ}$. Los esfuerzos axiles menores en ambos casos corresponden a la menor apertura de la figura (es decir, cuanto más cerrada está, menos esfuerzos axiles se generan en esta barra). Los esfuerzos axiles mayores corresponden a la mayor apertura de la figura (es decir, cuanto más abierta está, más esfuerzos axiles se generan en esta barra).

Para la barra d los valores de los esfuerzos axiles sin cargas son: mínimo de -0,246 a -0,328 para $90^{\circ}$ y máximos para los valores $-0,363$ a $-0,528$ para $48^{\circ}$. Los valores de los esfuerzos 
axiles con carga son: mínimo de -0,557 a -0,393 para 48 y máximo de $-1,111$ a -0,947 para $68^{\circ}$. Los esfuerzos axiles menores para la estructura sin cargar corresponden a la mayor apertura de la figura (es decir, cuanto más abierta está, menos esfuerzos axiles se generan en esta barra). Los esfuerzos axiles en esta barra para la estructura cargada, al igual que para la estructura sin cargar, siguen una distribución lineal en función de la apertura, pero se observa una ruptura de esta distribución para el caso de $68^{\circ}$.

Para la barra e los valores de los esfuerzos axiles sin cargas son: mínimo de -0,246 a -0,328 para $90^{\circ}$ y máximo de $-0,363$ a $-0,528$ para $48^{\circ}$. Los valores de los esfuerzos axiles con carga son: mínimo de $-1,961$ a $-1,797$ para $48^{\circ}$ y máximo de $-2,44$ a $-2,276$ para $68^{\circ}$. Los esfuerzos axiles menores para la estructura sin cargar corresponden a la mayor apertura de la figura (es decir, cuanto más abierta está, menos esfuerzos axiles se generan en esta barra). Los esfuerzos axiles en esta barra para la estructura cargada, al igual que para la estructura sin cargar, siguen una distribución lineal en función de la apertura, pero se observa una ruptura de esta distribución para el caso de $68^{\circ}$.

Para la barra f los valores de los esfuerzos axiles sin cargas son: mínimo de 0,031 para 90 y máximo de 0,115 para $48^{\circ}$. Los valores de los esfuerzos axiles con cargas son: mínimo de 0,514 para $90^{\circ}$ y máximo de 1,487 para $68^{\circ}$. Los esfuerzos axiles menores para la estructura sin cargar corresponden a la mayor apertura de la figura (es decir, cuanto más abierta está, menos esfuerzos axiles se generan en esta barra). Los esfuerzos axiles en esta barra para la estructura cargada, al igual que para la estructura sin cargar, siguen una distribución lineal en función de la apertura, pero se observa una ruptura de esta distribución para el caso de $68^{\circ}$.

De este modo, se puede concluir que los esfuerzos axiles en barras para una estructura reentrante hexagonal metálica rígida para diversas aperturas aumentan con la carga, siendo mayores en general cuanto más se cierra la estructura, salvo en la excepción de las barras b y c, que se aprecia el comportamiento contrario. Generalmente se obtiene un comportamiento lineal de esfuerzo axil según la apertura o cierre de la estructura, salvo para el caso comentado de la apertura de $68^{\circ}$ cuando la estructura está cargada, en el que obtenemos los esfuerzos axiles mayores de las barras. 


\section{Esfuerzos cortantes en barras}

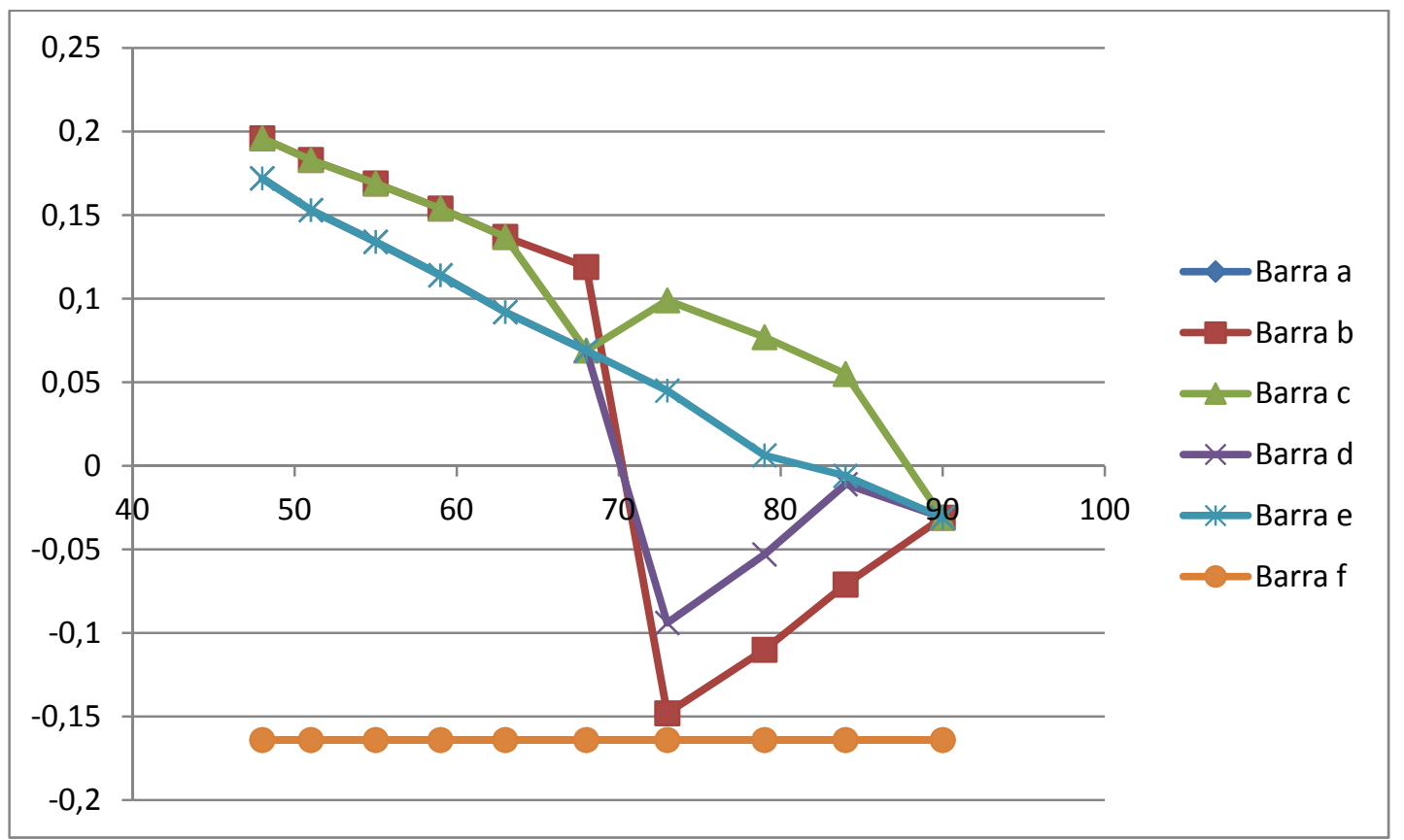

Gráfica 21 Gráfica comparativa de esfuerzos cortantes mínimos ( $K N$, eje y) en barras para la estructura reentrante hexagonal metálica rígida para diversas aperturas sin carga (grados ${ }^{\circ}$, eje $x$ ), elaboración propia

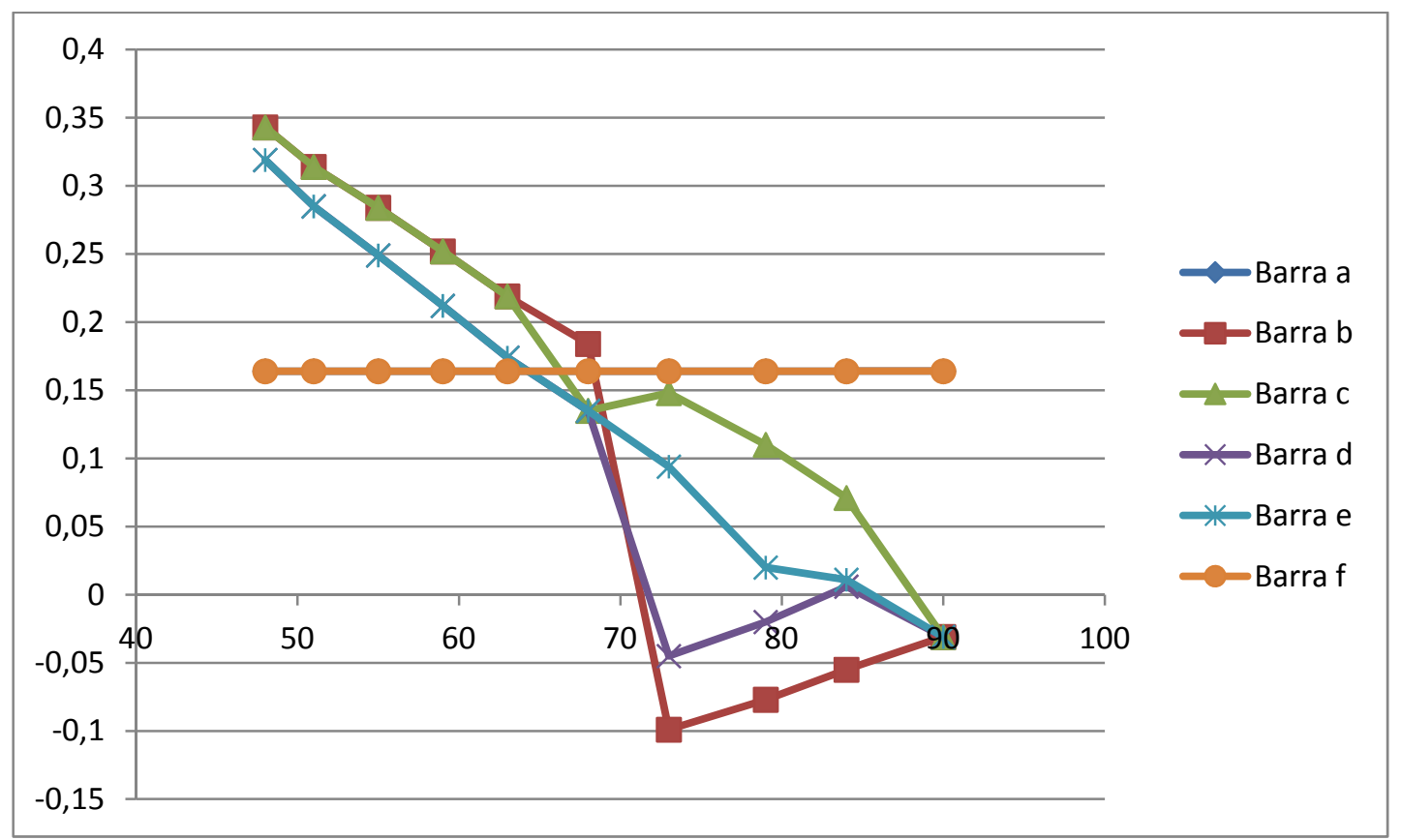

Gráfica 22 Gráfica comparativa de esfuerzos cortantes máximos (KN, eje y) en barras para la estructura reentrante hexagonal metálica rígida para diversas aperturas sin carga (grados ${ }^{\circ}$, eje $x$ ), elaboración propia 


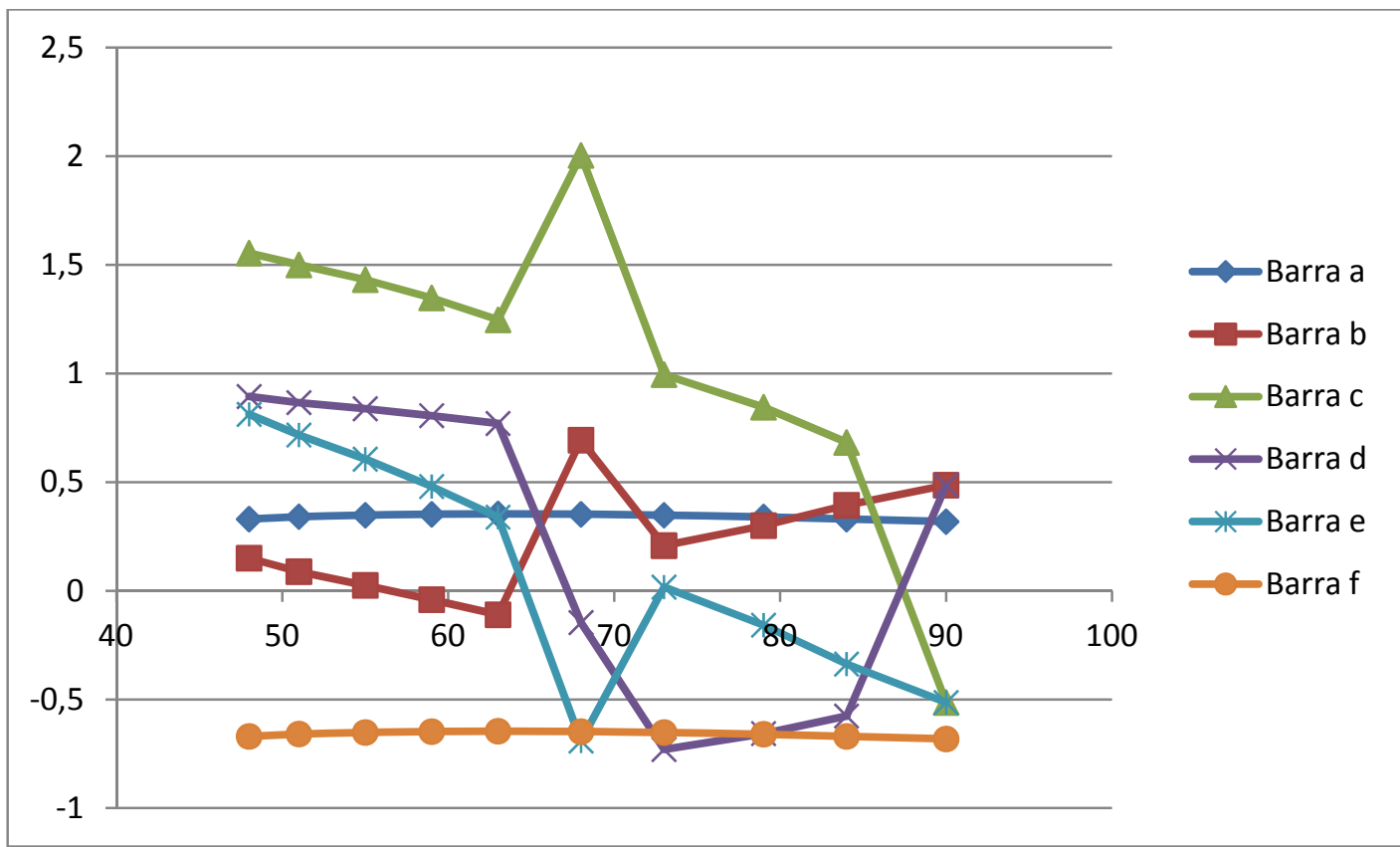

Gráfica 23 Gráfica comparativa de esfuerzos cortantes mínimos ( $K N$, eje y) en barras para la estructura reentrante hexagonal metálica rígida para diversas aperturas con carga (grados ${ }^{\circ}$, eje $x$ ), elaboración propia

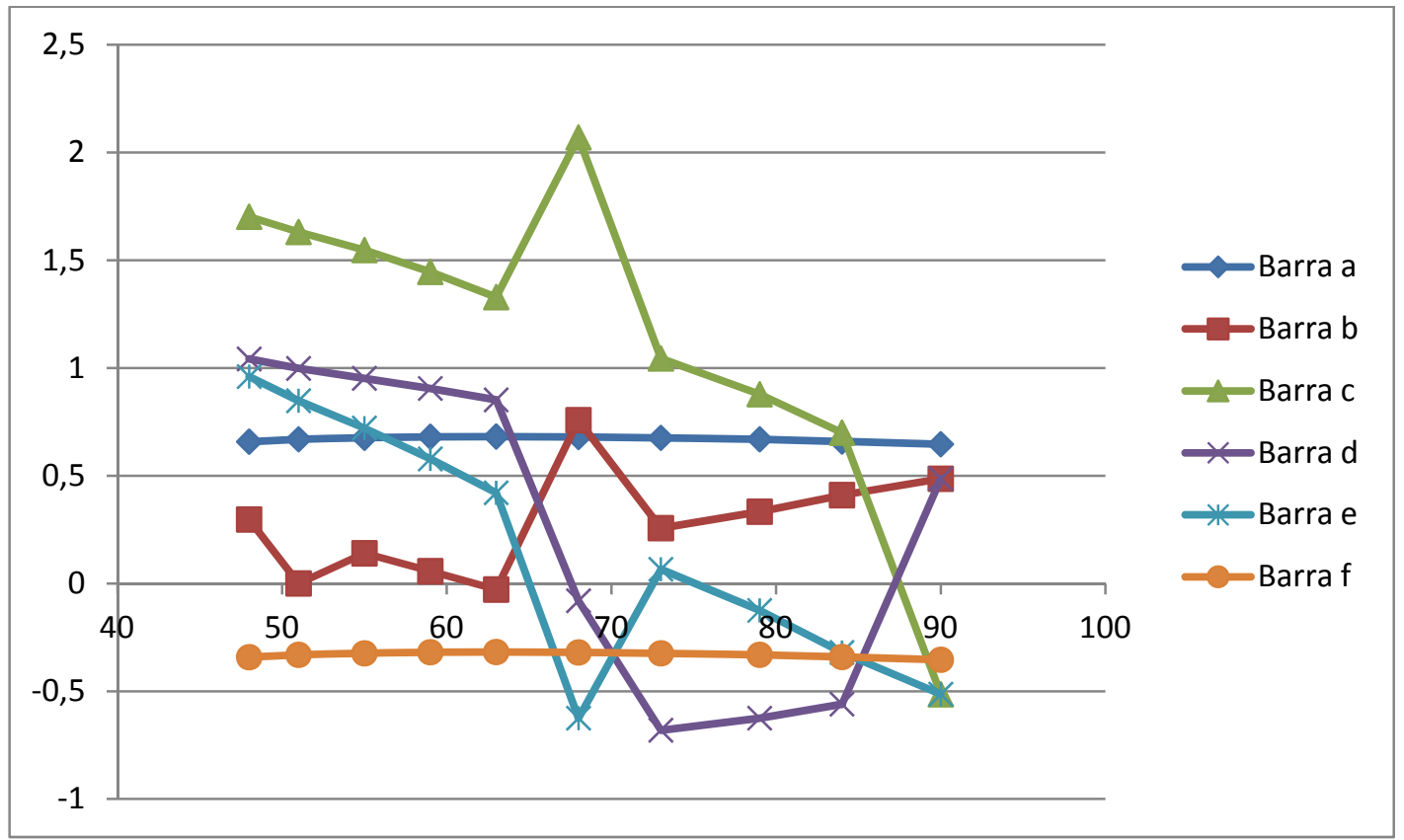

Gráfica 24 Gráfica comparativa de esfuerzos cortantes máximos (KN, eje y) en barras para la estructura reentrante hexagonal metálica rígida para diversas aperturas con carga (grados ${ }^{\circ}$, eje $x$ ), elaboración propia 
Como puede observarse en las gráficas anteriores, realizadas a partir de la Tabla 33, esfuerzos cortantes estructura reentrante hexagonal metálica rígida para diversas aperturas sin carga y con carga, del Apéndice 2: Tablas de cálculo estructural, se observan unos esfuerzos cortantes en barras con comportamientos muy diversos dependiendo de las aperturas de la estructura y la carga de la misma, así como de la barra a que afectan dichos esfuerzos cortantes.

Para la barra a los valores sin carga son: tanto el mínimo como el máximo tienen un valor de $-0,164$ a 0,164 para todos los valores angulares. Los valores con carga son: mínimo 0,318 a 0,646 para $90^{\circ}$ y máximo 0,354 a 0,682 para $63^{\circ}$, siendo la diferencia entre valores mínimos y máximos no significativa. Sí se aprecian diferencias entre esfuerzos respecto a la estructura cargada y sin cargar.

Para la barra b los valores sin carga son: mínimo para -0,031 para $90^{\circ}$ y máximo 0,196 a 0,343 para $48^{\circ}$. Los valores con carga son: mínimo de 0,025 a 0,14 para $55^{\circ}$ y máximo de 0,693 a 0,758 para $68^{\circ}$. Los esfuerzos cortantes mayores en la estructura sin cargar corresponden a la menor apertura de la figura (es decir, cuanto más cerrada está, más esfuerzos cortantes se generan en esta barra). En ambos casos (estructura cargada y sin cargar) se aprecia que el comportamiento es no lineal.

Para la barra c los valores sin carga son: mínimo de 0,031 para $90^{\circ}$ y máximo de 0,196 a 0,343 para $48^{\circ}$. Los valores con carga son: mínimo de $-0,514$ para $90^{\circ}$ y máximo de 2,004 a 2,07 para $68^{\circ}$. Los esfuerzos cortantes mayores en la estructura sin cargar corresponden a la menor apertura de la figura (es decir, cuanto más cerrada está, más esfuerzos cortantes se generan en esta barra). En ambos casos (estructura cargada y sin cargar) se aprecia que el comportamiento es generalmente lineal, salvo para el caso de $68^{\circ}$.

Para la barra d los valores sin carga son: mínimo -0,011 a 0,006 para $84^{\circ}$ y máximo 0,172 a 0.319 para $48^{\circ}$. Los valores con carga son: mínimo $-0,146$ a-0,08 para $68^{\circ}$ y máximo de 0,894 a 1,042 para $48^{\circ}$. Puede apreciarse en las gráficas que no es un comportamiento lineal.

Para la barra e los valores sin carga son: mínimo de 0,0063 a 0,02 para $79^{\circ}$ y máximo de 0,172 a 0,319 para $48^{\circ}$. Los valores con carga son: mínimo de 0,017 a 0,066 para $73^{\circ}$ y máximo de 0,812 a 0,96 para $48^{\circ}$. El comportamiento es lineal, salvo para la apertura de $68^{\circ}$ en el caso de la estructura cargada, que se genera una discontinuidad. 
Para la barra f los valores sin carga son: mínimo y máximo de -0,164 a 0,64 para todos los ángulos. Los valores con carga son: mínimo de -0,646 a -0,318 para $63^{\circ}$ y máximo de $-0,682$ a -0,354 para $90^{\circ}$, siendo la diferencia entre valores mínimos y máximos no significativa. Sí se aprecian diferencias entre esfuerzos respecto a la estructura cargada y sin cargar.

De este modo, se puede concluir que los esfuerzos cortantes para una estructura reentrante hexagonal metálica rígida para diversas aperturas aumentan con la carga, siendo generalmente mayores cuanto más se cierra la estructura. Generalmente se obtiene un comportamiento lineal de esfuerzo cortante según la apertura o cierre de la estructura, salvo para el caso comentado de la apertura de $68^{\circ}$ cuando la estructura está cargada, en el que obtenemos los esfuerzos cortantes mayores de las barras. 


\section{Momentos en barras}

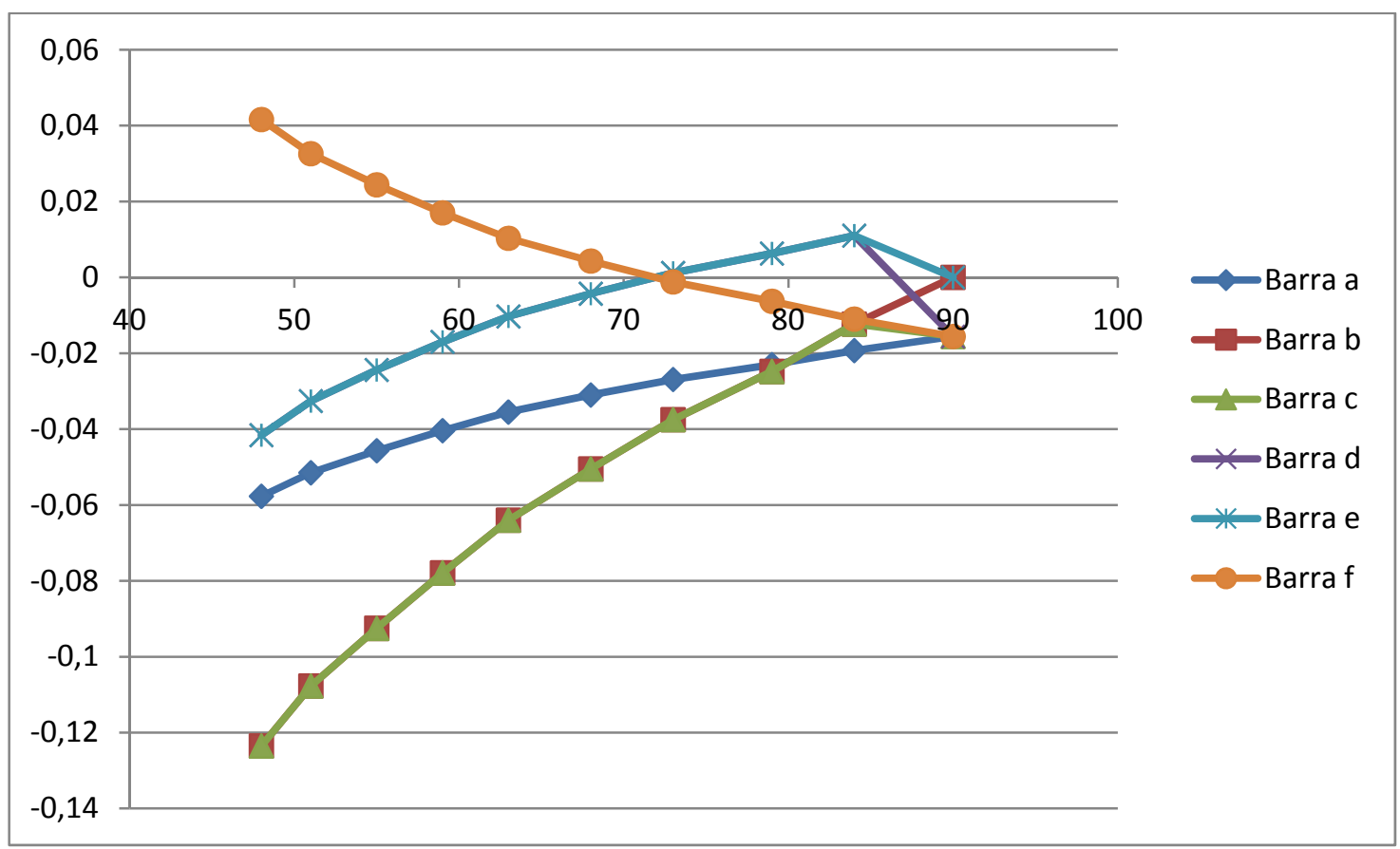

Gráfica 25 Gráfica comparativa de momentos mínimos ( $K N \cdot m$, eje y) en barras para la estructura reentrante hexagonal metálica rígida para diversas aperturas sin carga (grados ${ }^{\circ}$, eje $x$ ), elaboración propia

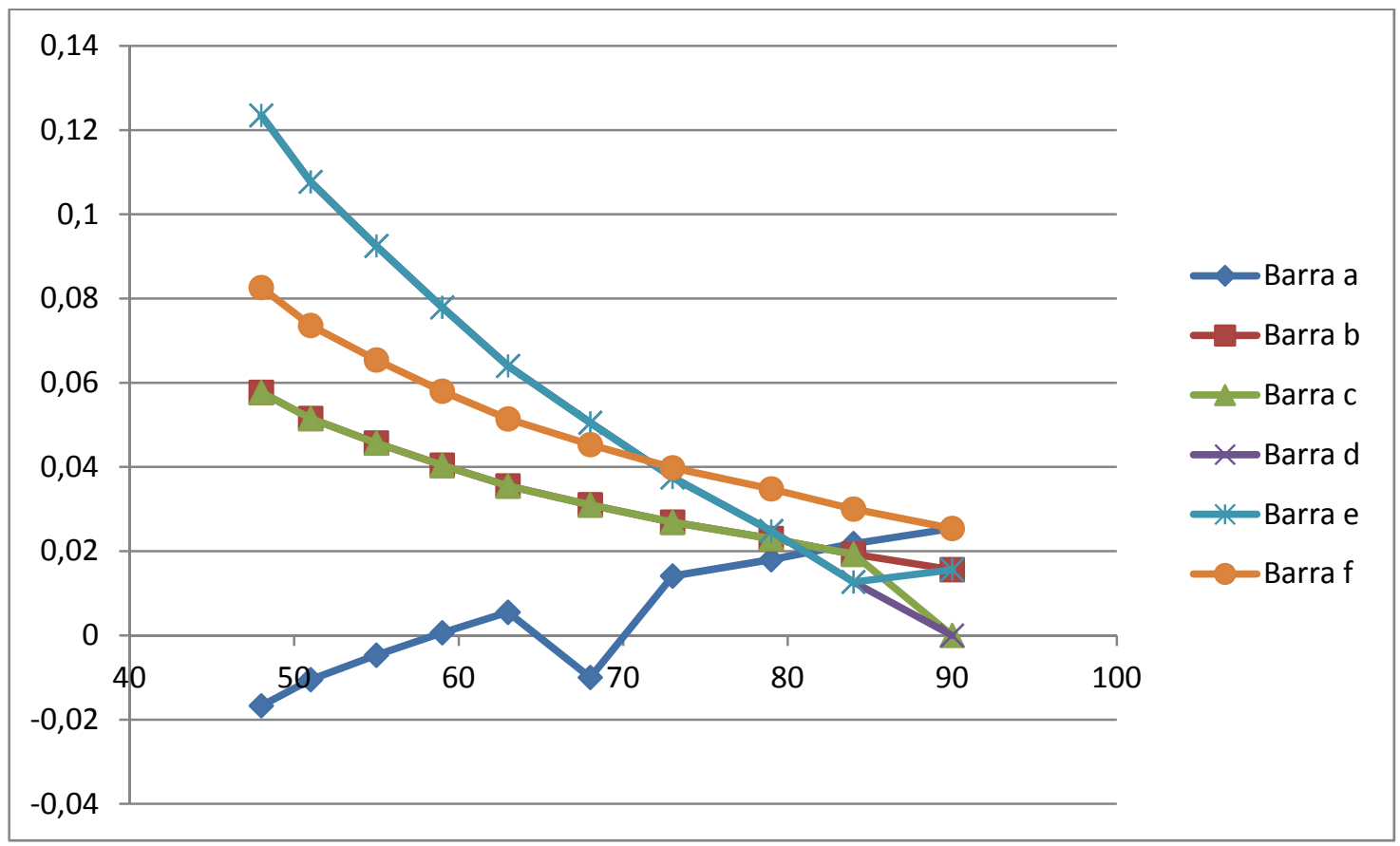

Gráfica 26 Gráfica comparativa de momentos máximos ( $K N \cdot m$, eje y) en barras para la estructura reentrante hexagonal metálica rígida para diversas aperturas sin carga (grados ${ }^{\circ}$, eje x), elaboración propia 


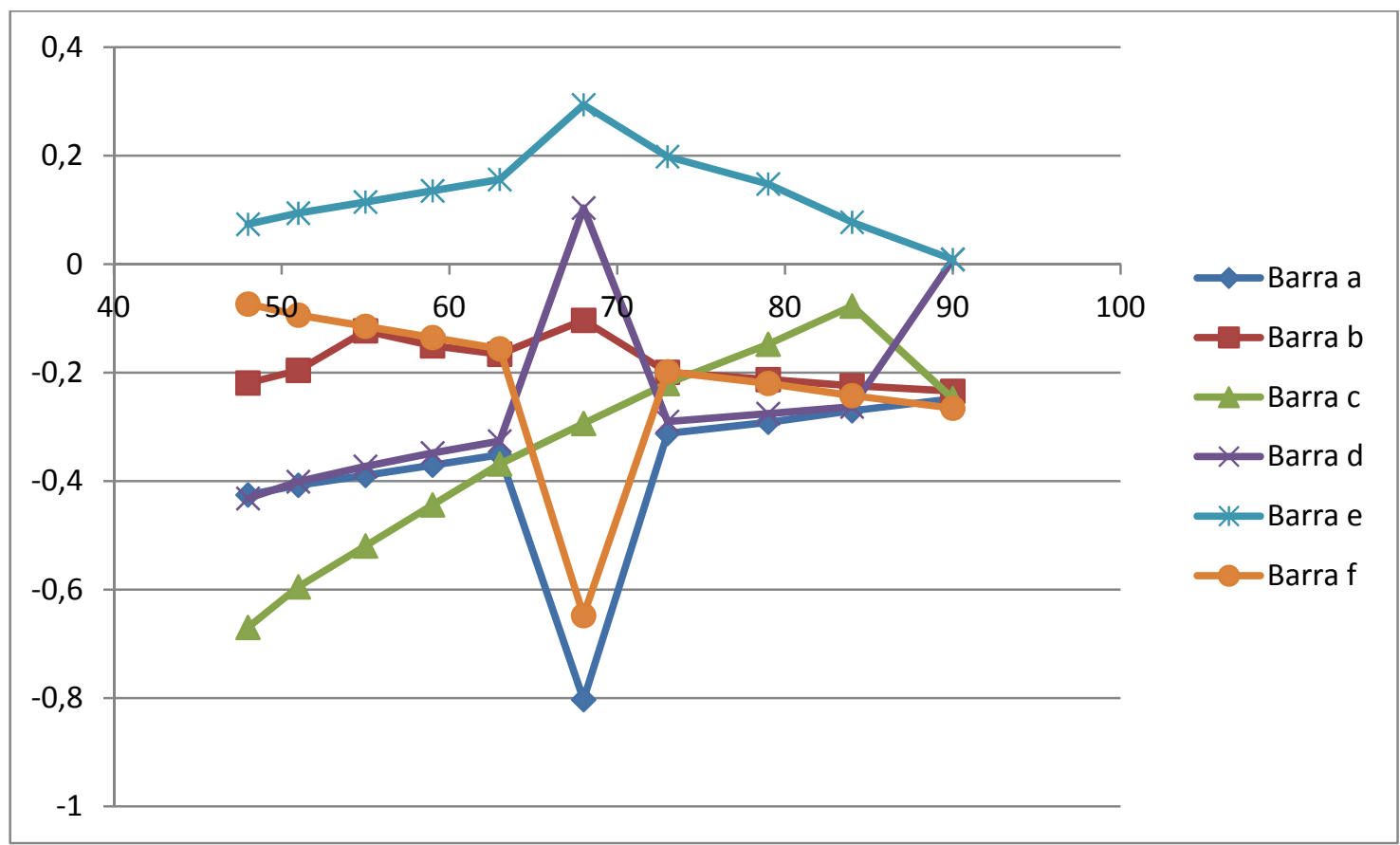

Gráfica 27 Gráfica comparativa de momentos mínimos ( $K N \cdot m$, eje y) en barras para la estructura reentrante hexagonal metálica rígida para diversas aperturas con carga (grados ${ }^{\circ}$, eje x), elaboración propia

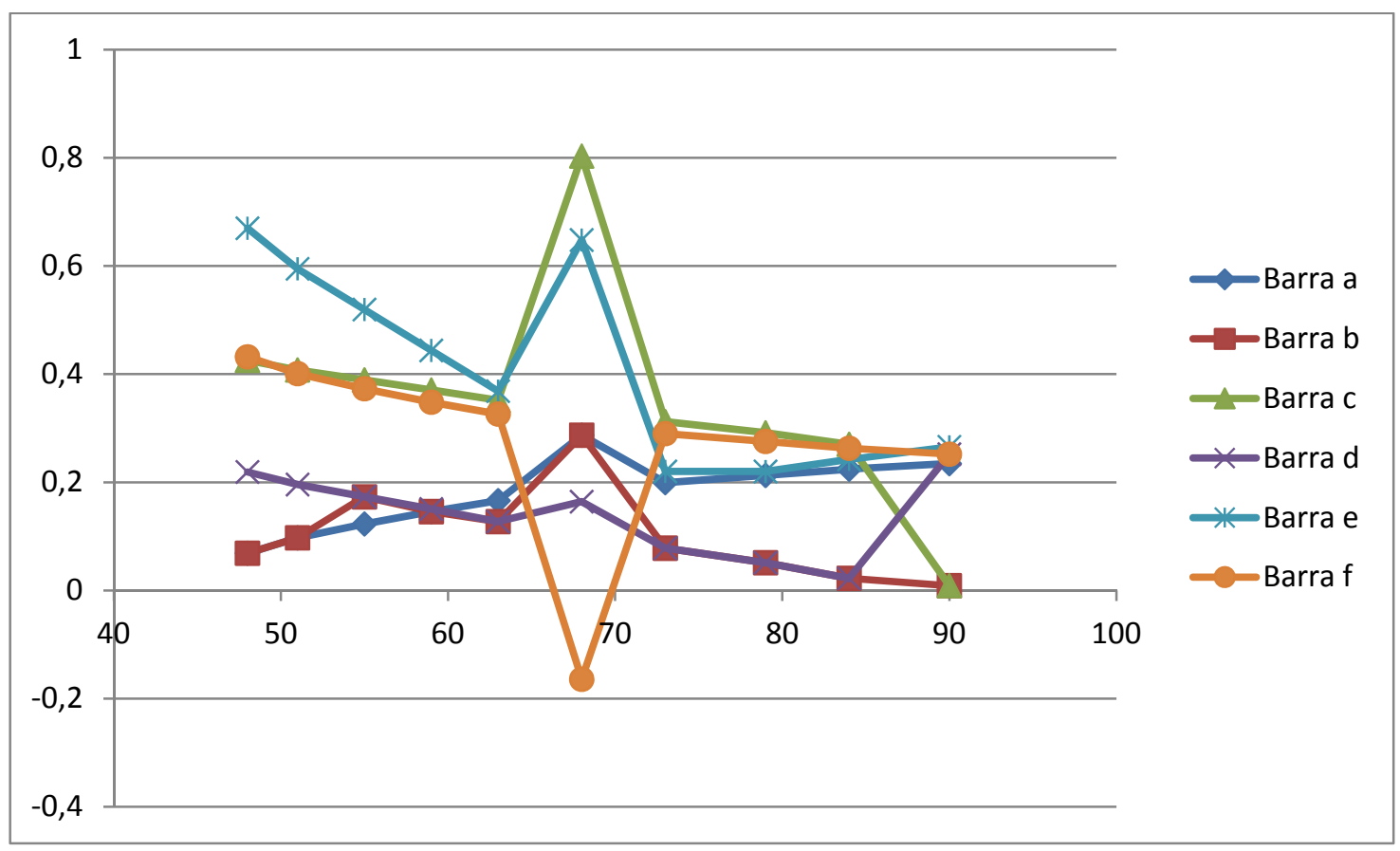

Gráfica 28 Gráfica comparativa de momentos máximos (KN·m, eje y) en barras para la estructura reentrante hexagonal metálica rígida para diversas aperturas con carga (grados o , eje x), elaboración propia 
Como puede observarse en las gráficas anteriores, realizadas a partir de la Tabla 33, momentos estructura reentrante hexagonal metálica rígida para diversas aperturas sin carga y con carga, del Apéndice 2: Tablas de cálculo estructural, se observan unos momentos en barras con comportamientos muy diversos dependiendo de las aperturas de la estructura y la carga de la misma, así como de la barra a que afectan dichos momentos.

Para la barra a se dan los valores siguientes: valor sin carga mínimo de -0,0156 a 0,0254 para un ángulo de $90^{\circ}$ y un máximo de $-0,0577$ a 0,0167 para un ángulo de $48^{\circ}$. Los valores con carga son: mínimo de $-0,248$ a 0,2344 para un ángulo de $90^{\circ}$ y máximo de $-0,8032$ a 0,2872 para un ángulo de $68^{\circ}$. Los momentos mayores para la estructura sin cargar corresponden a la menor apertura de la figura (es decir, cuanto más cerrada está, más momentos se generan en esta barra). Los momentos para la estructura cargada en general también siguen un comportamiento lineal, pero en el caso de la apertura de $68^{\circ}$ se aprecia una discontinuidad donde se hacen máximos.

Para la barra b se dan los siguientes valores: valor sin carga mínimo de 6,939 $10^{-18}$ a 0,0156 para un ángulo de $90^{\circ}$ y máximo de $-0,1235$ a 0,0577 para un ángulo de $48^{\circ}$. Los valores con carga son: mínimo de 0,135 a 0,2872 para un ángulo de $68^{\circ}$ y máximo de 0,2344 a 0,0088 para un ángulo de $90^{\circ}$. Los momentos mayores para la estructura sin cargar corresponden a la menor apertura de la figura (es decir, cuanto más cerrada está, más momentos se generan en esta barra). Los momentos para la estructura cargada en general también siguen un comportamiento lineal, pero en el caso de la apertura de $68^{\circ}$ se aprecia una discontinuidad donde se hacen máximos.

Para la barra c los valores son los siguientes: valor sin carga mínimo de -0,0123 a 0,0193 para un ángulo de $84^{\circ}$ y un máximo de $-0,1235$ a 0,0577 para un ángulo de $48^{\circ}$. Los valores con carga son: mínimo de 0,0772 0,2703 para un ángulo de 84 ${ }^{\circ}$ aumentando progresivamente hasta un valor de 0,6698 a 0,4255 para un ángulo de $48^{\circ}$, con un máximo de $-0,2938$ a 0,8032 para una apertura de $68^{\circ}$. Los momentos mayores para la estructura sin cargar corresponden a la menor apertura de la figura (es decir, cuanto más cerrada está, más momentos se generan en esta barra). Los momentos para la estructura cargada en general también siguen un comportamiento lineal, pero en el caso de la apertura de $68^{\circ}$ se aprecia una discontinuidad donde se hacen máximos.

Para la barra d los valores son: valor sin carga mínimo de 0,0012 a 0,037 para un ángulo de $73^{\circ}$ y un máximo de 0,046 a 0,1235 para un ángulo de $48^{\circ}$. Los valores con carga son: mínimo de 0,0088 a 0,252 para un ángulo de $90^{\circ}$ y un máximo de -0,432 a 0,2192 para un 
ángulo de $48^{\circ}$. Los momentos mayores en ambos casos corresponden a la menor apertura de la figura (es decir, cuanto más cerrada está, más momentos se generan en esta barra). Los momentos para la estructura en general siguen un comportamiento lineal, pero en el caso de la apertura de $73^{\circ}$ para la estructura cargada se aprecia una discontinuidad donde se hacen mínimos.

Para la barra e los valores encontrados son: valor sin carga mínimo de 6,939 $10^{-18}$ a 0,0156 para un ángulo de $90^{\circ}$ y máximo de $-0,0416$ a 0,1235 para un ángulo de $48^{\circ}$. Los valores con carga son: mínimo de 0,0088 a 0,2556 para un ángulo de $90^{\circ}$ y máximo de 0,2938 a 0,6481 para un ángulo de $68^{\circ}$. Los momentos mayores para la estructura sin cargar corresponden a la menor apertura de la figura (es decir, cuanto más cerrada está, más momentos se generan en esta barra), siendo el comportamiento totalmente lineal. Los momentos para la estructura cargada, sin embargo, no siempre siguen un comportamiento lineal: en el caso de la apertura de $68^{\circ}$ se aprecia una discontinuidad donde se hacen máximos.

Para la barra f se dan los siguientes valores: valor sin carga mínimo de -0,0012 a 0,0398 para un ángulo de $73^{\circ}$ y máximo de 0,046 a 0,0826 para un ángulo de $48^{\circ}$. Los valores con carga son: mínimo de -0,0736 a 0,432 para un ángulo de $48^{\circ}$ y máximo de 0,6481 a 0,1642 para un ángulo de $68^{\circ}$. Los momentos mayores para la estructura sin cargar corresponden a la menor apertura de la figura (es decir, cuanto más cerrada está, más momentos se generan en esta barra), siendo el comportamiento totalmente lineal. Los momentos para la estructura cargada en general también siguen un comportamiento lineal, pero en el caso de la apertura de $68^{\circ}$ se aprecia una discontinuidad donde se hacen máximos.

De este modo, se puede concluir que los momentos para una estructura reentrante hexagonal metálica rígida para diversas aperturas generalmente aumentan con la carga, siendo mayores cuanto más se cierra la estructura. Habitualmente se obtiene un comportamiento lineal de los momentos en función de la apertura o cierre de la estructura, salvo para el caso comentado de la apertura de $68^{\circ}$ cuando la estructura está cargada, en el que obtenemos los momentos mayores de las barras. 


\subsection{Discusión de resultados}

Los resultados obtenidos para la estructura metálica rígida son los esperados, ya que según va aumentando su auxeticidad los desplazamientos son mayores, lo que se traduce en una estructura más flexible que las tradicionales. Los esfuerzos en los apoyos también van aumentando a medida que se cierra la estructura, pero este aumento se considera despreciable, ya que se produce porque aumenta ligeramente la longitud de las barras diagonales al estar dibujada la estructura en función de una cuadrícula. Los esfuerzos axiles en las barras verticales van disminuyendo con el cierre de la estructura en las barras de arriba, mientras que aumentan con dicho cierre en las barras inferiores verticales; en las barras horizontales aumentan en todos los casos según se cierra la estructura: este comportamiento es normal, teniendo en cuenta que esta estructura es muy flexible, y las partes ancladas al suelo lógicamente soportarán mayores esfuerzos al permitir el movimiento del resto de la estructura. No obstante, estos esfuerzos son perfectamente admisibles por dicha estructura. El cortante y los momentos también aumentan con la auxeticidad, pero igualmente de una manera perfectamente admisible, por lo que estas estructuras tan flexibles nos resultan muy útiles.

En el caso de la estructura cargada el funcionamiento es similar: aumentan los desplazamientos y las reacciones en los apoyos con la auxeticidad, los esfuerzos axiles disminuyen o aumentan en función de la posición de la barra, los cortantes en general son mayores con una estructura semiabierta y disminuyen según se abre o se cierra la estructura, y los momentos en general aumentan con la auxeticidad. Ahora bien, aunque los esfuerzos siguen siendo admisibles, aumentan considerablemente respecto a la estructura sin cargar, por lo que el próximo paso será estudiar una estructura auxética con una apertura intermedia para ir aumentando su carga progresivamente y ver cómo le afecta. 


\subsubsection{Cálculo para apertura de $63^{\circ}$ y aumento de carga progresiva}

\subsection{Metodología}

Calcularemos la estructura metálica auxética reentrante hexagonal unitaria de nudos rígidos del apartado anterior para una apertura de $63^{\circ}$, aumentándole la carga de manera gradual en diferentes sentidos, de acuerdo a los casos representados en la figura 195. Las barras son también los mismos perfiles metálicos del apartado anterior, representados en la figura 194, y sus dimensiones serán: barras "a" y "f" de longitud $1 \mathrm{~m}$ y resto de barras de longitud 0,559m. Nuevamente la estructura tendrá 6 restricciones, repartidas de la siguiente manera: en el apoyo de la izquierda 3 restricciones al desplazamiento + 1 restricción a la rotación respecto al eje $\mathrm{x}$, y 2 restricciones al desplazamiento en los ejes y y $z$ en el apoyo de la derecha.

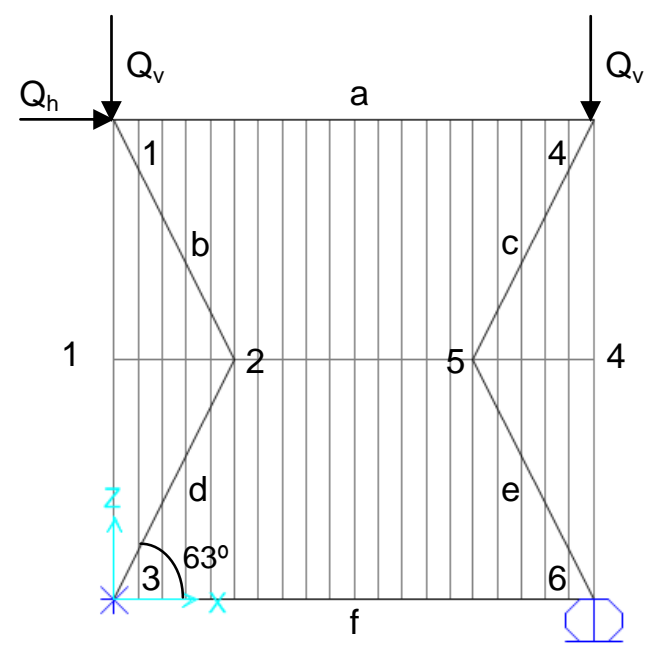

Figura 195 Estructura auxética reentrante hexagonal unitaria con cargas con apertura de 63, elaboración propia

\subsubsection{Resultados}

Para las estructuras reentrantes hexagonales metálicas rígidas sin tendones y con una apertura de $63^{\circ}$ se obtienen los resultados que aparecen en las tablas 36 a 42 del Apéndice 1 para las diferentes aperturas y nudos, y que se representan en las gráficas que se presentan a continuación. 
Desplazamientos horizontales

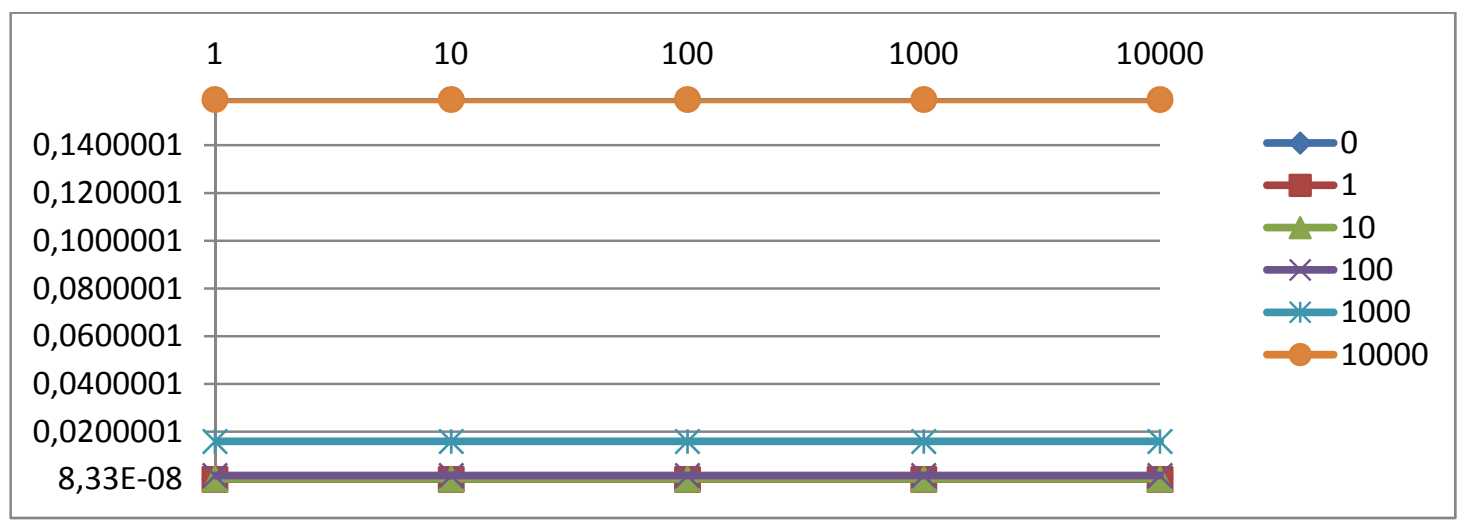

Gráfica 29 Comparación de desplazamientos horizontales ( $m$, eje y) en el nudo 1 para la estructura reentrante hexagonal metálica rígida para una apertura de $63^{\circ}$ y diversas combinaciones de carga (KN, eje $x$ y leyenda), elaboración propia

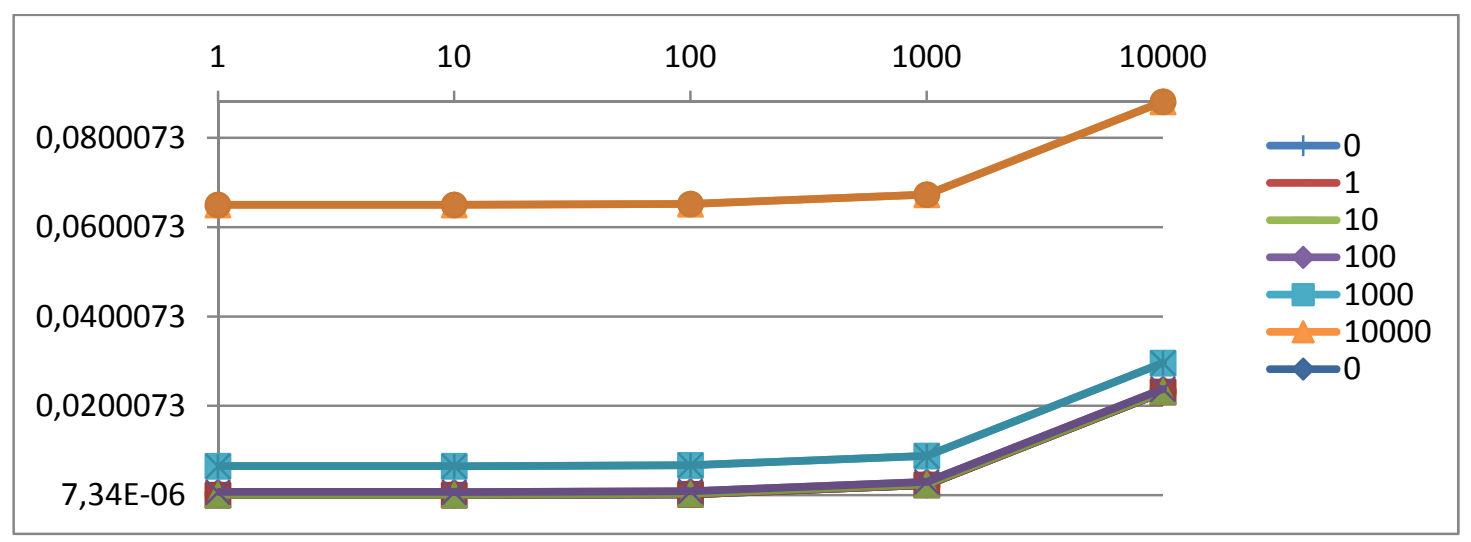

Gráfica 30 Comparación de desplazamientos horizontales ( $m$, eje y) en el nudo 2 para la estructura reentrante hexagonal metálica rígida para una apertura de $63^{\circ}$ y diversas combinaciones de carga (KN, eje $x$ y leyenda), elaboración propia

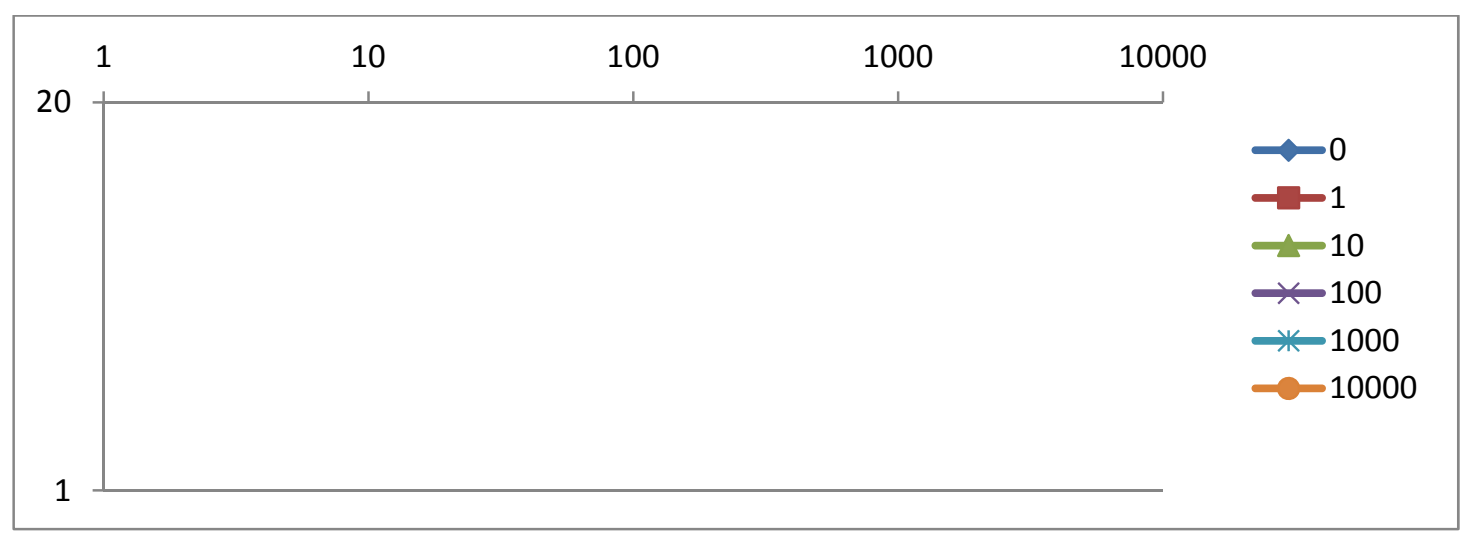

Gráfica 31 Comparación de desplazamientos horizontales ( $m$, eje y) en el nudo 3 para la estructura reentrante hexagonal metálica rígida para una apertura de $63^{\circ}$ y diversas combinaciones de carga (KN, eje $x$ y leyenda), elaboración propia 


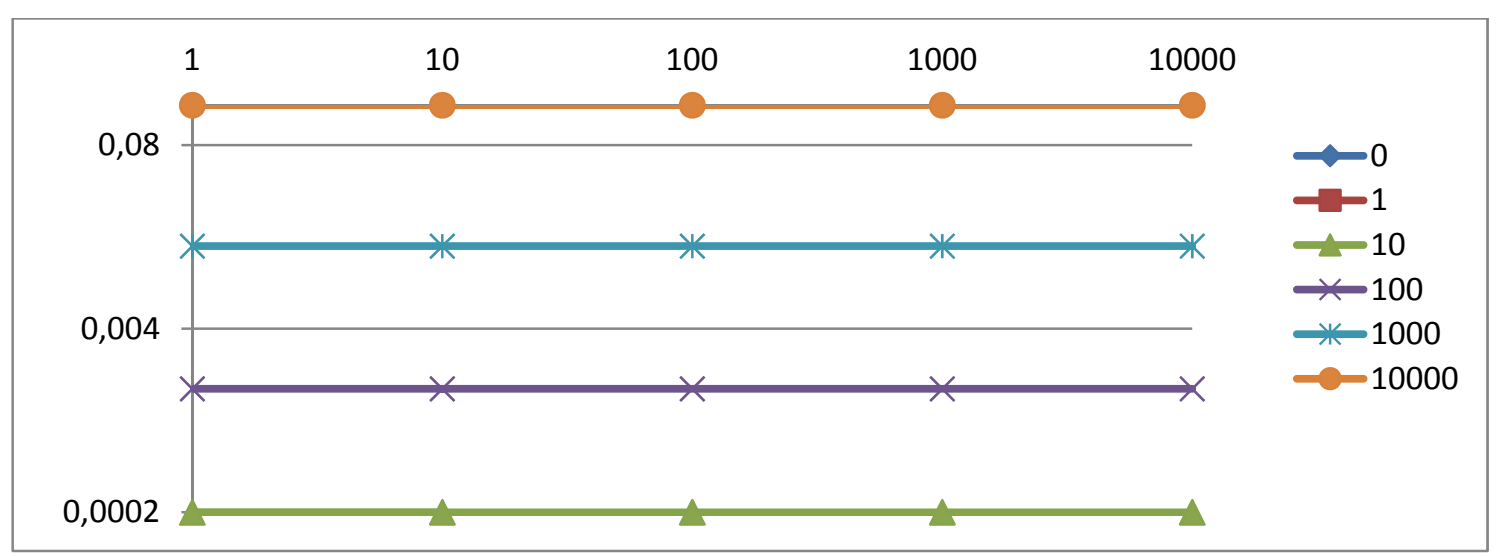

Gráfica 32 Comparación de desplazamientos horizontales ( $m$, eje y) en el nudo 4 para la estructura reentrante hexagonal metálica rígida para una apertura de $63^{\circ}$ y diversas combinaciones de carga (KN, eje $x$ y leyenda), elaboración propia

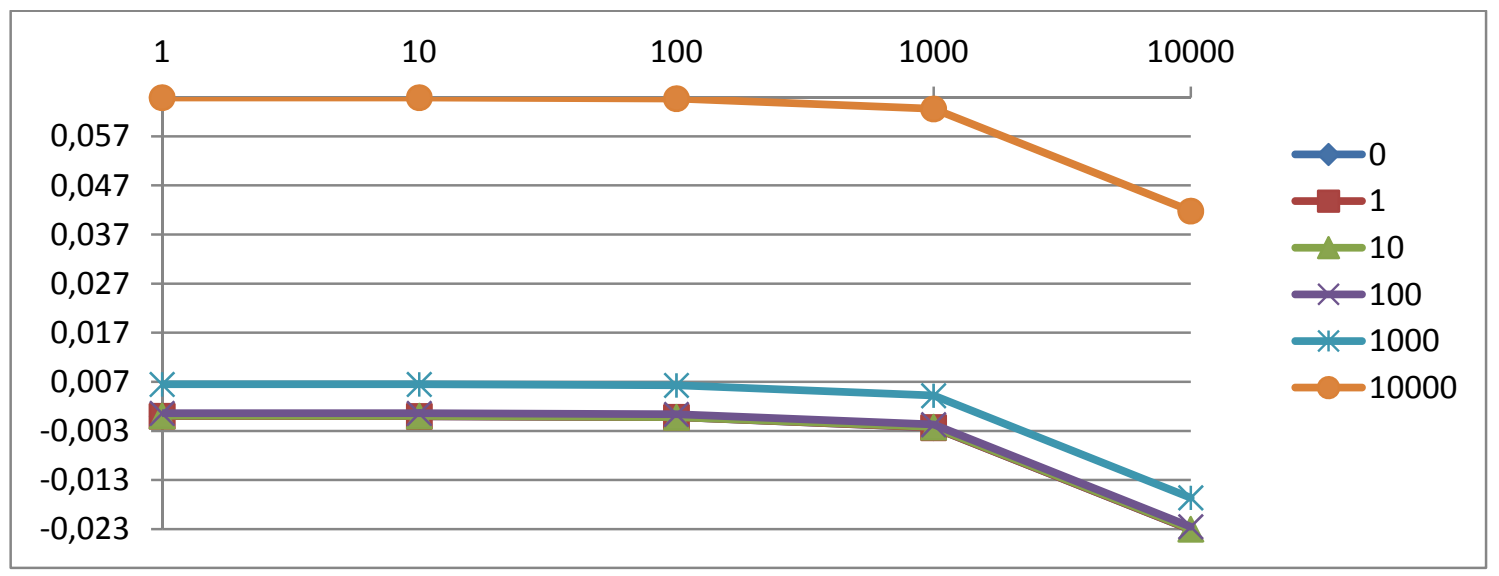

Gráfica 33 Comparación de desplazamientos horizontales ( $m$, eje y) en el nudo 5 para la estructura reentrante hexagonal metálica rígida para una apertura de $63^{\circ}$ y diversas combinaciones de carga (KN, eje $x$ y leyenda), elaboración propia

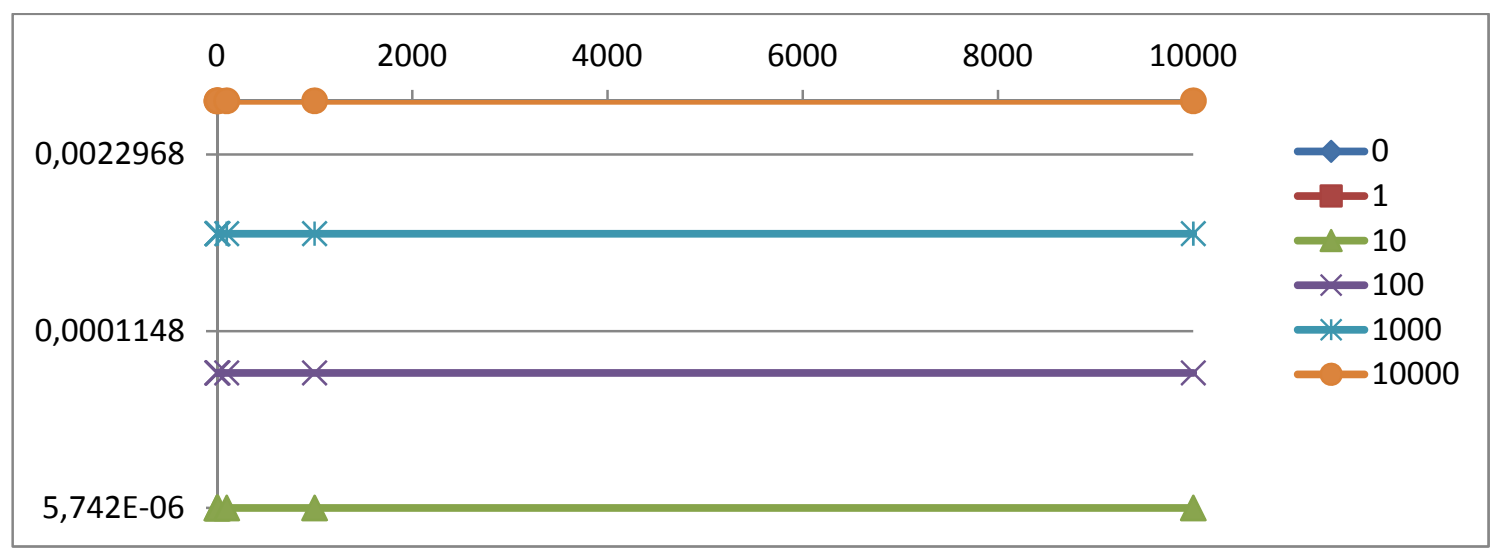

Gráfica 34 Comparación de desplazamientos horizontales ( $m$, eje y) en el nudo 6 para la estructura reentrante hexagonal metálica rígida para una apertura de $63^{\circ}$ y diversas combinaciones de carga (KN, eje $x$ y leyenda), elaboración propia 
Como puede observarse en las gráficas anteriores, Tabla 36, desplazamientos horizontales estructura reentrante hexagonal metálica rígida para una apertura de $63^{\circ}$ y diversas cargas horizontales y verticales, del Apéndice 2: tablas de cálculo estructural, se observan unos desplazamientos horizontales con comportamientos muy diversos dependiendo de las diferentes combinaciones de cargas verticales y cargas horizontales.

Para el nudo 1 los desplazamientos horizontales dependen de las cargas horizontales. Las cargas verticales no le afectan. $Y$ cuanto mayor es la carga horizontal, mayor es el desplazamiento en este nudo. Sin embargo, cuando la carga vertical es nula el desplazamiento no es nulo, sino que es 0,00000008335: esto es debido al peso de la propia estructura, ya que en reposo total también sufre este desplazamiento.

Para el nudo 2, los desplazamientos horizontales dependen tanto de las cargas verticales como de las cargas horizontales. Cuanto mayor son estas cargas mayor es el desplazamiento horizontal de este nudo. Bajo la misma cantidad de carga vertical como de carga horizontal, el nudo se desplazara más en el caso de carga vertical.

Para el nudo 3 se aprecian unos desplazamientos horizontales nulos en todos los casos. Esto es debido a que este nudo corresponde a uno de los apoyos de la estructura y tiene impuestas restricciones a los desplazamientos en todas las direcciones.

Para el nudo 4, al igual que en el caso del nudo 1, los desplazamientos horizontales dependen de las cargas horizontales. Las cargas verticales no le afectan. Y cuanto mayor es la carga horizontal, mayor es el desplazamiento en este nudo. Cuando la carga horizontal es nula el desplazamiento horizontal de este nudo también es nulo.

Para el nudo 5, el desplazamiento horizontal se ve afectado tanto por las cargas verticales como por las horizontales. Cuando $\mathrm{Q}_{\mathrm{h}}>\mathrm{Q}_{\mathrm{v}}$ entonces el desplazamiento horizontal de este nudo tiene un sentido positivo. Cuando $\mathrm{Q}_{v}>\mathrm{Q}_{\mathrm{h}}$ entonces el desplazamiento horizontal de este nudo tiene un sentido negativo. La carga vertical y la carga horizontal tiran del nudo en sentidos opuestos. El nudo se ve más afectado por la carga horizontal que por la carga vertical, por eso cuando $\mathrm{Q}_{v}=\mathrm{Q}_{h}$ entonces el desplazamiento horizontal tiene un sentido positivo.

Para el nudo 6, al igual que en el caso del nudo 1 y el nudo 4, los desplazamientos horizontales dependen de las cargas horizontales. Las cargas verticales no le afectan. $Y$ cuanto mayor es la carga horizontal, mayor es el desplazamiento en este nudo. Sin embargo, cuando la carga vertical es nula el desplazamiento no es nulo sino que es 
0,00000008335: esto es debido al peso de la propia estructura ya que en reposo total también sufre este desplazamiento.

De este modo, se puede concluir que los desplazamientos horizontales para una estructura reentrante hexagonal metálica rígida para una apertura de $63^{\circ}$ y diversas cargas horizontales y verticales, aumentan con la carga, siendo mayores cuanto mayor sea la carga. Se puede decir que las cargas horizontales tienen una mayor importancia que las cargas verticales porque influencian a todos los nudos y en los casos en que los nudos están bajo la influencia tanto de cargas verticales como horizontales, las cargas horizontales son más determinantes. Se pueden distinguir 3 tipos de nudos: nudos afectados solo por las cargas horizontales (nudo 1,4 y 6), nudos afectados tanto por cargas verticales como horizontales en que estas se suman (nudo 2) y nudos afectados tanto por cargas verticales como horizontales en que estas actúan en sentidos opuestos (nudo 5). 


\section{Desplazamientos verticales}

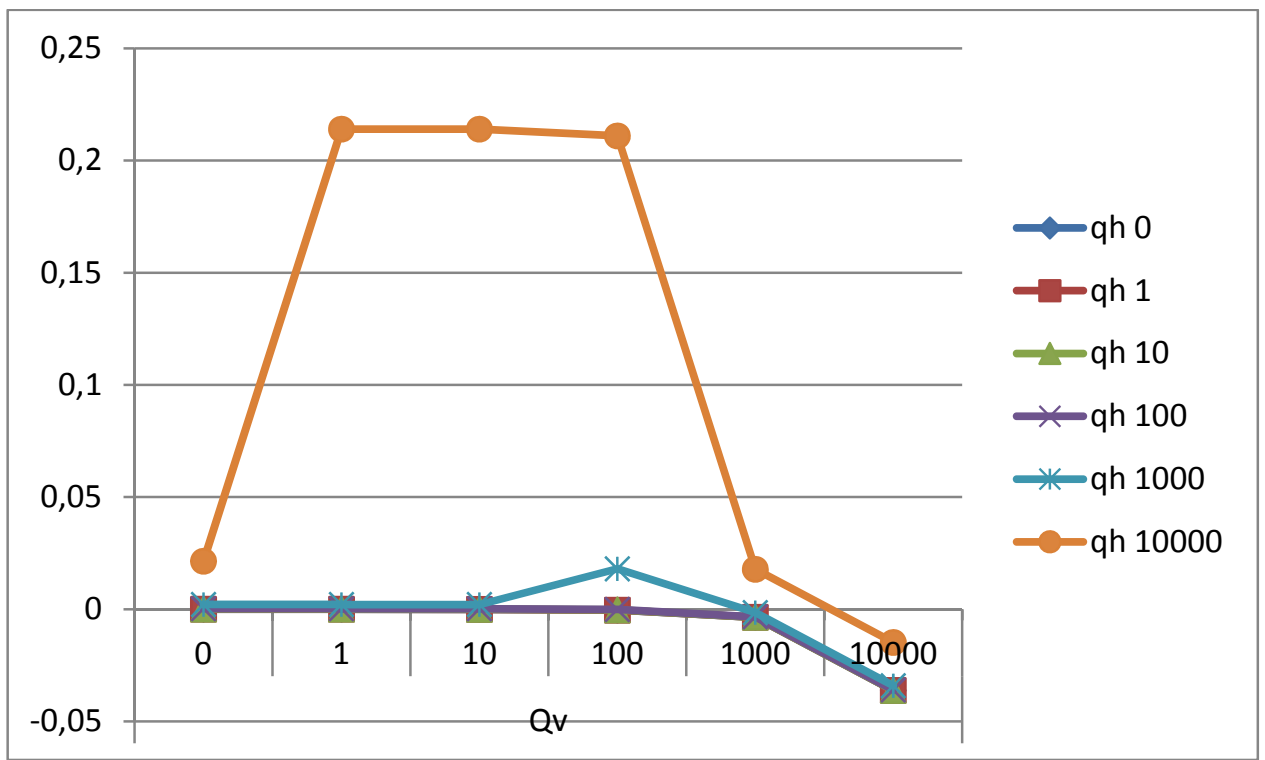

Gráfica 35 Comparación de desplazamientos verticales ( $m$, eje y) en el nudo 1 para la estructura reentrante hexagonal metálica rígida para una apertura de $63^{\circ}$ y diversas combinaciones de carga ( $K N$, eje $x$ y leyenda), elaboración propia

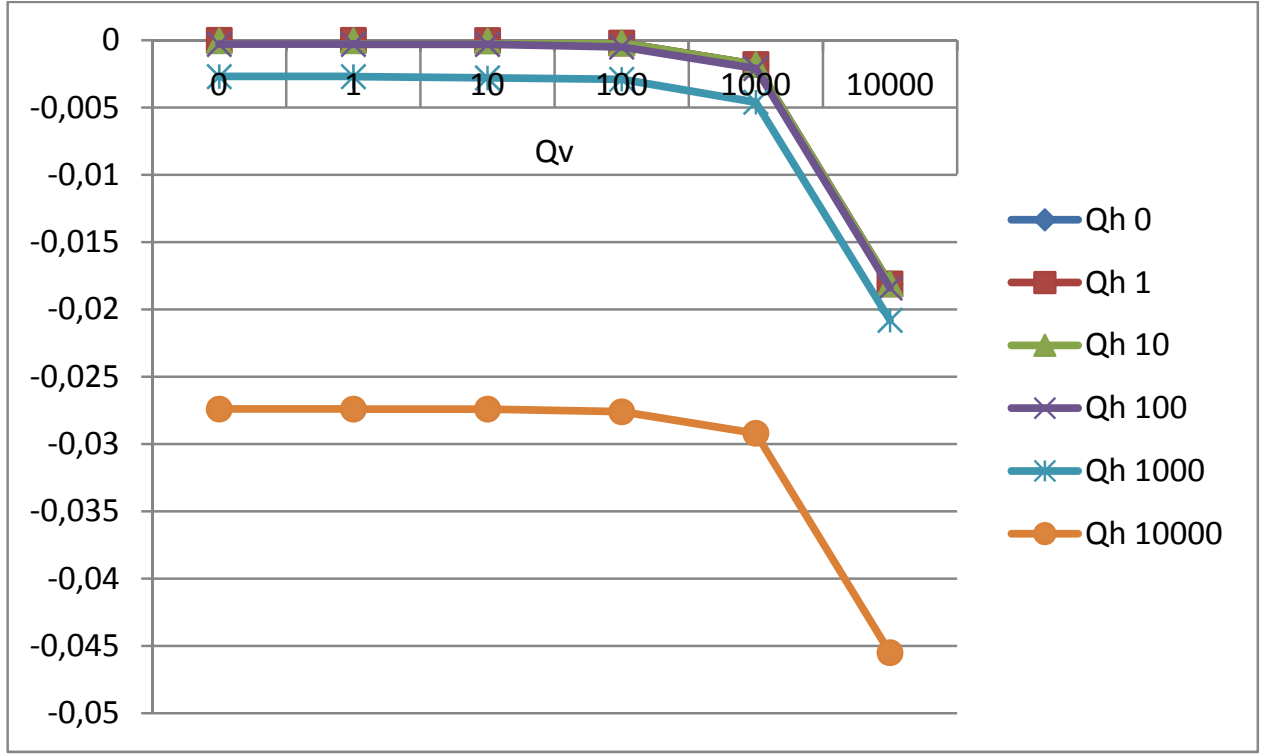

Gráfica 36 Comparación de desplazamientos verticales ( $m$, eje y) en el nudo 2 para la estructura reentrante hexagonal metálica rígida para una apertura de $63^{\circ}$ y diversas combinaciones de carga (KN, eje $x$ y leyenda), elaboración propia 


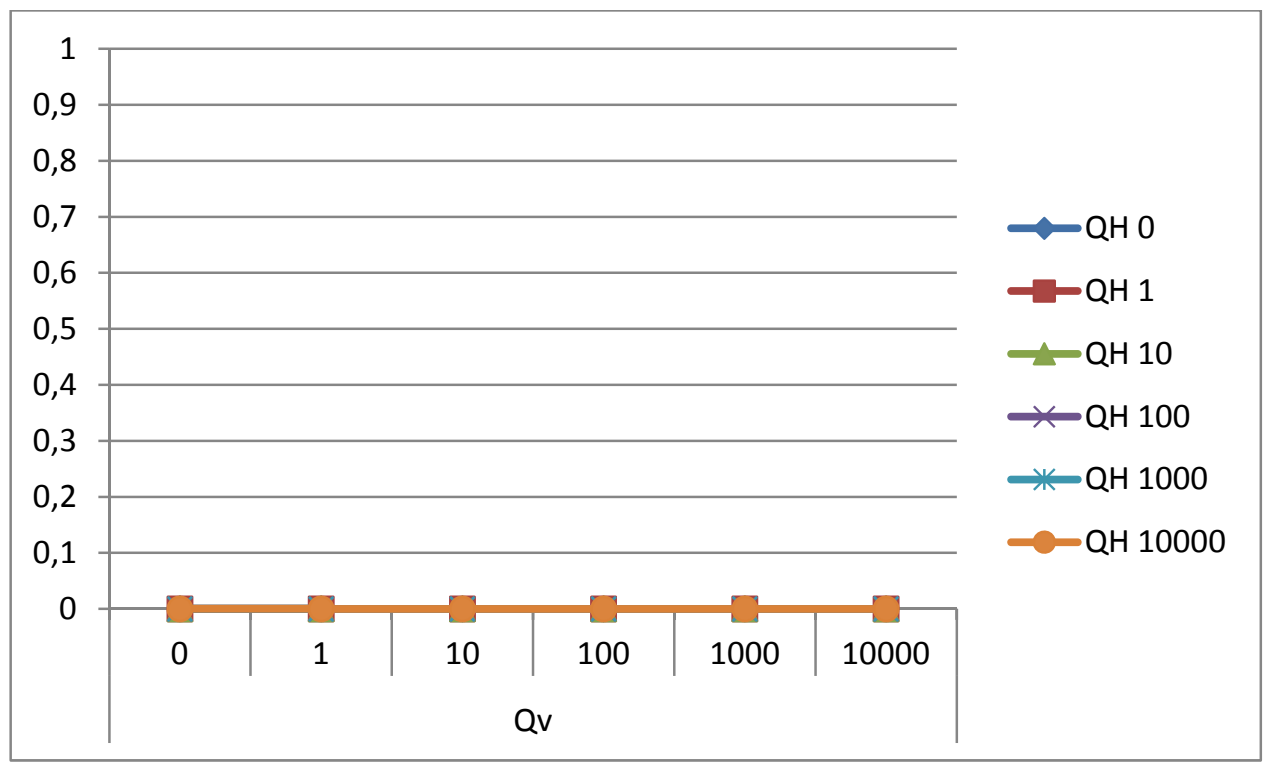

Gráfica 37 Comparación de desplazamientos verticales ( $m$, eje y) en el nudo 3 para la estructura reentrante hexagonal metálica rígida para una apertura de $63^{\circ}$ y diversas combinaciones de carga (KN, eje $x$ y leyenda), elaboración propia

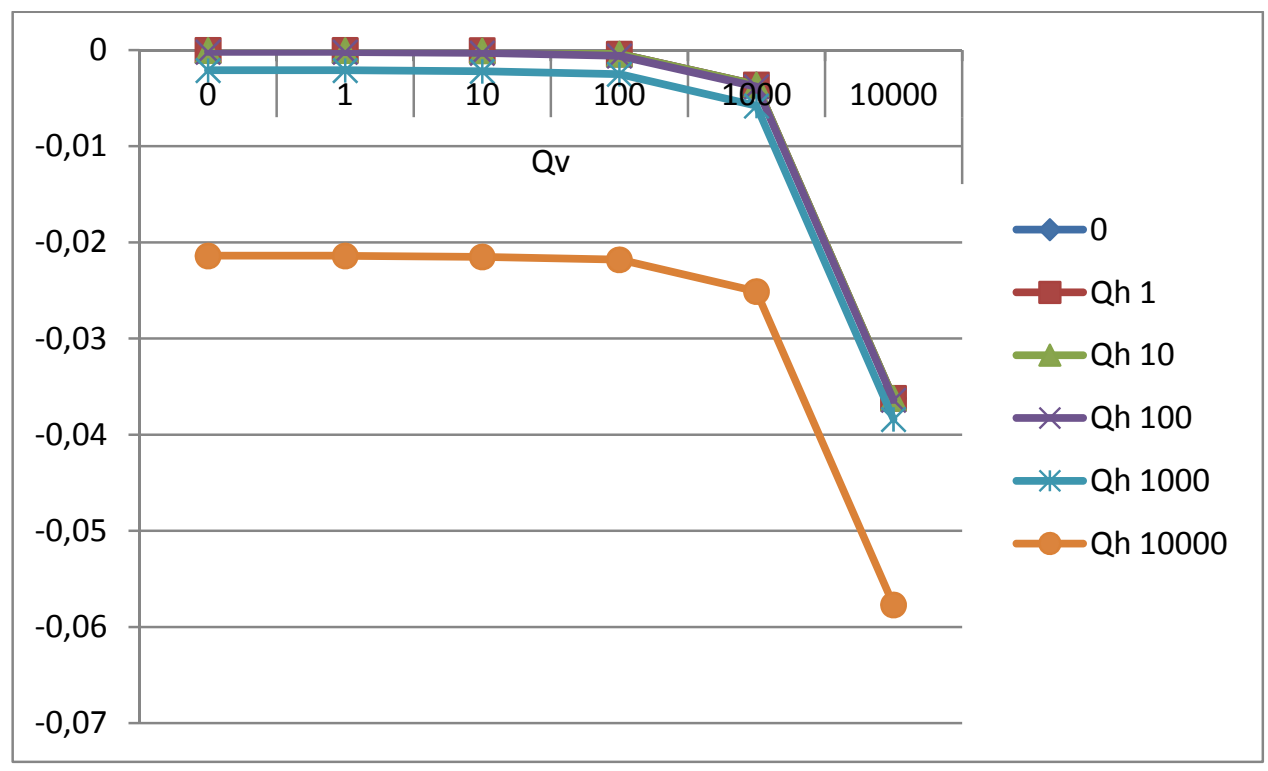

Gráfica 38 Comparación de desplazamientos verticales ( $m$, eje y) en el nudo 4 para la estructura reentrante hexagonal metálica rígida para una apertura de $63^{\circ}$ y diversas combinaciones de carga (KN, eje $x$ y leyenda), elaboración propia 
Aplicaciones de las propiedades auxéticas en la arquitectura

CÁLCULO ESTRUCTURAL DE ESTRUCTURAS AUXÉTICAS

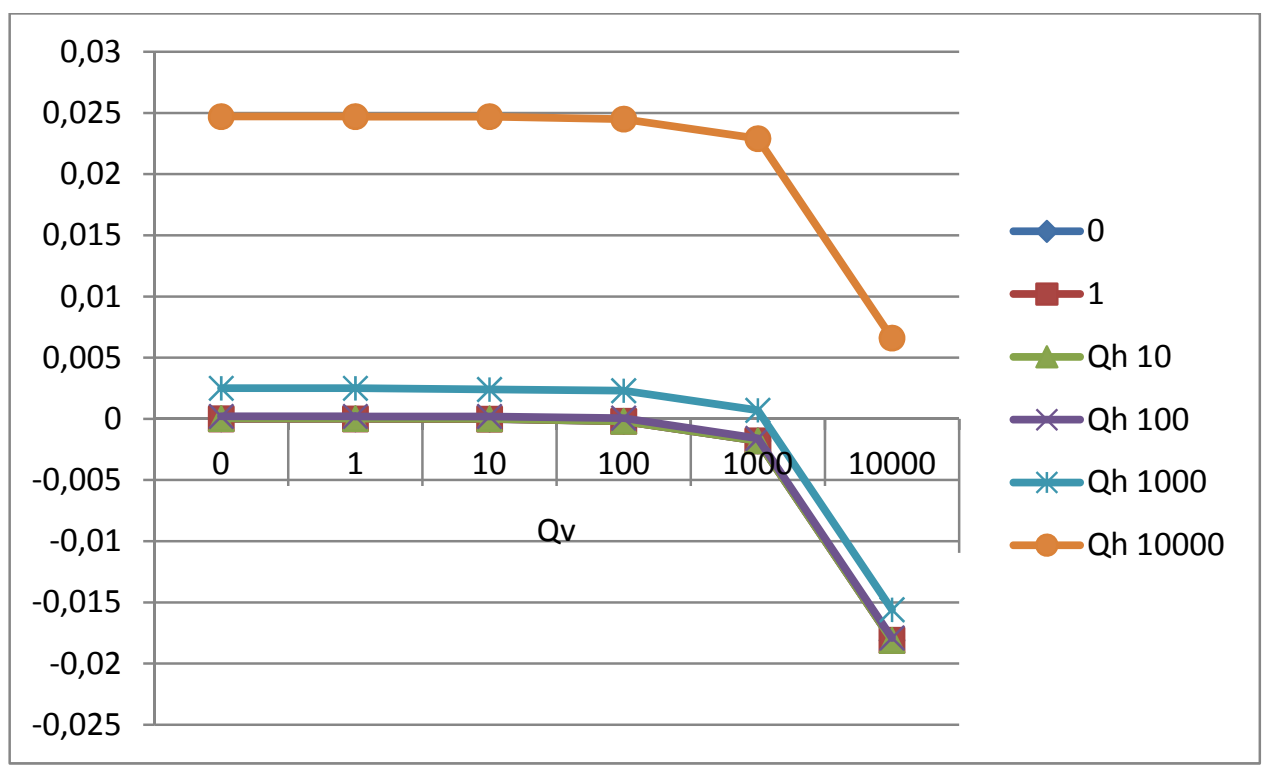

Gráfica 39 Comparación de desplazamientos verticales ( $m$, eje y) en el nudo 5 para la estructura reentrante hexagonal metálica rígida para una apertura de $63^{\circ}$ y diversas combinaciones de carga (KN, eje $x$ y leyenda), elaboración propia

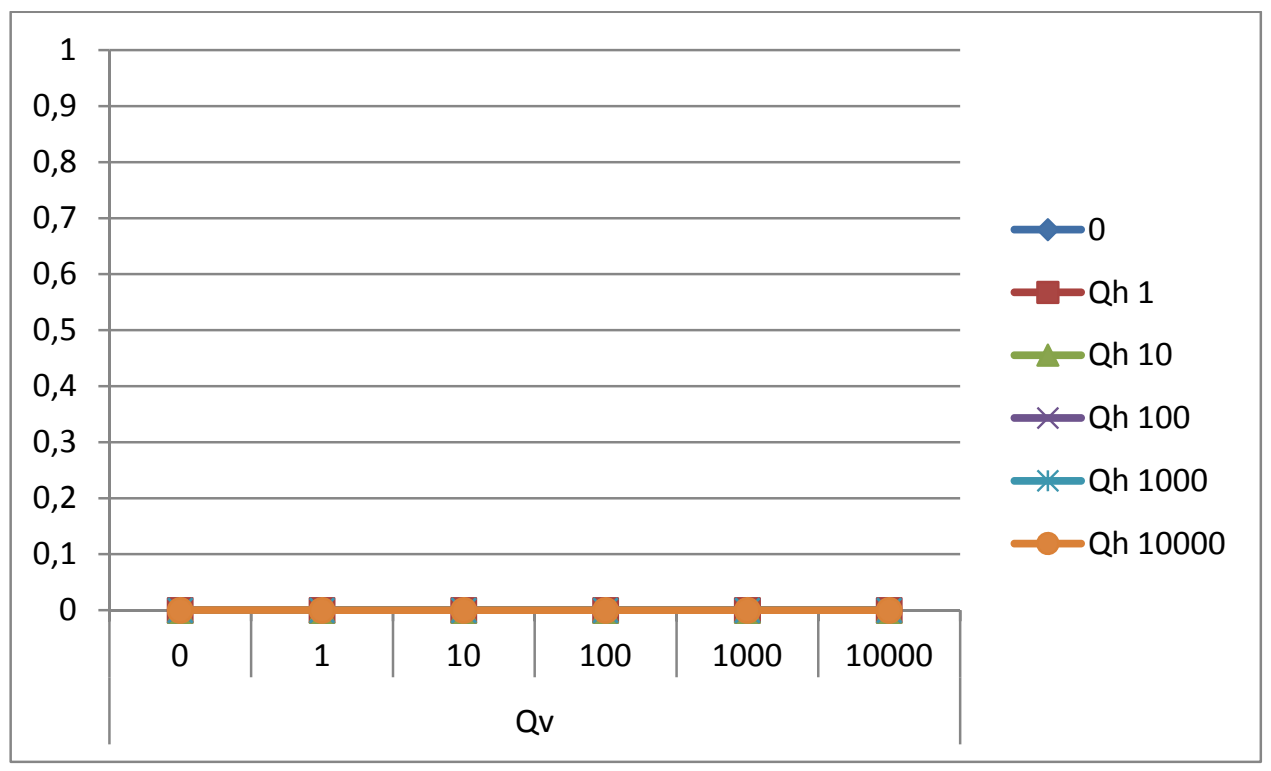

Gráfica 40 Comparación de desplazamientos verticales ( $m$, eje y) en el nudo 6 para la estructura reentrante hexagonal metálica rígida para una apertura de $63^{\circ}$ y diversas combinaciones de carga (KN, eje $x$ y leyenda), elaboración propia 
Como puede observarse en las gráficas anteriores, correspondientes a la Tabla 37, desplazamientos verticales estructura reentrante hexagonal metálica rígida para una apertura de $63^{\circ}$ y diversas cargas horizontales y verticales, del Apéndice 2. Tablas de cálculo estructural, se observan unos desplazamientos verticales con comportamientos muy diversos dependiendo de las diferentes combinaciones de cargas verticales y cargas horizontales.

Para el nudo 1 los desplazamientos verticales dependen de las cargas verticales y horizontales, influyéndose unas cargas a las otras. Siempre toman mayor protagonismo a la hora de generar desplazamientos verticales las cargas elevadas, ya sean horizontales o verticales. Sin embargo, cuando las cargas verticales y horizontales son nulas el desplazamiento no es nulo sino que es -0,000001259, esto es debido al peso de la propia estructura ya que en reposo total también sufre este desplazamiento.

Para el nudo 2, los desplazamientos verticales dependen tanto de las cargas verticales como de las cargas horizontales, influyéndose unas cargas a las otras. Siempre toman mayor protagonismo a la hora de generar desplazamientos verticales las cargas elevadas, ya sean horizontales o verticales. Sin embargo, cuando las cargas verticales y horizontales son nulas el desplazamiento no es nulo sino que es $-0,0000007338$, esto es debido al peso de la propia estructura ya que en reposo total también sufre este desplazamiento.

Para el nudo 3 se aprecian unos desplazamientos horizontales nulos en todos los casos. Esto es debido a que este nudo corresponde a uno de los apoyos de la estructura y tiene impuestas restricciones a los desplazamientos en todas las direcciones.

Para el nudo 4 los desplazamientos verticales dependen de las cargas verticales y horizontales, influyéndose unas cargas a las otras. Siempre toman mayor protagonismo a la hora de generar desplazamientos verticales las cargas elevadas, ya sean horizontales o verticales. Sin embargo, cuando las cargas verticales y horizontales son nulas el desplazamiento no es nulo sino que es -0,000001259, esto es debido al peso de la propia estructura ya que en reposo total también sufre este desplazamiento.

Para el nudo 5 los desplazamientos verticales dependen de las cargas verticales y horizontales, influyéndose unas cargas a las otras. Siempre toman mayor protagonismo a la hora de generar desplazamientos verticales las cargas elevadas, ya sean horizontales o verticales. Sin embargo, cuando las cargas verticales y horizontales son nulas el desplazamiento no es nulo sino que es $-0,0000007378$, esto es debido al peso de la propia 
estructura ya que en reposo total también sufre este desplazamiento. El nudo se ve más afectado por la carga horizontal que por la carga vertical, por eso cuando Qv $\leq$ Qh entonces el desplazamiento horizontal tiene un sentido positivo.

Para el nudo 6 se aprecian unos desplazamientos verticales nulos en todos los casos. Esto es debido a que este nudo corresponde a uno de los apoyos de la estructura y tiene impuestas restricciones a los desplazamientos.

De este modo, se puede concluir que los desplazamientos verticales para una estructura reentrante hexagonal metálica rígida para una apertura de $63^{\circ}$ y diversas cargas horizontales y verticales, aumentan con la carga, siendo mayores cuanto mayor sea dicha carga. Se puede decir que las cargas horizontales tienen una mayor importancia que las cargas verticales porque influencian a todos los nudos y en los casos en que los nudos están bajo la influencia tanto de cargas verticales como horizontales, las cargas horizontales son más determinantes. Los nudos son afectados tanto por cargas verticales como horizontales, generando estas cargas sentidos opuestos de desplazamiento. 
Gráfica comparativa de rotaciones en articulaciones para la estructura reentrante hexagonal metálica rígida para una apertura de $63^{\circ}$ y diversas combinaciones de carga:

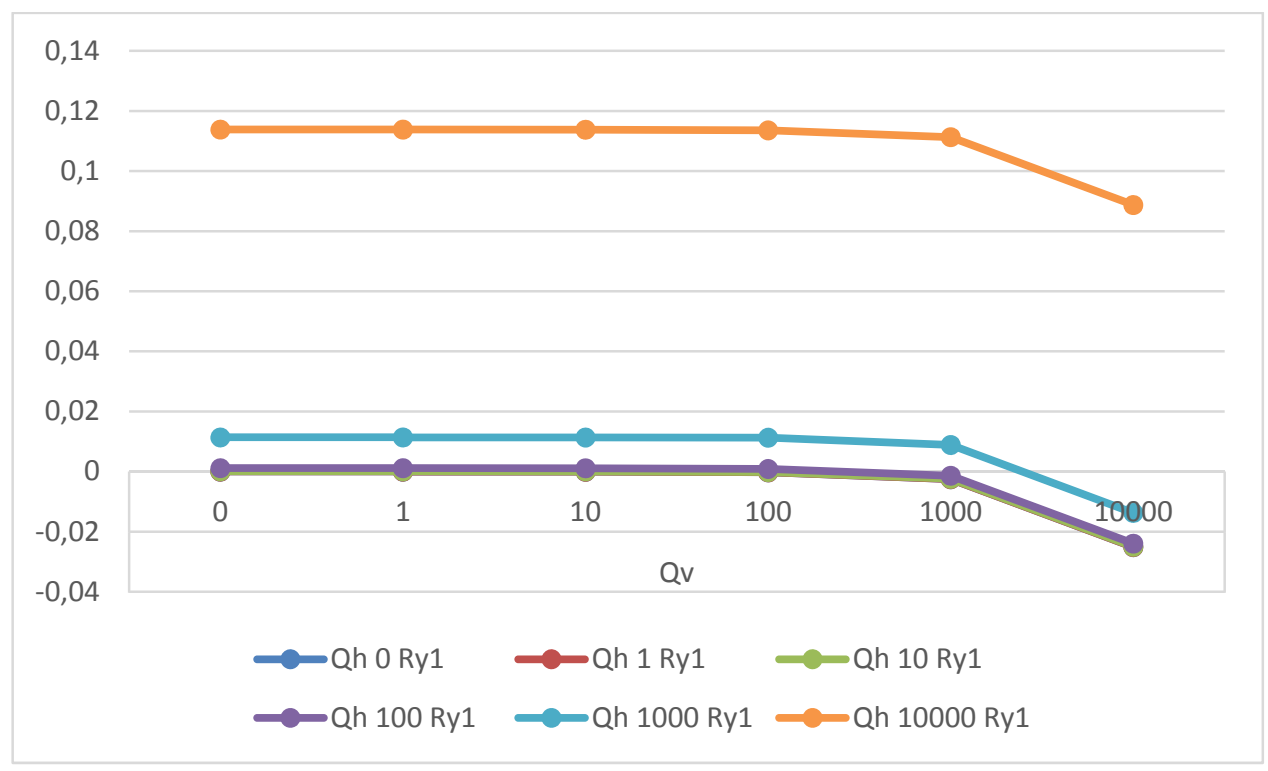

Gráfica 41 Comparación de rotaciones en articulaciones (rad, eje y) en el nudo 1 para la estructura reentrante hexagonal metálica rígida para una apertura de $63^{\circ}$ y diversas combinaciones de carga (KN, eje $x$ y leyenda), elaboración propia

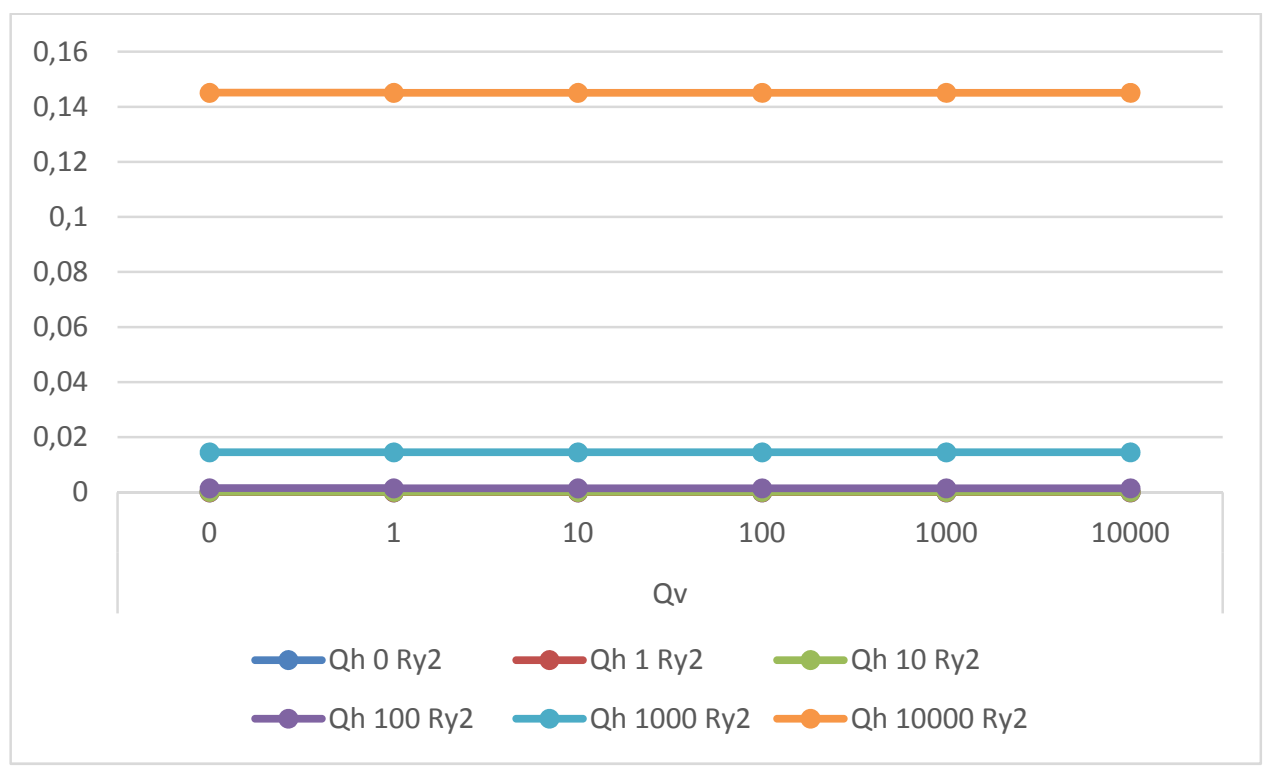

Gráfica 42 Comparación de rotaciones en articulaciones (rad, eje y) en el nudo 2 para la estructura reentrante hexagonal metálica rígida para una apertura de $63^{\circ}$ y diversas combinaciones de carga (KN, eje $x$ y leyenda), elaboración propia 


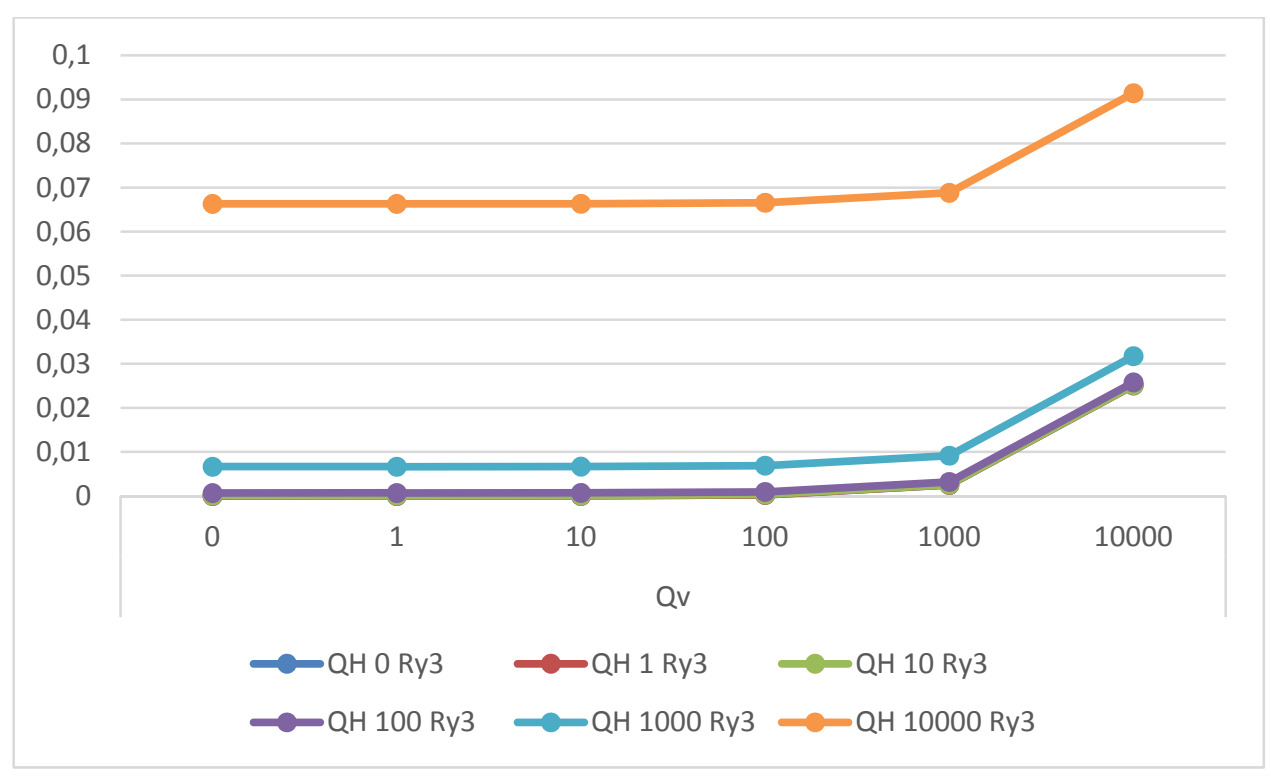

Gráfica 43 Comparación de rotaciones en articulaciones (rad, eje y) en el nudo 3 para la estructura reentrante hexagonal metálica rígida para una apertura de $63^{\circ}$ y diversas combinaciones de carga (KN, eje $x$ y leyenda), elaboración propia

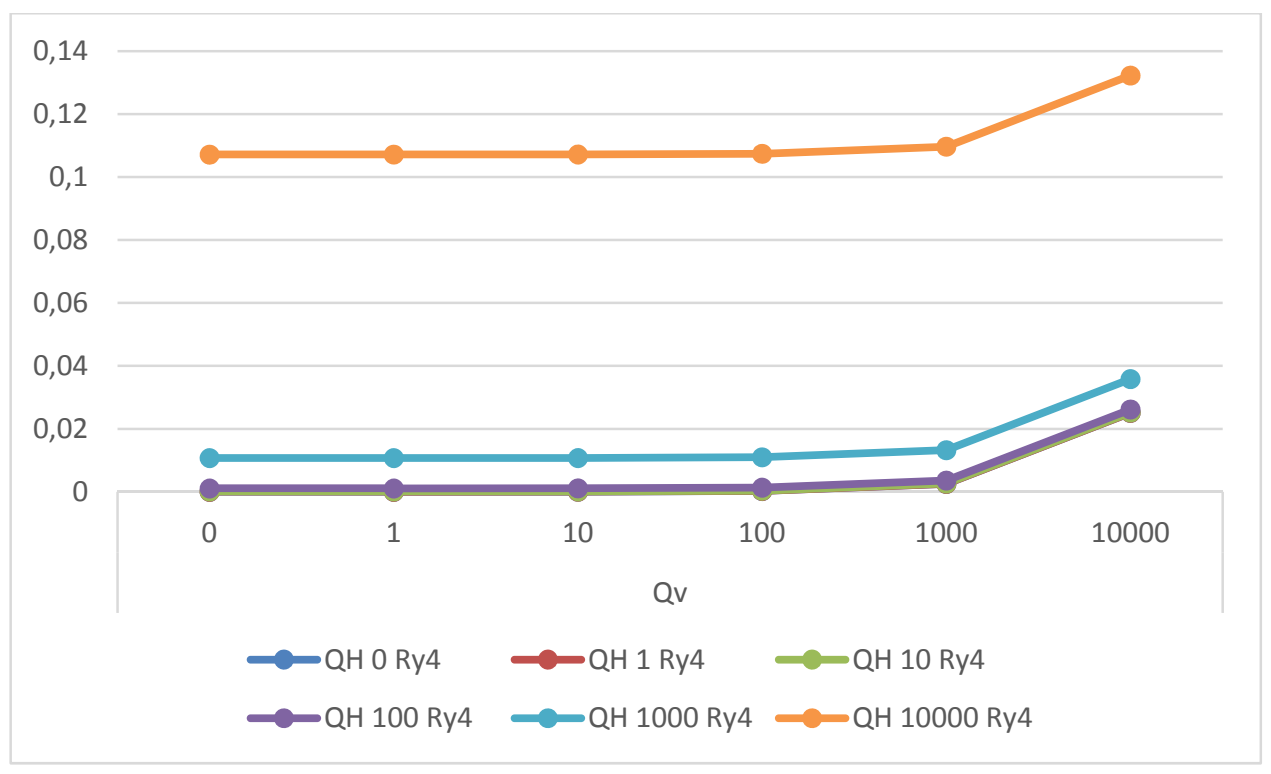

Gráfica 44 Comparación de rotaciones en articulaciones (rad, eje y) en el nudo 4 para la estructura reentrante hexagonal metálica rígida para una apertura de $63^{\circ}$ y diversas combinaciones de carga (KN, eje $x$ y leyenda), elaboración propia 


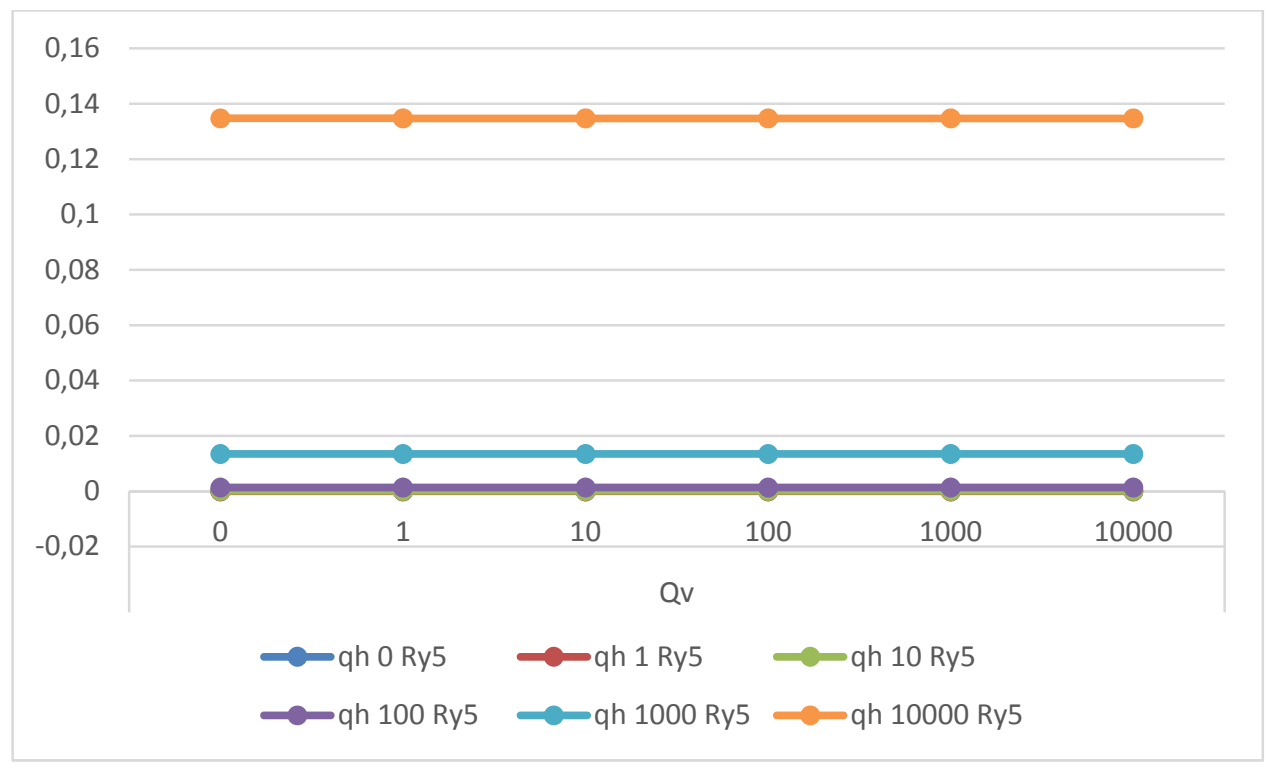

Gráfica 45 Comparación de rotaciones en articulaciones (rad, eje y) en el nudo 5 para la estructura reentrante hexagonal metálica rígida para una apertura de $63^{\circ}$ y diversas combinaciones de carga (KN, eje $x$ y leyenda), elaboración propia

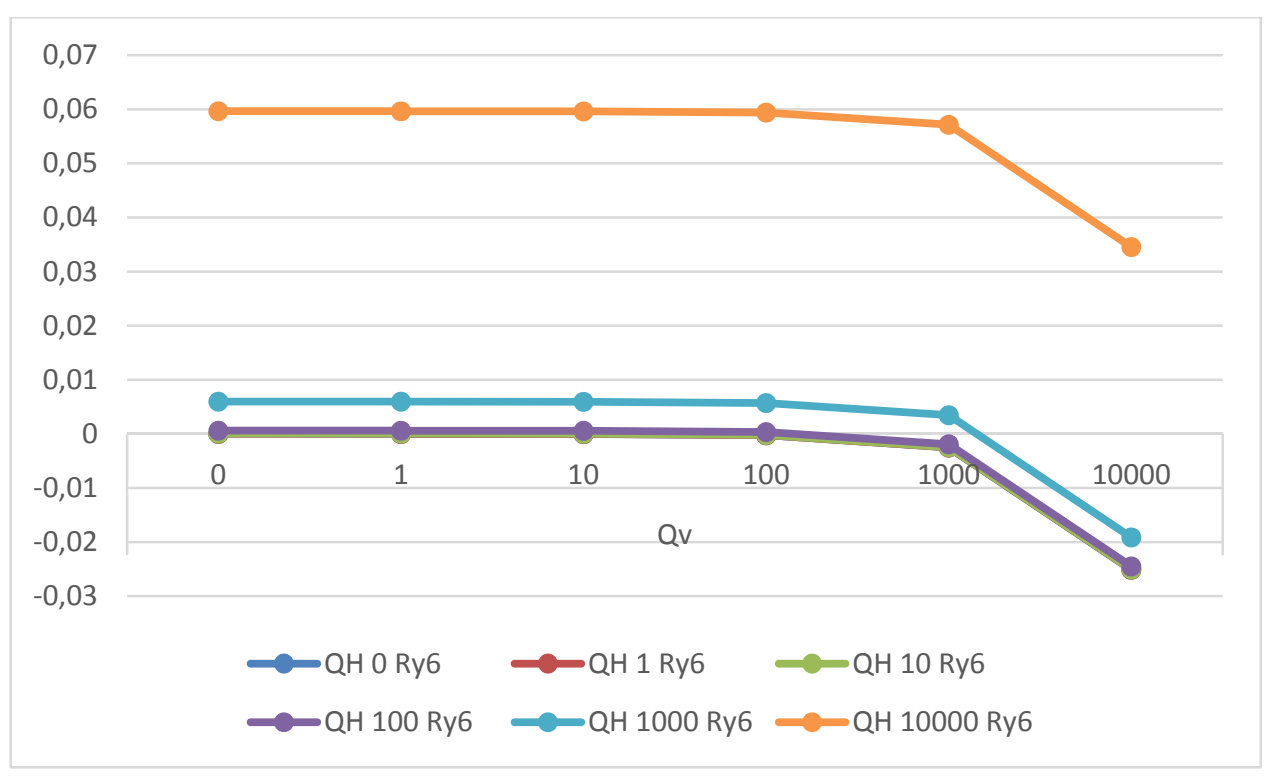

Gráfica 46 Comparación de rotaciones en articulaciones ( $r a d$, eje y) en el nudo 6 para la estructura reentrante hexagonal metálica rígida para una apertura de $63^{\circ}$ y diversas combinaciones de carga (KN, eje $x$ y leyenda), elaboración propia 
Como puede observarse en las gráficas anteriores, correspondientes a la Tabla 38, rotaciones en articulaciones para la estructura reentrante hexagonal metálica rígida para una apertura de $63^{\circ}$ y diversas cargas horizontales y verticales, del Apéndice 2. Tablas de cálculo estructural, se observan diversas rotaciones en articulaciones con comportamientos muy diversos dependiendo de las diferentes combinaciones de cargas verticales y cargas horizontales.

Para el nudo 1, observamos que las cargas horizontales son las que más le afectan, puesto que la rotación va subiendo conforme aumenta dicha carga horizontal. Además, esta carga es la que contribuye al cambio de dirección, pasando de un sentido antihorario cuando la carga horizontal es nula a sentidos horarios cuando empieza a tener valores mayores que 0. Los valores máximos de rotaciones en este nudo son de 0,11131.

Para el nudo 2, se observa que las cargas horizontales son las únicas que afectan a la rotación en esta articulación, girando siempre el nudo en sentido horario. Las mayores rotaciones en el nudo se obtienen para las cargas horizontales más altas, llegando a valores máximos de 0,1451.

Para el nudo 3, las cargas horizontales y verticales afectan a la rotación. Cuando ambas cargas son nulas, la rotación es de 0,000001434, afectándole la carga vertical cuando es muy alta hasta obtener el valor de 0,02511. En el momento en que se aplica la carga horizontal de $1 \mathrm{KN}$, el valor de la rotación cambia a 0,000008065 y va aumentando progresivamente hasta valores máximos de 0,06631.

Para el nudo 4, las cargas horizontales y verticales afectan en distintos momentos. Para cargas nulas verticales y horizontales, la rotación es de 0,0000003113, y aumenta de manera significativa a medida que las cargas verticales suben, alcanzando el valor de 0,02511 con la carga vertical más alta. Sin embargo, las mayores rotaciones en el nudo se obtienen para las cargas horizontales más altas, llegando a valores máximos de 0,10717.

Para el nudo 5, se observa que las cargas horizontales son las únicas que afectan a la rotación en esta articulación, girando siempre el nudo en sentido horario. Las mayores rotaciones en el nudo se obtienen para las cargas horizontales más altas, llegando a valores máximos de 0,13473 .

Para el nudo 6, las cargas horizontales y verticales afectan en distintos momentos. Para cargas nulas verticales y horizontales, la rotación es de -0,000001434, y aumenta de manera significativa a medida que las cargas verticales suben, alcanzando el valor de 
$-0,02511$ con la carga vertical más alta. Sin embargo, las mayores rotaciones en el nudo se obtienen para las cargas horizontales más altas, llegando a valores máximos de 0,05966.

De este modo, se puede concluir que las rotaciones en articulaciones para la estructura reentrante hexagonal metálica rígida para una apertura de $63^{\circ}$ y diversas cargas horizontales y verticales, aumentan con la carga, siendo mayores cuanto mayor sea dicha carga. Se puede decir que las cargas horizontales tienen una mayor importancia que las cargas verticales porque influencian a todos los nudos, y además son las que hacen aumentar de forma considerable las rotaciones en los nudos generalmente. 


\section{Reacciones en apoyos:}

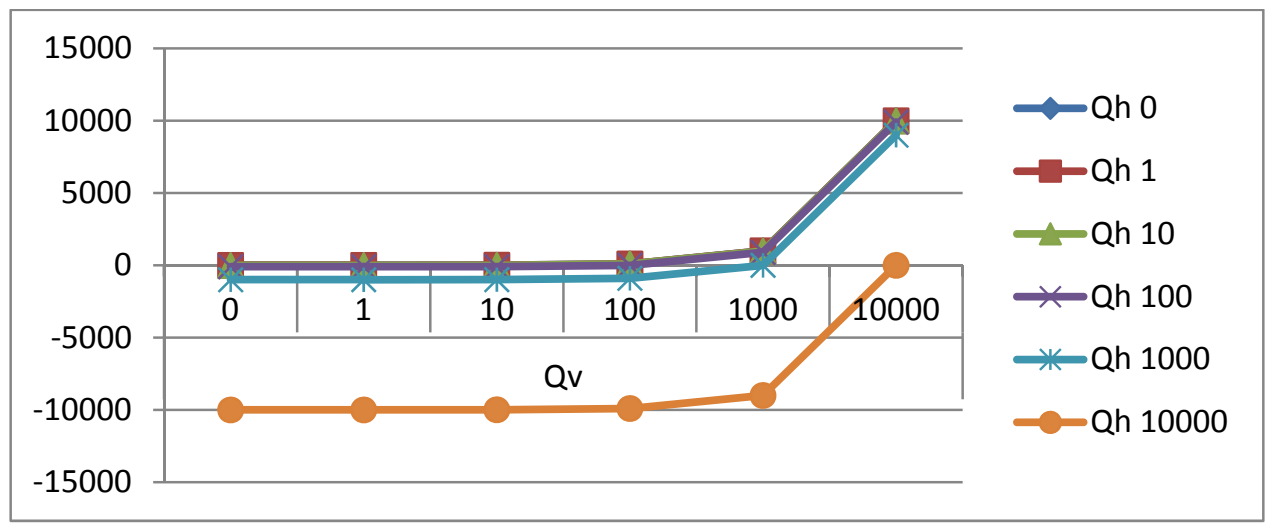

Gráfica 47 Comparación de reacciones verticales en apoyos ( $K N$, eje y) en el nudo 3 para la estructura reentrante hexagonal metálica rígida para una apertura de $63^{\circ}$ y diversas combinaciones de carga $(K N$, eje $x y$ leyenda), elaboración propia

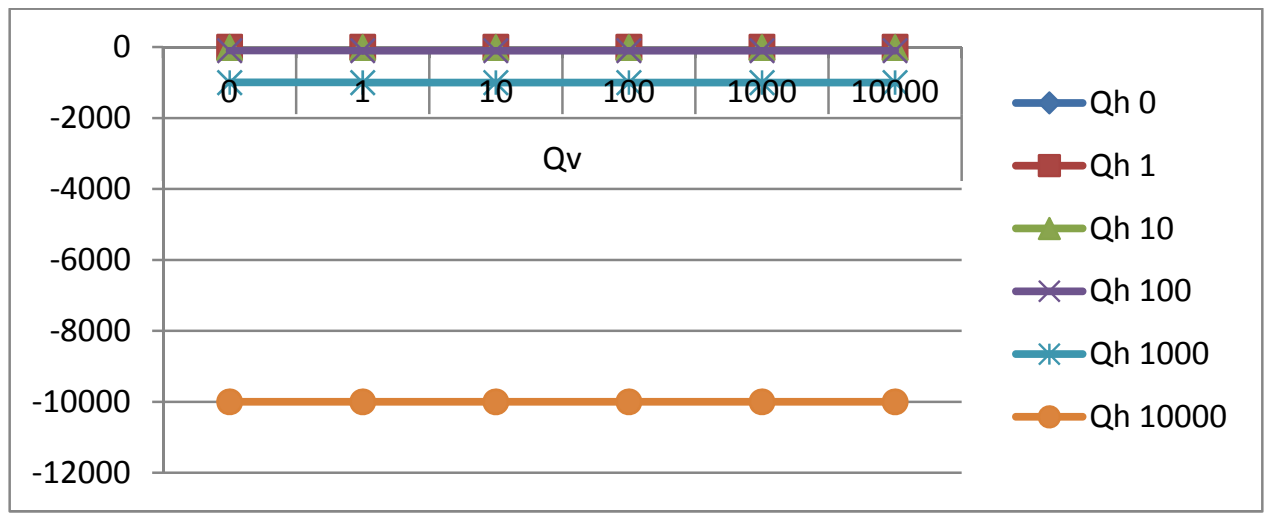

Gráfica 48 Comparación de reacciones horizontales en apoyos ( $K N$, eje y) en el nudo 3 para la estructura reentrante hexagonal metálica rígida para una apertura de $63^{\circ}$ y diversas combinaciones de carga $(K N$, eje $x$ y leyenda), elaboración propia

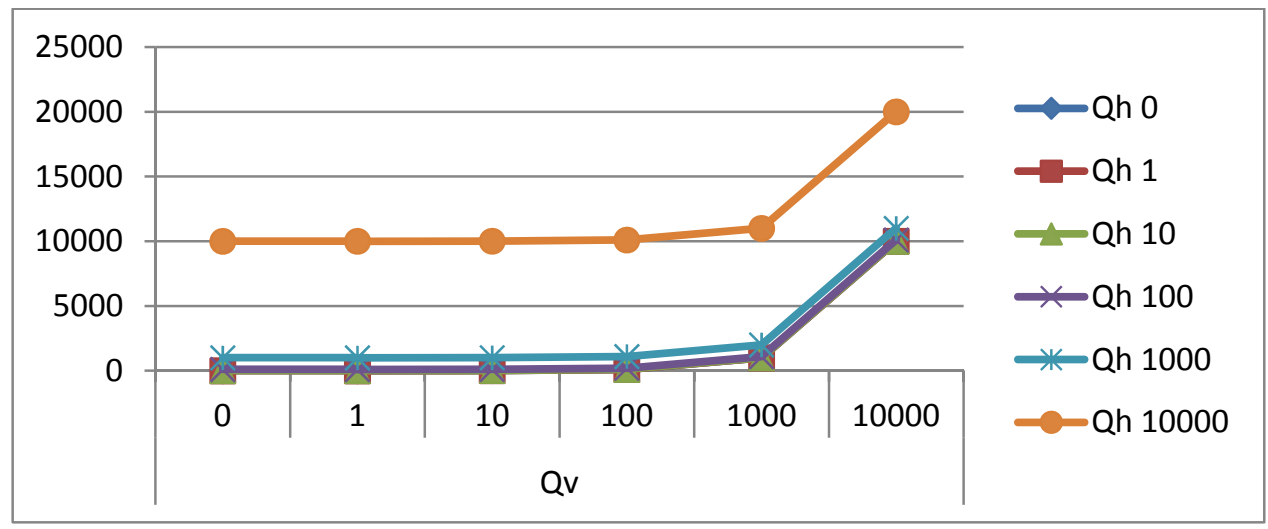

Gráfica 49 Comparación de reacciones verticales en apoyos ( $K N$, eje y) en el nudo 6 para la estructura reentrante hexagonal metálica rígida para una apertura de $63^{\circ}$ y diversas combinaciones de carga (KN, eje $x y$ leyenda), elaboración propia 
Como puede observarse en las gráficas correspondientes a la Tabla 39, reacciones en apoyos para la estructura reentrante hexagonal metálica rígida para una apertura de $63^{\circ}$ y diversas cargas horizontales y verticales, del Apéndice 2. Tablas de cálculo estructural, se observan diversas reacciones en apoyos con comportamientos muy diversos dependiendo de las diferentes combinaciones de cargas verticales y cargas horizontales.

Para el nudo 3, observamos que las cargas horizontales producen reacciones verticales en sentido gravitatorio, mientras que las cargas verticales las reacciones las generan en sentido antigravitatorio. De este modo, cuando tenemos una carga vertical nula y una horizontal de $10000 \mathrm{KN}$, se observan reacciones muy altas, de magnitud -9999,30 KN. Del mismo modo, cuando tenemos una carga horizontal nula y una vertical de $10000 \mathrm{KN}$, se observan también reacciones muy altas, de magnitud 10000,70 KN. Sin embargo, cuando los dos tipos de carga (horizontal y vertical) son de $10000 \mathrm{KN}$, las reacciones producidas por ambos en sentido inverso, se compensan entre sí, bajando la reacción final en el nudo a 0,70 KN.

Para el mismo nudo 3, observamos que las cargas horizontales son las que producen reacciones horizontales, mientras que las cargas verticales no generan reacciones en esta dirección. De este modo, cuando tenemos unas cargas nulas, se observa una reacción en el apoyo también nula. Sin embargo, conforme aumentamos el valor de la carga horizontal, la reacción en el apoyo cobra valores iguales a la carga aplicada, pero de sentido contrario, llegando a reacciones horizontales máximas de -10000 KN.

Para el nudo 6, observamos que tanto las cargas horizontales como las verticales producen reacciones verticales en el apoyo de sentido positivo. De este modo, cuando tenemos una carga vertical nula y una horizontal de $10000 \mathrm{KN}$, se observan reacciones muy altas, de magnitud 10000,70 KN. Del mismo modo, cuando tenemos una carga horizontal nula y una vertical de $10000 \mathrm{KN}$, se observan también reacciones muy altas, de magnitud 10000,70 $\mathrm{KN}$. Además, cuando los dos tipos de carga (horizontal y vertical) son de $10000 \mathrm{KN}$, las reacciones producidas por ambos se suman, aumentando la reacción final en el nudo a $20000,70 \mathrm{KN}$.

De este modo, se puede concluir que las reacciones en apoyos para la estructura reentrante hexagonal metálica rígida para una apertura de $63^{\circ}$ y diversas cargas horizontales y verticales, aumentan con la carga, siendo mayores las verticales cuanto mayor sea dicha carga para el nudo 6 y compensándose para el nudo 3. Se puede decir que las cargas horizontales tienen una mayor importancia que las cargas verticales al generar reacciones horizontales. 
Esfuerzos axiles

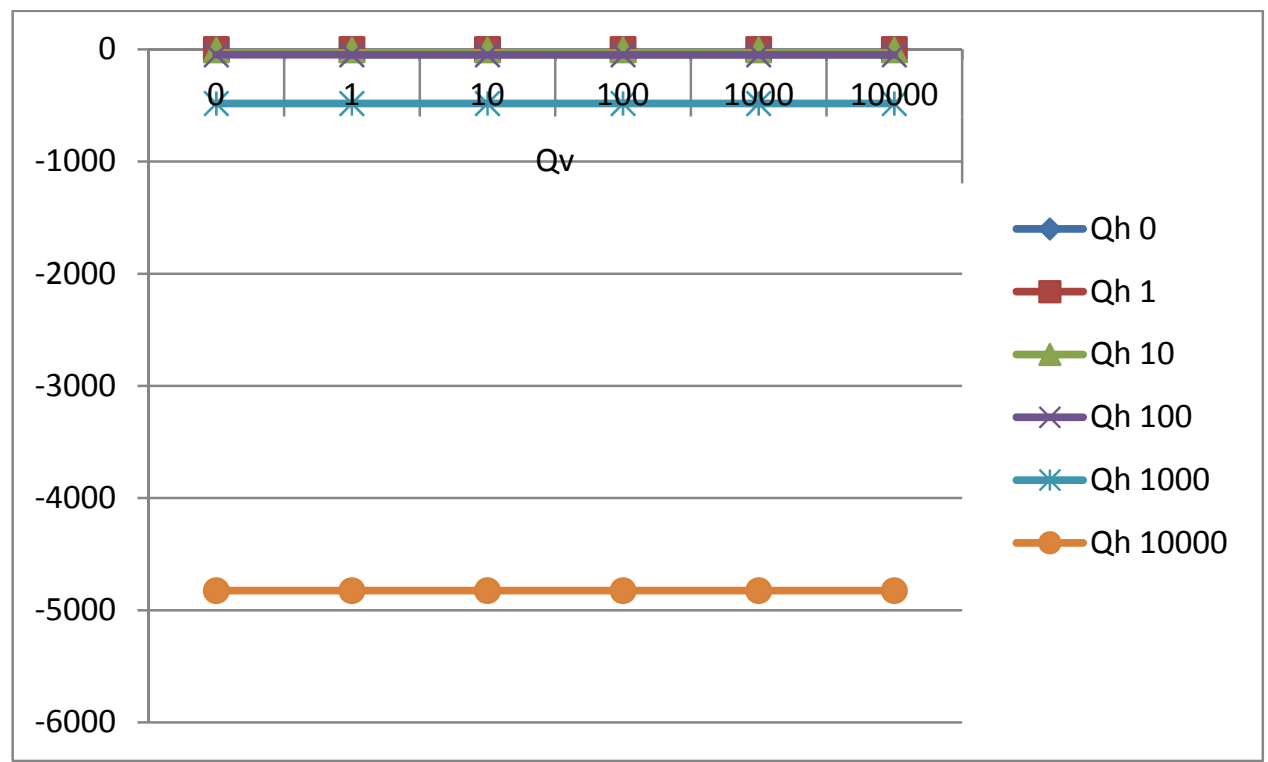

Gráfica 50 Comparación de esfuerzos axiles (KN, eje y) en la barra a para la estructura reentrante hexagonal metálica rígida para una apertura de $63^{\circ}$ y diversas combinaciones de carga ( $K N$, eje $x$ y leyenda), elaboración propia

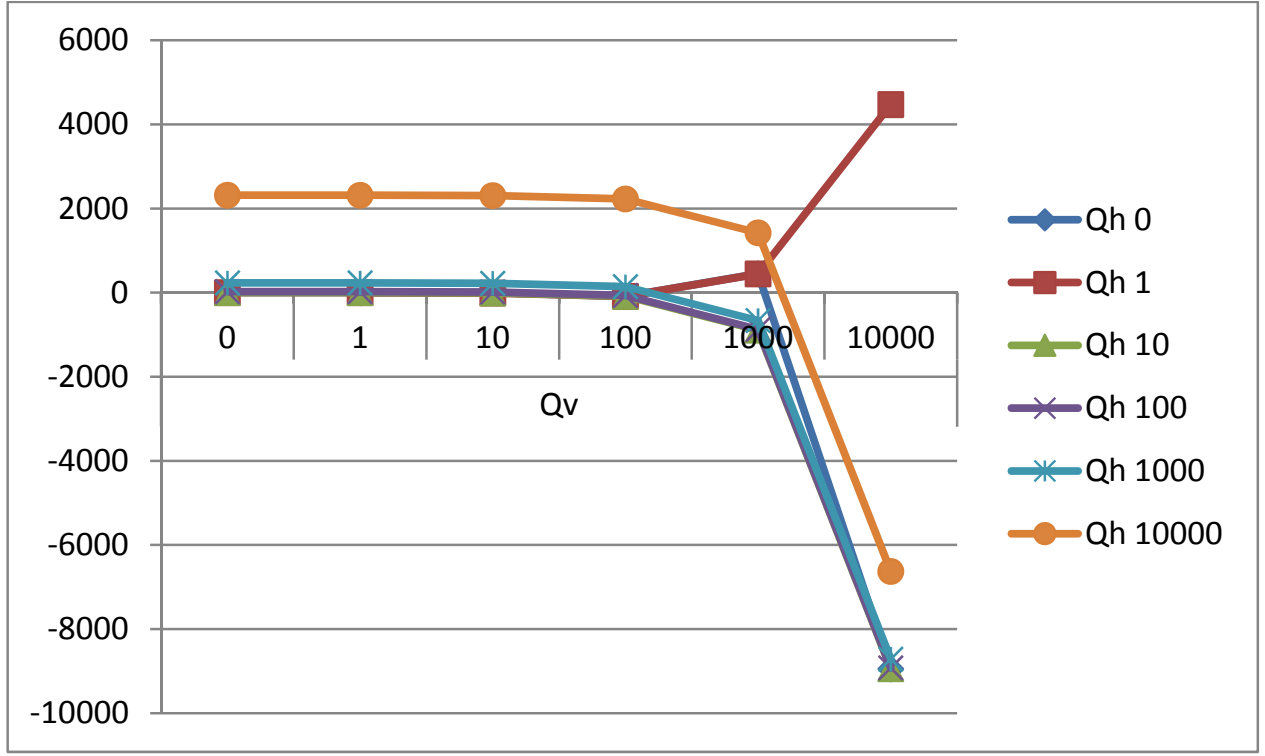

Gráfica 51 Comparación de esfuerzos axiles mínimos ( $K N$, eje y) en la barra b para la estructura reentrante hexagonal metálica rígida para una apertura de $63^{\circ}$ y diversas combinaciones de carga (KN, eje $x$ y leyenda), elaboración propia 


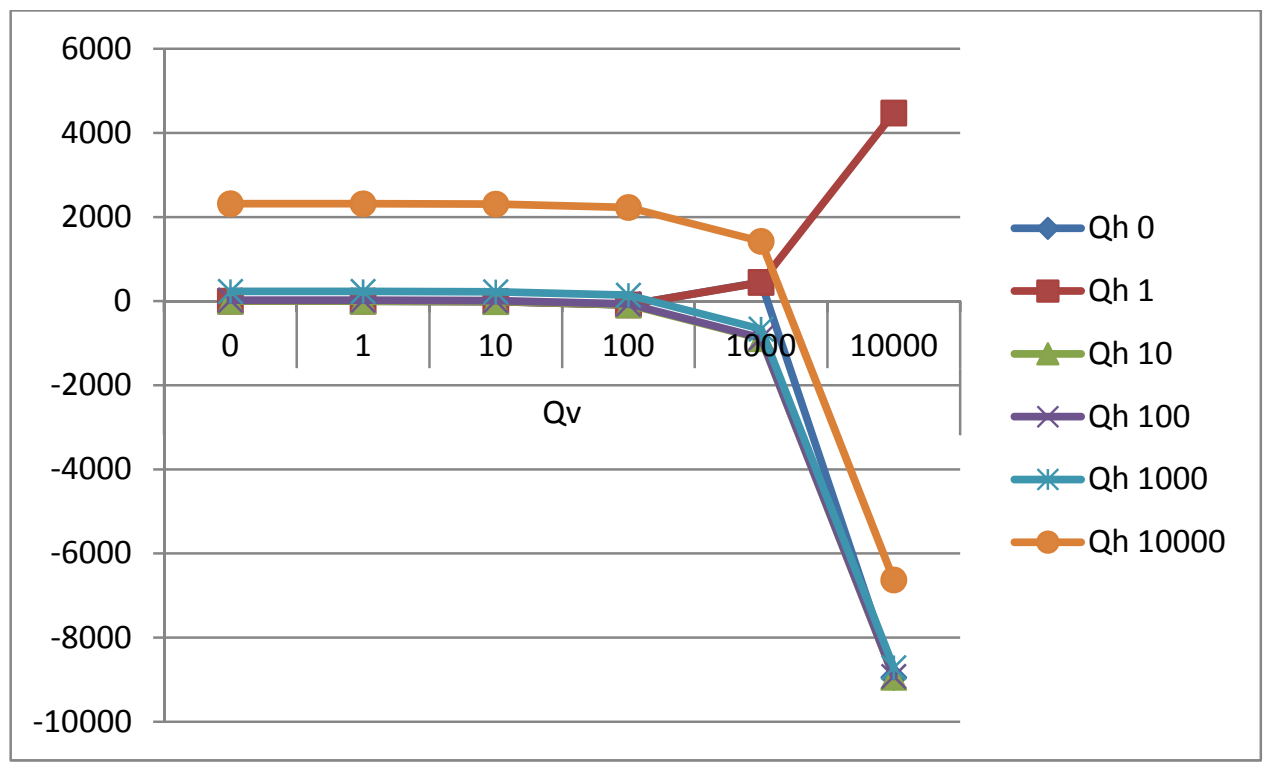

Gráfica 52 Comparación de esfuerzos axiles máximos ( $K N$, eje y) en la barra b para la estructura reentrante hexagonal metálica rígida para una apertura de $63^{\circ}$ y diversas combinaciones de carga (KN, eje $x$ y leyenda), elaboración propia

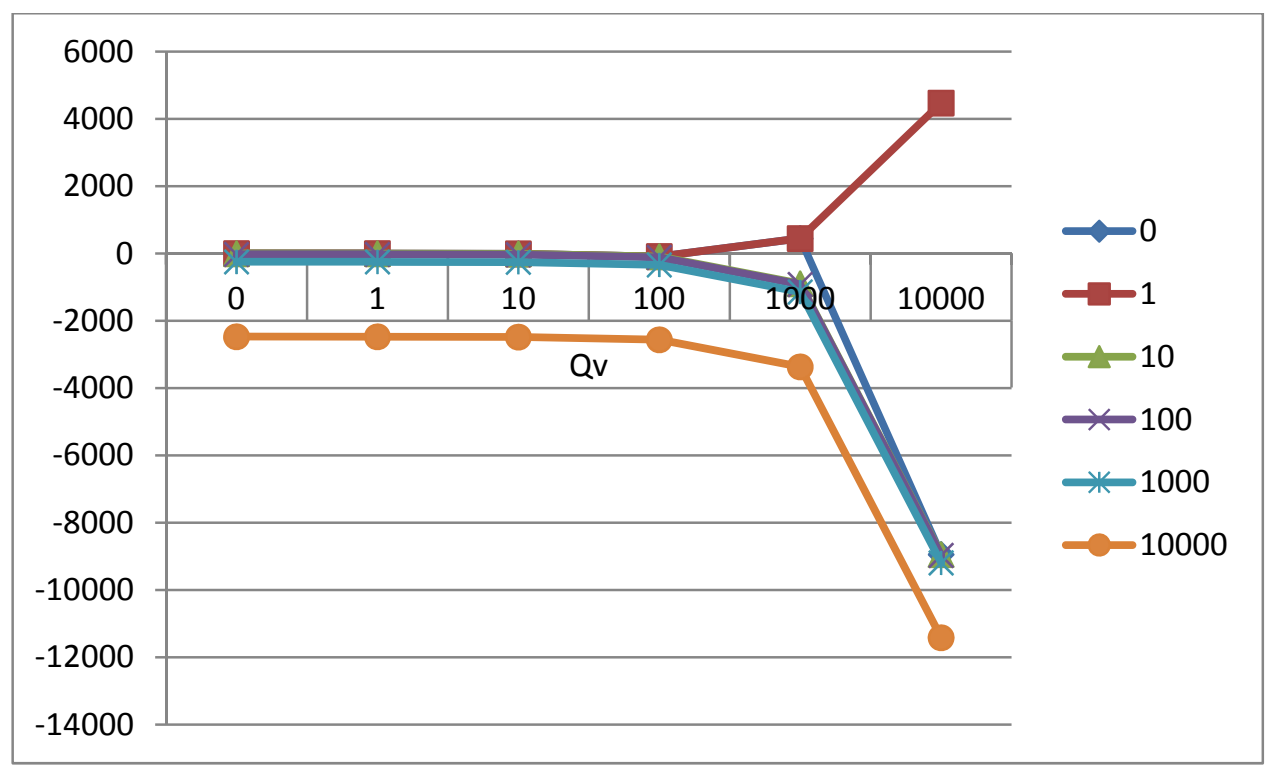

Gráfica 53 Comparación de esfuerzos axiles mínimos (KN, eje y) en la barra c para la estructura reentrante hexagonal metálica rígida para una apertura de $63^{\circ}$ y diversas combinaciones de carga (KN, eje $x$ y leyenda), elaboración propia 


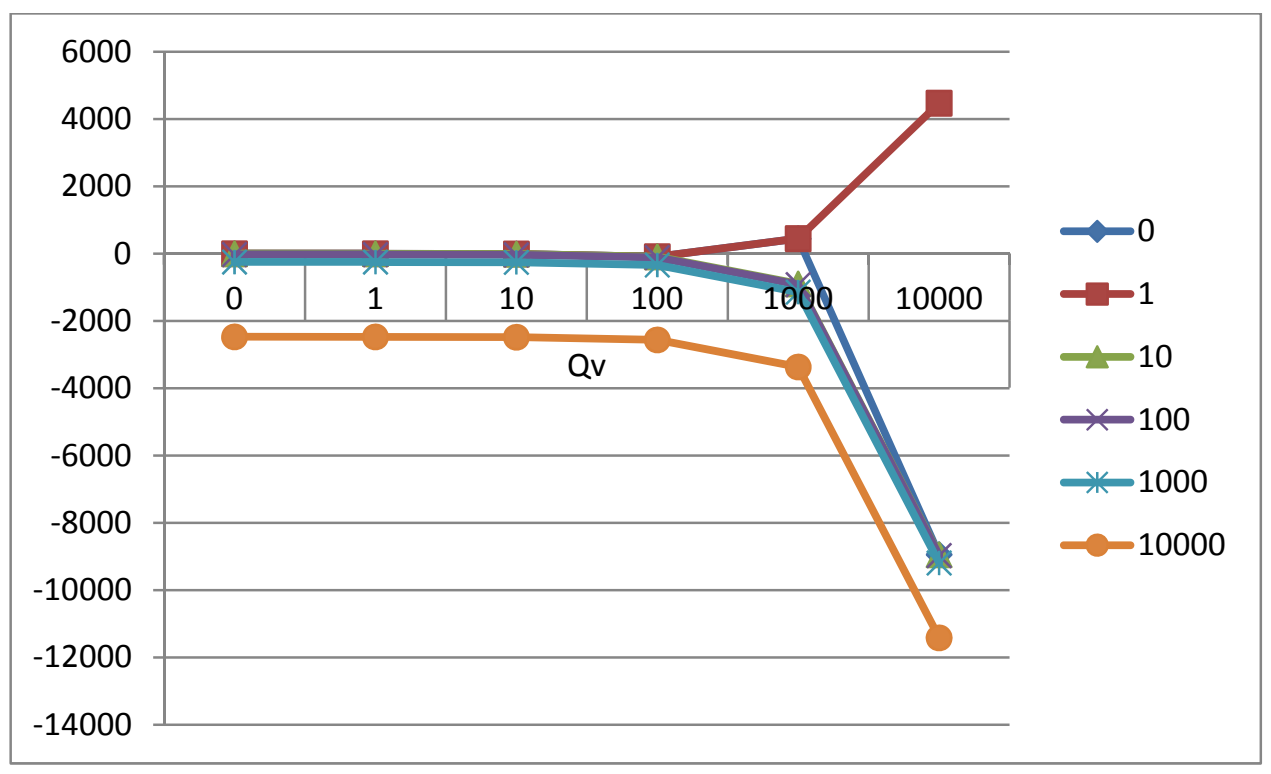

Gráfica 54 Comparación de esfuerzos axiles máximos ( $K N$, eje y) en la barra c para la estructura reentrante hexagonal metálica rígida para una apertura de $63^{\circ}$ y diversas combinaciones de carga (KN, eje $x$ y leyenda), elaboración propia

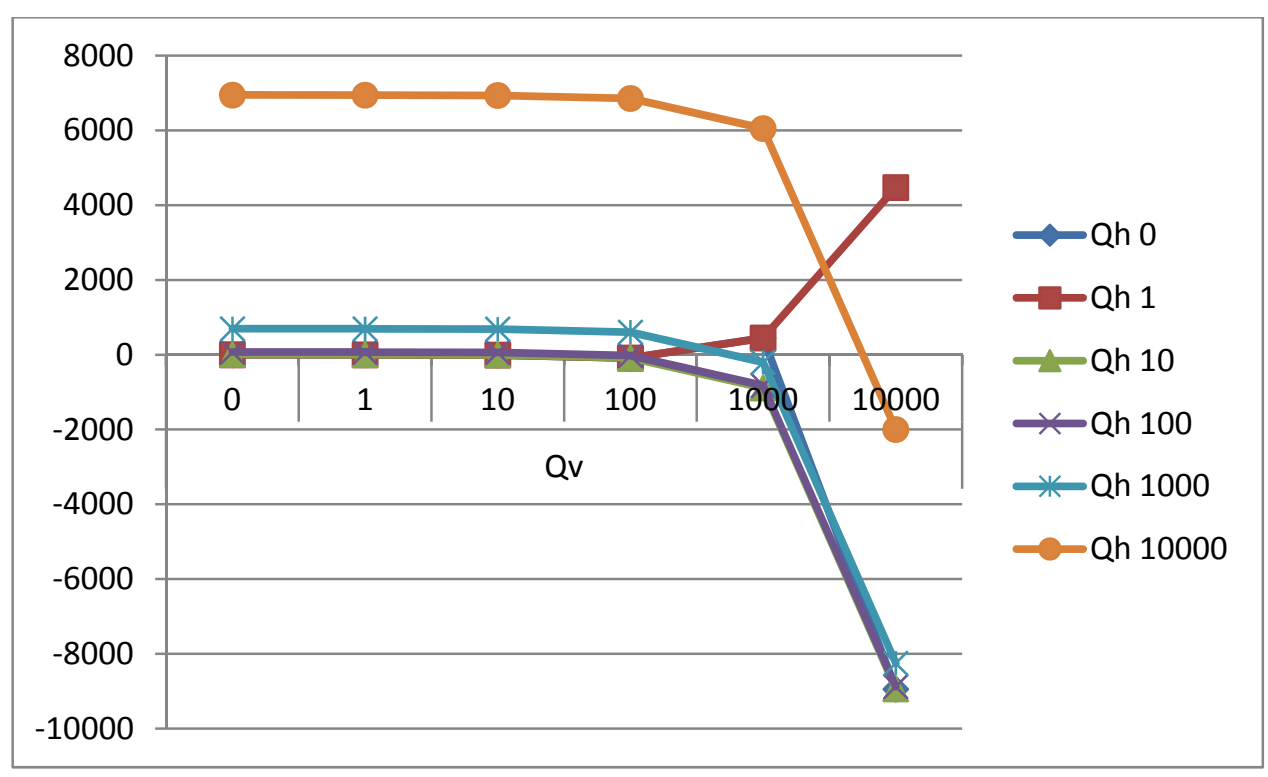

Gráfica 55 Comparación de esfuerzos axiles mínimos ( $K N$, eje y) en la barra d para la estructura reentrante hexagonal metálica rígida para una apertura de $63^{\circ}$ y diversas combinaciones de carga (KN, eje $x$ y leyenda), elaboración propia 


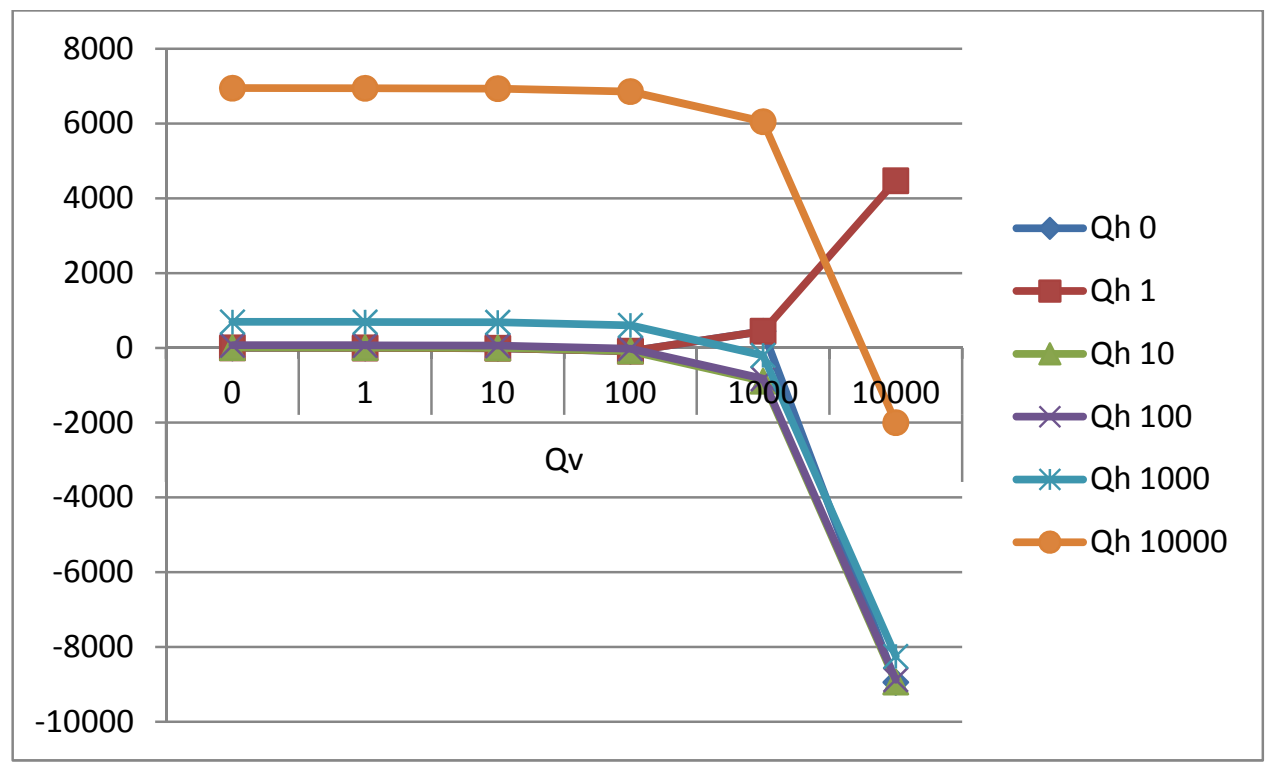

Gráfica 56 Comparación de esfuerzos axiles máximos ( $K N$, eje y) en la barra d para la estructura reentrante hexagonal metálica rígida para una apertura de $63^{\circ}$ y diversas combinaciones de carga (KN, eje $x$ y leyenda), elaboración propia

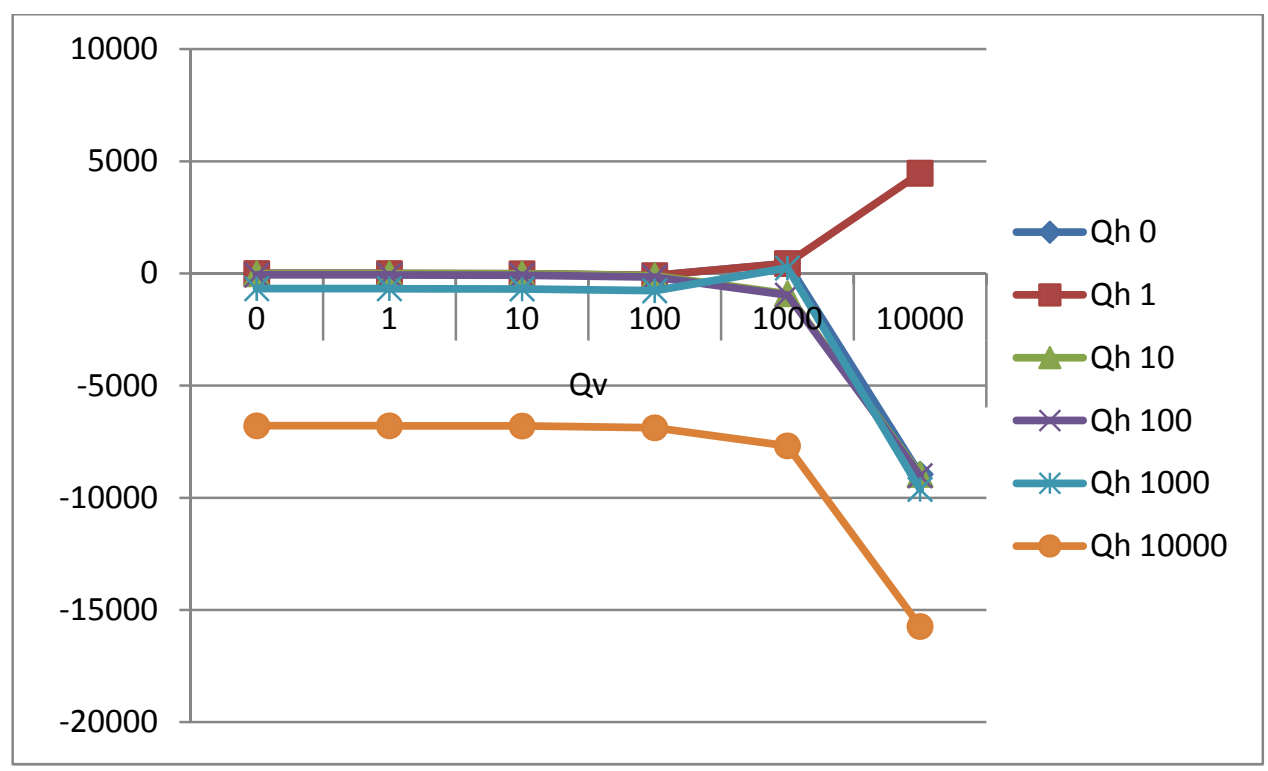

Gráfica 57 Comparación de esfuerzos axiles mínimos ( $K N$, eje y) en la barra e para la estructura reentrante hexagonal metálica rígida para una apertura de $63^{\circ}$ y diversas combinaciones de carga (KN, eje $x$ y leyenda), elaboración propia 
Aplicaciones de las propiedades auxéticas en la arquitectura

CÁLCULO ESTRUCTURAL DE ESTRUCTURAS AUXÉTICAS

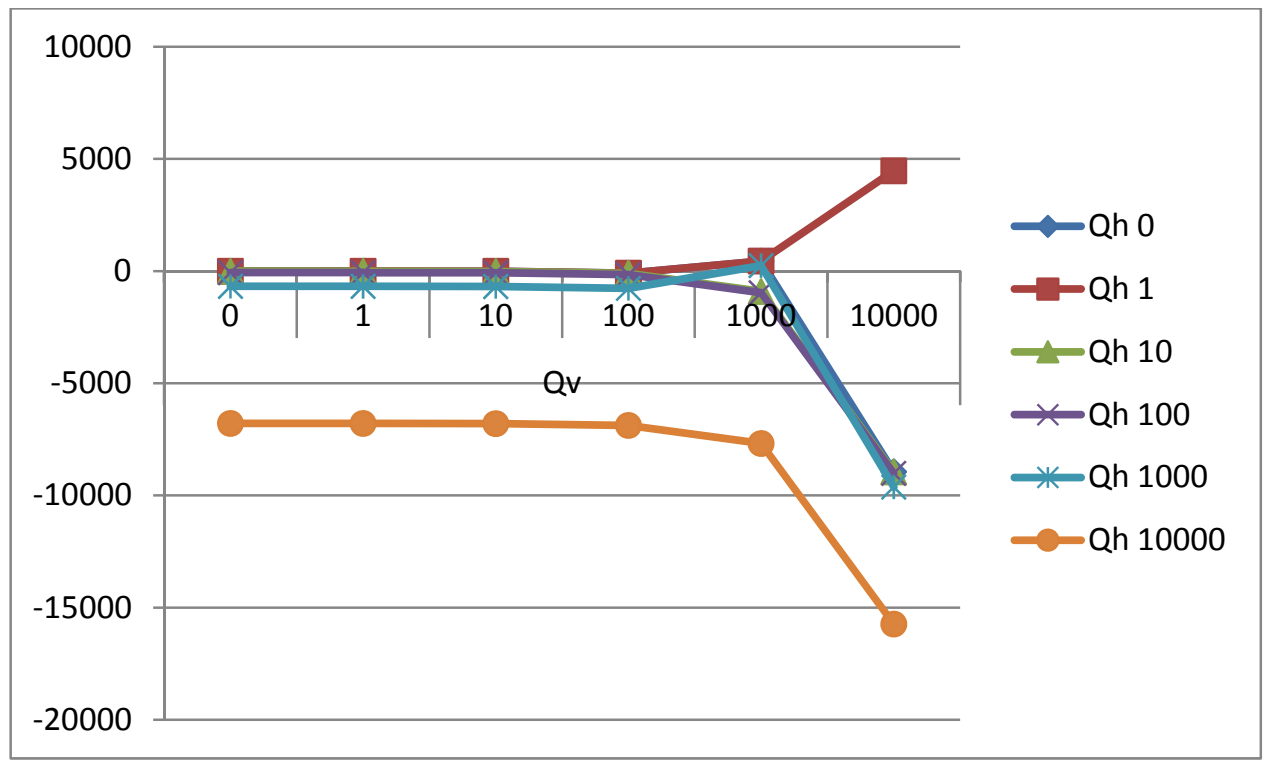

Gráfica 58 Comparación de esfuerzos axiles máximos ( $K N$, eje y) en la barra e para la estructura reentrante hexagonal metálica rígida para una apertura de $63^{\circ}$ y diversas combinaciones de carga (KN, eje $x$ y leyenda), elaboración propia

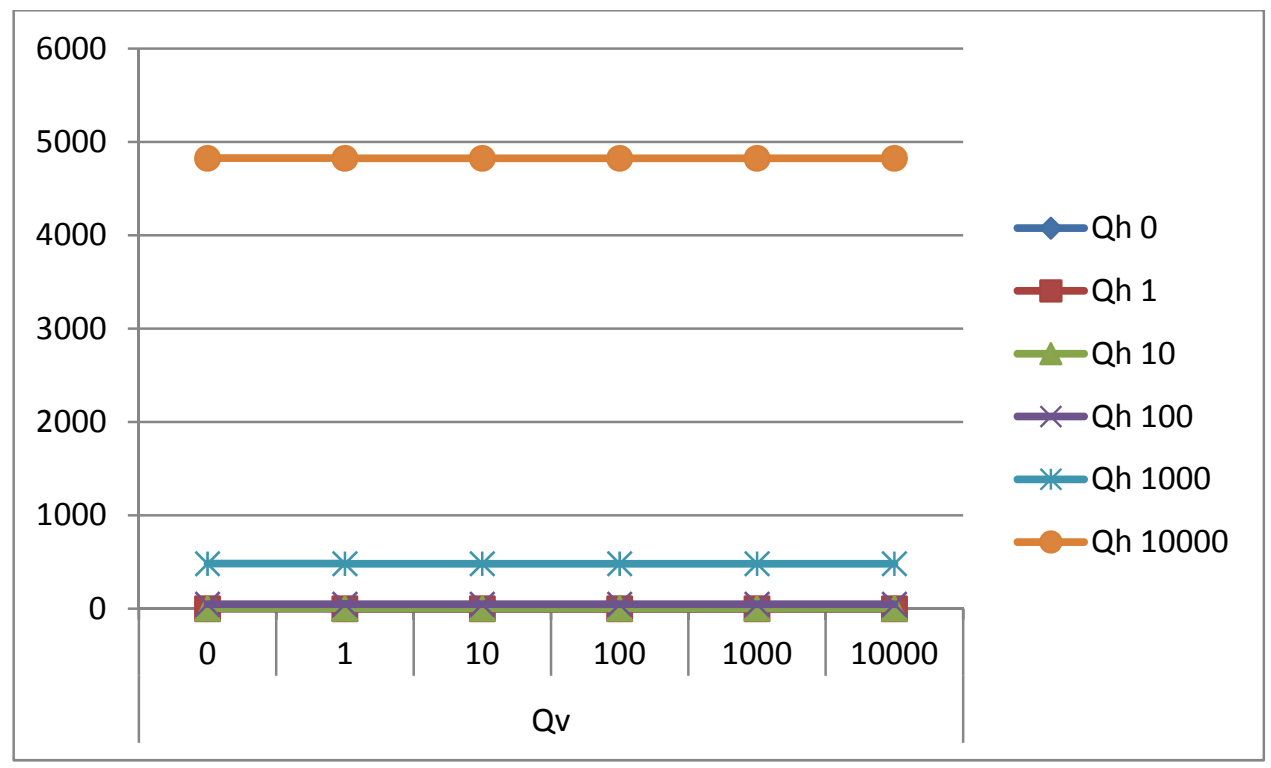

Gráfica 59 Comparación de esfuerzos axiles (KN, eje y) en la barra f para la estructura reentrante hexagonal metálica rígida para una apertura de $63^{\circ}$ y diversas combinaciones de carga ( $K N$, eje $x$ y leyenda), elaboración propia 
Como puede observarse en las gráficas anteriores, correspondientes a la Tabla 40, esfuerzos axiles estructura reentrante hexagonal metálica rígida para una apertura de $63^{\circ}$ y diversas cargas horizontales y verticales ( $m$ y $K N$ ), del Apéndice 2. Tablas de cálculo estructural, se observan unos esfuerzos axiles con comportamientos muy diversos dependiendo de las diferentes combinaciones de cargas verticales y cargas horizontales.

En la barra a, las cargas horizontales son las que más afectan al esfuerzo, porque el aumento bajo la carga horizontal llega a registrar cambios muy altos, desde -0,071 en para una carga horizontal nula, pasando a -0,554 con carga de 1, -4,896 en carga 10, -48,324 en carga $100 \ldots$, hasta $-4825,331$ para una carga de 10000 . El esfuerzo aumenta en todos los casos unas 10 veces respecto al caso anterior, pero se mantiene estable a pesar de la influencia de las diferentes cargas verticales, por lo que estas últimas no le afectan.

En la barra b, las cargas horizontales y verticales afectan por igual, yendo en la misma dirección. El esfuerzo aumenta en todos los casos unas 10 veces respecto al caso anterior. Para cargas verticales pasa de $-0,279$ a $-0,115$ cuando esta carga es nula a valores que oscilan de $-8944,387$ a $-8944,551$ cuando la carga pasa a ser 10000. Para cargas horizontales pasa de -0,279 a -0,115 cuando esta carga es nula a valores que oscilan de 2316,243 a 2316,407 cuando la carga pasa a ser 10000. Llama la atención que muchas veces cambian los signos del esfuerzo, lo que significa que, según la carga aplicada, se generan esfuerzos de compresión (-) o tracción (+).

En la barra c, las cargas horizontales y verticales influyen, aunque las cargas verticales más altas suponen un esfuerzo mayor. Por ejemplo, cuando $Q v=1000$ y $Q h=1000$, el esfuerzo es de -1141,988 a -1141,824; al subir la carga vertical a 10000, se pasa a -9191,832 a 9191,668 , mientras que si la carga que se aumenta es la horizontal, también a 10000, el esfuerzo sube a valores menores, oscilando entre -3367,52 y -3367,356. Llama la atención que muchas veces cambian los signos del esfuerzo, lo que significa que, según la carga aplicada, se generan esfuerzos de compresión (-) o tracción (+).

En la barra d, vemos que cada carga genera esfuerzos contrarios. A medida que la carga horizontal aumenta, los esfuerzos generados son de tracción, mientras que si influye más la carga vertical los esfuerzos suelen ser de compresión. Así, si bien para cargas nulas el esfuerzo es de -0,507 a -0,343 (compresión), en el momento en que la carga horizontal es 1 y la vertical es nula, pasamos a un esfuerzo de 0,188 a 0,352 (tracción). Así, el aumento de carga horizontal aumenta el esfuerzo axil en un sentido distinto de forma progresiva, como 
se observa cuando $\mathrm{Qh}=10000$ y $\mathrm{Qv}=1000$, donde la alta carga vertical no afecta a la dirección de la horizontal, dando como resultado 6050,016 a 6050,18.

En la barra e, las cargas verticales y horizontales más altas muestran un esfuerzo mucho mayor que el del resto de cargas, llegando al máximo de $-15733,437$ a $-15733,273$. Cuando $\mathrm{Q}_{\mathrm{v}}=1000$ y $\mathrm{Q}_{\mathrm{h}}=1$, el esfuerzo cambia de dirección, generando tracciones que van de 447,105 a 447,188 . Algo parecido ocurre con la misma carga vertical y la horizontal nula, llegando a un esfuerzo de 447,305 a 447,388.

En la barra $f$, las únicas que afectan al esfuerzo axil son las cargas horizontales, que aumentan de forma progresiva de 0,071 para cargas horizontales nulas, a 0,554 con carga $1,4,896$ con carga $10,48,324$ con carga $100,482,597$ con carga 1000 y 4825,331 con carga 10000. Las cargas verticales no alteran estas cifras, por lo que no le afectan. Este es el único caso en que la dirección del esfuerzo, en este caso de tracción, se mantiene estable.

De este modo, se puede concluir que los esfuerzos axiles para una estructura reentrante hexagonal metálica rígida para una apertura de $63^{\circ}$ y diversas cargas horizontales y verticales, aumentan con la carga, siendo mayores cuanto mayor sea dicha carga. Las barras son afectadas tanto por cargas verticales como horizontales, generando estas cargas sentidos opuestos de esfuerzo, asignando a cada barra esfuerzos de tracción o compresión en función de la carga que más la influencie. 
Gráfica comparativa de esfuerzos cortantes para la estructura reentrante hexagonal metálica rígida para una apertura de $63^{\circ}$ y diversas combinaciones de carga:

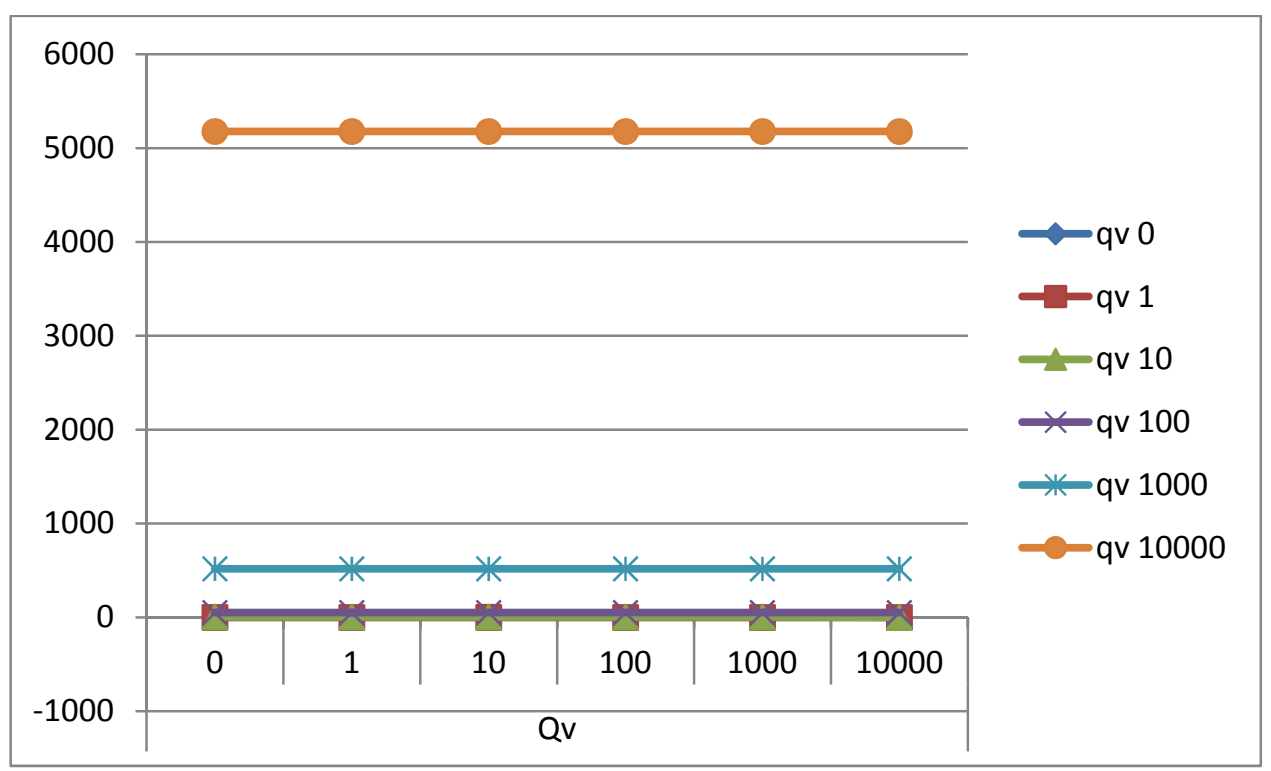

Gráfica 60 Comparación de esfuerzos cortantes mínimos (KN, eje y) en la barra a para la estructura reentrante hexagonal metálica rígida para una apertura de $63^{\circ}$ y diversas combinaciones de carga (KN, eje $x$ y leyenda), elaboración propia

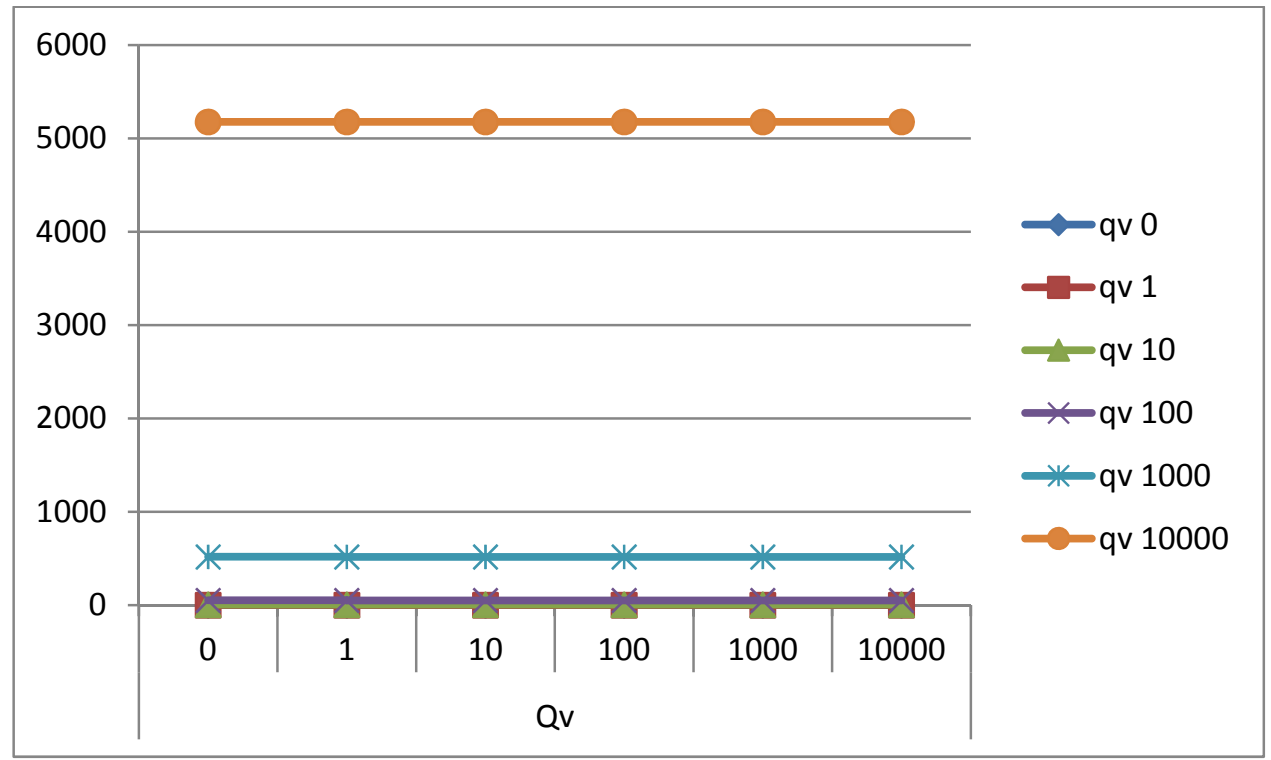

Gráfica 61 Comparación de esfuerzos cortantes máximos (KN, eje y) en la barra a para la estructura reentrante hexagonal metálica rígida para una apertura de $63^{\circ}$ y diversas combinaciones de carga (KN, eje $x$ y leyenda), elaboración propia 
Aplicaciones de las propiedades auxéticas en la arquitectura

CÁLCULO ESTRUCTURAL DE ESTRUCTURAS AUXÉTICAS

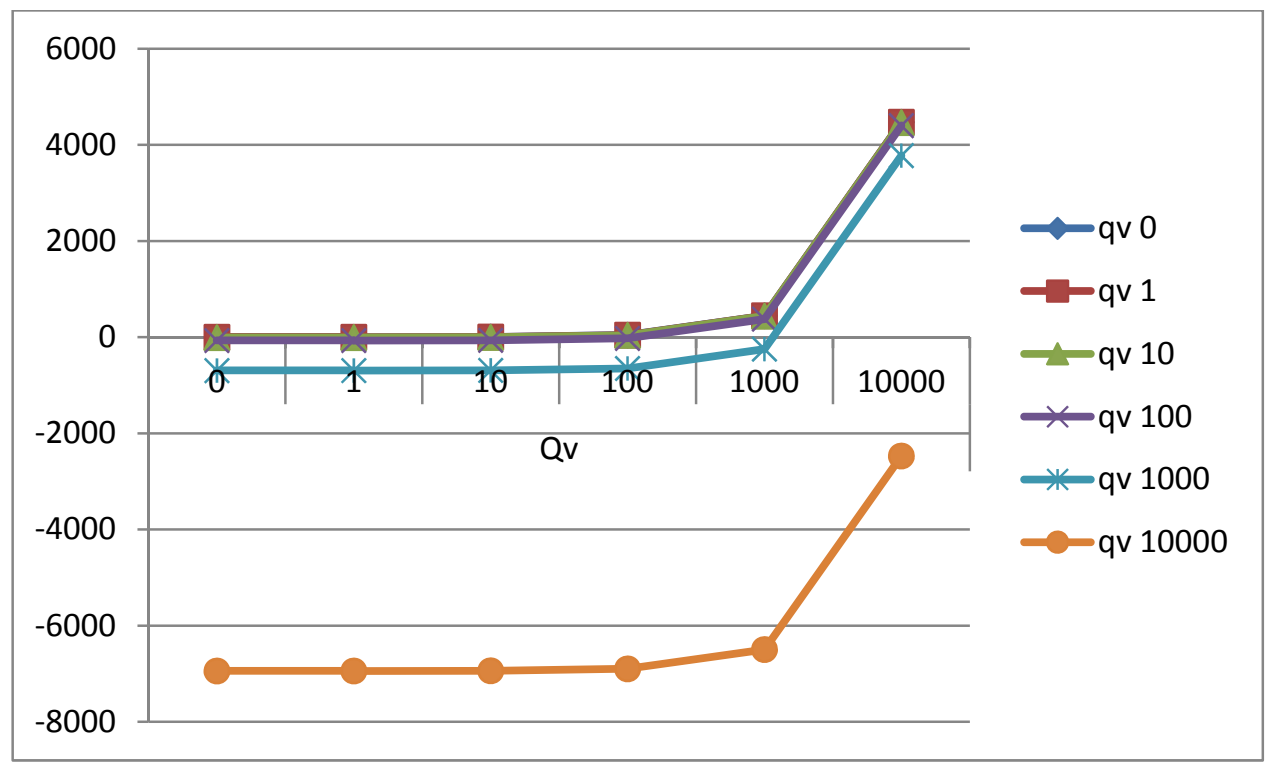

Gráfica 62 Comparación de esfuerzos cortantes mínimos ( $K N$, eje y) en la barra b para la estructura reentrante hexagonal metálica rígida para una apertura de $63^{\circ}$ y diversas combinaciones de carga (KN, eje $x$ y leyenda), elaboración propia

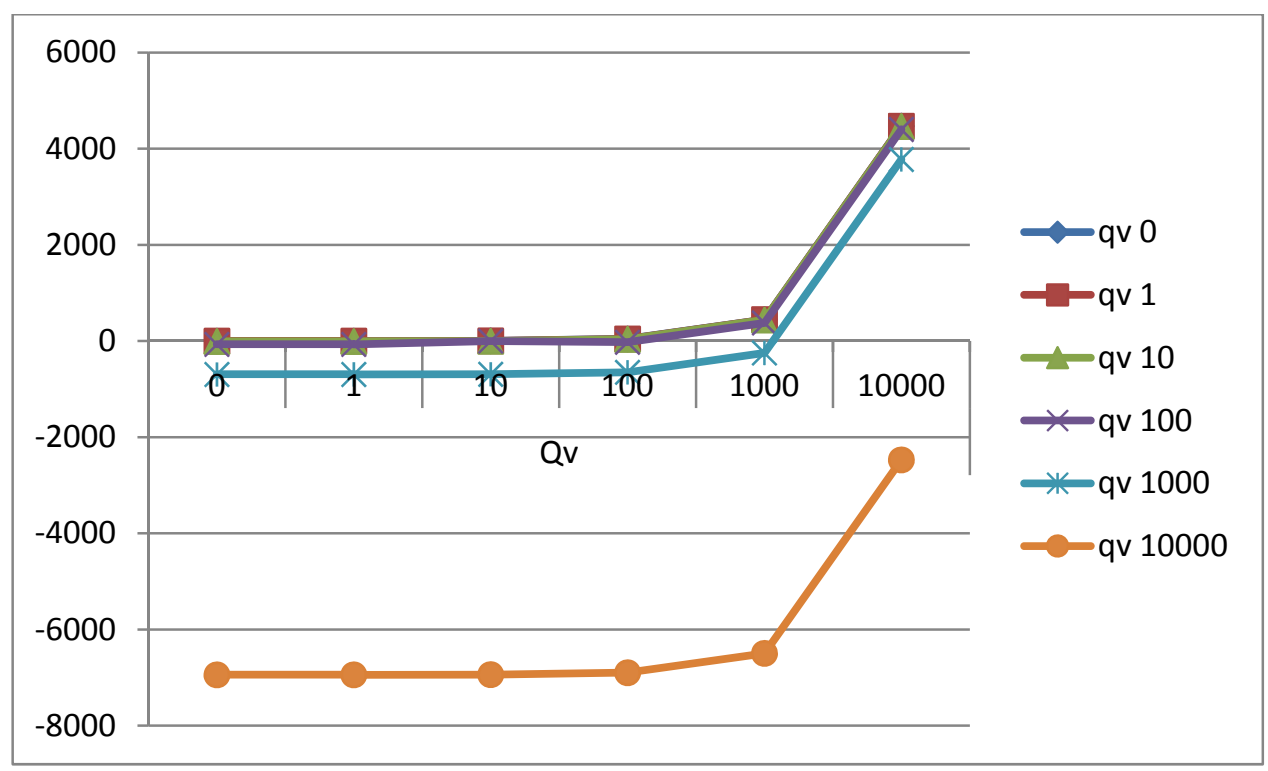

Gráfica 63 Comparación de esfuerzos cortantes máximos ( $K N$, eje y) en la barra a para la estructura reentrante hexagonal metálica rígida para una apertura de $63^{\circ}$ y diversas combinaciones de carga (KN, eje $x$ y leyenda), elaboración propia 


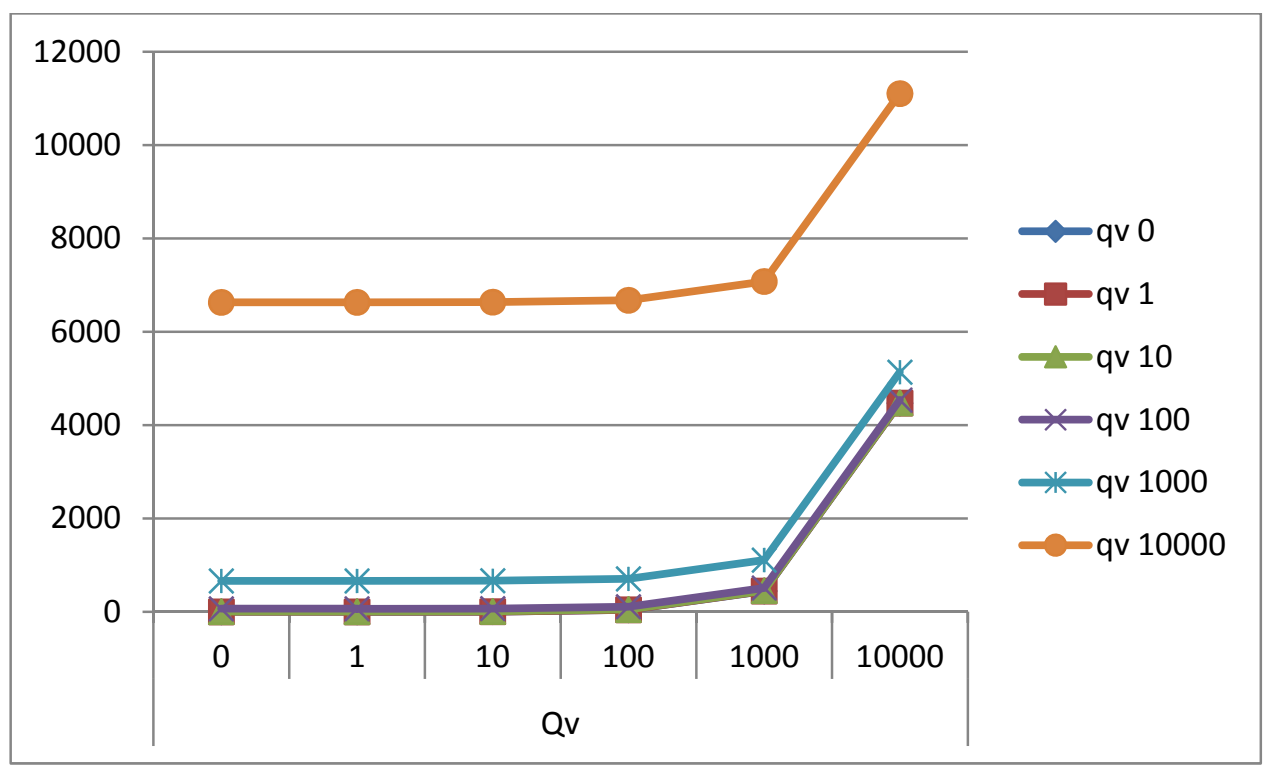

Gráfica 64 Comparación de esfuerzos cortantes mínimos (KN, eje y) en la barra c para la estructura reentrante hexagonal metálica rígida para una apertura de $63^{\circ}$ y diversas combinaciones de carga (KN, eje $x$ y leyenda), elaboración propia

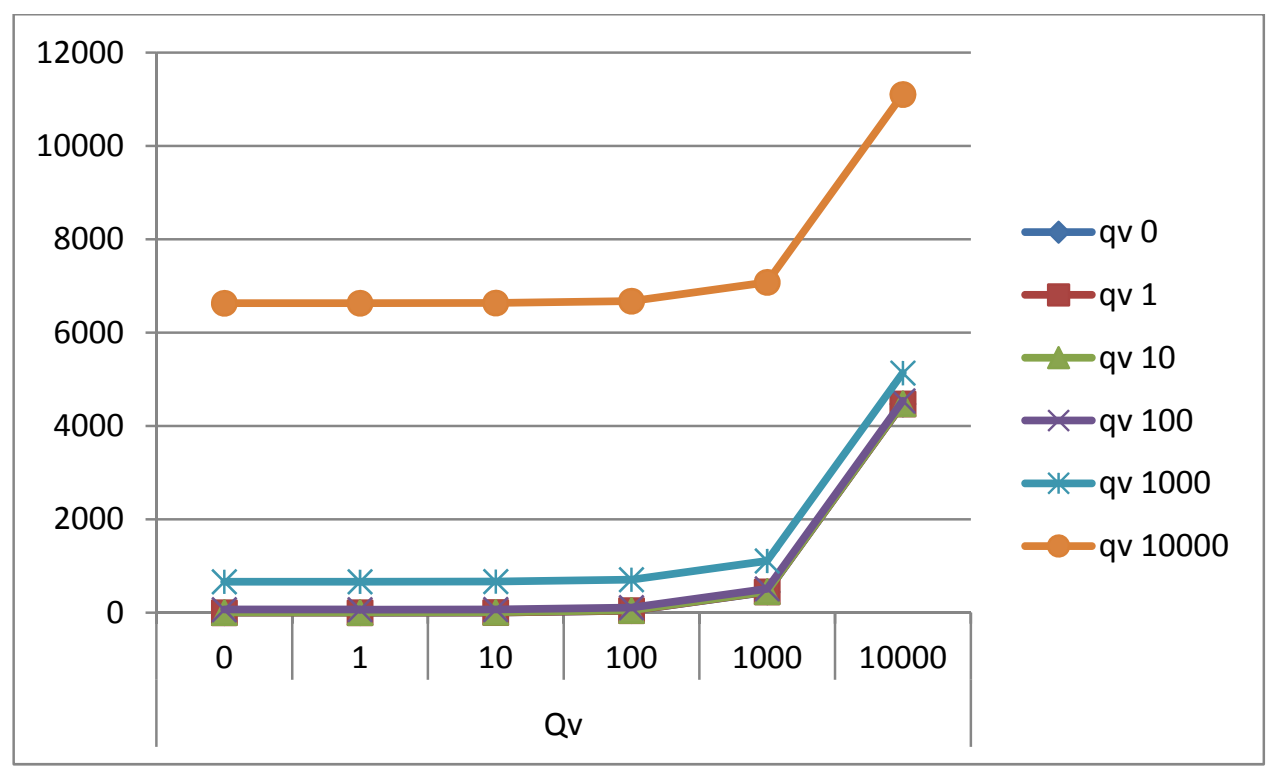

Gráfica 65 Comparación de esfuerzos cortantes máximos ( $K N$, eje y) en la barra c para la estructura reentrante hexagonal metálica rígida para una apertura de $63^{\circ}$ y diversas combinaciones de carga (KN, eje $x$ y leyenda), elaboración propia 
Aplicaciones de las propiedades auxéticas en la arquitectura

CÁLCULO ESTRUCTURAL DE ESTRUCTURAS AUXÉTICAS

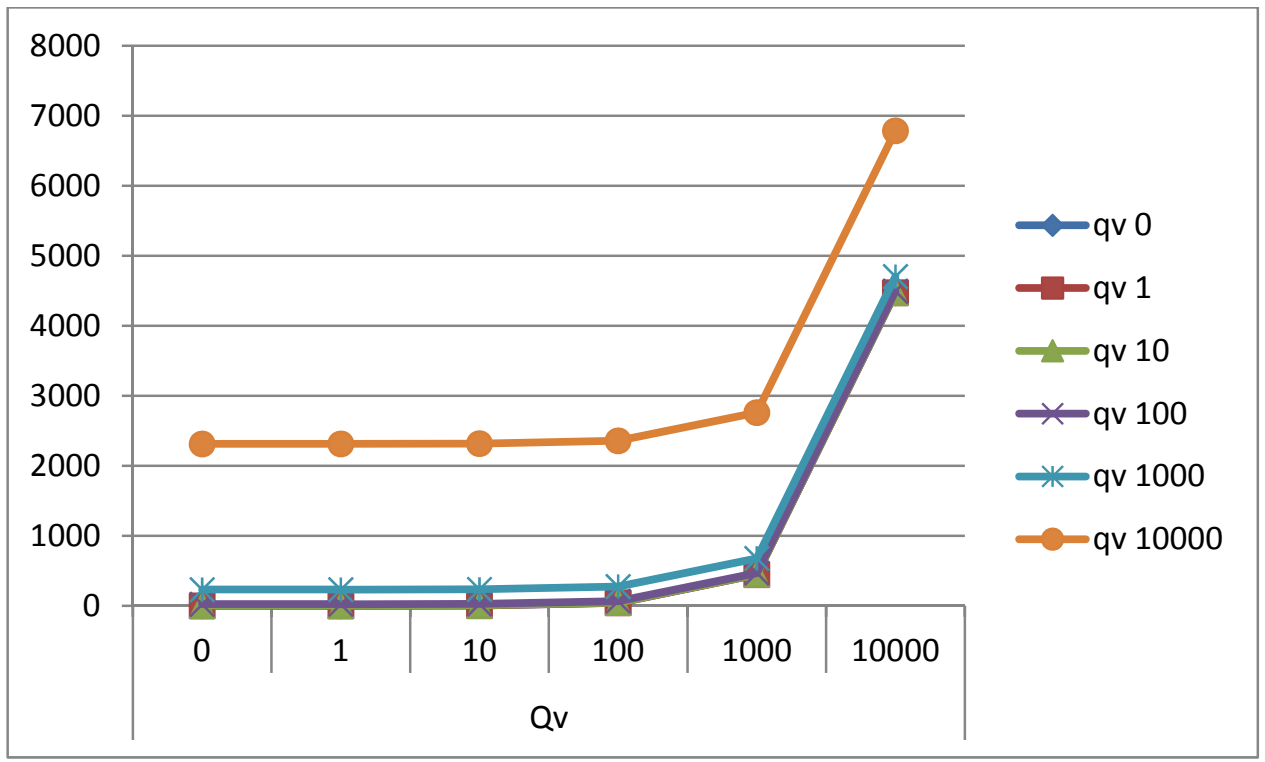

Gráfica 66 Comparación de esfuerzos cortantes mínimos ( $K N$, eje y) en la barra d para la estructura reentrante hexagonal metálica rígida para una apertura de $63^{\circ}$ y diversas combinaciones de carga (KN, eje $x$ y leyenda), elaboración propia

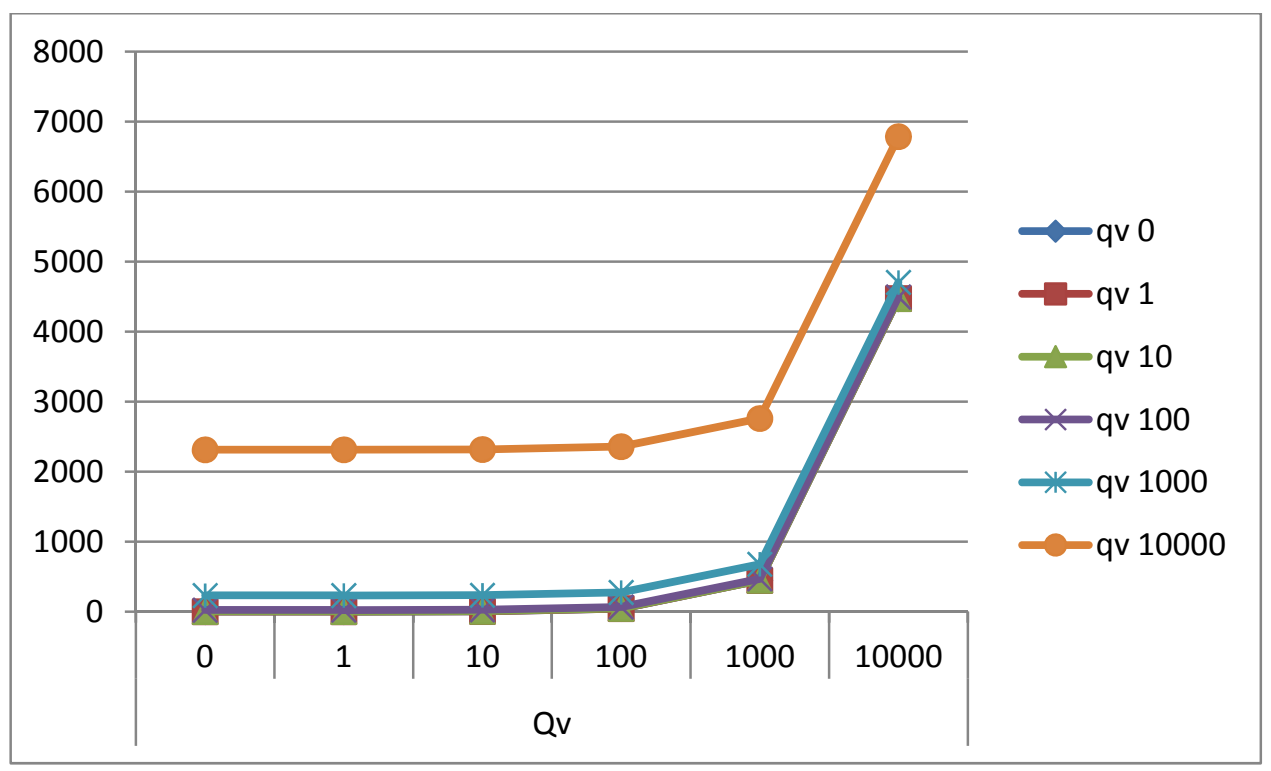

Gráfica 67 Comparación de esfuerzos cortantes máximos ( $K N$, eje y) en la barra d para la estructura reentrante hexagonal metálica rígida para una apertura de $63^{\circ}$ y diversas combinaciones de carga (KN, eje $x$ y leyenda), elaboración propia 


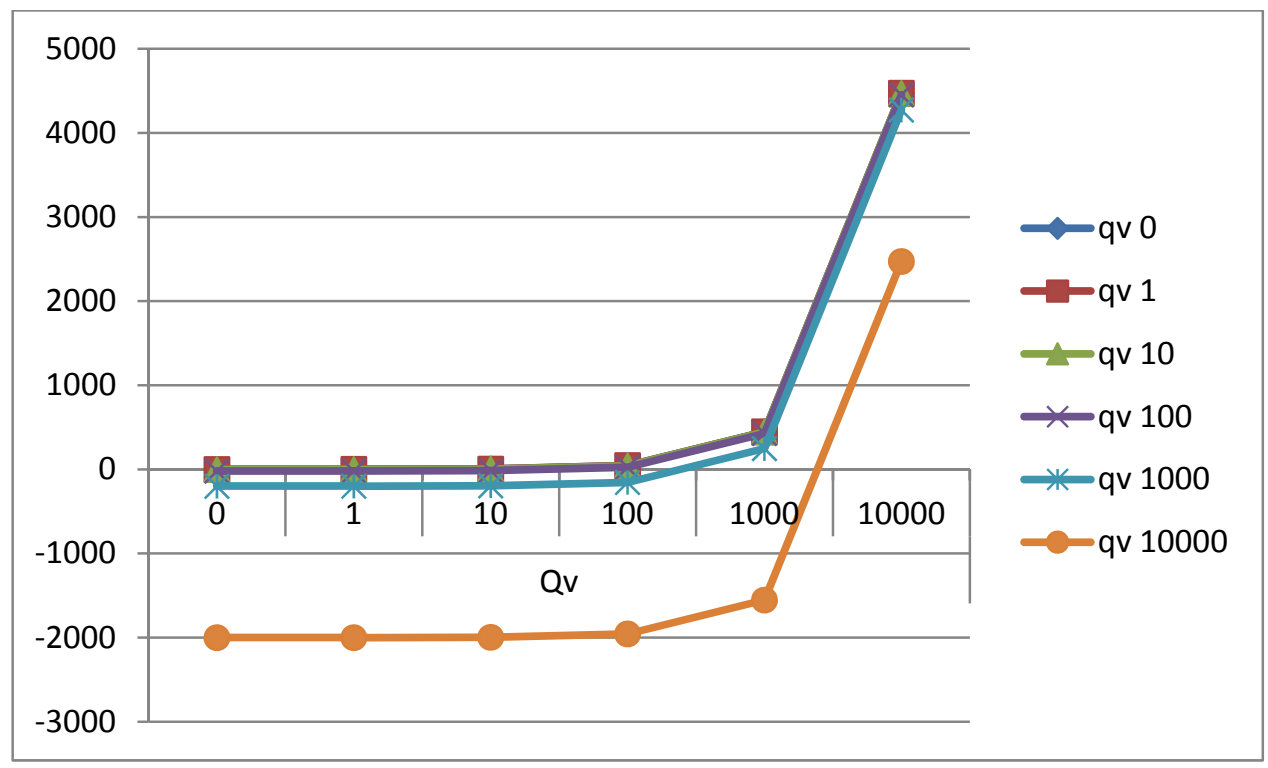

Gráfica 68 Comparación de esfuerzos cortantes mínimos ( $K N$, eje y) en la barra e para la estructura reentrante hexagonal metálica rígida para una apertura de $63^{\circ}$ y diversas combinaciones de carga (KN, eje $x$ y leyenda), elaboración propia

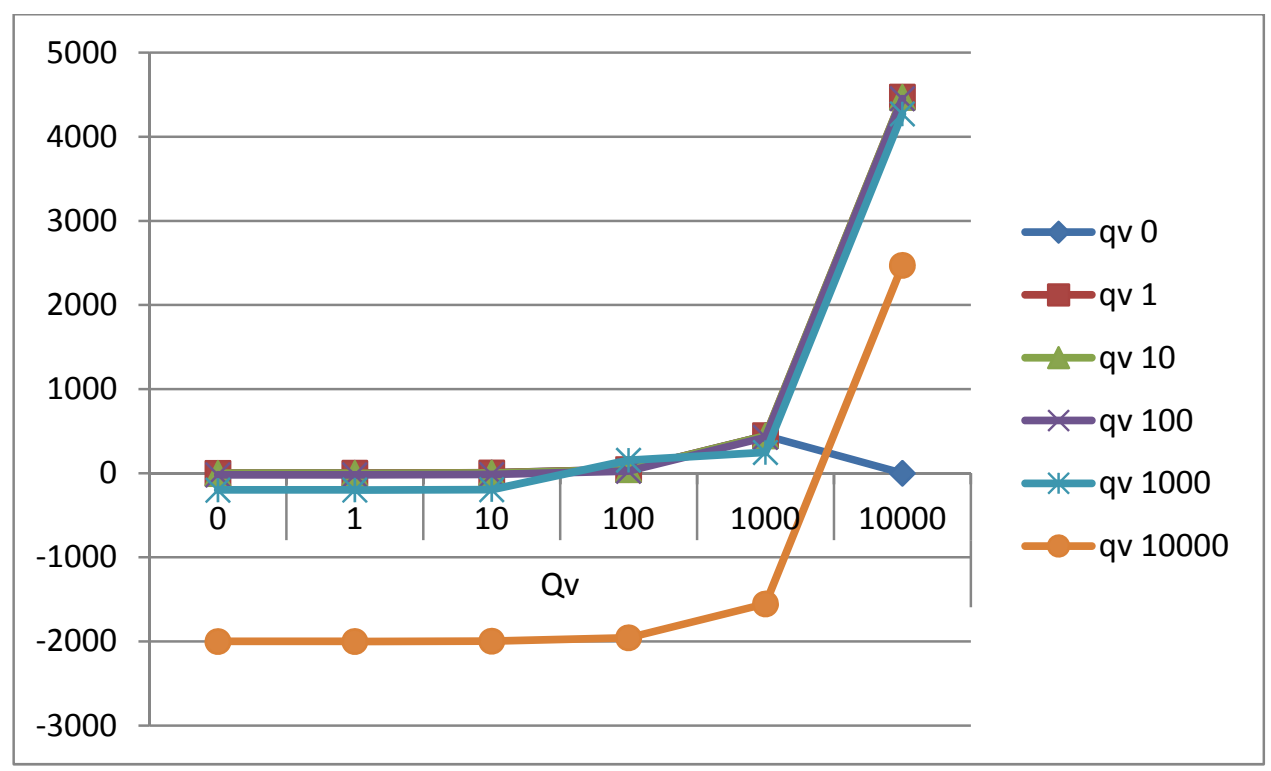

Gráfica 69 Comparación de esfuerzos cortantes máximos ( $K N$, eje y) en la barra e para la estructura reentrante hexagonal metálica rígida para una apertura de $63^{\circ}$ y diversas combinaciones de carga (KN, eje $x$ y leyenda), elaboración propia 


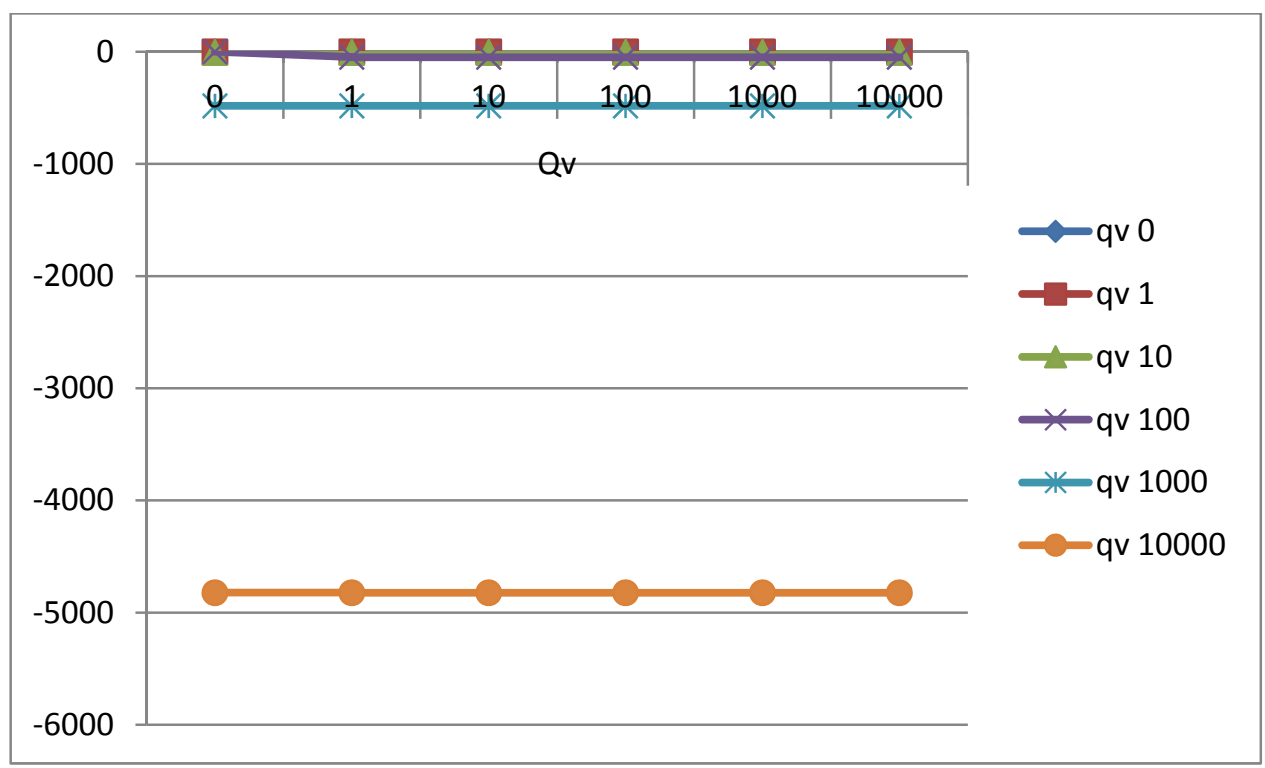

Gráfica 70 Comparación de esfuerzos cortantes mínimos ( $K N$, eje y) en la barra f para la estructura reentrante hexagonal metálica rígida para una apertura de $63^{\circ}$ y diversas combinaciones de carga (KN, eje $x$ y leyenda), elaboración propia

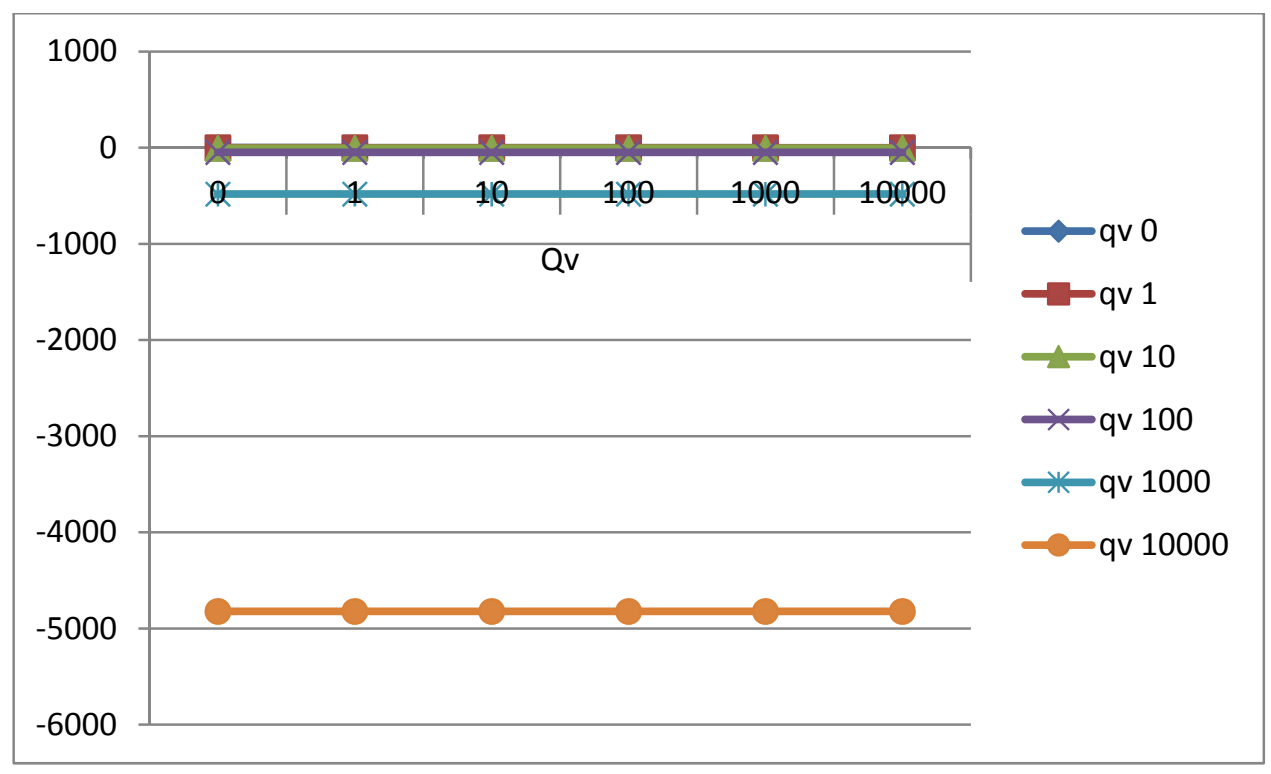

Gráfica 71 Comparación de esfuerzos cortantes máximos (KN, eje y) en la barra f para la estructura reentrante hexagonal metálica rígida para una apertura de $63^{\circ}$ y diversas combinaciones de carga (KN, eje $x$ y leyenda), elaboración propia 
Como puede observarse en las gráficas anteriores, correspondientes a la la tabla 41 , esfuerzos cortantes en estructura reentrante hexagonal metálica rígida para una apertura de $63^{\circ}$ y diversas cargas horizontales y verticales, del Apéndice 2. Tablas de cálculo estructural, se observan unos esfuerzos cortantes con comportamientos muy diversos dependiendo de las diferentes combinaciones de cargas verticales y cargas horizontales.

En la barra a, las cargas horizontales afectan al esfuerzo cortante, mientras que las verticales no. Esto se observa en que dicho esfuerzo aumenta progresivamente con las cargas horizontales, estando para cargas horizontales nulas de -0,164 a 0,164, y llegando a 5177,156 a 5177,485 con la carga máxima horizontal de 10000. Estas cifras se mantienen a pesar de añadir cargas verticales.

En la barra b, cada una de las cargas influye en el esfuerzo en direcciones diferentes. Para cargas nulas, el esfuerzo es de 0,137 a 0,219. Esta dirección se mantiene y aumenta con el aumento de la carga vertical y la carga horizontal nula. Sin embargo, cuando la carga horizontal es de 1 y la vertical es 0 el esfuerzo es de -0,557 a -0,475, cifra que disminuye cuando ambas cargas están en 1. A medida que las cargas horizontales aumentan, la dirección irá cambiando y aumentando progresivamente. Finalmente, cuando ambas cargas llegan a su máximo de 10000, el esfuerzo es de -2471,523 a -2471,441, por lo que la carga horizontal afecta más al esfuerzo que la vertical.

En la barra c, las cargas horizontales y verticales afectan al esfuerzo por igual, sin embargo, en cargas bajas el aumento es más leve, pasando de 0,137 a 0,219 cuando la carga es nula; a 1,247 a 1,329 cuando ambas cargas son de 1 . A partir de las cargas de 10, las cifras de esfuerzo aumentan considerablemente, pues se pasa de 0,8 a 0,882 cuando Qh=1 y $\mathrm{Qv}=0$, a 6,768 a 6,85 cuando $\mathrm{Qh}=10$ y $\mathrm{Qv}=0$. La carga horizontal, por lo tanto, afecta sobre todo a partir de la carga 10. Por su parte, ocurre algo similar en las cargas verticales, pues se pasa de 1,247 a 1,329 cuando Qh=1 y Qv=1, a 5,272 a 5,354 cuando Qh=1 y $Q v=10$. A partir de 10, el aumento de las cargas llega a más del doble del valor anterior, aumentando considerablemente, llegando a valores de 11103,485 a 11103,567 cuando ambas cargas son iguales a 10000.

En la barra d, las cargas horizontales afectan al esfuerzo, llegando a máximas de 2313,152 a 2313,234 cuando Qh=10000 y Qv=0, pero la aplicación de las cargas verticales supone un aumento mucho mayor del esfuerzo, pasando de 2760,365 a 2760,447 a 6785,288 a 6785,37 con unas cargas vertical y horizontal máximas. 
En la barra e, las cargas horizontal y vertical generan un esfuerzo en direcciones distintas. Cuando la carga horizontal es nula, la carga vertical va aumentando de forma progresiva en una dirección. Sin embargo, cuando se añaden cargas horizontales, estas fuerzan un cambio de dirección progresivo a medida que dicha carga aumenta. El único caso en que la carga vertical afecta más al esfuerzo se da cuando ambas cargas están a 10000. En ese caso, el valor del esfuerzo es de 2471,752 a 2471,834 frente al esfuerzo de -1553,171a 1553,088 cuando Qh=10000 y Qv=1000, manteniendo la dirección original que la barra tiene cuando no hay cargas exteriores, de esfuerzo 0,092 a 0,174.

En la barra f, afectan más las cargas horizontales, que aumentan el esfuerzo de forma progresiva, produciéndose un aumento considerable en las cargas más altas, a partir de $\mathrm{Qh}=100$, donde vemos que se pasa de $-4,987$ a -4,659 a -48,391 a -48,063. Al pasar a 1000, el esfuerzo aumenta a -482,432 a -482,104; y en 10000, el esfuerzo llega a -4822,844 a 4822,515 . Estos valores se mantienen aun cuando se contraponen a cargas verticales, por lo que estas últimas no le afectan.

De este modo, se puede concluir que los esfuerzos cortantes para una estructura reentrante hexagonal metálica rígida para una apertura de $63^{\circ}$ y diversas cargas horizontales y verticales, aumentan con la carga, siendo mayores cuanto mayor sea dicha carga. Las barras son afectadas tanto por cargas verticales como horizontales, generando estas cargas, en algunas ocasiones, sentidos opuestos de esfuerzo y, en otras ocasiones, afectando únicamente al esfuerzo en las barras el aumento de la carga horizontal. 
Momentos en estructura reentrante hexagonal metálica rígida para una apertura de $63^{\circ} \mathrm{y}$ diversas cargas horizontales y verticales

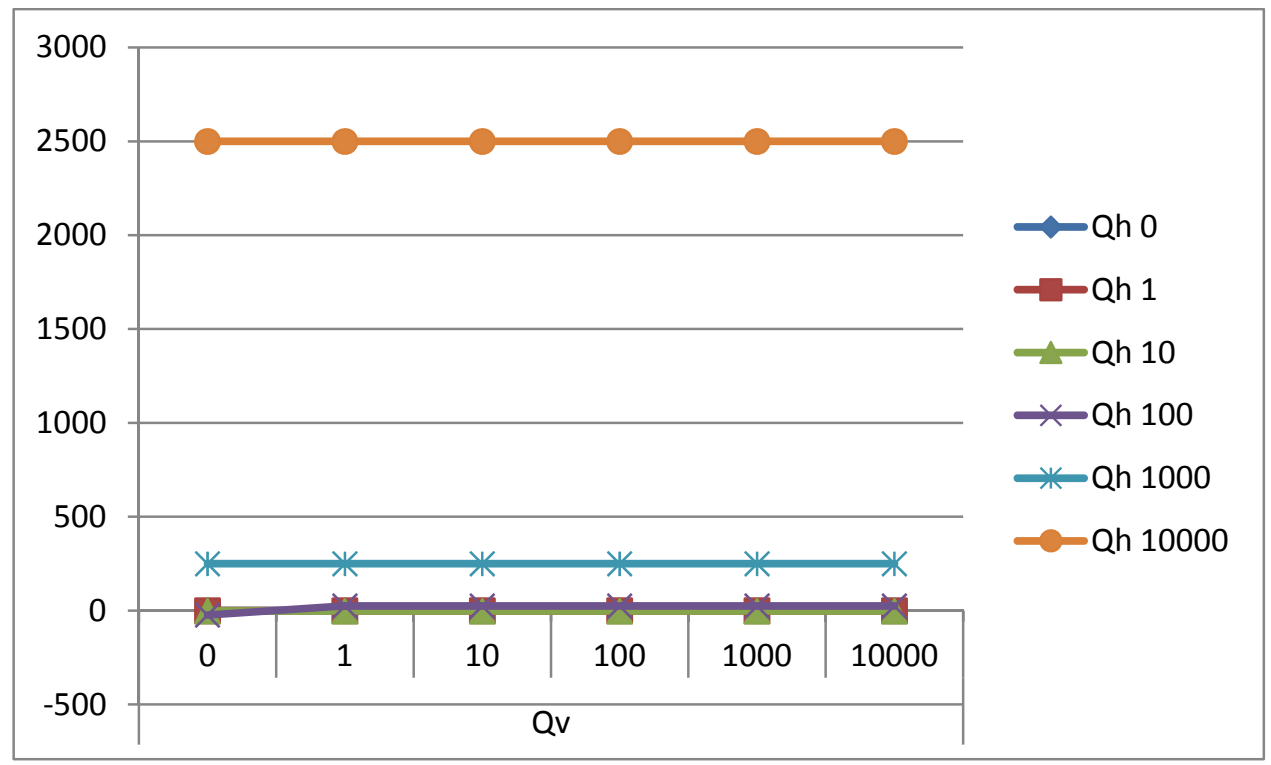

Gráfica 72 Comparación de momentos mínimos en la barra a $(K N \cdot m$, eje y) de la estructura reentrante hexagonal metálica rígida para una apertura de $63^{\circ}$ y diversas cargas horizontales y verticales (KN, eje $x$ y leyenda), elaboración propia

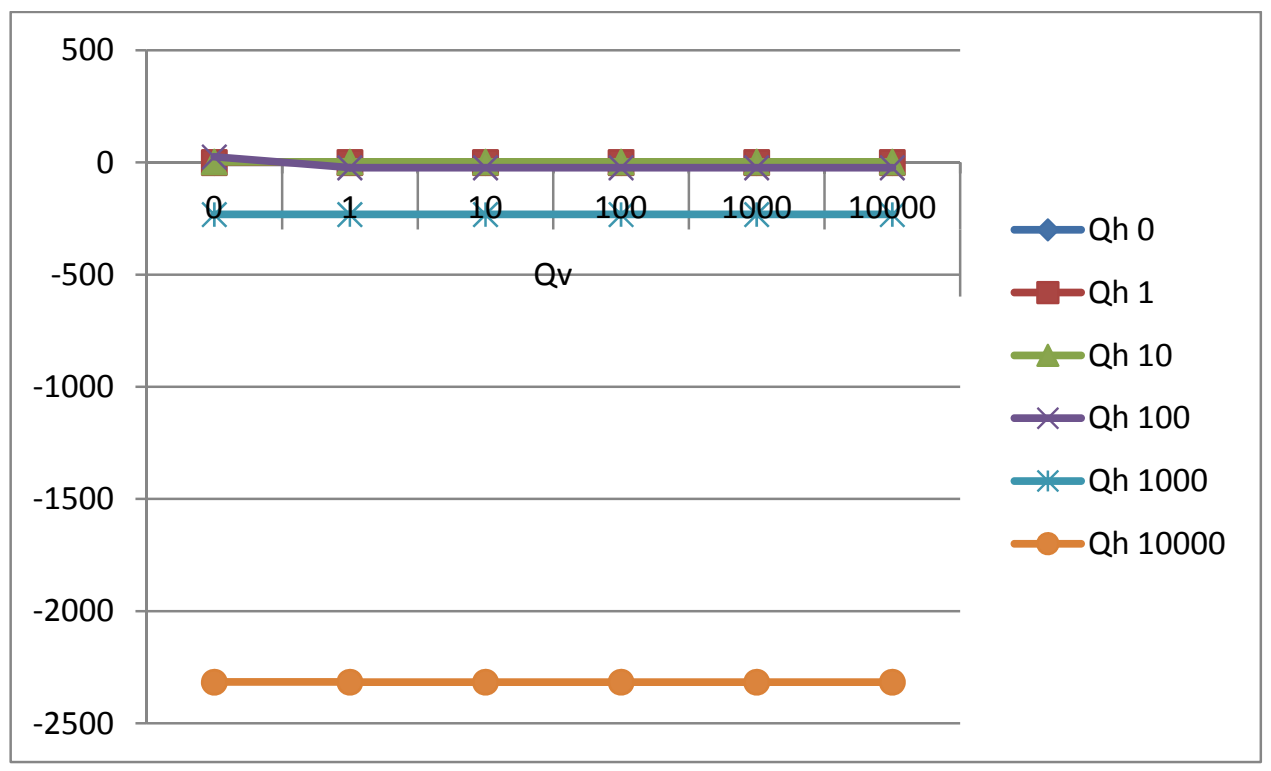

Gráfica 73 Comparación de momentos máximos en la barra a $(K N \cdot m$, eje y) de la estructura reentrante hexagonal metálica rígida para una apertura de $63^{\circ}$ y diversas cargas horizontales y verticales (KN, eje $x$ y leyenda), elaboración propia 
Aplicaciones de las propiedades auxéticas en la arquitectura

CÁLCULO ESTRUCTURAL DE ESTRUCTURAS AUXÉTICAS

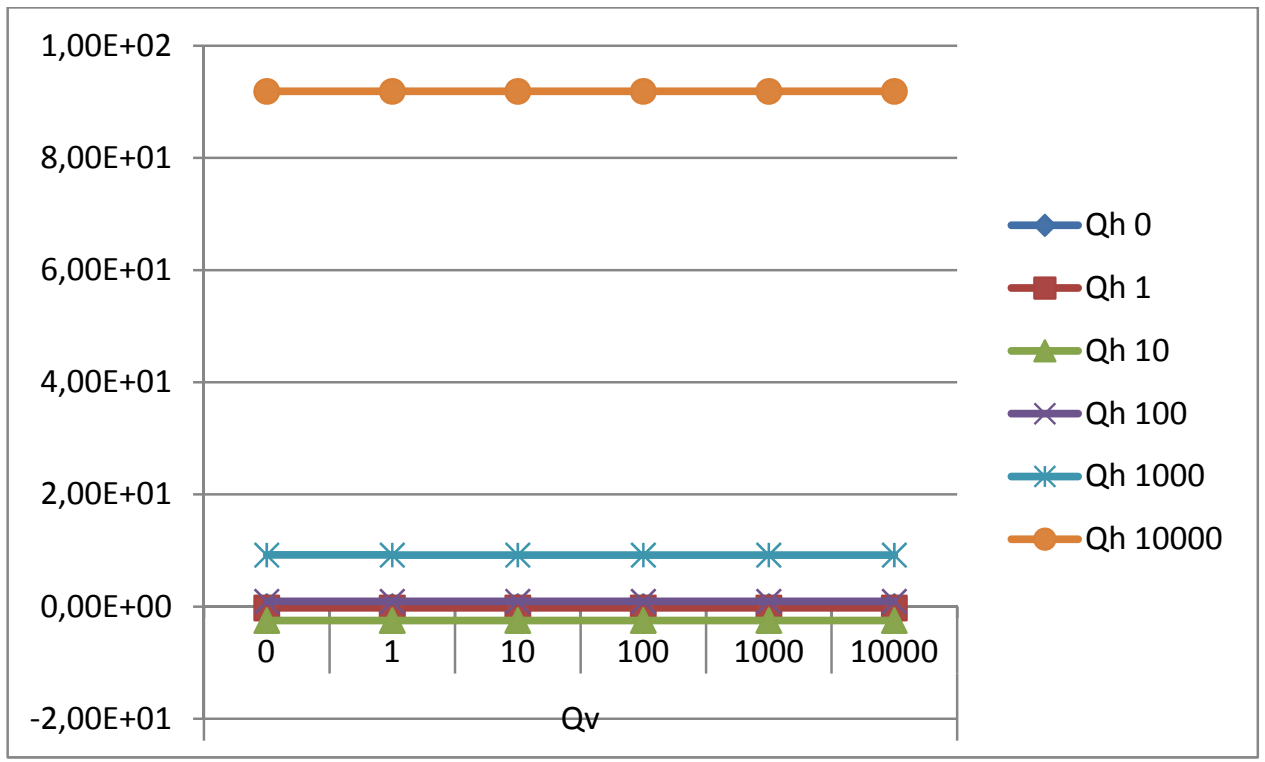

Gráfica 74 Comparación de momentos mínimos en la barra b $(K N \cdot m$, eje y) de la estructura reentrante hexagonal metálica rígida para una apertura de $63^{\circ}$ y diversas cargas horizontales y verticales (KN, eje $x$ y leyenda), elaboración propia

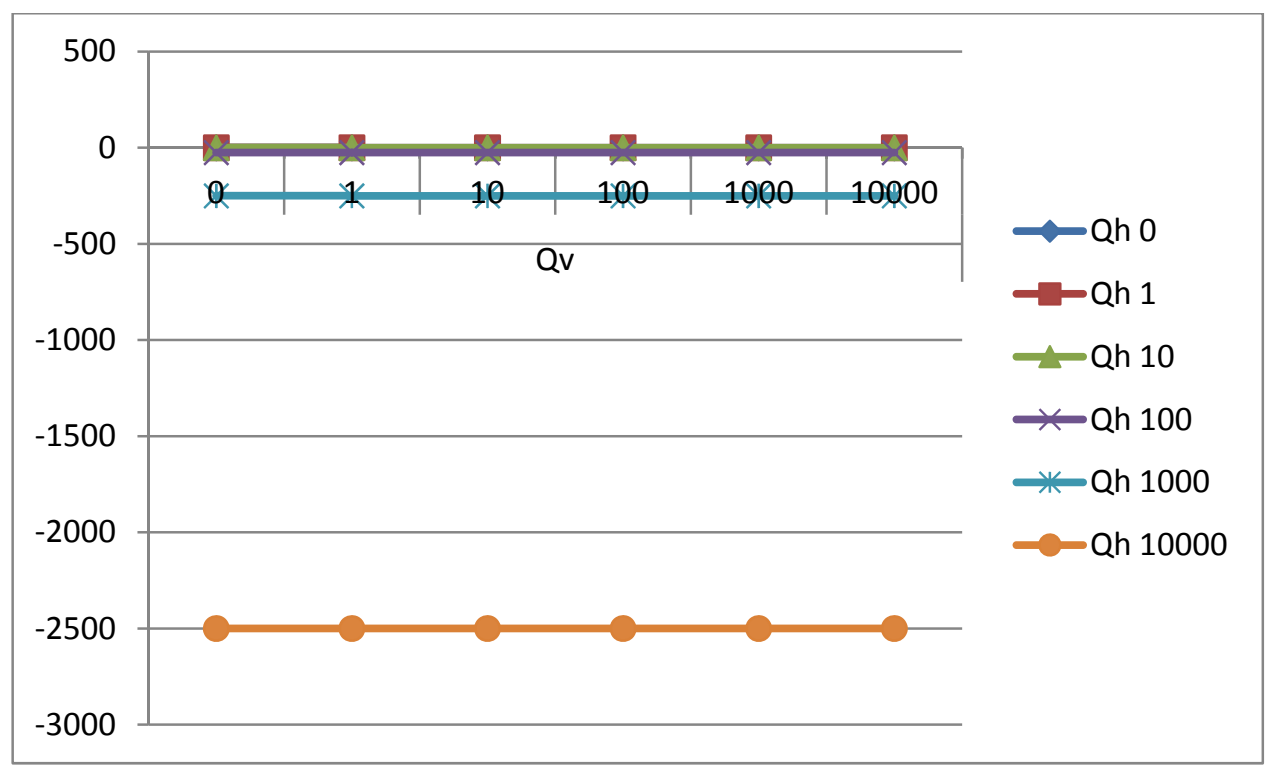

Gráfica 75 Comparación de momentos máximos en la barra b $(K N \cdot m$, eje y) de la estructura reentrante hexagonal metálica rígida para una apertura de $63^{\circ}$ y diversas cargas horizontales y verticales (KN, eje $x$ y leyenda), elaboración propia 


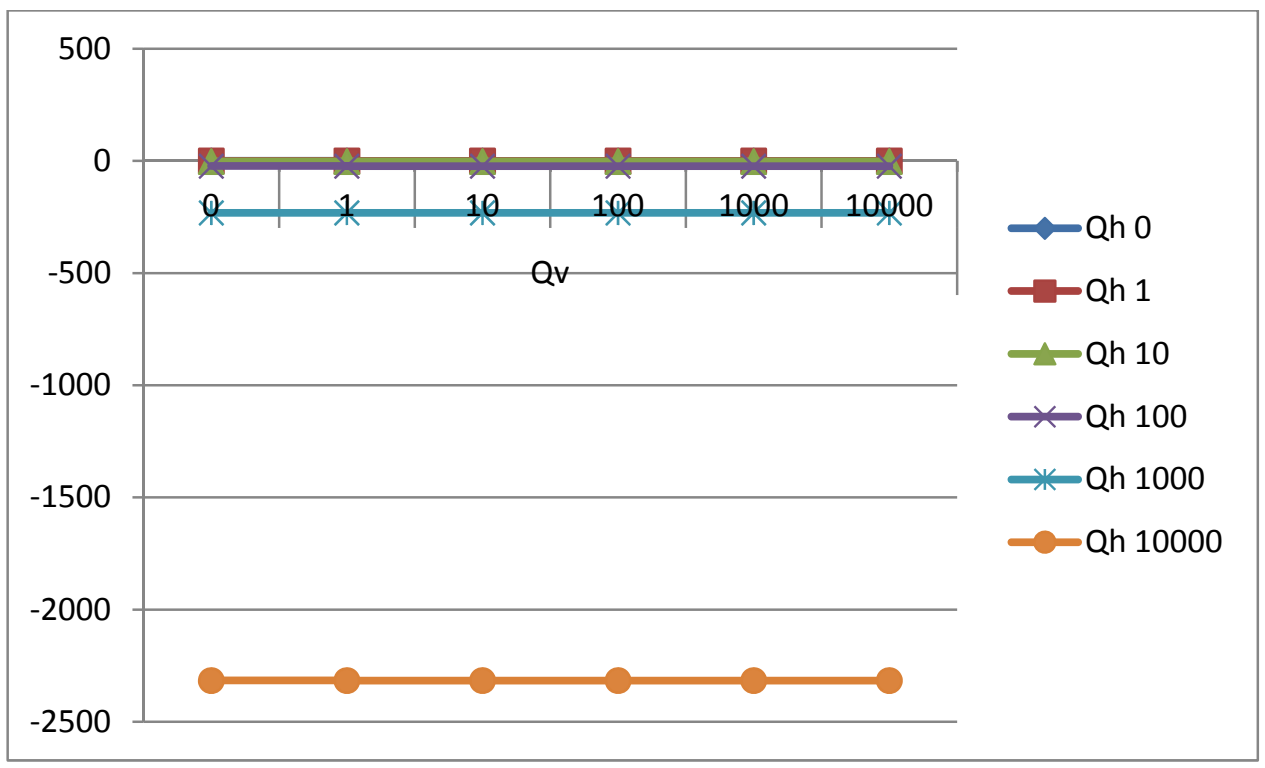

Gráfica 76 Comparación de momentos mínimos en la barra c $(K N \cdot m$, eje y) de la estructura reentrante hexagonal metálica rígida para una apertura de $63^{\circ}$ y diversas cargas horizontales y verticales (KN, eje $x$ y leyenda), elaboración propia

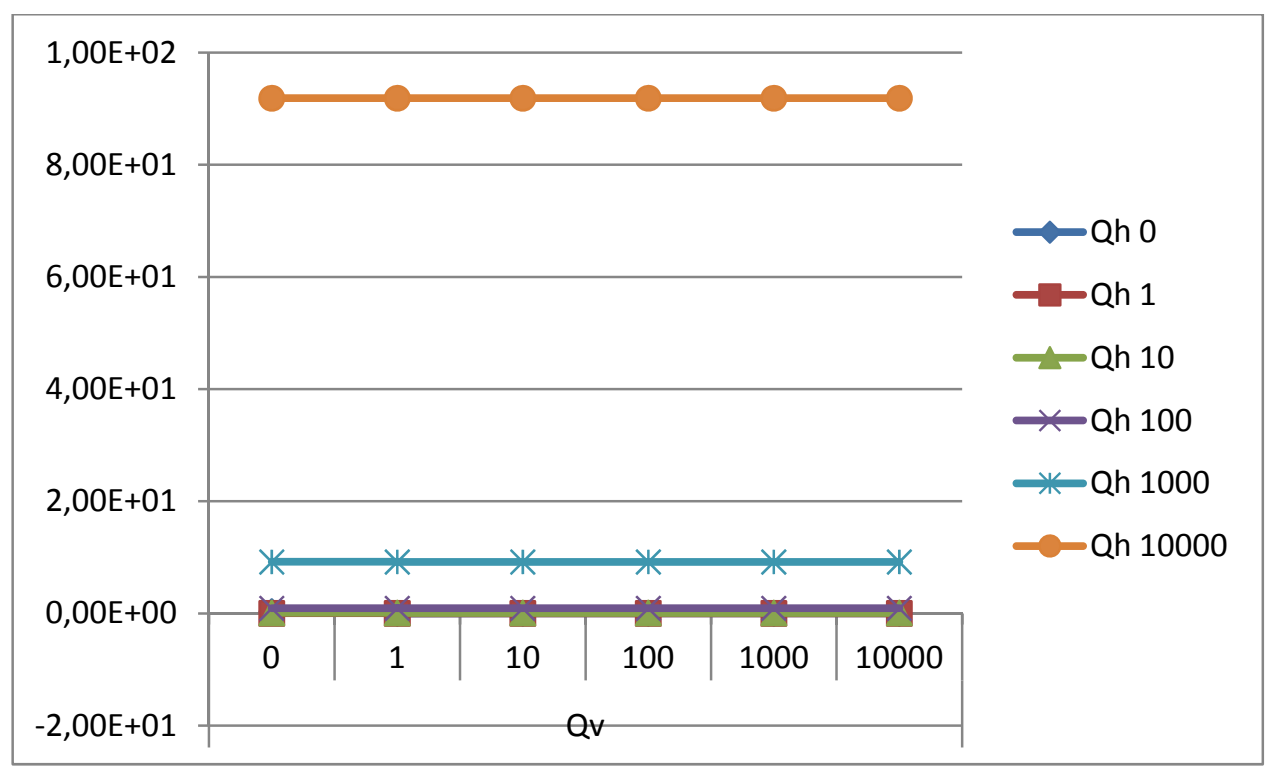

Gráfica 77 Comparación de momentos máximos en la barra c (KN·m, eje y) de la estructura reentrante hexagonal metálica rígida para una apertura de $63^{\circ}$ y diversas cargas horizontales y verticales (KN, eje $x$ y leyenda), elaboración propia 
Aplicaciones de las propiedades auxéticas en la arquitectura

CÁLCULO ESTRUCTURAL DE ESTRUCTURAS AUXÉTICAS

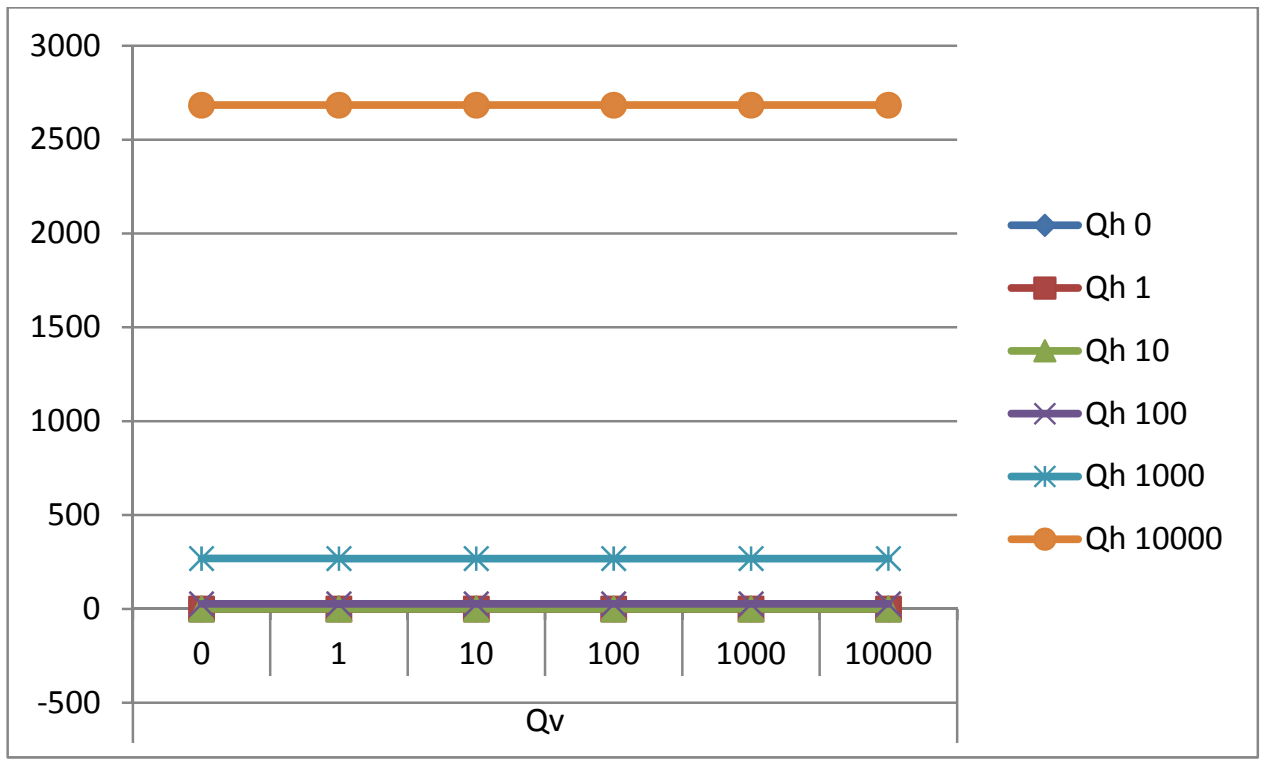

Gráfica 78 Comparación de momentos mínimos en la barra d $(K N \cdot m$, eje y) de la estructura reentrante hexagonal metálica rígida para una apertura de $63^{\circ}$ y diversas cargas horizontales y verticales (KN, eje $x$ y leyenda), elaboración propia

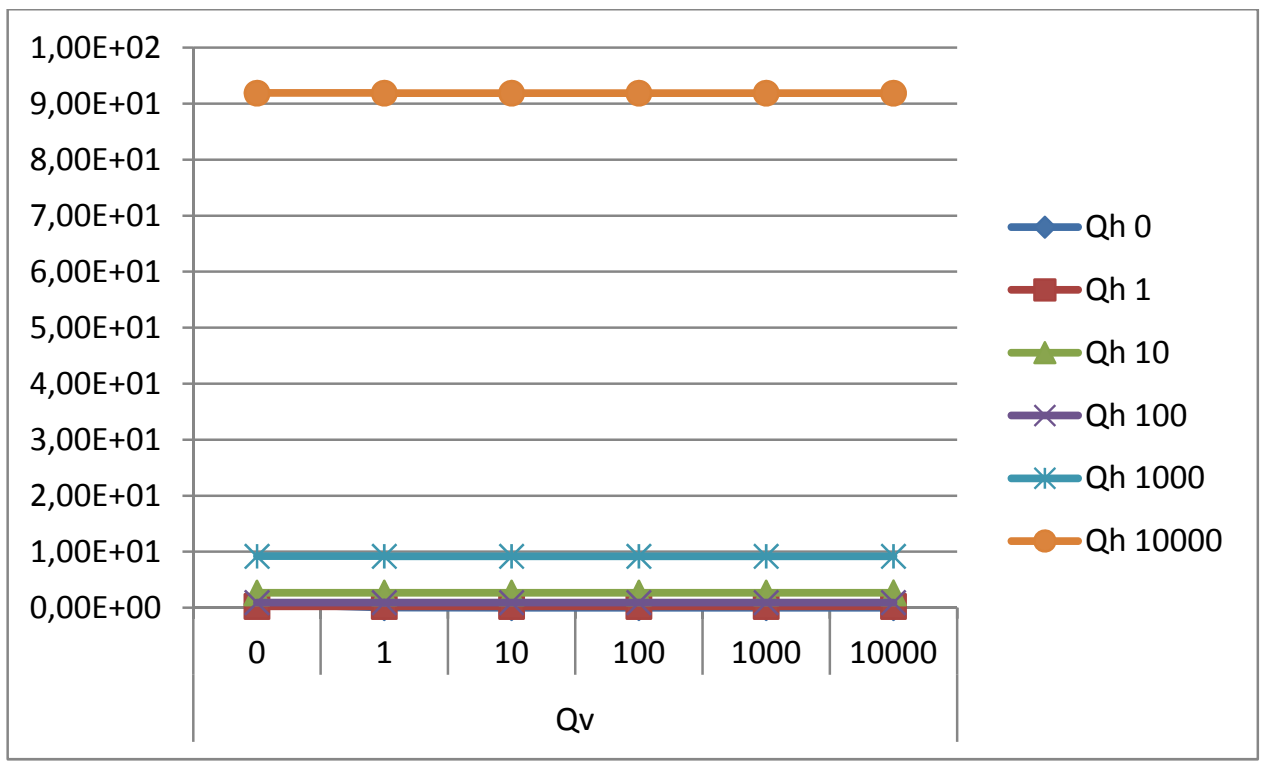

Gráfica 79 Comparación de momentos máximos en la barra $d(K N \cdot m$, eje y) de la estructura reentrante hexagonal metálica rígida para una apertura de $63^{\circ}$ y diversas cargas horizontales y verticales (KN, eje $x$ y leyenda), elaboración propia 


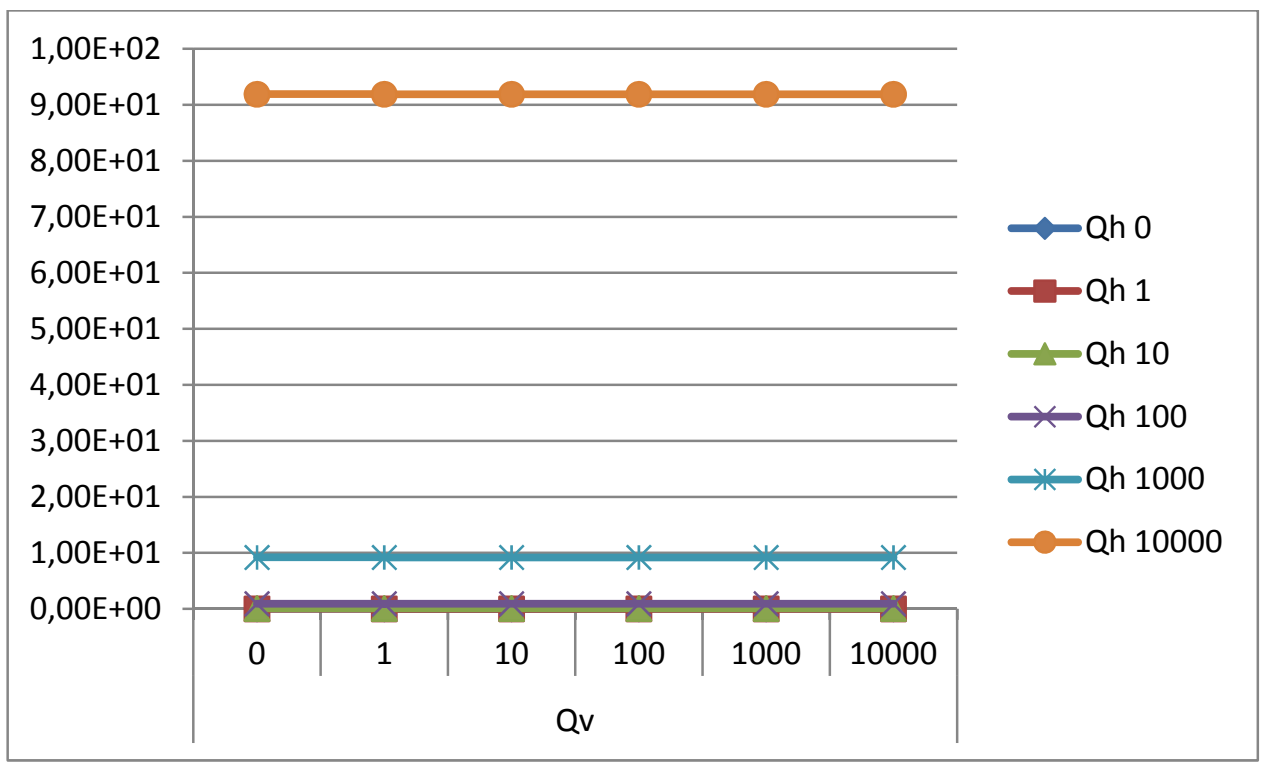

Gráfica 80 Comparación de momentos mínimos en la barra e $(K N \cdot m$, eje y) de la estructura reentrante hexagonal metálica rígida para una apertura de $63^{\circ}$ y diversas cargas horizontales y verticales (KN, eje $x$ y leyenda), elaboración propia

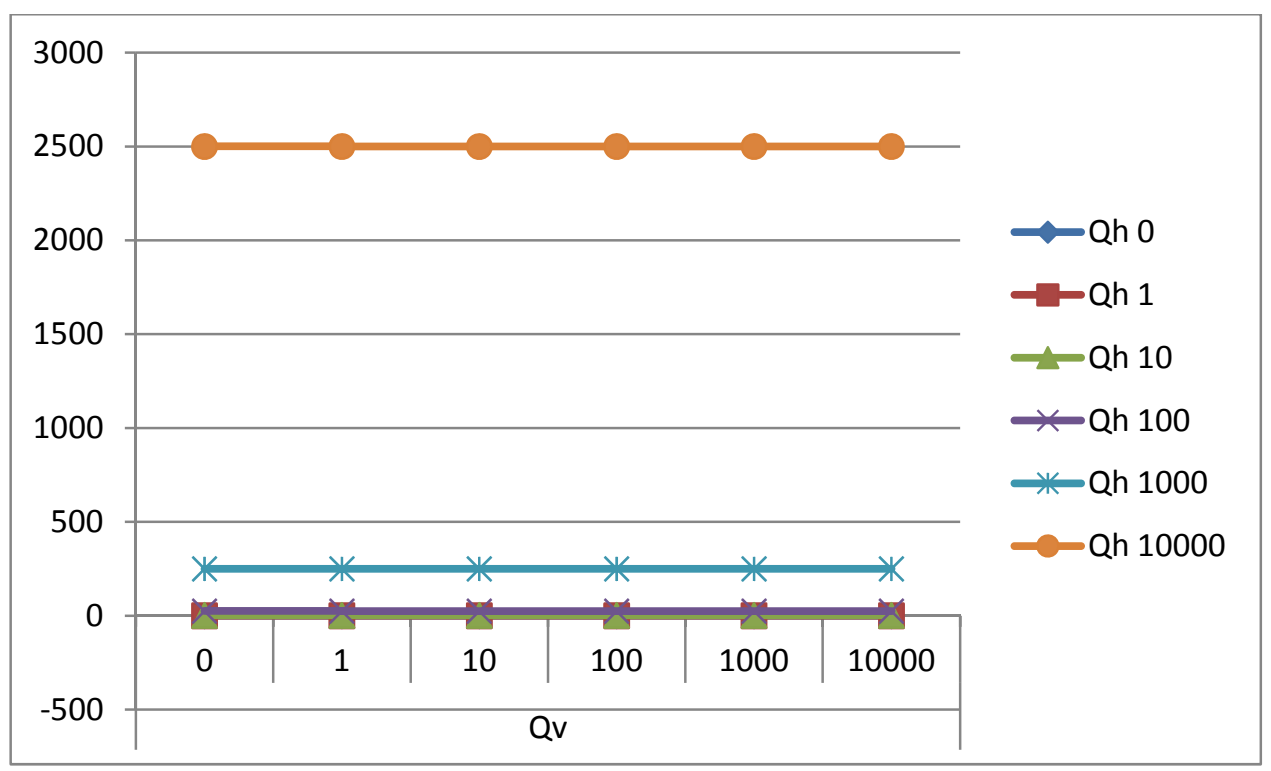

Gráfica 81 Comparación de momentos máximos en la barra e $(K N \cdot m$, eje y) de la estructura reentrante hexagonal metálica rígida para una apertura de $63^{\circ}$ y diversas cargas horizontales y verticales (KN, eje $x$ y leyenda), elaboración propia 


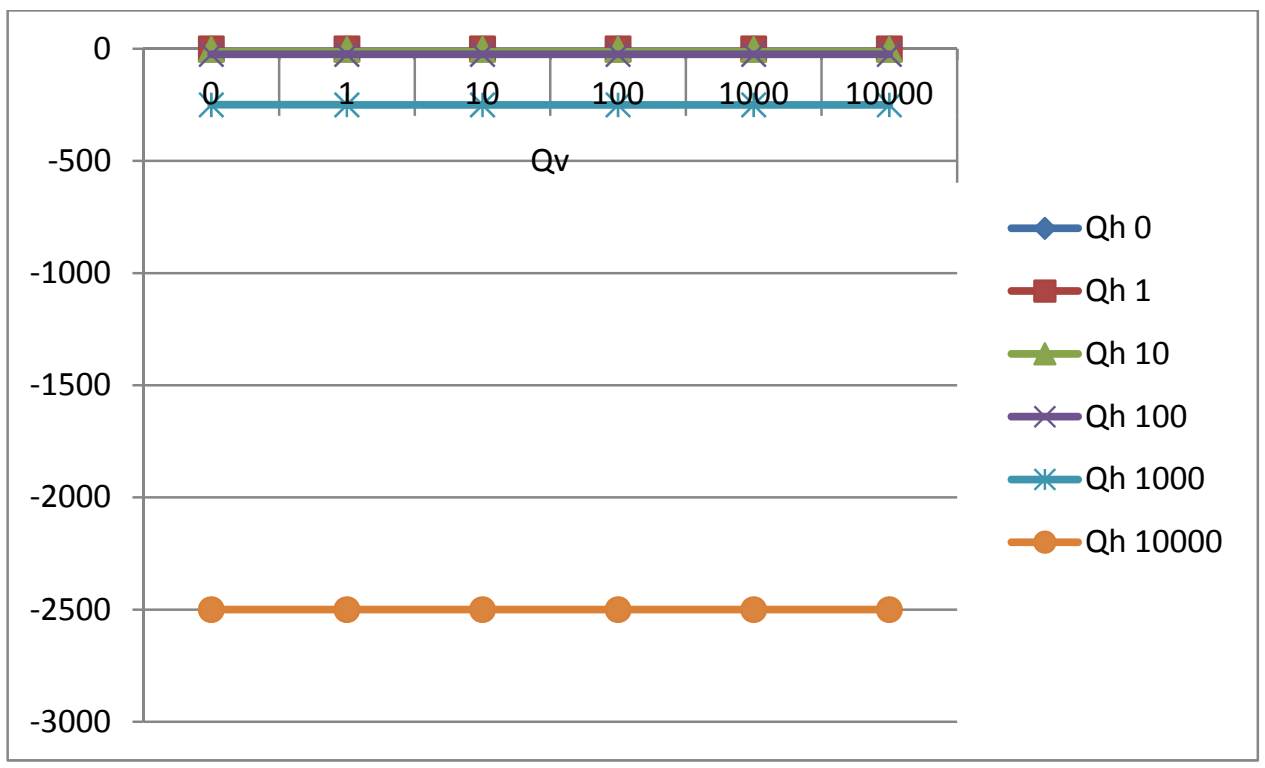

Gráfica 82 Comparación de momentos mínimos en la barra $f(K N \cdot m$, eje y) de la estructura reentrante hexagonal metálica rígida para una apertura de $63^{\circ}$ y diversas cargas horizontales y verticales (KN, eje $x$ y leyenda), elaboración propia

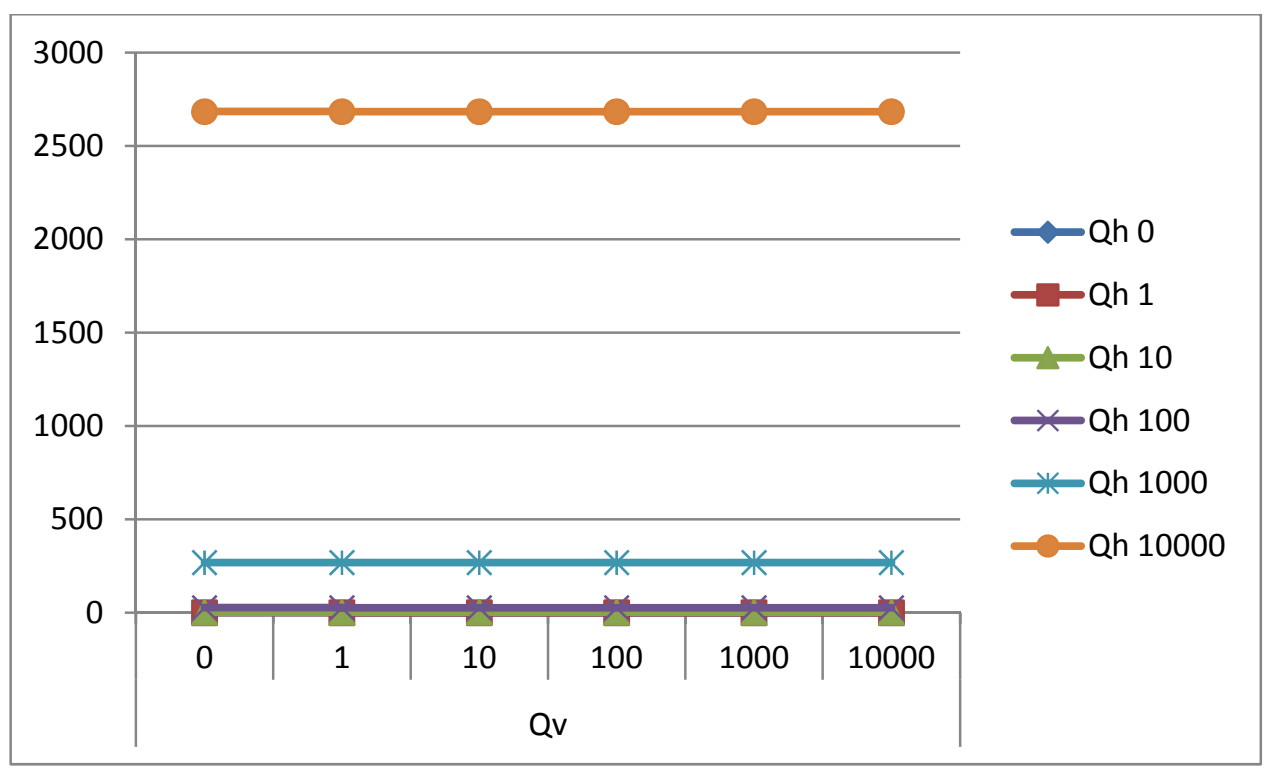

Gráfica 83 Comparación de momentos máximos en la barra $f(K N \cdot m$, eje y) de la estructura reentrante hexagonal metálica rígida para una apertura de $63^{\circ}$ y diversas cargas horizontales y verticales (KN, eje $x$ y leyenda), elaboración propia 
Como puede observarse en las gráficas anteriores, correspondientes a la tabla 42, momentos en estructura reentrante hexagonal metálica rígida para una apertura de $63^{\circ}$ y diversas cargas horizontales y verticales, del Apéndice 2. Tablas de cálculo estructural, se observan unos momentos con comportamientos muy diversos dependiendo de las diferentes combinaciones de cargas verticales y cargas horizontales.

En la barra a, las cargas verticales son las que más afectan al esfuerzo. Este aumenta de forma progresiva a medida que las cargas crecen, pasando de -6,6338 a -6,5928 cuando Qv=100 y Qh=0 a $-66,0185$ a $-65,9775$ cuando Qv=1000 y Qh=0. Las cargas máximas implican un esfuerzo sumamente alto. En algunos casos las cargas horizontales afectarán al esfuerzo y cambiarán su dirección, sobre todo a altos niveles de carga. Cuando Qh=100 y $\mathrm{Qv}=0$, el esfuerzo cambia de dirección y aumenta de -2,5368 a 2,6405 a 51,609 a 51,937. Cuando Qh=10000 y Qv=10, se pasa de $-2501,392$ a 2675,9285 a 5177,156 a 5177,485. En el resto de casos, las cargas horizontales casi no afectan al esfuerzo.

En la barra b, las cargas horizontal y vertical afectan al esfuerzo por igual. Sin embargo, se observa que, cuando Qv>Qh, el esfuerzo aumenta, pero cuando Qh>Qv, el esfuerzo disminuye, por ejemplo, cuando $\mathrm{Qh}=100$, siendo $\mathrm{Qv}=0$, el esfuerzo es de $-69,301$ a $-69,219$, y cuando $Q h=100$ y $Q v=1$, el esfuerzo se reduce a $-26,6588$ a 11,8087.

En la barra c, ambas cargas afectan al esfuerzo. A pesar de que las cargas más altas aumentan el valor del esfuerzo, las cargas verticales son las que lo hacen subir más, puesto que el valor máximo de la carga horizontal cuando la vertical es nula es de -1205,7339 a 2501,326 , mientras que en el caso inverso el valor del esfuerzo llega a valores que van de $-1840,2339$ a 659 . Si se observan los aumentos de forma progresiva, el que aportan las cargas verticales siempre es mayor.

En la barra d, se observa un caso parecido al de la barra c. Las cargas vertical y horizontal influyen en el esfuerzo, pero es la vertical la que genera un esfuerzo mayor que la horizontal. Como excepción, puede verse que, cuando Qh=10000 y Qv=10, la dirección del esfuerzo cambia, siendo de 5177,156 a 5177,485.

En la barra e, cada una de las cargas aporta una dirección. Cuando la carga horizontal es nula, la carga vertical afecta más al esfuerzo en su propia dirección, y a medida que las cargas horizontales aumentan, el crecimiento de las cargas verticales supone un alto valor de esfuerzo, pero en la dirección marcada por las cargas horizontales, por lo que estas últimas son las que más afectan al esfuerzo. 
En la barra f, las dos cargas aportan direcciones diferentes. Para cargas nulas, el esfuerzo es de 0,0103 a 0,0514. Al aplicar cargas verticales, la dirección del esfuerzo se invierte en las cargas más bajas y más altas. Cuando $Q v=1$ y $Q h=0$, el esfuerzo es de -0,0763 a 0,1174; y cuando $Q v=10000$ y $Q h=0$, el esfuerzo es de $-659,8404$ a 659,8404. A medida que van creciendo las cargas horizontales, el esfuerzo irá aumentando en la misma dirección que cuando la carga es nula, en lugar de en la dirección de las cargas verticales.

De este modo, se puede concluir que los momentos para una estructura reentrante hexagonal metálica rígida para una apertura de $63^{\circ}$ y diversas cargas horizontales y verticales, aumentan con la carga, siendo mayores cuanto mayor sea dicha carga. Las barras son afectadas tanto por cargas verticales como horizontales, generando estas cargas, en algunas ocasiones, sentidos opuestos de esfuerzo.

\subsection{Discusión de resultados}

Los resultados obtenidos para la estructura metálica rígida de apertura $63^{\circ}$ son los esperados, ya que según va aumentando la carga los desplazamientos son mayores (pero siguen siendo admisibles), lo que se traduce en una estructura más flexible que las tradicionales.

Sin embargo, según aumenta la carga, los esfuerzos en las barras dejan de ser admisibles, con lo que estas estructuras sólo admitirían los esfuerzos hasta unas cargas determinadas (también hay que decir que las cargas mayores con las que se ha testeado el modelo son excesivas). Para intentar solucionar este problema, a continuación se comprobará esta misma estructura con un tendón interno. 


\subsubsection{Cálculo para apertura de $90^{\circ}$ (tradicional) y aumento de carga progresiva}

\subsection{Metodología}

Calcularemos la estructura metálica auxética reentrante hexagonal unitaria de nudos rígidos del apartado anterior para una apertura de $90^{\circ}$, aumentándole la carga de manera gradual en diferentes sentidos, de acuerdo a los casos representados en la figura 196. Las barras son también los mismos perfiles metálicos del apartado anterior, representados en la figura 194, y sus dimensiones serán: barras "a" y "f" de longitud $1 \mathrm{~m}$ y resto de barras de longitud 0,559m. Nuevamente la estructura tendrá 6 restricciones, repartidas de la siguiente manera: en el apoyo de la izquierda 3 restricciones al desplazamiento +1 restricción a la rotación respecto al eje $\mathrm{x}, \mathrm{y} 2$ restricciones al desplazamiento en los ejes y y $z$ en el apoyo de la derecha.

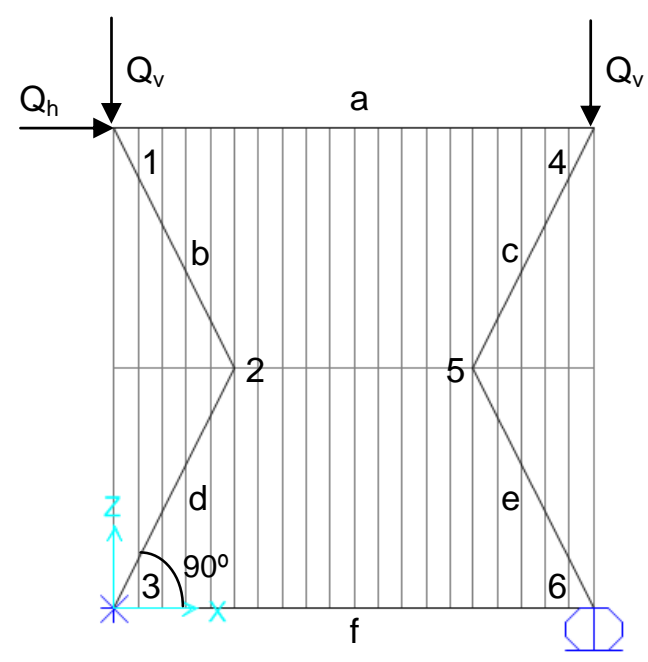

Figura 196 Estructura auxética reentrante hexagonal unitaria con cargas con apertura de 90, elaboración propia

\subsection{Resultados}

Para las estructuras reentrantes hexagonales metálicas rígidas sin tendones y con una apertura de $90^{\circ}$ se obtienen los resultados representados en las gráficas que aparecen a continuación. 


\section{Desplazamientos horizontales}

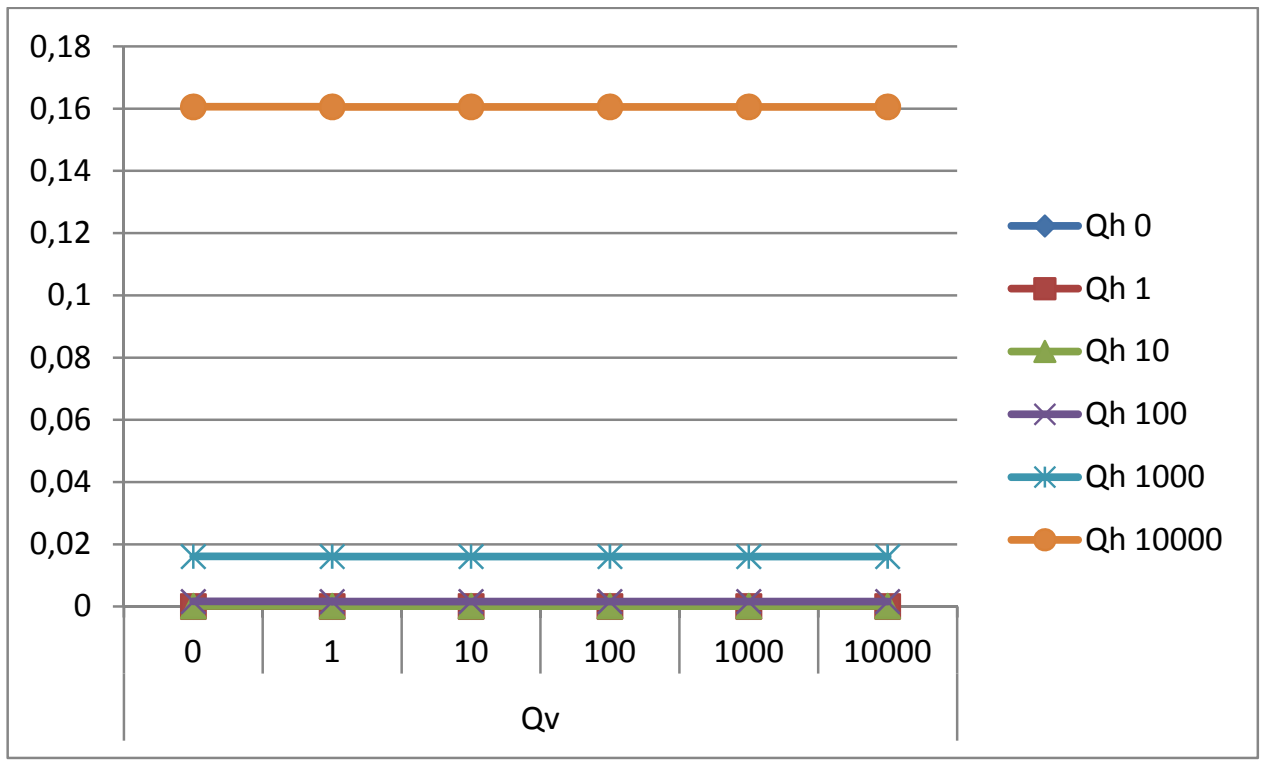

Gráfica 84 Comparación de desplazamientos horizontales ( $m$, eje y) en el nudo 1 de estructura tradicional generada a partir de estructura reentrante hexagonal metálica rígida para una apertura de $90^{\circ}$ y diversas cargas horizontales y verticales (KN, eje x y leyenda), elaboración propia

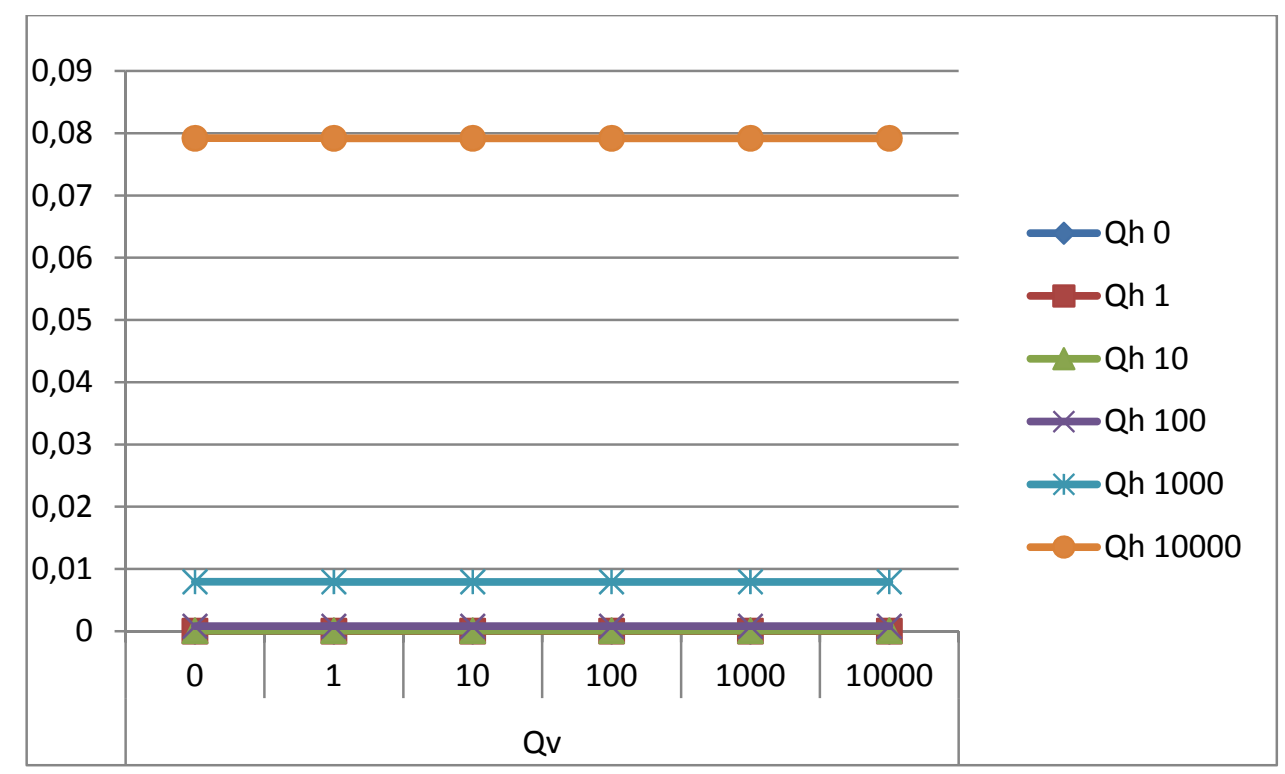

Gráfica 85 Comparación de desplazamientos horizontales ( $m$, eje y) en el nudo 2 de estructura tradicional generada a partir de estructura reentrante hexagonal metálica rígida para una apertura de $90^{\circ}$ y diversas cargas horizontales y verticales (KN, eje $x$ y leyenda), elaboración propia 


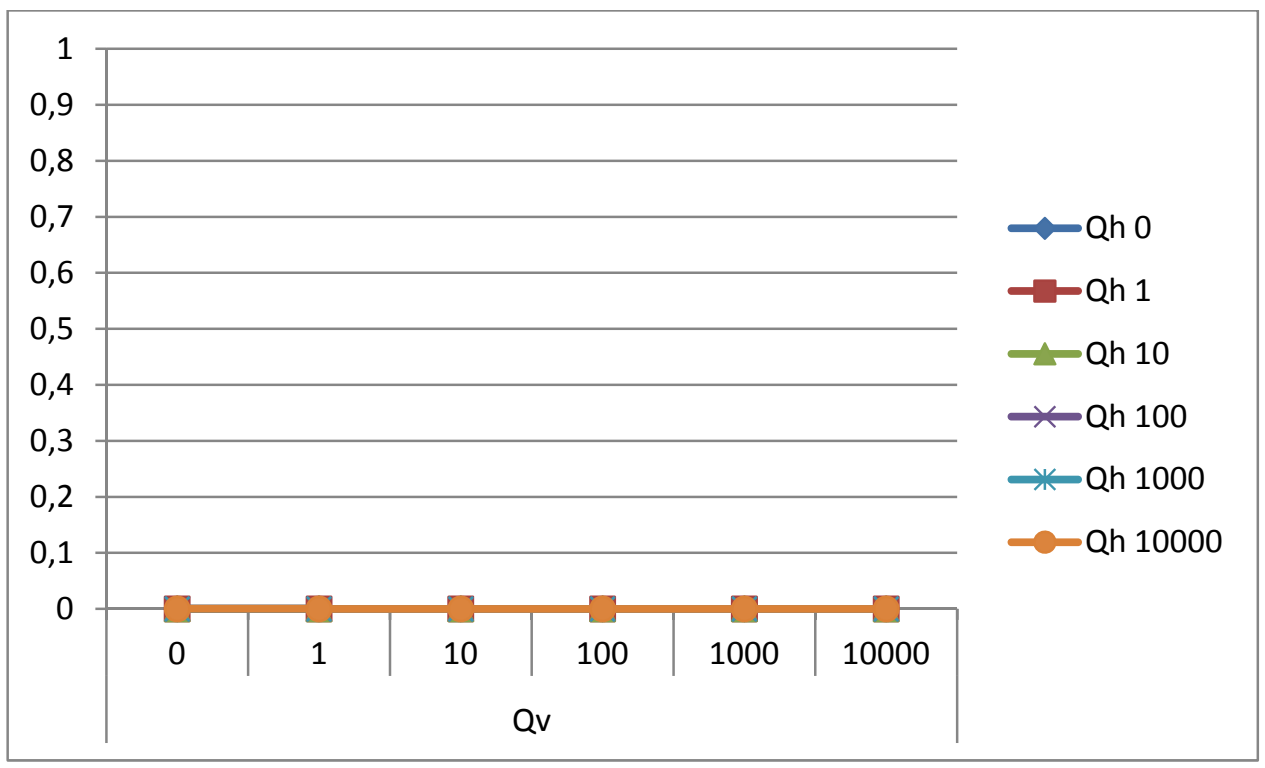

Gráfica 86 Comparación de desplazamientos horizontales ( $m$, eje y) en el nudo 3 de estructura tradicional generada a partir de estructura reentrante hexagonal metálica rígida para una apertura de $90^{\circ}$ y diversas cargas horizontales y verticales (KN, eje $x$ y leyenda), elaboración propia

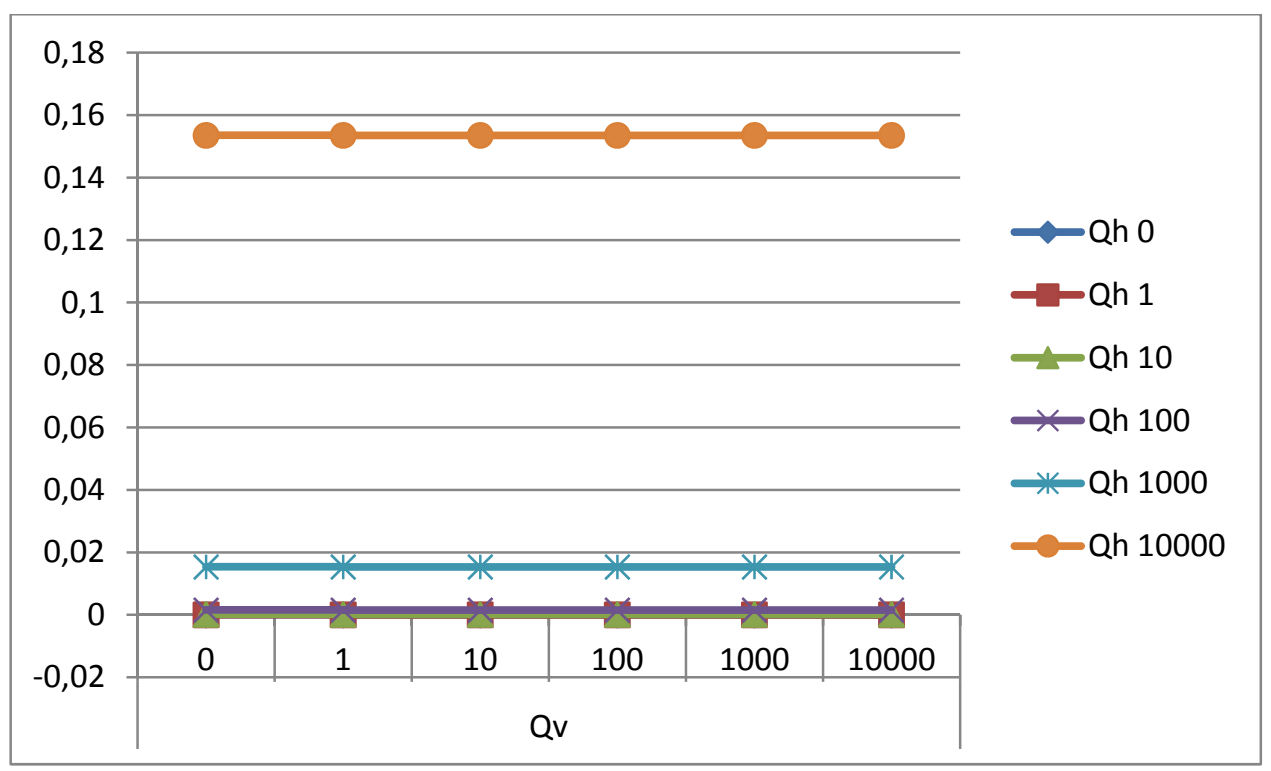

Gráfica 87 Comparación de desplazamientos horizontales ( $m$, eje y) en el nudo 4 de estructura tradicional generada a partir de estructura reentrante hexagonal metálica rígida para una apertura de $90^{\circ}$ y diversas cargas horizontales y verticales ( $K N$, eje $x$ y leyenda), elaboración propia 
Aplicaciones de las propiedades auxéticas en la arquitectura

CÁLCULO ESTRUCTURAL DE ESTRUCTURAS AUXÉTICAS

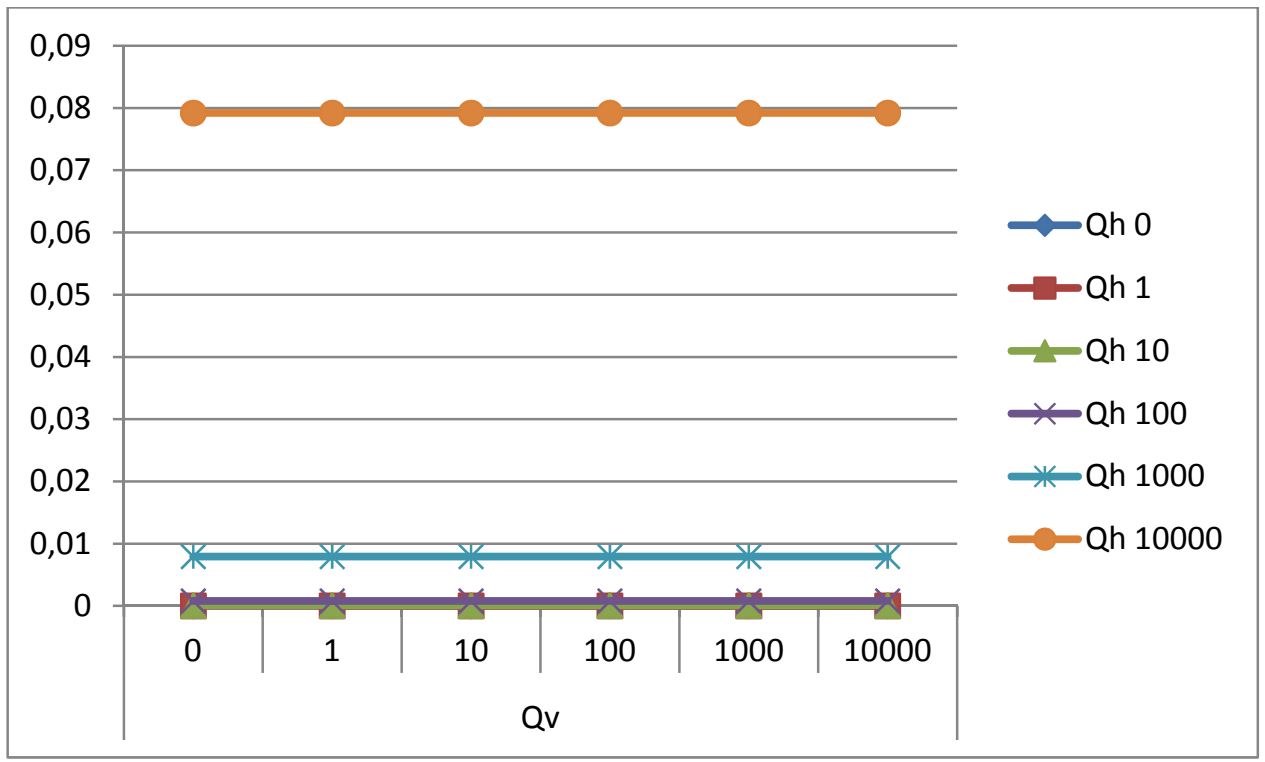

Gráfica 88 Comparación de desplazamientos horizontales ( $m$, eje y) en el nudo 5 de estructura tradicional generada a partir de estructura reentrante hexagonal metálica rígida para una apertura de $90^{\circ}$ y diversas cargas horizontales y verticales (KN, eje x y leyenda), elaboración propia

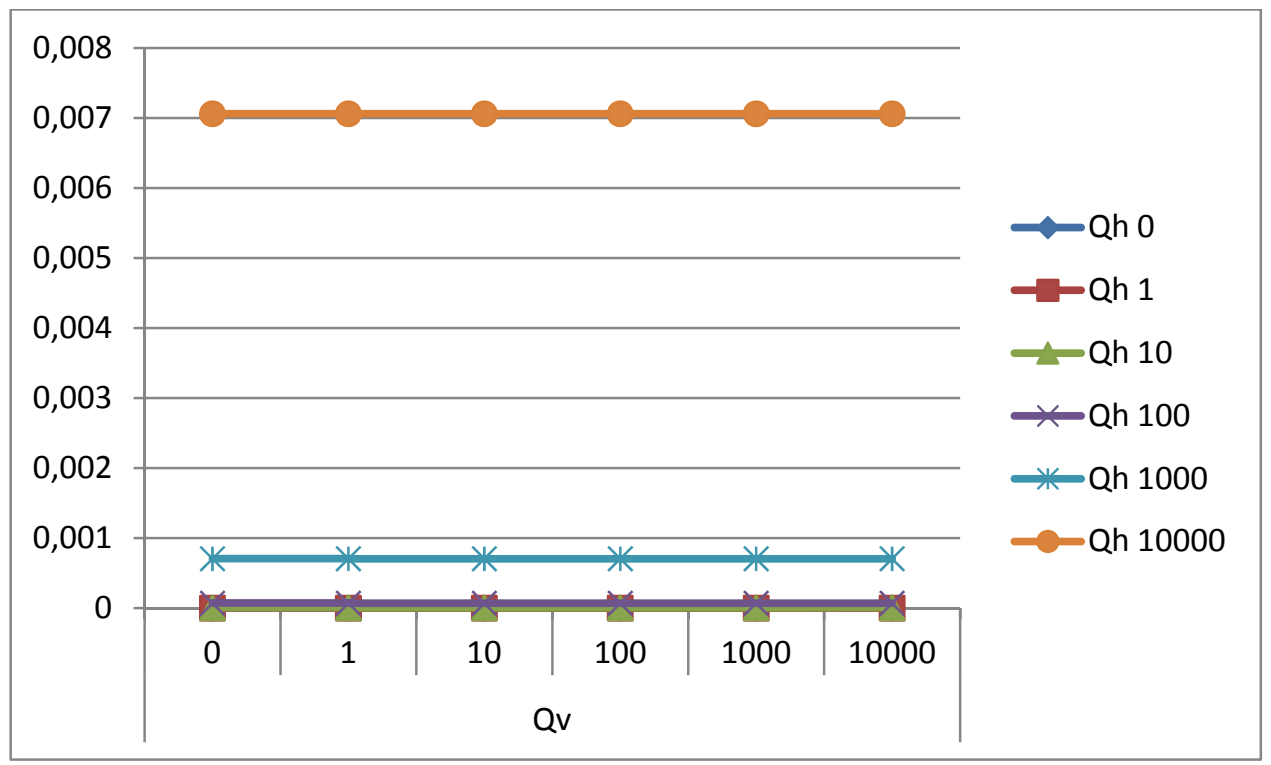

Gráfica 89 Comparación de desplazamientos horizontales ( $m$, eje y) en el nudo 6 de estructura tradicional generada a partir de estructura reentrante hexagonal metálica rígida para una apertura de $90^{\circ}$ y diversas cargas horizontales y verticales (KN, eje x y leyenda), elaboración propia 
Como puede observarse en las gráficas anteriores, correspondientes a la Tabla 43, desplazamientos horizontales de estructura tradicional generada a partir de estructura reentrante hexagonal metálica rígida para una apertura de $90^{\circ}$ y diversas cargas horizontales y verticales, del Apéndice 2. Tablas de cálculo estructural, se observan unos desplazamientos horizontales en los nudos con comportamientos muy diversos dependiendo de las diferentes combinaciones de cargas verticales y cargas horizontales.

Para el nudo 1 los desplazamientos horizontales dependen de las cargas horizontales. Las cargas verticales le afectan cuando dicha carga es de 10000, aumentando dicho desplazamiento horizontal en el nudo de 0,0000000367 a 0,00000004781. Las cargas horizontales son las que van aumentando estos desplazamientos de forma progresiva, obteniendo valores con diferencias muy significativas, que van de 0,0000000367 a 0,160571. Aun así, cuando está en reposo, el desplazamiento horizontal total en el nudo asciende a 0,0000000367, esto es debido al peso de la propia estructura.

Para el nudo 2, las cargas horizontales son las que determinan los desplazamientos horizontales en el nudo en todos los casos, excepto cuando en algunos casos la carga vertical llega a 10000, donde se produce un repunte no significativo cuando el nudo está en reposo horizontal, por ejemplo, que pasa de 0,00000001835 a 0,000000023. Las diferencias significativas se obtienen al aumentar la carga horizontal, generando unos desplazamientos horizontales que van de 0,00000001835 a 0,079193. Cuando está en reposo, el desplazamiento horizontal total en el nudo asciende a 0,00000001835, esto es debido al peso de la propia estructura.

Para el nudo 3 se aprecian unos desplazamientos horizontales y verticales nulos en todos los casos. Esto es debido a que este nudo corresponde a uno de los apoyos de la estructura y tiene impuestas restricciones a los desplazamientos en todas las direcciones.

Para el nudo 4 las cargas horizontales son determinantes para el desplazamiento horizontal, mucho más que las verticales. Sin embargo, en los casos en que la carga horizontal no existe, las altas cargas verticales de 100, 1000 y 10000 dan un repunte, pasando de 0 a 1,196E-20 con carga 100, a 5,929E-20 con carga 1000 y a -4,244E-19 con carga 10000 . El resto del tiempo, el aumento de rotación depende por completo de las cargas horizontales, observándose diferencias, aunque no demasiado importantes, que van de 0 a 0,153511. Cuando está en reposo, no existe ningún desplazamiento horizontal en este nudo, siendo totalmente nulo dicho desplazamiento. 
Para el nudo 5, el desplazamiento horizontal se ve afectado tanto por las cargas verticales como por las horizontales, siendo más influyentes las horizontales. Sin embargo, cuando $\mathrm{Q}_{v}>\mathrm{Q}_{h}$, el desplazamiento horizontal disminuye de forma considerable en comparación con la estabilidad del resto de la tabla. Cuando la carga horizontal es de 10 y la vertical de 10000 se observa un repunte de 0,00007 a 0,000079, por lo que en ese caso el nudo se ve más afectado por la carga vertical. Sin embargo, el repunte que se observa para cargas nulas verticales y aumento progresivo de 0 a $10000 \mathrm{KN}$ en las horizontales va de 0,00000001835 a 0,079193 , siendo más significativo.

El nudo 6, se ve afectado sobre todo por las cargas horizontales. En reposo el desplazamiento horizontal es nulo, y en la mayor parte de la tabla las cargas verticales y horizontales se estabilizan. Las cargas verticales de 10000 suelen mostrar repuntes coincidiendo con cargas horizontales bajas, como por ejemplo, cuando la carga horizontal es nula, y la carga vertical es de 10000 , el desplazamiento horizontal en el nudo pasa de 0,0000000367 a 0,00000004781 . Sin embargo, el repunte que se observa para cargas nulas verticales y aumento progresivo de 0 a $10000 \mathrm{KN}$ en las horizontales va de 0 a 0,007061, siendo más significativo.

De este modo, se puede concluir que los desplazamientos horizontales para una estructura tradicional generada a partir de estructura reentrante hexagonal metálica rígida para una apertura de $90^{\circ}$ y diversas cargas horizontales y verticales, aumentan con la carga, siendo mayores cuanto mayor sea dicha carga. Se puede decir que las cargas horizontales tienen una mayor importancia que las cargas verticales porque influencian a todos los nudos y en los casos en que los nudos están bajo la influencia tanto de cargas verticales como horizontales, las cargas horizontales son más determinantes. 


\section{Desplazamientos verticales}

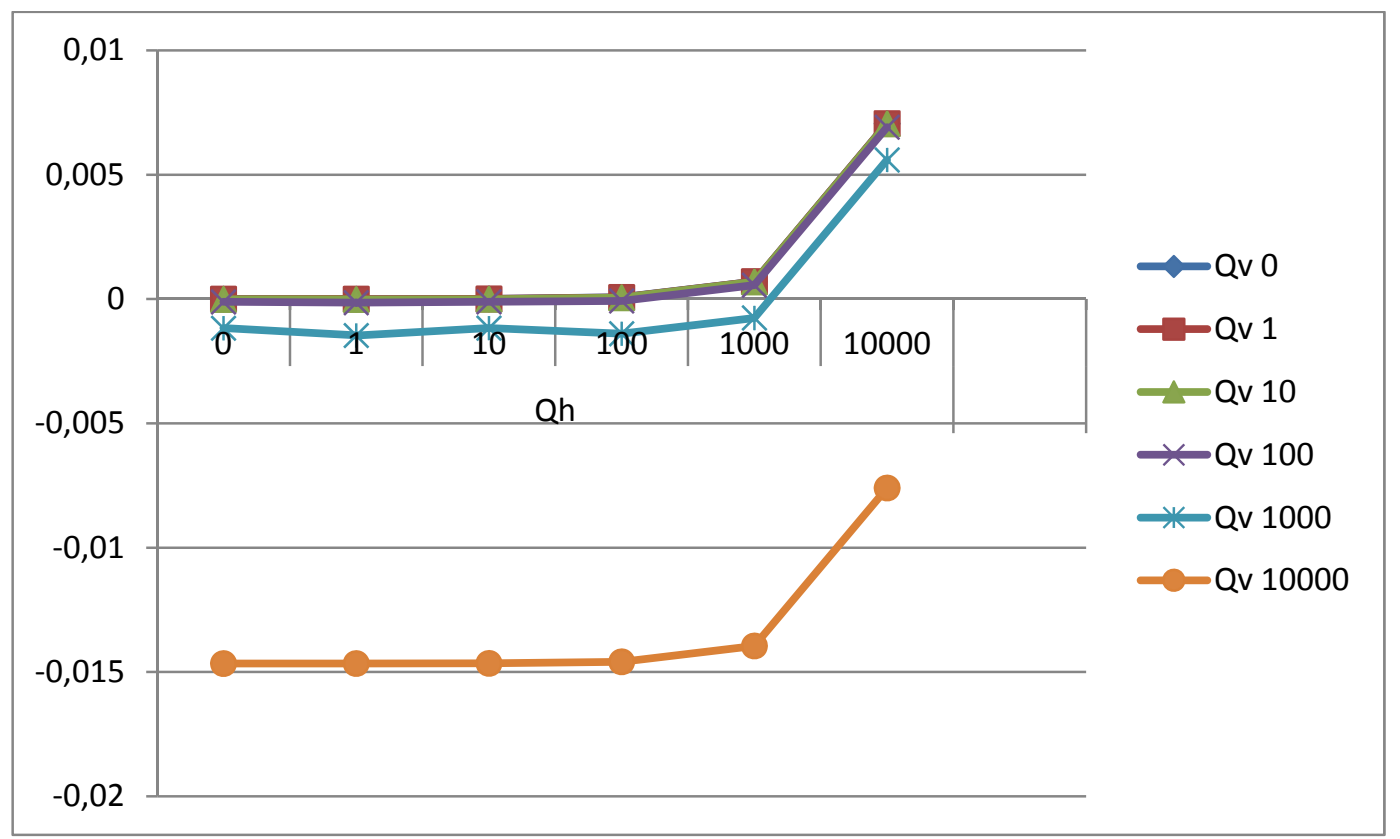

Gráfica 90 Comparación de desplazamientos verticales ( $m$, eje y) en el nudo 1 de estructura tradicional generada a partir de estructura reentrante hexagonal metálica rígida para una apertura de $90^{\circ}$ y diversas cargas horizontales y verticales (KN, eje $x$ y leyenda), elaboración propia

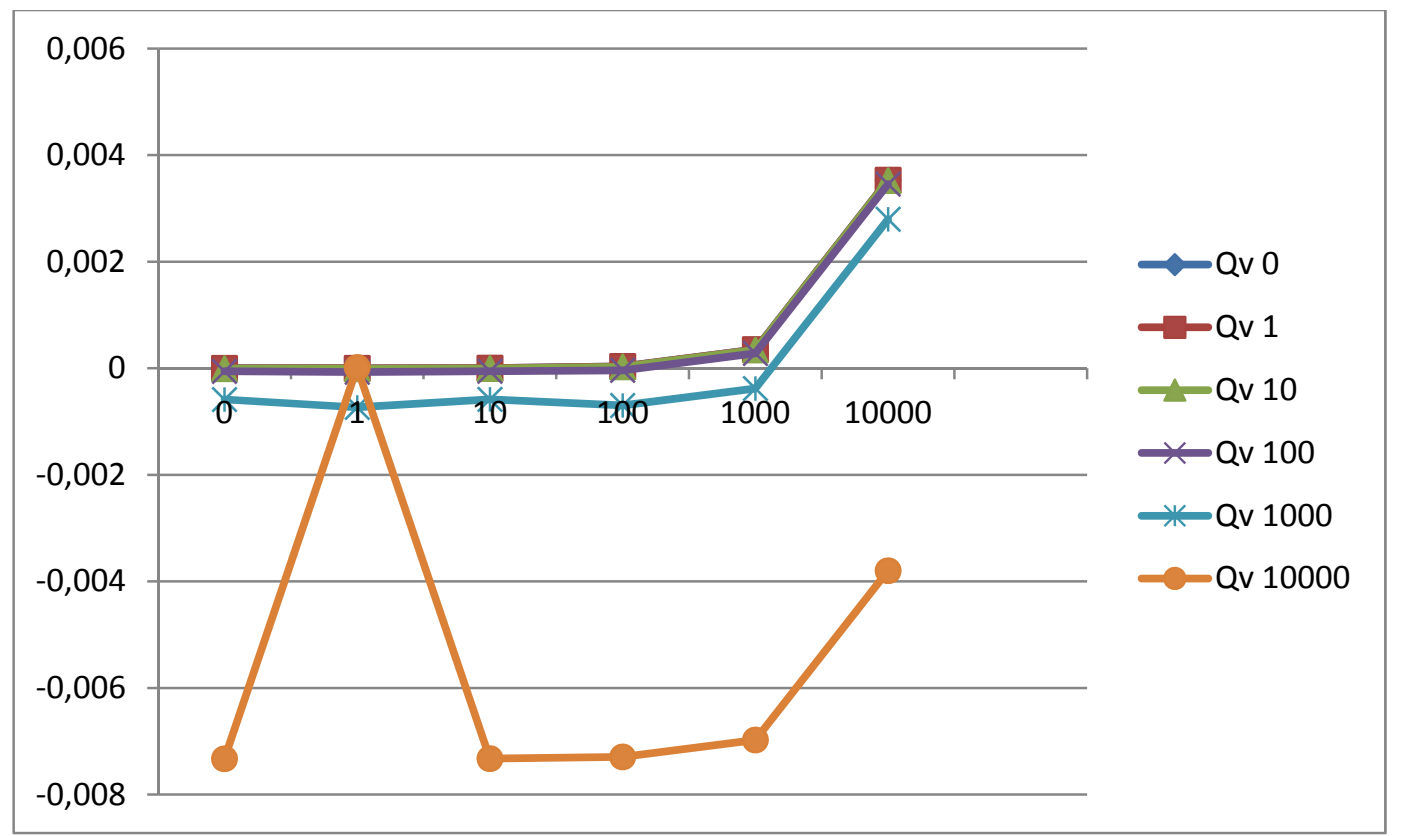

Gráfica 91 Comparación de desplazamientos verticales ( $m$, eje y) en el nudo 2 de estructura tradicional generada a partir de estructura reentrante hexagonal metálica rígida para una apertura de $90^{\circ}$ y diversas cargas horizontales y verticales (KN, eje $x$ y leyenda), elaboración propia 


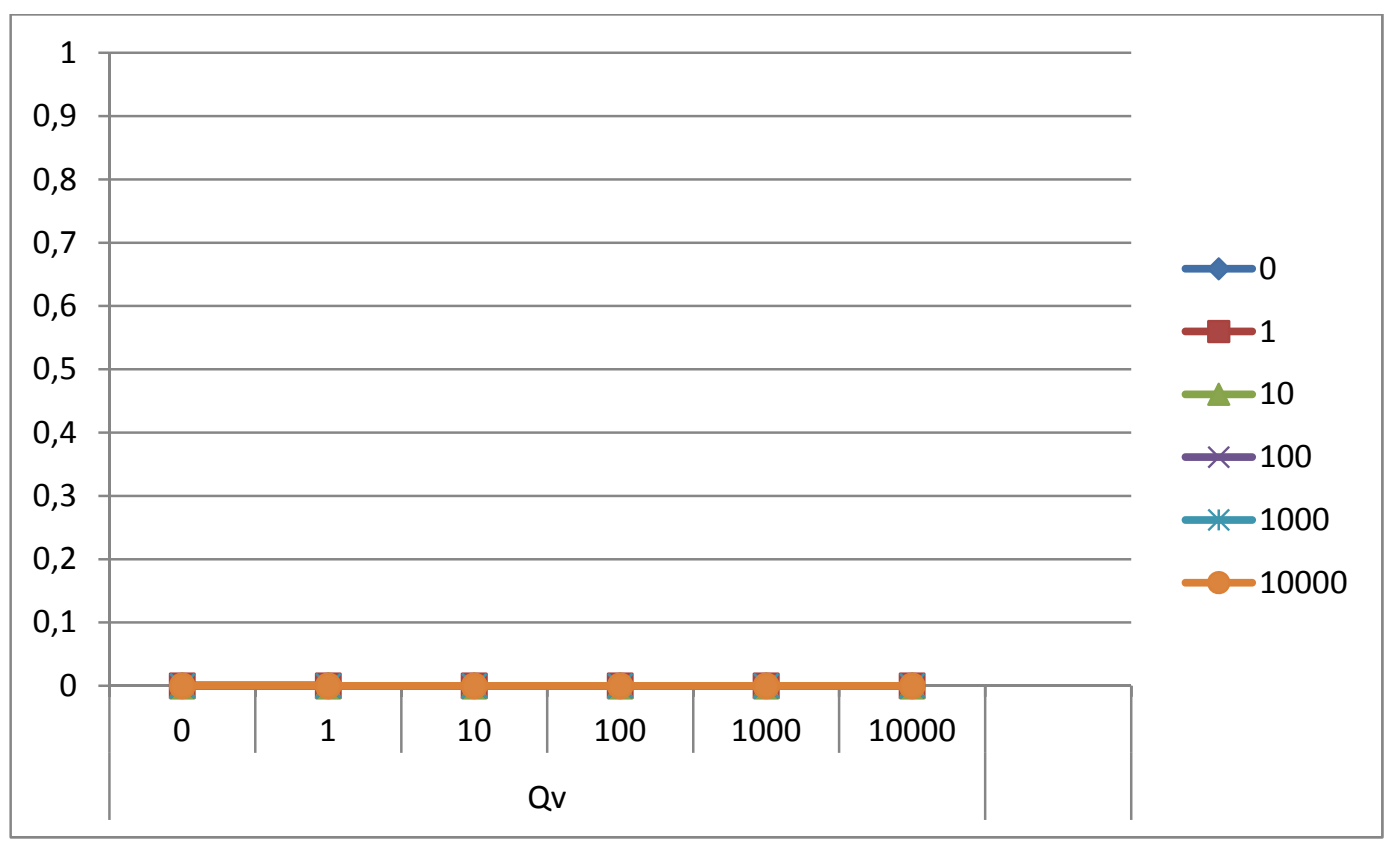

Gráfica 92 Comparación de desplazamientos verticales ( $m$, eje y) en el nudo 3 de estructura tradicional generada a partir de estructura reentrante hexagonal metálica rígida para una apertura de $90^{\circ}$ y diversas cargas horizontales y verticales (KN, eje $x$ y leyenda), elaboración propia

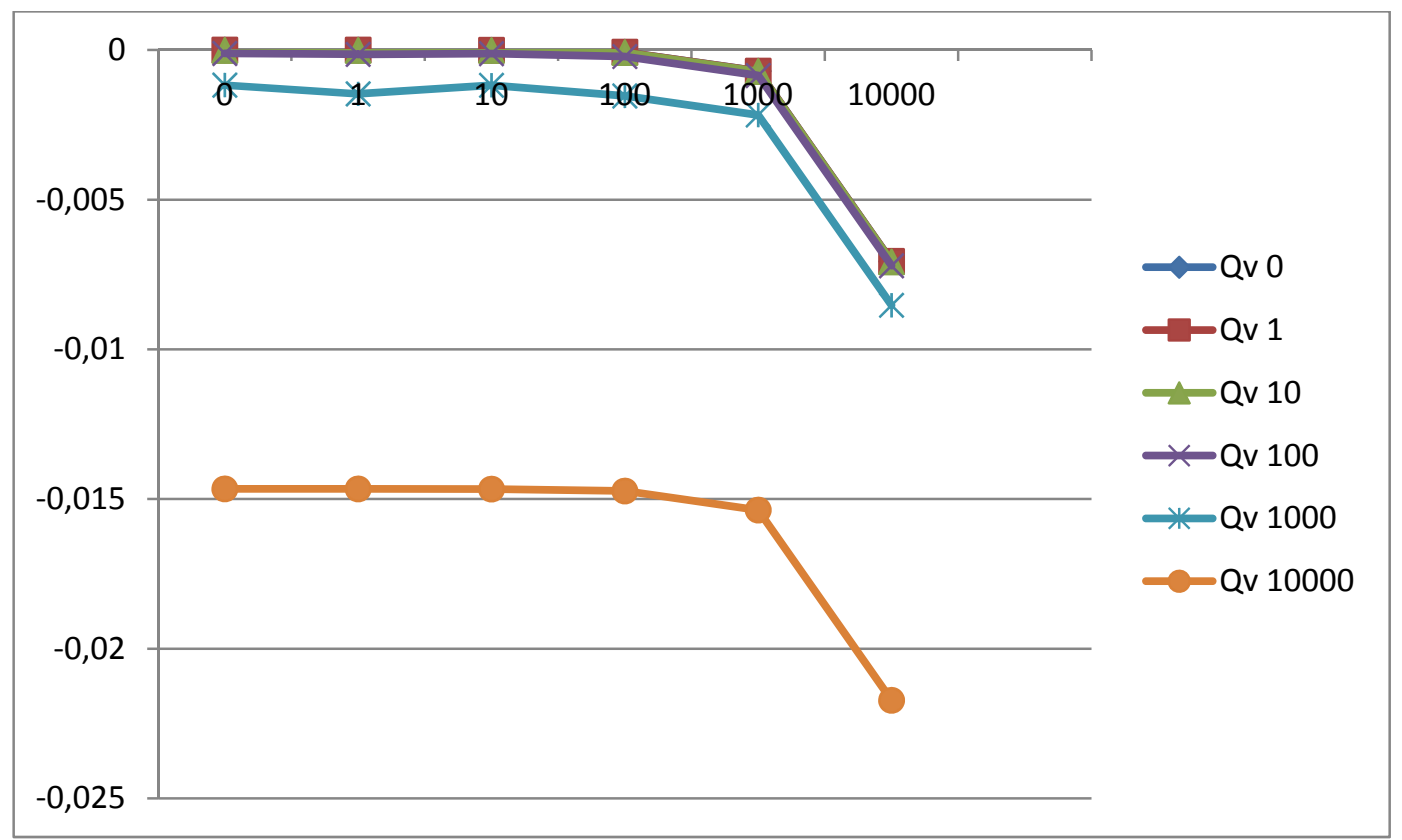

Gráfica 93 Comparación de desplazamientos verticales ( $m$, eje y) en el nudo 4 de estructura tradicional generada a partir de estructura reentrante hexagonal metálica rígida para una apertura de $90^{\circ}$ y diversas cargas horizontales y verticales (KN, eje $x$ y leyenda), elaboración propia 


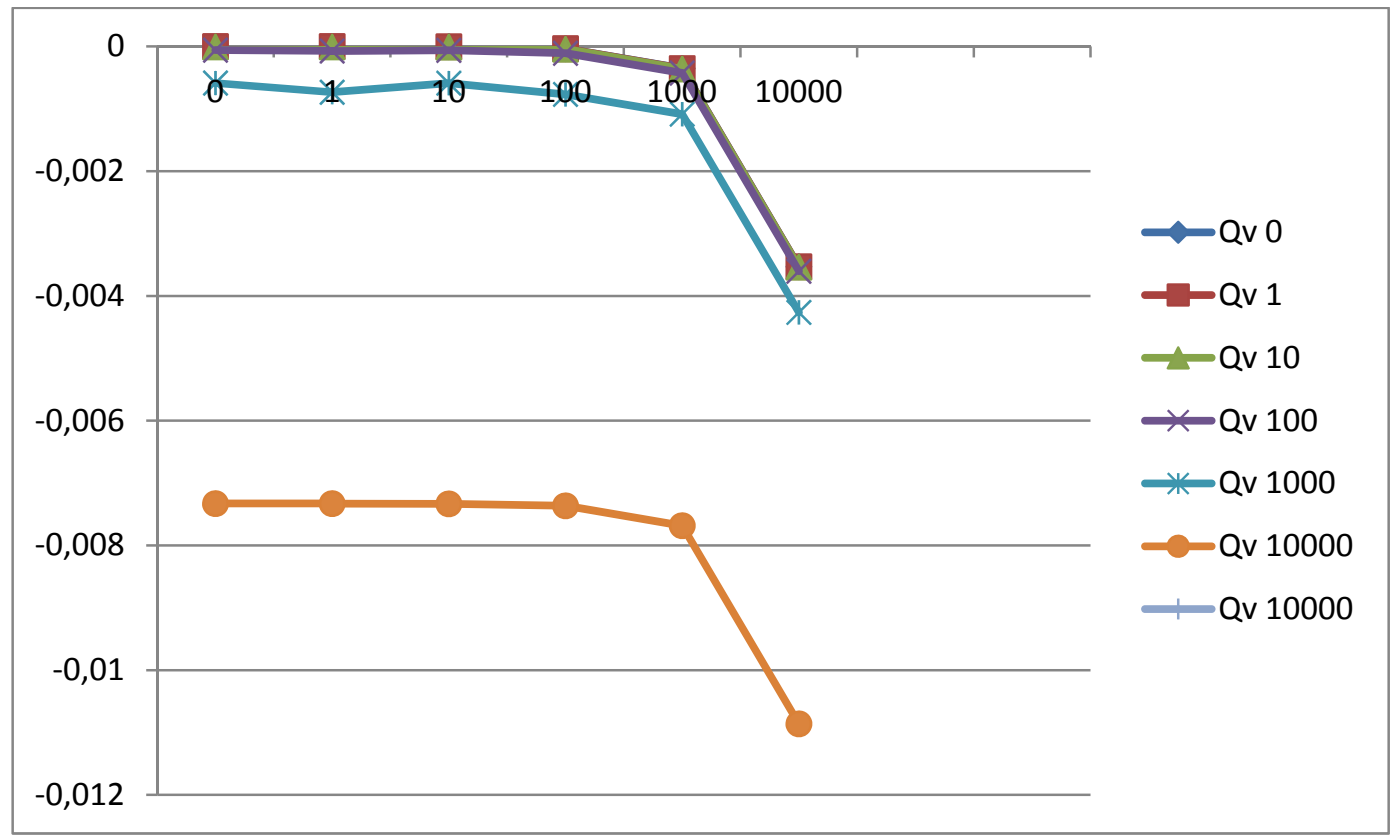

Gráfica 94 Comparación de desplazamientos verticales ( $m$, eje y) en el nudo 5 de estructura tradicional generada a partir de estructura reentrante hexagonal metálica rígida para una apertura de $90^{\circ}$ y diversas cargas horizontales y verticales (KN, eje x y leyenda), elaboración propia

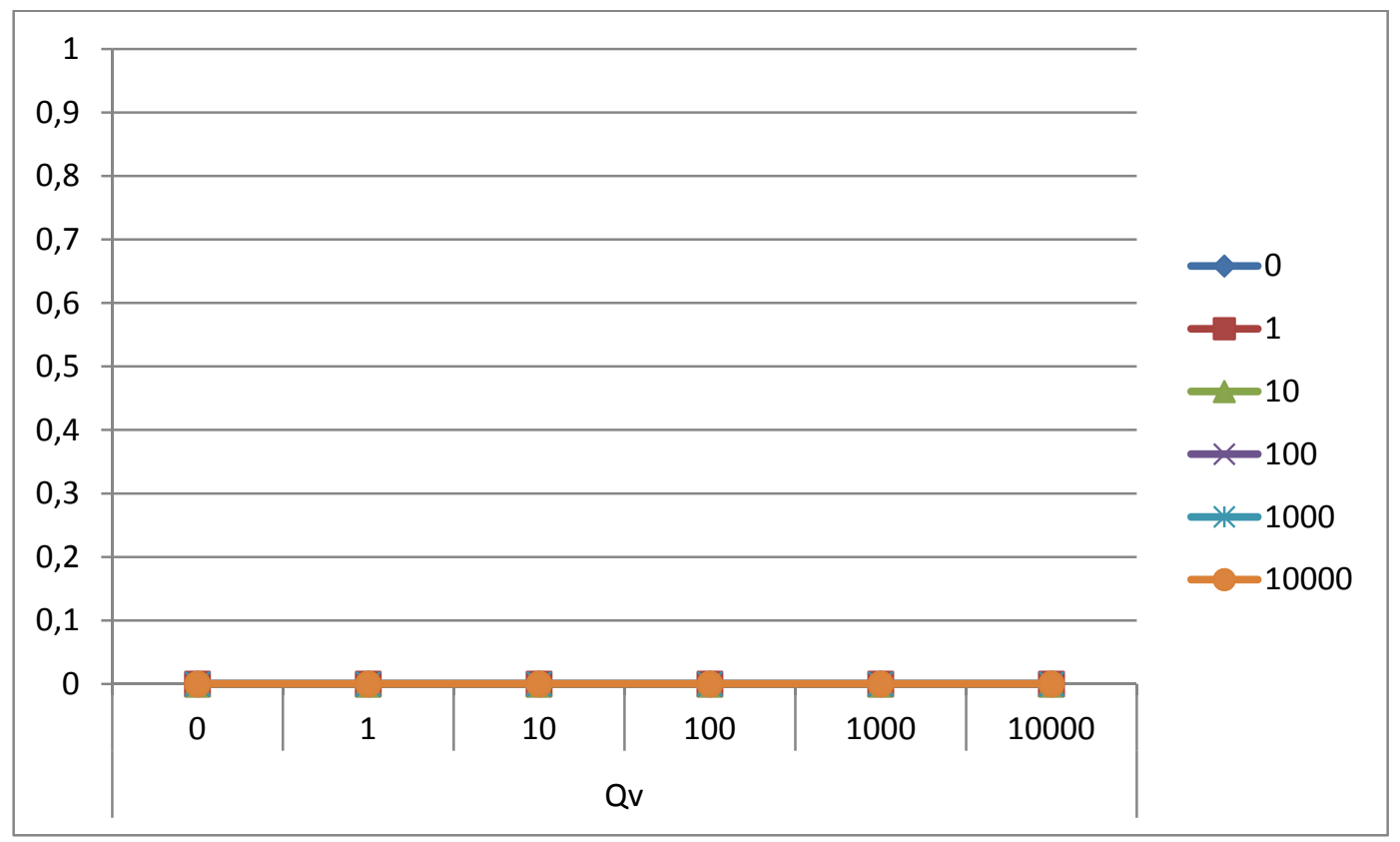

Gráfica 95 Comparación de desplazamientos verticales ( $m$, eje y) en el nudo 6 de estructura tradicional generada a partir de estructura reentrante hexagonal metálica rígida para una apertura de $90^{\circ}$ y diversas cargas horizontales y verticales (KN, eje $x$ y leyenda), elaboración propia 
Como puede observarse en las gráficas anteriores, correspondientes a la Tabla 44, desplazamientos verticales de estructura tradicional generada a partir de estructura reentrante hexagonal metálica rígida para una apertura de $90^{\circ}$ y diversas cargas horizontales y verticales, del Apéndice 2. Tablas de cálculo estructural, se observan unos desplazamientos verticales con comportamientos muy diversos dependiendo de las diferentes combinaciones de cargas verticales y cargas horizontales.

Para el nudo 1, vemos que las cargas horizontales y verticales le afectan por igual, aunque en direcciones diferentes. El desplazamiento vertical aumenta de forma progresiva de $-0,000000385$ para una carga horizontal nula a 0,00706 con carga de 10000 . Con respecto a las cargas verticales, cuando la carga es nula el desplazamiento vertical es de $-0,000000385$, mientras que con 10000 pasa a $-0,01466$.

Para el nudo 2, al igual que en el nudo 1, la carga horizontal aumenta el desplazamiento vertical en sentido contrario a la gravedad. Las cargas verticales producen desplazamientos en el sentido de la carga, y contrarios a los que generan las cargas horizontales. Por ejemplo, cuando la carga horizontal es de 10, el desplazamiento cambia progresivamente de 0,000002588 en reposo de la carga vertical, hasta llegar a -0,007327 cuando esta última llega a 10000.

Para el nudo 3, el desplazamiento se mantiene nulo en todos los casos, por lo que las cargas no le afectan. Esto es debido a que este nudo corresponde a uno de los apoyos de la estructura y tiene impuestas restricciones a los desplazamientos en todas las direcciones.

Para el nudo 4, las cargas horizontales y verticales afectan por igual, aunque las cargas verticales parecen afectar más que las horizontales, puesto que el desplazamiento vertical se mantiene en -0,01466 con carga vertical de 10000 y cargas horizontales de 0, 1 y 10 . Esta tendencia va aumentando de forma progresiva a partir de la carga horizontal de 100. Cuando ambas cargas llegan al punto máximo, se llega al punto máximo de desplazamientos vertical de -0,021721. En ambos casos se mantiene la dirección del desplazamiento.

Para el nudo 5, se presenta un caso similar al del nudo 4. Todos los desplazamientos están influidos por ambas cargas, aunque las cargas verticales parecen afectar más que las horizontales, puesto que el desplazamiento vertical se mantiene en -0,00733 con carga vertical de 10000 y cargas horizontales de 0, 1 y 10. Esta tendencia va aumentando de forma progresiva a partir de la carga horizontal de 100. Cuando ambas cargas llegan al 
punto máximo, se llega al punto máximo de desplazamientos vertical de -0,01086. En ambos casos se mantiene la dirección del desplazamiento.

Para el nudo 6, al igual que en el nudo 3, el desplazamiento es nulo en todos los casos, por lo que las cargas no le afectan. Esto es debido a que este nudo corresponde a uno de los apoyos de la estructura y tiene impuestas restricciones a los desplazamientos.

De este modo, se puede concluir que los desplazamientos verticales para una estructura tradicional generada a partir de estructura reentrante hexagonal metálica rígida para una apertura de $90^{\circ}$ y diversas cargas horizontales y verticales, aumentan con la carga, siendo mayores cuanto mayor sea dicha carga. Se puede decir que las cargas verticales tienen una mayor importancia que las cargas horizontales porque influencian a todos los nudos, y en los casos en que los nudos están bajo la influencia tanto de cargas verticales como horizontales, las cargas horizontales algunas veces generan desplazamientos en sentido contrario, con lo que contribuyen a un desplazamiento vertical menor. 
Rotaciones en articulaciones

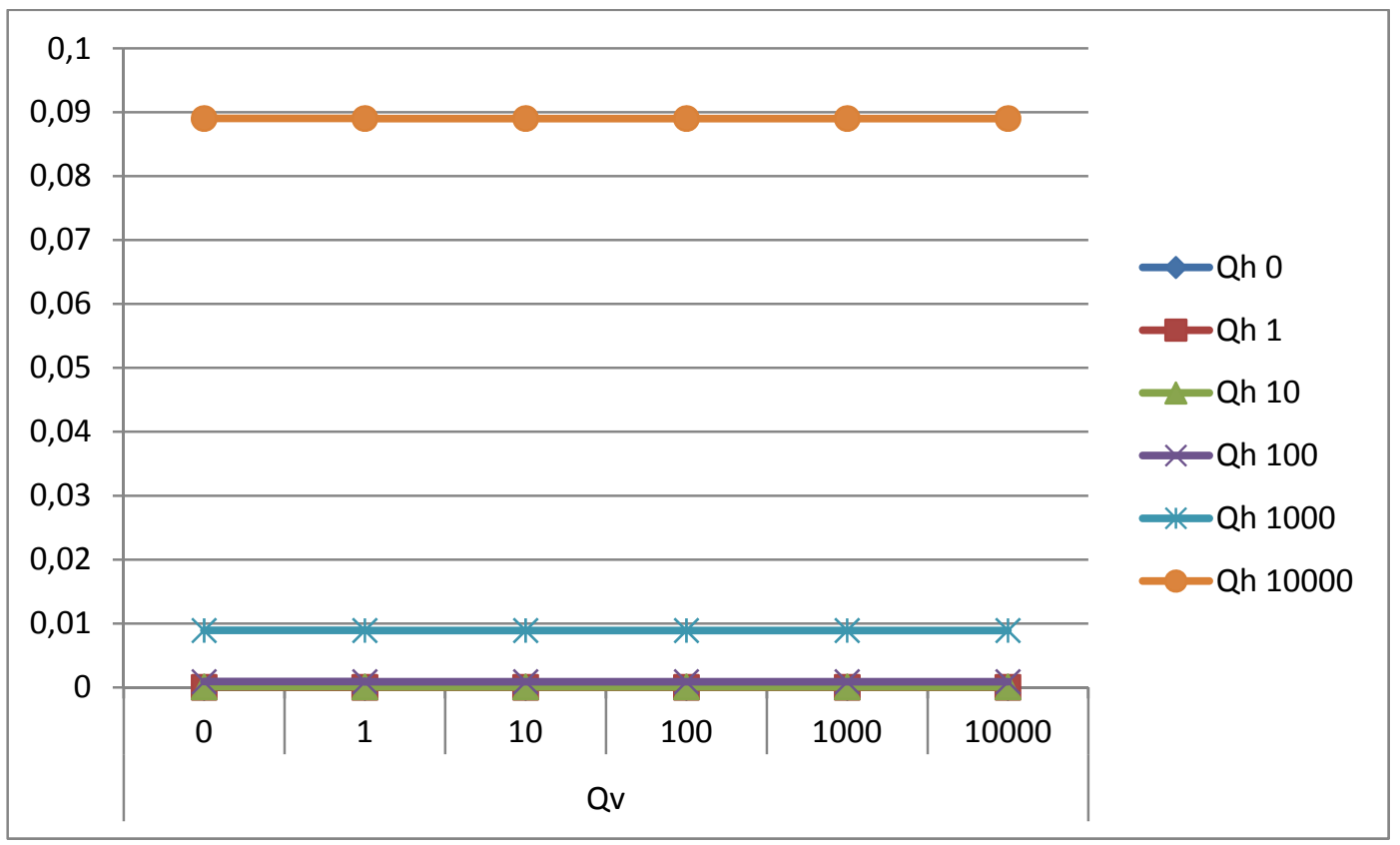

Gráfica 96 Comparación de rotaciones en articulaciones (rad, eje y) en el nudo 1 de estructura tradicional generada a partir de estructura reentrante hexagonal metálica rígida para una apertura de $90^{\circ}$ y diversas cargas horizontales y verticales (KN, eje $x$ y leyenda), elaboración propia

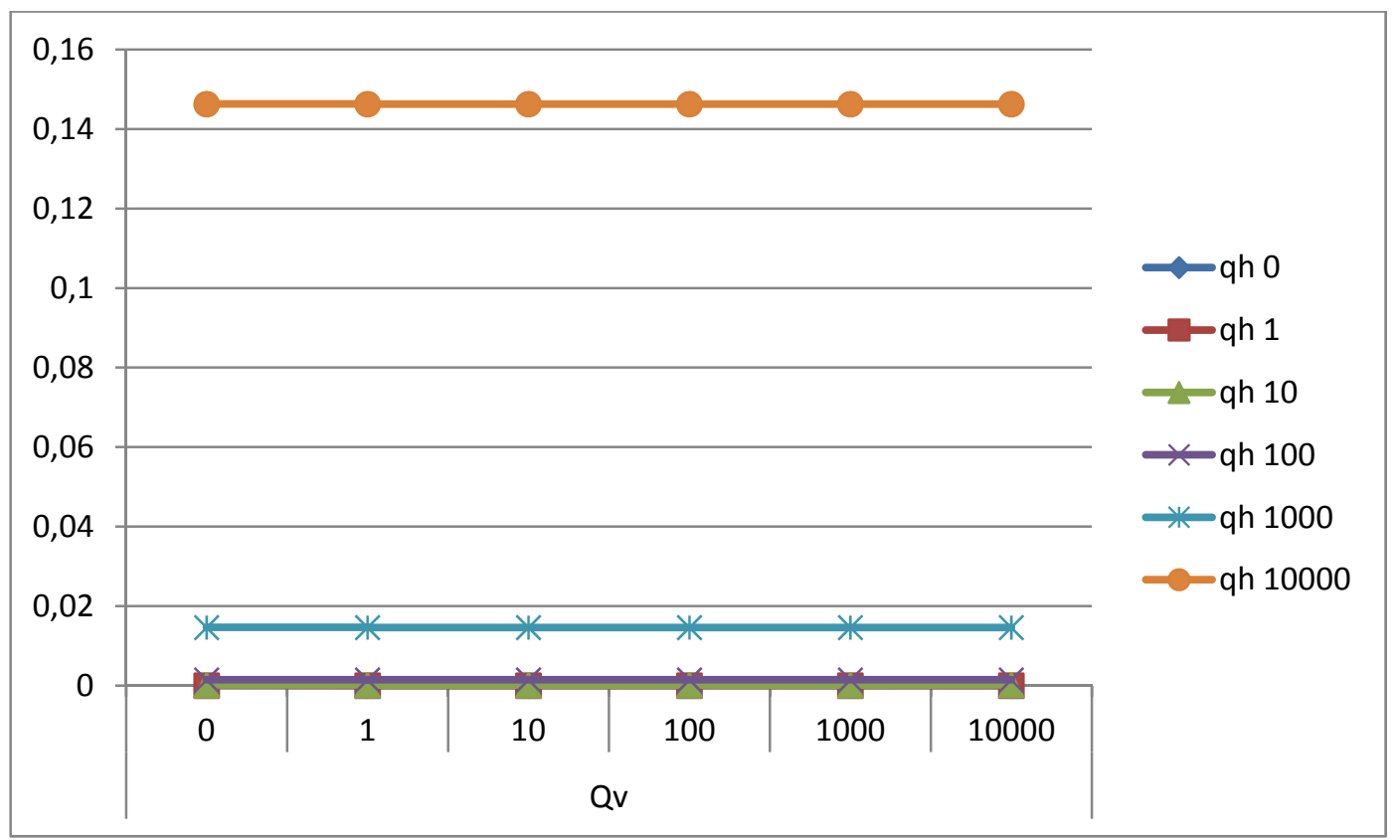

Gráfica 97 Comparación de rotaciones en articulaciones (rad, eje y) en el nudo 2 de estructura tradicional generada a partir de estructura reentrante hexagonal metálica rígida para una apertura de $90^{\circ}$ y diversas cargas horizontales y verticales (KN, eje $x$ y leyenda), elaboración propia 


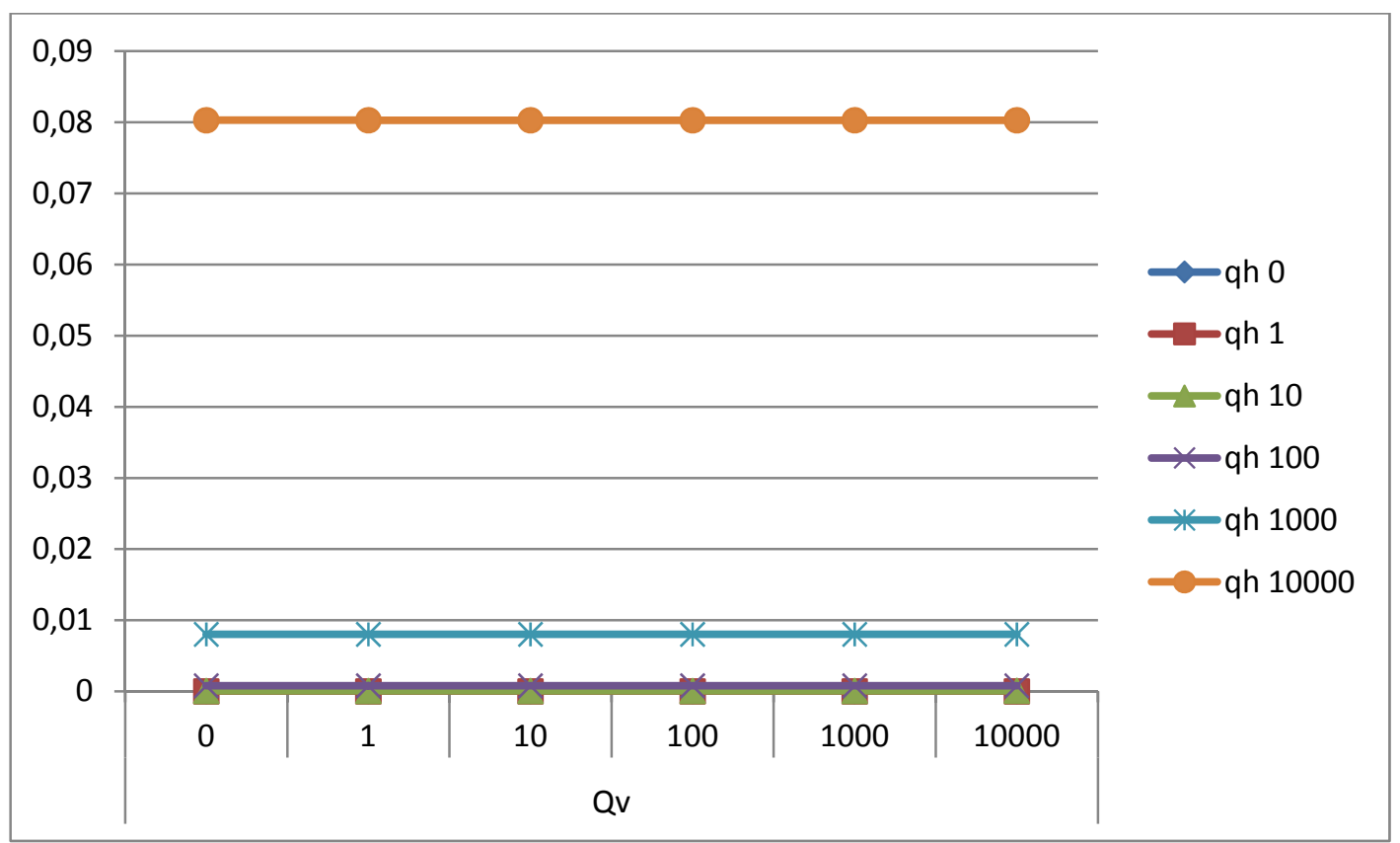

Gráfica 98 Comparación de rotaciones en articulaciones (rad, eje y) en el nudo 3 de estructura tradicional generada a partir de estructura reentrante hexagonal metálica rígida para una apertura de $90^{\circ}$ y diversas cargas horizontales y verticales (KN, eje $x$ y leyenda), elaboración propia

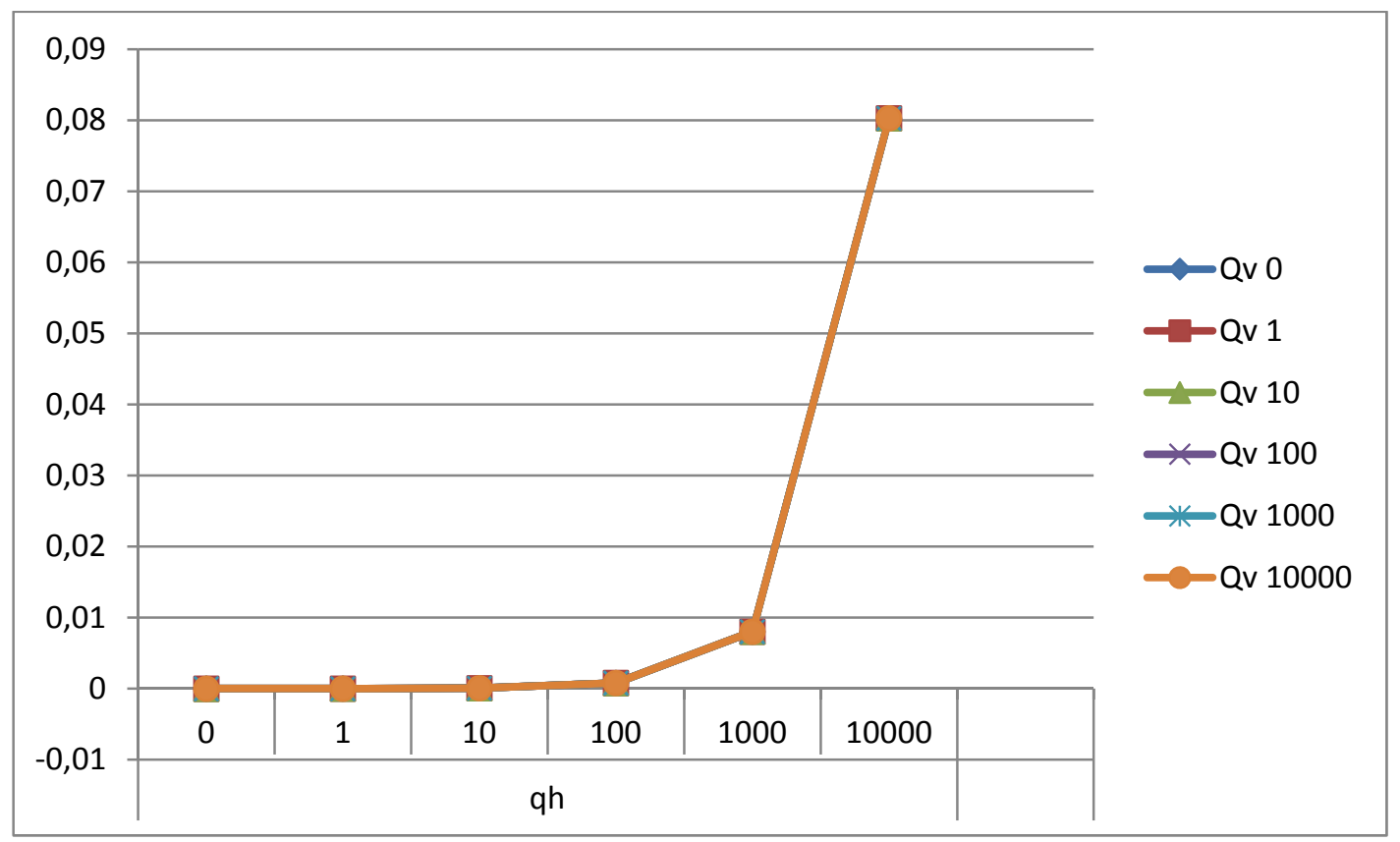

Gráfica 99 Comparación de rotaciones en articulaciones (rad, eje y) en el nudo 4 de estructura tradicional generada a partir de estructura reentrante hexagonal metálica rígida para una apertura de $90^{\circ}$ y diversas cargas horizontales y verticales (KN, eje $x$ y leyenda), elaboración propia 


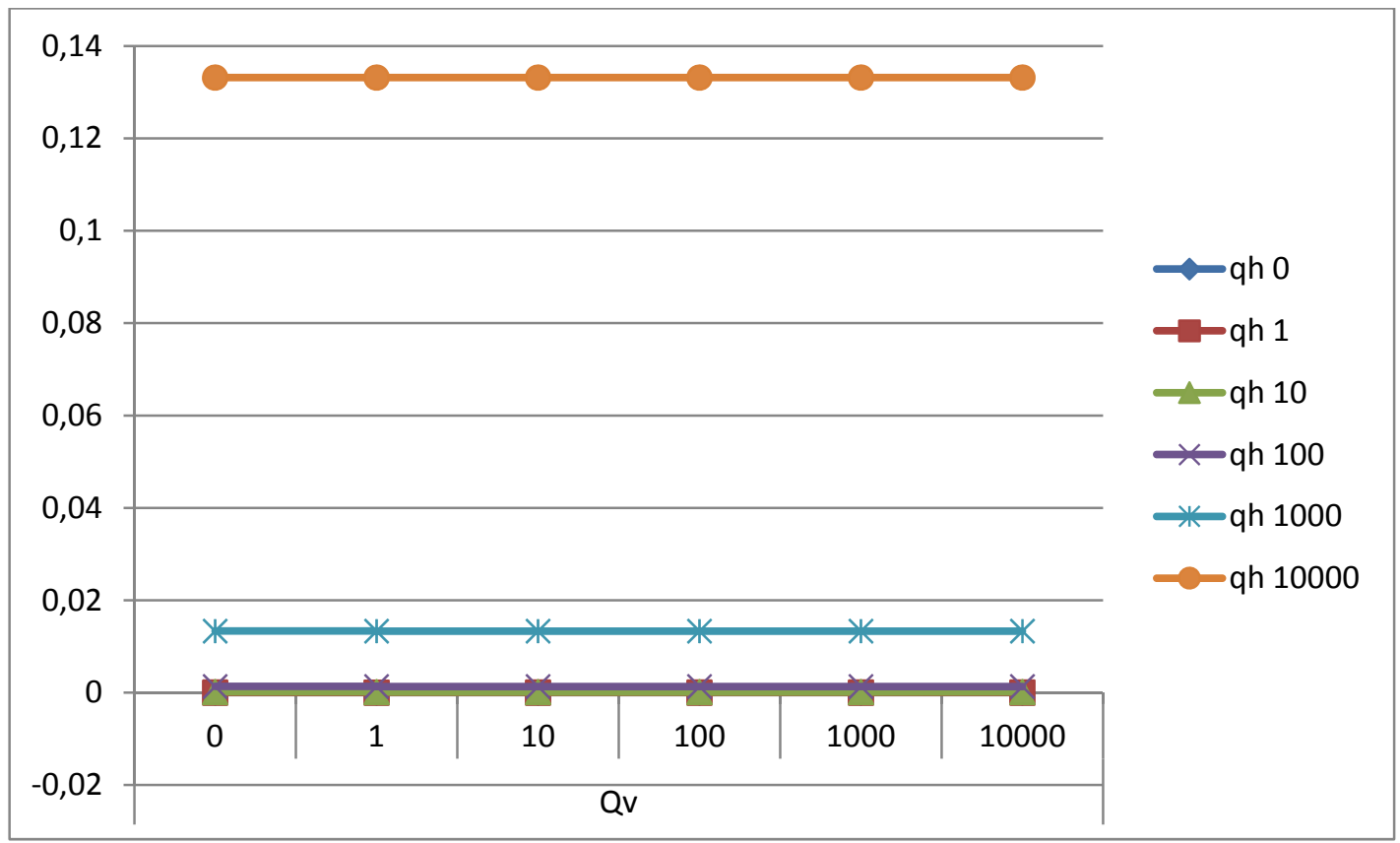

Gráfica 100 Comparación de rotaciones en articulaciones ( $r a d$, eje y) en el nudo 5 de estructura tradicional generada a partir de estructura reentrante hexagonal metálica rígida para una apertura de $90^{\circ}$ y diversas cargas horizontales y verticales (KN, eje $x$ y leyenda), elaboración propia

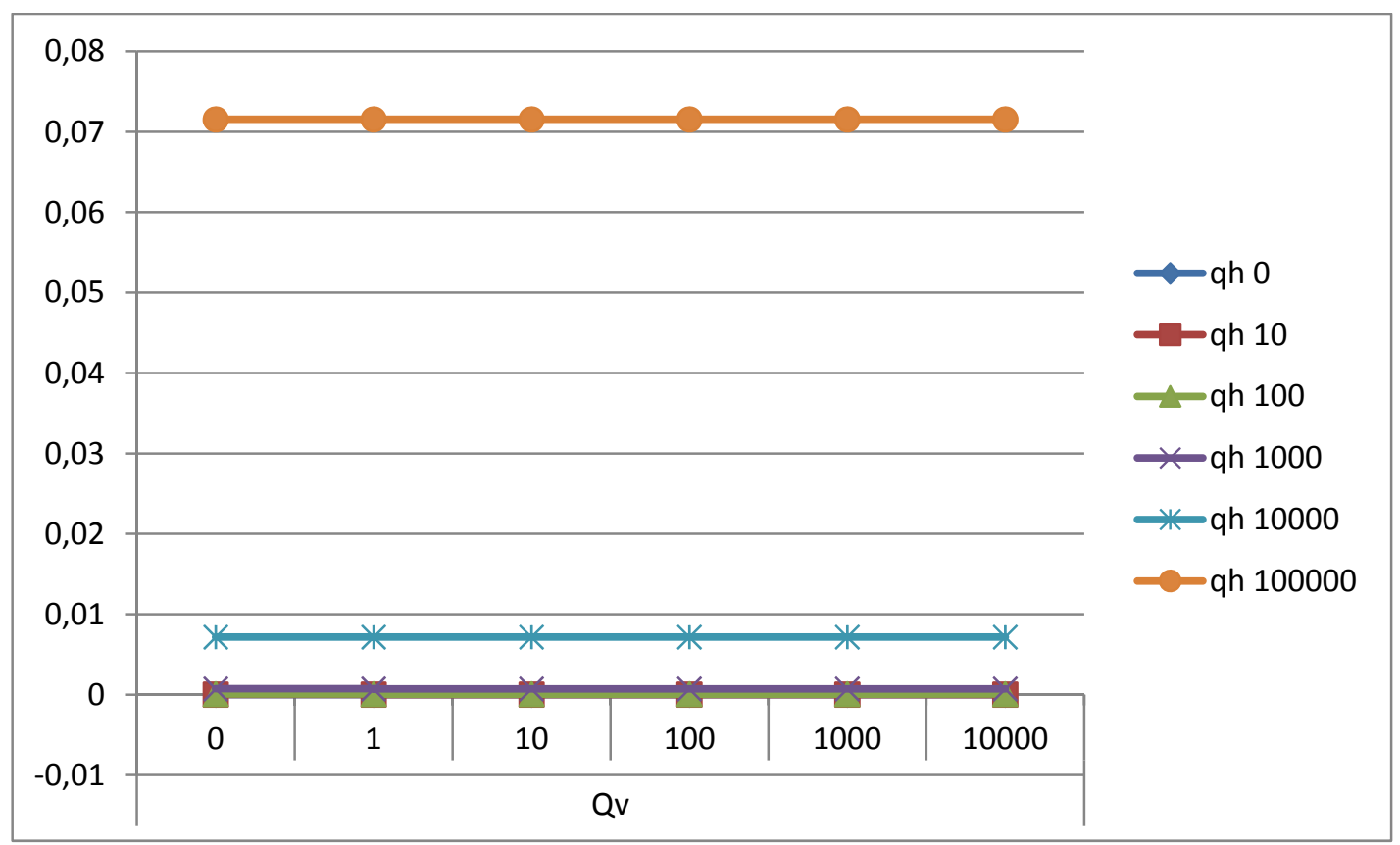

Gráfica 101 Comparación de rotaciones en articulaciones (rad, eje y) en el nudo 6 de estructura tradicional generada a partir de estructura reentrante hexagonal metálica rígida para una apertura de $90^{\circ}$ y diversas cargas horizontales y verticales (KN, eje x y leyenda), elaboración propia 
Como puede observarse en las gráficas anteriores, correspondientes a la Tabla 45, rotaciones en articulaciones de estructura tradicional generada a partir de estructura reentrante hexagonal metálica rígida para una apertura de $90^{\circ}$ y diversas cargas horizontales y verticales, del Apéndice 2. Tablas de cálculo estructural, se observan diversas rotaciones en articulaciones con comportamientos muy diversos dependiendo de las diferentes combinaciones de cargas verticales y cargas horizontales.

Para el nudo 1, observamos que las cargas horizontales son las que más le afectan, puesto que la rotación va subiendo conforme aumenta dicha carga horizontal. Cuando esta última es de 10 y la carga vertical es nula, la rotación aumenta de 0,000009428 a 0,000078; y también cuando la carga horizontal es de 10 y la vertical de 10000, pasando de 0,000078 a 0,00009. El resto del tiempo las altas cargas verticales influyen, llegando a valores máximos de 0,089025 .

Para el nudo 2, se observa que las cargas horizontales afectan a la rotación, salvo en casos concretos. Cuando la carga vertical está en 10000 y la horizontal es nula, la rotación disminuye con respecto, incluso, a la que se da cuando ambas cargas son nulas, pasando de 0,0000001477 a 0,0000001377. Cuando la carga horizontal es de 10 y la vertical es de 10000, la rotación también aumenta de 0,000124 a 0,000146, por lo que la carga vertical influye en ese caso. Sin embargo, las mayores rotaciones en el nudo se obtienen para las cargas horizontales más altas, llegando a valores máximos de 0,146289.

Para el nudo 3, las cargas horizontales y verticales afectan a la rotación. Cuando la carga horizontal es nula, la rotación es de 0,0000004454, afectándole de forma despreciable la carga vertical cuando es muy alta. En el momento en que se aplica la carga horizontal de 1 $\mathrm{KN}$, el valor de la rotación cambia a 0,000008554 y va aumentando progresivamente hasta valores máximos de 0,080286.

Para el nudo 4, las cargas horizontales y verticales afectan en distintos momentos. Para cargas nulas verticales y horizontales, la rotación es de -0,000000385, y aumenta de manera no significativa a medida que las cargas verticales suben, alcanzando el valor de $-0,0000005254$ con la carga vertical más alta. Sin embargo, las mayores rotaciones en el nudo se obtienen para las cargas horizontales más altas, llegando a valores máximos de 0,080285 .

Para el nudo 5, se observa claramente cómo influyen las cargas horizontales, pues, como en el nudo 4, una carga horizontal nula da como resultado una dirección, mientras que en 
los siguientes niveles de carga horizontal esta dirección cambia. Cuando la carga vertical está en 10000 y la horizontal es nula, la rotación disminuye con respecto, incluso, a la que se da cuando ambas cargas son nulas, pasando de $-0,0000001477$ a $-0,0000001377$. Sin embargo, cuando los valores de carga horizontal aumentan, se llega a una rotación máxima de 0,133181 .

Para el nudo 6, encontramos el mismo caso para cargas nulas horizontales que en los nudos 4 y 5 . Cuando la carga horizontal es nula, la rotación es de -0,0000004454, afectándole de forma despreciable la carga vertical cuando es muy alta. En el momento en que se aplica la carga horizontal de $1 \mathrm{KN}$, el valor de la rotación cambia a 0,000006629, aumentando y valor y variando su dirección, y va aumentando progresivamente hasta valores máximos de 0,071546.

De este modo, se puede concluir que las rotaciones en articulaciones para una estructura tradicional generada a partir de estructura reentrante hexagonal metálica rígida para una apertura de $90^{\circ}$ y diversas cargas horizontales y verticales, aumentan con la carga, siendo mayores cuanto mayor sea dicha carga. Se puede decir que las cargas horizontales tienen una mayor importancia que las cargas verticales porque influencian a todos los nudos, y además son las que hacen aumentar de forma considerable las rotaciones en los nudos. 


\section{Reacciones en apoyos}

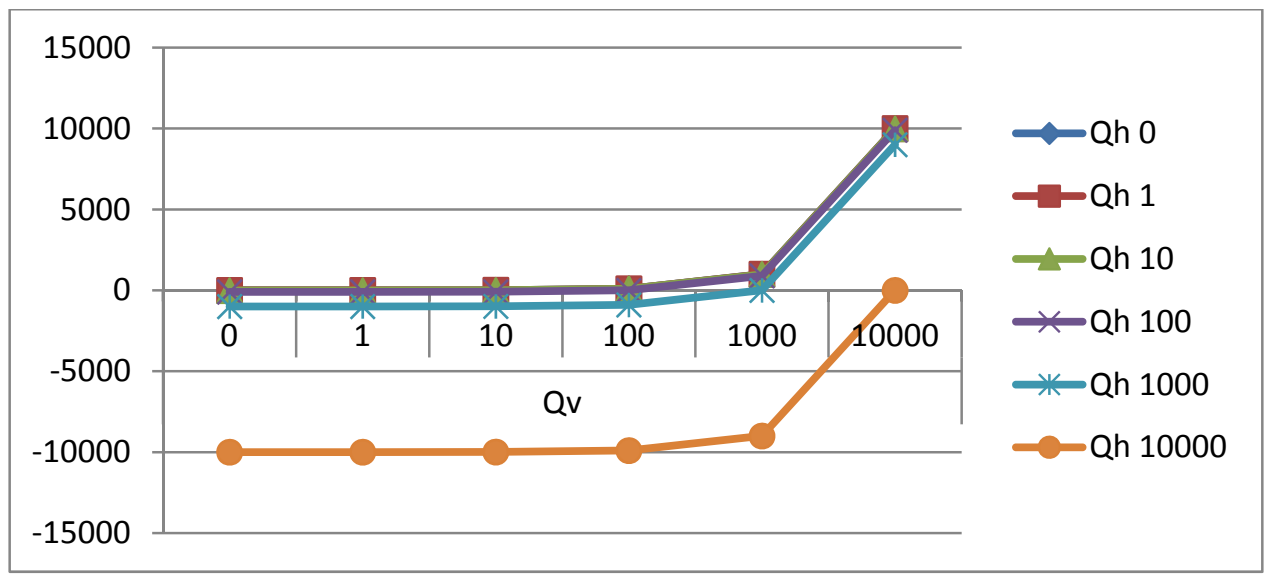

Gráfica 102 Comparación de reacciones verticales en apoyos (KN, eje y) en el nudo 3 de estructura tradicional generada a partir de estructura reentrante hexagonal metálica rígida para una apertura de $90^{\circ}$ y diversas cargas horizontales y verticales (KN, eje x y leyenda), elaboración propia

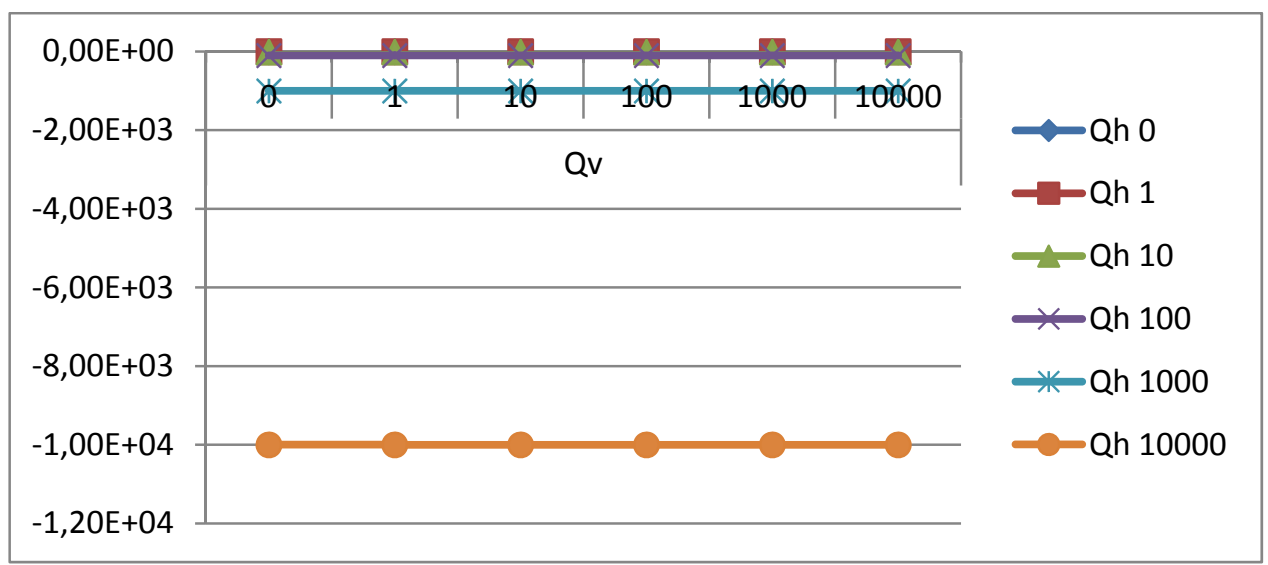

Gráfica 103 Comparación de reacciones horizontales en apoyos (KN, eje y) en el nudo 3 de estructura tradicional generada a partir de estructura reentrante hexagonal metálica rígida para una apertura de $90^{\circ}$ y diversas cargas horizontales y verticales (KN, eje $x$ y leyenda), elaboración propia

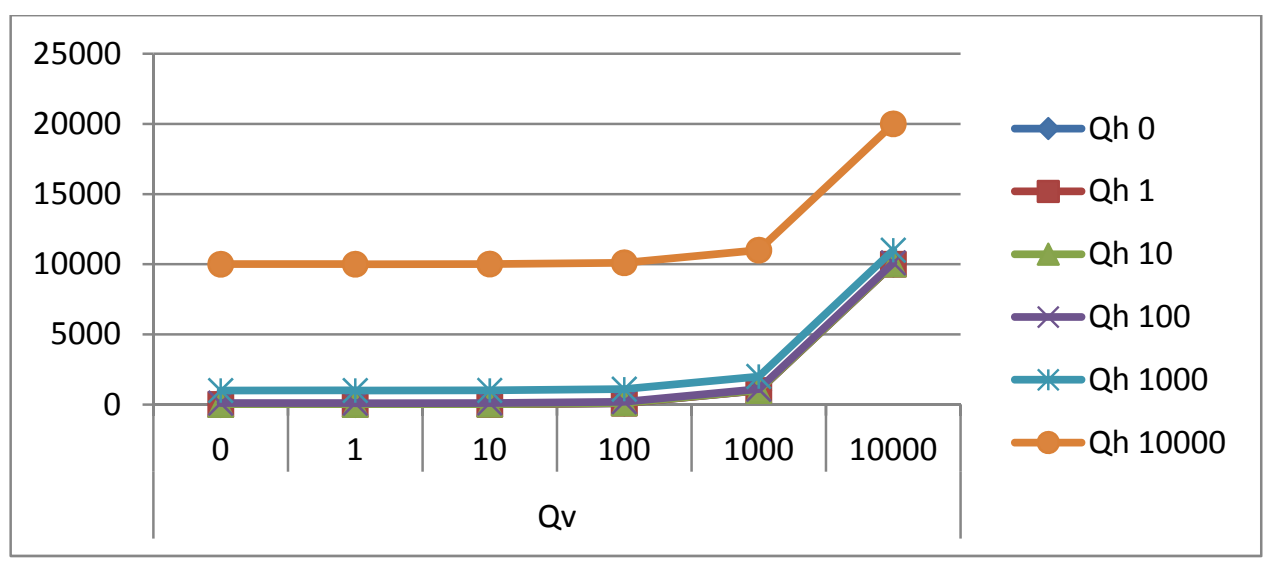

Gráfica 104 Comparación de reacciones verticales en apoyos (KN, eje y) en el nudo 6 de estructura tradicional generada a partir de estructura reentrante hexagonal metálica rígida para una apertura de $90^{\circ}$ y diversas cargas horizontales y verticales (KN, eje $x$ y leyenda), elaboración propia 
Como puede observarse en las gráficas anteriores, correspondientes a la Tabla 46, reacciones en apoyos de estructura tradicional generada a partir de estructura reentrante hexagonal metálica rígida para una apertura de $90^{\circ}$ y diversas cargas horizontales y verticales, del Apéndice 1. Desplazamientos verticales, se observan diversas reacciones en apoyos con comportamientos muy diversos dependiendo de las diferentes combinaciones de cargas verticales y cargas horizontales.

Para el nudo 3, observamos que las cargas horizontales producen reacciones verticales en sentido gravitatorio, mientras que las cargas verticales las reacciones las generan en sentido antigravitatorio. De este modo, cuando tenemos una carga vertical nula y una horizontal de $10000 \mathrm{KN}$, se observan reacciones muy altas, de magnitud -9999,34 KN. Del mismo modo, cuando tenemos una carga horizontal nula y una vertical de $10000 \mathrm{KN}$, se observan también reacciones muy altas, de magnitud 10000,66 KN. Sin embargo, cuando los dos tipos de carga (horizontal y vertical) son de $10000 \mathrm{KN}$, las reacciones producidas por ambos en sentido inverso, se compensan entre sí, bajando la reacción final en el nudo a 0,66 KN.

Para el mismo nudo 3, observamos que las cargas horizontales son las que producen reacciones horizontales, mientras que las cargas verticales no generan reacciones en esta dirección. De este modo, cuando tenemos unas cargas nulas, se observa una reacción en el apoyo también nula. Sin embargo, conforme aumentamos el valor de la carga horizontal, la reacción en el apoyo cobra valores iguales a la carga aplicada, pero de sentido contrario, llegando a reacciones horizontales máximas de -10000 KN.

Para el nudo 6, observamos que tanto las cargas horizontales como las verticales producen reacciones verticales en el apoyo de sentido positivo. Así, cuando tenemos una carga vertical nula y una horizontal de $10000 \mathrm{KN}$, se observan reacciones muy altas, de magnitud 10000,66 KN. Del mismo modo, cuando tenemos una carga horizontal nula y una vertical de 10000 KN, se observan también reacciones muy altas, de magnitud 10000,66 KN. Además, cuando los dos tipos de carga (horizontal y vertical) son de $10000 \mathrm{KN}$, las reacciones producidas por ambos se suman, aumentando la reacción final en el nudo a 20000,66 KN.

De este modo, se puede concluir que las reacciones en los apoyos para una estructura tradicional generada a partir de estructura reentrante hexagonal metálica rígida para una apertura de $90^{\circ}$ y diversas cargas horizontales y verticales, aumentan con la carga, siendo mayores las verticales cuanto mayor sea dicha carga para el nudo 6 y compensándose para el nudo 3. Se puede decir que las cargas horizontales tienen una mayor importancia que las cargas verticales al generar reacciones horizontales. 
Esfuerzos axiles

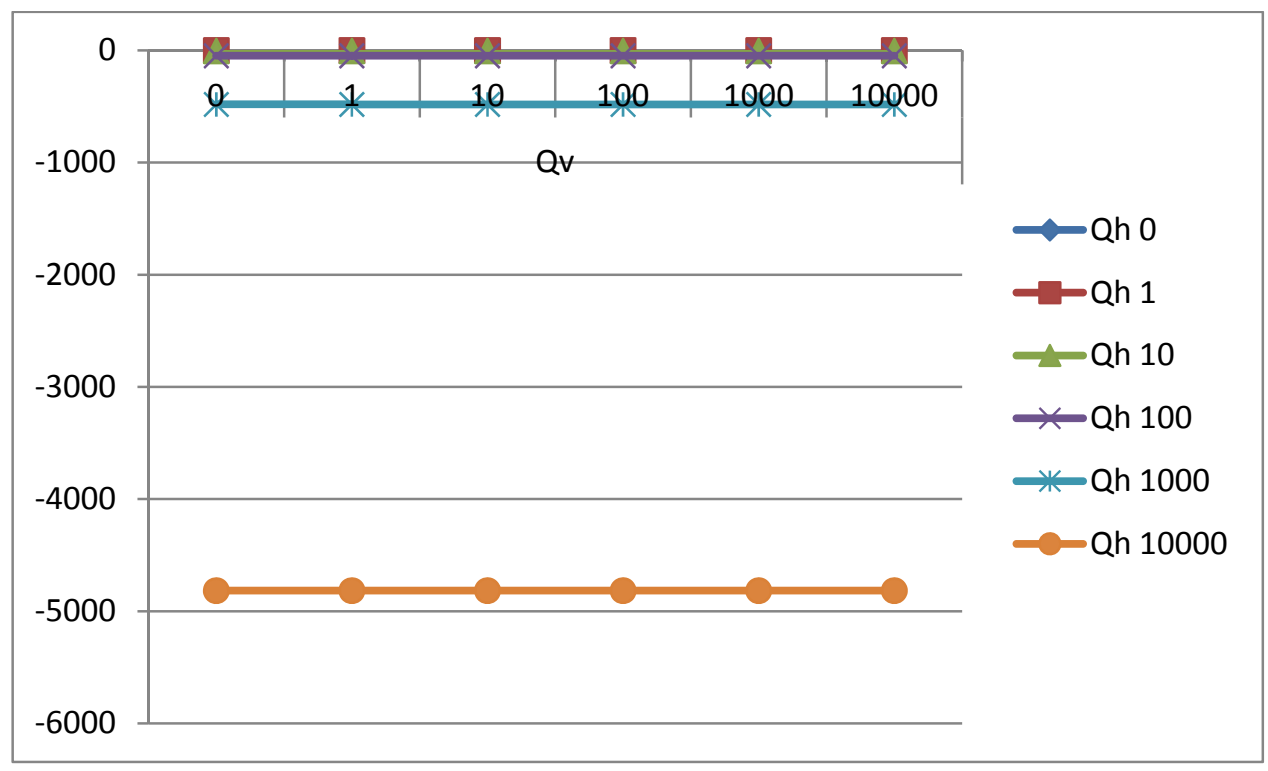

Gráfica 105 Comparación de esfuerzos axiles (KN, eje y) en la barra a de estructura tradicional generada a partir de estructura reentrante hexagonal metálica rígida para una apertura de $90^{\circ}$ y diversas cargas horizontales $y$ verticales ( $K N$, eje $x$ y leyenda), elaboración propia

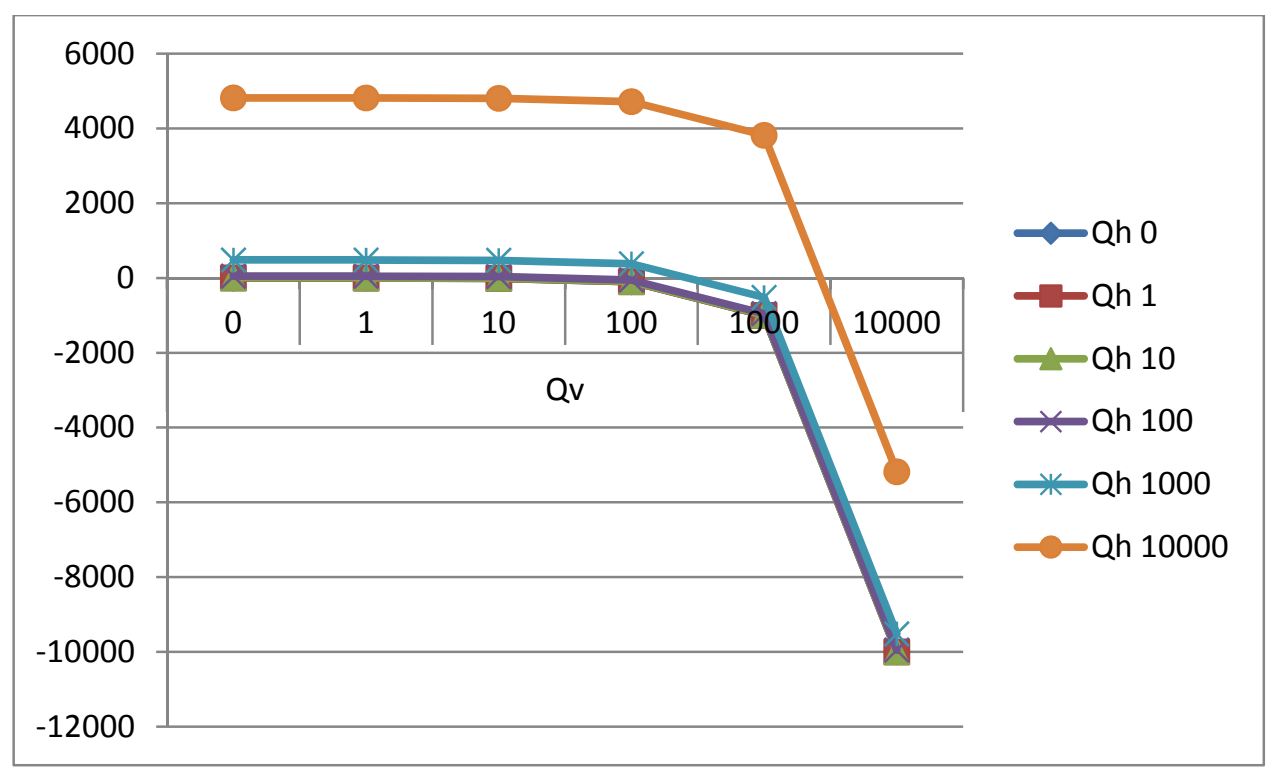

Gráfica 106 Comparación de esfuerzos axiles mínimos (KN, eje y) en la barra $b$ de estructura tradicional generada a partir de estructura reentrante hexagonal metálica rígida para una apertura de $90^{\circ}$ y diversas cargas horizontales y verticales (KN, eje $x$ y leyenda), elaboración propia 
Aplicaciones de las propiedades auxéticas en la arquitectura

CÁLCULO ESTRUCTURAL DE ESTRUCTURAS AUXÉTICAS

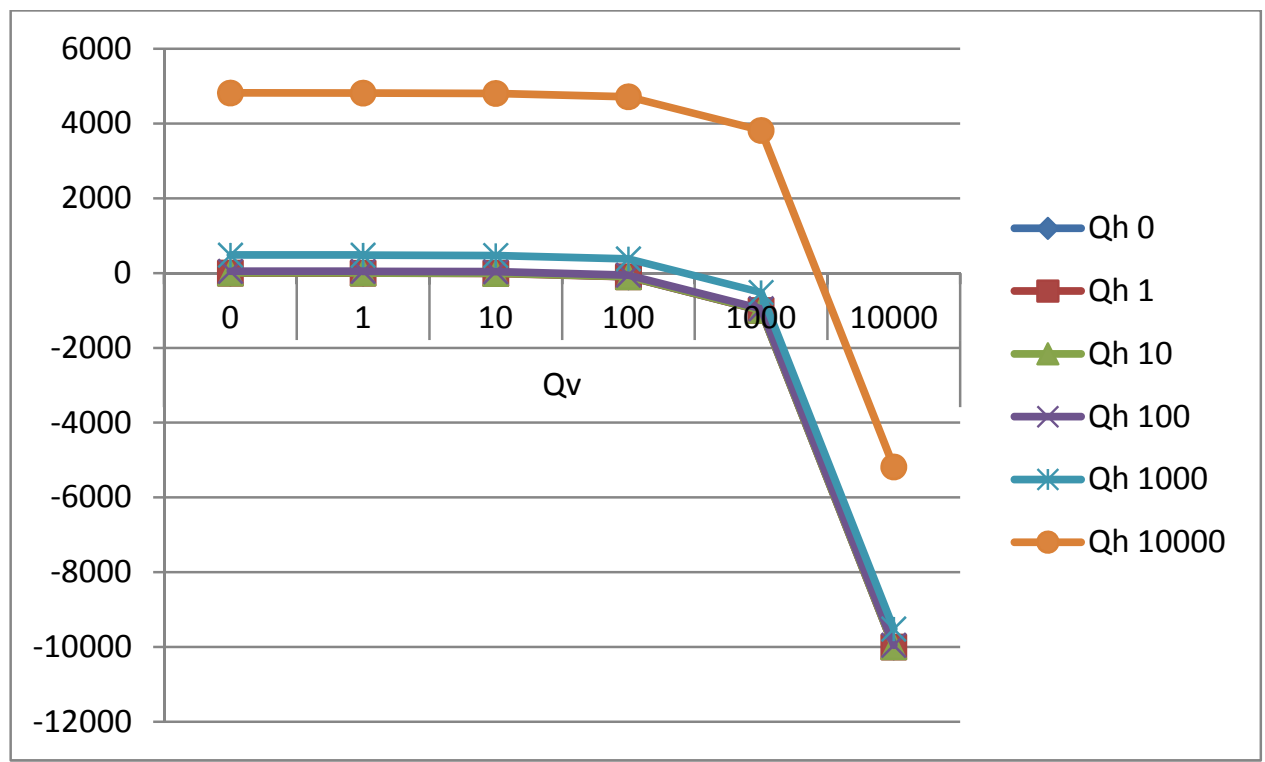

Gráfica 107 Comparación de esfuerzos axiles máximos ( $K N$, eje y) en la barra $b$ de estructura tradicional generada a partir de estructura reentrante hexagonal metálica rígida para una apertura de $90^{\circ}$ y diversas cargas horizontales y verticales (KN, eje $x$ y leyenda), elaboración propia

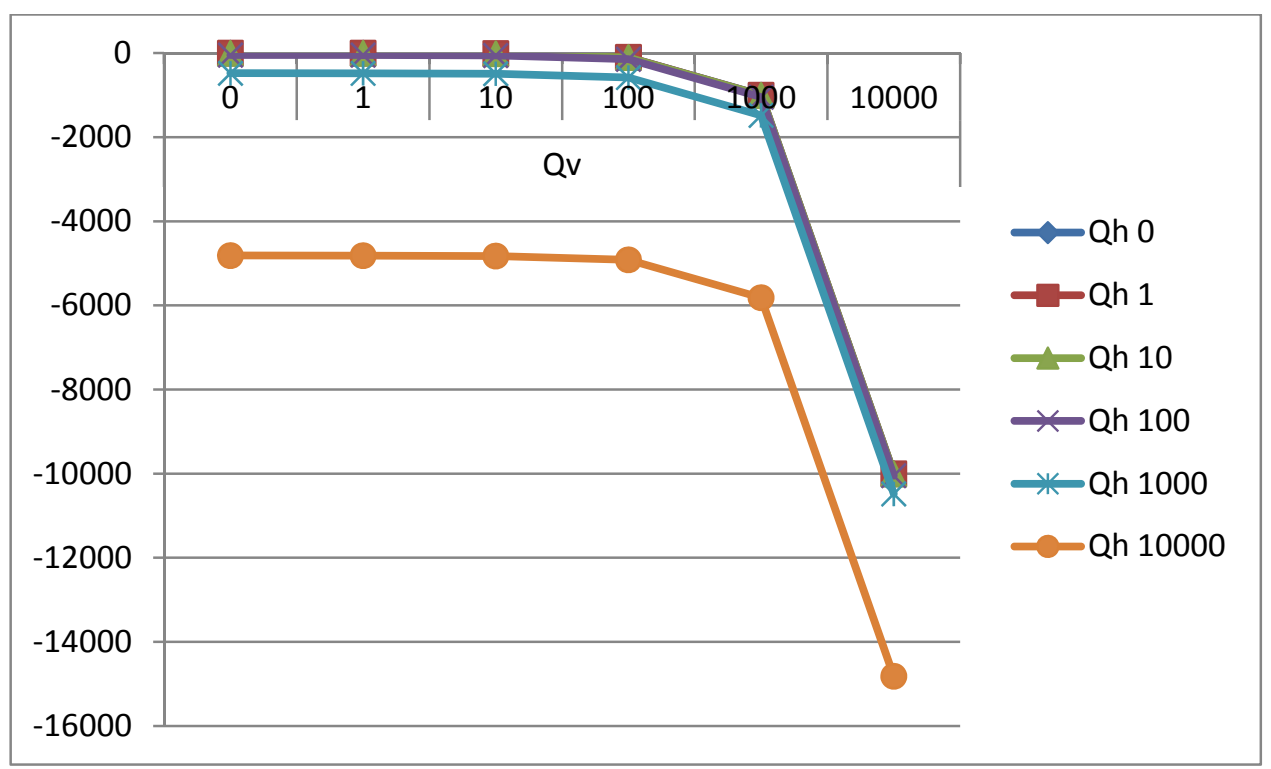

Gráfica 108 Comparación de esfuerzos axiles mínimos (KN, eje y) en la barra c de estructura tradicional generada a partir de estructura reentrante hexagonal metálica rígida para una apertura de $90^{\circ}$ y diversas cargas horizontales y verticales (KN, eje $x$ y leyenda), elaboración propia 


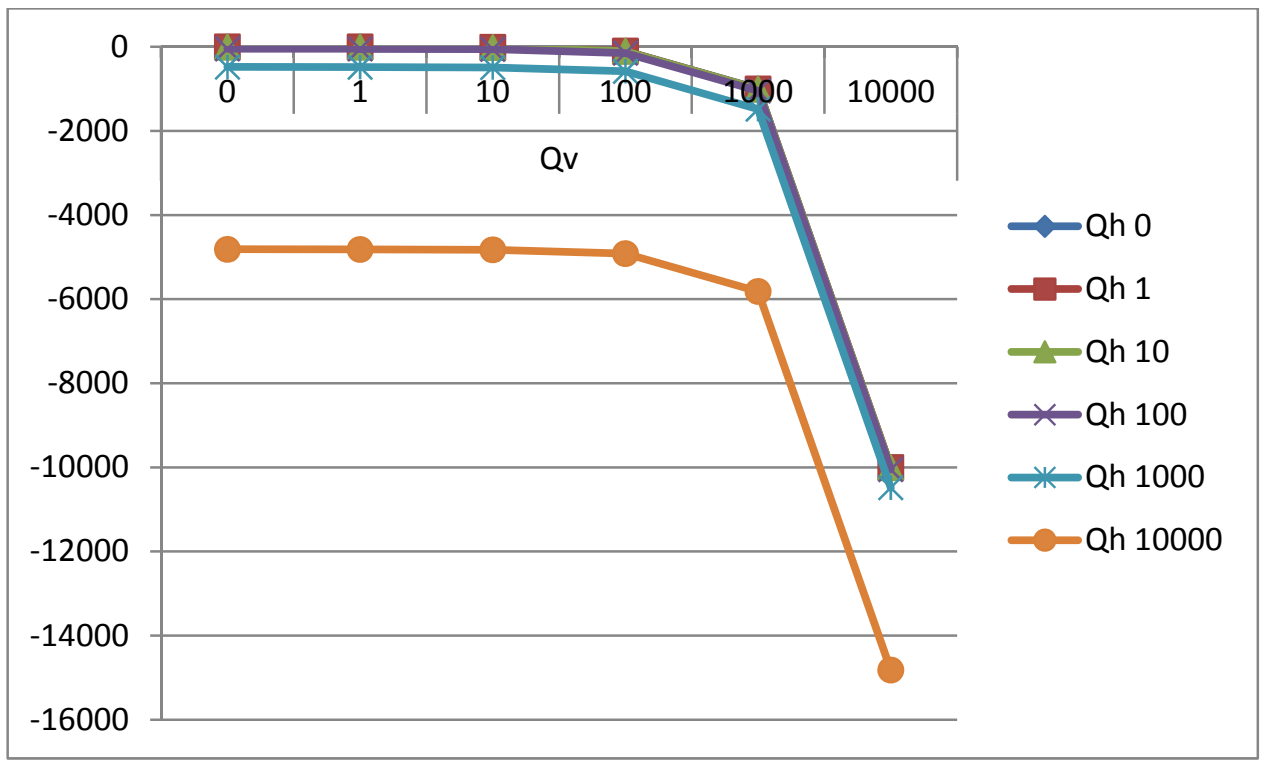

Gráfica 109 Comparación de esfuerzos axiles máximos ( $K N$, eje y) en la barra c de estructura tradicional generada a partir de estructura reentrante hexagonal metálica rígida para una apertura de $90^{\circ}$ y diversas cargas horizontales y verticales (KN, eje $x$ y leyenda), elaboración propia

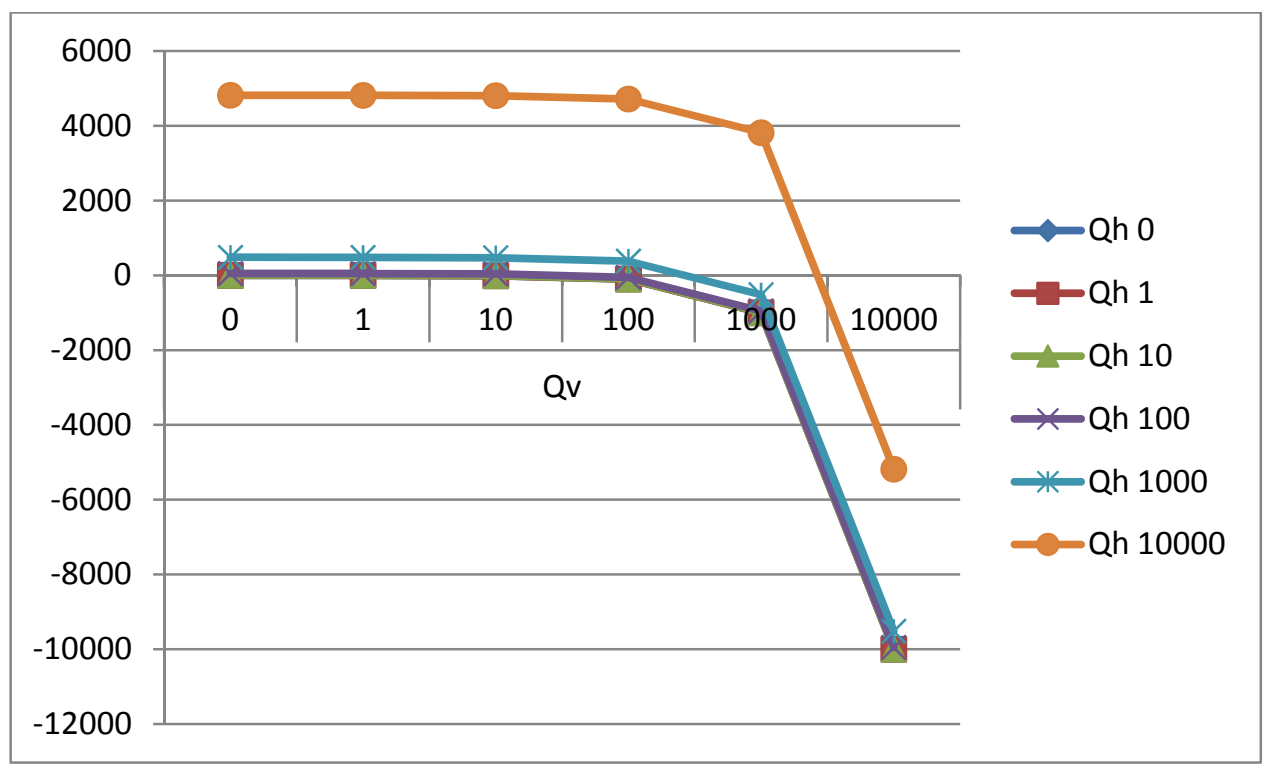

Gráfica 110 Comparación de esfuerzos axiles mínimos (KN, eje y) en la barra d de estructura tradicional generada a partir de estructura reentrante hexagonal metálica rígida para una apertura de $90^{\circ}$ y diversas cargas horizontales y verticales (KN, eje $x$ y leyenda), elaboración propia 
Aplicaciones de las propiedades auxéticas en la arquitectura

CÁLCULO ESTRUCTURAL DE ESTRUCTURAS AUXÉTICAS

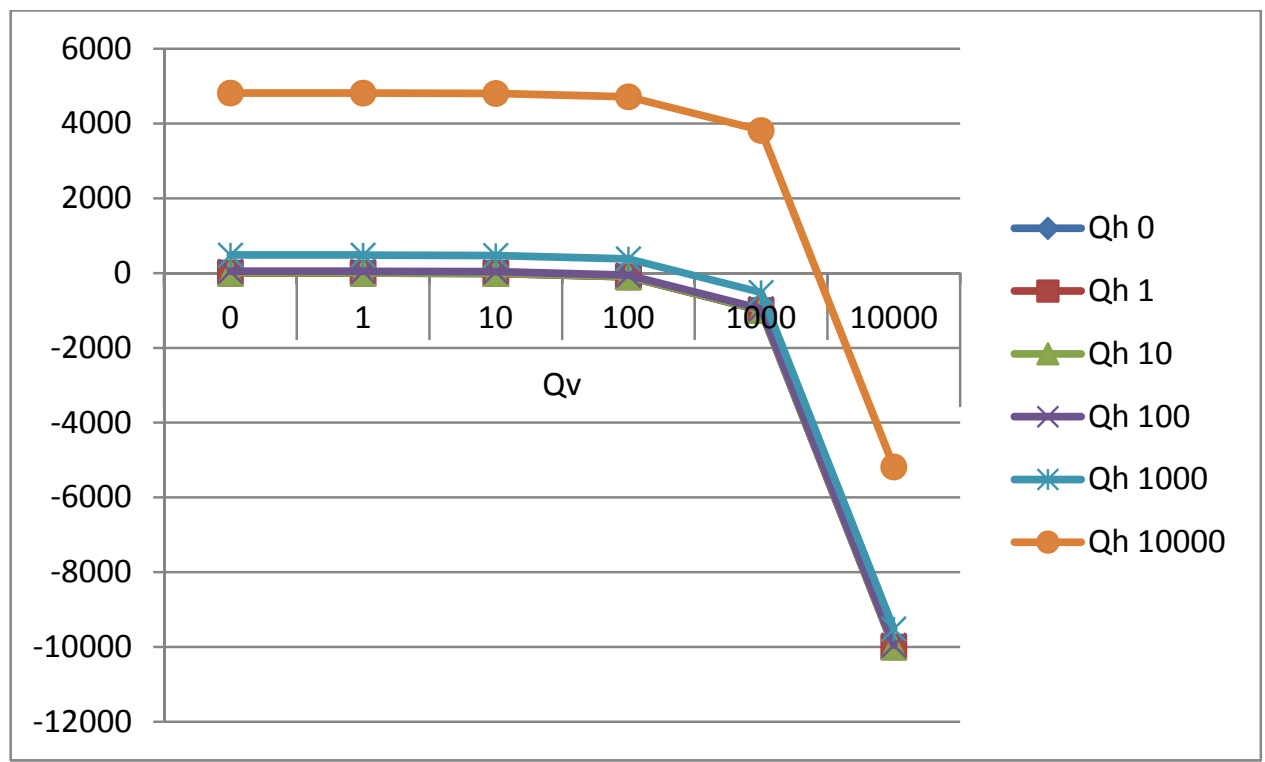

Gráfica 111 Comparación de esfuerzos axiles máximos ( $K N$, eje y) en la barra $d$ de estructura tradicional generada a partir de estructura reentrante hexagonal metálica rígida para una apertura de $90^{\circ}$ y diversas cargas horizontales y verticales (KN, eje $x$ y leyenda), elaboración propia

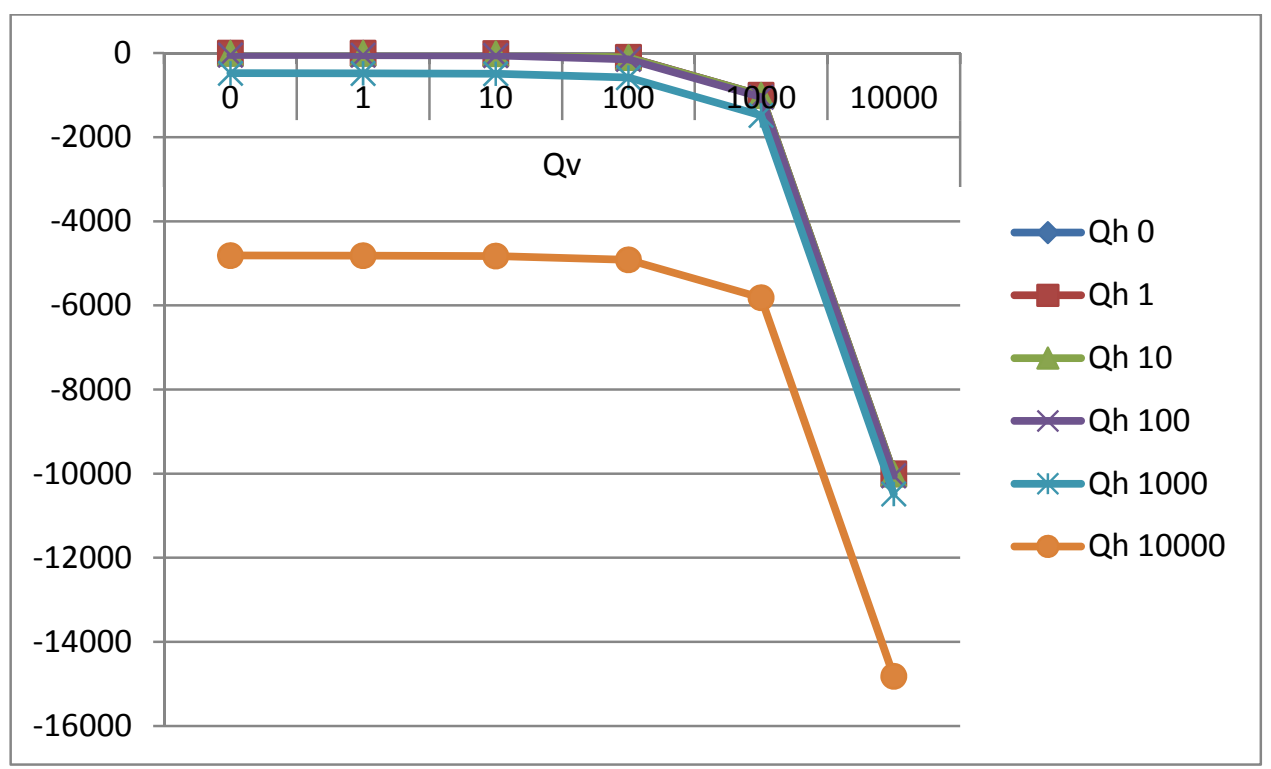

Gráfica 112 Comparación de esfuerzos axiles mínimos (KN, eje y) en la barra e de estructura tradicional generada a partir de estructura reentrante hexagonal metálica rígida para una apertura de $90^{\circ}$ y diversas cargas horizontales y verticales (KN, eje $x$ y leyenda), elaboración propia 


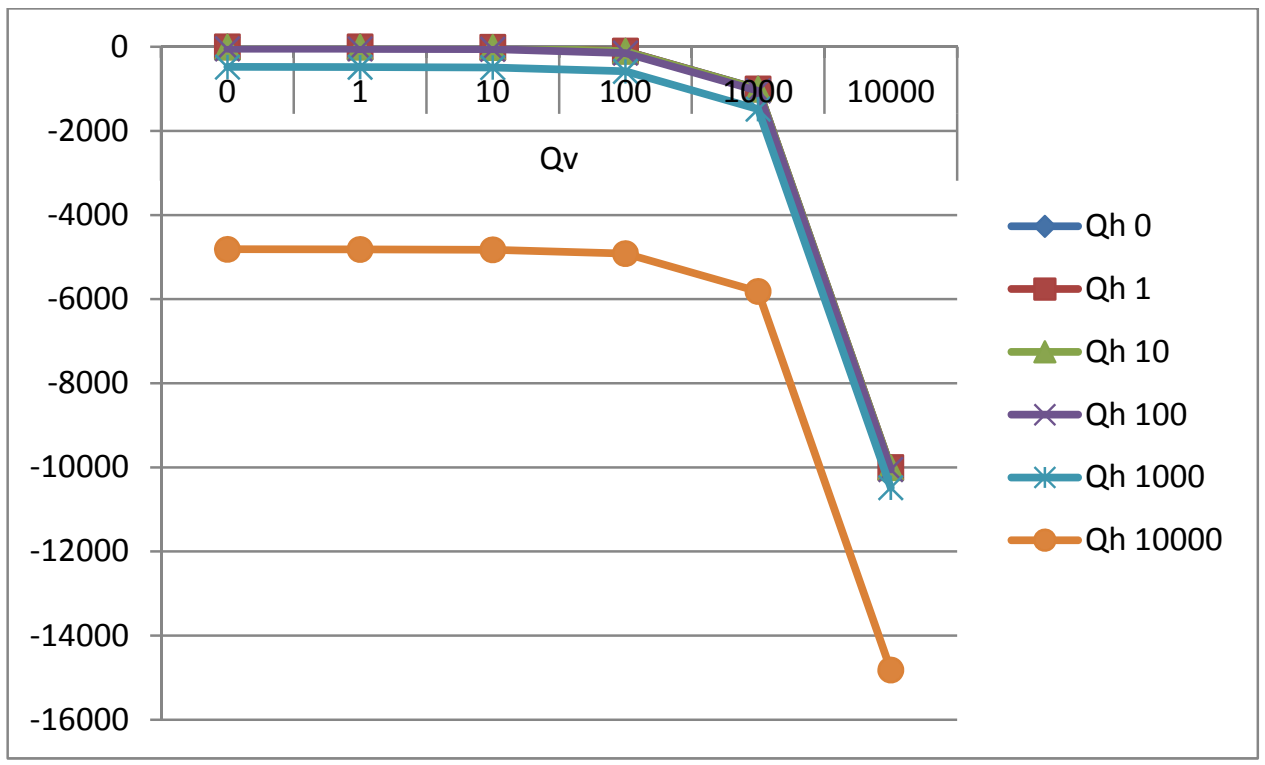

Gráfica 113 Comparación de esfuerzos axiles máximos ( $K N$, eje y) en la barra e de estructura tradicional generada a partir de estructura reentrante hexagonal metálica rígida para una apertura de $90^{\circ}$ y diversas cargas horizontales y verticales (KN, eje $x$ y leyenda), elaboración propia

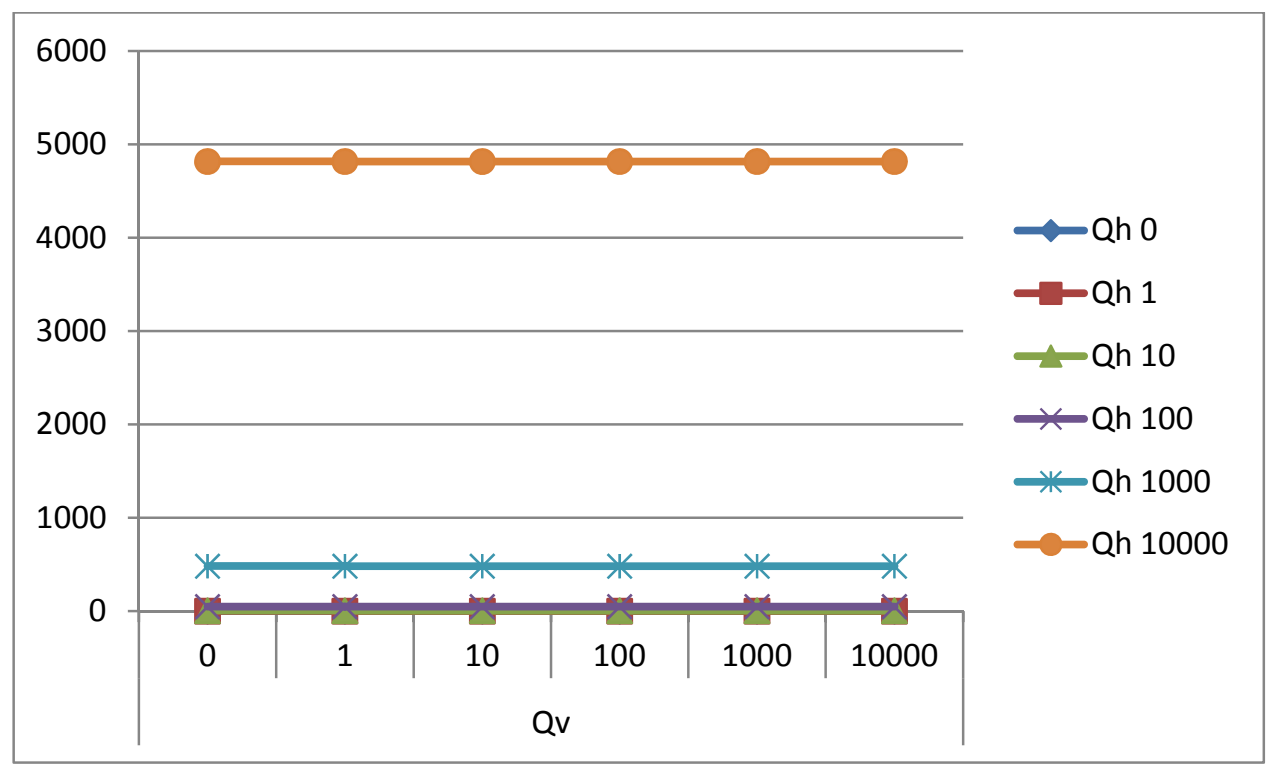

Gráfica 114 Comparación de esfuerzos axiles (KN, eje y) en la barra $f$ de estructura tradicional generada a partir de estructura reentrante hexagonal metálica rígida para una apertura de $90^{\circ}$ y diversas cargas horizontales $y$ verticales ( $K N$, eje $x$ y leyenda), elaboración propia 
Como puede observarse en las gráficas anteriores, correspondientes a la tabla 47, esfuerzos axiles de estructura tradicional generada a partir de estructura reentrante hexagonal metálica rígida para una apertura de $90^{\circ}$ y diversas cargas horizontales y verticales, del Apéndice 2. Tablas de cálculo estructural, se observan diversas esfuerzos axiles con comportamientos muy diversos dependiendo de las diferentes combinaciones de cargas verticales y cargas horizontales.

En la barra a, las cargas horizontales afectan al esfuerzo, que aumenta progresivamente según aumenta esta carga. Solo en dos casos las altas cargas verticales de 10000 afectan al ligeramente al esfuerzo. Cuando la carga horizontal es nula, se pasa de -0,031 a -0,033; y cuando la carga horizontal es de 10 , se pasa de $-4,855$ a $-4,849$. Sin embargo, cuando la nula es la carga vertical y la carga horizontal aumenta de 0 a 10000 se pasa de un esfuerzo de $-0,031 \mathrm{KN}$ a un esfuerzo de $-4816,285 \mathrm{KN}$.

En la barra b, las cargas horizontales y verticales influyen en la dirección del esfuerzo. Para ambas cargas nulas, el esfuerzo es de -0,164 a -0,246. Esta dirección es de compresión cuando se somete a cargas verticales. Sin embargo, al aplicar una carga horizontal de 1, la dirección cambia a tracción hacia valores que oscilan de 0,153 a 0,317, aunque al ser una carga baja, las cargas verticales siguen influyendo en la dirección. La tendencia va cambiando según aumenta la carga horizontal, que alcanza su máximo cuando Qh=10000 y $\mathrm{Qv}=1000$, llegando a 3815,924 a 3816,088. A pesar de ello, la carga vertical máxima siempre supera su influencia sobre el esfuerzo, pues equiparándola con la carga horizontal superior, llega a $-5184,076$ a $-5183,912$.

En la barra c, las cargas horizontales y verticales afectan por igual, viéndose aumentado el esfuerzo de forma progresiva en ambos casos. Para cargas nulas, el esfuerzo es de -0,164 a -0,246, y para cargas máximas se obtiene un esfuerzo de compresión que oscila entre 5184,24 y $-5184,076$.

En la barra d, al igual que en la barra b, las cargas verticales y las horizontales generan diferentes direcciones de esfuerzo. Las cargas horizontales bajas no afectan a la dirección del esfuerzo, e incluso, como cuando la carga horizontal aumenta a 1, disminuyen, pasando de $-0,246$ a $-0,328$ para una carga horizontal nula a -0,011 a 0,153 con carga horizontal 1 y carga vertical nula. Sin embargo, a medida que las cargas horizontales aumentan, las cargas verticales ceden y la dirección del esfuerzo cambia, excepto en el caso de Qh=10000 y Qv=10000. En ese caso, el esfuerzo es de $-5184,24$ a $-5184,076$, por lo que mantiene la dirección. 
En la barra e, las cargas horizontales y verticales afectan por igual, puesto que en ambas se observa un aumento del esfuerzo axil de forma progresiva, de forma directamente proporcional a la carga que se aplica en cada caso. Para cargas nulas, el esfuerzo es de 0,246 a -0,328 y para cargas máximas se genera un esfuerzo de compresión de 14816,581 a $-14816,745$.

En la barra f, las cargas horizontales son las que afectan en mayor grado al esfuerzo, pues se observa un aumento progresivo del mismo de 0,031 para una carga horizontal nula, a 0,514 con carga 1, 4,855 con carga 10,48,195 con carga 100, 481,658 con carga 1000 y 4816,285 con carga 10000. Al aplicar las cargas verticales, el esfuerzo se mantiene estable, por lo que no le afecta, excepto cuando $Q h=0$ y $Q v=10000$, que pasa de 0,031 a 0,033; y cuando Qh=10 y Qv=10000, que disminuye de 4,855 a 4,849.

De este modo, se puede concluir que los esfuerzos axiles en barras para una estructura tradicional generada a partir de estructura reentrante hexagonal metálica rígida para una apertura de $90^{\circ}$ y diversas cargas horizontales y verticales, aumentan con la carga, siendo mayores cuanto mayor sea dicha carga. Se puede decir que las cargas horizontales tienen una mayor importancia que las cargas verticales porque son las únicas que influencian a algunas barras, y además son las que hacen aumentar de forma considerable el esfuerzo axil en las barras. 


\section{Esfuerzos cortantes}

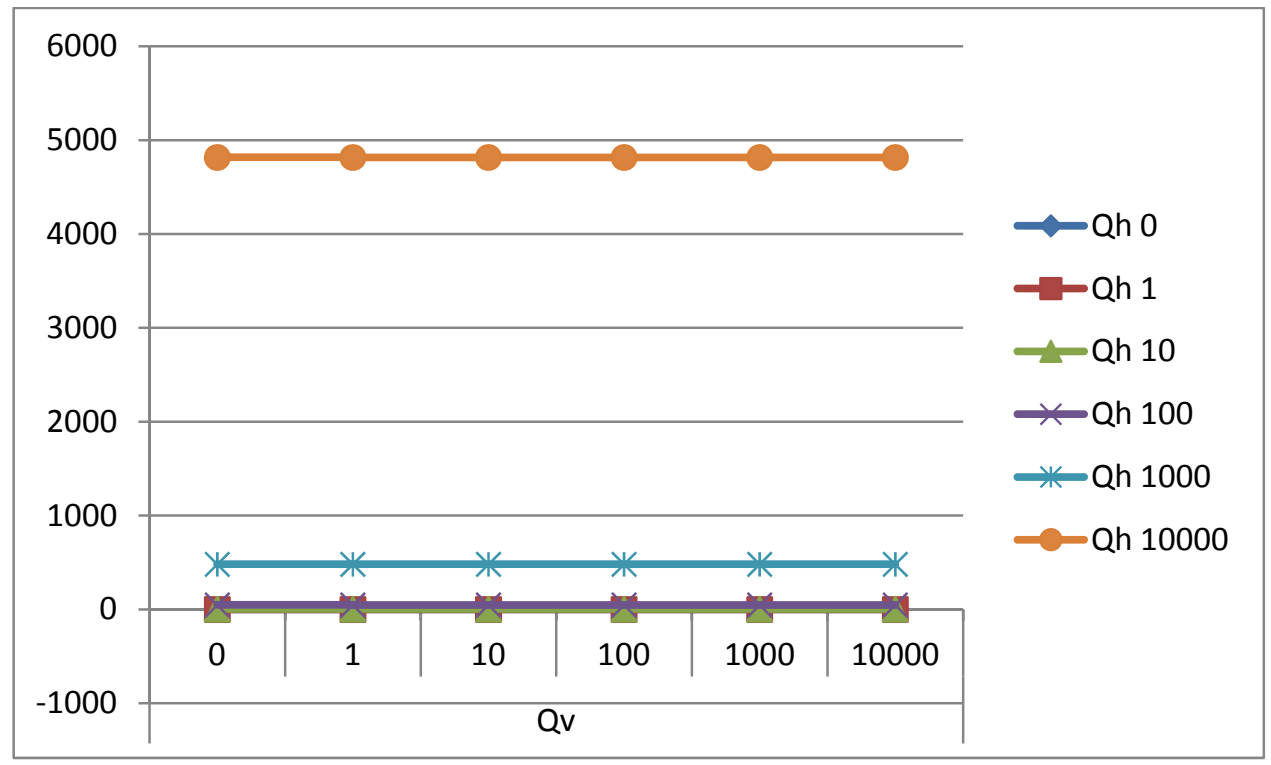

Gráfica 115 Comparación de esfuerzos cortantes mínimos (KN, eje y) en la barra a de estructura tradicional generada a partir de estructura reentrante hexagonal metálica rígida para una apertura de $90^{\circ}$ y diversas cargas horizontales y verticales (KN, eje x y leyenda), elaboración propia

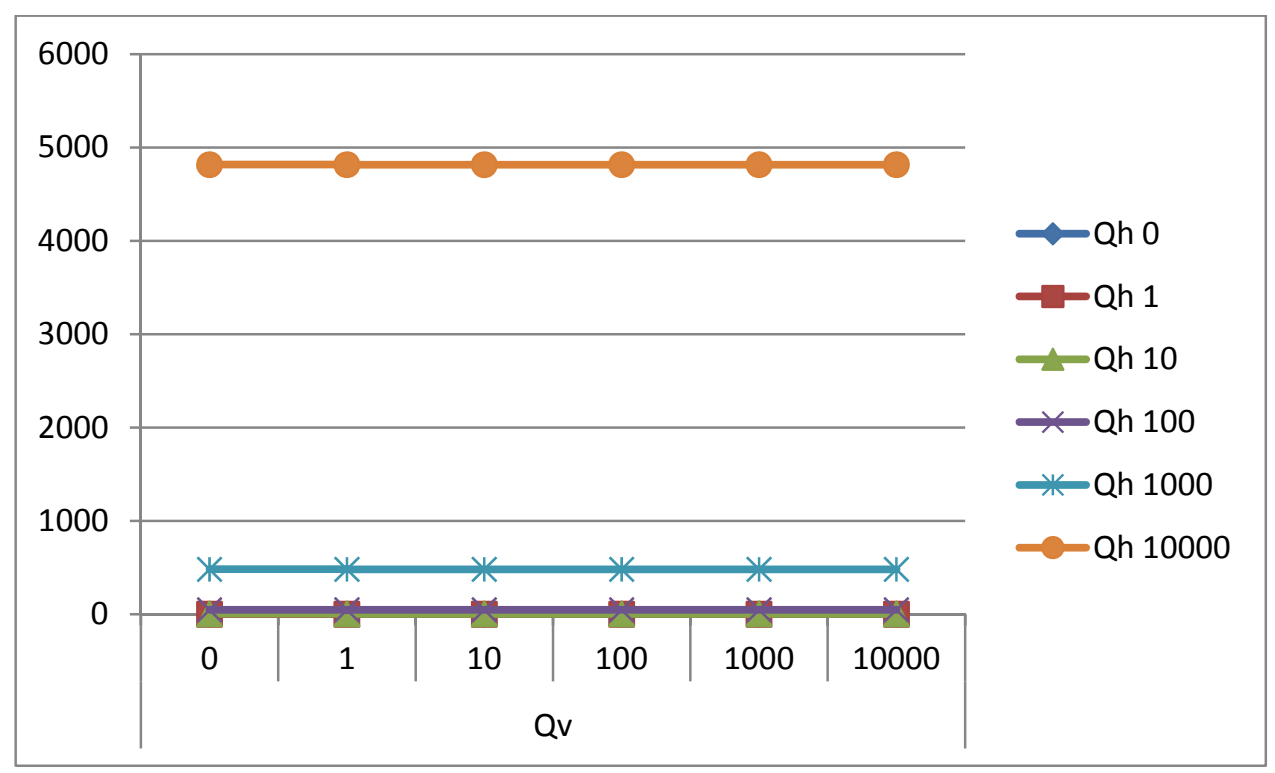

Gráfica 116 Comparación de esfuerzos cortantes máximos ( $K N$, eje y) en la barra a de estructura tradicional generada a partir de estructura reentrante hexagonal metálica rígida para una apertura de $90^{\circ}$ y diversas cargas horizontales y verticales ( $K N$, eje $x$ y leyenda), elaboración propia 


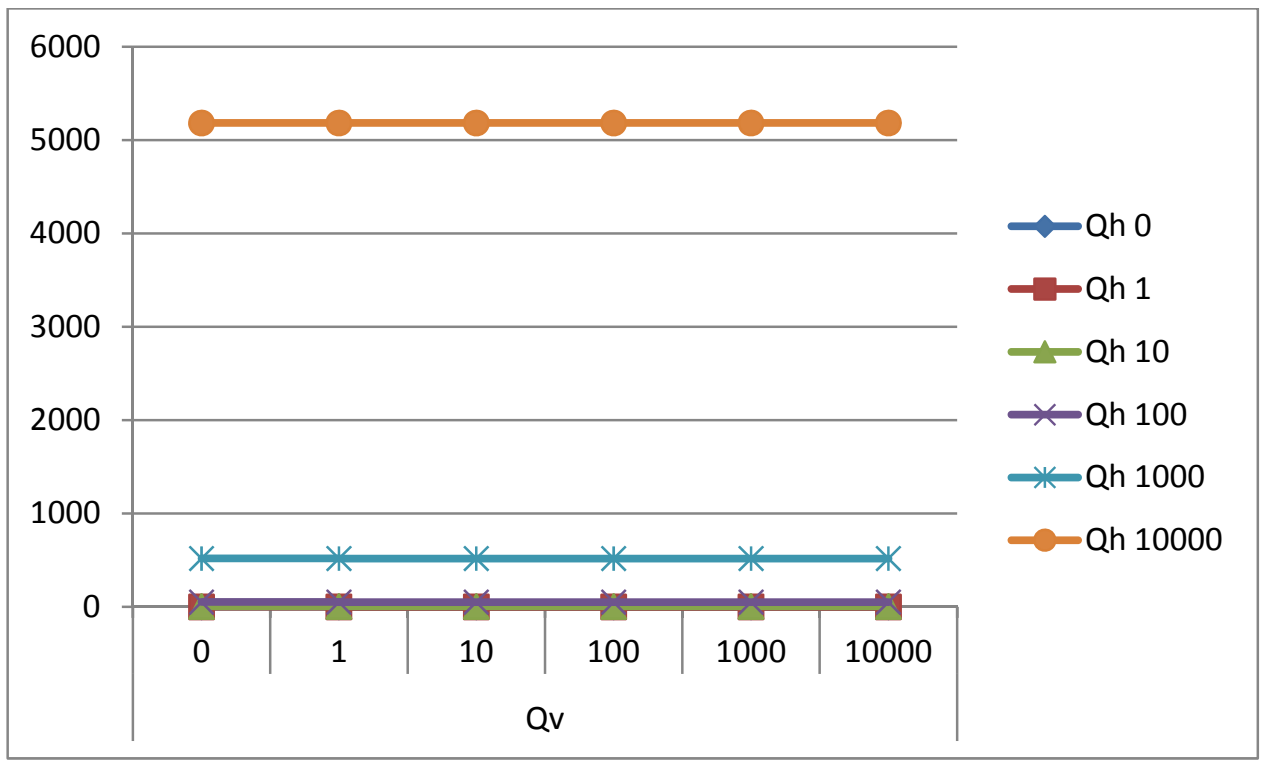

Gráfica 117 Comparación de esfuerzos cortantes mínimos (KN, eje y) en la barra b de estructura tradicional generada a partir de estructura reentrante hexagonal metálica rígida para una apertura de $90^{\circ}$ y diversas cargas horizontales y verticales (KN, eje $x$ y leyenda), elaboración propia

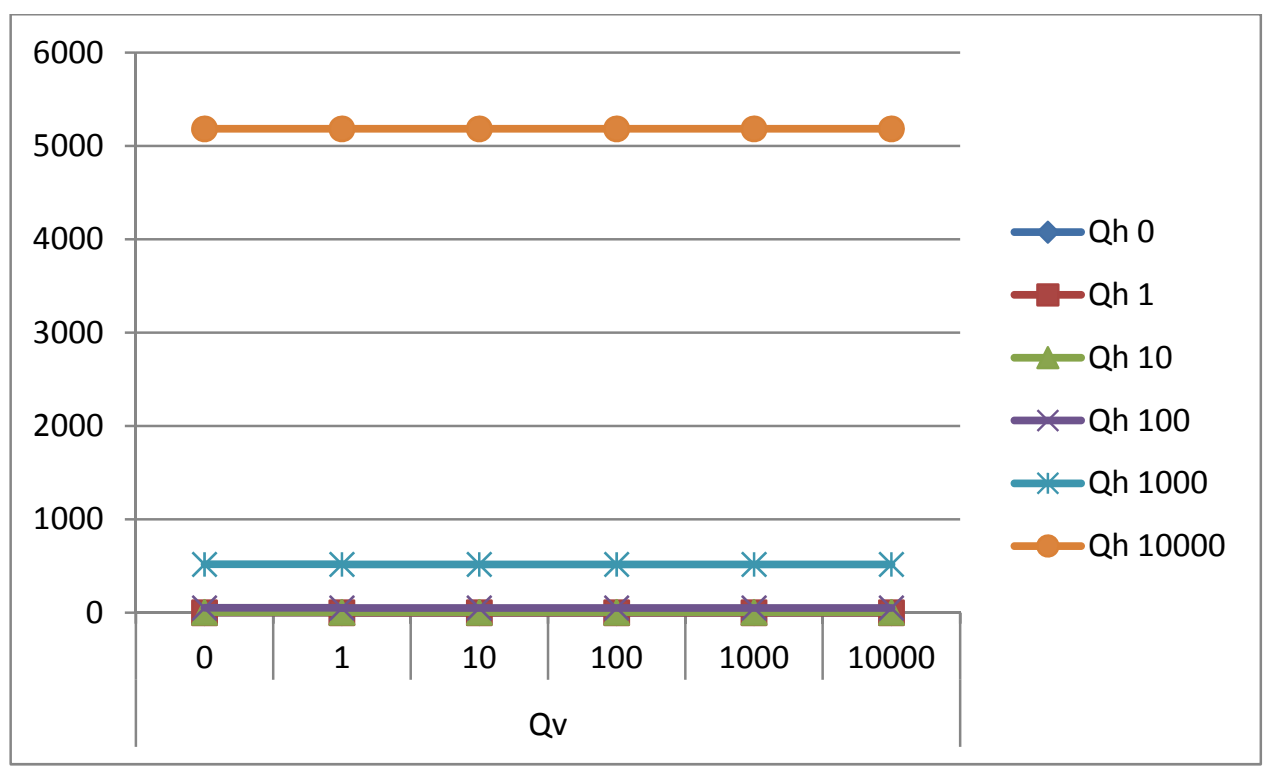

Gráfica 118 Comparación de esfuerzos cortantes máximos ( $K N$, eje y) en la barra b de estructura tradicional generada a partir de estructura reentrante hexagonal metálica rígida para una apertura de $90^{\circ}$ y diversas cargas horizontales y verticales (KN, eje $x$ y leyenda), elaboración propia 


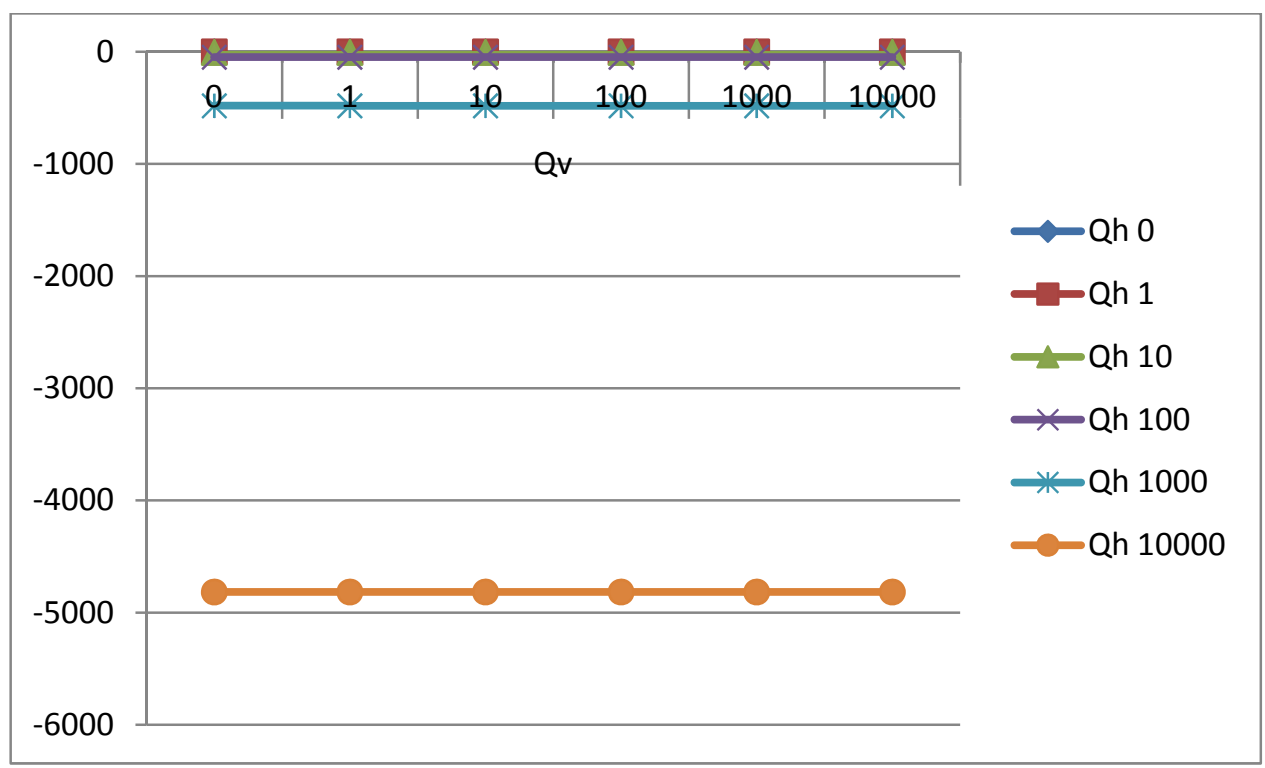

Gráfica 119 Comparación de esfuerzos cortantes mínimos (KN, eje y) en la barra c de estructura tradicional generada a partir de estructura reentrante hexagonal metálica rígida para una apertura de $90^{\circ}$ y diversas cargas horizontales y verticales (KN, eje $x$ y leyenda), elaboración propia

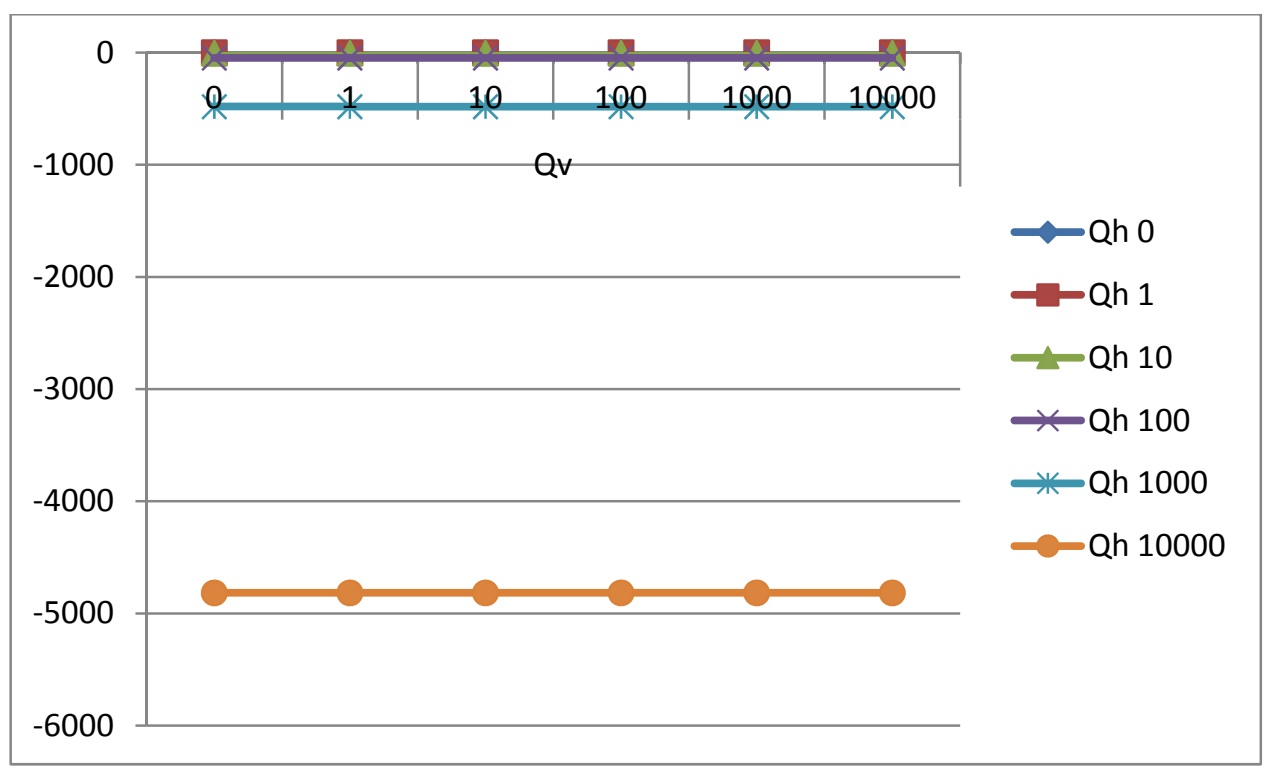

Gráfica 120 Comparación de esfuerzos cortantes máximos (KN, eje y) en la barra c de estructura tradicional generada a partir de estructura reentrante hexagonal metálica rígida para una apertura de $90^{\circ}$ y diversas cargas horizontales y verticales (KN, eje $x$ y leyenda), elaboración propia. 


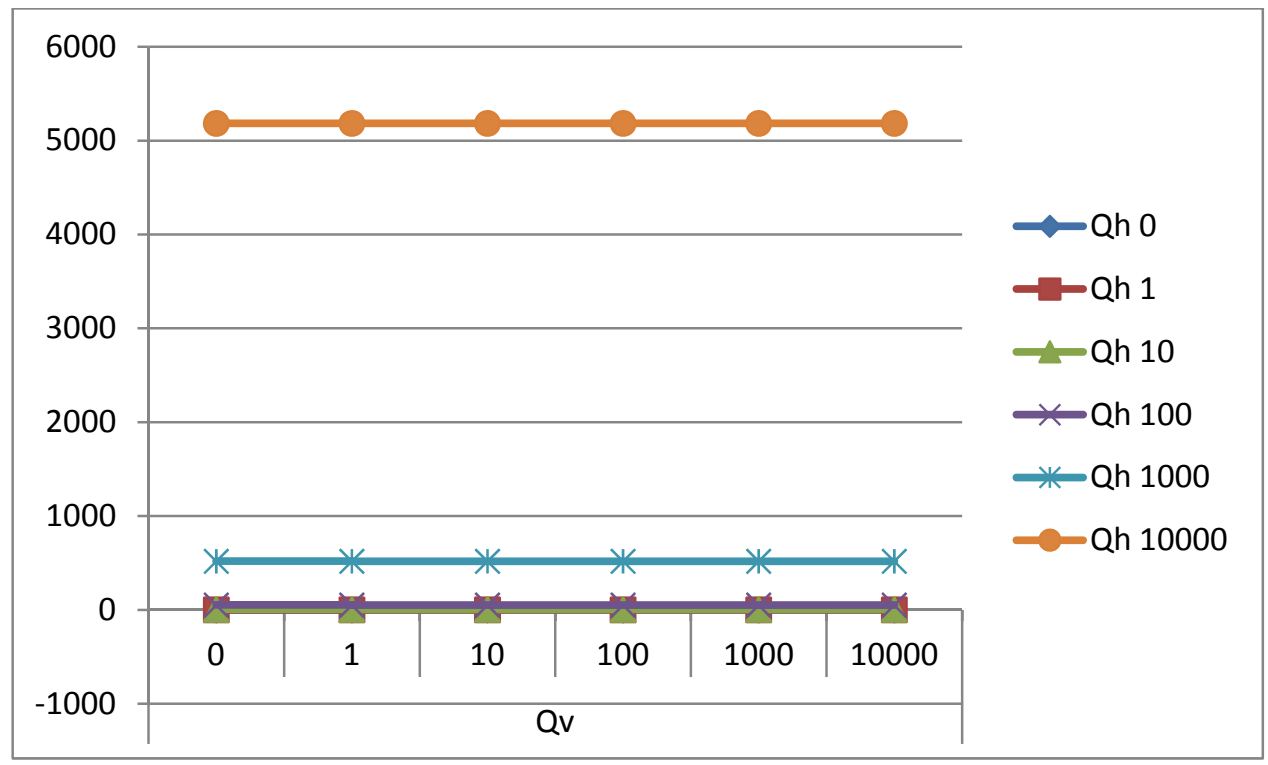

Gráfica 121 Comparación de esfuerzos cortantes mínimos (KN, eje y) en la barra d de estructura tradicional generada a partir de estructura reentrante hexagonal metálica rígida para una apertura de $90^{\circ}$ y diversas cargas horizontales y verticales (KN, eje $x$ y leyenda), elaboración propia

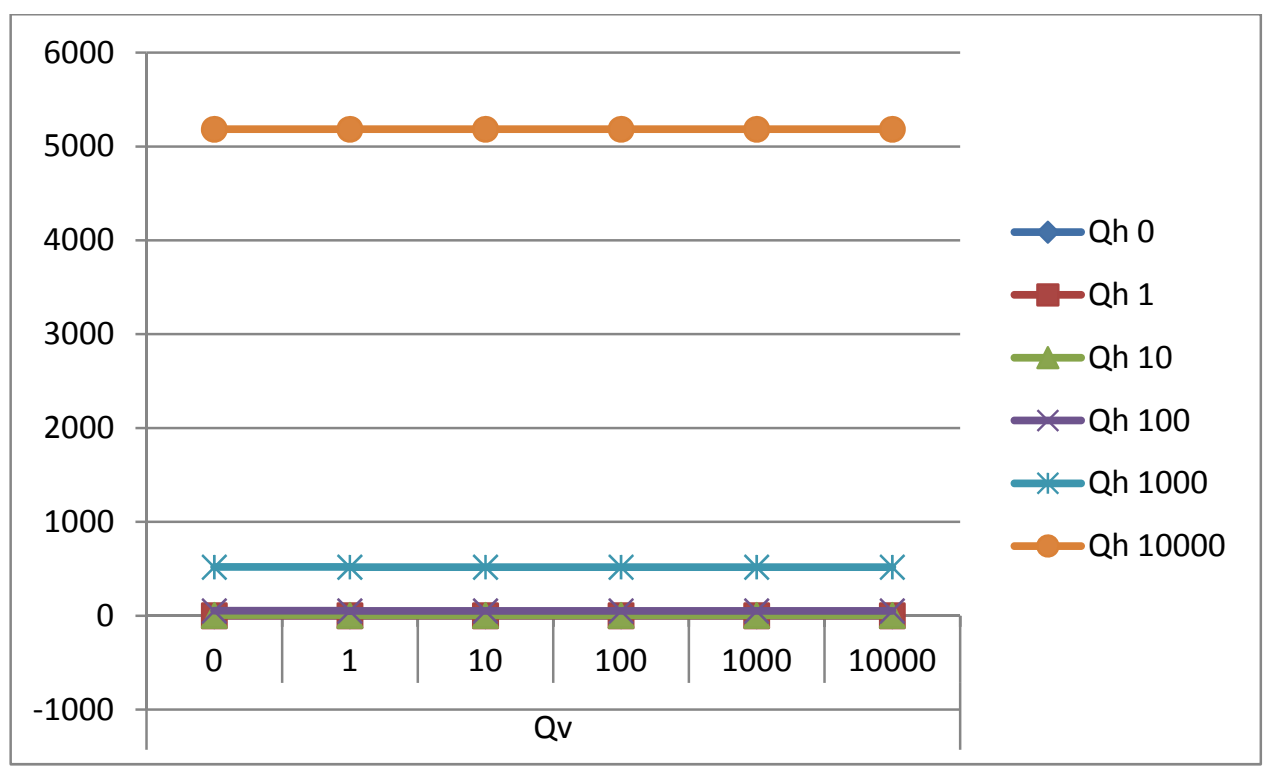

Gráfica 122 Comparación de esfuerzos cortantes máximos ( $K N$, eje y) en la barra d de estructura tradicional generada a partir de estructura reentrante hexagonal metálica rígida para una apertura de $90^{\circ}$ y diversas cargas horizontales y verticales (KN, eje $x$ y leyenda), elaboración propia 


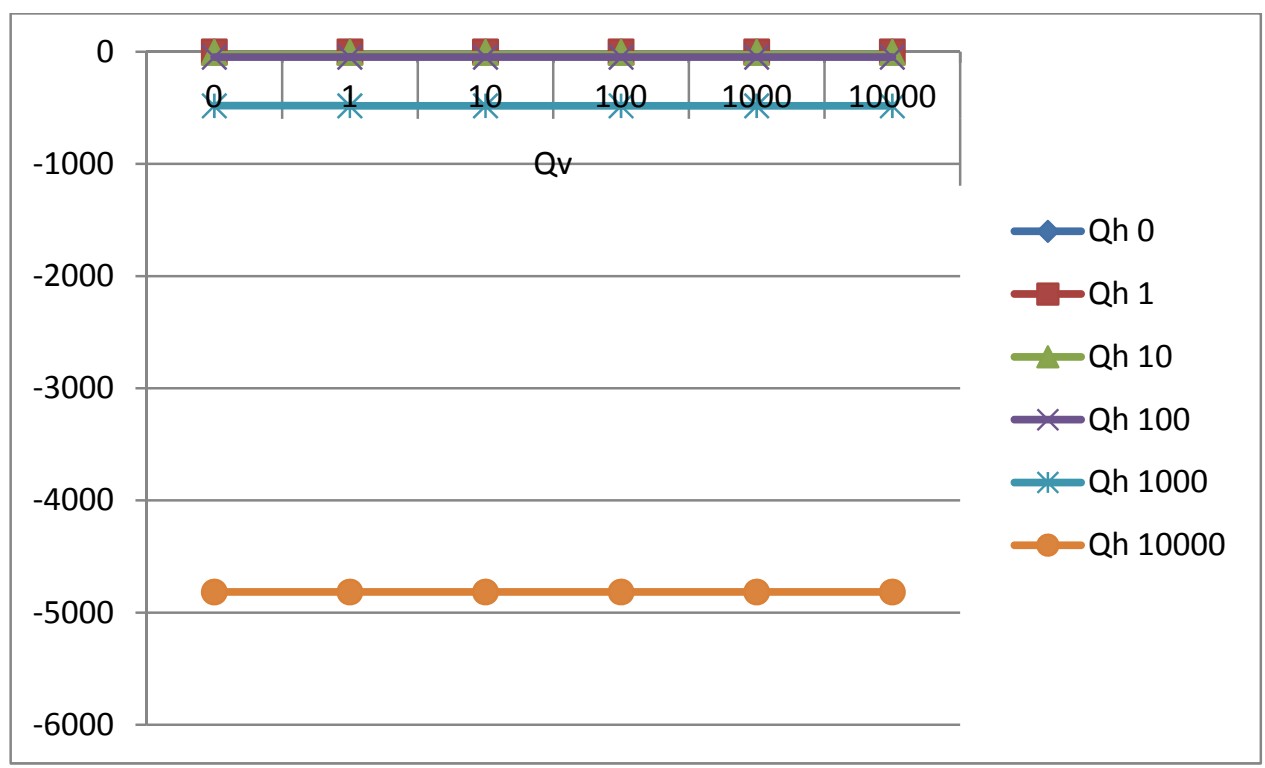

Gráfica 123 Comparación de esfuerzos cortantes mínimos (KN, eje y) en la barra e de estructura tradicional generada a partir de estructura reentrante hexagonal metálica rígida para una apertura de $90^{\circ}$ y diversas cargas horizontales y verticales (KN, eje $x$ y leyenda), elaboración propia

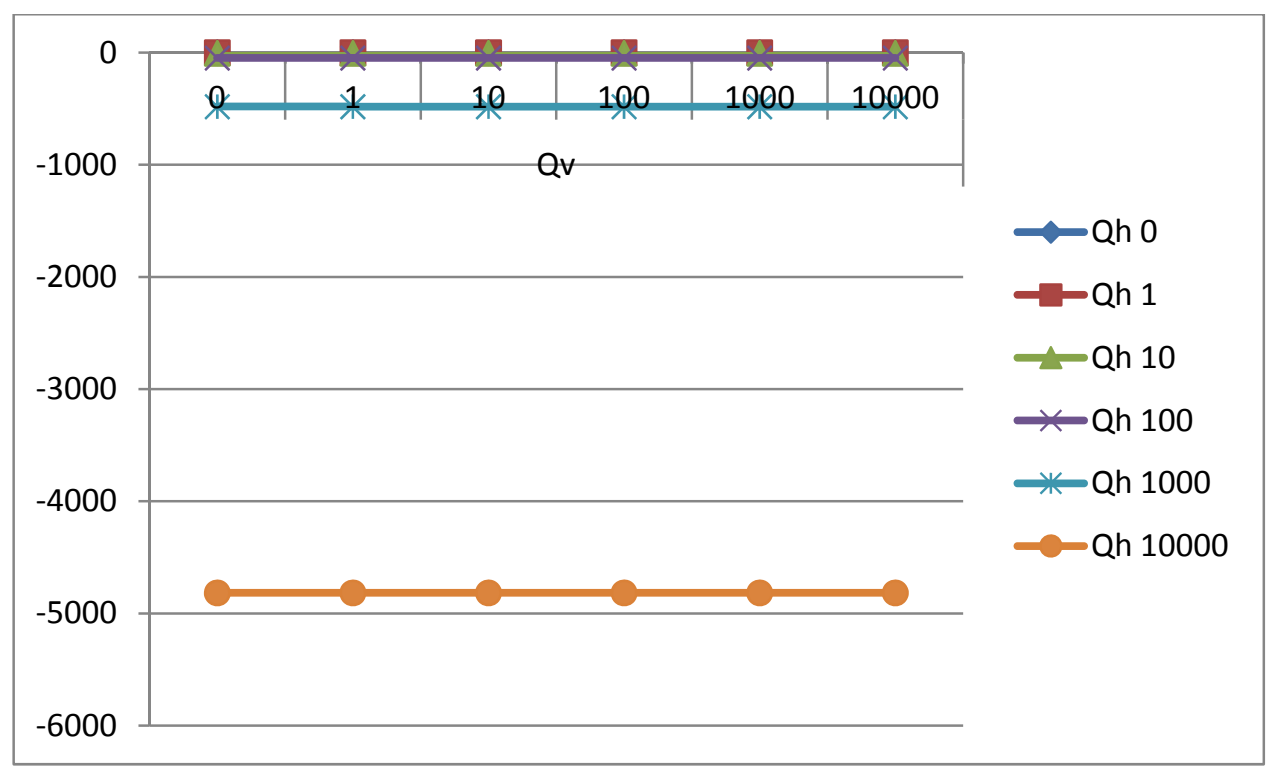

Gráfica 124 Comparación de esfuerzos cortantes máximos (KN, eje y) en la barra e de estructura tradicional generada a partir de estructura reentrante hexagonal metálica rígida para una apertura de $90^{\circ}$ y diversas cargas horizontales y verticales (KN, eje $x$ y leyenda), elaboración propia 


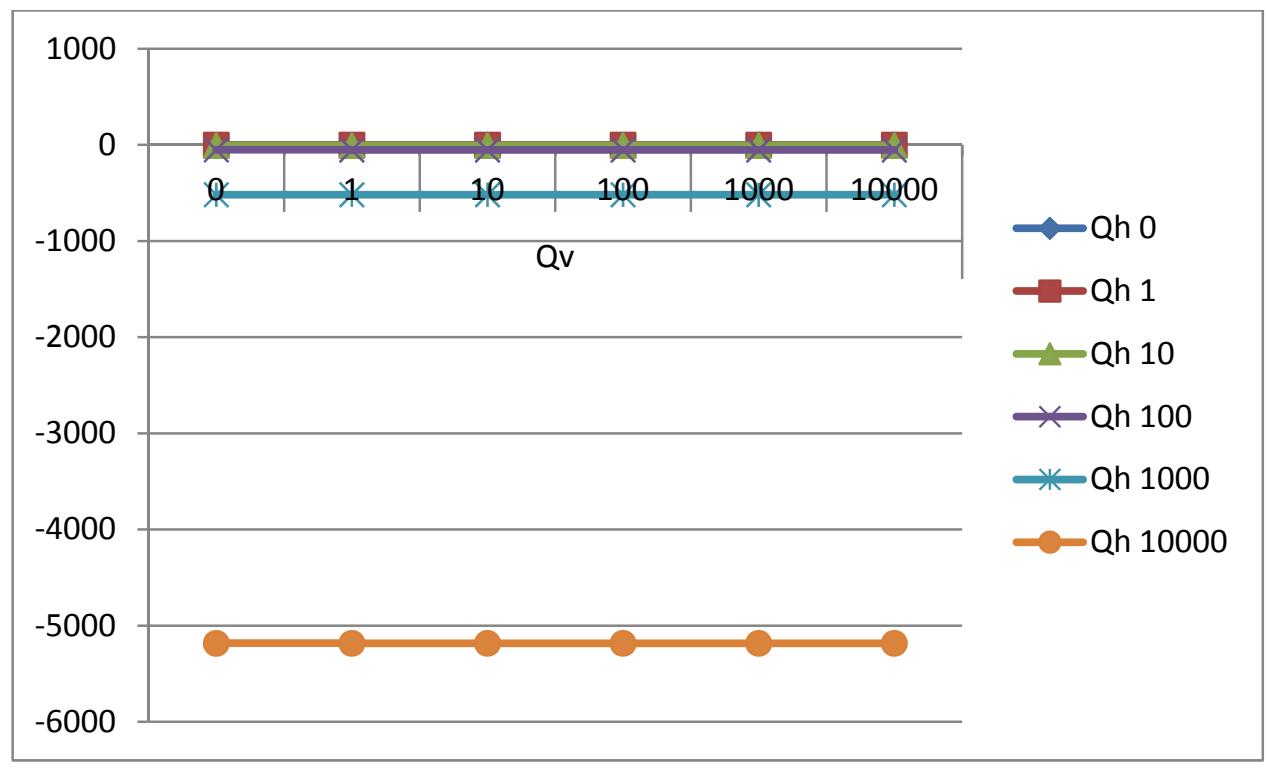

Gráfica 125 Comparación de esfuerzos cortantes mínimos ( $K N$, eje y) en la barra $f$ de estructura tradicional generada a partir de estructura reentrante hexagonal metálica rígida para una apertura de $90^{\circ}$ y diversas cargas horizontales y verticales (KN, eje $x$ y leyenda), elaboración propia

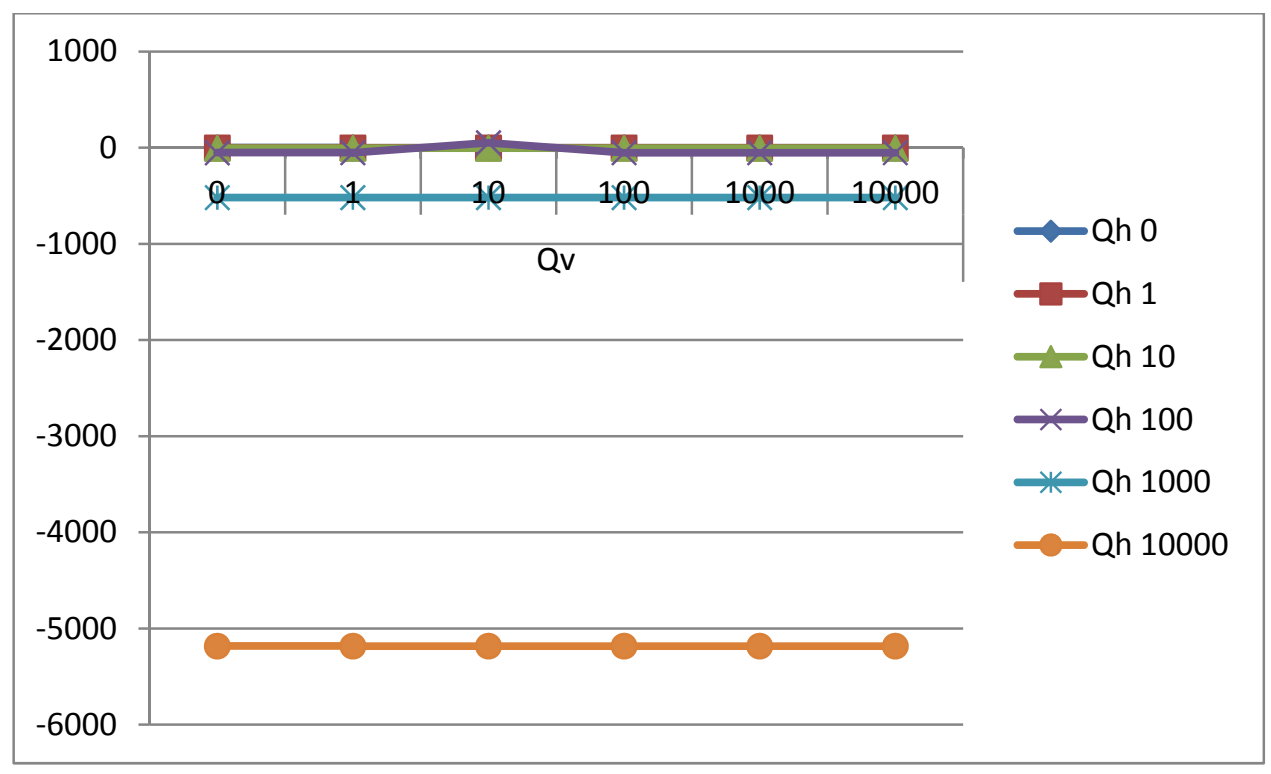

Gráfica 126 Comparación de esfuerzos cortantes máximos (KN, eje y) en la barra $f$ de estructura tradicional generada a partir de estructura reentrante hexagonal metálica rígida para una apertura de $90^{\circ}$ y diversas cargas horizontales y verticales (KN, eje $x$ y leyenda), elaboración propia 
Como puede observarse en las gráficas anteriores, correspondientes a la tabla 48, esfuerzos cortantes en estructura tradicional generada a partir de estructura reentrante hexagonal metálica rígida para una apertura de $90^{\circ}$ y diversas cargas horizontales y verticales, del Apéndice 2. Tablas de cálculo estructural, se observan diversas esfuerzos cortantes con comportamientos muy diversos dependiendo de las diferentes combinaciones de cargas verticales y cargas horizontales.

En la barra a, las cargas horizontales afectan plenamente al esfuerzo y cambian su dirección. Para cargas nulas, el esfuerzo es de -0,164 a 0,164, pasando a 0,317 a 0,646 cuando se aumenta a Qh=1. Este cambio de dirección se mantiene con la inclusión de todas las cargas horizontales, que presentan un considerable aumento del esfuerzo cuando se llega a cargas altas. Cuando $\mathrm{Qh}=10$, el esfuerzo es de 4,66 a 4,988; sin embargo, cuando $\mathrm{Qh}=100$, el esfuerzo aumenta a 47,998 a 48,327. Cuando $\mathrm{Qh}=1000$, el esfuerzo es de 481,461 a 481,789 y, finalmente, cuando $\mathrm{Qh}=10000$, el esfuerzo es de 4816,088 a 4816,417 . Las cargas verticales no varían estas cifras, por lo que se hace evidente que no afectan al esfuerzo.

En la barra b, se da un caso muy similar al del nudo a. Las cargas horizontales van aumentando, con un claro repunte cuando $\mathrm{Qh}=10$, donde se ve un esfuerzo de 4,66 a 4,988; y se compara con $\mathrm{Qh}=100$, donde el esfuerzo es de 47,998 a 48,327. Este aumento del esfuerzo será progresivo y muy alto, al igual que en el nudo a. En este caso, la diferencia estriba en dos casos en que la carga vertical de 10000 afecta levemente al esfuerzo. En el primero, siendo la carga horizontal nula, la alta carga vertical supone un leve aumento del esfuerzo de $-0,031$ a $-0,033$. Cuando esta alta carga se contrapone con una carga horizontal de 10 , el esfuerzo pasa de 5,145 a 5,151.

En la barra c, encontramos un caso muy similar al de los nudos a y b. De nuevo, las cargas horizontales afectan al esfuerzo, con un paso muy alto cuando dichas cargas aumentan, pasando de $-48,195$ a $-481,658$ a $-481,658$ en cargas de 10 y 100 respectivamente. Las únicas excepciones en las que la carga vertical parece afectar se dan en las cargas verticales máximas, cuando se contraponen, primero, a una carga horizontal nula, pasando de -0,031 a -0,033; y cuando se contraponen a cargas horizontales de 10, pasando de 4,855 a -4,849. En este caso, además, el esfuerzo disminuye ligeramente. El resto de cifras no varía, por lo que el resto de cargas verticales no afectan al esfuerzo.

En la barra d, se presenta un caso idéntico al del nudo c. Las cargas verticales que afectan al esfuerzo de nuevo son las máximas, contrapuestas a carga horizontal nula, pasando de 
$-0,031$ a -0,033; y a carga horizontal de 10, pasando de 5,145 a 5,151. El valor más elevado de esfuerzo cortante generado en esta barra corresponde a una carga horizontal de 10000 , y alcanza unos valores van de 5183,715 a 5183,715.

En la barra e, se observan unos valores de esfuerzo muy similares a los del nudo b, por lo que los datos a observar son del mismo tipo, ascendiendo con el aumento de carga horizontal el esfuerzo cortante en la barra, llegando a un esfuerzo máximo que va de 4816,285 a $-4816,285$.

En la barra $f$, al igual que en todas las barras anteriores, las cargas horizontales son las que afectan al esfuerzo cortante, aumentándolo a medida que aumenta dicha carga. El esfuerzo máximo observado va de $-5183,912$ a $-5183,583$.

De este modo, se puede concluir que los esfuerzos cortantes en barras para una estructura tradicional generada a partir de estructura reentrante hexagonal metálica rígida para una apertura de $90^{\circ}$ y diversas cargas horizontales y verticales, aumentan con la carga, siendo mayores cuanto mayor sea dicha carga. Se puede decir que las cargas horizontales tienen una mayor importancia que las cargas verticales porque son las únicas que influencian a las barras, y además son las que hacen aumentar de forma considerable el esfuerzo cortante en dichas barras. 


\section{Momentos flectores}

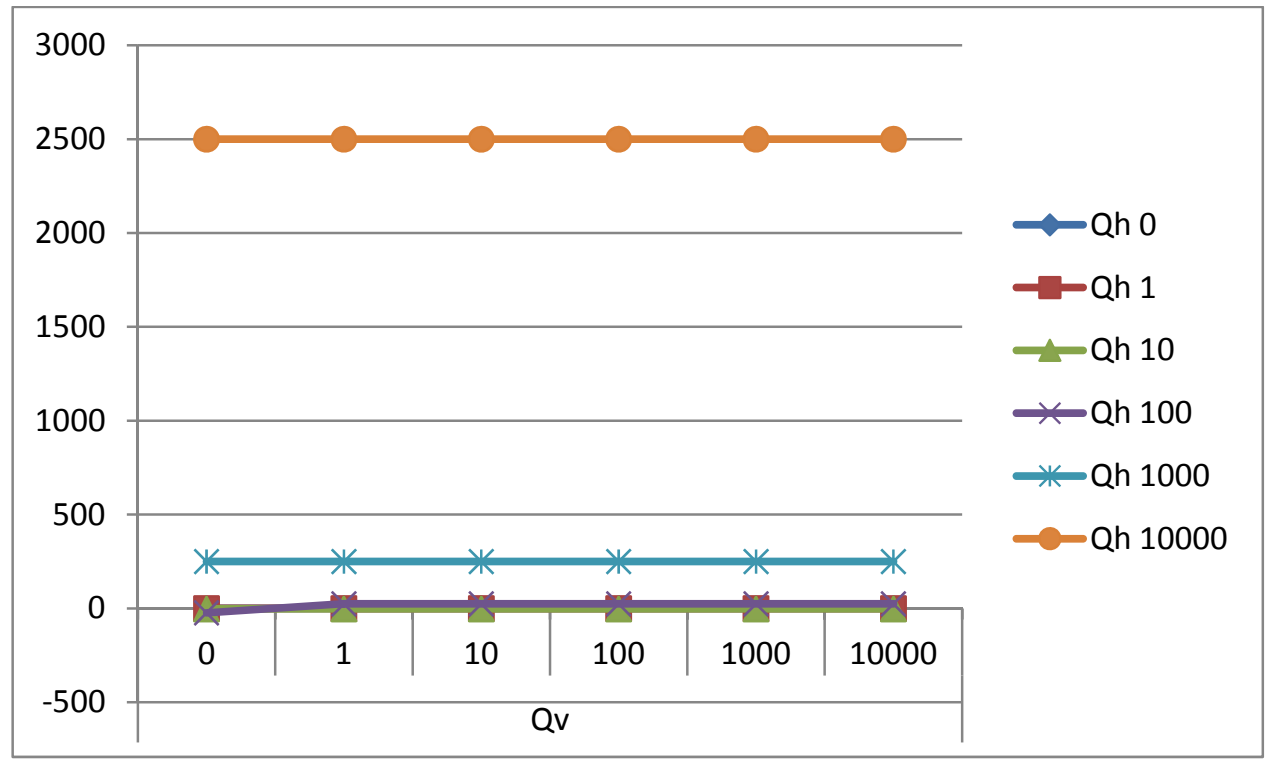

Gráfica 127 Comparación de momentos mínimos (KN.m, eje y) en la barra a de estructura tradicional generada a partir de estructura reentrante hexagonal metálica rígida para una apertura de $90^{\circ}$ y diversas cargas horizontales y verticales (KN, eje x y leyenda), elaboración propia

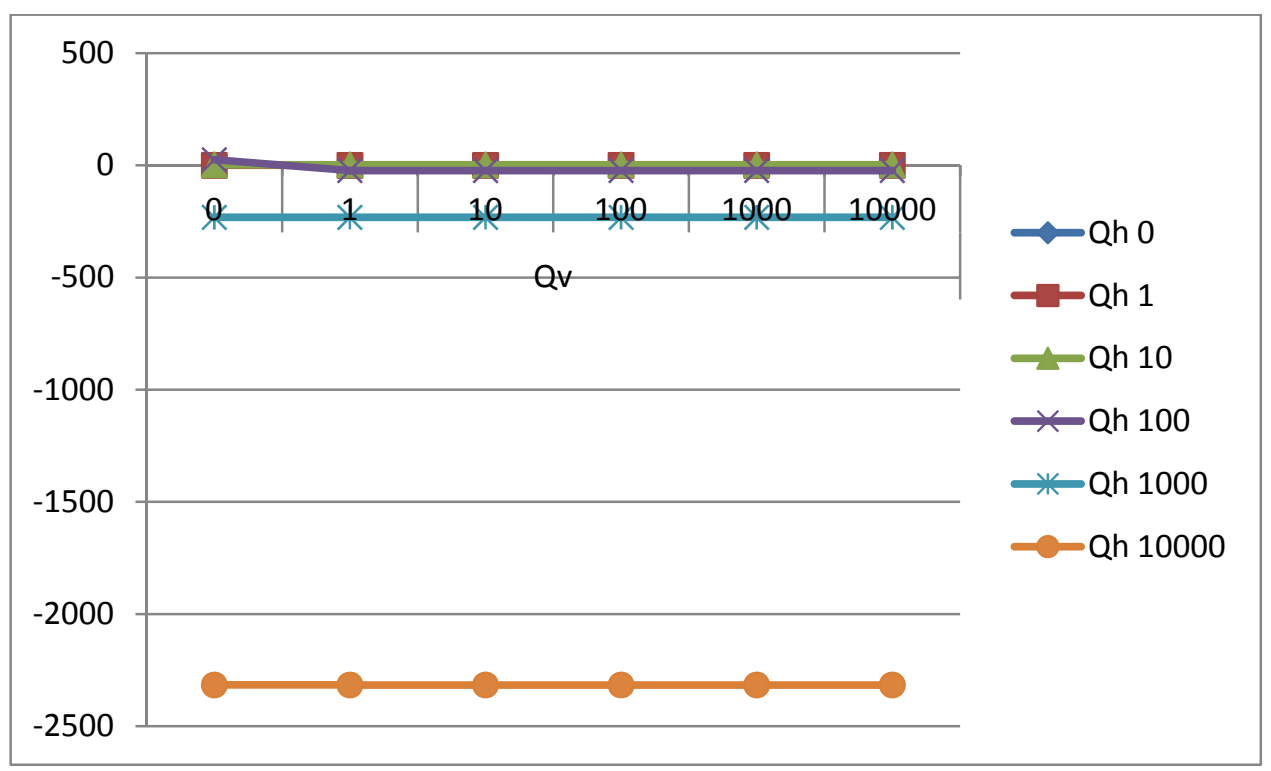

Gráfica 128 Comparación de momentos máximos ( $K N \cdot m$, eje y) en la barra a de estructura tradicional generada a partir de estructura reentrante hexagonal metálica rígida para una apertura de $90^{\circ}$ y diversas cargas horizontales y verticales (KN, eje x y leyenda), elaboración propia 


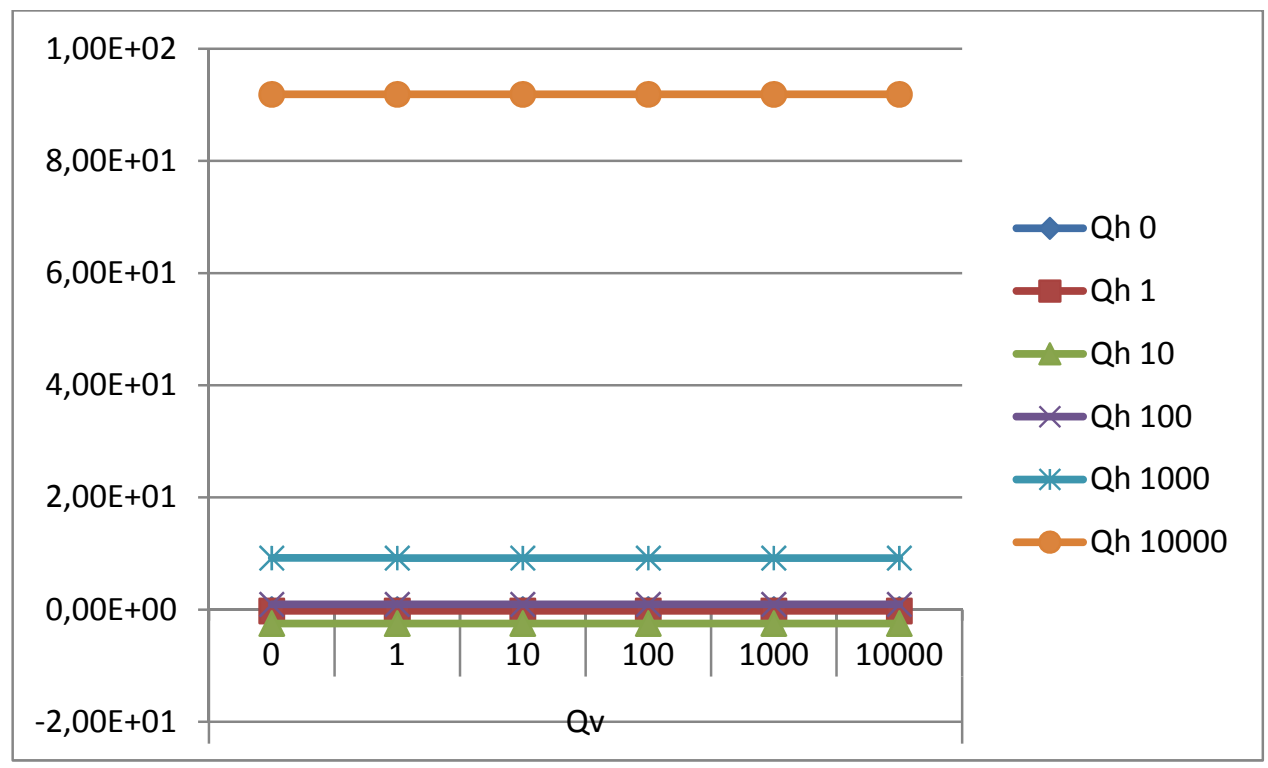

Gráfica 129 Comparación de momentos mínimos (KN·m, eje y) en la barra b de estructura tradicional generada a partir de estructura reentrante hexagonal metálica rígida para una apertura de $90^{\circ}$ y diversas cargas horizontales y verticales (KN, eje x y leyenda), elaboración propia

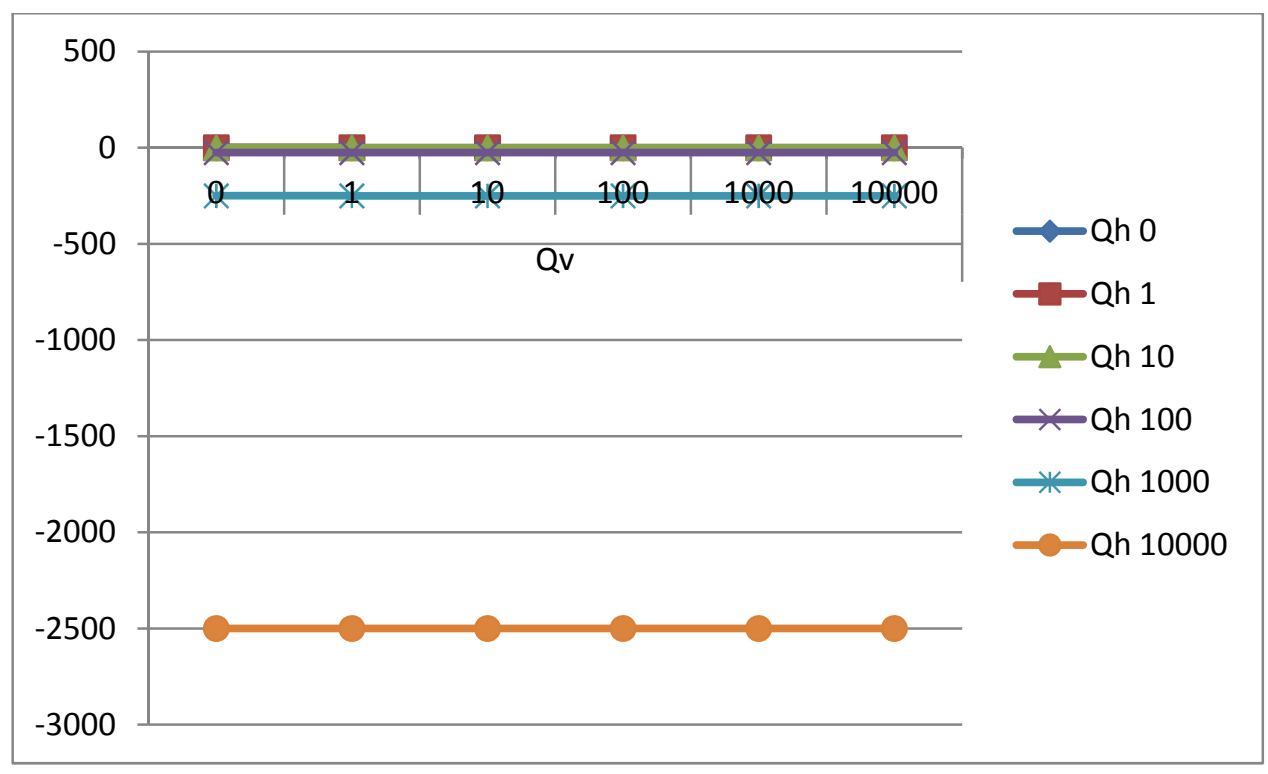

Gráfica 130 Comparación de momentos máximos ( $K N \cdot m$, eje y) en la barra b de estructura tradicional generada a partir de estructura reentrante hexagonal metálica rígida para una apertura de $90^{\circ}$ y diversas cargas horizontales y verticales (KN, eje x y leyenda), elaboración propia 
Aplicaciones de las propiedades auxéticas en la arquitectura

CÁLCULO ESTRUCTURAL DE ESTRUCTURAS AUXÉTICAS

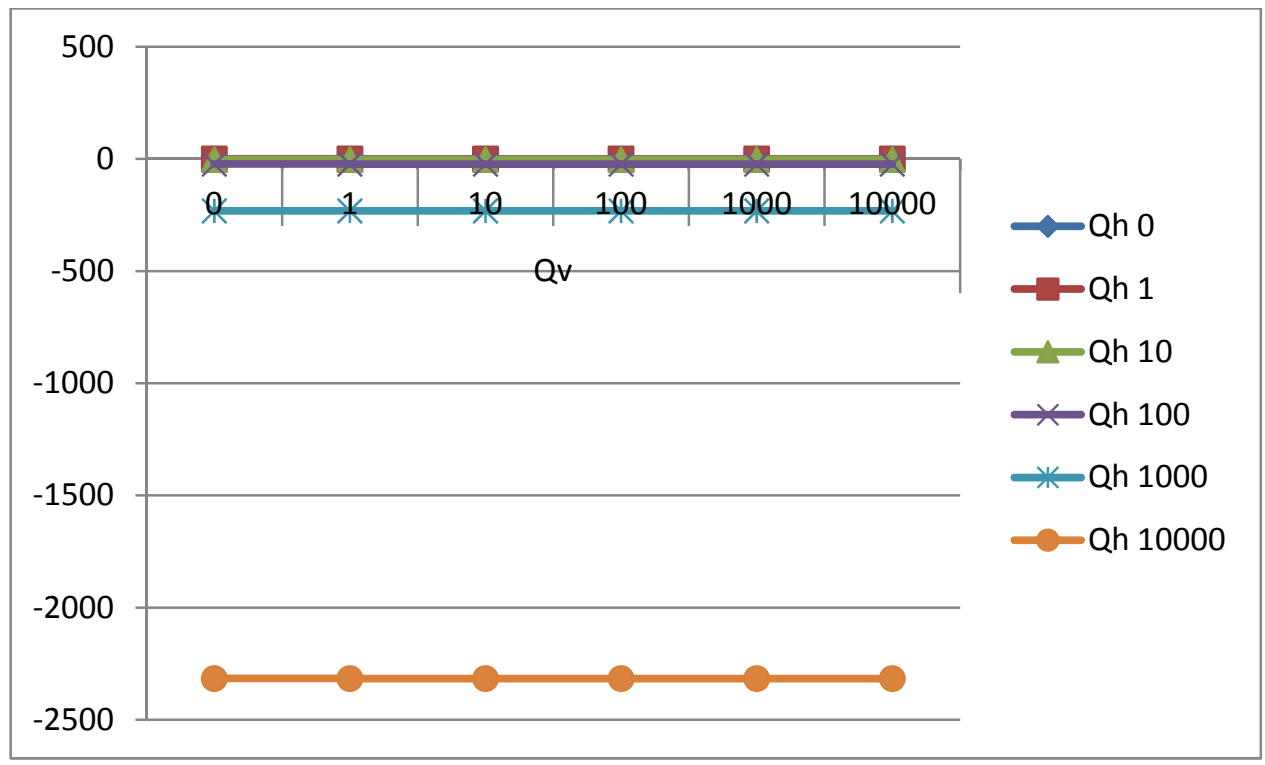

Gráfica 131 Comparación de momentos mínimos (KN·m, eje y) en la barra c de estructura tradicional generada a partir de estructura reentrante hexagonal metálica rígida para una apertura de $90^{\circ}$ y diversas cargas horizontales y verticales (KN, eje $x$ y leyenda), elaboración propia.

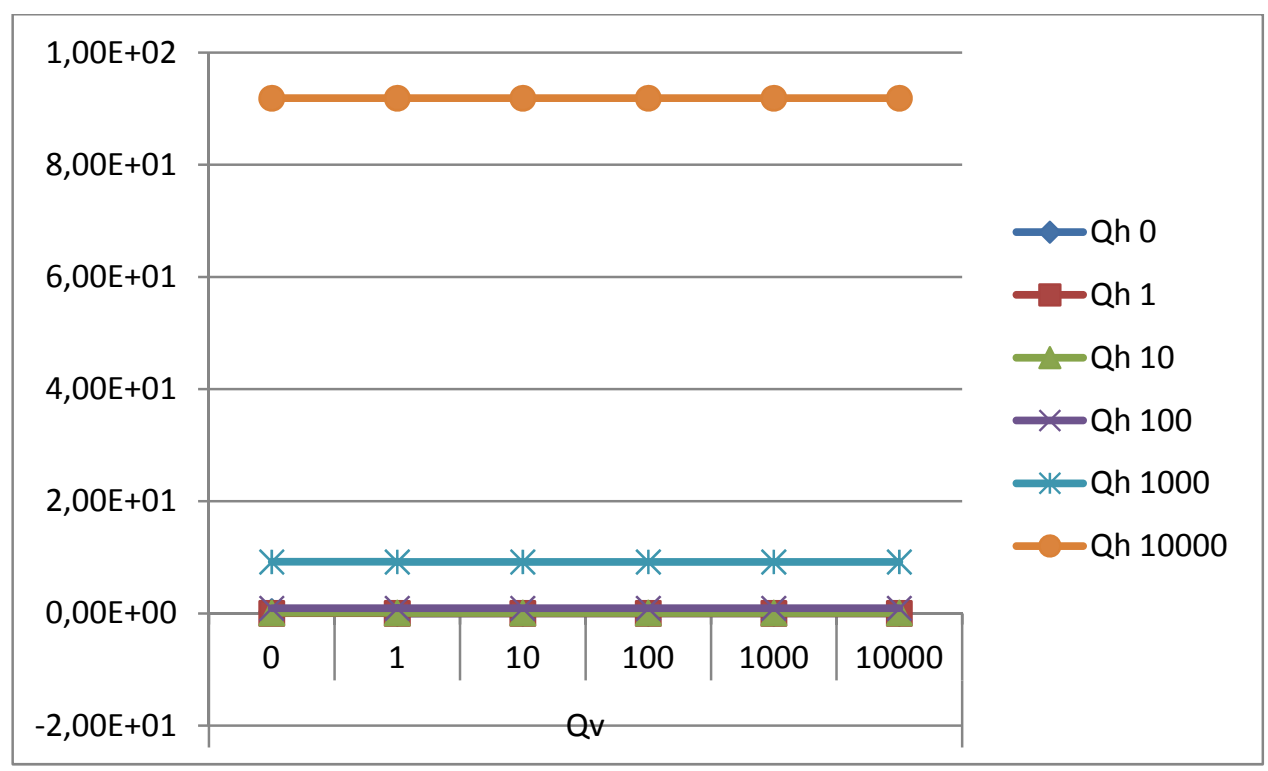

Gráfica 132 Comparación de momentos máximos ( $K N \cdot m$, eje y) en la barra c de estructura tradicional generada a partir de estructura reentrante hexagonal metálica rígida para una apertura de $90^{\circ}$ y diversas cargas horizontales y verticales (KN, eje x y leyenda), elaboración propia 


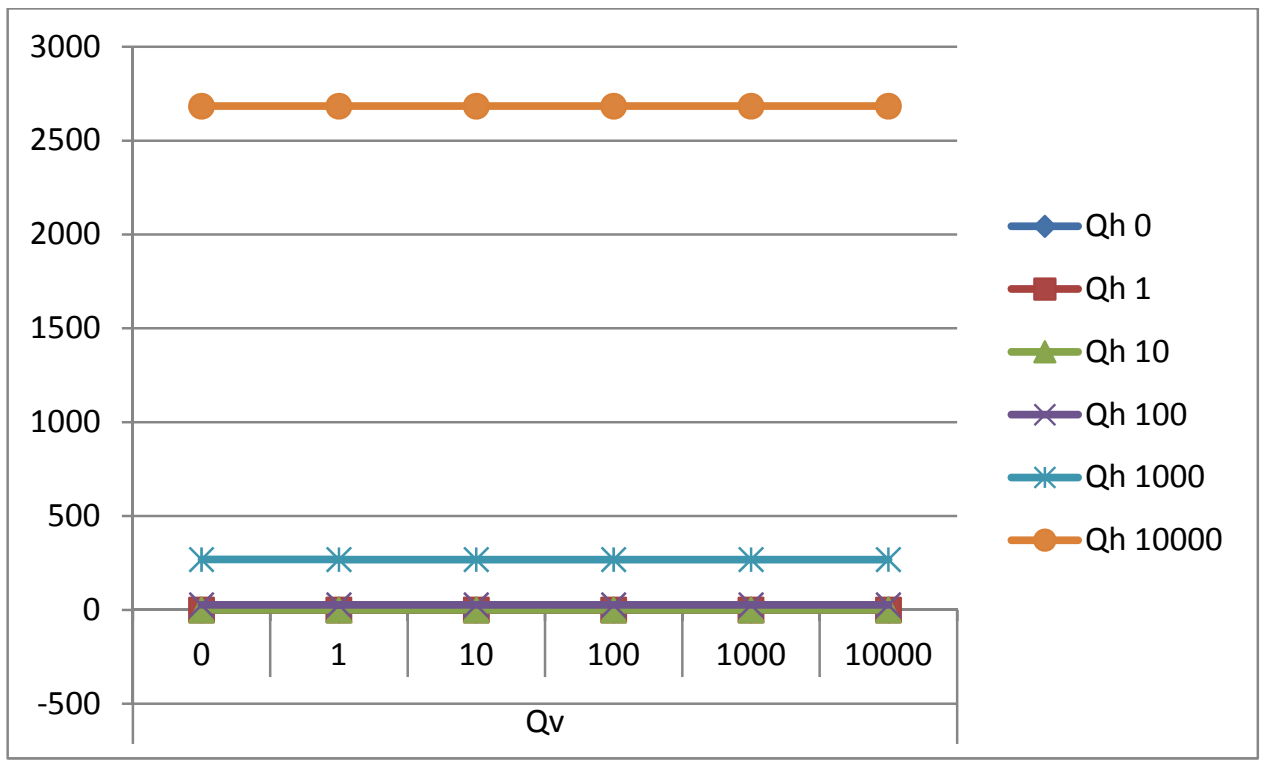

Gráfica 133 Comparación de momentos mínimos (KN·m, eje y) en la barra d de estructura tradicional generada a partir de estructura reentrante hexagonal metálica rígida para una apertura de $90^{\circ}$ y diversas cargas horizontales y verticales (KN, eje $x$ y leyenda), elaboración propia

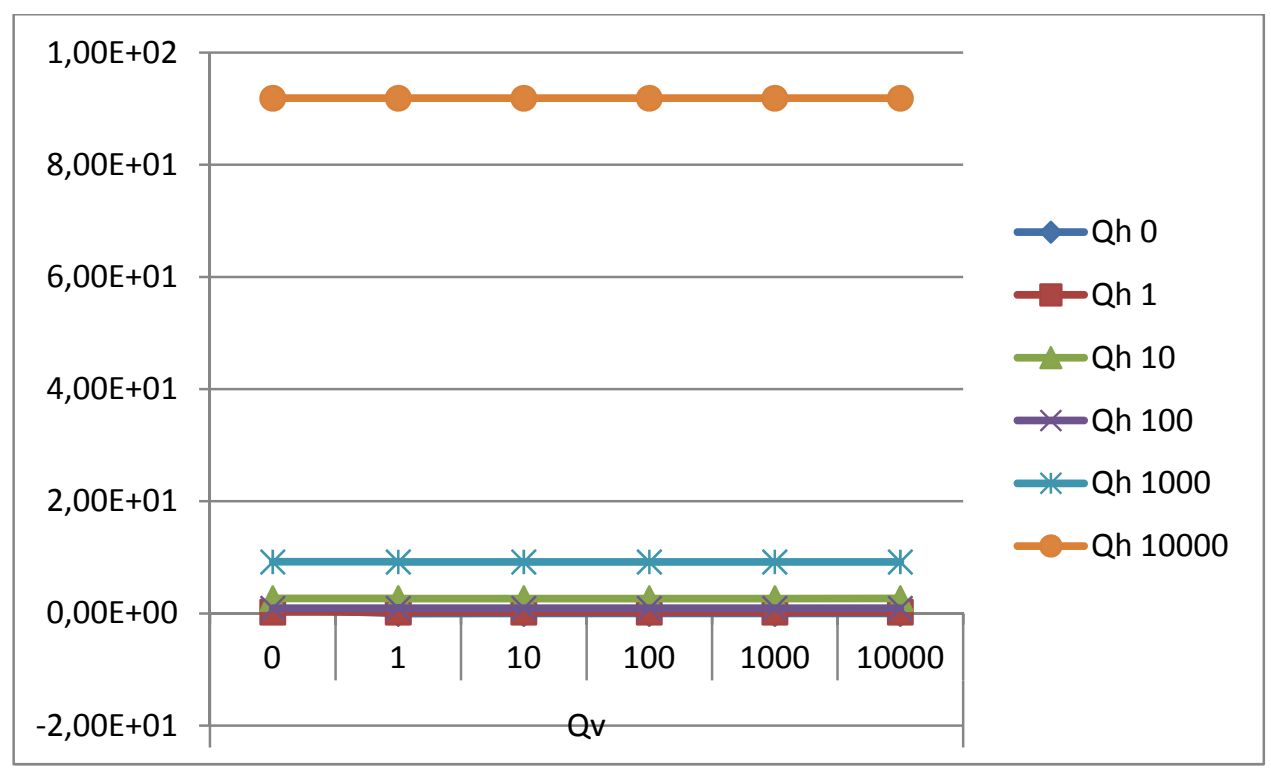

Gráfica 134 Comparación de momentos máximos ( $K N \cdot m$, eje y) en la barra d de estructura tradicional generada a partir de estructura reentrante hexagonal metálica rígida para una apertura de $90^{\circ}$ y diversas cargas horizontales y verticales (KN, eje x y leyenda), elaboración propia 
Aplicaciones de las propiedades auxéticas en la arquitectura

CÁLCULO ESTRUCTURAL DE ESTRUCTURAS AUXÉTICAS

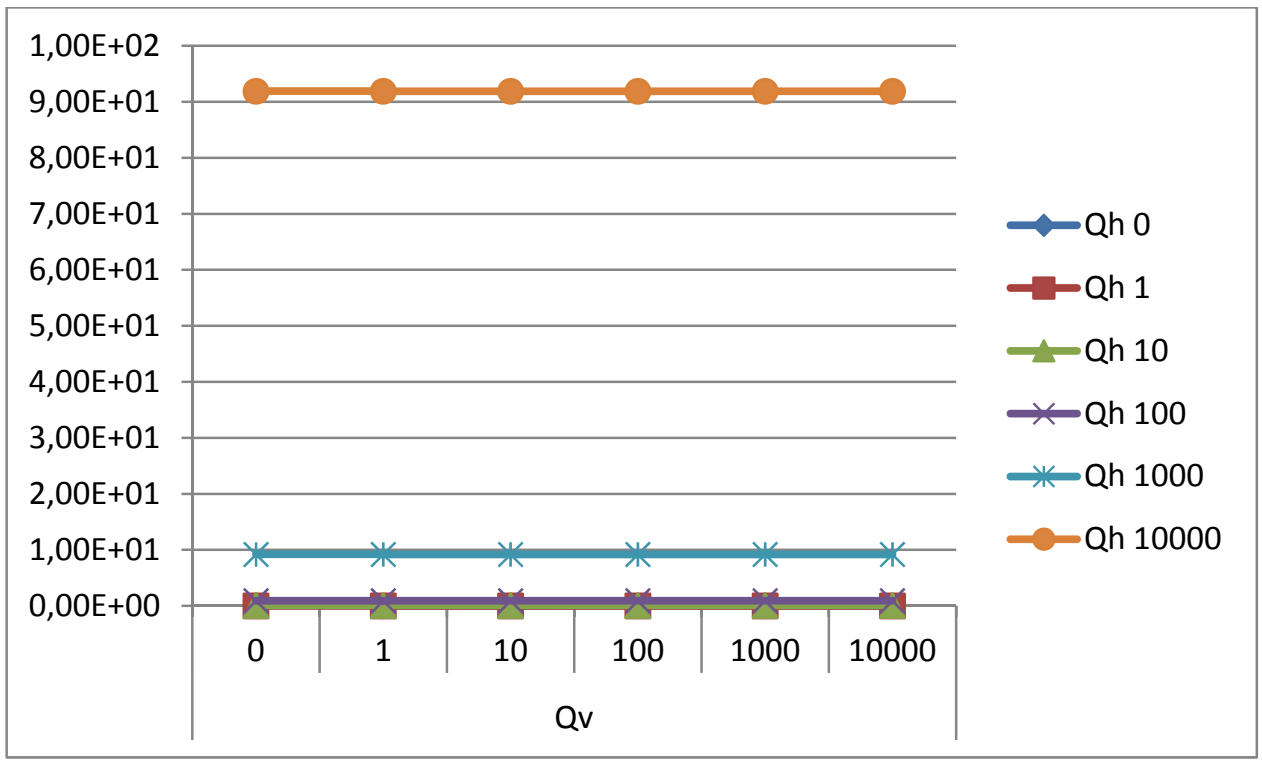

Gráfica 135 Comparación de momentos mínimos (KN.m, eje y) en la barra e de estructura tradicional generada a partir de estructura reentrante hexagonal metálica rígida para una apertura de $90^{\circ}$ y diversas cargas horizontales y verticales (KN, eje $x$ y leyenda), elaboración propia

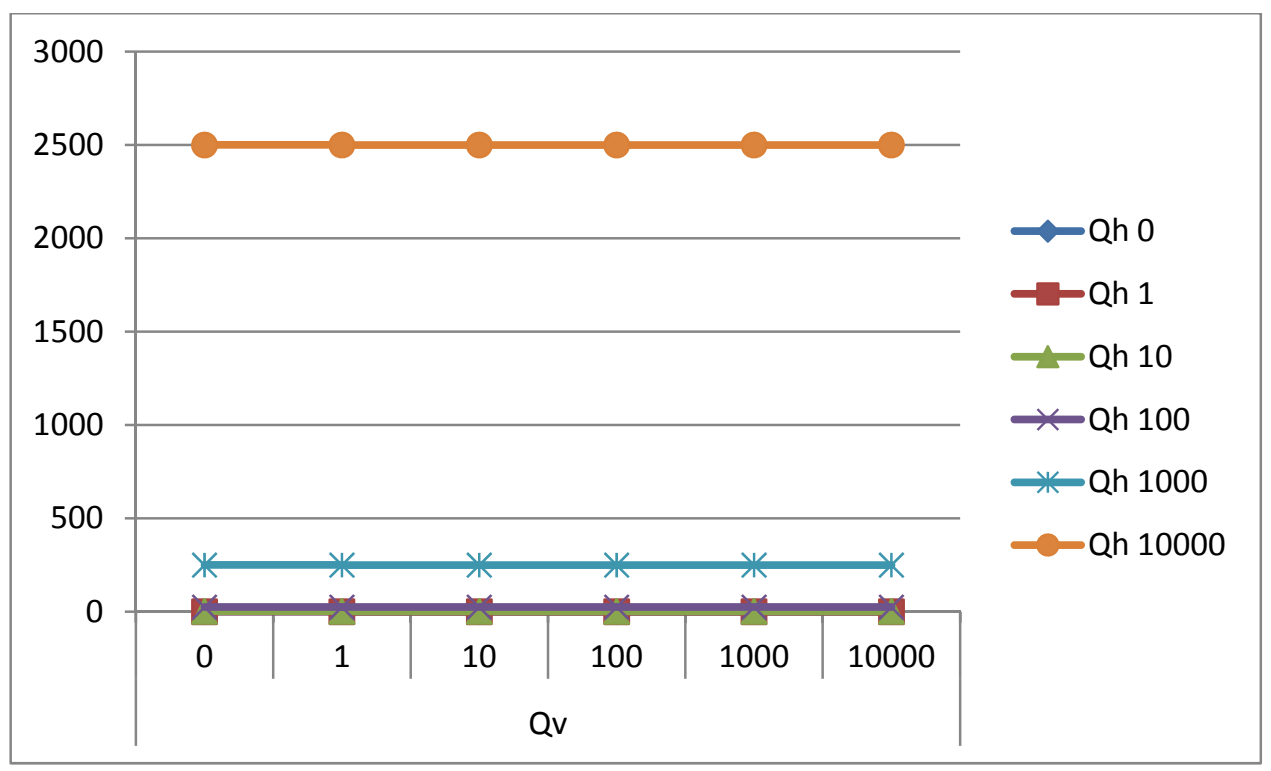

Gráfica 136 Comparación de momentos máximos (KN·m, eje y) en la barra e de estructura tradicional generada a partir de estructura reentrante hexagonal metálica rígida para una apertura de $90^{\circ}$ y diversas cargas horizontales y verticales (KN, eje $x$ y leyenda), elaboración propia 


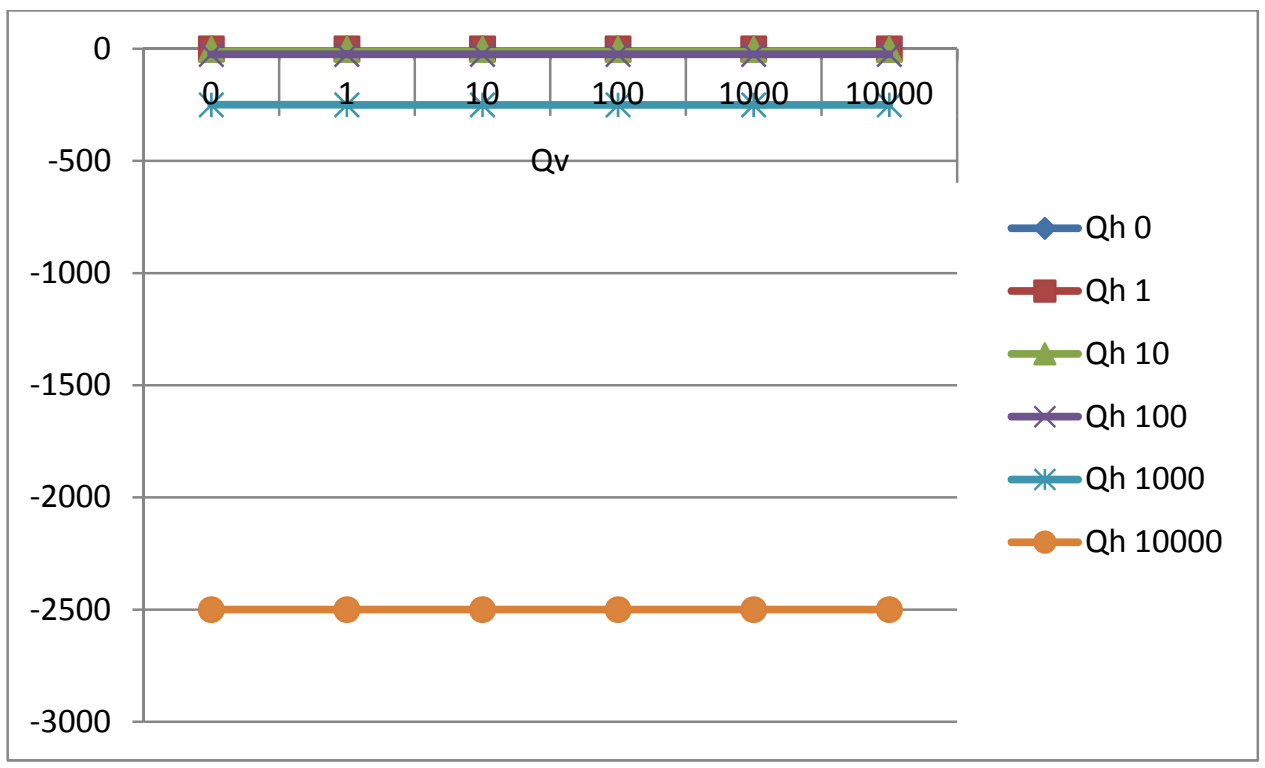

Gráfica 137 Comparación de momentos mínimos (KN·m, eje y) en la barra $f$ de estructura tradicional generada a partir de estructura reentrante hexagonal metálica rígida para una apertura de $90^{\circ}$ y diversas cargas horizontales y verticales (KN, eje $x$ y leyenda), elaboración propia

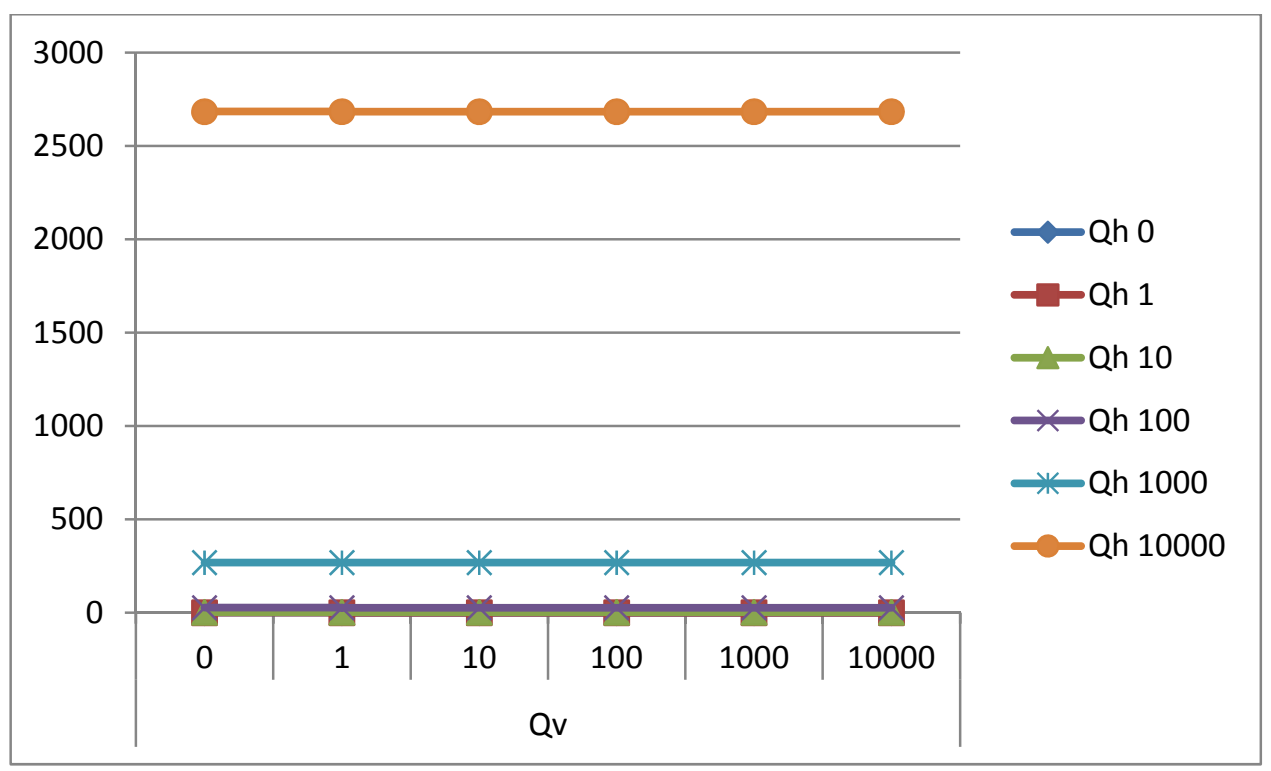

Gráfica 138 Comparación de momentos máximos (KN·m, eje y) en la barra $f$ de estructura tradicional generada a partir de estructura reentrante hexagonal metálica rígida para una apertura de $90^{\circ}$ y diversas cargas horizontales y verticales (KN, eje x y leyenda), elaboración propia 
Como puede observarse en las gráficas anteriores, correspondientes a la tabla 49, momentos en estructura tradicional generada a partir de estructura reentrante hexagonal metálica rígida para una apertura de $90^{\circ}$ y diversas cargas horizontales y verticales, del Apéndice 2. Tablas de cálculo estructural, se observan diversos momentos con comportamientos muy diversos dependiendo de las diferentes combinaciones de cargas verticales y cargas horizontales.

En la barra a, las cargas horizontales afectan más al esfuerzo que las verticales, salvo en algunas excepciones. Cuando la carga horizontal es nula, una alta carga vertical de 10000 varía levemente el esfuerzo de -0,0156 a 0,0254 a -0,0163 a 0,0247. En el caso en que $\mathrm{Qh}=10$ y $\mathrm{Qv}=10000$, el esfuerzo disminuye de $-2,3393$ a 2,4844 a -2,3326 a 2,4837. En la carga horizontal de 1000 y 10000 , esta es la que predomina, dejando estable el esfuerzo frente a las cargas verticales.

En la barra b, se da un caso parecido al de la barra a. Si bien es cierto que la mayor parte de los cambios en el esfuerzo se dan por las cargas horizontales, existen excepciones en que las cargas verticales afectan a dicho esfuerzo. Cuando la carga horizontal es nula, las cargas verticales hacen aumentar el esfuerzo. En el caso de una carga vertical de 1, dicho esfuerzo cambia de dirección (-6,072E-18 a 0,0156). Una vez que comienzan a aplicarse cargas horizontales, los valores se estabilizan y no varían a pesar de las cargas verticales, excepto cuando $\mathrm{Qh}=10$ y $\mathrm{Qv}=10000$, donde se pasa de $-2,4844$ a 0,0882 a $-2,4837$ a 0,0919 .

En la barra c, sucede lo mismo que en las barras a y b. Las cargas horizontales afectan en mayor medida al esfuerzo. Las excepciones se darían cuando las cargas horizontales son nulas, cuando Qv=1 el esfuerzo varía de -0,0156 a 3,469E-1 a 1,041E-17 a -0,0156; y cuando $Q v=10000$, el esfuerzo cambia y pasa a $-0,0163$ a 1,898E-15. Del mismo modo, cuando $\mathrm{Qh}=10$ y $\mathrm{Qv}=10000$, se pasa de $-2,3393$ a 0,0882 a -2,3326 a 0,0919. En el resto de casos, las cargas verticales no afectan.

En la barra d, de nuevo, el paradigma dominante indica que las cargas horizontales afectan al esfuerzo más que las verticales. Sin embargo, cuando se aplica una carga vertical de 1 , al no existir carga horizontal, el esfuerzo cambia de -0,0156 a 6,939E-1 a 6,939E-18 a -0,0156. De nuevo con la carga horizontal en reposo, al aumentar la carga vertical a 10000 , se pasa a -0,0163 a 3,844E-14. Finalmente, cuando es la carga vertical la que es nula, y se le añade una carga horizontal de 100 , el esfuerzo es de 0,9187 a 26,8212 , frente al valor de 26,8212 a 0,9187 que se aprecia al añadir las cargas verticales, y en el que se mantienen estables. 
En la barra e, se sigue el criterio general de que las cargas horizontales son las que más afectan generando momentos, sin embargo, los valores son más pequeños que en las anteriores. En este caso, el esfuerzo para cargas nulas es de 6,939E-18 a 0,0156. Al aplicarse las cargas verticales y horizontales, dicho esfuerzo va a disminuir en lugar de aumentar. Cuando Qh=1, el esfuerzo es de 0,0092 a 0,2663; y cuando Qv=1, el esfuerzo es de 1,214E-17 a 0,0156. Sólo cuando las cargas horizontales aumenten a sus niveles más altos, el esfuerzo aumentará, viéndose afectado por las cargas horizontales y verticales.

En la barra $f$, las cargas horizontales determinan el esfuerzo, aumentando de forma progresiva, con fuertes subidas como -2,5156 a 2,6607 cuando $Q v=0$ y $Q h=10 ;$ que pasa a 250,0163 a 268,3585 cuando Qv=0 y Qh=1000. Las únicas excepciones se dan con la carga máxima vertical, donde el valor del esfuerzo cuando $Q h=0$ y $Q v=10000$ es de $-0,0163$ a 0,0247 frente al -0,0156 a 0,0254 del valor para ambas cargas nulas; y cuando $\mathrm{Qh}=10$ y $\mathrm{Qv}=10000$, donde el valor del esfuerzo es $-2,5163$ a 2,6674, frente al valor nulo de la carga vertical cuando $\mathrm{Qh}=10$ de $-2,5156$ a 2,6607. El resto de cargas verticales no afectan al esfuerzo.

De este modo, se puede concluir que los momentos en barras para una estructura tradicional generada a partir de estructura reentrante hexagonal metálica rígida para una apertura de $90^{\circ}$ y diversas cargas horizontales y verticales, aumentan con la carga, siendo mayores cuanto mayor sea dicha carga. Se puede decir que las cargas horizontales tienen una mayor importancia que las cargas verticales porque son las que principalmente influencian a las barras, y además son las que hacen aumentar de forma considerable el momento en dichas barras.

\subsection{Discusión de resultados}

Los resultados obtenidos para la estructura metálica rígida de apertura $90^{\circ}$ son los esperados, ya que según va aumentando la carga los desplazamientos son mayores (pero siguen siendo admisibles).

Sin embargo, según aumenta la carga, los esfuerzos en las barras dejan de ser admisibles, con lo que estas estructuras sólo admitirían los esfuerzos hasta unas cargas determinadas (también hay que decir que las cargas mayores con las que se ha testeado el modelo son excesivas). Para intentar solucionar este problema, a continuación se comprobará esta misma estructura con un tendón interno. 


\subsubsection{Estructura auxética con nudos articulados y tendón interno: cálculo manual.} (Tensioned auxetic structures with articulated knots: manual calculus)

Auxetic materials have several properties very useful to be applied to architecture structures. This section is aimed to test structurally a specific auxetic structure model. This hypothesis will be check: if auxetic materials have innovative properties in nanoscale then they will also have these properties in macroscale. But there are some differences for these different scales. In the nanoscale auxetic structures have rigid knots with flexible bars, but in the scale of architecture they will have articulated knots and a cable that stabilizes the set.

A unity of the hexagonal re-entrant structure will be tested in order to obtain their structural characteristics. The application of this structure and their behavior in architecture are not yet known, that's why this auxetic model will become an experimental model to establish a structural evaluation of one of the most innovative auxetic geometries, to apply to the construction of new architectures. The results of research and investigation will become apparent by their structural evaluation, through the utilization of manual calculus.

The re-entrant hexagonal geometry provides a strong foundation for research of application of new structural systems on the production of architecture, while identifying transformations that new geometries and their application techniques, will contribute to the development and divulgation of new spatial and typological solutions. That is the reason to claim a detailed analysis to advance on the design and construction of new architectures.

\subsection{Material and methods}

A single unit of hexagonal re-entrant auxetic structure exposed in "Transformables 2013 International Congress" by Álvarez and Anaya (2013) will be calculated. The analysis will be realized using bar structures with articulated joints and external pre-forces (tendons) that keep the structure balanced, this mean using auxetic structures as a structure that works due a forces balance. The idea is obtaining the equilibrated positions (aperture angles depending on the force that the tendon supports) defining equilibrium of forces equations.

So, the first item will be calculating a simple auxetic hexagonal structure with balance forces of tendons in order to test if it is auto stabilized and if it improves its structural behavior. All this will be done by hand. 


\subsection{Theory/calculation}

A six articulated bars structure in which the bars are called $a, b, c, d$, e and $f$, and the knots are called 1,2, 3, 4, 5 and 6 will be studied. The structure have two tendons in order to stabilized the structure (one of these going to knot 1 to knot 3 , and the other going to knot 4 to knot 6) as the figure 197 shows. The turns are only permitted in the $y$ axe because it is the axe in which the structure is opened and closed). The structure has 6 restrictions. It has 3 restrictions to the displacements +1 restriction to the rotation respecting to the $x$ axe in the left support. And it has 2 restrictions to the displacements in the $y$ and $z$ axes in the right support.

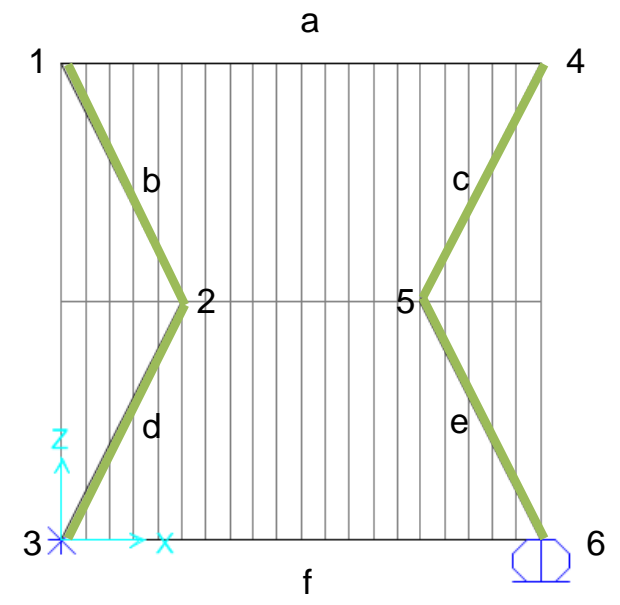

Figure 197. Six articulated bars with tendons structure

The structure will be calculated by manual methods in this manner: if the figure 197 is supposed to appear only with bars and articulated, (without external forces), the system is folded only by the own height action. That is why the own height depends on the gravity acceleration.

If we insert a cable or tendon in the interior of the bars, the structure will remain open in a certain position depending on the traction force applied. This force depends on the longitude of the cable: if the cable is shorter more tension will be obtained and therefore, more opening.

Through this way, the first thing that we need to know is the mass and the length of the bars: we will consider $b_{b}=b_{c}=b_{d}=b_{e}=1 \mathrm{~m}$ and $b_{a}=b_{f}=2 \mathrm{~m}$, where "b" is the bar. To graphical effects of calculation we consider despicable the dimensions of the bars (like thickness and density of the knots) to be able to fold totally the structure. 
A standardized $\phi 100.6$ round hollow profile is considered to effects of calculus. This profile is showed in the figure 198.

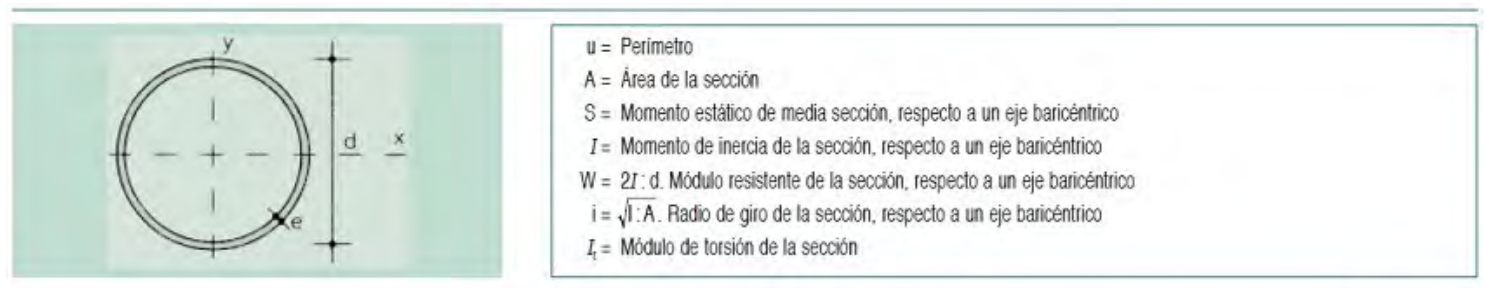

\begin{tabular}{|c|c|c|c|c|c|c|c|c|c|c|c|c|}
\hline \multirow{2}{*}{\multicolumn{2}{|c|}{ Perfil }} & \multicolumn{3}{|c|}{ Dimensiones } & \multicolumn{6}{|c|}{ Términos de secciớn } & \multirow{2}{*}{$\frac{\text { Peso }}{\underset{\mathrm{kp} / \mathrm{m}}{\mathrm{p}}}$} & \\
\hline & & $\underset{\mathrm{mm}}{\mathrm{d}}$ & $\begin{array}{c}\mathrm{e} \\
\mathrm{mm}\end{array}$ & $\begin{array}{c}\mathrm{u} \\
\mathrm{mm}\end{array}$ & $\begin{array}{c}\mathrm{A} \\
\mathrm{cm}^{2}\end{array}$ & $\begin{array}{c}\mathrm{s} \\
\mathrm{cm}^{3}\end{array}$ & $\stackrel{I}{\mathrm{~cm}^{4}}$ & $\begin{array}{l}W \\
\mathrm{~cm}^{3}\end{array}$ & $\frac{i}{c m}$ & $\begin{array}{c}I_{\mathrm{f}} \\
\mathrm{cm}^{4}\end{array}$ & & \\
\hline$\varnothing$ & 40.2 & 40 & 2 & 126 & 2,39 & 1,44 & 4,33 & 2,16 & 1,35 & 8,66 & 1,88 & $P$ \\
\hline$\varnothing$ & 40.3 & 40 & 3 & 126 & 3,49 & 2,05 & 6,01 & 3,00 & 1,31 & 12,00 & 2,74 & $\mathrm{P}$ \\
\hline$\varnothing$ & 40.4 & 40 & 4 & 126 & 4,52 & 2,60 & 7,42 & 3,71 & 1,28 & 14,80 & 3,55 & C \\
\hline$\varnothing$ & 45.2 & 45 & 2 & 141 & 2,70 & 1,85 & 6,26 & 2,78 & 1,52 & 12,50 & 2,12 & $\mathrm{P}$ \\
\hline$\varnothing$ & 45.3 & 45 & 3 & 141 & 3,96 & 2,65 & 8,77 & 3,90 & 1,49 & 17,50 & 3,11 & $\mathrm{P}$ \\
\hline$\varnothing$ & 45.4 & 45 & 4 & 141 & 5,15 & 3,37 & 10,90 & 4,84 & 1,45 & 21,80 & 4,04 & C \\
\hline$\varnothing$ & 50.2 & 50 & 2 & 157 & 3,02 & 2,30 & 8,70 & 3,48 & 1,69 & 17,40 & 2,37 & $\mathrm{P}$ \\
\hline$\varnothing$ & 50.3 & 50 & 3 & 157 & 4,43 & 3,31 & 12,20 & 4,91 & 1,66 & 24,50 & 3,47 & P \\
\hline$\varnothing$ & 50.4 & 50 & 4 & 157 & 5,78 & 4,23 & 15,40 & 6,16 & 1,63 & 30,80 & 4,53 & $\mathrm{P}$ \\
\hline$\varnothing$ & 55.2 & 55 & 2 & 173 & 3,33 & 2,81 & 11,70 & 4,25 & 1,87 & 23,40 & 2,61 & C \\
\hline$\varnothing$ & 55.3 & 55 & 3 & 173 & 4,90 & 4,06 & 16,60 & 6,04 & 1,84 & 33,20 & 3,85 & C \\
\hline$\varnothing$ & 55.4 & 55 & 4 & 173 & 6,41 & 5,21 & 21,00 & 7,64 & 2,01 & 42,00 & 5,03 & C \\
\hline$\varnothing$ & 60.2 & 60 & 2 & 188 & 3,64 & 3,36 & 15,30 & 5,11 & 2,05 & 30,60 & 2,86 & $\mathrm{P}$ \\
\hline$\varnothing$ & 60.3 & 60 & 3 & 188 & 5,37 & 4,87 & 21,80 & 7,29 & 2,01 & 43,70 & 4,21 & P \\
\hline$\varnothing$ & 60.4 & 60 & 4 & 188 & 7,04 & 6,27 & 27,70 & 9,24 & 1,98 & 55,40 & 5,52 & $\mathrm{P}$ \\
\hline$\varnothing$ & 65.2 & 65 & 2 & 204 & 3,96 & 3,97 & 19,70 & 6,06 & 2,23 & 39,40 & 3,11 & C \\
\hline$\varnothing$ & 65.3 & 65 & 3 & 204 & 5,84 & 5,78 & 28,10 & 8,65 & 2,19 & 56,20 & 4,58 & C \\
\hline$\varnothing$ & 65.4 & 65 & 4 & 204 & 7,67 & 7,46 & 35,80 & 11,60 & 2,16 & 71,60 & 6,02 & C \\
\hline$\varnothing$ & 70.2 & 70 & 2 & 220 & 4,27 & 4,62 & 24,70 & 7,05 & 2,41 & 49,40 & 3,35 & $\mathrm{P}$ \\
\hline$\varnothing$ & 70.3 & 70 & 3 & 220 & 6,31 & 6,73 & 35,50 & 10,10 & 2,37 & 71,00 & 4,95 & $\mathrm{P}$ \\
\hline$\varnothing$ & 70.4 & 70 & 4 & 220 & 8,29 & 8,72 & 45,30 & 12,90 & 2,34 & 90,60 & 6,51 & C \\
\hline$\varnothing$ & 75.2 & 75 & 2 & 236 & 4,58 & 5,33 & 30,50 & 8,15 & 2,58 & 61,10 & 3,60 & $\mathrm{P}$ \\
\hline$\varnothing$ & 75.3 & 75 & 3 & 236 & 6,78 & 7,78 & 44,00 & 11,70 & 2,54 & 88,00 & 5,32 & $P$ \\
\hline$\varnothing$ & 75.4 & 75 & 4 & 236 & 8,92 & 10,10 & 56,30 & 15,00 & 2,51 & 113,00 & 7,00 & $\mathrm{P}$ \\
\hline$\varnothing$ & 80.2 & 80 & 2 & 251 & 4,90 & 6,09 & 37,30 & 9,33 & 2,76 & 74,60 & 3,85 & C \\
\hline$\varnothing$ & 80.3 & 80 & 3 & 251 & 7,26 & 8,90 & 53,90 & 13,50 & 2,72 & 108,00 & 5,70 & C \\
\hline$\varnothing$ & 80.4 & 80 & 4 & 251 & 9,55 & 11,60 & 69,10 & 17,30 & 2,69 & 138,00 & 7,50 & C \\
\hline$\varnothing$ & 90.3 & 90 & 3 & 283 & 8,19 & 11,40 & 77,60 & 17,30 & 3,07 & 155,00 & 6,43 & $\mathrm{P}$ \\
\hline$\varnothing$ & 90.4 & 90 & 4 & 283 & 10,80 & 14,80 & 100,00 & 22,30 & 3,04 & 200,00 & 8,48 & $\mathrm{P}$ \\
\hline$\varnothing$ & 90.5 & 90 & 5 & 283 & 13,40 & 18,10 & 121,00 & 26,90 & 3,01 & 242,00 & 10,50 & $\mathrm{P}$ \\
\hline$\varnothing$ & 100.3 & 100 & 3 & 314 & 9,14 & 14,10 & 108,00 & 21,50 & 3,43 & 215,00 & 7,17 & $\mathrm{P}$ \\
\hline$\varnothing$ & 100.4 & 100 & 4 & 314 & 12,10 & 18,40 & 139,00 & 27,80 & 3,39 & 278,00 & 9,47 & $\mathrm{P}$ \\
\hline$\varnothing$ & 100.5 & 100 & 5 & 314 & 14.90 & 22.60 & 169.00 & 33,80 & 3.36 & 238,00 & 11.70 & $\mathrm{P}$ \\
\hline$\varnothing$ & 100.6 & 100 & 6 & 314 & 17.70 & 26.50 & 196.00 & 39.30 & 3.33 & 393.00 & 13.90 & C \\
\hline$\varnothing$ & 125.4 & 125 & 4 & 393 & 15,20 & 29,30 & 279,00 & 44,60 & 4,28 & 557,00 & 11,90 & C \\
\hline$\varnothing$ & 125.5 & 125 & 5 & 393 & 18,80 & 36,00 & 340,00 & 54,40 & 4,24 & 680,00 & 14,80 & C \\
\hline$\varnothing$ & 125.6 & 125 & 6 & 393 & 22,40 & 42,50 & 398,00 & 63,70 & 4,21 & 796,00 & 17,60 & C \\
\hline$\varnothing$ & 155.5 & 155 & 5 & 487 & 23,60 & 56,20 & 663,00 & 85,50 & 5,30 & $1.330,00$ & 18,50 & C \\
\hline$\varnothing$ & 155.6 & 155 & 6 & 487 & 28,10 & 66,60 & 781,00 & 101,00 & 5,27 & $1.560,00$ & 22,10 & C \\
\hline$\varnothing$ & 155.8 & 155 & 8 & 487 & 36,90 & 86,50 & $1.000,00$ & 129,00 & 5,21 & $2.000,00$ & 29,00 & C \\
\hline$\varnothing$ & 175.5 & 175 & 5 & 550 & 26,70 & 72,30 & 966,00 & 110,00 & 6,01 & $1.330,00$ & 21,00 & C \\
\hline$\varnothing$ & 175.6 & 175 & 6 & 550 & 31,90 & 85,70 & $1.140,00$ & 130,00 & 5,98 & $2.280,00$ & 25,00 & C \\
\hline$\varnothing$ & 175.8 & 175 & 8 & 550 & 42,00 & 112,00 & $1.470,00$ & 168,00 & 5,92 & $2.940,00$ & 33,00 & C \\
\hline$\varnothing$ & 200.5 & 200 & 5 & 628 & 30,60 & 95,10 & $1.460,00$ & 146,00 & 6,91 & $2.920,00$ & 24,00 & C \\
\hline$\varnothing$ & 200.6 & 200 & 6 & 628 & 36,60 & 113,00 & $1.720,00$ & 172,00 & 6,86 & $3.440,00$ & 28,70 & C \\
\hline$\varnothing$ & 200.8 & 200 & 8 & 628 & 48,30 & 148,00 & $2.230,00$ & 223,00 & 6,79 & $4.460,00$ & 37,90 & C \\
\hline
\end{tabular}

Figure 198. Table of metallic round hollow profiles 
This profile has a maximum traction resistance of $N_{t, u}=A \cdot f_{y}=1770 m^{2} \cdot 215 \mathrm{~N} / \mathrm{mm}^{2}=$ $380550 \mathrm{~N}=380,55 \mathrm{KN}$

In where

A, area of the transversal section

$f_{y}$, calculus resistance of steel

$f_{y}=215 \mathrm{~N} / \mathrm{mm}^{2}$ is chosen because it is the $f_{y}$ more unfavorable for the different types of designations and nominal thicknesses in steels. $\mathrm{f}_{\mathrm{y}}=215 \mathrm{~N} / \mathrm{mm}^{2}$ corresponds to a steel S235. As buckling capability by bending, in centered compression, of a constant section bar, it can be taken

$N_{b, R d}=x \cdot A \cdot f_{y d}$

In where

$A$, area of the transversal section in classes 1,2 y 3 , or effective area $A_{\text {eff }}$ in sections of class 4 ,

$f_{y d}$, calculus resistance of steel, when it is chosen $f_{y d}=f_{y} / \gamma_{M 1}$ with $\gamma_{M 1}=1,05$ according to 2.3.3 section of the CTE'S DBSE-A, where $\gamma_{M 1}$ is the partial safety factor for instability phenomena.

$X$, reduction coefficient by buckling, the value of which can be obtained in the 6.3.2.1 section of the CTE'S DBSE-A on the basis of the reduced slenderness and the appropriate buckling curve.

The square root of the ratio between the plastic resistance of the calculation section and the critical compression by buckling is called reduced slenderness $(\lambda)$. Its value is

$$
\begin{aligned}
& \bar{\lambda}=\sqrt{A f_{y}} \\
& N_{c r i t}=N_{E v t}:=\frac{\pi^{2} E I_{f}}{L^{2}}
\end{aligned}
$$

where

$E$, modulus of elasticity $\left(E_{\text {steel }}=210000 \mathrm{MPa}=210000 \cdot 10^{6} \mathrm{~Pa}=210000 \cdot 10^{6} \frac{\mathrm{kg}}{\mathrm{m} \cdot \mathrm{s}^{2}}\right)$;

I, moment of inertia of the area of the section for flexion in the considered plane;

$\mathrm{L}$, buckling length of the piece. It is equivalent to the distance between points of inflection of the buckling deformation that is greater. For canonical cases it is defined in the table 6.1 of the CTE'S DBSE-A depending on the length of the piece. For different conditions for axial load or section it is defined in later sections.

The Area Moment of Inertia for a hollow cylindrical section is as follows:

$I_{x}=I_{y}=\frac{1}{4} \pi R^{4}$ 
To the proposed case, $\mathrm{I}=490,87 \mathrm{~cm}^{4}-294,37 \mathrm{~cm}^{4}=196,5 \mathrm{~cm}^{4}=1,965 \cdot 10^{-6} \mathrm{~m}^{4}$ (it is the same that the number given in the table)

And the Area of a hollow cylindrical section is:

$A=\pi \cdot R^{2}$

Where

$\mathrm{R}$, radius of the hollow cylindrical section

To the proposed case,

$A=\pi \cdot 50^{2} \mathrm{~mm}^{2}-\pi \cdot 44^{2} \mathrm{~mm}^{2}=1771,86 \mathrm{~mm}^{2}=17,7 \mathrm{~cm}^{2}$ (it is the same that the number given in the table)

In this way,

$\mathrm{N}_{\mathrm{cr}}=\pi^{2} \quad . \quad \frac{210000 \cdot 10^{6} \frac{\mathrm{kg}}{\mathrm{m} \cdot \mathrm{s}^{2}} \cdot\left(1 / 4 \cdot \pi \cdot \mathrm{R}^{4}-1 / 4 \cdot \pi \cdot \mathrm{r}^{4}\right)}{(2 \mathrm{~m})^{2}}=\pi^{2}$.

$\frac{210000 \cdot 10^{6} \frac{\mathrm{kg}}{\mathrm{m} \cdot \mathrm{s}^{2}} \cdot\left(1 / 4 \cdot \pi \quad \cdot(0,05 \mathrm{~m})^{4}-1 / 4 \cdot \pi \quad \cdot(0,044 \mathrm{~m})^{4}\right)}{(2 \mathrm{~m})^{2}}$

$\mathrm{N}_{\mathrm{cr}}=\pi^{2} \cdot \frac{210000 \cdot 10^{6} \frac{\mathrm{kg}}{\mathrm{m} \cdot \mathrm{s}^{2}} \cdot\left(4,9087385212 \cdot 10^{-6} \mathrm{~m}^{4}-2,9437477146 \cdot 10^{-6} \mathrm{~m}^{4}\right)}{(2 \mathrm{~m})^{2}}$

$\mathrm{N}_{\mathrm{cr}}=\pi^{2} \cdot \frac{210000 \cdot 10^{6} \frac{\mathrm{kg}}{\mathrm{m} \cdot \mathrm{s}^{\mathrm{s}}} \cdot 1,9649908066 \cdot 10^{-6} \mathrm{~m}^{4}}{(2 \mathrm{~m})^{2}}=1018173,06 \mathrm{~kg} \cdot \mathrm{m} / \mathrm{s}^{2}(\mathrm{~N})$

Then,

$\lambda=\sqrt{\frac{\left(\pi \bullet 50^{2} \mathrm{~mm}^{2}-\pi \bullet 44^{2} \mathrm{~mm}^{2}\right) \bullet 215 \mathrm{~N} / \mathrm{mm}^{2}}{1018173,06 \mathrm{~N}}}=\sqrt{0,37415}=0,611678$

$X$ is determined from the reduced slenderness and according to the figure 6.3 of the CTE's DBSE-A exposed in continuation like figure 199. It is supposed a cold formed profile because it is the most unfavorable case of round hollow profiles exposed in the table 6.2 Buckling curve depending on the cross section of the CTE's DBSE-A. 


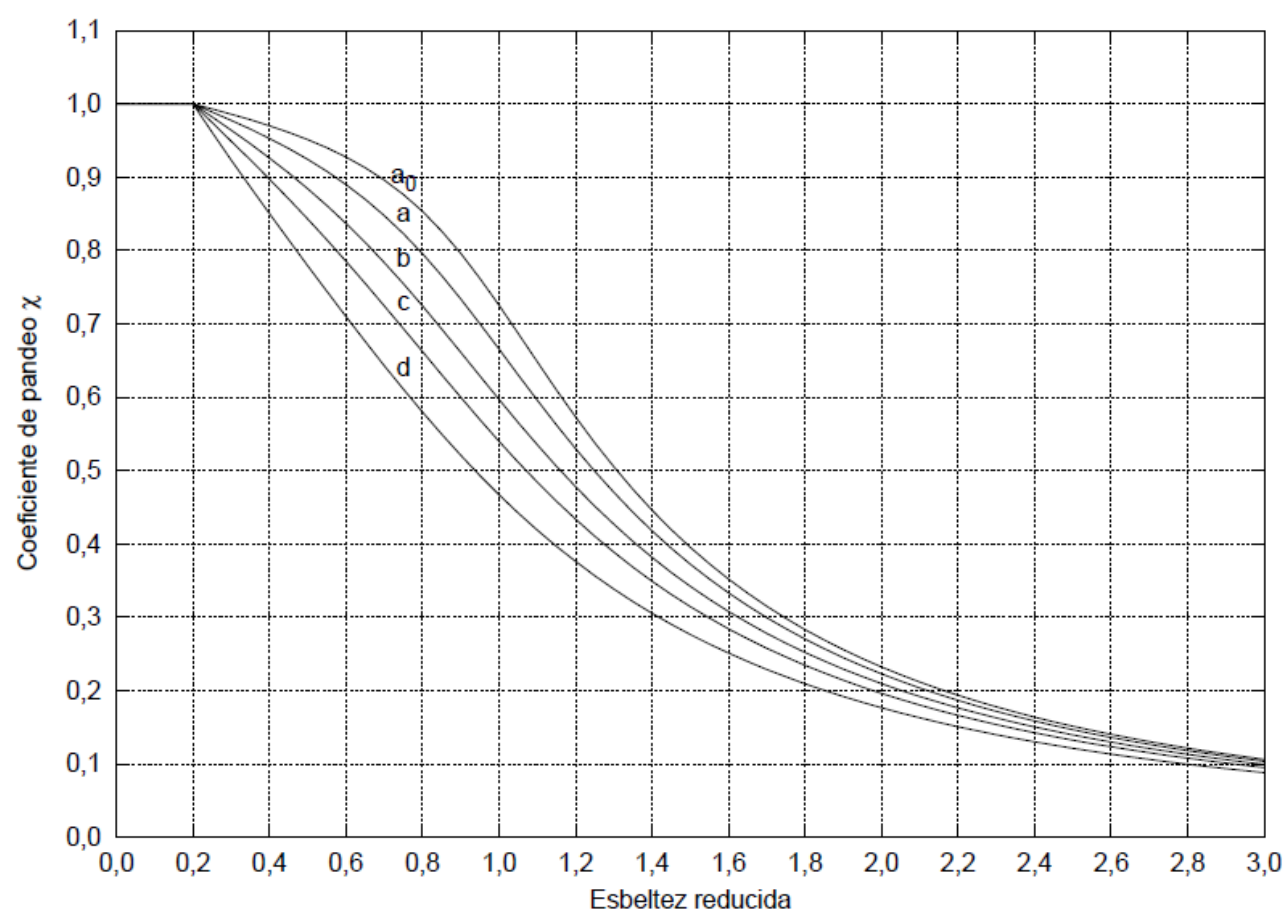

Figura 6.3 Curvas de pandeo

Figure 199. Buckling curves, CTE's DBSE-A

A buckling coefficient $X$ of 0,775 is obtained according to the figure 199 and the provided dates. So, for these bars the buckling capacity by flexion in centered compression can be taken like:

$\mathrm{N}_{\mathrm{b}, \mathrm{Rd}}=\mathrm{X} \cdot \mathrm{A} \cdot \mathrm{f}_{\mathrm{yd}}=0,775 \cdot 1771,86 \mathrm{~mm}^{2} \cdot \frac{215 \mathrm{~N} / \mathrm{mm}^{2}}{1,05}=281177,03 \mathrm{~N}=281,177 \mathrm{KN}$

A maximum compression effort of $280 \mathrm{KN}$ will be considered. So, a cable that supports 280 $\mathrm{KN}$ of traction will have to be calculated in order to compensate the compression effort and to balance the structure:

$\sigma=\frac{F}{A}=>\sigma_{b}=\frac{F_{b}}{A_{b}}=\frac{280 \mathrm{KN}}{17,70 \mathrm{~cm}^{2}}=15,82 \mathrm{KN} / \mathrm{cm}^{2}$

The tension which supports the cable will have to be much greater than the one that supports the bar, because its section is much smaller. So, a cable 19×7GALVA $\phi 8$ will be chosen, because it owns a very high tensile strength and a very big section. The properties of this cable appear on figure 200. 


\begin{tabular}{|c|c|c|}
\hline 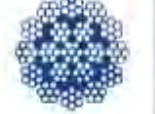 & \multicolumn{2}{|l|}{ Cables antigiratorio/elevación } \\
\hline $19 \times 7$ Galva & $1960 \mathrm{~N} / \mathrm{mm}_{2}$ & EN $12385-4$ \\
\hline \multicolumn{2}{|c|}{ Diametro Nominal (mm) } & Carga de rotura $(\mathrm{Kg})$ \\
\hline 4 & 0,064 & 1040 \\
\hline 5 & 0,1 & 1630 \\
\hline 6 & 0.145 & 2355 \\
\hline 7 & 0,197 & 3210 \\
\hline 8 & 0,257 & 4200 \\
\hline 9 & 0,326 & 5300 \\
\hline 10 & 0,402 & 6560 \\
\hline 11 & 0.486 & 7935 \\
\hline 12 & 0,579 & 9435 \\
\hline
\end{tabular}

Figure 200. Table of steel cables

The maximum tensile strength that the cable is capable of support is $1960 \cdot 50,24=98470,4$ $\mathrm{N}=98,47 \mathrm{KN}$

With all these data different positions of the structure will be calculated in order to verify the structural behavior of these balanced forces structures. In no case the maximum tension admissible of compression for the bar will can be exceeded. In the same way, in no case the maximum tension admissible of traction for the cable will can be exceeded.

\subsection{Results}

According to the Figure 221 , the $\phi 100.6$ considered standard hollow round profile has a bar "d" mass of $m_{b d}=13,90 \mathrm{kp} / \mathrm{m}=13,90 \mathrm{~kg}$

The cable has a mass of $m_{c}=0,257 \mathrm{~kg} / \mathrm{m}=>m_{c 1 m}=0,257 \mathrm{~kg}$

So, the total mass to the bar + the cable is $m_{T d}=m_{b d}+m_{c 1 m}=13,89 \mathrm{~kg}+0,257 \mathrm{~kg}=14,147 \mathrm{~kg}$ The own weight for a total mass of $m_{T d}$ is $P_{p d}=m_{T d} \cdot g=14,147 \mathrm{~kg} \cdot 9,81 \mathrm{~m} / \mathrm{s}^{2}=138,78 \mathrm{~N}$, where " $g$ " is the gravitational acceleration.

The vertical component of the force that the cable supports is the equivalent to the reaction that would have the structure in the basis. The results of the all cases of calculus are exposed in continuation. 


\section{Results for own weight of the vertical bar and cable d}

In this calculus case the masses of the weight force of the vertical bar and the proportional cable are the only ones considered.

For a totally deployed structure $\left(\alpha=90^{\circ}\right)$, the base reaction in the knot 3 is

$R_{3}=P_{b d+c d}+P_{b b+c b}=138,78 \mathrm{~N}+138,78 \mathrm{~N}=277,56 \mathrm{~N}=0,27756 \mathrm{KN}$

Where

$P_{b d+c d}$, own weight of " $d$ " bar and the "d" cable

$\mathrm{P}_{\mathrm{bb}+\mathrm{cb}}$, own weight of "b" bar and the "b" cable

The bar and the cable support perfectly this force.

Calculus with this weight will be done in order to find the aperture of the structure depending on the components of the force on bar " $d$ " in the axes represents in the figure 201 . The obtained results are in the figure 201 too.

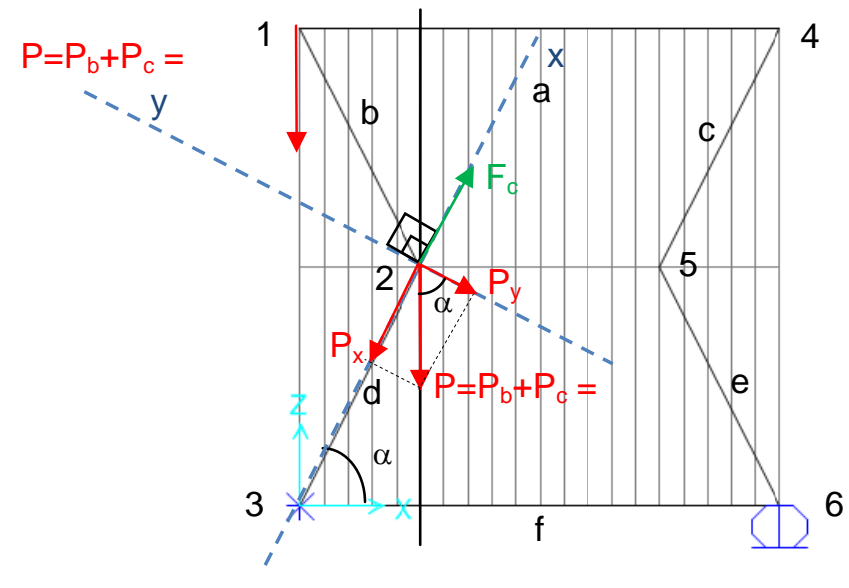

$$
\begin{aligned}
& \operatorname{sen} \alpha=\frac{|\mathrm{Px}|}{\mathrm{P}}=\frac{|\mathrm{FC}|}{\mathrm{P}} \\
& \operatorname{sen} \alpha=\frac{138,78 \mathrm{~N}}{138,78 \mathrm{~N}}=1=>\alpha=90^{\circ} \\
& \operatorname{sen} \alpha=\frac{120 \mathrm{~N}}{138,78 \mathrm{~N}}=0,86=>\alpha=59,85^{\circ} \\
& \operatorname{sen} \alpha=\frac{100 \mathrm{~N}}{138,78 \mathrm{~N}}=0,72=>\alpha=46,1^{\circ} \\
& \operatorname{sen} \alpha=\frac{85 \mathrm{~N}}{138,78 \mathrm{~N}}=0,61=>\alpha=37,77^{\circ} \\
& \operatorname{sen} \alpha=\frac{50 \mathrm{~N}}{138,78 \mathrm{~N}}=0,36=>\alpha=21,12^{\circ}
\end{aligned}
$$

Figure 201. Considered loads and structure apertures for these loads

The result is totally coherent because when tension and force (these two properties are directly proportional) decreases the structure is more closed.

\section{Own weight of the vertical and horizontal bars and cable}

The weight of the vertical and horizontal elements that fall over to the considered bar " $d$ " is added to the own weight of the bar " $\mathrm{d}$ " and the cable. So:

$$
\begin{aligned}
& \mathrm{m}_{\mathrm{bd}}=13,90 \mathrm{kp} / \mathrm{m}=13,90 \mathrm{~kg} \\
& \mathrm{~m}_{\mathrm{cd}}=0,257 \mathrm{~kg} / \mathrm{m}=>\mathrm{m}_{\mathrm{c} 1 \mathrm{~m}}=0,257 \mathrm{~kg} \\
& \mathrm{~m}_{\mathrm{Td}}=\mathrm{m}_{\mathrm{bd}}+\mathrm{m}_{\mathrm{cd}}=13,89 \mathrm{~kg}+0,257 \mathrm{~kg}=14,147 \mathrm{~kg} \\
& \mathrm{P}_{\mathrm{pd}}=\mathrm{m}_{\mathrm{Td}} \cdot \mathrm{g}=14,147 \mathrm{~kg} \cdot 9,81 \mathrm{~m} / \mathrm{s}^{2}=138,78 \mathrm{~N} \\
& \mathrm{~m}_{\text {over d }}=\mathrm{m}_{\mathrm{bb}}+\mathrm{m}_{\mathrm{cb}}+\frac{1}{2} \mathrm{~m}_{\mathrm{ba}}=13,89 \mathrm{~kg}+0,257 \mathrm{~kg}+13,89 \mathrm{~kg}=28,037 \mathrm{~kg}
\end{aligned}
$$


where

$\mathrm{m}_{\text {over d }}$, mass over "d" bar

$\mathrm{m}_{\mathrm{bb}}$, "b" bar mass

$\mathrm{m}_{\mathrm{cb}}$, "b" cable mass

$\mathrm{m}_{\mathrm{ba}}$, "a" bar mass

$P_{\text {over d }}=m_{\text {over } d} \cdot g=28,037 \mathrm{~kg} \cdot 9,81 \mathrm{~m} / \mathrm{s}^{2}=275,04 \mathrm{~N}$

$F_{\mathrm{T} 2 \mathrm{~d}}=\mathrm{P}_{\mathrm{pd}}+\mathrm{P}_{\text {over d }}=138,78 \mathrm{~N}+275,04 \mathrm{~N}=413,82 \mathrm{~N}$

Where

$\mathrm{F}_{\mathrm{T} 2 \mathrm{~d}}$, total force on "d" to the case 2

Calculus with this weight will be done in order to find the aperture of the structure depending on the components of the force on bar " $d$ " in the axes represents in the figure 202 . The obtained results are in the figure 202 too.

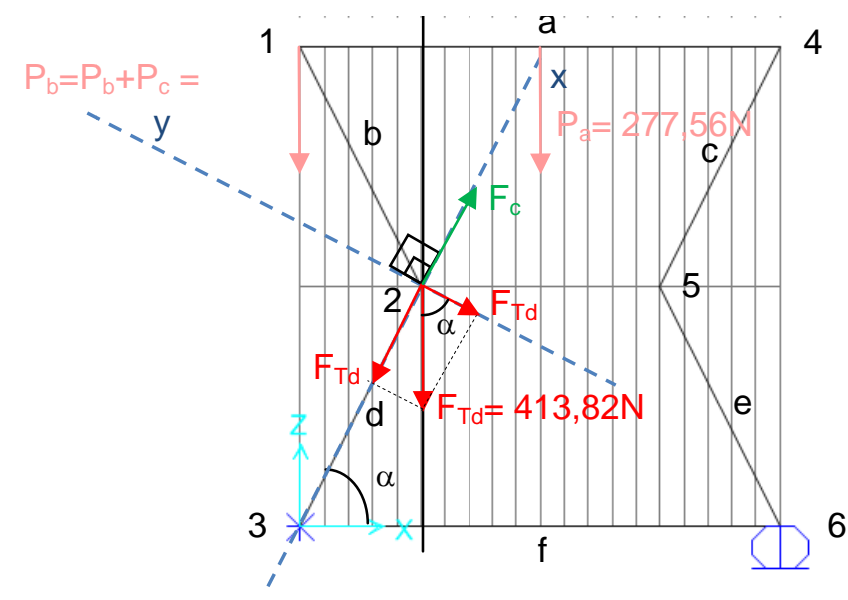

$$
\begin{aligned}
& \operatorname{sen} \alpha=\frac{|\mathrm{FTdx}|}{\mathrm{FTd}}=\frac{|\mathrm{FC}|}{\mathrm{FTd}} \\
& \operatorname{sen} \alpha=\frac{413,82 \mathrm{~N}}{413,82 \mathrm{~N}}=1=>\alpha=90^{\circ} \\
& \operatorname{sen} \alpha=\frac{300 \mathrm{~N}}{413,82 \mathrm{~N}}=0,72=>\alpha=46,46^{\circ} \\
& \operatorname{sen} \alpha=\frac{200 \mathrm{~N}}{413,82 \mathrm{~N}}=0,48=>\alpha=28,90^{\circ} \\
& \operatorname{sen} \alpha=\frac{100 \mathrm{~N}}{413,82 \mathrm{~N}}=0,24=>\alpha=13,98^{\circ} \\
& \operatorname{sen} \alpha=\frac{50 \mathrm{~N}}{413,82 \mathrm{~N}}=0,12=>\alpha=6,94^{\circ}
\end{aligned}
$$

Figure 202. Considered loads and structure apertures for these loads

The result is totally coherent because when tension and force (these two properties are directly proportional) decreases the structure is more closed.

\section{Own weight of the vertical and horizontal bars and cable and vertical exterior forces}

The vertical exterior forces than can affect are:

- Ported constructional elements, 1,2 KN/m

- Use overload, $5 \mathrm{KN} / \mathrm{m}$

- Snow, 5KN/m 
These loads have been defined with a basis of the CTE DB-SE-AE. The forces considered are:

$F_{T 2 d}=P_{p d}+P_{\text {over d }}=138,78 \mathrm{~N}+275,04 N=413,82 \mathrm{~N}$

$\mathrm{F}_{\text {ved }}=11,2 \mathrm{KN}=11200 \mathrm{~N}$

Where

$F_{\text {ve d, }}$ vertical exterior force on "d"

$F_{T 3 d}=F_{T 2 d}+F_{\text {ved }}=413,82 \mathrm{~N}+11200 \mathrm{~N}=11613,82 \mathrm{~N}$

Where

$\mathrm{F}_{\mathrm{T} 3 \mathrm{~d}}$, total force on "d" to the case 3

Calculus with this weight will be done in order to find the aperture of the structure depending on the components of the force on bar " $d$ " in the axes represents in the figure 203. The obtained results are in the figure 203 too.

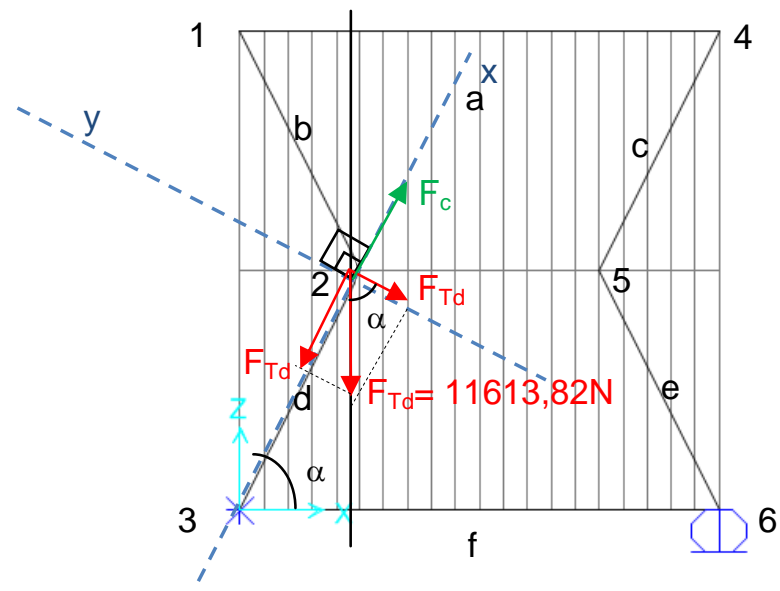

$$
\begin{aligned}
& \operatorname{sen} \alpha=\frac{|\mathrm{FTd}|}{\mathrm{FTd}}=\frac{|\mathrm{FC}|}{\mathrm{FTd}} \\
& \operatorname{sen} \alpha=\frac{11613,82 \mathrm{~N}}{11613,82 \mathrm{~N}}=1=>\alpha=90^{\circ} \\
& \operatorname{sen} \alpha=\frac{7000 \mathrm{~N}}{11613,82 \mathrm{~N}}=0,60=>\alpha=37,07^{\circ} \\
& \operatorname{sen} \alpha=\frac{2000 \mathrm{~N}}{11613,82 \mathrm{~N}}=0,17=>\alpha=9,92^{\circ} \\
& \operatorname{sen} \alpha=\frac{500 \mathrm{~N}}{11613,82 \mathrm{~N}}=0,04=>\alpha=2,47^{\circ} \\
& \operatorname{sen} \alpha=\frac{50 \mathrm{~N}}{11613,82 \mathrm{~N}}=0,004=>\alpha=0,25^{\circ}
\end{aligned}
$$

Figure 203. Considered loads and structure apertures for these loads

The result is totally coherent because when tension and force (these two properties are directly proportional) decreases the structure is more closed.

Own weight of the vertical and horizontal bars and cable, vertical exterior forces and horizontal exterior forces

The horizontal exterior force which can affect is 1,6 KN like horizontal load of wind. This load has been defined with a basis of the CTE DB-SE-AE. The wind action $\mathrm{q}_{\mathrm{e}}$ can be expressed like $\mathrm{q}_{\mathrm{e}}=\mathrm{q}_{\mathrm{b}} \cdot \mathrm{c}_{\mathrm{e}} \cdot \mathrm{c}_{\mathrm{p}}$, where:

$\mathrm{q}_{\mathrm{b}}$, dynamic pressure of the wind. In simplified form can be adopted $0,5 \mathrm{KN} / \mathrm{m}^{2}$ in all points of Spain. More accurate values can be obtained by the annexed D of the CTE DB-SE-AE. These more accurate values evaluate the geographical location of the work. 
$\mathrm{C}_{\mathrm{e}}$, exposition coefficient, variable with the height of the point considered. This coefficient evaluates the roughness of the environment where the construction is located. To urban buildings until 8 floors can be taken a constant height independent value of 2,0.

$\mathrm{c}_{\mathrm{p}}$, wind coefficient or pressure coefficient. It depends on the shape and orientation of the surface respect to the wind. It also depends on the situation of the point respect to the surface edges. A negative value indicates suction. For this structure a value of 0,8 is taken. So:

$q_{e}=q_{b} \cdot c_{e} \cdot c_{p}=0,5 \mathrm{KN} / \mathrm{m}^{2} \cdot 2 \cdot 0,8=0,8 \mathrm{KN} / \mathrm{m}^{2}=800 \mathrm{~N} / \mathrm{m}^{2}$

The forces considered are:

$F_{T 3 d}=F_{T 2 d}+F_{\text {ved }}=413,82 \mathrm{~N}+11200 \mathrm{~N}=11613,82 \mathrm{~N}$

$\mathrm{F}_{\mathrm{Tdh}}=1600 \mathrm{~N}$

Where

$\mathrm{F}_{\mathrm{Tdh}}$, total applied horizontal force on "d" to the case 4

$\mathrm{F}_{\mathrm{T} 4 \mathrm{~d}}=\mathrm{F}_{\mathrm{T} 3 \mathrm{~d}}+\mathrm{F}_{\mathrm{Tdh}}=11613,82 \mathrm{~N}+1600 \mathrm{~N}=13213,82 \mathrm{~N}$

Where

$F_{T 4 d}$, total force on "d" to the case 4

Calculus with this weight will be done in order to find the aperture of the structure depending on the components of the force on bar " $d$ " in the axes represents in the figure 204. The obtained results are in the figure 204 too.

$$
\begin{aligned}
& F_{c}=F_{T d v x}+F_{T d h x} \\
& \operatorname{sen} \alpha=\frac{|F T d v|}{F T d v}=\frac{|F c|}{F T d} \\
& \operatorname{sen} \alpha=\frac{13213,82 \mathrm{~N}}{13213,82 \mathrm{~N}}=1=>\alpha=90^{\circ} \\
& \operatorname{sen} \alpha=\frac{10000 \mathrm{~N}}{13213,82 \mathrm{~N}}=0,76=>\alpha=49,18^{\circ} \\
& \operatorname{sen} \alpha=\frac{7000 \mathrm{~N}}{13213,82 \mathrm{~N}}=0,53=>\alpha=31,99^{\circ} \\
& \operatorname{sen} \alpha=\frac{2000 \mathrm{~N}}{13213,82 \mathrm{~N}}=0,15=>\alpha=8,71^{\circ} \\
& \operatorname{sen} \alpha=\frac{1000 \mathrm{~N}}{13213,82 \mathrm{~N}}=0,08=>\alpha=4,34^{\circ}
\end{aligned}
$$

Figure 204. Considered loads and structure apertures for these loads

The result is totally coherent because when tension and force (these two properties are directly proportional) decreases the structure is more closed. 


\subsection{Discussion}

In this section an analysis of forces and positions in structures with articulated joints with external pre-forces that keep the structure balanced has been made. This mean using auxetic structures as a structure that works due a forces balance.

As a result we have obtained very elastic structures that receive only small forces on their bars when a load is applied. These structures could work fine if we piled them and apply loads caused by wind, quakes...

The maximum force that is supported by the cable in the proposed conditions is $13213,82 \mathrm{~N}$ or $13,21 \mathrm{KN}$. This force satisfies the characteristics of the cables that exist in the market.

The opening and closing positions according to the applied stresses are totally coherent. All these positions support the external forces typical in architecture. 


\subsubsection{Estructura reentrante hexagonal de hormigón}

\subsubsection{Estructura individual reentrante hexagonal de hormigón: estudio comparativo}

\subsection{Metodología}

Calcularemos una estructura auxética reentrante hexagonal unitaria sin ningún tipo de carga y con nudos rígidos y empotramientos, con secciones cuadradas de hormigón de 30×30 como las que se indican a continuación (figura 205):

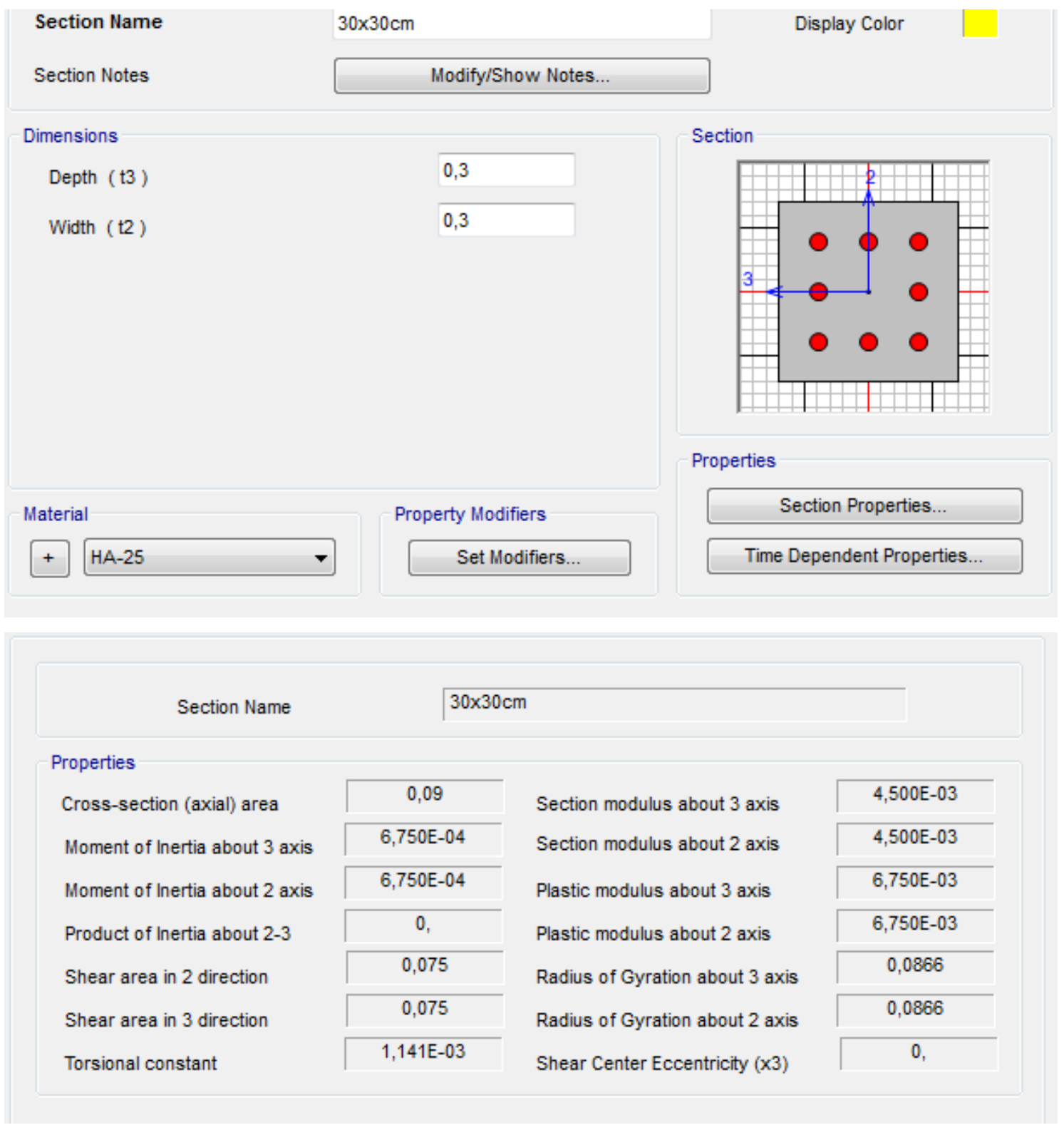

Figura 205 Características de secciones cuadradas de hormigón, SAP2000 
A esta estructura, en ciertos casos, se le insertan tendones con fuerzas previas de $1000 \mathrm{KN}$ como los indicados a continuación (figura 206):

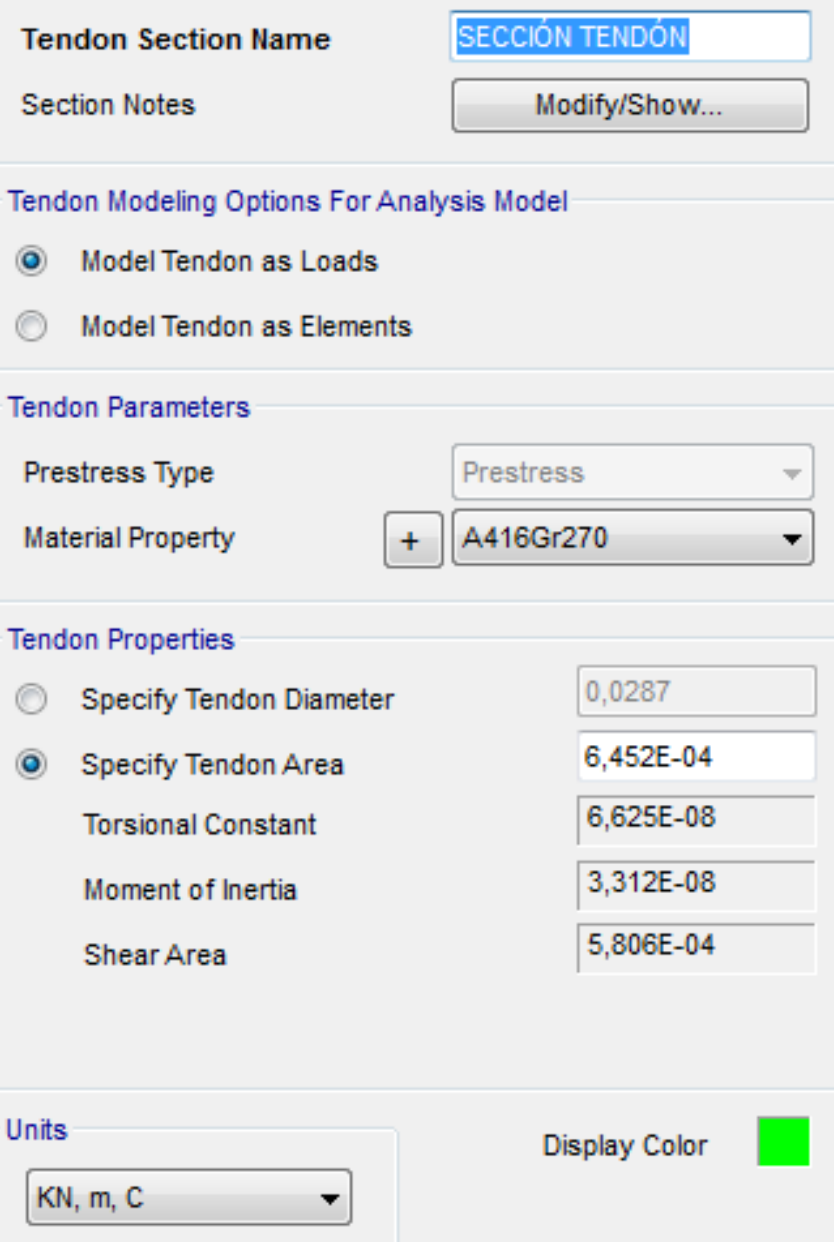

Tabular Data
\begin{tabular}{|l|c}
\hline Load Pattern & DEAD \\
\hline Load Type & Force \\
\hline Jack From This Location & Both Ends \\
\hline Tendon End Force (KN) & 1000, \\
\hline Tendon End Stress (KN/m2) & 0,15 \\
\hline Curvature Coefficient (Unitless) & $3,281 \mathrm{E}-03$ \\
\hline Wobble Coefficient (1/m) & $6,350 \mathrm{E}-03$ \\
\hline Anchorage Set Slip (m) & 20684,274 \\
\hline Loss - Elastic Shortening Stress (KN/m2) & 34473,79 \\
\hline Loss - Creep Stress (KN/m2) & 48263,31 \\
\hline Loss - Shrinkage Stress (KN/m2) & 34473,79 \\
\hline Loss - Steel Relaxation Stress (KN/m2)
\end{tabular}


Los supuestos de cálculo son los siguientes:

1) Pórtico no auxético con tendón continuo en barras vertical y horizontal superior

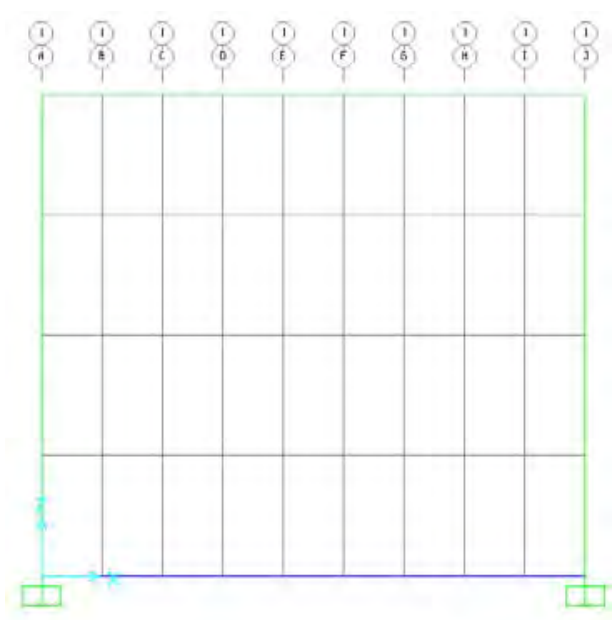

Figura 207 Pórtico no auxético con tendón continuo en barras vertical y horizontal superior, elaboración propia

2) Pórtico auxético sin tendón con ángulo de $75,96^{\circ}$

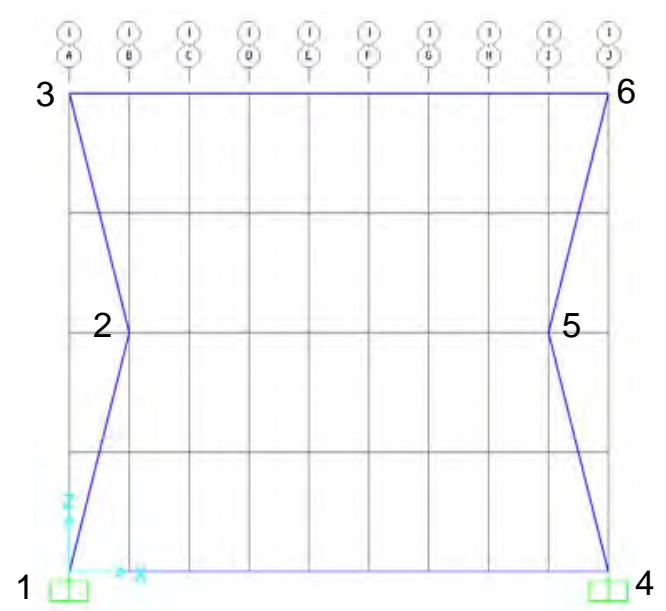

Figura 208 Pórtico auxético sin tendón con ángulo de 75,96º, elaboración propia 
3) Pórtico auxético con tendón en barras verticales con ángulo de $75,96^{\circ}$

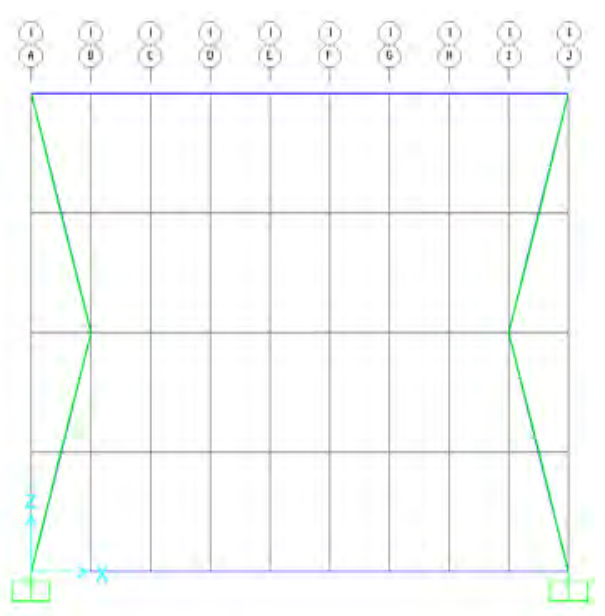

Figura 209 Pórtico auxético con tendón en barras verticales con ángulo de 75,96 , elaboración propia

4) Pórtico auxético con tendón continuo en barras vertical y horizontal superior con ángulo de $75,96^{\circ}$

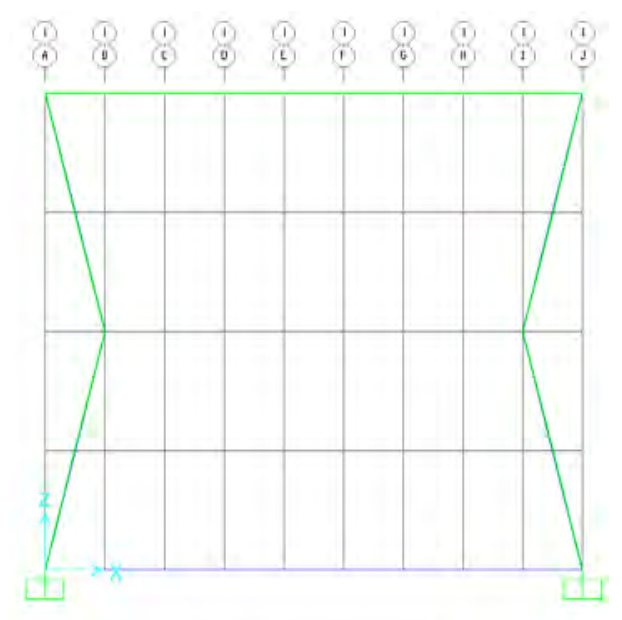

Figura 210 Pórtico auxético con tendón continuo en barras vertical y horizontal superior con ángulo de 75,96 elaboración propia 
Aplicaciones de las propiedades auxéticas en la arquitectura

CÁLCULO ESTRUCTURAL DE ESTRUCTURAS AUXÉTICAS

5) Pórtico auxético con tendón continuo en todas sus barras con ángulo de $75,96^{\circ}$

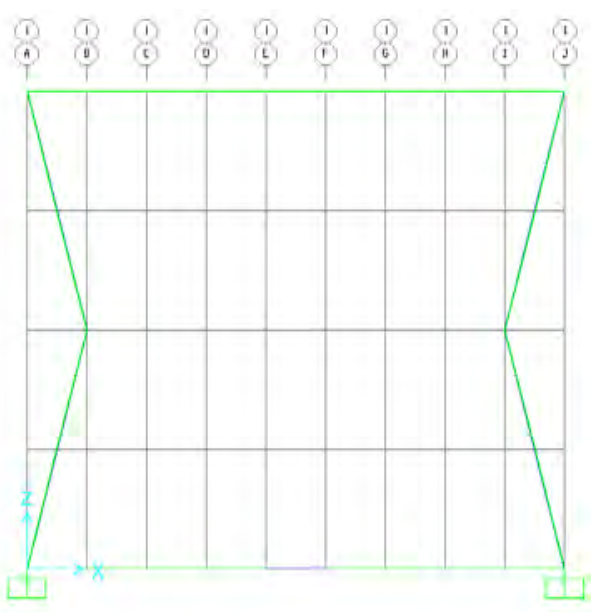

Figura 211 Pórtico auxético con tendón continuo en todas sus barras con ángulo de 75,96 , elaboración propia

6) Pórtico auxético con tendón en barras verticales con ángulo de $63,43^{\circ}$

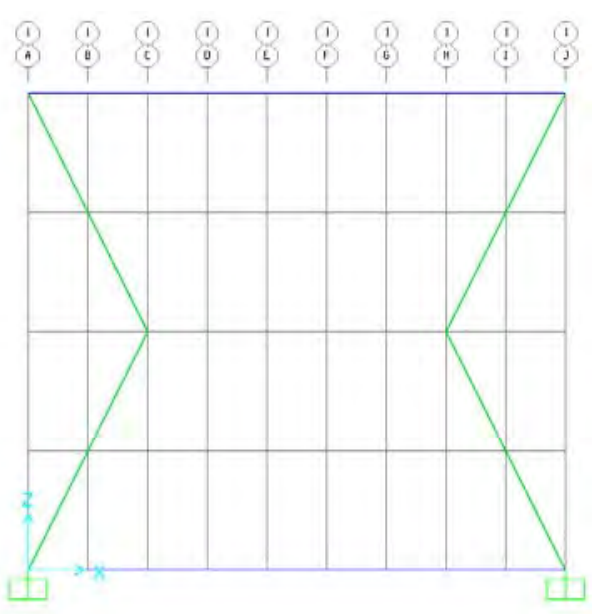

Figura 212 Pórtico auxético con tendón en barras verticales con ángulo de $63,43^{\circ}$, elaboración propia 
7) Pórtico auxético con tendón continuo en barras vertical y horizontal superior con ángulo de $63,43^{\circ}$

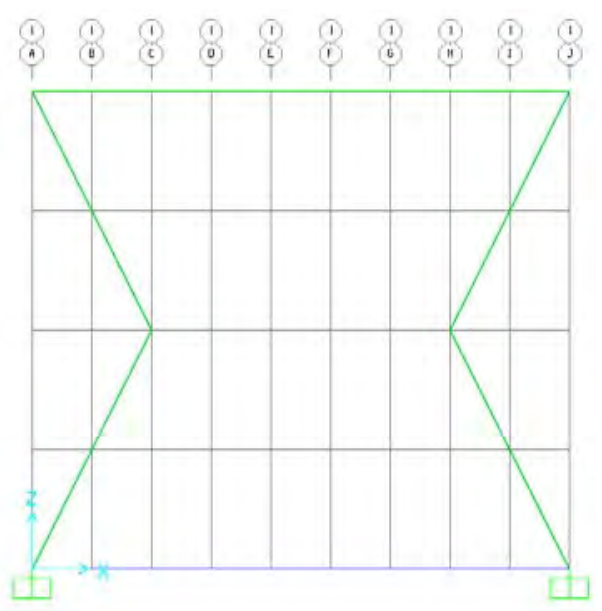

Figura 213 Pórtico auxético con tendón continuo en barras vertical y horizontal superior con ángulo de $63,43^{\circ}$, elaboración propia

8) Pórtico auxético con tendón en barras verticales con ángulo de $53,13^{\circ}$

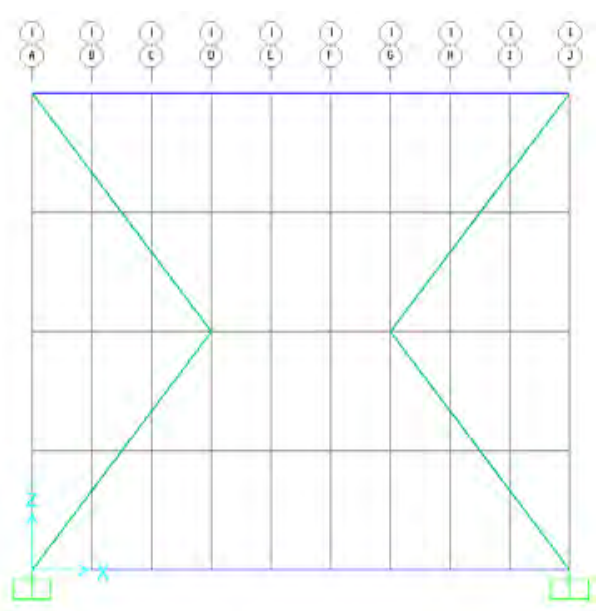

Figura 214 Pórtico auxético con tendón en barras verticales con ángulo de 53,13², elaboración propia 
9) Pórtico auxético con tendón continuo en barras vertical y horizontal superior con ángulo de $53,13^{\circ}$

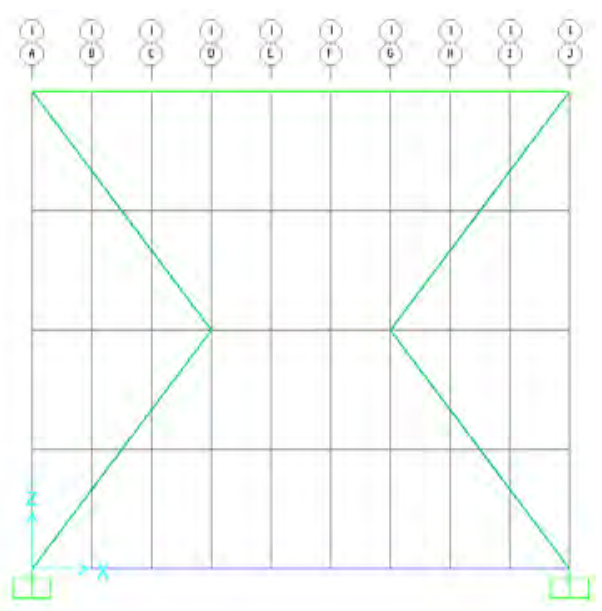

Figura 215 Pórtico auxético con tendón continuo en barras vertical y horizontal superior con ángulo de 53,13ㄹ, elaboración propia

10) Pórtico auxético con tendón en barras verticales con ángulo de $45^{\circ}$

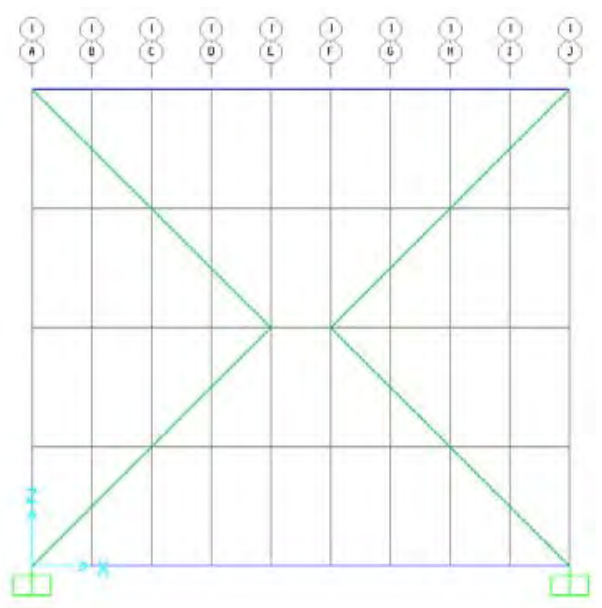

Figura 216 Pórtico auxético con tendón en barras verticales con ángulo de $45^{\circ}$, elaboración propia 


\subsection{Resultados}

Para la estructura de hormigón, se obtienen los siguientes resultados:

Desplazamientos horizontales

\begin{tabular}{|c|c|c|c|c|c|c|}
\hline $\begin{array}{c}\text { Número } \\
\text { figura }\end{array}$ & $\begin{array}{c}\delta \mathbf{x} \text { Nudo } \\
\mathbf{1}(\mathbf{m})\end{array}$ & $\begin{array}{c}\delta \mathbf{x} \text { Nudo } \\
\mathbf{2}(\mathbf{m})\end{array}$ & $\begin{array}{c}\delta \mathbf{x} \text { Nudo } \\
\mathbf{3} \mathbf{( m )}\end{array}$ & $\begin{array}{c}\delta \mathbf{x} \text { Nudo } \\
\mathbf{4}(\mathbf{m})\end{array}$ & $\begin{array}{c}\delta \mathbf{x} \text { Nudo } \\
\mathbf{5}(\mathbf{m})\end{array}$ & $\begin{array}{c}\delta \mathbf{~ N u d o} \\
\mathbf{6}(\mathbf{m})\end{array}$ \\
\hline 1 & 0 & - & 0,0006 & $-0,0006$ & - & 0 \\
\hline 2 & 0 & $5,297 \mathrm{E}-05$ & $6,688 \mathrm{E}-07$ & $-6,688 \mathrm{E}-07$ & $-5,297 \mathrm{E}-05$ & 0 \\
\hline 3 & 0 & $-5,574 \mathrm{E}-05$ & $6,726 \mathrm{E}-07$ & $-6,726 \mathrm{E}-07$ & $5,574 \mathrm{E}-05$ & 0 \\
\hline 4 & 0 & 0,0001 & 0,0005 & $-0,0005$ & $-0,0001$ & 0 \\
\hline 5 & 0 & $9,868 \mathrm{E}-05$ & 0,0004 & $-0,0004$ & $-9,868 \mathrm{E}-05$ & 0 \\
\hline 6 & 0 & $-1,888 \mathrm{E}-05$ & $6,22 \mathrm{E}-07$ & $-6,22 \mathrm{E}-07$ & $1,888 \mathrm{E}-05$ & 0 \\
\hline 7 & 0 & 0,0001 & 0,0004 & $-0,0004$ & $-0,0001$ & 0 \\
\hline 8 & 0 & $6,765 \mathrm{E}-05$ & $6,546 \mathrm{E}-07$ & $-6,546 \mathrm{E}-07$ & $-6,765 \mathrm{E}-05$ & 0 \\
\hline 9 & 0 & 0,0004 & 0,0002 & $-0,0002$ & $-0,0004$ & 0 \\
\hline 10 & 0 & 0,000203 & $7,786 \mathrm{E}-07$ & $-7,786 \mathrm{E}-07$ & $-0,000203$ & 0 \\
\hline
\end{tabular}

Tabla 8 Desplazamientos horizontales en nudos para las figuras estudiadas, elaboración propia

Para el Nudo 1, todos los desplazamientos horizontales son nulos.

Para el Nudo 2, el mayor desplazamiento 0.0004 corresponde a la figura 9, seguidos de la figura 3 y 8 ambas con el mismo valor 0.0001; el menor desplazamiento -5.574E-05 corresponde a la figura 3 seguida de la 6 con un valor -1.888E-05.

Para el nudo 3, el mayor valor corresponde a la figura 3 con valor de 0.0005 seguido de las figuras 5 y / ambas con el mismo valor 0.0004; el menor valor con 7.786E-07 corresponde a la figura 10 seguido de las figura 3 y 2 con $6.726 \mathrm{E}-07$ y $6.888 \mathrm{E}-07$ respectivamente.

Para el Nudo 4, el mayor desplazamiento con -0.0002 corresponde a la figura 9 seguida de las figuras 5 y 7 ambas con el mismo valor -0.0004; correspondiendo el menor desplazamiento al valor -7.786E-07 correspondiente a la figura 10.

Para el Nudo 5 el mayor desplazamiento con -0.0001 corresponden a la figura 4 y 7 con el mismo valor; el menor valor del desplazamiento con -9.868E-05 corresponde a la figura 5 seguido de la figura 8 con un valor de -6.765E-05.

Para el Nudo 6 todos los desplazamientos horizontales son nulos. 
Desplazamientos verticales

\begin{tabular}{|c|c|c|c|c|c|c|}
\hline $\begin{array}{c}\text { Número } \\
\text { figura }\end{array}$ & $\begin{array}{c}\delta \mathbf{z} \text { Nudo } \\
\mathbf{1}(\mathbf{m})\end{array}$ & $\begin{array}{c}\delta \mathbf{z} \text { Nudo } \\
\mathbf{2}(\mathbf{m})\end{array}$ & $\begin{array}{c}\delta \mathbf{z} \text { Nudo } \\
\mathbf{3}(\mathbf{m})\end{array}$ & $\begin{array}{c}\delta \mathbf{z} \text { Nudo } \\
\mathbf{4}(\mathbf{m})\end{array}$ & $\begin{array}{c}\delta \mathbf{z} \text { Nudo } \\
\mathbf{5}(\mathbf{m})\end{array}$ & $\begin{array}{c}\delta \mathbf{z} \text { Nudo } \\
\mathbf{6}(\mathbf{m})\end{array}$ \\
\hline 1 & 0 & - & $-0,001$ & $-0,001$ & - & 0 \\
\hline 2 & 0 & $-2,199 \mathrm{E}-05$ & $-4,018 \mathrm{E}-05$ & $-4,018 \mathrm{E}-05$ & $-2,199 \mathrm{E}-05$ & 0 \\
\hline 3 & 0 & $-0,0005$ & $-0,0009$ & $-0,0009$ & $-0,0005$ & 0 \\
\hline 4 & 0 & $-0,0006$ & $-0,0012$ & $-0,0012$ & $-0,0006$ & 0 \\
\hline 5 & 0 & $-0,0006$ & $-0,0011$ & $-0,0011$ & $-0,0006$ & 0 \\
\hline 6 & 0 & $-0,0005$ & $-0,0011$ & $-0,0011$ & $-0,0005$ & 0 \\
\hline 7 & 0 & $-0,0006$ & $-0,001$ & $-0,001$ & $-0,0006$ & 0 \\
\hline 8 & 0 & $-0,0007$ & $-0,0014$ & $-0,0014$ & $-0,0007$ & 0 \\
\hline 9 & 0 & $-0,0004$ & $-0,0008$ & $-0,0008$ & $-0,0004$ & 0 \\
\hline 10 & 0 & $-0,001073$ & $-0,002138$ & $-0,002138$ & $-0,001073$ & 0 \\
\hline
\end{tabular}

Tabla 9 Desplazamientos verticales en nudos para las figuras estudiadas, elaboración propia

Para el Nudo 1, todos los desplazamientos verticales son nulos.

Para el Nudo 2 el mayor desplazamiento con -0.0004 corresponde a la figura 9; siendo el menor desplazamiento el de la figura 2 con un valor de -0.199E-05.

Para el Nudo 3 el mayor desplazamiento corresponde con -0.001 a la figura 7 seguido de 0.0011 de las figura 5 y 6 ; el menor desplazamiento corresponde a la figura 2 con un valor de $-4.018 \mathrm{E}-05$

Para el Nudo 4 el mayor desplazamiento con un valor de -0.001 corresponde a la figura 7 seguido de las figuras 5 y 6 con el mismo valor de -0.0011; el menor desplazamiento corresponde a la figura 2 con un valor de -4.018E-05.

Para el Nudo 5 el mayor desplazamiento con un valor de -0.0004 corresponde a la figura 4; correspondiendo el menor desplazamiento a la figura 2 con un valor de -2.199E-05.

Para el nudo 6 todos los desplazamientos verticales son nulos. 
Rotaciones en articulaciones

\begin{tabular}{|c|c|c|c|c|c|c|}
\hline $\begin{array}{c}\text { Número } \\
\text { figura }\end{array}$ & $\begin{array}{c}\text { Ry Nudo } \\
\mathbf{1}(\mathbf{r a d})\end{array}$ & $\begin{array}{c}\text { Ry Nudo } \\
\mathbf{2}(\mathbf{r a d})\end{array}$ & $\begin{array}{c}\text { Ry Nudo } \\
\mathbf{3} \text { (rad) }\end{array}$ & $\begin{array}{c}\text { Ry Nudo } \\
\mathbf{4} \text { (rad) }\end{array}$ & $\begin{array}{c}\text { Ry Nudo } \\
\mathbf{5} \text { (rad) }\end{array}$ & $\begin{array}{c}\text { Ry Nudo } \\
\mathbf{6} \text { (rad) }\end{array}$ \\
\hline 1 & 0 & - & 0,00026 & $-0,00026$ & - & 0 \\
\hline 2 & 0 & $-2 \mathrm{E}-05$ & $5 \mathrm{E}-05$ & $-5 \mathrm{E}-05$ & $2 \mathrm{E}-05$ & 0 \\
\hline 3 & $7 \mathrm{E}-05$ & $-6 \mathrm{E}-05$ & $5 \mathrm{E}-05$ & $-5 \mathrm{E}-05$ & $6 \mathrm{E}-05$ & $-7 \mathrm{E}-05$ \\
\hline 4 & 0,00038 & $-0,0008$ & 0,00392 & $-0,00392$ & 0,0008 & $-0,00038$ \\
\hline 5 & 0,00028 & $-0,00072$ & 0,00377 & $-0,00377$ & 0,00072 & $-0,00028$ \\
\hline 6 & 0,00019 & $-0,0001$ & $1 \mathrm{E}-05$ & $-1 \mathrm{E}-05$ & 0,0001 & $-0,00019$ \\
\hline 7 & 0,00022 & $4 \mathrm{E}-05$ & 0,0004 & $-0,0004$ & $-4 \mathrm{E}-05$ & $-0,00022$ \\
\hline 8 & 0,00036 & $-0,00017$ & $-2 \mathrm{E}-05$ & $2 \mathrm{E}-05$ & 0,00017 & $-0,00036$ \\
\hline 9 & 0,00038 & $-0,00011$ & 0,00029 & $-0,00029$ & 0,00011 & $-0,00038$ \\
\hline 10 & 0 & $2,6 \mathrm{E}-05$ & $-0,000243$ & 0,000243 & $-2,6 \mathrm{E}-05$ & 0 \\
\hline
\end{tabular}

Tabla 10 Rotaciones en articulaciones para las figuras estudiadas, elaboración propia

La mayor rotación del Nudo 1 corresponde al valor 0,00038 alcanzado tanto en la figura 4 como en la 9; correspondiendo la menor rotación a las figuras 1 y 2 con valor 0 seguida de la 3 con un valor de 7E-05

Respecto al Nudo 2 la mayor rotación corresponde a la figura 4 con un valor de -0,0008 siendo la menor rotación la correspondiente a la figura 2 con un valor de -2E-05; no existiendo valor para la figura 1.

Para el Nudo 3 la mayor rotación corresponde a la figura 5 con un valor de 0,00377 siendo la menor rotación con valor de 1E-05 correspondiente a la figura 6.

Respecto al Nudo 4 la mayor rotación con un valor de -0,00377 corresponde a la figura 5 y la menor a la figura 6 con un valor de 1E-05.

Para el Nudo 5 la mayor rotación corresponde a la figura 4 con un valor de 0,0008 y la menor rotación a la figura 10 con un valor de 2E-05.

En cuando al Nudo 6 la mayor rotación con un valor de -0,00038 corresponde a las figuras 4 y 9 y la menor rotación con un valor de 0 a las figuras 1,2 y 10. 
Reacciones en apoyos

\begin{tabular}{|c|c|c|}
\hline $\begin{array}{c}\text { Número } \\
\text { figura }\end{array}$ & $\mathbf{R v}(\mathbf{K N})$ & $\mathbf{R h}$ (KN) \\
\hline 1 & 19,12 & 0,09 (hacia afuera) \\
\hline 2 & 19,4 & 0,86 (hacia adentro) \\
\hline 3 & 19,6 & 0,86 (hacia adentro) \\
\hline 4 & 244,71 & 28,68 (hacia adentro) \\
\hline 5 & 244,81 & 462,46 (hacia afuera) \\
\hline 6 & 20,4 & 0,8 (hacia adentro) \\
\hline 7 & 20,52 & 0,1 (hacia adentro) \\
\hline 8 & 21,62 & 0,84 (hacia adentro) \\
\hline 9 & 21,73 & 0,63 (hacia adentro) \\
\hline 10 & 22,85 & 1 (hacia adentro) \\
\hline
\end{tabular}

Tabla 11 Reacciones en apoyos para las figuras estudiadas, elaboración propia

Los mayores valores de reacciones verticales en apoyos (Rv) corresponden a la figuras 4 y 5 con unos valores de $244,71 \mathrm{KN}$ y $244,81 \mathrm{KN}$ respectivamente. Estos valores son unas diez veces mayores que los del resto de las estructuras consideradas, correspondiendo a figuras con una apertura de $75,96^{\circ}$ y un tendón continuo que enlaza toda la figura (en el caso de la figura 4 la barra horizontal inferior carece de tendón, lo cual no afecta prácticamente al resultado debido a que la estructura está empotrada en su base).

Los mayores valores de reacciones horizontales en apoyos ( $R h)$ corresponden a la figura 5 con un valor de $462,46 \mathrm{KN}$, seguida de la figura 4 con un valor de $28,68 \mathrm{KN}$. Estos valores son considerablemente mayores que los del resto de las estructuras consideradas, correspondiendo a figuras con una apertura de $75,96^{\circ}$ y un tendón continuo que enlaza toda la figura (en el caso de la figura 4 la barra horizontal inferior carece de tendón, lo cual no afecta prácticamente al resultado debido a que la estructura está empotrada en su base). 
Esfuerzos axiles:

\begin{tabular}{|c|c|c|c|c|c|c|}
\hline $\begin{array}{c}\text { Número } \\
\text { figura }\end{array}$ & Barra a & Barra b & Barra c & Barra d & Barra e & Barra f \\
\hline 1 & $-715,93$ & $\begin{array}{l}\text { B: }-757,083 \\
\text { a - } 714,824 \\
\text { T: } 576,184 \text { a } \\
535,383\end{array}$ & $\begin{array}{c}\text { B: }-757,083 \\
\text { a - 714,824 } \\
\mathrm{T}: 576,184 \mathrm{a} \\
535,383\end{array}$ & $\begin{array}{c}\text { B: }-714,824 \mathrm{a} \\
-562,917 \\
\mathrm{~T}: 535,383 \mathrm{a} \\
538,405\end{array}$ & $\begin{array}{c}-714,824 \mathrm{a} \\
-562,917 \\
\mathrm{~T}: 535,383 \mathrm{a} \\
538,405 \\
\end{array}$ & 0 \\
\hline 2 & $-0,857$ & $\begin{array}{c}-4,702 \mathrm{a}- \\
9,201\end{array}$ & $\begin{array}{c}-4,702 \mathrm{a}- \\
9,201 \\
\end{array}$ & $\begin{array}{c}-9,616 \text { a - } \\
14,115 \\
\end{array}$ & $\begin{array}{c}-9,616 \mathrm{a}- \\
14,115\end{array}$ & 0 \\
\hline 3 & $-0,862$ & $\begin{array}{c}\text { B: }-628,631 \mathrm{a} \\
-652,606 \\
\mathrm{~T}: 623,572 \mathrm{a} \\
643,24\end{array}$ & $\begin{array}{c}\text { B: }-628,631 \mathrm{a} \\
-652,606 \\
\mathrm{~T}: 623,572 \mathrm{a} \\
643,24\end{array}$ & $\begin{array}{c}\text { B: }-652,959 \mathrm{a} \\
-637,887 \\
\mathrm{~T}: 643,24 \mathrm{a} \\
623,572\end{array}$ & $\begin{array}{c}\text { B: }-652,959 \mathrm{a} \\
-637,887 \\
\mathrm{~T}: 643,24 \mathrm{a} \\
623,572\end{array}$ & 0 \\
\hline 4 & $\begin{array}{c}\text { B: }-658,386 \\
(-607,101) \\
\text { T: } 601,044 \\
(578,42) \\
\end{array}$ & $\begin{array}{c}\text { B: }-906,202 \mathrm{a} \\
-893,03 \\
\mathrm{~T}: 689,858 \mathrm{a} \\
601,044\end{array}$ & $\begin{array}{c}\text { B: }-906,202 \mathrm{a} \\
-893,03 \\
\mathrm{~T}: 689,858 \mathrm{a} \\
601,044\end{array}$ & $\begin{array}{c}\text { B: }-835,899 \mathrm{a} \\
-753,52 \\
\mathrm{~T}: 601,044 \mathrm{a} \\
514,066\end{array}$ & $\begin{array}{c}\text { B: }-835,899 \mathrm{a} \\
-753,52 \\
\mathrm{~T}: 601,044 \mathrm{a} \\
514,066\end{array}$ & 0 \\
\hline 5 & $\begin{array}{c}\text { B: }-484,276 \\
(-445,475) \\
\text { T: } 455,383 \\
(416,582)\end{array}$ & $\begin{array}{c}\text { B: }-744,693 \mathrm{a} \\
-807,029 \\
\mathrm{~T}: 586,184 \mathrm{a} \\
455,383\end{array}$ & $\begin{array}{c}\text { B: }-744,693 \mathrm{a} \\
-807,029 \\
\mathrm{~T}: 586,184 \mathrm{a} \\
455,383\end{array}$ & $\begin{array}{c}\text { B: }-813,075 \text { a } \\
-790,075 \\
\text { T: } \mathrm{T}: 586,184 \\
\text { a } 550,583\end{array}$ & $\begin{array}{c}\text { B: }-813,075 \mathrm{a} \\
-790,075 \\
\mathrm{~T}: 586,184 \mathrm{a} \\
550,583\end{array}$ & $\begin{array}{c}\text { B: }-87,579 \\
(340,434) \\
\text { T: } 550,583 \\
(525,023) \\
\end{array}$ \\
\hline 6 & $-0,797$ & $\begin{array}{c}\text { B: }-600,062 \mathrm{a} \\
-637,334 \\
\mathrm{~T}: 595,522 \mathrm{a} \\
628,566\end{array}$ & $\begin{array}{c}\text { B: }-600,062 \mathrm{a} \\
-637,334 \\
\mathrm{~T}: 595,522 \mathrm{a} \\
628,566\end{array}$ & $\begin{array}{c}\text { B: }-637,969 \mathrm{a} \\
-609,601 \\
\mathrm{~T}: 628,566 \mathrm{a} \\
595,522\end{array}$ & $\begin{array}{c}\text { B: }-637,969 \mathrm{a} \\
-609,601 \\
\mathrm{~T}: 628,566 \mathrm{a} \\
595,522\end{array}$ & 0 \\
\hline 7 & $\begin{array}{c}\text { B: }-568,919 \\
(-516,661) \\
\text { T: } 568,818 \\
(516,56) \\
\end{array}$ & $\begin{array}{c}\text { B: }-669,312 \mathrm{a} \\
-683,559 \\
\mathrm{~T}: 568,818 \mathrm{a} \\
674,38 \\
\end{array}$ & $\begin{array}{c}\text { B: }-669,312 \mathrm{a} \\
-683,559 \\
\mathrm{~T}: 568,818 \mathrm{a} \\
674,38 \\
\end{array}$ & $\begin{array}{c}\text { B: }-615,488 \mathrm{a} \\
-522,272 \\
\mathrm{~T}: 674,38 \mathrm{a} \\
508,405\end{array}$ & $\begin{array}{c}\text { B: }-615,488 \mathrm{a} \\
-522,272 \\
\mathrm{~T}: 674,38 \mathrm{a} \\
508,405 \\
\end{array}$ & 0 \\
\hline 8 & $-0,839$ & $\begin{array}{c}\text { B: }-585,166 \mathrm{a} \\
-632,504 \\
\mathrm{~T}: 581,238 \mathrm{a} \\
624,27\end{array}$ & $\begin{array}{c}\text { B: }-585,166 \mathrm{a} \\
-632,504 \\
\mathrm{~T}: 581,238 \mathrm{a} \\
624,27\end{array}$ & $\begin{array}{c}\text { B: }-633,421 \mathrm{a} \\
-594,986 \\
\mathrm{~T}: 624,27 \mathrm{a} \\
581,238\end{array}$ & $\begin{array}{c}\text { B: }-633,421 \mathrm{a} \\
-594,986 \\
\mathrm{~T}: 624,27 \mathrm{a} \\
581,238\end{array}$ & 0 \\
\hline 9 & $\begin{array}{c}\text { B: }-218,714 \\
(-201,106) \\
\text { T: } 235,783 \\
(191,673) \\
\end{array}$ & $\begin{array}{c}\text { B: }-239,544 \mathrm{a} \\
-218,046 \\
\mathrm{~T}: 235,783 \mathrm{a} \\
175,525 \\
\end{array}$ & $\begin{array}{c}\text { B: }-239,544 \mathrm{a} \\
-218,046 \\
\mathrm{~T}: 235,783 \mathrm{a} \\
175,525\end{array}$ & $\begin{array}{c}\text { B: }-184,639 a \\
-135,342 \\
\mathrm{~T}: 175,525 \mathrm{a} \\
121,63\end{array}$ & $\begin{array}{c}\text { B: }-184,639 \text { a } \\
-135,342 \\
\mathrm{~T}: 175,525 \mathrm{a} \\
121,63 \\
\end{array}$ & 0 \\
\hline 10 & $-0,998$ & $\begin{array}{c}\text { B: }-504,504 a \\
-684,111 \\
\text { T: } 501,288 \mathrm{a} \\
594,27\end{array}$ & $\begin{array}{c}\text { B: }-504,504 \mathrm{a} \\
-684,111 \\
\mathrm{~T}: 501,288 \mathrm{a} \\
594,27\end{array}$ & $\begin{array}{c}\text { B: }-685,522 \mathrm{a} \\
-514,912 \\
\mathrm{~T}: 594,27 \mathrm{a} \\
501,238\end{array}$ & $\begin{array}{c}\text { B: }-685,522 \mathrm{a} \\
-514,912 \\
\mathrm{~T}: 594,27 \mathrm{a} \\
501,238\end{array}$ & 0 \\
\hline
\end{tabular}

Tabla 12 Esfuerzos axiles en barras $(B)$ y tendones $(T)$ para las figuras estudiadas, elaboración propia

Con el estudio de esfuerzos axiles se pretende visualizar si el esfuerzo de la barra se ve compensado con el del tendón, manteniendo el equilibrio. Se puede observar que los esfuerzos se compensan, pero los valores son demasiado altos, llegando en algunos casos a valores que rondan los $900 \mathrm{KN}$. Se observa que en la figura 9, consistente en un pórtico auxético con tendón continuo en barras vertical y horizontal superior con ángulo de 53,13, estos esfuerzos son menores, estando sus valores entorno a los $200 \mathrm{KN}$. 


\subsection{Discusión de resultados}

En el caso de la estructura de hormigón se observa que los desplazamientos aumentan al meter tendones, cosa desfavorable. Además, varían (especialmente en el caso horizontal) en función del ángulo de apertura, siendo la posición mejor de las consideradas el ángulo de $63,43^{\circ}$. En cuanto a las reacciones en los apoyos, aumentan con el cierre de la estructura, y con los tendones (a más cantidad de tendón para una estructura, más reacciones en los apoyos). En cuanto a esfuerzos axiles son menores sin tendón: cuando metemos el tendón la idea es igualar las cargas de compresión y tracción que sufren las barras y el tendón respectivamente, pero cuando conseguimos esto los esfuerzos son desorbitados... Habría que tener en cuenta que los tendones en hormigón se ponen para mejorar las tracciones de este, y si estas barras están funcionando a compresión no tiene mucho sentido ponerlos. Tendría sentido en estructuras articuladas, para que dejen de ser mecanismos.

Hay una clara diferencia entre la estructura metálica y la de hormigón, y es que, en el caso de la de hormigón, los desplazamientos son totalmente simétricos. Esto es porque la estructura de hormigón tiene dos empotramientos, y la metálica tiene en el apoyo de la izquierda 3 restricciones al desplazamiento +1 restricción a la rotación respecto al eje $x, y 2$ restricciones al desplazamiento en los ejes y y z en el apoyo de la derecha (dos tipos de coacciones diferentes, por lo que no es una estructura simétrica, y por eso los desplazamientos no lo son). En el caso de las reacciones en apoyos son claramente más pequeñas en la estructura metálica sin tendones.

\subsubsection{Estructura auxética individual reentrante hexatruss de hormigón (Re-entrant individual hexatruss concrete structure)}

The hexatruss lattice is an extension of auxetic lattices to 3D (Dirrenberger et al., 2013). This structure can make symmetrical collapse of a 24-sided polyhedron with cubic symmetry if it is triangulated. It is very comparable to the unit-cell used in Doyoyo and Hu for modelling auxetic foams. The application of this structure and their behavior in architecture are not yet known, that's why this auxetic model will become an experimental model to establish a structural and constructive evaluation of one of the most innovative auxetic geometries, to apply to the construction of new architectures. The results of research and investigation will become apparent by their structural evaluation, with the utilization of calculation programs, by comparison of traditional structures. 
The re-entrant hexatruss geometry provides a strong foundation for research of application of new structural and constructive systems on the production of architecture, while identifying transformations that new geometries and their application techniques, will contribute to the development and divulgation of new spatial and typological solutions. That is the reason to claim a detailed analysis to advance on the design and construction of new architectures.

\subsection{Methodology}

The used methodology consists on studying auxetic hextatruss structure using SAP2000 software. A single unit of this kind of auxetic structure will be tested and compared with itself in its open position that structurally has a traditional behavior. We will consider a reinforced concrete (defined as HA-25 in SAP2000) structure with rigid knots in order to simulate the auxetic effect as it appears in the nature at nanoscale. For calculus porpoise we consider housing use for this cell, two 2,5m external bars in each direction for each façade and two diagonals to tie together. Bar section are $30 \times 30 \mathrm{~cm}$ (supports, red), $25 \times 25 \mathrm{~cm}$ (vertical tie together elements, cyan), $60 \times 30 \mathrm{~cm}$ (beams, blue) and $50 \times 30 \mathrm{~cm}$ (horizontal tie together elements, green). Loads appear on table 13.

\begin{tabular}{|c|c|c|c|c|c|}
\hline & $\begin{array}{l}\text { Permanent } \\
\text { loads }\end{array}$ & Use loads & Snow loads & $\begin{array}{l}\text { Wind X } \\
\text { (direction }+l-\text { ) }\end{array}$ & $\begin{array}{l}\text { Wind } Y \\
\text { (direction }+/- \text { ) }\end{array}$ \\
\hline Housing beam & $22 \mathrm{KN} / \mathrm{m}$ & $5 \mathrm{KN} / \mathrm{m}$ & - & - & - \\
\hline Roof beam & $16,25 \mathrm{KN} / \mathrm{m}$ & $2,5 \mathrm{KN} / \mathrm{m}$ & $1,25 \mathrm{KN} / \mathrm{m}$ & - & - \\
\hline Pressure supports & - & - & - & $1,875 \mathrm{KN} / \mathrm{m}$ & $2,2 \mathrm{KN} / \mathrm{m}$ \\
\hline Suction supports & - & - & - & $1 \mathrm{KN} / \mathrm{m}$ & $1,375 \mathrm{KN} / \mathrm{m}$ \\
\hline \multicolumn{6}{|c|}{$\begin{array}{l}\text { Note: Structure own weight is automatically considered by SAP2000 depending on the sections defined. } \\
\text { Masses used to calculate quake effects are defined in NCSE-02 section 3.2, including own structure masses, } \\
\text { permanent masses and a percentage of } 50 \% \text { of use overload. Snow overload and ceiling use overload are not } \\
\text { considered for quake effects. }\end{array}$} \\
\hline
\end{tabular}

Table 13: loads considered table

These loads are distributed according a static lineal analysis associated to gravitational actions and wind; and a modal analysis to obtain structure vibration modes for quake spectral modal analysis. EHE-08 different calculus combinations will be made for Last Limit States (LLS) and Service Limit States (SLS), as well as surrounding combination in LLS aimed to find out the worst forces. 
Obtained results that we will analyze will be vibration modes, displacements and rotations, worst forces in the structure and reactions in foundations.

\subsection{Results}

After the completion of structural analysis we have obtained the results shown below:

\section{Vibration modes}

The vibration modes have been obtained for a linear response spectrum, to the traditional structure (table 14) and to the auxetic structure (table 15):

\begin{tabular}{|l|l|l|l|l|l|l|l|}
\hline OutputCase & StepType & GlobalFX & GlobalFY & GlobalFZ & GlobalMX & GlobalMY & GlobalMZ \\
\hline Text & Text & KN & KN & KN & KN-m & KN-m & KN-m \\
\hline MOD-ESP-X & Max & 38,969 & 4,353 & $2,793 E-07$ & 21,7697 & 197,1595 & 90,2447 \\
\hline MOD-ESP-Y & Max & 4,353 & 38,969 & 0,000001429 & 197,1595 & 21,7697 & 105,2393 \\
\hline
\end{tabular}

Table 14. Traditional structure base reactions

\begin{tabular}{|l|l|l|l|l|l|l|l|}
\hline OutputCase & StepType & GlobalFX & GlobalFY & GlobalFZ & GlobalMX & GlobalMY & GlobalMZ \\
\hline Text & Text & KN & KN & KN & KN-m & KN-m & KN-m \\
\hline MOD-ESP-X & Max & 35,369 & 10,982 & 0,000007657 & 50,6233 & 166,9826 & 69,3989 \\
\hline MOD-ESP-Y & Max & 10,982 & 35,368 & 0,000003939 & 166,9823 & 50,6232 & 103,2259 \\
\hline
\end{tabular}

Table 15. Auxetic structure base reactions

$\underline{\text { Joint displacements and rotations }}$

The table 16 shows the most unfavorable joint displacements and rotations for the traditional pattern and for the auxetic pattern:

\begin{tabular}{|l|l|l|l|l|l|l|l|}
\hline & \multicolumn{5}{|l|}{ Displacements $(\mathbf{m})$} & \multicolumn{2}{l|}{ Rotations (rad) } \\
\hline & & $\mathbf{x}$ & $\mathbf{y}$ & $\mathbf{z}$ & $\mathbf{x}$ & $\mathbf{y}$ & $\mathbf{z}$ \\
\hline \multirow{2}{*}{$\begin{array}{l}\text { Traditional } \\
\text { pattern }\end{array}$} & Max & 0,000095 & 0,000095 & $5,605 \mathrm{E}-13$ & 0,000902 & 0,000892 & $1,537 \mathrm{E}-13$ \\
\cline { 2 - 8 } & Min & $-0,000095$ & $-0,000095$ & $-0,002597$ & $-0,000902$ & $-0,000903$ & $-1,537 \mathrm{E}-13$ \\
\hline \multirow{2}{*}{$\begin{array}{l}\text { Auxetic } \\
\text { pattern }\end{array}$} & Max & 0,000122 & 0,000122 & $5,298 \mathrm{E}-12$ & 0,000173 & 0,000167 & $7,333 \mathrm{E}-13$ \\
\cline { 2 - 8 } & Min & $-0,000122$ & $-0,000122$ & $-0,000552$ & $-0,000173$ & $-0,000174$ & $-7,334 \mathrm{E}-13$ \\
\hline
\end{tabular}

Table 16. The most unfavorable displacements and rotations to the traditional and auxetic pattern 


\section{Structure forces}

The table 17 shows the most unfavorable forces for the traditional structure and for the auxetic structure for different combinations: axial, moment, shear and torsion.

\begin{tabular}{|l|l|l|l|l|l|}
\hline & & Shear V2 (KN) & Axial P (KN) & $\begin{array}{l}\text { Torsion T } \\
(\mathbf{K N} / \mathbf{m})\end{array}$ & Moment M3 (KN/m) \\
\hline \multirow{2}{*}{$\begin{array}{l}\text { Traditional } \\
\text { pattern }\end{array}$} & Max & 93 & $-6,15$ & 1,2894 & 0,2967 \\
\cline { 2 - 6 } & Min & -93 & $-44,626$ & $-1,2894$ & $-0,3287$ \\
\hline $\begin{array}{l}\text { Auxetic } \\
\text { pattern }\end{array}$ & Max & 0,262 & $-10,469$ & 0,0699 & 0,5111 \\
\cline { 2 - 6 } & Min & 0,12 & $-44,049$ & $-0,0045$ & $-0,4341$ \\
\hline
\end{tabular}

Table 17. The most unfavorable forces for the traditional structure and for the auxetic structure

\section{Foundation reactions}

The table 18 shows the most unfavorable foundation reactions:

\begin{tabular}{|l|l|l|l|l|l|l|l|}
\hline & \multicolumn{4}{|l|}{ Forces (KN) } & \multicolumn{2}{l|}{ Moments (KN/m) } \\
\hline & & $\mathbf{x}$ & $\mathbf{y}$ & $\mathbf{z}$ & $\mathbf{x}$ & $\mathbf{y}$ & $\mathbf{z}$ \\
\hline \multirow{2}{*}{$\begin{array}{l}\text { Traditional } \\
\text { pattern }\end{array}$} & Max & 27,931 & 30,602 & 321,073 & 82,0662 & 81,8468 & 0,0681 \\
\cline { 2 - 8 } & Min & $-27,931$ & $-30,602$ & 175,983 & $-82,0662$ & $-81,8468$ & $-0,0681$ \\
\hline \multirow{2}{*}{$\begin{array}{l}\text { Auxetic } \\
\text { pattern }\end{array}$} & Max & 244,081 & 245,683 & 321,072 & 40,4348 & 40,2262 & 0,5317 \\
\cline { 2 - 8 } & Min & $-244,081$ & $-245,683$ & 176,655 & $-40,4348$ & $-40,2262$ & $-0,5317$ \\
\hline
\end{tabular}

Table 18. The most unfavorable foundation reactions to the traditional and auxetic structure

\subsection{Discussion}

There are more reactions in foundations in the auxetic structure than in the traditional one, as well as joints displacements much greater in the auxetic one. This unfavorable effect is balanced out with much lesser rotations in the joints and moments in structure horizontal axis of approximately half of the value than in the traditional structure (on the vertical axis this moments are greater on the auxetic one).

Observing forces in the structure we can see that shear and torsion forces that appear in auxetic structure are much smaller than the ones in the traditional structure, and moments are more or less equal, maybe a bit greater. 


\subsubsection{Estructura auxética conjunto reentrante hexatruss de hormigón (Re-entrant set hexatruss concrete structure)}

The hexatruss lattice is an extension of auxetic lattices to 3D (Dirrenberger et al., 2013). This structure can make symmetrical collapse of a 24-sided polyhedron with cubic symmetry if it is triangulated. It is very comparable to the unit-cell used in Doyoyo and Hu for modelling auxetic foams. The application of this structure and their behavior in architecture are not yet known, that's why this auxetic model will become an experimental model to establish a structural and constructive evaluation of one of the most innovative auxetic geometries, to apply to the construction of new architectures. The results of research and investigation will become apparent by their structural evaluation, with the utilization of calculation programs, by comparison of traditional structures.

The re-entrant hexatruss geometry provides a strong foundation for research of application of new structural and constructive systems on the production of architecture, while identifying transformations that new geometries and their application techniques, will contribute to the development and divulgation of new spatial and typological solutions. That is the reason to claim a detailed analysis to advance on the design and construction of new architectures.

\subsection{Methodology}

The used methodology consists on studying auxetic hexatruss structure using SAP2000 software. A building design by repetition of this kind of auxetic structural pattern will be tested and compared with itself in its open position that structurally has a traditional behavior. We will consider a reinforced concrete (defined as HA-25 in SAP2000) structure with rigid knots in order to simulate the auxetic effect as it appears in the nature at nanoscale. For calculus purpose we consider a residential building with a facade of 3 (Y direction) $\times 5$ (X direction) $\mathrm{X}$ 5 ( $Z$ direction) auxetic cells. We consider for each cell 2,5m external bars. Sections are $30 \times 30 \mathrm{~cm}$ (supports of the 3 highest floors and bracing of the 2 lower floors), $35 \times 35 \mathrm{~cm}$ (supports of the 2 lower floors), $25 \times 25 \mathrm{~cm}$ (vertical tie together elements of the 3 highest floors), $70 \times 30 \mathrm{~cm}$ (interior beams), $60 \times 30 \mathrm{~cm}$ (facade beams) and $50 \times 30 \mathrm{~cm}$ (horizontal tie together elements), according to the figure 217. 

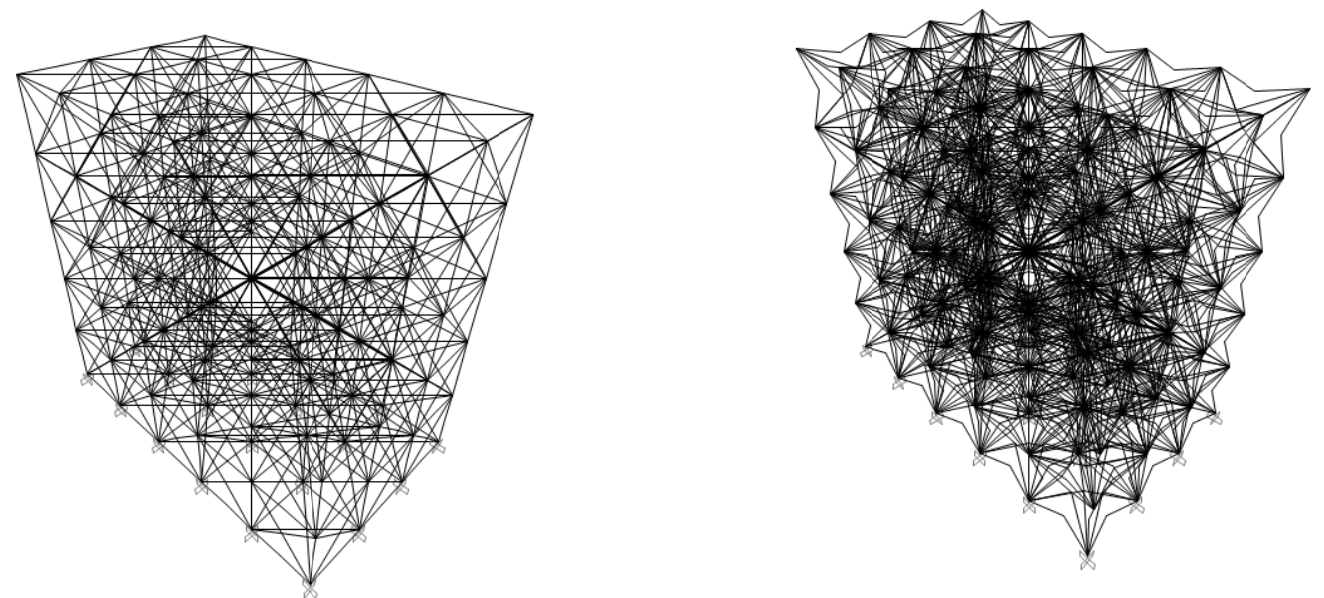

Figure 217. Left: Traditional structure. Right: Auxetic structure.

Loads appear on table 19. These loads are distributed according a static lineal analysis associated to gravitational actions and wind; and a modal analysis to obtain structure vibration modes for quake spectral modal analysis. EHE-08 different calculus combinations will be made for Last Limit States (LLS) and Service Limit States (SLS), as well as surrounding combination in LLS aimed to find out the worst forces. Obtained results that we will analyze will be vibration modes, displacements and rotations, worst forces in the structure and reactions in foundations.

\begin{tabular}{|c|c|c|c|c|c|}
\hline $\begin{array}{r}1 \\
1 \\
1\end{array}$ & $\begin{array}{c}\text { Permanent } \\
\text { loads }\end{array}$ & Use loads & Snow loads & $\begin{array}{c}\text { Wind } X \\
\text { (direction }+l-)\end{array}$ & $\begin{array}{c}\text { Wind } Y \\
\text { (direction }+/- \text { ) }\end{array}$ \\
\hline $\mathbf{V}_{\text {interior housing }}$ & $33 \mathrm{KN} / \mathrm{m}$ & $11 \mathrm{KN} / \mathrm{m}$ & - & - & - \\
\hline $\mathbf{V}_{\text {perimeter housing }}$ & $22 \mathrm{KN} / \mathrm{m}$ & $5 \mathrm{KN} / \mathrm{m}$ & - & - & - \\
\hline $\mathbf{V}_{\text {interior roof }}$ & $30,25 \mathrm{KN} / \mathrm{m}$ & $5,5 \mathrm{KN} / \mathrm{m}$ & $2,75 \mathrm{KN} / \mathrm{m}$ & - & - \\
\hline$V_{\text {perimeter roof }}$ & $16,25 \mathrm{KN} / \mathrm{m}$ & $2,5 \mathrm{KN} / \mathrm{m}$ & $1,25 \mathrm{KN} / \mathrm{m}$ & - & - \\
\hline$P_{1}$ pressure & - & - & - & $1,875 \mathrm{KN} / \mathrm{m}$ & $2,2 \mathrm{KN} / \mathrm{m}$ \\
\hline $\mathbf{P}_{1 \text { suction }}$ & - & - & - & $1 \mathrm{KN} / \mathrm{m}$ & $1,375 \mathrm{KN} / \mathrm{m}$ \\
\hline$P_{2}$ pressure & - & - & - & $4,125 \mathrm{KN} / \mathrm{m}$ & $4,4 \mathrm{KN} / \mathrm{m}$ \\
\hline $\mathbf{P}_{2 \text { suction }}$ & - & - & - & $2,2 \mathrm{KN} / \mathrm{m}$ & $2,75 \mathrm{KN} / \mathrm{m}$ \\
\hline$P_{3 \text { pressure }}$ & - & - & - & - & $3,8 \mathrm{KN} / \mathrm{m}$ \\
\hline$P_{3}$ suction & - & - & - & - & $2,375 \mathrm{KN} / \mathrm{m}$ \\
\hline \multicolumn{6}{|c|}{$\begin{array}{l}\text { Note: Structure own weight is automatically considered by SAP2000 depending on the sections defined. Masses } \\
\text { used to calculate quake effects are defined in NCSE-02 section 3.2, including own structure masses, permanent } \\
\text { masses and a percentage of } 50 \% \text { of use overload. Snow overload and ceiling use overload are not considered } \\
\text { for quake effects. }\end{array}$} \\
\hline
\end{tabular}

Table 19: loads considered table 


\subsection{Results}

After the completion of structural analysis we have obtained the results shown below:

\section{Vibration modes}

The vibration modes have been obtained for a linear response spectrum, to the traditional structure (table 20) and to the auxetic structure (table 21):

\begin{tabular}{|c|c|c|c|c|c|c|c|}
\hline OutputCase & StepType & GlobalFX & GlobalFY & GlobalFZ & GlobalMX & GlobalMY & GlobalMZ \\
\hline Text & Text & KN & KN & KN & KN-m & KN-m & KN-m \\
\hline MOD-ESP-X & Max & 3372,148 & 0,001627 & 0,00111 & 0,018 & 64603,0939 & 42136,4422 \\
\hline MOD-ESP-Y & Max & 0,0002906 & 3484,668 & 0,0003548 & 68539,3527 & 0,0055 & 26135,6291 \\
\hline
\end{tabular}

Table 20. Traditional structure base reactions

\begin{tabular}{|c|c|c|c|c|c|c|c|}
\hline OutputCase & StepType & GlobalFX & GlobalFY & GlobalFZ & GlobalMX & GlobalMY & GlobalMZ \\
\hline Text & Text & KN & KN & KN & KN-m & KN-m & KN-m \\
\hline MOD-ESP-X & Max & 7386,85 & 0,00005496 & 0,034 & 0,4021 & 126195,9057 & 87719,3536 \\
\hline MOD-ESP-Y & Max & 0,0000347 & 7830,036 & 0,03 & 135188,5066 & 0,2156 & 55792,9251 \\
\hline
\end{tabular}

Table 21. Auxetic structure base reactions

\section{Joint displacements and rotations}

The table 22 shows the most unfavorable joint displacements and rotations for the traditional pattern and for the auxetic pattern:

\begin{tabular}{|c|c|c|c|c|c|c|c|}
\hline & & \multicolumn{3}{|c|}{ Displacements (m) } & \multicolumn{3}{c|}{ Rotations (rad) } \\
\hline & & $\mathbf{X}$ & $\mathbf{y}$ & $\mathbf{z}$ & $\mathbf{x}$ & $\mathbf{y}$ & $\mathbf{z}$ \\
\hline \multirow{2}{*}{$\begin{array}{c}\text { Traditional } \\
\text { pattern }\end{array}$} & Max & 0,005426 & 0,003601 & $6,87 \mathrm{E}-09$ & 0,000823 & 0,000914 & $2,38 \mathrm{E}-11$ \\
\cline { 2 - 8 } & Min & $-0,005426$ & $-0,003601$ & $-0,006204$ & $-0,000823$ & $-0,000914$ & $-2,38 \mathrm{E}-11$ \\
\hline \multirow{2}{*}{$\begin{array}{c}\text { Auxetic } \\
\text { pattern }\end{array}$} & Max & 0,008032 & 0,005309 & 0 & 0,030294 & 0,03046 & 0,000001024 \\
\cline { 2 - 8 } & Min & $-0,008033$ & $-0,005306$ & $-0,59533$ & $-0,03036$ & $-0,030508$ & $-1,246 \mathrm{E}-08$ \\
\hline
\end{tabular}

Table 22. The most unfavorable displacements and rotations to the traditional and auxetic pattern 


\section{$\underline{\text { Structure forces }}$}

The table 23 shows the most unfavorable forces for the traditional structure and for the auxetic structure for different combinations: axial, moment, shear and torsion.

\begin{tabular}{|c|c|c|c|c|c|}
\hline & & Shear V2 (KN) & Axial P (KN) & $\begin{array}{c}\text { Torsion T } \\
(\mathrm{KN} / \mathbf{m})\end{array}$ & Moment M3 (KN/m) \\
\hline \multirow{2}{*}{$\begin{array}{c}\text { Traditional } \\
\text { pattern }\end{array}$} & Max & 159,783 & 48,957 & 7,7422 & 72,4205 \\
\cline { 2 - 6 } & Min & $-159,783$ & $-1182,27$ & $-7,7422$ & $-136,5229$ \\
\hline \multirow{2}{*}{$\begin{array}{c}\text { Auxetic } \\
\text { pattern }\end{array}$} & Max & 6135,487 & 24644,078 & 421,7042 & 2419,5087 \\
\cline { 2 - 6 } & Min & $-6135,481$ & $-118220,952$ & $-416,7547$ & $-3494,4493$ \\
\hline
\end{tabular}

Table 23. The most unfavorable forces for the traditional structure and for the auxetic structure

\section{Foundation reactions}

The table 24 shows the most unfavorable foundation reactions:

\begin{tabular}{|c|c|c|c|c|c|c|c|}
\hline & & \multicolumn{3}{|c|}{ Forces (KN) } & \multicolumn{3}{c|}{ Moments (KN/m) } \\
\hline & & $\mathbf{X}$ & $\mathbf{y}$ & $\mathbf{z}$ & $\mathbf{x}$ & $\mathbf{y}$ & $\mathbf{z}$ \\
\hline \multirow{2}{*}{$\begin{array}{c}\text { Traditional } \\
\text { pattern }\end{array}$} & Max & 325,939 & 318,259 & 3009,912 & 139,1585 & 139,9978 & 0,7564 \\
\cline { 2 - 8 }$y$ \\
\hline \multirow{2}{*}{$\begin{array}{c}\text { Auxetic } \\
\text { pattern }\end{array}$} & Max & $-325,939$ & $-318,259$ & 239,631 & $-139,1585$ & $-139,9978$ & $-0,7564$ \\
\cline { 2 - 8 }$y$ & Min & $-169887,91$ & 170235,57 & 716568,755 & 11982,264 & 11976,583 & 22,1062 \\
\hline
\end{tabular}

Table 24. The most unfavorable foundation reactions to the traditional and auxetic structure

\subsection{Discussion}

There are more reactions in foundations in the auxetic structure than in the traditional one. These results are worse than the obtained in the individual pattern (Álvarez and Anaya, 2014) in which the worst base reactions and the biggest displacements were balanced out with much lesser rotations in the joints and moments in structure horizontal axis of approximately half of the value than in the traditional structure (on the vertical axis this moments are greater on the auxetic one).

Observing forces that were produced in the individual pattern of auxetic structure we could see that shear and torsion forces that appeared in auxetic structure, were much smaller than 
the ones in the traditional structure, and moments were more or less equal, maybe a bit greater.

It is considered that the unfavourable results in the whole pattern of auxetic structure have been obtained by the increase of its own weight due to the greater number of bars according to the way of combining the structure. They are also considered to be unfavourable for having made such a structure as a linear structural form constructed from bars. 


\subsection{Desarrollo constructivo de estructuras auxéticas}

Después del estudio desarrollado, para las estructuras estudiadas se hizo una nueva clasificación en función de sus articulaciones ${ }^{36}$. De este modo tendríamos:

1. Articulaciones en un solo plano de varias barras.

2. Articulaciones en el espacio, con confluencia de tres o más barras.

3. Articulaciones en un solo plano uniendo el vértice de un polígono con el final de una barra.

4. Articulaciones en el espacio uniendo el vértice de un polígono con el final de una barra.

5. Articulaciones en un solo plano uniendo vértices de polígonos.

6. Articulaciones en el espacio uniendo vértices de polígonos.

De tal manera que lo que nos preocupa es cómo resolver constructivamente al nivel escalar de la construcción estas uniones en función de su número de barras, ángulo de rotación y dirección de cada una de esas barras.

Se intentarán proponer dos sistemas que traten de solucionar estas articulaciones para el conjunto de las estructuras propuestas. Por un lado, se buscará una articulación para las estructuras que permiten el giro de barras únicamente en el plano; y por otro, se desarrollará otra articulación para aquellas estructuras que permitan el giro de sus barras en el espacio.

\subsubsection{Articulaciones en el plano}

Revisando los antecedentes se aprecia un dibujo que resulta bastante gráfico para realizar articulaciones en el plano. Este dibujo corresponde a la patente de Zeigler (1984), a partir del cual se buscará una configuración general que sirva como nudo constructivo para estructuras articuladas en el plano a las que ataquen cualquier número de barras o vértices de polígonos, permitiendo su movimiento.

\footnotetext{
${ }^{36}$ Ver apartado 3.2. Discusión de resultados del subcapítulo 3.1. Estudio geométrico de estructuras auxéticas. Patrones auxéticos desarrollados y su plegabilidad
} 
Por tanto, el objeto de la invención es un nudo cuya configuración le permita adaptarse a todas las configuraciones de movimiento de la estructura plana auxética, desde soluciones sencillas a soluciones más complejas que permitan incluso el cruce de varias estructuras en dos dimensiones.

El nudo para estructuras reticulares móviles planas propone una solución de gran simplicidad, en cuanto al movimiento de la estructura, en base a la incorporación de un núcleo, de reducido peso y precio, que permite acoplar barras que utilicen sistemas de unión móviles con la particularidad de que el nudo obtenido presenta buenas características mecánicas en todas las uniones.

En concreto, el nudo de la invención comprende un núcleo (1) que presenta una superficie plana poligonal provista de tantos orificios radiales como barras ataquen al nudo. Adicionalmente, el nudo de la invención también comprende el sistema de anclaje de barras, provisto de unas articulaciones roscadas en las que, mediante unos pernos (2), se sujetan las barras. Dichas barras constan en sus extremos de un aplastamiento agujereado (3), que permite la incrustación del perno; asegurando así una buena transmisión de esfuerzos en la unión.

De esta forma, se consigue un nudo que permite adaptarse a todas las uniones en el plano requeridas, a la vez que permite el movimiento dentro de la configuración escogida. Es decir, el nudo de la invención presenta muy buenas propiedades mecánicas y de movimiento que lo hacen válido para estructuras planas desplegables auxéticas de todo tipo.

Para complementar la descripción que se está realizando y con objeto de ayudar a una mejor comprensión de las características de la invención, se acompaña como parte integrante de dicha descripción, un juego de dibujos en donde con carácter ilustrativo y no limitativo, se ha representado lo siguiente:

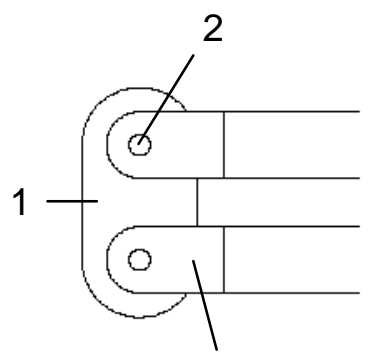

3
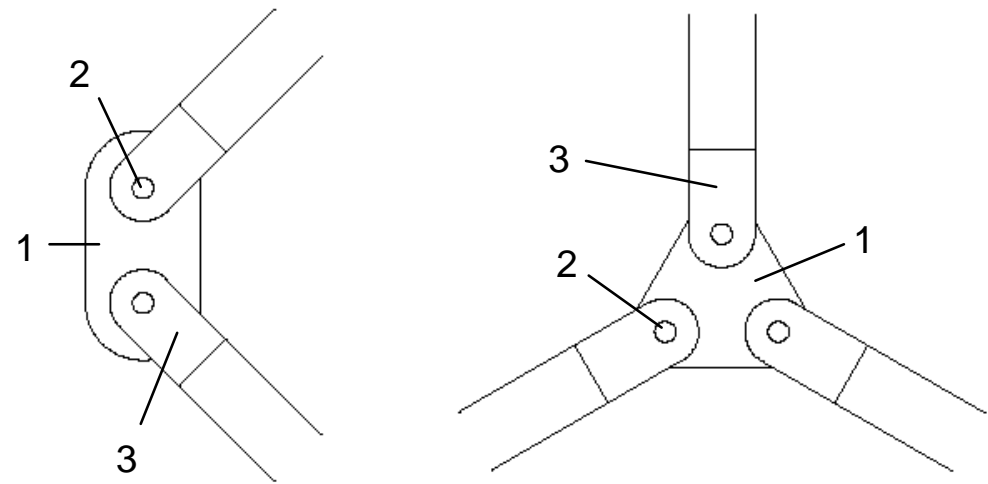

Figura 218 Ejemplos de nudo plano desplegable para estructuras en dos dimensiones 


\subsubsection{Articulaciones en el espacio}

Revisando los antecedentes llaman la atención los nudos esféricos para resolver uniones de barras en el espacio. A partir de ahí se buscará una configuración general que sirva como nudo constructivo para estructuras articuladas en el espacio a las que ataquen cualquier número de barras o vértices de polígonos, permitiendo su movimiento.

Por tanto, el objeto de la invención es un nudo cuya configuración le permita adaptarse a todas las configuraciones de movimiento de la estructura reticular auxética, desde soluciones sencillas a soluciones más complejas que permitan incluso el montaje de estructuras espaciales curvadas o con diferentes ángulos, todo ello con una única pieza de unión, reduciendo considerablemente el precio y la estandarización respecto a las soluciones actuales.

El nudo para estructuras reticulares móviles auxéticas desarrollado con Jesús Anaya ${ }^{37}$ propone una solución de gran flexibilidad, en cuanto al movimiento de la estructura, en base a la incorporación de un núcleo, de reducido peso y precio, que permite acoplar barras que utilicen sistemas de unión móviles con la particularidad de que el nudo obtenido presenta buenas características mecánicas en todas las uniones.

En concreto, el nudo de la invención comprende un núcleo que presenta una superficie exterior, con forma de esfera dividida en dos casquetes esféricos y provista de orificios radiales, y una esfera interior.

Adicionalmente, el nudo de la invención también comprende el sistema de anclaje de barras, provisto de unas pequeñas piezas cónicas dotadas en el extremo de menor radio de pequeños casquetes esféricos algo más grandes que los orificios de la esfera exterior, y en el extremo de radio mayor, de una terminación cilíndrica donde se acoplan las barras; asegurando así una buena transmisión de esfuerzos en la unión.

El cuerpo de cierre o esfera exterior incluye una serie de orificios, en dirección radial, para el amarre de barras que se prolongan radialmente, para constituir una estructura reticular compleja.

\footnotetext{
${ }^{37}$ Inventor del nudo esférico móvil. La autora de esta tesis, Mª Dolores Álvarez Elipe, realiza la redacción de la patente y busca su aplicación en estructuras auxéticas.
} 
En los orificios de la esfera exterior se acopla el sistema de anclaje de barras, que queda dispuesto radialmente, en un mismo plano o en diferentes planos, consiguiéndose un nudo de reducido peso y precio pero que permite obtener unas buenas cualidades mecánicas y de movimiento de las barras.

Para la colocación del sistema de anclaje de las barras, la mitad exterior del casquete del núcleo queda libre realizándose las uniones exclusivamente a través de dicho casquete esférico, que después de su manipulación quedará cerrado tras la inserción de la esfera interior y su unión con el otro medio casquete esférico.

La zona cónica del casquillo de unión facilita su introducción a través de los orificios previstos en los casquetes exteriores del nudo, para quedar finalmente acoplado a través de su sector cilíndrico que queda ajustado en los orificios de las barras.

De esta forma, se consigue un nudo que permite adaptarse a todas las uniones espaciales requeridas, a la vez que permite el movimiento dentro de la configuración escogida. Es decir, el nudo de la invención presenta muy buenas propiedades mecánicas y de movimiento que lo hacen válido para estructuras reticulares de todo tipo.

Para complementar la descripción que se está realizando y con objeto de ayudar a una mejor comprensión de las características de la invención, se acompaña como parte integrante de dicha descripción, un juego de dibujos en donde con carácter ilustrativo y no limitativo, se ha representado lo siguiente:

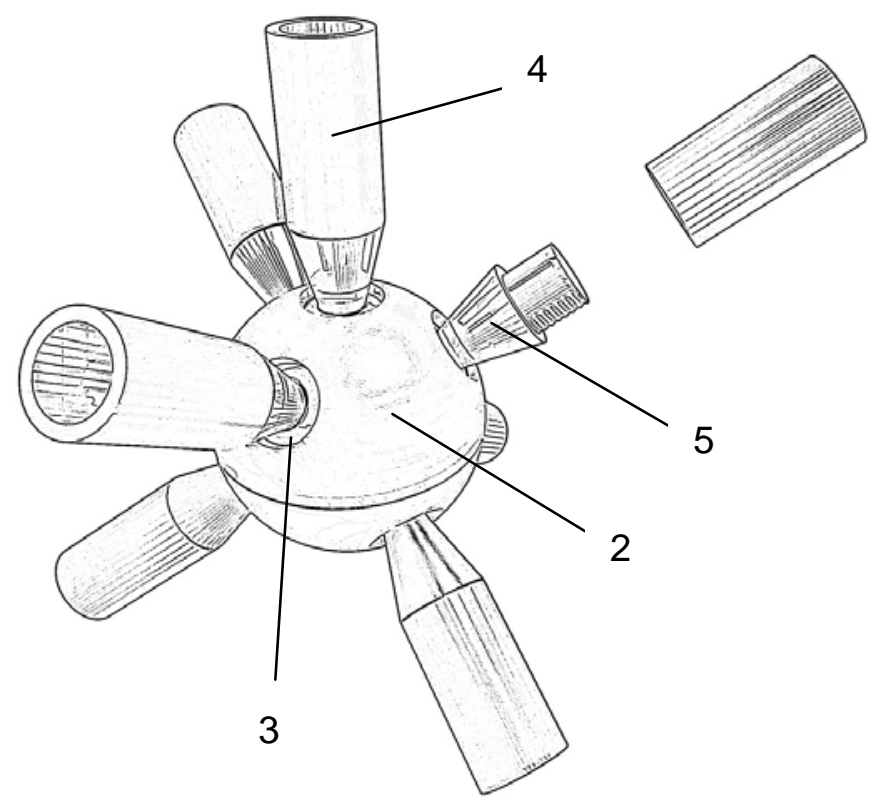

Figura 219 Muestra una vista de un nudo para estructuras reticulares móviles que comprende un núcleo, con forma de esfera, y un conjunto de barras que salen de orificios del núcleo, en una distribución radial. 


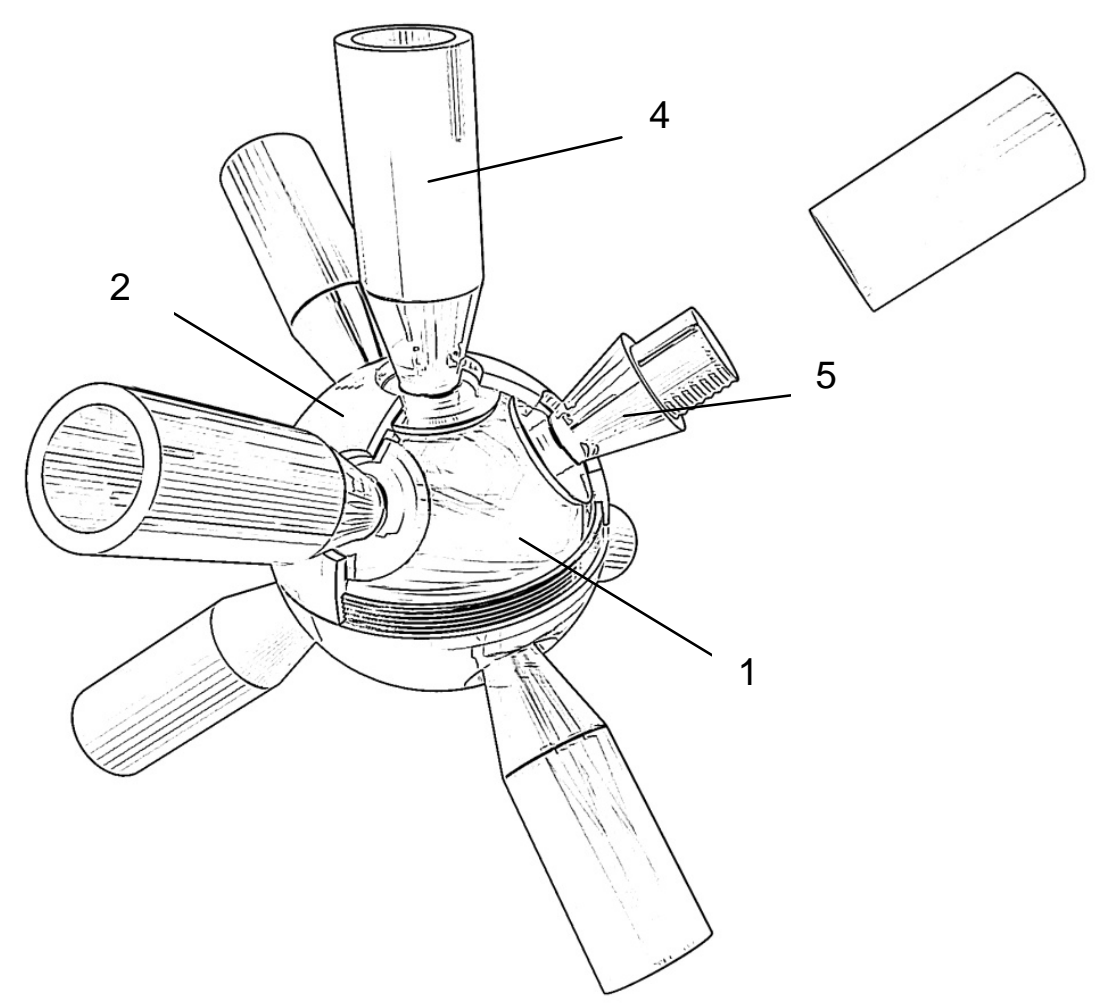

Figura 220 Muestra una vista de un nudo para estructuras reticulares móviles cuyo casquete exterior está seccionado, que comprende un núcleo central con forma de esfera, y un conjunto de barras que salen de orificios del núcleo, en una distribución radial.
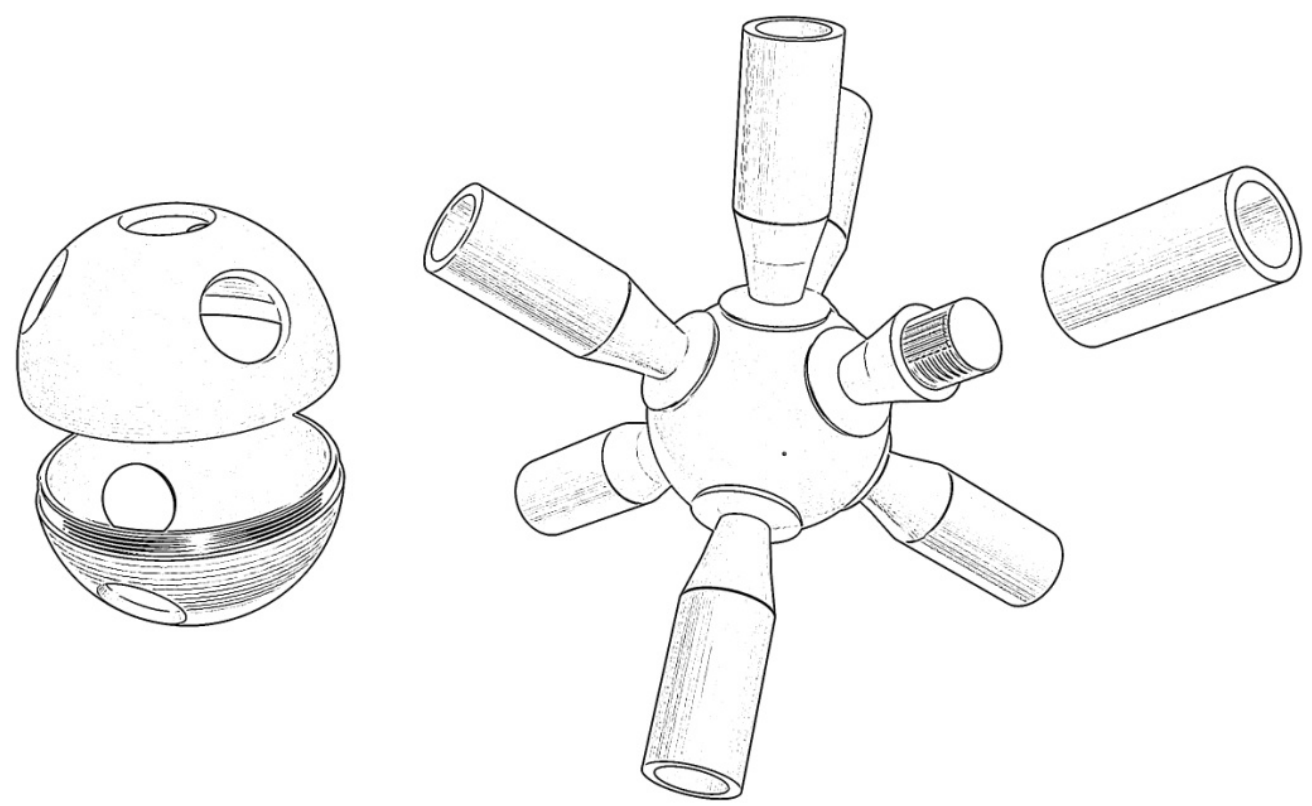

Figura 221 Muestra una vista en explosión correspondiente al nudo representado en la figura 219. 


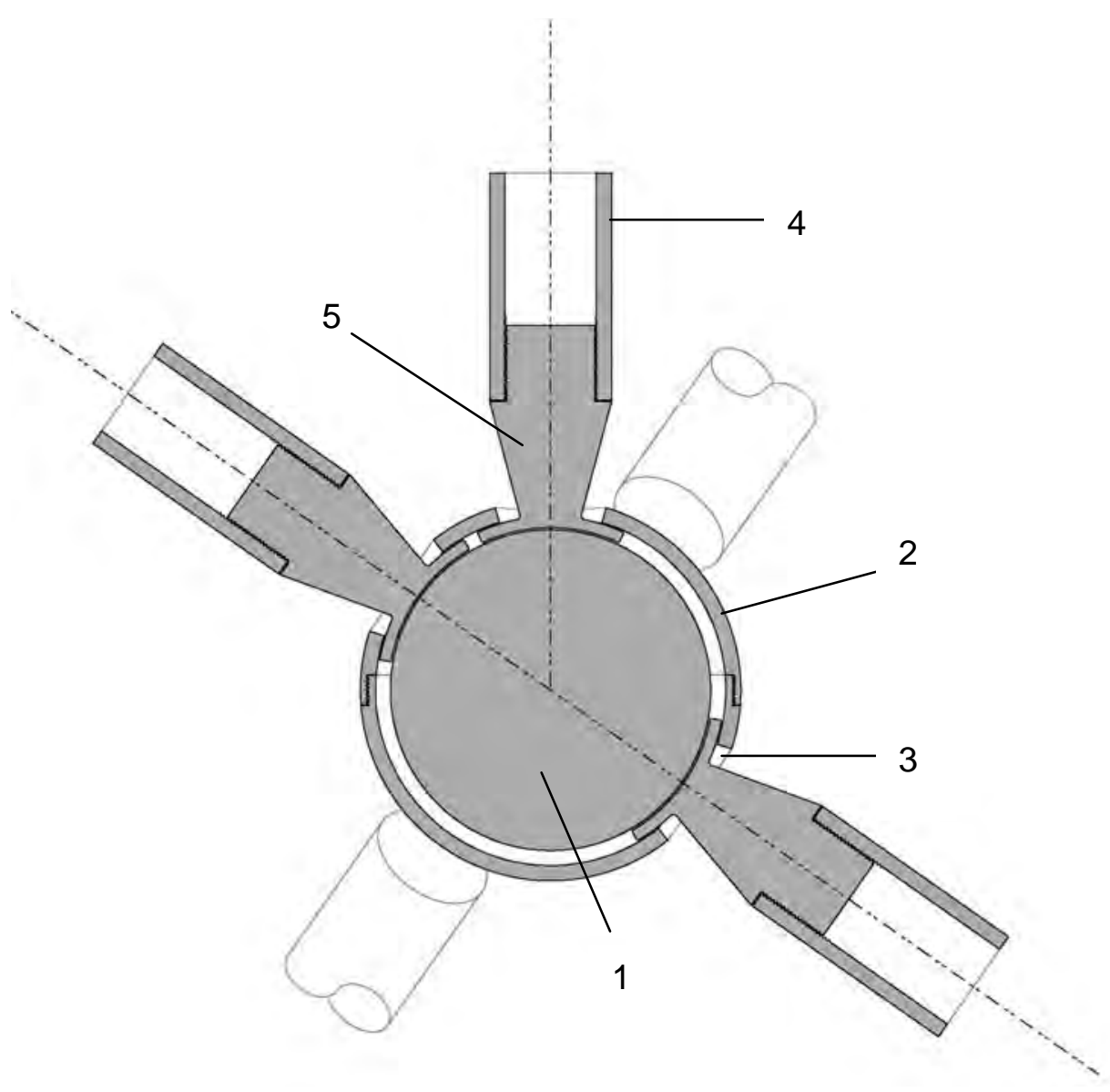

Figura 222 Muestra una vista parcialmente seccionada del nudo montado.

El nudo para estructuras reticulares móviles que constituye el objeto de esta invención está compuesto por un núcleo (1) que presenta una superficie exterior (2), con forma esférica compuesta por dos casquetes esféricos roscados, presentando una serie de orificios radiales (3), distribuidos a lo largo de la superficie exterior (2), para el acoplamiento de las barras (4), dotadas en sus extremos de los correspondientes elementos de acople (5). Este nudo se muestra en las figuras adjuntas.

Tal y como se observa en las figuras, el nudo incorpora también un casquillo de unión (5), formado por un sector cilíndrico (6) de diámetro equivalente al diámetro interior de las barras (7), por un sector cónico (8) que facilita la penetración del casquillo de unión (5), y por un pequeño casquete esférico (9) algo más grande que los orificios de la esfera exterior, consiguiendo el movimiento de las barras sin variar el centro de rotación. 
En la figura 221 se observan en despiece los elementos del nudo antes del montaje, que queda asegurado por roscado de los dos casquetes esféricos exteriores (2) sobre el núcleo interior (1), una vez que han sido insertados los casquillos de unión (5) dentro de los orificios exteriores (3). También se aprecia en la figura 221 la unión roscada de los casquillos de unión (5) con las barras (4).

En las figuras 220 y 222 se observa el resultado seccionado de la unión de estos elementos conformando el nudo; y en la figura 219 se observa el resultado final de la unión de estos elementos conformando el nudo.

En resumen, el nudo para estructuras reticulares móviles comprende un núcleo (1), que presenta una superficie exterior (2), con forma esférica conseguida mediante la unión de dos casquetes esféricos roscados, provista de orificios radiales (3), y un conjunto de barras (4), dotadas en sus extremos de elementos roscados, para su acoplamiento en las piezas de anclaje (5). El casquillo de unión (5) está formado por un sector cilíndrico (6) de diámetro equivalente al diámetro interior de las barras (7), por un sector cónico (8) que facilita la penetración del citado casquillo de unión (5).

Ahora bien, este nudo se adapta a todas las configuraciones requeridas, pero la rotación de las barras que permite es muy limitada, siendo útil para generar diferentes configuraciones en las estructuras y para absorber movimientos de sus barras, pero no siendo apto para generar estructuras desplegables. De este modo, la solución inmediata pasa por realizar los orificios exteriores con la dirección del movimiento de plegado de cada estructura auxética en particular. Si bien esta solución es inmediata, cuando se intenta materializar, tiene el problema de que las barras confluyen según se va plegando la estructura, con lo que habría que realizar un análisis más pormenorizado para generar nudos aptos para este tipo de estructuras. 


\section{CONCLUSIONES Y VÍAS FUTURAS}

\subsection{Conclusiones}

Con esto se finaliza el cuerpo principal de investigación y trabajo de diseño desarrollado durante los últimos años. Personalmente se considera que se han alcanzado los objetivos programados al principio.

Este trabajo presenta las posibles aplicaciones de las propiedades auxéticas en el área de la construcción, exponiendo las diferentes escalas que nos dan la posibilidad de usar estructuras auxéticas en arquitectura. Se analizan primeramente las estructuras auxéticas conocidas en la nanoescala, y después, la escala de la arquitectura, en la que se han analizado arquitecturas cuya geometría tiene una simbiosis con la naturaleza, arquitecturas desplegables, tensegrities y los nudos que hacen posibles todas estas arquitecturas en las que la estructura es igual a la forma.

Se comprende que, hasta la fecha, algunos métodos científicos siguieron la secuencia: investigar, desarrollar sistemas/teorías, encontrarlos en la Naturaleza. Los materiales auxeticos y la experiencia de los arquitectos mencionados anteriormente muestra que tal vez sea más lógico seguir esta otra secuencia: investigar en la Naturaleza, encontrar sistemas/teorías, desarrollarlos en otros campos.

Así, en primer lugar, 22 modelos auxéticos han sido estudiados geométricamente. Como D'Arcy Thompson (1945) fundamenta, no se pueden transportar las propiedades de una escala a otra, porque hay algunas restricciones impuestas por las leyes físicas (relaciones entre masa y peso, aumento de volumen, etc.). Esto lo demuestra a partir de desarrollos de la naturaleza. Sin embargo, las estructuras geométricas auxéticas, al cambiar la escala, mantienen sus propiedades geométricas, variando su volumetría para una misma masa.

Las estructuras analizadas de elementos lineales, tanto superficiales como espaciales, tienen implicaciones en las propiedades físico-mecánicas que representan. Las estructuras geométricas auxéticas rígidas que aparecen en las espumas funcionan estructuralmente por flexión. Este funcionamiento se ha modificado añadiendo articulaciones en los nudos para que estas estructuras puedan formar parte de la escala de la arquitectura.

La formación de estructuras ordenadas que se ha trabajado es el resultado de procesos colectivos de repetición de la unidad. En estos sistemas tenemos agrupaciones que van 
desde el tamaño de una sola unidad hasta el que caracteriza a todo el grupo. En estos casos, el comportamiento individual indica sólo algo de lo que le sucede al conjunto. En general, el comportamiento se conserva, pero el crecimiento es potencialmente mayor cuando tenemos un conjunto, ya que al repetir la unidad los factores de crecimiento son sensiblemente mayores, especialmente en la estructura tipo torre, que es la que más aumenta su volumen con menor cantidad de material.

Se han analizado geométricamente cuatro tipologías de sistemas auxéticos atendiendo a su formación, que se pueden englobar en patrones unitarios, estructuras 2D, estructuras 3D y estructuras tipo torre. Estudiando la relación entre el área (A) o el volumen (V) con la longitud $(L)$ se ha obtenido una relación $(K)$ entre dichas unidades, determinante para comprender los factores de crecimiento de estas estructuras tan particulares.

De este análisis geométrico se concluye que la estructura reentrante estrellada tiene un factor de crecimiento que se halla muy por encima de la media para todos los patrones estudiados, por lo que es muy interesante su aplicación como estructura auxética desplegable. Sin embargo, tiene la limitación de que es una de las estructuras que menos se pliega de forma auxética, por lo que habría que diseñar sus articulaciones de tal forma que permitieran giros que generasen un plegado no auxético.

Por otra parte, también en el análisis geométrico realizado, se han observado factores de crecimiento globalmente mayores para las estructuras quirales, concluyendo que el plegado máximo de este tipo de estructuras es el polígono alrededor del cual giran las barras. Para una compactación mayor, al igual que en la estructura anterior, habría que recurrir a plegados finales no auxéticos (y esto contando siempre con que el polígono base no tenga masa en su interior). Para las estructuras quirales el plegado no auxético es más fácil de conseguir, ya que únicamente consiste en abrir uno de los vértices del polígono y dotar de más giro a las articulaciones para que se puedan doblar unas barras sobre otras.

Del análisis geométrico realizado se concluye también que las estructuras reentrantes hexagonales, reentrantes triangulares y reentrantes tetraédricas se pliegan totalmente de forma auxética, lo que supone una propiedad excepcional a la hora de trabajar con estas geometrías para estructuras desplegables.

Del estudio geométrico también se ha desarrollado otra clasificación en función de los nudos: articulaciones en un solo plano de varias barras, articulaciones en el espacio con confluencia de tres o más barras, articulaciones en un solo plano uniendo el vértice de un 
polígono con el final de una barra, articulaciones en el espacio uniendo el vértice de un polígono con el final de una barra, articulaciones en un solo plano uniendo vértices de polígonos y articulaciones en el espacio uniendo vértices de polígonos; generando un desarrollo de nudo para estructuras planas auxéticas desplegables y otro nudo para estructuras espaciales; y concluyendo que en estos nudos hay que estudiar el ángulo de rotación de las barras, el número de barras que convergen en cada nudo y la dirección relativa de cada barra, ya que una proporción mayor de nudo respecto a las barras admite mayores cantidades de giros y direcciones de dichas barras.

Los comportamientos estructurales se han planteado dependiendo de los materiales, nudos y sistemas estabilizados. Por lo tanto, los criterios tipológicos son numerosos: topología, geometría, características mecánicas (en términos de estados de autoestabilización y mecanismos infinitesimales), etc. Se han analizado estructuras reentrantes hexagonales individuales metálicas de nudos rígidos, estructuras reentrantes hexagonales individuales metálicas de nudos articulados autoestabilizadas mediante un tendón interno y estructuras reentrantes hexagonales en 2 y 3 dimensiones de hormigón.

Los resultados obtenidos para la estructura metálica rígida concluyen que según va aumentando su auxeticidad los desplazamientos son mayores, lo que se traduce en una estructura más flexible que las tradicionales. Los esfuerzos en los apoyos, esfuerzos axiles, cortantes y momentos también aumentan con la auxeticidad, pero de una manera perfectamente admisible y con valores no muy superiores a estructuras tradicionales, por lo que estas estructuras tan flexibles nos resultan muy útiles.

Para la estructura metálica reentrante hexagonal articulada autoestabilizada mediante un tendón interno se concluye que es una estructura muy elástica en la que se generan sólo pequeños esfuerzos en sus barras cuando una carga es aplicada. Las fuerzas de tracción generadas por el tendón son aplicadas en las barras verticales, que son aquellas que posibilitan la apertura o cierre de la estructura, estableciendo el equilibrio en una determinada posición en función de una tensión determinada aplicada al cable interno.

En el caso de la estructura de hormigón se concluye que los esfuerzos aumentan al meter tendones, hecho que se debe a que los tendones en hormigón se ponen para mejorar las tracciones de este, y si las barras están funcionando a compresión no tiene mucho sentido ponerlos, por lo que este sistema únicamente es válido en estructuras articuladas, para que dejen de ser mecanismos. También se concluye que se generan mayores esfuerzos en la 
estructura auxética que en la tradicional, aumentando estos esfuerzos a medida que se aumenta el número de barras multiplicando el patrón individual para generar una estructura conjunto.

Para finalizar, se han resuelto constructivamente las articulaciones para estructuras auxéticas desplegables según el número de barras, ángulo de rotación y dirección de cada barra. Estos estudios han sido realizados sin consideraciones de equilibrio, analizando estas tipologías desde un punto de vista geométrico y estructural, que como consecuencia final, deben contener de forma general componentes potencialmente tensados en su interior con el fin de estabilizar el conjunto.

Según el efecto que tiene la relación negativa de Poisson en las estructuras, del estudio analítico que justifica la investigación se ha podido comprobar:

1. Porosidad. Esto significa que se generan estructuras muy transparentes y ligeras, destacando por encima de todas la estructura reentrante estrellada de 6 puntas. Aunque, también hay que tener en cuenta que, a mayor porosidad peores propiedades mecánicas en general, con menor rigidez y estabilidad estructural.

2. Cortadura. A la vista de las ecuaciones de elasticidad, si mantenemos constante el módulo de elasticidad y se consigue un coeficiente de Poisson negativo, se pueden variar las propiedades del material. La teoría dice que con un coeficiente de Poisson negativo, se obtendría un material muy difícil de deformar a cortadura, pero muy fácil de deformar volumétricamente. Pero en el capítulo de cálculo estructural, un valor ligeramente más elevado de cortante en estructuras auxéticas ha sido obtenido en relación con las estructuras tradicionales.

3. Módulo de rigidez. La capacidad de las estructuras auxéticas para variar su relación de esbeltez cuando se produce una transformación auxética puede ser decisiva para el diseño de soluciones estructurales a gran escala. Es por ello que estas estructuras reconfiguran sus módulos de rigidez con un aumento de volumen para la misma masa. Se aprecia que los módulos de rigidez mayores los tienen los polímeros microporosos y unidades rotatorias, igualándose entre tipos de estructuras según aumenta el número de barras para cada una de ellas.

4. Permeabilidad variable. Los materiales auxéticos son capaces de abrir los poros cuando son sometidos a tracción y de cerrarlos cuando son sometidos a compresión, lo cual abre un 
gran abanico de posibilidades de cara a aplicaciones de estructuras desplegables de arquitectura con capacidad de crecimiento, siendo la estructura reentrante estrellada de 6 puntas la que mayor capacidad tiene de variar su permeabilidad.

Concretamente, se concluye que estas estructuras funcionan correctamente con las tensiones y cargas propuestas. La deformidad se considera como una característica útil e importante de las estructuras auxéticas, con diferencias entre el comportamiento en los modos de construcción tradicional y auxética de los edificios. Las deformaciones que se desarrollan en las estructuras auxéticas son mayores que en las estructuras tradicionales, pero los valores aptos de los esfuerzos para su construcción están dentro del mismo orden en ambos tipos de estructuras. Por lo tanto, es una nueva posibilidad para explorar en la disciplina de la arquitectura.

Dependiendo del nivel de auxeticidad, algunas aplicaciones podrían ser brevemente señaladas, pero obviamente podrían ser investigadas con más detalle: estaciones lunares, torres de comunicación, parques eólicos, marquesinas para entradas, carpas para cubrir lugares de estacionamiento, estructuras para áreas sísmicas, etc. Algunas otras aplicaciones podrían depender de la evolución de las investigaciones en estructuras auxéticas plegables. Como resultado, podrían utilizarse para el socorro en zonas devastadas por terremotos, huracanes, inundaciones, etc., instalando sistemas desplegables en forma de viviendas temporales, puentes, hospitales de campaña, etc. Las estructuras más adecuadas para grandes luces son aquellas que tienen mayor módulo de rigidez, y las estructuras con mayor capacidad de deformación volumétrica o permeabilidad variable serían útiles para mobiliario transformable. Sin embargo, en cuanto a otras propuestas mencionadas en este trabajo, se deben realizar más investigaciones para desarrollar estas aplicaciones potenciales.

Por estas razones, el conjunto de geometrías auxéticas es útil para aplicarlas en arquitectura y proporciona una base sólida para la investigación de la aplicación de nuevos sistemas estructurales y constructivos en la producción de nuevas arquitecturas. Contribuirá al desarrollo y divulgación de nuevas soluciones espaciales y tipológicas, identificando las transformaciones que generarán las nuevas geometrías y sus técnicas de aplicación. 


\subsection{Futuras líneas de investigación}

Una vez concluida la investigación y establecidas las conclusiones, en este apartado se describen las futuras líneas de desarrollo que se inician a partir de las conclusiones propuestas en esta tesis.

\section{- Criterios de estabilización y materiales para llevar a cabo estructuras} arquitectónicas basadas en crecimientos auxéticos.

Tal y como se ha expuesto en el apartado 3.1. Estudio geométrico de estructuras auxéticas. Patrones auxéticos desarrollados y su plegabilidad, habría que desarrollar a fondo el concepto de estabilización en un determinado momento de apertura de las estructuras auxéticas aplicables a la arquitectura, tema que únicamente se ha tocado de forma sucinta en el apartado 3.3. Cálculo estructural de estructuras auxéticas.

Esta investigación es totalmente imprescindible al hablar de arquitectura, ya que un estudio geométrico desarrollado únicamente sobre los puntos de apertura y cierre de los mecanismos correspondientes a las geometrías auxéticas resulta insuficiente convertir en estructuras de arquitectura las geometrías auxéticas, por lo que se establece como objetivo fundamental desarrollar los criterios de estabilización y materiales para llevar a cabo estructuras arquitectónicas basadas en crecimientos auxéticos.

\section{- Desarrollo constructivo de estructuras auxéticas para arquitectura.}

Tal y como se ha expuesto en el apartado 3.4. Desarrollo constructivo de estructuras auxéticas, es necesario estudiar el desarrollo constructivo para que estas estructuras puedan llevarse a cabo.

En el estudio propuesto se ha realizado una clasificación muy general de nudos, con sus consiguientes desarrollos constructivos. Habría que desarrollar a fondo este aspecto, de manera individual para cada estructura, teniendo muy en cuenta los giros que se producen y cómo afecta la cantidad de material a la configuración geométrica escogida, para conseguir unos resultados reales y no teóricos. 
- Procedimiento de cálculo de estabilización de estructuras auxéticas mediante la aplicación de fuerzas externas

Tal y como se ha expuesto en el apartado 3.3.2.4. Estructura auxética con nudos articulados y tendón interno, es necesario estudiar el comportamiento estructural de estabilización de las estructuras auxéticas desplegables en determinados puntos.

En el estudio propuesto se ha realizado un supuesto de cálculo manual de estabilización mediante un tendón interno de la estructura individual reentrante hexagonal. Habría que sistematizar estos cálculos de manera general mediante software de cálculo específico, teniendo muy en cuenta los criterios de aplicación de fuerzas sin introducir más masa en la estructura para una configuración geométrica escogida, consiguiendo de este modo unos resultados específicos en función del crecimiento.

\section{- Desarrollo de aplicaciones arquitectónicas auxéticas concretas}

En las conclusiones se han señalado brevemente algunas aplicaciones arquitectónicas de las propiedades auxéticas, como estaciones lunares, torres de comunicación, parques eólicos, marquesinas para entradas..., pero obviamente podrían ser investigadas con más detalle.

Por tanto, se deben realizar más investigaciones para desarrollar estas aplicaciones potenciales de forma concreta y con criterios constructivos, estructurales, materiales, etc. para que puedan ser llevadas a cabo de forma real en el terreno de la arquitectura. 


\section{CONCLUSIONS AND FUTURE LINES}

\subsection{Conclusions}

This concludes the main body of research and design work developed during the last years. Personally it is considered that the objectives programmed at the beginning have been achieved.

This paper presents possible applications in the construction area, exposing the different scales that give us the ability to use auxetic structures in architecture. Firstly, auxetic structures that are known in the nanoscale are analyzed. Secondly, architecture scale is analyzed. Architectures with geometries close to the nature, deployable architectures and tensegrities have been analyzed. The knots have also analyzed, because they are the responsible that the structure is equal that the form.

It is realized that, to date, some scientific methods followed the sequence: researching, developing systems/theories, finding them in Nature. Auxetics and the experience of the architects mentioned above shows that maybe it is more logical to follow this other sequence: researching in Nature, finding systems/theories, developing them in other fields.

So, firstly, 22 auxetics models have been geometrically studied. Like D'Arcy Thompson (2003) said, we can't have an arbitrary form in all spatial scales, because there are some restrictions imposed by physical laws (mass-weight ratios, volume increase, etc.). This proves it from developments in nature. However, auxetic geometric structures, by changing the scale, maintain their geometrical properties, varying their volumetry for the same mass.

The analyzed structures of linear elements, both superficial and spatial, have implications on the physical-mechanical properties they represent. The rigid auxetic geometric structures appearing in the foams function structurally by flexing. This operation has been modified by adding joints in the knots so that these structures can be part of the scale of the architecture.

The formation of ordered structures that has been worked on is the result of collective processes of repetition of the unit. In these systems we have groups ranging from the size of a single unit to the one that characterizes the whole group. In these cases, individual behavior indicates only some of what happens to the whole. In general, the behavior is conserved, but the growth is potentially greater when we have a set, since when repeating 
the unit the growth factors are significantly higher, especially in the tower type structure, which is the one that increases its volume with less Amount of material.

Four types of auxetic systems have been geometrically analyzed according to their formation, which can be included in unit patterns, 2D structures, 3D structures and tower structures. By studying the relationship between area (A) or volume (V) and length (L) a relationship $(K)$ has been obtained between these units, determining to understand the growth factors of these very particular structures.

From this geometric analysis we conclude that the starry reentrant structure has a growth factor that is well above the average for all the studied patterns, so it is very interesting its application as an unfoldable auxetic structure. However, it has the limitation that it is one of the structures that less folds of auxetic form, reason why its articulations would have to be designed in such a way that they allowed turns that generated a non-auxetic folding.

On the other hand, also in the realized geometric analysis, global growth factors for the chiral structures have been observed, concluding that the maximum folding of this type of structures is the polygon around which the bars rotate. For a larger compaction, as in the previous structure, it would be necessary to resort to non-auxetic final folds (and this always counting on the fact that the base polygon has no mass inside). For chiral structures, nonauxetic folding is easier to achieve, since it only consists of opening one of the vertices of the polygon and giving more rotation to the joints so that some bars can be folded over others.

From the geometric analysis carried out, it is also concluded that the reentrant hexagonal, triangular reentrant and reentrant tetrahedral structures are fully folded in an auxetic form, which is an exceptional property when working with these geometries for deployable structures.

The geometric study has also developed another classification according to the knots: articulations in a single plane of several bars, joints in space with confluence of three or more bars, joints in a single plane joining the apex of a polygon with the end Of a bar, joints in space joining the apex of a polygon with the end of a bar, joints in a single plane joining vertices of polygons and joints in space joining vertices of polygons; Generating a node development for planar auxetic deployables and another node for spatial structures; And concluding that in these nodes we must study the angle of rotation of the bars, the number of bars that converge in each node and the relative direction of each bar, since a greater 
proportion of node with respect to the bars admits larger amounts of turns And directions of said bars.

Structural behaviors have been raised depending on materials, knots and stabilized systems. Therefore, the typological criteria are numerous: topology, geometry, mechanical characteristics (in terms of states of self-stabilization and infinitesimal mechanisms), etc. Individual metallic hexagonal reentrant structures of rigid knots, individual hexagonal reentrant structures of self - stabilized articulated knots were analyzed by means of an internal tendon and hexagonal reentrant structures in 2 and 3 dimensions of concrete.

The results obtained for the rigid metallic structure conclude that as its auxeticity increases, the displacements are greater, which translates into a more flexible structure than the traditional ones. The efforts in the supports, axillary, cutting and momentary efforts also increase with the auxeticity, but in a perfectly admissible way and with values not much superior to traditional structures, reason why these flexible structures are very useful to us.

For the self-stabilized articulated hexagonal hexagonal reentrant metal structure it is concluded that it is a very elastic structure in which only small stresses are generated in its bars when a load is applied. The tensile forces generated by the tendon are applied to the vertical bars, which are those that enable the opening or closing of the structure, establishing the equilibrium in a certain position as a function of a determined voltage applied to the internal cable.

In the case of the concrete structure it is concluded that the stresses increase when inserting tendons, a fact that is due to the tendons in concrete are put to improve the tractions of this, and if the bars are working to compression it does not make much sense to put them , So this system is only valid in articulated structures, so that they stop being mechanisms. It is also concluded that greater efforts are generated in the auxetic structure than in the traditional one, increasing these efforts as the number of bars is increased by multiplying the individual pattern to generate a joint structure.

Finally, the joints for expandable auxetic structures have been resolved constructively according to the number of bars, angle of rotation and direction of each bar. These studies have been carried out without balance considerations, analyzing these typologies from a geometric and structural point of view, which as a final consequence should contain in general components that are potentially tensioned in their interior in order to stabilize the whole. 
According to the effect of the Poisson negative relation on structures, the analytical study justifying the research has been able to verify:

1. Porosity. This means that structures are generated very transparent and light, standing out above all the starry reentrant structure of 6 points. However, it must also be taken into account that, at higher porosity, poor mechanical properties in general, with less rigidity and structural stability.

2. Shear properties: According the elasticity equations, if we have constant the elasticity modulus and we obtain a negative Poisson's ratio, we can change the properties of structure. The theory say that with a negative Poisson's ratio, we obtain that it is very difficult to deform by shear the structure, but very easy to deform in volume. But in the chapter of structural calculus, a very little more elevated value on shear in auxetic structures was obtained in relation to the traditional structures.

3. Stiffness modulus: The capacity of the auxetic structures to vary their slenderness ratio when an auxetic transformation occurs can be decisive to the design of structural solutions in a large scale. That is why these structures reconfigure their stiffness modules with an increase of volume for the same mass. It is appreciated that the greater stiffness modules have the microporous polymers and rotating units, matching between types of structures as the number of bars for each of them increases.

4. Variable permeability: Auxetic materials are able to open pores by stretching and close these pores by compression. By it we can realize deployable structures with that we have an architecture according to growth form or structure, being the reentrant structure of 6 points that has the greatest capacity to vary its permeability.

Concretely, it is concluded that this structure work correctly to the tensions and loads proposed. The deformity is considered as a useful and important characteristic of auxetic structures with differences with the behavior in the modes of traditional and auxetic construction of buildings. The deformations that are developed in auxetic structures are greater than in traditional structures, but the apt values of efforts for their construction are in the same order in both types of structures. So, it is a new possibility to explorer in the discipline of architecture.

Depending on the level of auxeticity, some applications could be briefly pointed out, but obviously they could be investigated in more detail: moon stations, communication towers, 
wind parks, marquees for entrances, marquees to cover parking places, structures for seismic areas, etc. Some other applications could depend on the evolution of the investigations on foldable auxetic structures. As a result, they could be used for disaster relief in areas devastated by earthquakes, hurricanes, floods and so on, by installing deployable systems in the form of temporal dwellings, bridges, field hospitals, etc. The most suitable structures for large lights are those with higher stiffness modulus, and structures with greater volumetric deformability or variable permeability would be useful for transformable furniture. However, as for other proposals mentioned in this work, further research must be carried out to develop these potential applications.

For these reasons the set of auxetic geometries is useful to us to apply in architecture, and provides a strong foundation for research of application of new structural and constructive systems on the production of new architectures, while identifying transformations that new geometries and their application techniques, will contribute to the development and divulgation of new spatial and typological solutions.

\subsection{Future investigation lines}

Once the research is concluded and the conclusions established, this section describes the future lines of development that start from the conclusions proposed in this thesis.

\section{- Stabilization criteria and materials to carry out architectural structures based on auxetic growth.}

As discussed in section 3.1. Geometric study of auxetic structures. Auxetic developed patterns and their pliability, the concept of stabilization should be thoroughly developed at a certain point in the opening of the auxetic structures applicable to architecture, an issue that has only been touched briefly in section 3.3. Structural calculation of auxetic structures.

This research is absolutely essential when talking about architecture, since a geometric study developed only on the opening and closing points of the mechanisms corresponding to the auxetic geometries is insufficient to convert into architectural structures the auxetic geometries, so it is established as a fundamental goal to develop stabilization criteria and materials to carry out architectural structures based on auxetic growth. 


\section{- Constructive development of auxetic structures for architecture.}

As discussed in section 3.4. Constructive development of auxetic structures, it is necessary to study the constructive development so that these structures can be carried out.

In the proposed study a very general classification of knots has been carried out, with consequent constructive developments. This aspect should be developed in depth, individually for each structure, taking very into account the turns that occur and how the amount of material affects the geometric configuration chosen, to achieve real and not theoretical results.

\section{- Procedure for calculating the stabilization of auxetic structures by the application of external forces}

As discussed in section 3.3.2.4. Auxetic structure with articulated knots and internal tendon, it is necessary to study the structural behavior of stabilization of the auxetic structures deployable in certain points.

In the proposed study, a manual calculation of stabilization was performed using an internal tendon of the individual hexagonal reentrant structure. These calculations should be systematized in a general way using specific calculation software, taking into account the criteria for application of forces without introducing more mass into the structure for a chosen geometric configuration, thus achieving specific results in terms of growth.

\section{- Development of specific auxetic architectural applications}

Some architectural applications of auxetic properties such as lunar stations, communication towers, wind farms, canopies for entrances... have been pointed out briefly in the conclusions, but they could obviously be investigated in more detail.

Therefore, more research should be done to develop these potential applications in a concrete way and with constructive, structural, material, etc. criteria. So, they can be carried out in a real way in the field of architecture. 


\section{FUENTES BIBLIOGRÁFICAS}

\subsection{Bibliografía}

(1) AKT (2008). Design engineering: AKT, Adams, Kara, Taylor. Kara, Hanif \& Kara Taylor, Adams (ed. lit.). Barcelona: Actar, 2008.

(2) Alderson, A. \& RASBURN, J. \& EVANS, K. E. \& GRIMA J. N. (2001). Auxetic polymeric filters display enhanced de-fouling and pressure compensation properties. Membrane Technol, 137. pp. 6-8.

(3) ALDERSON A. (1999). A triumph of lateral thought. Chemistry \& Industry. pp. 384391.

(4) AlegriA, L. \& TeMmerman, N. D. \& THRALL, A. P. (2013). Construction of a Deployable Scissor Arch for Shelters. New proposals for transformable architecture, engineering and design. Ed. STARBOOKS Structural Architecture, pp. 93-98.

(5) ÁlVAREZ, J. C. (2012). Diseño y fabricación de estructuras auxéticas y porosas con aplicación en bioingeniería. Proyecto Fin de Carrera no 11406013. Escuela Técnica Superior de Ingenieros Industriales. Universidad Politécnica de Madrid.

(6) ÁlVAREZ, J. C. \& DÍAZ, A. (2012). Comparative study of auxetic geometries by means of computer-aided design and engineering. Smart Materials and Structures, 21, 105004. pp. 1-12.

(7) AlVAREZ, M. A. \& CóRdobA, F. J. \& PELLUZ, F. J. \& díAZ, E. \& SÁNCHEZ, M. \& BARBERO, J. M. (2009). Proceso constructivo del Rockódromo Arena de Madrid, España. Informes de la Construcción, Vol. 61. pp. 514, 5-18.

(8) ÁLVAREZ, M.D. \& ANAYA, J. (2013). Development of transformable structures from auxetic geometries. New proposals for transformable architecture, engineering and design. In the honor of Emilio Pérez Piñero. School of Architecture Seville, Spain. Ed. Starbooks 2013; pp. 269-274.

(9) ÁLVAREZ, M. D. \& ANAYA, J. (2014). Development of re-entrant hexatruss structures to be applied in architecture. Miradas a la investigación arquitectónica: construcción, gestión, tecnología. Madrid, pp. 193-196

(10) ALVERMANN, S. (2007). Effective viscoelastic behaviour of cellular auxetic materials. Monographic Series TU Graz. Computation in Engineering and Science.

(11) ANAYA, J. (2012). Digital Domes. Architecture's engineering with geometry of high indetermination degree. Florence. International Congress Domus in the World. 
(12) ANAYA, J. (2014). The construction engineering of the digital design of free forms. Proceedings of 37 th International Association for Bridge \& Structural Engineering Symposium Madrid.

(13) ANAYA, J. (2014). Transformaciones tipológicas estructurales y constructivas del diseño digital de edificios en altura con geometrías complejas. Miradas a la investigación arquitectónica: construcción, gestión, tecnología. Madrid, pp. 202-204

(14) ARMILLAS, I. (2004). R. Buckminster Fuller. Un innovador del diseño del siglo XX. Diseño y sociedad. pp. 32-41.

(15) AVELLANEDA, O. (2013). Transformable Architecture. Experimental solution for a square mesh deployable cover. New proposals for transformable architecture, engineering and design. Ed. STARBOOKS Structural Architecture, pp. 71-75.

(16) BALAGUER, M. \& SASTRE, R. (2013). Mobility and transformability in architectural structures. Proposal of a transformable system of telescopic and x-articulated bars: cinematic, geometric, and structural analysis. New proposals for transformable architecture, engineering and design. Ed. STARBOOKS Structural Architecture, pp. 47-52.

(17) BETCHTHOLD, M. (2008). Innovative Surface Structures. Technologies and Applications. New York, Taylor \& Francis.

(18) BEYLERIAN, G. y DENT, A. (2008). (1st.2007). Ultramateriales. Formas en que la innovación en los materiales cambia el mundo. Barcelona, Blume.

(19) BHULLAR, S. K. \& WEGNER, J. L. (2009). Some Transient Thermoelastic Plate Problems. J. Thermal Stresses, 32(8). pp. 768-790.

(20) BHULLAR S. K. \& WEGNER J. L. \& MIODUCHOWSKI A. (2010). Auxetic behavior of a thermoelastic layered plate. Journal of Engineering and Technology Research, Vol. 2(9). pp. 161-167.

(21) BILLINGTON, D.P. (2003). The art of structural design. A swiss legacy. New Haven. Princeton University Art Museum. Yale University Press.

(22) BILLINGTON, D.P. (1983). The Tower and the Bridge: The New Art of Structural Engineering. New York, Basic Books.

(23) BILLINGTON, D. P. (1982). Thin shell concrete structures. New York, McGraw-Hill.

(24) BLACK, S.J. (1972) Cords and countercords. Proposal for a tensile building system. Unpublished BArch dissertation. School of Architecture, Queen's University Belfast.

(25) BRAYER, F. \& MARIE-ANGE \& MIGAYROU (2013) Naturaliser l'architecture. p. 295. 
(26) BROTHERS, A. H. \& DUNAND, D. C. (2008). Mechanical properties of a density graded replicated aluminum foam. Materials Science and Engineering.: A., 489(1-2). pp. 439-443.

(27) BUCHANAN, P. (2011). In the Autopoiesis of Architecture, Patrick Schumacher introduces a new unifying Thoeory of Architecture. Peter Buchanan Decodes, Dissects an Wighs up Schumacher's arguments. Archit. Rev., vol. Mar 2011. pp. 6876.

(28) BURFORD, N. K. \& SMITH, F. W. (1999). Developing a new military shelter system: a case study in innovation. Building Research \& Information, 27:1, 35-55, DOI:10.1080/096132199369633

(29) BURKHARDT, R.W. (1994-2017) A practical guide to tensegrity design, [on-line], Cambridge (USA). Disponible en http://www.channel1.com/users/bobwb/tenseg/book/cover.html Último acceso 27 de mayo de 2017

(30) BURSTOW, R. (1996). Symbols for '51, the Royal Festival Hall, Skylon and Sculptures for the Festival of Britain, The Ballroom, Main Foyer, Royal Festival Hall, London, 2 March - 21 April 1996.

(31) CALATRAVA, S. (1981). Acerca de la plegabilidad de las estructuras. Tesis Doctoral. Escuela Politécnica Federal de Zúrich (Suiza).

(32) CALVO, J. \& SANZ, J. P. (2011). Arquitectura plegable para una década prodigiosa: la obra de Emilio Pérez Piñero y la arquitectura de los años sesenta. Expresión Gráfica Arquitectónica. Universitat Politècnica de València. pp. 114-127.

(33) CECCATO, C. (2010). Advances in Architectural Geometry 2010. Wien, SpringerVerlag.

(34) CHURTICHAGA, J.M. La estructura veloz: trayectorias estructurales a proposito de la obra de Emilio Perez Piñero y Felix Candela.

(35) CONNELLY, R. \& BACK, A. (1998a) Mathematics and Tensegrity. American Scientist. Vol.86, No.2, March-April 1998.

(36) CONNELLY, R. and BACK, A. (1998b) Catalogue of Symmetric Tensegrities, [online], Cornell University, Ithaca (USA) http://mathlab.cit.cornell.edu/visualization/tenseg/in progress/short top.html Último acceso 28 de mayo de 2017

(37) CRUICKSHANK, D. (1995). The 1951 Dome of Discovery, London. The Architectural Review; No.197.1175, pp.80-85. 
(38) DÍAZ, A. \& LAFONT, P. \& MUÑOZ, J. L. \& MUÑOZ-GUIJOSA, J. M. \& ECHÁBARRI, J. Actuators based on shape-memory polymers with auxetic structures. Grupo de Investigación en Ingeniería de Máquinas - E.T.S.I. Industriales. Universidad Politécnica de Madrid.

(39) DÍAZ, A. (2009). Metodología para el desarrollo de dispositivos médicos basados en el empleo de polímeros activos como sensores y actuadores. Tesis doctoral. Departamento de Ingeniería Mecánica y Fabricación. Escuela Técnica Superior de Ingenieros Industriales. Universidad Politécnica de Madrid.

(40) DIRECCIÓN GENERAL DE ARQUITECTURA, VIVIENDA Y SUELO. Documento Básico SE-A del CTE. Seguridad Estructural. Acero. Texto modificado por RD 1371/2007, de 19 de octubre (BOE 23/10/2007) y corrección de errores (BOE 25/01/2008)

(41) DIRECCIÓN GENERAL DE ARQUITECTURA, VIVIENDA Y SUELO. Documento Básico SE-AE del CTE. Seguridad Estructural. Acciones en la edificación. Abril 2009.

(42) DIRRENBERGER, J. \& FOREST, S. \& JEULIN, D. \& COLIN, C. \& BARTOUT. (2011). Homogenization of periodic auxetic materials. MINES-ParisTech / Procedia Engineering 10. pp. 1847-1852.

(43) DIRRENBERGER, J. \& FOREST, S. \& JEULIN, D. \& COLIN, C. \& BARTOUT, J. D. \& FAESSEL, M. \& WILLOT, F. Effective properties of architectured materials. MINESParisTech.

(44) DIRRENBERGER, J. \& FOREST, S. \& JEULIN, D. (2013). Effective elastic properties of auxetic microstructures: anisotropy and structural applications. International Journal of Mechanics and Materials in Design 9:21-33.

(45) DREW, P. (1976). Frei Otto. Form and structure. London: Crosby Lockwood Staples.

(46) EDMONDSON, A. C. (1987). A Fuller Explanation: The Synergetic Geometry of R. Buckminster Fuller. Cambridge, Mass, (USA): Birkhäuser Boston.

(47) ESCRIG, F. (2013). Modular, Light and Transformable Architecture. New proposals for transformable architecture, engineering and design. Ed. STARBOOKS Structural Architecture, pp. 11-22.

(48) ESTRELA, C. (2014). The innovative structural conception in Stéphane du Château's work: from metallic trusses to the development of spatial frames. Architectus 2014, 4(40), pp. 51-64.

(49) EVANS, K. (1991). Auxetic polymers: a new range of materials. Endeavour 15.4: 170-174. 
(50) FIGUERES, G. (1998). La cúpula del museo Dalí: sustitución y restitución de un elemento arquitectónico característico. Annals 98/3.

(51) FOX, H. N. (1981) Portrait of an Atomist. Catalog Essay for Kenneth Snelson Exhibition at Hirshhorn Museum and Sculpture Garden, Smithsonian Institution, Washington, D.C., Junio - Agosto 1981. También disponible en http://www.kennethsnelson.net/icons/art.htm

(52) FRAILE, M. (2014). Morfogénesis digital. La creación de un paradigma sostenible. Buenos Aires.

(53) FRAILE, M. (2014). Morfogénesis digital. Del diseño en serie al parametrismo eficiente. Buenos Aires.

(54) FRANCIS, A.J. (1980). Introducing Structures. Oxford: Pergammon Press.

(55) FULLER, R. B. (1951). Building construction. US Patent 2682235 (12.12.1951).

(56) FULLER, R. B. (1959). Tensile-integrity structures. US Patent 3063521 (31.08.1959).

(57) FULLER, R.B. (1961) Tensegrity. Portfolio and Art News Annual, No.4. pp.112-127, 144, $148 . \quad$ También en http://www.rwgrayprojects.com/rbfnotes/fpapers/tensegrity/tenseg01.html

(58) FULLER, R.B. (1964) Suspension Building, U.S. Patent No. 3,139,957, July 7, 1964.

(59) FULLER, R.B. (1967) Octahedronal building truss, U.S. Patent No. 3,354,591, November 28, 1967.

(60) FULLER, R.B. (1975) Non-symmetrical tensegrity, U.S. Patent No. 3,866,366, February 18, 1975.

(61) FULLER, R.B. (1982) Correspondence with Robert Burkhardt, Enero 29 - Marzo 18, 1982. También disponible en http://www.bfi.org/burkhardt/section1.html

(62) GANTES, C. J. \& KALOCHAIRETIS, K. E. \& AKGÜN, Y. (2013). On the trade-off between structural performance and deployability. New proposals for transformable architecture, engineering and design. Ed. STARBOOKS Structural Architecture, pp. 131-136.

(63) GARCÍA GONZÁLEZ, R. Sistema estructural desplegable fractal. Patente española 2 368639 (21.11.2011).

(64) GAOYUAN, W. \& EDWARS, S. F. (1998). Auxeticity windows for composites. Physica A: Statistical Mechanics and its Applications. 258 (1-2), pp. 5-10.

(65) GASPAR, N. \& REN, X. J. \& SMITH, C. W. \& GRIMA, J. N. \& EVANS, K. E. (2005). Novel honeycombs with auxetic behaviour. Acta Materialia, 53(8). pp. 2439- 2445. 
(66) GATT, R. \& ATTARD, D. \& GRIMA, J. N. (2009). On the behaviour of bi-material strips when subjected to changes in external hydrostatic pressure. Scripta Materialia, 60(2). pp. 65-67.

(67) GEIGER, D.H. (1988). Roof structure. U.S. Patent No. 4,736,553, April 12, 1988.

(68) GOLDSMITH, M. (1987). Buildings and Concepts. Edition Rizzoli New York.

(69) GÓMEZ, D. E. (2013). An expandable pendentive dome and polyhedral mechanisms using angulated scissors with sliding elements. New proposals for transformable architecture, engineering and design. Ed. STARBOOKS Structural Architecture, pp. 53-58.

(70) GÓMEZ, V. (2004). Tensegrity Structures and their Application to Architecture. Tesis Doctoral. School of Architecture, Queen's University, Belfast.

(71) GRIMA, J. N. (2010). Auxetic Metamaterials. European Summer Campus 2010.

(72) GUO, C. Y. \& WHEELER, L. (2006). Extreme Poisson's ratios and related elastic crystal properties. Journal of the Mechanics and Physics of Solids, 54(4). pp. 690707.

(73) HALIS GUNEL, M. \& EMRE ILGIN, H. (2007). A proposal for the classification of structural systems of tall buildings. Building and Environment, 42. pp. 2667-2675.

(74) HANAOR, A. (1987) Preliminary Investigation of Double-Layer Tensegrities. H.V. Topping, ed., Proceedings of International Conference on the Design and Construction of Non-conventional Structures (Vol.2), Edinburgh, Scotland: Civil-Comp Press.

(75) HENSEL, M. \& MENGES, A. (2006).Techniques and Technologies in Morphogenetic Design. Architectural Design, Wiley Publisher.

(76) HERNÁNDEZ, C. H. (2013). Experiences in Deployable Structures. New proposals for transformable architecture, engineering and design. Ed. STARBOOKS Structural Architecture, pp. 41-46.

(77) IWAMOTO, L. (2009). Digital Fabrications: Architectural and Material Techniques. New York, Princeton Architectural Press.

(78) JIANG, J.-W. \& KIM, S.Y. \& PARK, H.S. (2016). Auxetic nanomaterials: Recent progress and future development. Applied Physics Reviews, Volume 3, Issue 4, 1 December 2016, Article number 041101.

(79) KENNER, H. (1976) Geodesic Math and How to Use It, Berkeley, California: University of California Press.

(80) KHAN, Y. S. (2004). Engineering Architecture. The vision of Fazlur R. Khan. New York: W.W. Norton \& Company. 
(81) KIM, S-D., D. \& PARK, S-K. \& JANG, J-P. \& SIN, I-A. \& LEE, J-B. \& HA, C-W. \& JUNG, S-T. (2013). A Study on Deployable Shelters Considering Biaxial Rotations of Joints. New proposals for transformable architecture, engineering and design. Ed. STARBOOKS Structural Architecture, pp. 111-114.

(82) KOLAREVIC, B. (2001). Designing and manufacturing architecture in the digital age. Architectural Information Management, vol. 05 Design. pp. 117-123.

(83) KOLAREVIC, B. (2005). Architecture in the digital age: design and manufacturing. New York, Taylor \& Francis.

(84) KORKMAZ, K. \& SUSAM, G. \& AKGÜN, Y. (2013). A novel 8R Mechanism for Reconfigurable Hypar Surface. New proposals for transformable architecture, engineering and design. Ed. STARBOOKS Structural Architecture, pp. 77-82.

(85) KURZWEIL, R. (2005). La singularidad está cerca. Lola Books, p. 702.

(86) KYOUNG SUN MOONA. (2011). Diagrid Structures for Complex-Shaped Tall Buildings. Procedia Engineering, 14. pp. 1343-1350.

(87) LAKES, R. S. \& WITT, R. (2000). Making and characterizing negative Poisson's ratio materials. International Journal of Mechanical Engineering Education, Vol 30, No 1. pp. 50-58.

(88) LAKES, R. S. (1987). Foam structures with a negative Poisson's ratio. Science, 235. pp. 1038-40.

(89) LARSEN, U. D. \& SIGMUND, O \& BOUWSTRA, S. (1997). Design and fabrication of compliant micromechanisms and structures with negative Poisson's ratio. Journal of microelectromechanical systems, Vol. 6, No. 2. pp. 99-106.

(90) LECUYER, A. (2003). Steel and Beyond: New Strategies for Metals in Architecture. Basel, Birkhäuser.

(91) LEE, D. S-H. \& POPOVIC, O. \& KIM, S-D. (2013). Study of the connection joint for scissor-type deployable structure for the possible application in emergency evacuation shelter. New proposals for transformable architecture, engineering and design. Ed. STARBOOKS Structural Architecture, pp. 105-109.

(92) LIU, Q. (2006). Literature review: materials with negative Poisson's ratios and potential applications to aerospace and defense. DSTO Defence Science and Technology Organisation.

(93) MANTEROLA ARMISÉN, J. (1985). La estructura resistente de los edificios altos. Informes de la Construcción, Vol. 37, n 371. pp. 5-30.

(94) MANTEROLA ARMISÉN, J. (2005). La estructura resistente en la arquitectura actual. Informes de la Construcción, Vol. 57, no 499-500. pp. 9-35. 
(95) MANTEROLA ARMISÉN, J. (2008). La forma de lo resistente. IT, n̊81. pp. 32-37.

(96) MAYDANA, A. (2009). Guía de estudio 11: Estereoestructuras. Facultad de Arquitectura y Urbanismo, Universidad Nacional de la Plata, Argentina.

(97) MENGES, A. and HENSEL, M. (2008). Versatility and Vicissitude. An Introduction to Performance in Morpho-Ecological Design. Archit. Des., vol. 78 no2. pp. 6-12.

(98) MEREDITH.M, y LASCH. A. (2008). From Control to Design: Parametric /Algorithmic Architecture. New York. Actar-D. Publications.

(99) MIMRAM, M. (1983). Structures et formes: étude appliquée à l'ouvre de Robert Le Ricolais. Paris. Dunod.

(100) MIR M. ALI \& KYOUNG SUN MOON. (2007). Structural Developments in Tall Buildings: Current Trends and Future Prospects. Architectural Science Review, Volume 50, Number 3. pp. 205-223.

(101) MORALES, C. C. (2013). Retractable System Design for Light Covers. New proposals for transformable architecture, engineering and design. Ed. STARBOOKS Structural Architecture, pp. 119-124.

(102) MORATTI, S. \& ALDRED, P. (2005). Dynamic simulations of potentially auxetic liquidcrystaline polymers incorporating swivelling mesogens. Molecular Simulation I Journal of Experimental Nanoscience.

(103) MOTRO, R. (2003). Tensegrity: Structural Systems for the Future. London: Kogan Page Science.

(104) MOTRO, R. (2013). Nodes and Structures - A tribute to Stéphane Du Château. (IASS) Symposium 2013 Beyond the limits of man", Sep 2013, Wroclaw, Poland. 8 p., 2013.

(105) NELSON, E. (1998). Dynamic building enclosures: the design of an innóvate constructive system which permits mechanically-driven, computer-controlled shaped transformations to the building envelope. Tesis Doctoral. Department of Architecture. Massachusetts Institute of Technology.

(106) NESTOROVIC, M. (1987) Metallic Integrally Tensioned (Tensegrity) Cupola. H.V. Topping, ed., Proceedings of International Conference on the Design and Construction of Non-conventional Structures (Vol.2), Edinburgh, Scotland: Civil-Comp Press.

(107) NIETO, J. (1978). Síntesis de mecanismos. Editorial AC, Madrid.

(108) O'BRIEN MELIN, N. (2004). Application of Bennett Mechanism to Long-Span Shelters. Tesis Doctoral. Department of Engineering Science. University of Oxford.

(109) ORTIZ BERROCAL, L. (1998). Elasticidad. McGraw-Hill, ISBN 84-481-2046-9. 
(110) OXMAN, N. (2004). Performative Morphologies: The vertical Helix. MorphoEcologies. AA Diploma Unit 4. pp. 66-67.

(111) OXMAN, N. (2010). Material-based design computation. PhD Thesis. Massachusetts Institute of Technology.

(112) OXMAN, R. (2010). The New Structuralism: Design, Engineering and Architectural Technologies. London, Architectural Design. John Wiley and Sons.

(113) PEEL, L. D. (2005). Investigation of high and negative Poisson's ratio laminates. Society for the Advancement of Material and Process Engineering with Permission.

(114) PÉREZ PIÑERO, E. Estructura reticular estérea plegable. Patente española ES0266801 A1 (01.11.1961). US Patent 3.185.164.

(115) PÉREZ PIÑERO, E. Estructura reticular estérea plegable. Patente española ES0283206 A2 (01.02.1963).

(116) PÉREZ PIÑERO, E. Sistema de montaje de una estructura resistente esferica triangulada. Patente española ES0311901 A1 (01.02.1966).

(117) PÉREZ PIÑERO, E. (1968). Reticular structures.

(118) PETERS, S. (2011). Material Revolution.Sustainable and multi-purpose materials for design and architecture. Basel, Birkhäuser.

(119) PONCE, A. \& SÁNCHEZ, J. (2013). Formal definition of the spatial deployable of rectangular module $x$-frames structures over frustoconical surfaces. New proposals for transformable architecture, engineering and design. Ed. STARBOOKS Structural Architecture, pp. 59-64.

(120) PRALL, D. \& LAKES, R. S. (1997). Properties of a chiral honeycomb with a poisson's ratio of -1. International Journal of Mechanical Sciences, 39. pp. 305-314.

(121) PUERTAS DEL RÍO, L. (1989). Estructuras espaciales desmontables y desplegables. Estudio de la obra del arquitecto Emilio Pérez Piñero. Tesis Doctoral. Departamento Estructuras de Edificación. Escuela Técnica Superior de Arquitectura de Madrid.

(122) PUERTAS DEL RíO, L. (1990). Estructuras espaciales desmontables y desplegables. Informes de la Construcción, Vol. 42, $\mathrm{n}^{\circ}$ 409. pp. 43-53.

(123) PUERTAS DEL RÍO, L. Primeras propuestas en España de estructuras desplegables de barras. Estructuras y movimiento. Vniversitats Stvdiorvm Navarrensis. pp. 48-54.

(124) PUGH, A. (1976) An Introduction to Tensegrity. Berkeley, California: University of California Press.

(125) RAMOS, C. \& MACIÁ, A. \& OLIVER, J. L. (2013). Curvature of Deployable Spherical Grids. New proposals for transformable architecture, engineering and design. Ed. STARBOOKS Structural Architecture, pp. 65-70. 
(126) RAMOS, R. (2013). New geometry deployable structure of $x$-frame. New proposals for transformable architecture, engineering and design. Ed. STARBOOKS Structural Architecture, pp. 89-92.

(127) RODRÍGUEZ, N. (2005). Diseño de estructura transformable por deformación de una malla plana en su aplicación a un refugio de rápido montaje. Tesis, Universidad Politécnica de Catalunya, Escuela Técnica Superior de Arquitectura de Barcelona, Barcelona.

(128) ROVATI, M. (2004). Directions of auxeticity for monoclinic crystals. Scripta Materialia, 51(11). pp. 1087-1091.

(129) SASAKI, M. (2007). (1st. 2005). Flux Structure. Tokyo, Toto Edition.

(130) SASAKI, M. (2007). Morphogenesis of Flux Structure. London, AA Publications.

(131) SMITH, C. W. \& GRIMA, J. N. \& EVANS, K. E. (2000). A novel mechanism for generating auxetic behaviour in reticulated foams: missing rib foam model. Elsevier Science Ltd. Acta mater. 48 (2000). pp. 4349-4356

(132) STERK, T. \& MARUZEVSKI, B. \& NAROJCZYK, J. W. \& WOJCIECHOWSKI, K. W. (2008). Finite element analysis of auxetic plate deformation. Journal of NonCrystalline Solids, 354(35-39). pp. 4475-4480.

(133) THOMPSON, D. A. (2003). Sobre el Crecimiento y la Forma. Ediciones AKAL.

(134) TIBERT, G. (1999). Numerical Analyses of Cable Roof Structures. Unpublished Licentiate thesis. Royal Institute of Technology, Stockholm (Sweden).

(135) TORRES, N. P. (2013). Desarrollo de un escenario desplegable basado en la aplicación de estructuras tipo tijera, sistema de plegadura y membranas. New proposals for transformable architecture, engineering and design. Ed. STARBOOKS Structural Architecture, pp. 125-130.

(136) VALCÁRCEL, J. P. Introducción a la geometría de las estructuras espaciales desplegables de barras. Departamento de estructuras. E. T. S. Arquitectura. La Coruña. pp. 48-57.

(137) VALCÁRCEL, J. P. La obra arquitectónica de Emilio Pérez Piñero. Departamento de Tecnología de la Construcción. E. T. S. Arquitectura. La Coruña.

(138) VALCÁRCEL, J. P. Movilidad de grandes estructuras. Departamento de Tecnología de la Construcción. E. T. S. Arquitectura. La Coruña.

(139) VAN SCHAIK, L. (2008). Spatial Intelligence: New Futures for Architecture. West Sussex, John Wiley \& Sons Ltd.

(140) VEDOYA, D. E. \& PRAT, E. S. (2009). Estructuras de grandes luces. Tecnología y diseño. Corrientes: Ediciones del ITDAHu. 
(141) WILLIAMS, W.O. (2003). A Primer on the Mechanics of Tensegrity Structures. Pittsburgh (USA).

(142) YANPING Liu \& HONG Hu. (2010). A review on auxetic structures and polymeric materials. Scientific Research and Essays, Vol. 5 (10). pp. 1052-1063.

(143) YOKOSUKA, Y. \& MATSUZAWA, T. (2013). Shape-finding Analysis for Variable Geometry Structures Formed by a Multilink Spherical Joint. New proposals for transformable architecture, engineering and design. Ed. STARBOOKS Structural Architecture, pp. 83-88.

(144) YOU, Z. \& PELLEGRINO, S. (1997). Foldable bar structures. Int. J. Solids Structures, Vol 34, No 15. pp. 1825-1847.

(145) YOU, Z. (2007). Motion structures extend their reach. Materials today, Vol 10, № 12. pp. 52-57.

(146) ZHEUNG, Dong-Ma \& ARBOR, A. (2010). Three-dimensional auxetic structures and applications thereof. US Patent 20100119792A1.

\subsection{Páginas web}

(147) Adrian Rossiter. (2012, Octubre 16). Antiprism. Recuperado el 1 de Noviembre, 2012, de http://www.antiprism.com/index.html

(148) Amorós Figueroa, R. Cúpulas geodésicas. Recuperado el 27 de Febrero, 2017, de http://www.usmp.edu.pe/publicaciones/boletin/fia/info39/arquitectura.html

(149) Andy Alderson. (2011, Octubre 24). Auxetic materials: stretching the imagination. Recuperado el 1 de Noviembre, 2012, de http://www.soci.org/Chemistry-andIndustry/Cnl-Data/2011/2/Auxetic-materials stretching-the-imagination

(150) Bostjan. (2017, Feb 20). City Tower. Recuperado el 29 de mayo, 2017, de http://architectuul.com/architecture/city-tower

(151) Bramgeenen. (2012, Apr 2). Gaudi Stool. Recuperado el 30 de mayo, 2017, de https://www.thingiverse.com/thing:18014

(152) Buckminster Fuller Institute. (2010). Buckminster Fuller Institute. Recuperado el 1 de Noviembre, 2012, de http://www.bfi.org/about-bucky/resources/world-design-sciencedecade-documents 
(153) Casiopea. (2012, Enero 25). Richard Buckminster Fuller: cúpula geodésica / estructuras de tensegridad. Recuperado el 1 de Noviembre, 2012, de http://wiki.ead.pucv.cl/index.php/RICHARD_BUCKMINSTER_FULLER:_C\%C3\%9AP ULA_GEOD\%C3\%89SICA_IESTRUCTURAS_DE_TENSEGRIDAD

(154) Ciencia y educación. (2012). Cúpula geodésica, estructuras futuristas. Recuperado el 1 de Noviembre, 2012, de http://www.taringa.net/posts/cienciaeducacion/14198303/Cupula-geodesica_estructuras-futuristas.html

(155) Charles. (2012, Abril 21). Energy-[R]evolution. Recuperado el 5 de junio, 2012, de http://www.e-rev.org/post/21508424864/vertical-village-tu-delft

(156) Cristina Doumpioti (2010). Material Effects by Christina Doumpioti -in progress... Recuperado el 6 de julio, 2012, de http://www.c-dmp.com/

(157) Dave Pigram. Supermanoeuvre. Recuperado el 6 de julio, 2012, de http://supermanoeuvre.com/

(158) Espacio Blanco. (2011, Agosto 14). Emmanuel Ruffo galardonado con el "Premio mejor presentación" en CAAD Futures. Recuperado el 29 de mayo, 2017, de http://espacio-blanco.com/2011/08/emmanuel-ruffo-galardonado-con-el$\%$ E2\%80\%9Cpremio-mejor-presentacion-en-caad-futures/

(159) Etalab. (2002). Tate in Space. Recuperado el 27 de febrero, 2017, de http://www2.tate.org.uk/space/etalab.htm

(160) Franken, B. (1999). Bubble. Recuperado el 26 de febrero, 2017, de http://www.franken-architekten.de/index.php?pagetype=projectdetail\&lang=en\&cat=1 \&param=overview \&param $2=21 \&$ param $3=0 \&$

(161) Fundación Emilio Pérez Piñero. Recuperado el 1 de Noviembre, 2012, de http://www.perezpinero.org/index.html

(162) Génesis construcciones geodésicas. (2012). Construcciones geodésicas. $\begin{array}{llll}\text { Recuperado el } 1 \text { de } & \text { Noviembre, }\end{array}$ http://www.genesisgeodesica.com.ar/index.php?option=com_content\&view=article\&id $=53 \& \mid$ temid $=54$

(163) Gilbert13. (2011). Auxbowl. Recuperado el 1 de Noviembre, 2012, de http://gilbert13.co.uk/auxbowl.html

(164) Greg Allen. (2009, December 02). 90-Strut Tensegrity Sphere by Buckminster Fuller. Recuperado el 5 de junio, 2012, de http://www.dinosaursandrobots.com/2009/12/90strut-tensegrity-sphere-by.html

(165) Harris Novick. (2009, Agosto 30). La periferia doméstica. Recuperado el 1 de Noviembre, 2012, de http://periferiadomestica.tumblr.com/post/175438997 
(166) HMXIF (2011, Marzo 22). The strange behaviour of auxetic foams. Recuperado el 3 de Noviembre, 2012, de http://www.youtube.com/watch?v=PLDbSWSm5i8

(167) Isar. Recuperado el 27 de febrero, 2017, de http://www.iwamotoscott.com/

(168) John Summerscales. (2012). Composites Design and Manufacture (BEng) - MATS 324. Core materials for sandwich panels. Recuperado el 2 de Noviembre, 2012, de http://www.tech.plym.ac.uk/sme/mats324/mats324a10\%20core.htm

(169) Jorl (2011, Agosto 26). Fractalnet. Recuperado el 6 de julio, 2012, de http://www.fractalnet.org/gallery2/v/GeoMath/ParabolicDomes/TensegrityBlocks/piner o.jpg.html

(170) Koala. (2008, Octubre 1). Exaxis: El auto de cristal. Recuperado el 30 de mayo, 2017, de http://rompiendomotores.blogspot.com.es/2008/10/exaxis-el-auto-decristal.html

(171) Matsys. Matsys. Recuperado el 6 de julio, 2012, de http://matsysdesign.com/

(172) Med-Tech Innovation. (2011). Smart Solutions from Auxetic Materials. Recuperado el 2 de Noviembre, 2012, de http://www.medtechinnovation.com/Articles/articles/article/20

(173) Norbert Palz. (2012). Grasshopper. Recuperado el 4 de Noviembre, 2012, de http://www.grasshopper3d.com/photo/photo/listForContributor?screenName=2ip6drlo khmef

(174) Pasemanadmin (2011, Marzo 27). Negative Poisson Ratio (or auxetic) Material. $\begin{array}{lllll}\text { Recuperado el } & \text { el } & \text { de }\end{array}$ http://www.youtube.com/watch?v=nDuR9hHIpZM

(175) Pasemanadmin (2011, Marzo 27). Negative Poisson Ratio (or auxetic) Material: Radial Pattern. Recuperado el 6 de Noviembre, 2012, de http://www.youtube.com/watch?v=IOjh yDQNEU

(176) Pasemanadmin (2011, Marzo 27). Negative Poisson Ratio (or auxetic) Material: Thin Bow Tie Pattern. Recuperado el 6 de Noviembre, 2012, de http://www.youtube.com/watch?v=bpdKsAiuBP8

(177) PatentGenius. (2006-2001). Three-dimensional auxetic structures and applications thereof. Recuperado el 4 de Noviembre, 2012, de http://www.patentgenius.com/patent/7910193.html

(178) Roland Snooks. (2005). Morphogenetic lattice. Recuperado el 29 de mayo, 2017, de http://www.kokkugia.com/MORPHOGENETIC-LATTICE

(179) Sandragm (2011). Sobre arquitectura e inquietudes. Recuperado el 6 de julio, 2012, de http://arki-actividad.blogspot.com.es/2011/11/estructuras-desplegables.html 
(180) Santo Antônio. (2011, Julio 28). Coisas da Arquitetura. Recuperado el 5 de junio, 2012, de http://coisasdaarquitetura.wordpress.com/2011/07/28/louis-i-kahn/

(181) Simpleware. Case study - Auxetic Foam Analysis. Recuperado el 30 de Octubre, 2012, de http://www.simpleware.com/industries/materials/case-study-auxetic-foamanalysis.html

(182) Toyo Ito \& Associates. Parque de la relajación, Torrevieja. Alicante. VIA Arquitectura 17. Recuperado el 29 de mayo, 2017, de https://www.via-arquitectura.net/17/112017.htm

(183) Wikipedia. (2012, Agosto 7). Malla espacial. Recuperado el 5 de junio, 2012, de http://es.wikipedia.org/wiki/Malla_espacial

(184) Wikipedia. (2012, Octubre 29). Tensegridad. Recuperado el 1 de Noviembre, 2012, de http://es.wikipedia.org/wiki/Tensegridad

(185) WithinLab. (2012). Within medical software. Recuperado el 30 de Octubre, 2012, de http://www.withinlab.com/medical/

(186) Yahoo!groups. (2011). Re: auxetic materials. Recuperado el 28 de Octubre, 2012, de http://tech.dir.groups.yahoo.com/group/antiprism/message/5620?o=1\&d=1\&var=1\&p= I 


\section{LISTA DE FIGURAS, GRÁFICAS Y TABLAS}

\subsection{Lista de figuras}

- Figura 1 Material no auxético: Cuando el material es estirado las celdas que lo componen se alargan en la dirección x pero se comprimen en la dirección y.

- Figura 2 Material auxético: Cuando el material es estirado las celdas que lo componen se alargan tanto en la dirección $\mathrm{x}$ como en la dirección y.

- $\quad$ Figura 3. Polímero convencional (izquierda) y polímero auxético (derecha)

- Figura 4. Célula unitaria reentrante idealizada producida por colapso simétrico de un poliedro de 24 caras con simetría cúbica, Lakes (1987)

- Figura 5 Estructuras reentrantes hexagonales (a) deformada (b) sin deformar

- Figura 6. Otros tipos de estructuras reentrantes (a) estructura de doble punta de flecha (b) estructura de panal de abeja en forma de estrella (c) estructura reentrante hexagonal de panal de abeja (d) estructura formada por mallas romboidales (e) estructura formada por mallas cuadradas (f) estructura formada por ligamentos sinusoidales

- $\quad$ Figura 7 Estructura tridimensional (a) convencional (b) auxética

- $\quad$ Figura 8 Estructuras quirales de panal de abeja (a) formada por las mismas unidades quirales (b) formadas por unidades quirales simétricas

- $\quad$ Figura 9 Unidades rotatorias (a) unidades triangulares (b) unidades cuadradas (c) unidades rectangulares $(\mathrm{d})$ unidades tetraédricas

- Figura 10 Composite auxético (a) estructura (b) modelo

- Figura 11 Geometría de hexámeros cíclicos

- Figura 12 Esquema de un modelo de nódulos y fibras representando el típico polímero auxético microporoso (a) polímero en reposo (b) polímero bajo carga de tracción

- Figura 13 Polímero líquido cristalino teórico (a) sin deformar (b) deformado

- Figura 14 Escalas de auxeticidad según Alderson (1999) + la escala de la arquitectura Figura 15 ETALAB interactive model. 2002.

- Figura 16 Izquierda arriba: Estructura ósea de cráneo humano. Izquierda abajo: Polígonos de Voronoy. Derecha: Vertical Village: A Sustainable Way of Village - Style Living

- $\quad$ Figura 17 Silk Pavilion, 2013. Neri Oxman.

- $\quad$ Figura 18 City Tower, Louis I Kahn. Izquierda: Maqueta. Derecha: Sección y plantas

- $\quad$ Figura 19 Trabajos realizados en el workshop Cross-Fabricated Scales

- Figura 20 Lámpara diploide, grupo Matsys

- Figura 21 Honeycomb Morphologies 
- $\quad$ Figura 22 Proyecto C_WALL, grupo Matsys

- Figura 23 Celosía morfogenética, Dave Pigram y Roland Snooks

- Figura 24 Fibrous Concrete Istambul Workshop, AKT. Izquierda: Enlace entre plástico y hormigón para crear un material compuesto. Derecha: Tubos delgados de hormigón que pueden torsionarse y moverse independientemente, pero a pesar de todo interactúan entre sí para asegurar la estabilidad.

- Figura 25 Hexagonal Panelization Strand Link Bridge

- Figura 26 Parque de la relajación, Torrevieja, Toyo Ito

- Figura 27 "Bubble" para BMV group, B. Franken

- $\quad$ Figura 28 Diseño de geometrías arquitectónicas mediante diseño computacional

- Figura 29 Catenaria o forma suspendida, Cristina Doumpioti

- Figura 30 Polímero sensible al calor basado en cristales termocrómicos, Cristina Doumpioti

Figura 31 Dublin Landmark Tower. Achim Menges. Emergence and Design Group.

- Figura 32 Teselas Dublín Landmark Tower. Achim Menges.

- Figura 33 The Vertical Helix,2004. London. Neri Oxman

- Figura 34 Jellyfish,L Iwamoto

- $\quad$ Figura 35 Coche plástico Exaxis, Bayer

- Figura 36 Edag Génesis 8, 2014, EDAG.

- $\quad$ Figura 37 Gaudí Stool, Furnistructures, Bram Geenen

- Figura 38 Bota motociclista PUMA

- $\quad$ Figura 39 Patente Barde Salden Watkins

- Figura 40 Sistema geodésico, 1954, Buckminster Füller

- Figura 41 División del icosaedro en patentes (izquierda) y división del icosaedro en construcciones (derecha), R. Buckminster Fuller

- Figura 42 Cúpula geodésica realizada con 3 dimensiones diferentes de barras (izquierda) y esfuerzos simples de tracción (amarillo) y compresión (rojo) en una cúpula geodésica (derecha), elaboración propia

- $\quad$ Figura 43 Flor de diente de león (izquierda) y 3 Lattice System, R. Le Ricolais (derecha)

- $\quad$ Figura 44 Pantograph, 1963, Pérez Piñero

- Figura 45 Cúpula del teatro del museo Dalí de Figueres, Gerona, Emilio Pérez Piñero (izquierda) y USA Montreal Pavilion EXPO1967, Richard Buckminster Fuller (derecha)

- $\quad$ Figura 46 Marco estructural preensamblado, Albert Moore

- Figura 47 Estructuras autoportantes plegables, Teodoro Zeigler

- Figura 48 Imágenes de la tesis de Santiago Calatrava 
- $\quad$ Figura 49 Pabellón de Venezuela en la EXPO 92 de Sevilla (izquierda) y STRAN 1 (derecha), Carlos Henrique Hernández

- Figura 50 Piscina cubierta en el área de deportes de San Pablo de Sevilla, Escrig, Sánchez y Valcárcel

- Figura 51 Esfera de Hoberman

- Figura 52 Configuración estructural revisada del refugio de prototipo a escala completa, N. K. Burford y F. W. Smith

- Figura 53 Proceso de transformación en sistema transformable de barras telescópicas y articuladas en $\mathrm{x}$

- Figura 54 Propuesta de Luis Sánchez Cuenca para generar formas arbitrarias

- Figura 55 Movimiento de un cuadrilátero truncado de base piramidal, Daniel Enrique Gómez Lizcano

- Figura 56 Análisis de la transmisión de movimientos entre caras: (a) Uniones articuladas, (b) Marco deslizable. Daniel Enrique Gómez Lizcano

- Figura 57 Modelo que muestra la capacidad de transformación del nuevo mecanismo con catorce enlaces intermedios, Koray Korkmaz, Gözde Susam y Yenal Akgün

- Figura 58 Generación de mallas troncocónicas, Antonio Ponce García y José Sánchez Sánchez

- Figura 59 Red unitaria curva, Cristina Ramos Jaime, Antonio Maciá Mateu y José Luis Oliver Ramírez

- Figura 60 Modelo con sistema de membrana rigidizada sinclástica, Omar F. Avellaneda L.

- $\quad$ Figura 61 Modelo de estudio de estructura de geometría variable, Yohei Yokosuka y Teruo Matsuzawa

- Figura 62 Modelo de cúpula hecha de dos troncos de cono, Rodrigo Ramos Jiménez

- Figura 63 Concepto para un uso de albergue desplegable de arcos de tijera con una membrana. Las dimensiones son indicadas a la derecha, Lara Alegria Mira, Niels De Temmerman y Ashley P. Thrall

- $\quad$ Figura 64 Prototipo físico, Daniel S-H Lee, Olga Popovic Larsen y Seung-Deog Kim

- Figura 65 Desarrollo orgánico de acuerdo a la geometría generada por formas y membranas modulares para su estandarización e iteración. Morales, 2010.

- Figura 66 Escenario plegable para eventos culturales, Natalia Paola Torres Londoño

- $\quad$ Figura 68 Pods, Hexagonal Glass and Glass Joint HUTCHINSON 3G, AKT

- Figura 69 Digital Weave, Lisa Iwamoto

- Figura 70 "Elementary Equilibrium" or "Simplex", David Georges Emmerich 
- Figura 71 Needle Tower II en el Kröller-Müller Museum en Holanda, Kenneth Snelson (1969)

- Figura 72 Buckminister Fuller sosteniendo una esfera geodésica tensegrítica

- Figura 73 T-Octahedron Dome (vista lateral), Burkhardt

- Figura 74 Carbon Tower, Testa

- Figura 75 Estadio Madrid Arena, Estudio Cano Lasso,

- Estructura de Cubierta diseñada por Julio Martínez Calzón

- Figura 76 Banco DZ, Pariser Platz, Berlín, Frank O Gehry

- Figura 77 Condiciones de los límites del puente de tensegridad, Landolf RhodeBarbarigos, Nicolas Veuve, Nizar Bel Hadj Ali, René Motro e lan F. C.

- Figura 78 Clasificación pares cinématicos, Nieto (1978)

- Figura 79 Clasificación de pares cinématicos según grados de libertad, Nieto (1978)

- Figura 80 Clasificación de los nudos de las estructuras transformables, Rodríguez (2005)

- Figura 81 Nudo cúpula geodésica "Building construction" (Fuller, 1951)

- Figura 82 Flying Seedpot (Fuller, 1953)

- Figura 83 Nudo de patente ES-0266801_A1, Emilio Pérez Piñero (1961)

- Figura 84 Nudo de patente US3325958, Albert Moore (1967)

- Figura 85 Nudos de barras deslizantes, patente US4026313, Zeigler (1977)

- Figura 86 Nudo de patente US4473986A, Zeigler (1984)

- Figura 87 Nudo de patente US 6591849 B1, Swetish y Baumann (2003)

- Figura 88 Nudo diseñado y construido por la Universidad de Semyung

- Figura 89 Nudo de maqueta para modelo de prueba

- Figura 90 Articulación esférica multiunión, Yohei Yokosuka y Teruo Matsuzawa

- Figura 91, generación de patrón 2D a partir de patrón unidad, elaboración propia

- Figura 92, generación de patrón 3D a partir de patrón unidad, elaboración propia

- Figura 93, generación de patrón 3D a partir de patrón unidad, elaboración propia

- Figura 94 Estructura reentrante hexagonal $b \leq 1 / 2 \mathrm{~B}$, elaboración propia

- Figura 95 Estructura reentrante hexagonal $b>1 / 2 \mathrm{~B}$, elaboración propia

- Figura 96 Estructura reentrante hexagonal, elaboración propia

- Figura 97 Primera combinación de estructura reentrante hexagonal, elaboración propia: a) vista 3D, b) planta, c) alzado, d) perfil, e) desarrollo desplegable auxético.

- Figura 98 Segunda combinación de estructura reentrante hexagonal, elaboración propia: a) vista 3D, b) planta, c) alzado, d) perfil, e) desarrollo desplegable auxético. 
- Figura 99 Tercera combinación de estructura reentrante hexagonal, elaboración propia: a) vista $3 D$, b) planta, c) alzado, d) perfil, e) desarrollo desplegable auxético.

- Figura 100 Desarrollo desplegable auxético de estructurra reentrante hexagonal torre, elaboración propia

- Figura 101 Unidad de estructura reentrante estrellada de tres puntas, elaboración propia

- Figura 102 Unidad de estructura reentrante estrellada de cuatro puntas, elaboración propia

- Figura 103 Unidad de estructura reentrante estrellada de seis puntas, elaboración propia

- Figura 104 Factores de crecimiento de estructuras reentrantes estrelladas, elaboración propia

- Figura 105 Conjunto de estructura reentrante estrellada de tres puntas, elaboración propia

- Figura 106 Conjunto de estructura reentrante estrellada de cuatro puntas, elaboración propia

- Figura 107 Conjunto de estructura reentrante estrellada de seis puntas, elaboración propia

- Figura 108 Superposición de estructuras reentrantes estrelladas de tres, cuatro y seis puntas, elaboración propia

- Figura 109 Estructura reentrante estrellada de 6 puntas 3D, elaboración propia: a) vista 3D, b) planta, c) alzado, d) perfil, e) desarrollo desplegable auxético.

- Figura 110 Estructura reentrante estrellada de 6 puntas tipo torre: desarrollo desplegable auxético. Elaboración propia

- Figura 111 Comportamientos geométricos de estructuras reentrantes triangulares unitarias en función de la longitud de sus barras, elaboración propia

- Figura 112 Comportamientos geométricos de estructuras reentrantes triangulares unitarias en función de la longitud de sus barras, elaboración propia

- Figura 113 Estructura reentrante triangular 3D, elaboración propia: a) vista 3D, b) planta, c) alzado, d) vista oblicua, e) desarrollo desplegable auxético.

- Figura 114 Estructura reentrante triangular torre, elaboración propia: a) vista 3D, b) planta, c) alzado, d) vista oblicua, e) desarrollo desplegable auxético.

- Figura 115 Desarrollo desplegable de estructura reentrante cuadrangular unidad, elaboración propia

- Figura 117 Estructura reentrante cuadrangular 3d, elaboración propia: a) vista 3D, b) planta, c) alzado, d) vista oblicua, e) desarrollo desplegable auxético. 
- Figura 118 Estructura reentrante cuadrangular torre, elaboración propia: a) vista 3D, b) planta, c) alzado, d) vista oblicua, e) desarrollo desplegable auxético.

- Figura 119 Desarrollo desplegable de estructura reentrante hexagonal de panal de abeja, elaboración propia

- Figura 120 Desarrollo desplegable de estructura reentrante de panal de abeja 2D, elaboración propia

- Figura 121 Desarrollo desplegable de estructura reentrante de panal de abeja 3D, elaboración propia

- Figura 122 Estructura reentrante de panal de abeja tipo torre, elaboración propia: a) vista 3D, b) planta, c) alzado, d) perfil, e) desarrollo desplegable auxético.

- Figura 123 Desarrollo desplegable de estructura reentrante tetraédrica individual, elaboración propia

- Figura 124 Desarrollo desplegable de estructura reentrante tetraédrica 2d, elaboración propia

- Figura 125 Desarrollo desplegable de estructura reentrante tetraédrica 3d, elaboración propia

- Figura 126 Desarrollo desplegable de estructura reentrante tetraédrica torre, elaboración propia

- Figura 127 Desarrollo desplegable de estructura reentrante idealized hexatruss individual, elaboración propia

- Figura 128 Desarrollo desplegable de estructura reentrante idealized hexatruss 2d, elaboración propia

- Figura 129 Desarrollo desplegable de estructura reentrante idealized hexatruss 3d, elaboración propia

- Figura 130 Desarrollo desplegable de estructura reentrante idealized hexatruss torre, elaboración propia

- Figura 131 Desarrollo desplegable de estructura reentrante tetracaidecaedro individual, elaboración propia

- Figura 132 Desarrollo desplegable de estructura reentrante tetracaidecaedro 2d, elaboración propia

- Figura 133 Estructura reentrante tetracaidecaedro 3d, elaboración propia: a) vista 3D, b) planta, c) alzado, d) perfil, e) desarrollo desplegable auxético.

- Figura 134 Desarrollo desplegable de estructura reentrante tetracaidecaedro torre, elaboración propia 
- Figura 135 Desarrollo desplegable de estructura reentrante de mallas cuadradas individual, elaboración propia

- Figura 136 Desarrollo desplegable de estructura de malla cuadrada en forma de esvástica, elaboración propia

- Figura 137 Estructura reentrante de mallas cuadradas 3d, elaboración propia: a) vista 3D, b) planta, c) alzado, d) perfil, e) desarrollo desplegable auxético.

- Figura 138 Estructura de malla cuadrada en forma de esvástica tipo torre, elaboración propia

- Figura 139 Desarrollo desplegable de estructura reentrante de mallas romboidales individual, elaboración propia

- Figura 140 Desarrollo desplegable de estructura de malla romboidal en forma de esvástica, elaboración propia

- Figura 141 Estructura reentrante de mallas romboidales 3d, elaboración propia: a) vista 3D, b) planta, c) alzado, d) perfil, e) desarrollo desplegable auxético.

- Figura 142 Estructura reentrante de mallas romboidales tipo torre, elaboración propia

- Figura 143 Desarrollo desplegable de estructura quiral triangular individual, elaboración propia

- Figura 144 Desarrollo desplegable de estructura quiral triangular 2d, elaboración propia

- Figura 145 Estructura quiral triangular 3D, elaboración propia

- Figura 146 Estructura quiral triangular tipo torre, elaboración propia

- Figura 147 Desarrollo desplegable de estructura quiral cuadrada individual, elaboración propia

- Figura 148 Desarrollo desplegable de estructura quiral cuadrada 2d, elaboración propia

- $\quad$ Figura 149 Estructura quiral cuadrangular 3d, elaboración propia

- Figura 150 Estructura quiral cuadrangular tipo torre, elaboración propia

- Figura 151 Desarrollo desplegable de estructura quiral rectangular individual, elaboración propia

- Figura 152 Desarrollo desplegable de estructura quiral rectangular simétrica 2d, elaboración propia

- $\quad$ Figura 153 Estructura quiral rectangular simétrica 3d, elaboración propia

- Figura 154 Estructura quiral rectangular simétrica tipo torre, elaboración propia

- Figura 155 Desarrollo desplegable de estructura quiral hexagonal individual, elaboración propia

- Figura 156 Desarrollo desplegable de estructura quiral hexagonal 2d, elaboración propia

- $\quad$ Figura 157 Estructura quiral hexagonal 3d, elaboración propia 
- $\quad$ Figura 158 Estructura quiral hexagonal tipo torre, elaboración propia

- Figura 159 Desarrollo desplegable de estructura quiral circular individual, elaboración propia

- Figura 160 Desarrollo desplegable de estructura quiral circular 2D, elaboración propia

- Figura 161 Desarrollo desplegable de estructura quiral circular 3D, elaboración propia

- Figura 163 Desarrollo desplegable de unidad rotatoria tetraédrica individual, elaboración propia

- Figura 164 Desarrollo desplegable de unidad rotatoria tetraédrica 2d, elaboración propia

- Figura 165 Unidad rotatoria tetraédrica 3D, elaboración propia

- $\quad$ Figura 166 Unidad rotatoria tetraédrica tipo torre, elaboración propia

- Figura 167 Desarrollo desplegable de unidad rotatoria triangular individual, elaboración propia

- Figura 168 Desarrollo desplegable de unidad rotatoria triangular 2d, elaboración propia

- Figura 169 Unidad rotatoria triangular 3D, elaboración propia

- Figura 170 Unidad rotatoria triangular tipo torre, elaboración propia

- Figura 171 Desarrollo desplegable de unidad rotatoria cuadrada individual, elaboración propia

- Figura 172 Desarrollo desplegable de unidad rotatoria cuadrada 2d, elaboración propia

- Figura 173 Desarrollo desplegable de unidad rotatoria cuadrada 3d, elaboración propia

- Figura 174 Unidad rotatoria cuadrangular tipo torre, elaboración propia

- Figura 175 Desarrollo desplegable de unidad rotatoria rectangular individual, elaboración propia

- Figura 176 Desarrollo desplegable de unidad rotatoria rectangular 2d, elaboración propia

- $\quad$ Figura 177 Unidad rotatoria rectangular 3d, elaboración propia

- Figura 178 Unidad rotatoria rectangular tipo torre, elaboración propia

- Figura 179 Desarrollo desplegable de unidad rotatoria de rectángulos diferentes individual, elaboración propia

- Figura 180 Desarrollo desplegable de unidad rotatoria de rectángulos diferentes 2d, elaboración propia

- $\quad$ Figura 181 Unidad rotatoria de rectángulos diferentes 3d, elaboración propia

- Figura 182 Unidad rotatoria de rectángulos diferentes tipo torre, elaboración propia

- Figura 183 Desarrollo desplegable de polímero microporoso cuadrado individual, elaboración propia 
- Figura 184 Desarrollo desplegable de polímero microporoso cuadrado 2d, elaboración propia

- Figura 185 Desarrollo desplegable de polímero microporoso cuadrado 3d, elaboración propia

- Figura 186 Polímero microporoso cuadrado tipo torre, elaboración propia

- Figura 187 Desarrollo desplegable de polímero microporoso rectangular individual, elaboración propia

- Figura 188 Desarrollo desplegable de polígono microporoso rectangular 2d, elaboración propia

- Figura 189 Desarrollo desplegable de polímero microporoso rectangular 3d, elaboración propia

- Figura 190 Polímero microporoso rectangular tipo torre, elaboración propia

- Figura 191Estructuras reentrantes hexagonales de nudos rígidos, elaboración propia

- Figura 192 Estructuras reentrantes hexagonales de nudos articulados, elaboración propia

- Figura 193 Estructura auxética reentrante hexagonal unitaria, elaboración propia. Izquierda: estructura sin carga. Derecha: estructura con carga

- Figura 194 Características de perfil metálico, SAP2000

- Figura 195 Estructura auxética reentrante hexagonal unitaria con cargas con apertura de $63^{\circ}$, elaboración propia

- Figura 196 Estructura auxética reentrante hexagonal unitaria con cargas con apertura de $90^{\circ}$, elaboración propia

- $\quad$ Figure 197. Six articulated bars with tendons structure

- $\quad$ Figure 198. Table of metallic round hollow profiles

- $\quad$ Figure 199. Buckling curves, CTE's DBSE-A

- Figure 200. Table of steel cables

- Figure 201. Considered loads and structure apertures for these loads

- $\quad$ Figure 202. Considered loads and structure apertures for these loads

- $\quad$ Figure 203. Considered loads and structure apertures for these loads

- $\quad$ Figure 204. Considered loads and structure apertures for these loads

- Figura 205 Características de secciones cuadradas de hormigón, SAP2000

- Figura 206 Características de tendones, SAP2000

- Figura 207 Pórtico no auxético con tendón continuo en barras vertical y horizontal superior, elaboración propia

- Figura 208 Pórtico auxético sin tendón con ángulo de $75,96^{\circ}$, elaboración propia 
- Figura 209 Pórtico auxético con tendón en barras verticales con ángulo de $75,96^{\circ}$, elaboración propia

- Figura 210 Pórtico auxético con tendón continuo en barras vertical y horizontal superior con ángulo de $75,96^{\circ}$, elaboración propia

- Figura 211 Pórtico auxético con tendón continuo en todas sus barras con ángulo de $75,96^{\circ}$, elaboración propia

- Figura 212 Pórtico auxético con tendón en barras verticales con ángulo de $63,43^{\circ}$, elaboración propia

- Figura 213 Pórtico auxético con tendón continuo en barras vertical y horizontal superior con ángulo de $63,43^{\circ}$, elaboración propia

- Figura 214 Pórtico auxético con tendón en barras verticales con ángulo de $53,13^{\circ}$, elaboración propia

- Figura 215 Pórtico auxético con tendón continuo en barras vertical y horizontal superior con ángulo de $53,13^{\circ}$, elaboración propia

- Figura 216 Pórtico auxético con tendón en barras verticales con ángulo de $45^{\circ}$, elaboración propia

- $\quad$ Figure 217. Left: Traditional structure. Right: Auxetic structure.

- Figura 218 Ejemplos de nudo plano desplegable para estructuras en dos dimensiones

- Figura 219 Muestra una vista de un nudo para estructuras reticulares móviles que comprende un núcleo, con forma de esfera, y un conjunto de barras que salen de orificios del núcleo, en una distribución radial.

- Figura 220 Muestra una vista de un nudo para estructuras reticulares móviles cuyo casquete exterior está seccionado, que comprende un núcleo central con forma de esfera, y un conjunto de barras que salen de orificios del núcleo, en una distribución radial.

- Figura 221 Muestra una vista en explosión correspondiente al nudo representado en la figura 219.

- Figura 222 Muestra una vista parcialmente seccionada del nudo montado.

\subsection{Lista de gráficas}

- Gráfica 01 Factores de crecimiento de estructuras auxéticas individuales generados por división FC (:), elaboración propia 
- Gráfica 02 Factores de crecimiento de estructuras auxéticas individuales generados por resta FC (-), elaboración propia

- Gráfica 03 Factores de crecimiento de estructuras auxéticas 2D generados por división FC (:), elaboración propia

- Gráfica 04 Factores de crecimiento de estructuras auxéticas 2D generados por resta FC (-), elaboración propia

- Gráfica 05 Factores de crecimiento de estructuras auxéticas 3D generados por división FC (:), elaboración propia

- Gráfica 06 Factores de crecimiento de estructuras auxéticas 3D generados por resta FC (-), elaboración propia

- Gráfica 07 Factores crecimiento de estructuras auxéticas torre generados por división FC (:), elaboración propia

- Gráfica 08 Factores crecimiento de estructuras auxéticas torre generados por resta FC (-), elaboración propia

- Gráfica 09 Desplazamientos horizontales (KN, eje y) en nudos estructura auxética reentrante hexagonal unitaria sin carga en función de la apertura (grados ${ }^{\circ}$, eje x), elaboración propia

- Gráfica 10 Desplazamientos horizontales (KN, eje y) en nudos estructura auxética reentrante hexagonal unitaria con carga en función de la apertura (grados ${ }^{\circ}$, eje x), elaboración propia

- Gráfica 11 Gráfica comparativa de desplazamientos verticales (KN, eje y) para la estructura reentrante hexagonal metálica rígida para diversas aperturas sin carga (grados ${ }^{\circ}$, eje $\mathrm{x}$ ), elaboración propia

- Gráfica 12 Gráfica comparativa de desplazamientos verticales (KN, eje y) para la estructura reentrante hexagonal metálica rígida para diversas aperturas con carga (grados ${ }^{\circ}$, eje $\mathrm{x}$ ), elaboración propia

- Gráfica 13 Gráfica comparativa de rotaciones (rad, eje y) en articulaciones para la estructura reentrante hexagonal metálica rígida para diversas aperturas sin carga (grados ${ }^{\circ}$, eje $\mathrm{x}$ ), elaboración propia

- Gráfica 14 Gráfica comparativa de rotaciones (rad, eje y) en articulaciones para la estructura reentrante hexagonal metálica rígida para diversas aperturas con carga (grados ${ }^{\circ}$, eje $\mathrm{x}$ ), elaboración propia

- Gráfica 15 Gráfica comparativa de reacciones en apoyos (KN, eje y) para la estructura reentrante hexagonal metálica rígida para diversas aperturas sin carga (grados ${ }^{\circ}$, eje $\mathrm{x}$ ), elaboración propia 
- Gráfica 16 Gráfica 15 Gráfica comparativa de reacciones en apoyos (KN, eje y) para la estructura reentrante hexagonal metálica rígida para diversas aperturas con carga (grados ${ }^{\circ}$, eje $\mathrm{x}$ ), elaboración propia

- Gráfica 17 Comparación de esfuerzos axiles mínimos (KN, eje y) en barras para la estructura reentrante hexagonal metálica rígida para diversas aperturas sin carga (grados ${ }^{\circ}$, eje $\mathrm{x}$ ), elaboración propia

- Gráfica 18 Gráfica comparativa de esfuerzos axiles máximos (KN, eje y) en barras para la estructura reentrante hexagonal metálica rígida para diversas aperturas sin carga (grados ${ }^{\circ}$, eje $\mathrm{x}$ ), elaboración propia

- Gráfica 19 Gráfica comparativa de esfuerzos axiles mínimos (KN, eje y) en barras para la estructura reentrante hexagonal metálica rígida para diversas aperturas con carga (grados ${ }^{\circ}$, eje $\mathrm{x}$ ), elaboración propia

- Gráfica 20 Gráfica comparativa de esfuerzos axiles máximos (KN, eje y) en barras para la estructura reentrante hexagonal metálica rígida para diversas aperturas con carga (grados ${ }^{\circ}$, eje $\mathrm{x}$ ), elaboración propia

- Gráfica 21 Gráfica comparativa de esfuerzos cortantes mínimos (KN, eje y) en barras para la estructura reentrante hexagonal metálica rígida para diversas aperturas sin carga (grados ${ }^{\circ}$, eje $\mathrm{x}$ ), elaboración propia

- Gráfica 22 Gráfica comparativa de esfuerzos cortantes máximos (KN, eje y) en barras para la estructura reentrante hexagonal metálica rígida para diversas aperturas sin carga (grados ${ }^{\circ}$, eje $\mathrm{x}$ ), elaboración propia

- Gráfica 23 Gráfica comparativa de esfuerzos cortantes mínimos (KN, eje y) en barras para la estructura reentrante hexagonal metálica rígida para diversas aperturas con carga (grados ${ }^{\circ}$, eje $\mathrm{x}$ ), elaboración propia

- Gráfica 24 Gráfica comparativa de esfuerzos cortantes máximos (KN, eje y) en barras para la estructura reentrante hexagonal metálica rígida para diversas aperturas con carga (grados ${ }^{\circ}$, eje $\mathrm{x}$ ), elaboración propia

- Gráfica 25 Gráfica comparativa de momentos mínimos (KN•m, eje y) en barras para la estructura reentrante hexagonal metálica rígida para diversas aperturas sin carga (grados ${ }^{\circ}$, eje $\mathrm{x}$ ), elaboración propia

- Gráfica 26 Gráfica comparativa de momentos máximos $(\mathrm{KN} \bullet \mathrm{m}$, eje y) en barras para la estructura reentrante hexagonal metálica rígida para diversas aperturas sin carga (grados ${ }^{\circ}$, eje x), elaboración propia 
- Gráfica 27 Gráfica comparativa de momentos mínimos (KN•m, eje y) en barras para la estructura reentrante hexagonal metálica rígida para diversas aperturas con carga (grados ${ }^{\circ}$, eje $\mathrm{x}$ ), elaboración propia

- Gráfica 28 Gráfica comparativa de momentos máximos (KN•m, eje y) en barras para la estructura reentrante hexagonal metálica rígida para diversas aperturas con carga (grados ${ }^{\circ}$, eje $\mathrm{x}$ ), elaboración propia

- Gráfica 29 Comparación de desplazamientos horizontales (m, eje y) en el nudo 1 para la estructura reentrante hexagonal metálica rígida para una apertura de $63^{\circ}$ y diversas combinaciones de carga ( $\mathrm{KN}$, eje x y leyenda), elaboración propia

- Gráfica 30 Comparación de desplazamientos horizontales (m, eje y) en el nudo 2 para la estructura reentrante hexagonal metálica rígida para una apertura de $63^{\circ}$ y diversas combinaciones de carga ( $\mathrm{KN}$, eje $\mathrm{x}$ y leyenda), elaboración propia

- Gráfica 31 Comparación de desplazamientos horizontales (m, eje y) en el nudo 3 para la estructura reentrante hexagonal metálica rígida para una apertura de $63^{\circ}$ y diversas combinaciones de carga ( $\mathrm{KN}$, eje x y leyenda), elaboración propia

- Gráfica 32 Comparación de desplazamientos horizontales (m, eje y) en el nudo 4 para la estructura reentrante hexagonal metálica rígida para una apertura de $63^{\circ}$ y diversas combinaciones de carga (KN, eje x y leyenda), elaboración propia

- Gráfica 33 Comparación de desplazamientos horizontales (m, eje y) en el nudo 5 para la estructura reentrante hexagonal metálica rígida para una apertura de $63^{\circ}$ y diversas combinaciones de carga ( $\mathrm{KN}$, eje $\mathrm{x}$ y leyenda), elaboración propia

- Gráfica 34 Comparación de desplazamientos horizontales (m, eje y) en el nudo 6 para la estructura reentrante hexagonal metálica rígida para una apertura de $63^{\circ}$ y diversas combinaciones de carga ( $\mathrm{KN}$, eje $x$ y leyenda), elaboración propia

- Gráfica 35 Comparación de desplazamientos verticales ( $m$, eje y) en el nudo 1 para la estructura reentrante hexagonal metálica rígida para una apertura de $63^{\circ}$ y diversas combinaciones de carga ( $\mathrm{KN}$, eje x y leyenda), elaboración propia

- Gráfica 36 Comparación de desplazamientos verticales ( $m$, eje y) en el nudo 2 para la estructura reentrante hexagonal metálica rígida para una apertura de $63^{\circ}$ y diversas combinaciones de carga ( $\mathrm{KN}$, eje $\mathrm{x}$ y leyenda), elaboración propia

- Gráfica 37 Comparación de desplazamientos verticales ( $m$, eje y) en el nudo 3 para la estructura reentrante hexagonal metálica rígida para una apertura de $63^{\circ}$ y diversas combinaciones de carga ( $\mathrm{KN}$, eje x y leyenda), elaboración propia 
- Gráfica 38 Comparación de desplazamientos verticales (m, eje y) en el nudo 4 para la estructura reentrante hexagonal metálica rígida para una apertura de $63^{\circ}$ y diversas combinaciones de carga ( $\mathrm{KN}$, eje $\mathrm{x}$ y leyenda), elaboración propia

- Gráfica 39 Comparación de desplazamientos verticales (m, eje y) en el nudo 5 para la estructura reentrante hexagonal metálica rígida para una apertura de $63^{\circ}$ y diversas combinaciones de carga ( $\mathrm{KN}$, eje $\mathrm{x}$ y leyenda), elaboración propia

- Gráfica 40 Comparación de desplazamientos verticales (m, eje y) en el nudo 6 para la estructura reentrante hexagonal metálica rígida para una apertura de $63^{\circ}$ y diversas combinaciones de carga ( $\mathrm{KN}$, eje $x$ y leyenda), elaboración propia

- Gráfica 41 Comparación de rotaciones en articulaciones (rad, eje y) en el nudo 1 para la estructura reentrante hexagonal metálica rígida para una apertura de $63^{\circ}$ y diversas combinaciones de carga ( $\mathrm{KN}$, eje $\mathrm{x}$ y leyenda), elaboración propia

- Gráfica 42 Comparación de rotaciones en articulaciones (rad, eje y) en el nudo 2 para la estructura reentrante hexagonal metálica rígida para una apertura de $63^{\circ}$ y diversas combinaciones de carga ( $\mathrm{KN}$, eje x y leyenda), elaboración propia

- Gráfica 43 Comparación de rotaciones en articulaciones (rad, eje y) en el nudo 3 para la estructura reentrante hexagonal metálica rígida para una apertura de $63^{\circ}$ y diversas combinaciones de carga ( $\mathrm{KN}$, eje $\mathrm{x}$ y leyenda), elaboración propia

- Gráfica 44 Comparación de rotaciones en articulaciones (rad, eje y) en el nudo 4 para la estructura reentrante hexagonal metálica rígida para una apertura de $63^{\circ}$ y diversas combinaciones de carga ( $\mathrm{KN}$, eje x y leyenda), elaboración propia

- Gráfica 45 Comparación de rotaciones en articulaciones (rad, eje y) en el nudo 5 para la estructura reentrante hexagonal metálica rígida para una apertura de $63^{\circ}$ y diversas combinaciones de carga ( $\mathrm{KN}$, eje x y leyenda), elaboración propia

- Gráfica 46 Comparación de rotaciones en articulaciones (rad, eje y) en el nudo 6 para la estructura reentrante hexagonal metálica rígida para una apertura de $63^{\circ}$ y diversas combinaciones de carga ( $\mathrm{KN}$, eje $\mathrm{x}$ y leyenda), elaboración propia

- Gráfica 47 Comparación de reacciones verticales en apoyos (KN, eje y) en el nudo 3 para la estructura reentrante hexagonal metálica rígida para una apertura de $63^{\circ} \mathrm{y}$ diversas combinaciones de carga ( $\mathrm{KN}$, eje x y leyenda), elaboración propia

- Gráfica 48 Comparación de reacciones horizontales en apoyos (KN, eje y) en el nudo 3 para la estructura reentrante hexagonal metálica rígida para una apertura de $63^{\circ}$ y diversas combinaciones de carga ( $\mathrm{KN}$, eje $\mathrm{x}$ y leyenda), elaboración propia 
- Gráfica 49 Comparación de reacciones verticales en apoyos (KN, eje y) en el nudo 6 para la estructura reentrante hexagonal metálica rígida para una apertura de $63^{\circ} \mathrm{y}$ diversas combinaciones de carga (KN, eje $x$ y leyenda), elaboración propia

- Gráfica 50 Comparación de esfuerzos axiles (KN, eje y) en la barra a para la estructura reentrante hexagonal metálica rígida para una apertura de $63^{\circ}$ y diversas combinaciones de carga ( $\mathrm{KN}$, eje $\mathrm{x}$ y leyenda), elaboración propia

- Gráfica 51 Comparación de esfuerzos axiles mínimos (KN, eje y) en la barra b para la estructura reentrante hexagonal metálica rígida para una apertura de $63^{\circ}$ y diversas combinaciones de carga ( $\mathrm{KN}$, eje x y leyenda), elaboración propia

- Gráfica 52 Comparación de esfuerzos axiles máximos (KN, eje y) en la barra b para la estructura reentrante hexagonal metálica rígida para una apertura de $63^{\circ}$ y diversas combinaciones de carga ( $\mathrm{KN}$, eje $\mathrm{x}$ y leyenda), elaboración propia

- Gráfica 53 Comparación de esfuerzos axiles mínimos (KN, eje y) en la barra c para la estructura reentrante hexagonal metálica rígida para una apertura de $63^{\circ}$ y diversas combinaciones de carga ( $\mathrm{KN}$, eje $x$ y leyenda), elaboración propia

- Gráfica 54 Comparación de esfuerzos axiles máximos (KN, eje y) en la barra c para la estructura reentrante hexagonal metálica rígida para una apertura de $63^{\circ}$ y diversas combinaciones de carga (KN, eje x y leyenda), elaboración propia

- Gráfica 55 Comparación de esfuerzos axiles mínimos (KN, eje y) en la barra d para la estructura reentrante hexagonal metálica rígida para una apertura de $63^{\circ}$ y diversas combinaciones de carga ( $\mathrm{KN}$, eje $\mathrm{x}$ y leyenda), elaboración propia

- Gráfica 56 Comparación de esfuerzos axiles máximos (KN, eje y) en la barra d para la estructura reentrante hexagonal metálica rígida para una apertura de $63^{\circ}$ y diversas combinaciones de carga ( $\mathrm{KN}$, eje $x$ y leyenda), elaboración propia

- Gráfica 57 Comparación de esfuerzos axiles mínimos (KN, eje y) en la barra e para la estructura reentrante hexagonal metálica rígida para una apertura de $63^{\circ}$ y diversas combinaciones de carga ( $\mathrm{KN}$, eje x y leyenda), elaboración propia

- Gráfica 58 Comparación de esfuerzos axiles máximos (KN, eje y) en la barra e para la estructura reentrante hexagonal metálica rígida para una apertura de $63^{\circ}$ y diversas combinaciones de carga ( $\mathrm{KN}$, eje x y leyenda), elaboración propia

- Gráfica 59 Comparación de esfuerzos axiles (KN, eje y) en la barra f para la estructura reentrante hexagonal metálica rígida para una apertura de $63^{\circ}$ y diversas combinaciones de carga ( $\mathrm{KN}$, eje $\mathrm{x}$ y leyenda), elaboración propia 
- Gráfica 60 Comparación de esfuerzos cortantes mínimos (KN, eje y) en la barra a para la estructura reentrante hexagonal metálica rígida para una apertura de $63^{\circ}$ y diversas combinaciones de carga ( $\mathrm{KN}$, eje $\mathrm{x}$ y leyenda), elaboración propia

- Gráfica 61 Comparación de esfuerzos cortantes máximos (KN, eje y) en la barra a para la estructura reentrante hexagonal metálica rígida para una apertura de $63^{\circ}$ y diversas combinaciones de carga ( $\mathrm{KN}$, eje $\mathrm{x}$ y leyenda), elaboración propia

- Gráfica 62 Comparación de esfuerzos cortantes mínimos (KN, eje y) en la barra b para la estructura reentrante hexagonal metálica rígida para una apertura de $63^{\circ}$ y diversas combinaciones de carga ( $\mathrm{KN}$, eje $x$ y leyenda), elaboración propia

- Gráfica 63 Comparación de esfuerzos cortantes máximos (KN, eje y) en la barra a para la estructura reentrante hexagonal metálica rígida para una apertura de $63^{\circ} \mathrm{y}$ diversas combinaciones de carga ( $\mathrm{KN}$, eje $\mathrm{x}$ y leyenda), elaboración propia

- Gráfica 64 Comparación de esfuerzos cortantes mínimos (KN, eje y) en la barra c para la estructura reentrante hexagonal metálica rígida para una apertura de $63^{\circ}$ y diversas combinaciones de carga ( $\mathrm{KN}$, eje x y leyenda), elaboración propia

- Gráfica 65 Comparación de esfuerzos cortantes máximos (KN, eje y) en la barra c para la estructura reentrante hexagonal metálica rígida para una apertura de $63^{\circ}$ y diversas combinaciones de carga (KN, eje x y leyenda), elaboración propia

- Gráfica 66 Comparación de esfuerzos cortantes mínimos (KN, eje y) en la barra d para la estructura reentrante hexagonal metálica rígida para una apertura de $63^{\circ}$ y diversas combinaciones de carga ( $\mathrm{KN}$, eje x y leyenda), elaboración propia

- Gráfica 67 Comparación de esfuerzos cortantes máximos (KN, eje y) en la barra d para la estructura reentrante hexagonal metálica rígida para una apertura de $63^{\circ}$ y diversas combinaciones de carga ( $\mathrm{KN}$, eje x y leyenda), elaboración propia

- Gráfica 68 Comparación de esfuerzos cortantes mínimos (KN, eje y) en la barra e para la estructura reentrante hexagonal metálica rígida para una apertura de $63^{\circ}$ y diversas combinaciones de carga ( $\mathrm{KN}$, eje $\mathrm{x}$ y leyenda), elaboración propia

- Gráfica 69 Comparación de esfuerzos cortantes máximos (KN, eje y) en la barra e para la estructura reentrante hexagonal metálica rígida para una apertura de $63^{\circ}$ y diversas combinaciones de carga ( $\mathrm{KN}$, eje x y leyenda), elaboración propia

- Gráfica 70 Comparación de esfuerzos cortantes mínimos (KN, eje y) en la barra f para la estructura reentrante hexagonal metálica rígida para una apertura de $63^{\circ}$ y diversas combinaciones de carga ( $\mathrm{KN}$, eje x y leyenda), elaboración propia 
- Gráfica 71 Comparación de esfuerzos cortantes máximos (KN, eje y) en la barra f para la estructura reentrante hexagonal metálica rígida para una apertura de $63^{\circ} \mathrm{y}$ diversas combinaciones de carga ( $\mathrm{KN}$, eje $\mathrm{x}$ y leyenda), elaboración propia

- Gráfica 72 Comparación de momentos mínimos en la barra a $(\mathrm{KN} \cdot \mathrm{m}$, eje y) de la estructura reentrante hexagonal metálica rígida para una apertura de $63^{\circ}$ y diversas cargas horizontales y verticales ( $\mathrm{KN}$, eje $\mathrm{x}$ y leyenda), elaboración propia

- Gráfica 73 Comparación de momentos máximos en la barra a $(\mathrm{KN} \bullet \mathrm{m}$, eje y) de la estructura reentrante hexagonal metálica rígida para una apertura de $63^{\circ}$ y diversas cargas horizontales y verticales ( $\mathrm{KN}$, eje $\mathrm{x}$ y leyenda), elaboración propia

- Gráfica 74 Comparación de momentos mínimos en la barra b $(K N \cdot m$, eje y) de la estructura reentrante hexagonal metálica rígida para una apertura de $63^{\circ}$ y diversas cargas horizontales y verticales ( $\mathrm{KN}$, eje $\mathrm{x}$ y leyenda), elaboración propia

- Gráfica 75 Comparación de momentos máximos en la barra b $(\mathrm{KN} \bullet \mathrm{m}$, eje y) de la estructura reentrante hexagonal metálica rígida para una apertura de $63^{\circ}$ y diversas cargas horizontales y verticales ( $\mathrm{KN}$, eje $\mathrm{x}$ y leyenda), elaboración propia

- Gráfica 76 Comparación de momentos mínimos en la barra c $(\mathrm{KN} \bullet \mathrm{m}$, eje y) de la estructura reentrante hexagonal metálica rígida para una apertura de $63^{\circ}$ y diversas cargas horizontales y verticales ( $\mathrm{KN}$, eje $\mathrm{x}$ y leyenda), elaboración propia

- Gráfica 77 Comparación de momentos máximos en la barra c $(\mathrm{KN} \cdot \mathrm{m}$, eje y) de la estructura reentrante hexagonal metálica rígida para una apertura de $63^{\circ}$ y diversas cargas horizontales y verticales ( $\mathrm{KN}$, eje $\mathrm{x}$ y leyenda), elaboración propia

- Gráfica 78 Comparación de momentos mínimos en la barra d (KN•m, eje y) de la estructura reentrante hexagonal metálica rígida para una apertura de $63^{\circ}$ y diversas cargas horizontales y verticales ( $\mathrm{KN}$, eje $\mathrm{x}$ y leyenda), elaboración propia

- Gráfica 79 Comparación de momentos máximos en la barra d $(\mathrm{KN} \bullet \mathrm{m}$, eje y) de la estructura reentrante hexagonal metálica rígida para una apertura de $63^{\circ}$ y diversas cargas horizontales y verticales ( $\mathrm{KN}$, eje $\mathrm{x}$ y leyenda), elaboración propia

- Gráfica 80 Comparación de momentos mínimos en la barra e $(\mathrm{KN} \cdot \mathrm{m}$, eje y) de la estructura reentrante hexagonal metálica rígida para una apertura de $63^{\circ}$ y diversas cargas horizontales y verticales ( $\mathrm{KN}$, eje $\mathrm{x}$ y leyenda), elaboración propia

- Gráfica 81 Comparación de momentos máximos en la barra e $(\mathrm{KN} \bullet \mathrm{m}$, eje y) de la estructura reentrante hexagonal metálica rígida para una apertura de $63^{\circ}$ y diversas cargas horizontales y verticales ( $\mathrm{KN}$, eje $\mathrm{x}$ y leyenda), elaboración propia 
- Gráfica 82 Comparación de momentos mínimos en la barra f $(\mathrm{KN} \cdot \mathrm{m}$, eje y) de la estructura reentrante hexagonal metálica rígida para una apertura de $63^{\circ}$ y diversas cargas horizontales y verticales ( $\mathrm{KN}$, eje $\mathrm{x}$ y leyenda), elaboración propia

- Gráfica 83 Comparación de momentos máximos en la barra $\mathrm{f}(\mathrm{KN} \bullet \mathrm{m}$, eje y) de la estructura reentrante hexagonal metálica rígida para una apertura de $63^{\circ}$ y diversas cargas horizontales y verticales ( $\mathrm{KN}$, eje $\mathrm{x}$ y leyenda), elaboración propia

- Gráfica 84 Comparación de desplazamientos horizontales (m, eje y) en el nudo 1 de estructura tradicional generada a partir de estructura reentrante hexagonal metálica rígida para una apertura de $90^{\circ}$ y diversas cargas horizontales y verticales $(\mathrm{KN}$, eje $\mathrm{x} y$ leyenda), elaboración propia

- Gráfica 85 Comparación de desplazamientos horizontales (m, eje y) en el nudo 2 de estructura tradicional generada a partir de estructura reentrante hexagonal metálica rígida para una apertura de $90^{\circ}$ y diversas cargas horizontales y verticales $(\mathrm{KN}$, eje $\mathrm{x} y$ leyenda), elaboración propia

- Gráfica 86 Comparación de desplazamientos horizontales (m, eje y) en el nudo 3 de estructura tradicional generada a partir de estructura reentrante hexagonal metálica rígida para una apertura de $90^{\circ}$ y diversas cargas horizontales y verticales $(\mathrm{KN}$, eje $\mathrm{x} y$ leyenda), elaboración propia

- Gráfica 87 Comparación de desplazamientos horizontales ( $m$, eje y) en el nudo 4 de estructura tradicional generada a partir de estructura reentrante hexagonal metálica rígida para una apertura de $90^{\circ}$ y diversas cargas horizontales y verticales $(\mathrm{KN}$, eje $\mathrm{x} y$ leyenda), elaboración propia

- Gráfica 88 Comparación de desplazamientos horizontales (m, eje y) en el nudo 5 de estructura tradicional generada a partir de estructura reentrante hexagonal metálica rígida para una apertura de $90^{\circ}$ y diversas cargas horizontales y verticales $(\mathrm{KN}$, eje $\mathrm{x}$ y leyenda), elaboración propia

- Gráfica 89 Comparación de desplazamientos horizontales (m, eje y) en el nudo 6 de estructura tradicional generada a partir de estructura reentrante hexagonal metálica rígida para una apertura de $90^{\circ}$ y diversas cargas horizontales y verticales $(\mathrm{KN}$, eje $\mathrm{x} y$ leyenda), elaboración propia

- Gráfica 90 Comparación de desplazamientos verticales ( $m$, eje y) en el nudo 1 de estructura tradicional generada a partir de estructura reentrante hexagonal metálica rígida para una apertura de $90^{\circ}$ y diversas cargas horizontales y verticales $(\mathrm{KN}$, eje $\mathrm{x}$ y leyenda), elaboración propia 
- Gráfica 91 Comparación de desplazamientos verticales (m, eje y) en el nudo 2 de estructura tradicional generada a partir de estructura reentrante hexagonal metálica rígida para una apertura de $90^{\circ}$ y diversas cargas horizontales y verticales $(\mathrm{KN}$, eje $\mathrm{x} y$ leyenda), elaboración propia

- Gráfica 92 Comparación de desplazamientos verticales ( $m$, eje y) en el nudo 3 de estructura tradicional generada a partir de estructura reentrante hexagonal metálica rígida para una apertura de $90^{\circ}$ y diversas cargas horizontales y verticales $(\mathrm{KN}$, eje $\mathrm{x}$ y leyenda), elaboración propia

- Gráfica 93 Comparación de desplazamientos verticales ( $m$, eje y) en el nudo 4 de estructura tradicional generada a partir de estructura reentrante hexagonal metálica rígida para una apertura de $90^{\circ}$ y diversas cargas horizontales y verticales $(\mathrm{KN}$, eje $\mathrm{x} y$ leyenda), elaboración propia

- Gráfica 94 Comparación de desplazamientos verticales ( $m$, eje y) en el nudo 5 de estructura tradicional generada a partir de estructura reentrante hexagonal metálica rígida para una apertura de $90^{\circ}$ y diversas cargas horizontales y verticales $(\mathrm{KN}$, eje $\mathrm{x}$ y leyenda), elaboración propia

- Gráfica 95 Comparación de desplazamientos verticales ( $m$, eje y) en el nudo 6 de estructura tradicional generada a partir de estructura reentrante hexagonal metálica rígida para una apertura de $90^{\circ}$ y diversas cargas horizontales y verticales $(\mathrm{KN}$, eje $\mathrm{x} y$ leyenda), elaboración propia

- Gráfica 96 Comparación de rotaciones en articulaciones (rad, eje y) en el nudo 1 de estructura tradicional generada a partir de estructura reentrante hexagonal metálica rígida para una apertura de $90^{\circ}$ y diversas cargas horizontales y verticales $(\mathrm{KN}$, eje $x$ y leyenda), elaboración propia

- Gráfica 97 Comparación de rotaciones en articulaciones (rad, eje y) en el nudo 2 de estructura tradicional generada a partir de estructura reentrante hexagonal metálica rígida para una apertura de $90^{\circ}$ y diversas cargas horizontales y verticales ( $\mathrm{KN}$, eje $\mathrm{x} y$ leyenda), elaboración propia

- Gráfica 98 Comparación de rotaciones en articulaciones (rad, eje y) en el nudo 3 de estructura tradicional generada a partir de estructura reentrante hexagonal metálica rígida para una apertura de $90^{\circ}$ y diversas cargas horizontales y verticales $(\mathrm{KN}$, eje $\mathrm{x}$ y leyenda), elaboración propia

- Gráfica 99 Comparación de rotaciones en articulaciones (rad, eje y) en el nudo 4 de estructura tradicional generada a partir de estructura reentrante hexagonal metálica 
rígida para una apertura de $90^{\circ}$ y diversas cargas horizontales y verticales $(\mathrm{KN}$, eje $\mathrm{x}$ y leyenda), elaboración propia

- Gráfica 100 Comparación de rotaciones en articulaciones (rad, eje y) en el nudo 5 de estructura tradicional generada a partir de estructura reentrante hexagonal metálica rígida para una apertura de $90^{\circ}$ y diversas cargas horizontales y verticales ( $\mathrm{KN}$, eje $\mathrm{x}$ y leyenda), elaboración propia

- Gráfica 101 Comparación de rotaciones en articulaciones (rad, eje y) en el nudo 6 de estructura tradicional generada a partir de estructura reentrante hexagonal metálica rígida para una apertura de $90^{\circ}$ y diversas cargas horizontales y verticales $(\mathrm{KN}$, eje $\mathrm{x}$ y leyenda), elaboración propia

- Gráfica 102 Comparación de reacciones verticales en apoyos (KN, eje y) en el nudo 3 de estructura tradicional generada a partir de estructura reentrante hexagonal metálica rígida para una apertura de $90^{\circ}$ y diversas cargas horizontales y verticales $(\mathrm{KN}$, eje $\mathrm{x} y$ leyenda), elaboración propia

- Gráfica 103 Comparación de reacciones horizontales en apoyos (KN, eje y) en el nudo 3 de estructura tradicional generada a partir de estructura reentrante hexagonal metálica rígida para una apertura de $90^{\circ}$ y diversas cargas horizontales y verticales $(\mathrm{KN}$, eje $\mathrm{x} y$ leyenda), elaboración propia

- Gráfica 104 Comparación de reacciones verticales en apoyos (KN, eje y) en el nudo 6 de estructura tradicional generada a partir de estructura reentrante hexagonal metálica rígida para una apertura de $90^{\circ}$ y diversas cargas horizontales y verticales $(\mathrm{KN}$, eje $\mathrm{x}$ y leyenda), elaboración propia

- Gráfica 105 Comparación de esfuerzos axiles (KN, eje y) en la barra a de estructura tradicional generada a partir de estructura reentrante hexagonal metálica rígida para una apertura de $90^{\circ}$ y diversas cargas horizontales y verticales ( $K N$, eje $x$ y leyenda), elaboración propia

- Gráfica 106 Comparación de esfuerzos axiles mínimos (KN, eje y) en la barra b de estructura tradicional generada a partir de estructura reentrante hexagonal metálica rígida para una apertura de $90^{\circ}$ y diversas cargas horizontales y verticales $(\mathrm{KN}$, eje $\mathrm{x} y$ leyenda), elaboración propia

- Gráfica 107 Comparación de esfuerzos axiles máximos (KN, eje y) en la barra b de estructura tradicional generada a partir de estructura reentrante hexagonal metálica rígida para una apertura de $90^{\circ}$ y diversas cargas horizontales y verticales $(\mathrm{KN}$, eje $\mathrm{x}$ y leyenda), elaboración propia 
- Gráfica 108 Comparación de esfuerzos axiles mínimos (KN, eje y) en la barra c de estructura tradicional generada a partir de estructura reentrante hexagonal metálica rígida para una apertura de $90^{\circ}$ y diversas cargas horizontales y verticales $(\mathrm{KN}$, eje $\mathrm{x} y$ leyenda), elaboración propia

- Gráfica 109 Comparación de esfuerzos axiles máximos (KN, eje y) en la barra c de estructura tradicional generada a partir de estructura reentrante hexagonal metálica rígida para una apertura de $90^{\circ}$ y diversas cargas horizontales y verticales ( $\mathrm{KN}$, eje $\mathrm{x}$ y leyenda), elaboración propia

- Gráfica 110 Comparación de esfuerzos axiles mínimos (KN, eje y) en la barra d de estructura tradicional generada a partir de estructura reentrante hexagonal metálica rígida para una apertura de $90^{\circ}$ y diversas cargas horizontales y verticales $(\mathrm{KN}$, eje $\mathrm{x} y$ leyenda), elaboración propia

- Gráfica 111 Comparación de esfuerzos axiles máximos (KN, eje y) en la barra d de estructura tradicional generada a partir de estructura reentrante hexagonal metálica rígida para una apertura de $90^{\circ}$ y diversas cargas horizontales y verticales $(\mathrm{KN}$, eje $\mathrm{x}$ y leyenda), elaboración propia

- Gráfica 112 Comparación de esfuerzos axiles mínimos (KN, eje y) en la barra e de estructura tradicional generada a partir de estructura reentrante hexagonal metálica rígida para una apertura de $90^{\circ}$ y diversas cargas horizontales y verticales ( $\mathrm{KN}$, eje $\mathrm{x}$ y leyenda), elaboración propia

- Gráfica 113 Comparación de esfuerzos axiles máximos (KN, eje y) en la barra e de estructura tradicional generada a partir de estructura reentrante hexagonal metálica rígida para una apertura de $90^{\circ}$ y diversas cargas horizontales y verticales $(\mathrm{KN}$, eje $x$ y leyenda), elaboración propia

- Gráfica 114 Comparación de esfuerzos axiles (KN, eje y) en la barra f de estructura tradicional generada a partir de estructura reentrante hexagonal metálica rígida para una apertura de $90^{\circ}$ y diversas cargas horizontales y verticales ( $K N$, eje $x$ y leyenda), elaboración propia

- Gráfica 115 Comparación de esfuerzos cortantes mínimos (KN, eje y) en la barra a de estructura tradicional generada a partir de estructura reentrante hexagonal metálica rígida para una apertura de $90^{\circ}$ y diversas cargas horizontales y verticales $(\mathrm{KN}$, eje $\mathrm{x}$ y leyenda), elaboración propia

- Gráfica 116 Comparación de esfuerzos cortantes máximos (KN, eje y) en la barra a de estructura tradicional generada a partir de estructura reentrante hexagonal metálica 
rígida para una apertura de $90^{\circ}$ y diversas cargas horizontales y verticales $(\mathrm{KN}$, eje $\mathrm{x}$ y leyenda), elaboración propia

- Gráfica 117 Comparación de esfuerzos cortantes mínimos (KN, eje y) en la barra b de estructura tradicional generada a partir de estructura reentrante hexagonal metálica rígida para una apertura de $90^{\circ}$ y diversas cargas horizontales y verticales $(\mathrm{KN}$, eje $\mathrm{x}$ y leyenda), elaboración propia

- Gráfica 118 Comparación de esfuerzos cortantes máximos (KN, eje y) en la barra b de estructura tradicional generada a partir de estructura reentrante hexagonal metálica rígida para una apertura de $90^{\circ}$ y diversas cargas horizontales y verticales ( $\mathrm{KN}$, eje $\mathrm{x}$ y leyenda), elaboración propia

- Gráfica 119 Comparación de esfuerzos cortantes mínimos (KN, eje y) en la barra c de estructura tradicional generada a partir de estructura reentrante hexagonal metálica rígida para una apertura de $90^{\circ}$ y diversas cargas horizontales y verticales $(\mathrm{KN}$, eje $\mathrm{x}$ y leyenda), elaboración propia

- Gráfica 120 Comparación de esfuerzos cortantes máximos (KN, eje y) en la barra c de estructura tradicional generada a partir de estructura reentrante hexagonal metálica rígida para una apertura de $90^{\circ}$ y diversas cargas horizontales y verticales $(\mathrm{KN}$, eje $\mathrm{x}$ y leyenda), elaboración propia.

- Gráfica 121 Comparación de esfuerzos cortantes mínimos (KN, eje y) en la barra d de estructura tradicional generada a partir de estructura reentrante hexagonal metálica rígida para una apertura de $90^{\circ}$ y diversas cargas horizontales y verticales $(\mathrm{KN}$, eje $\mathrm{x}$ y leyenda), elaboración propia

- Gráfica 122 Comparación de esfuerzos cortantes máximos (KN, eje y) en la barra d de estructura tradicional generada a partir de estructura reentrante hexagonal metálica rígida para una apertura de $90^{\circ}$ y diversas cargas horizontales y verticales $(\mathrm{KN}$, eje $x$ y leyenda), elaboración propia

- Gráfica 123 Comparación de esfuerzos cortantes mínimos (KN, eje y) en la barra e de estructura tradicional generada a partir de estructura reentrante hexagonal metálica rígida para una apertura de $90^{\circ}$ y diversas cargas horizontales y verticales $(\mathrm{KN}$, eje $\mathrm{x}$ y leyenda), elaboración propia

- Gráfica 124 Comparación de esfuerzos cortantes máximos (KN, eje y) en la barra e de estructura tradicional generada a partir de estructura reentrante hexagonal metálica rígida para una apertura de $90^{\circ}$ y diversas cargas horizontales y verticales ( $\mathrm{KN}$, eje $\mathrm{x}$ y leyenda), elaboración propia 
- Gráfica 125 Comparación de esfuerzos cortantes mínimos (KN, eje y) en la barra f de estructura tradicional generada a partir de estructura reentrante hexagonal metálica rígida para una apertura de $90^{\circ}$ y diversas cargas horizontales y verticales $(\mathrm{KN}$, eje $\mathrm{x} y$ leyenda), elaboración propia

- Gráfica 126 Comparación de esfuerzos cortantes máximos (KN, eje y) en la barra f de estructura tradicional generada a partir de estructura reentrante hexagonal metálica rígida para una apertura de $90^{\circ}$ y diversas cargas horizontales y verticales $(\mathrm{KN}$, eje $\mathrm{x}$ y leyenda), elaboración propia

- Gráfica 127 Comparación de momentos mínimos (KN•m, eje y) en la barra a de estructura tradicional generada a partir de estructura reentrante hexagonal metálica rígida para una apertura de $90^{\circ}$ y diversas cargas horizontales y verticales $(\mathrm{KN}$, eje $\mathrm{x} y$ leyenda), elaboración propia

- Gráfica 128 Comparación de momentos máximos $(\mathrm{KN} \cdot \mathrm{m}$, eje y) en la barra a de estructura tradicional generada a partir de estructura reentrante hexagonal metálica rígida para una apertura de $90^{\circ}$ y diversas cargas horizontales y verticales $(\mathrm{KN}$, eje $\mathrm{x}$ y leyenda), elaboración propia

- Gráfica 129 Comparación de momentos mínimos $(\mathrm{KN} \cdot \mathrm{m}$, eje y) en la barra b de estructura tradicional generada a partir de estructura reentrante hexagonal metálica rígida para una apertura de $90^{\circ}$ y diversas cargas horizontales y verticales $(\mathrm{KN}$, eje $\mathrm{x} y$ leyenda), elaboración propia

- Gráfica 130 Comparación de momentos máximos $(\mathrm{KN} \cdot \mathrm{m}$, eje y) en la barra b de estructura tradicional generada a partir de estructura reentrante hexagonal metálica rígida para una apertura de $90^{\circ}$ y diversas cargas horizontales y verticales $(\mathrm{KN}$, eje $x$ y leyenda), elaboración propia

- Gráfica 131 Comparación de momentos mínimos (KN•m, eje y) en la barra c de estructura tradicional generada a partir de estructura reentrante hexagonal metálica rígida para una apertura de $90^{\circ}$ y diversas cargas horizontales y verticales ( $\mathrm{KN}$, eje $\mathrm{x} y$ leyenda), elaboración propia.

- Gráfica 132 Comparación de momentos máximos (KN•m, eje y) en la barra c de estructura tradicional generada a partir de estructura reentrante hexagonal metálica rígida para una apertura de $90^{\circ}$ y diversas cargas horizontales y verticales $(\mathrm{KN}$, eje $\mathrm{x}$ y leyenda), elaboración propia

- Gráfica 133 Comparación de momentos mínimos $(\mathrm{KN} \cdot \mathrm{m}$, eje y) en la barra d de estructura tradicional generada a partir de estructura reentrante hexagonal metálica 
rígida para una apertura de $90^{\circ}$ y diversas cargas horizontales y verticales $(\mathrm{KN}$, eje $\mathrm{x}$ y leyenda), elaboración propia

- Gráfica 134 Comparación de momentos máximos $(\mathrm{KN} \cdot \mathrm{m}$, eje y) en la barra d de estructura tradicional generada a partir de estructura reentrante hexagonal metálica rígida para una apertura de $90^{\circ}$ y diversas cargas horizontales y verticales $(\mathrm{KN}$, eje $\mathrm{x}$ y leyenda), elaboración propia

- Gráfica 135 Comparación de momentos mínimos (KN•m, eje y) en la barra e de estructura tradicional generada a partir de estructura reentrante hexagonal metálica rígida para una apertura de $90^{\circ}$ y diversas cargas horizontales y verticales ( $\mathrm{KN}$, eje $\mathrm{x}$ y leyenda), elaboración propia

- Gráfica 136 Comparación de momentos máximos $(\mathrm{KN} \cdot \mathrm{m}$, eje y) en la barra e de estructura tradicional generada a partir de estructura reentrante hexagonal metálica rígida para una apertura de $90^{\circ}$ y diversas cargas horizontales y verticales $(\mathrm{KN}$, eje $\mathrm{x}$ y leyenda), elaboración propia

- Gráfica 137 Comparación de momentos mínimos $(\mathrm{KN} \cdot \mathrm{m}$, eje y) en la barra f de estructura tradicional generada a partir de estructura reentrante hexagonal metálica rígida para una apertura de $90^{\circ}$ y diversas cargas horizontales y verticales $(\mathrm{KN}$, eje $\mathrm{x}$ y leyenda), elaboración propia

- Gráfica 138 Comparación de momentos máximos $(\mathrm{KN} \cdot \mathrm{m}$, eje y) en la barra $\mathrm{f}$ de estructura tradicional generada a partir de estructura reentrante hexagonal metálica rígida para una apertura de $90^{\circ}$ y diversas cargas horizontales y verticales $(\mathrm{KN}$, eje $\mathrm{x} y$ leyenda), elaboración propia

\subsection{Lista de tablas}

- Tabla 1. Patrones auxéticos y sus diferentes combinaciones, elaboración propia

- Tabla 2. Relación entre áreas mínimas (Amín) y máximas (Amáx) con la longitud total de barras de la estructura, elaboración propia

- Tabla 3. Relación de volúmenes mínimos (Vmín) y máximos (Vmáx) con la longitud total de barras de la estructura, elaboración propia

- Tabla 4. Relación entre áreas mínimas (Amín) y máximas (Amáx) con la longitud total de barras de la estructura, elaboración propia

- Tabla 5. Relación entre áreas mínimas (Amín) y máximas (Amáx) con la longitud total de barras de la estructura, elaboració propia 
- Tabla 6. Relación entre áreas mínimas (Amín) y máximas (Amáx) con la longitud total de barras de la estructura, elaboración propia

- Tabla 7. Relación entre áreas mínimas (Amín) y máximas (Amáx) con la longitud total de barras de la estructura, elaboración propia

- Tabla 8 Desplazamientos horizontales en nudos para las figuras estudiadas, elaboración propia

- Tabla 9 Desplazamientos verticales en nudos para las figuras estudiadas, elaboración propia

- Tabla 10 Rotaciones en articulaciones para las figuras estudiadas, elaboración propia

- Tabla 11 Reacciones en apoyos para las figuras estudiadas, elaboración propia

- Tabla 12 Esfuerzos axiles en barras (B) y tendones (T) para las figuras estudiadas, elaboración propia

- Table 13: loads considered table

- Table 14. Traditional structure base reactions

- Table 15. Auxetic structure base reactions

- Table 16. The most unfavorable displacements and rotations to the traditional and auxetic pattern

- Table 17. The most unfavorable forces for the traditional structure and for the auxetic structure

- Table 18. The most unfavorable foundation reactions to the traditional and auxetic structure

- Table 19: loads considered table

- Table 20. Traditional structure base reactions

- Table 21. Auxetic structure base reactions

- Table 22. The most unfavorable displacements and rotations to the traditional and auxetic pattern

- Table 23. The most unfavorable forces for the traditional structure and for the auxetic structure

- Table 24. The most unfavorable foundation reactions to the traditional and auxetic structure 